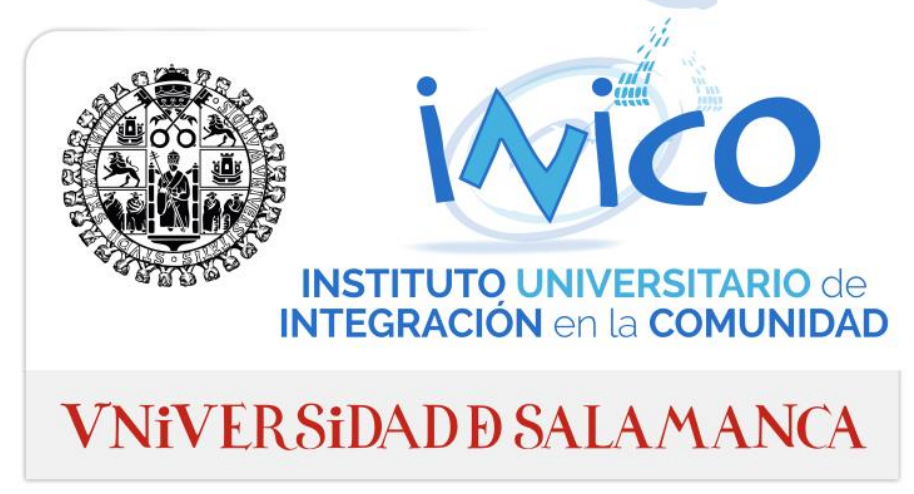

\author{
TESIS DOCTORAL
}

\title{
Impacto psicosocial de los productos y tecnologías de apoyo para la comunicación en personas con discapacidad auditiva y personas sordas
}

Autor: Estíbaliz Jiménez Arberas

Director: Emiliano Díez Villoria 


\section{AUTORIZACIÓN DIRECTOR DE TESIS}

FACULTAD DE PSICOLOGÍA

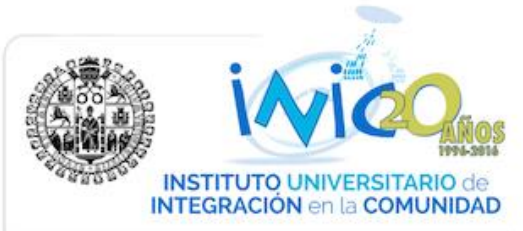

VNIVERSTIAS

SALAMANIINi

VNIVERSIDADĐSALAMANCA

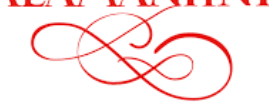

Dr. D. EMILIANO DÍEZ VILLORIA, Profesor Titular del Departamento de Psicología Básica, Psicobiología y Metodología de las Ciencias del Comportamiento y miembro investigador del INICO

\section{CERTIFICA:}

Que el presente trabajo de investigación titulado "Impacto psicosocial de los productos y tecnologías de apoyo para la comunicación en personas con discapacidad auditiva y personas sordas”, constituye el trabajo de investigación que presenta Estíbaliz Jiménez Arberas para optar al grado de Doctor. El trabajo, realizado bajo mi dirección, reúne los requisitos de calidad, originalidad y presentación exigibles a una investigación científica y está en condiciones de ser sometida a la valoración del Tribunal encargado de juzgarla.

Para que conste firmamos la presente en Salamanca, a 12 de julio de 2016,

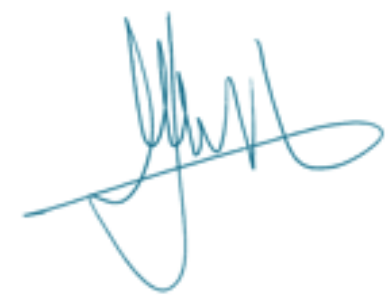

Fdo. Emiliano Díez Villoria 


\section{AGRADECIMIENTOS}

Al finalizar un trabajo tan arduo y lleno de dificultades como es el desarrollo de una tesis doctoral es inevitable mirar atrás y ver todos los obstáculos y como se han conseguido solucionar. Por ello, es para mí un verdadero placer utilizar estas líneas para agradecer a todas las personas que han hecho que pueda defender esta Tesis Doctoral. Debo agradecer de manera especial y sincera a mi Director de Tesis, por guiarme en todo este camino y animarme a continuar y no rendirme, gracias Emi. En estos años me has enseñado y reeducado mi visión sobre la Terapia Ocupacional, y siempre has creído en mí (incluso cuando yo misma había dejado de hacerlo).

Pero sobre todo debo de agradecer a todas esas personas e instituciones que han hecho posible llevar a cabo esta Tesis Doctoral por ello, mi más sincero GRACIAS.

Este trabajo no lo podría haber llevado a cabo sin el apoyo y la ayuda de amigos y allegados, gracias a Elena, Cris, Thais, Carmela, Virginia, Fátima, Amaia,.... Y a mis compañeros del colegio, COPTOCYL.

Y por supuesto, a mis padres y a Víctor, por animarme cada día y por hacer que sea la persona que soy. Gracias Papa por enseñarme el valor del trabajo y el esfuerzo diario, gracias mama por ser mi musa y mi ejemplo diario y, a ti Víctor, por estar siempre a mi lado. 


\section{ÍNDICE}

AGRADECIMIENTOS............................................................................................................ 2

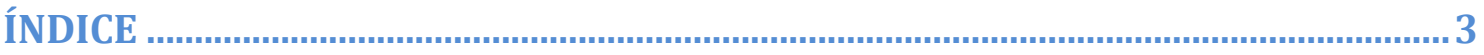

Índice de tablas ................................................................................................................. 6

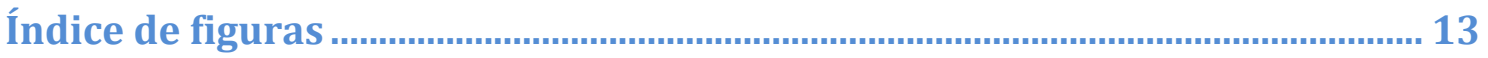

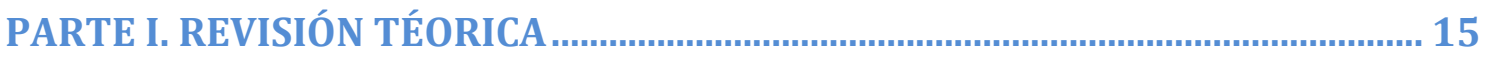

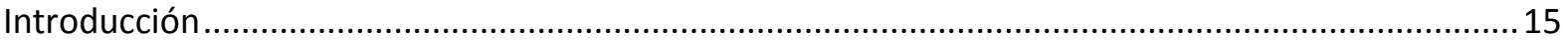

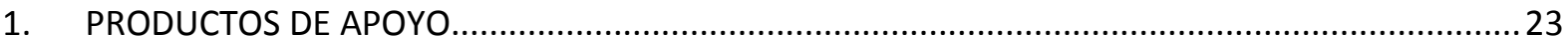

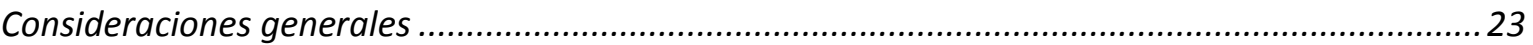

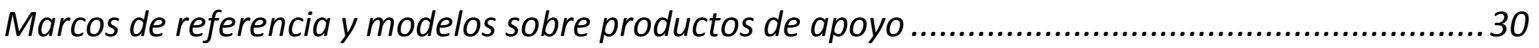

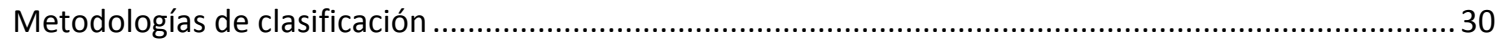

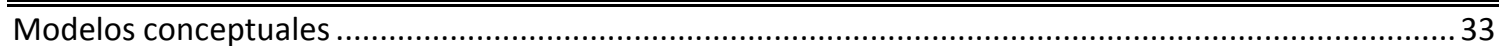

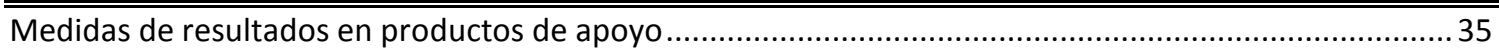

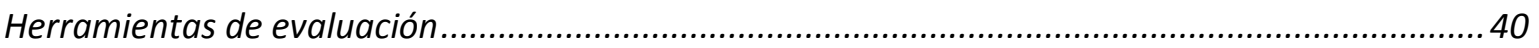

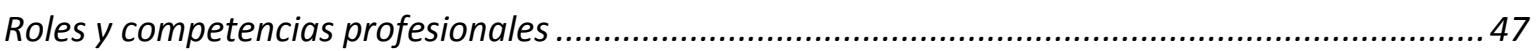

Problemas y limitaciones de los productos de apoyo. ................................................................... 52

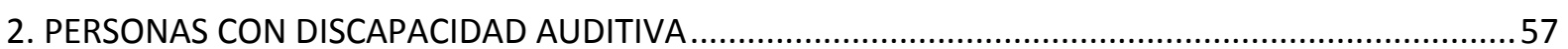

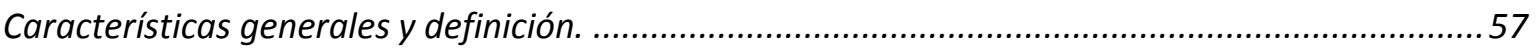

Capacidad comunicativa de las personas sordas y su problemática................................................63

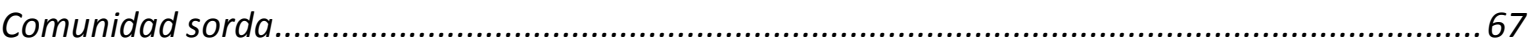

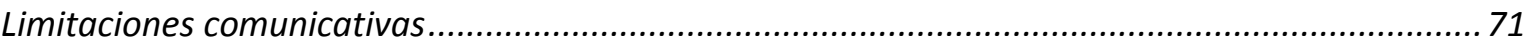

3.- PRODUCTOS DE APOYO PARA LA COMUNICACIÓN Y ACCESO A LA INFORMACIÓN EN PERSONAS

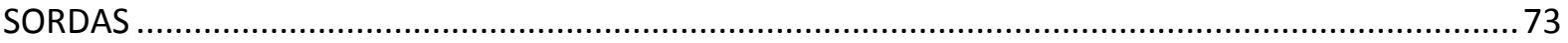

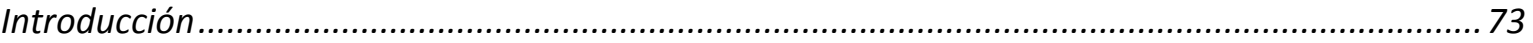

Medidas de resultados en productos de apoyo para personas sordas........................................... 78

Instrumentos de evaluación para el uso de PA en personas sordas o con discapacidad auditiva ........79

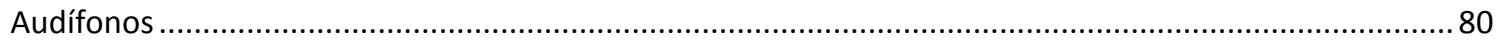

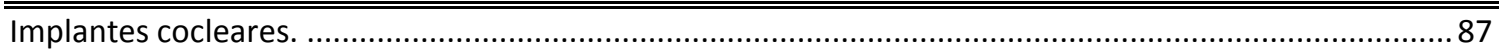

Sistemas de intermediación por vídeo. VRS.................................................................................... 96

Otros productos de apoyo para personas sordas y personas con discapacidad auditiva ...............100 
Bucles magneticos. 100

Equipos de Frecuencia Modulada (FM)

PARTE II. ESTUDIO EMPÍRICO

Justificación.

Objetivos. 107

Objetivo general 107

Objetivos específicos....

Estudio 1. Impacto psicosocial derivado del uso de sistemas de intermediación por vídeo (SIV) 109

Introducción 109

Método

Participantes.

Instrumentos.

Escala del impacto psicosocial de productos de apoyo (PIADS, Psychosocial Impact of assistive devices scale; Jutai \& Day, 1996)

Emparejando persona y tecnología- Cuestionario sobre uso de tecnología-usuario (MPT-SOTU-C,

Matching Person \& Technology- Survey of Technology use- Consumer, Scherer, 2005) 115

Procedimiento

Resultados.

Discusión y conclusiones

Estudio 2. Impacto psicosocial derivado del uso de audífonos.

Introducción

Método

Participantes

Instrumentos.

Procedimiento.

Resultados.

Discusión y Conclusiones

Estudio 3. Impacto psicosocial derivado del uso de implante coclear.

Introducción

Método

Participantes.

Instrumentos 


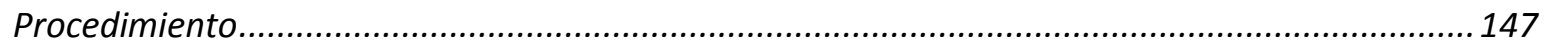

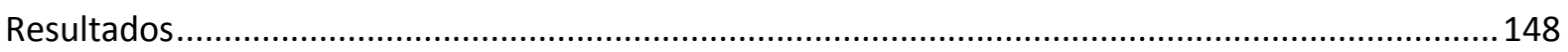

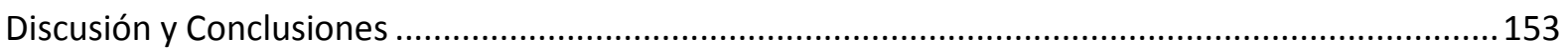

Impacto psicosocial en función de los productos de apoyo ( análisis conjunto de los resultados de los estudios 1,2 y 3 ). 156

Estudio 4.- Estudio cualitativo sobre factores relacionados con el uso de productos de apoyo: grupos focales de personas sordas, familiares y profesionales 164

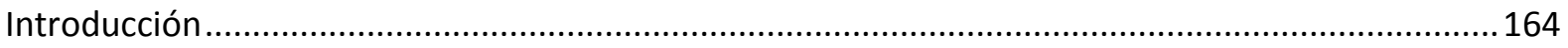

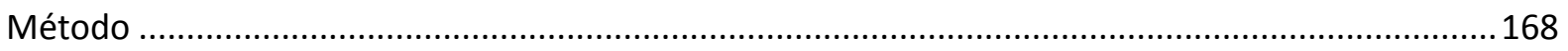

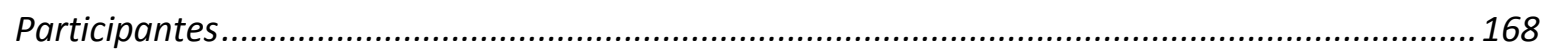

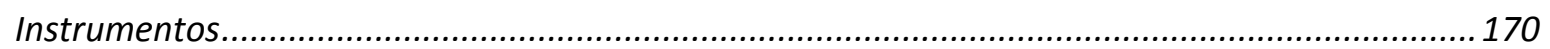

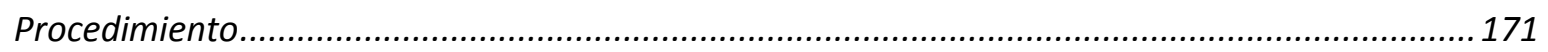

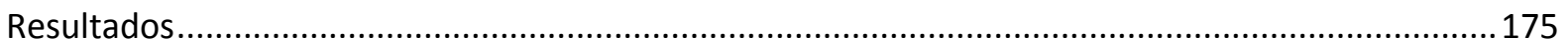

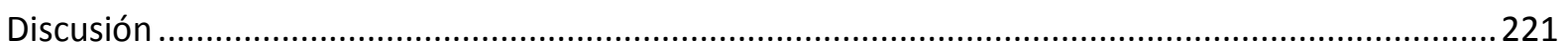

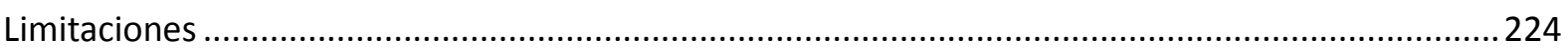

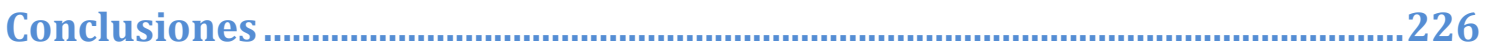

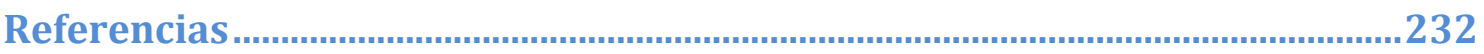

ANEXO I: CUESTIONARIO DE NUEVAS TECNOLOGÍAS......................................285

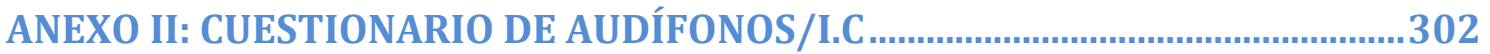

ANEXO III: CUESTIONARIO ORIGINAL PIADS ..............................................................

ANEXO IV: VÍDEOS PARA EL ESTUDIO 1 ADAPTADO ......................................... 316

ANEXO V: CONSENTIMIENTO INFORMADO _.......................................................... 317

ANEXO VI: Consentimiento informado grupos focales ....................................318 


\section{Índice de tablas}

Tabla 1. Revistas con más de 5 publicaciones que contienen la palabra clave "assistive technology" y número de artículos publicados de 2000 a 2015 .26

Tabla 2. Revisiones sistemáticas en el campo de medidas de resultados y PA por

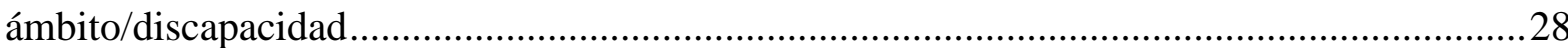

Tabla 3. Dimensiones de clasificación de PA (tomado de Pousada, 2011) .32

Tabla 4. Principales modelos para la selección de productos de apoyo (tomado y adaptado de Pousada, 2011) .34

Tabla 5. El modelo de la CIF aplicado a los PA en cuanto a medidas de resultado y práctica (tomado de Lenker \& Jutai, 2002)

Tabla 6. Principales herramientas de evaluación en productos de apoyo (Tomado y Adaptado de Pousada, 2011).

Tabla 7. Ejemplo de las secciones del "Guidelines for the prescription of a seated wheelchair or mobility scooter for people with a traumatic brain injury or spinal cord injury"

(EnableNSW, Lifetime Care \& Support Authority, 2011 .46

Tabla 8. Número de personas con dificultades auditivas en función de sus dificultades y el sexo. (Fuente: Encuesta de Discapacidad, Autonomía Personal y Situaciones de Dependencia 2008) .57

Tabla 9. Líneas prioritarias de carácter genérico del libro blanco .58

Tabla 10. Población (miles) con discapacidad según su satisfacción respecto a las ayudas técnicas que recibe para su discapacidad.

Tabla 11. Clasificación de PA para la comunicación y acceso a la información de personas con discapacidad auditiva (tomado de la norma ISO 9999)

Tabla 12. Clasificación de PA para personas sordas según la norma ISO 9999:2007

Tabla 13. Población con discapacidad auditiva en función del tipo de pérdida auditiva por rango de edad

Tabla 14. Población con discapacidad auditiva que no puede recibir mensajes hablados por rango de edad

Tabla 15. Población con discapacidad auditiva que emplea para la comunicación dispositivos y técnicas de comunicación 
Tabla 16. Población con discapacidad auditiva que produce mensajes hablados con/sin ayudas/ayudas técnicas

Tabla 17. Principales PA para personas con discapacidad auditiva (elaboración propia a partir de CEAPAT)

Tabla 18. Instrumentos de evaluación de resultados de PA específicos para personas sordas 79

Tabla 19. Dimensiones y sus Indicadores del modelo de Calidad de Vida (tomado de

Verdugo \& Schalock, 2003)

Tabla 20. Clasificación de sistemas de intermediación por vídeo para personas con y sin discapacidad auditiva

Tabla 21. Algunos de los factores de interrupción del uso de PA identificados según el modelo de Lauer \& Smith (2006)

Tabla 22. Perfil sociodemográfico de personas adultas con discapacidad auditiva usuarias de sistemas de intermediación por vídeo u otras tecnologías de la comunicación $(n=124) \ldots . . . .112$

Tabla 23. Composición de los ítems de la escala PIADS por subescala ....

Tabla 24. Número de tecnologías empleadas en función del uso o no de los SIV

Tabla 25. Número de participantes usuarios de sistemas de intermediación de video y otras tecnologías de vídeo en función del producto utilizado anteriormente

Tabla 26. Puntuaciones promedio (positivas, negativas y neutrales) del cuestionario SOTU-C por apartado del instrumento $(\mathrm{n}=124)$

Tabla 27. Puntuaciones promedio de las respuestas positivas y negativas por apartado del instrumento SOTU-C en función de si usan o no SIV

Tabla 28. Puntuaciones promedio (positivas y negativas) en relación al instrumento SOTU-C y la edad

Tabla 29. Diferencias en las puntuaciones promedio (positivas y negativas) en relación al instrumento SOTU-C y diferentes variables sociodemográficas.

Tabla 30. Puntuaciones globales en la escala PIADS y en sus tres subescalas en función del uso de SIV.

Tabla 31. Puntuaciones de las tres subescalas pertenecientes a la escala PIADS por tipo de producto de apoyo $(\mathrm{n}=124)$.....

Tabla 32. Puntuaciones por las subescalas de competencia, adaptabilidad y autoestima de la escala PIADS

Tabla 33. Puntuación por ítem de la escala PIADS en función de si usa SIV o no usa SIV $(n=124)$. 
Tabla 34. Impacto psicosocial percibido en función del uso o no de SIV y de la frecuencia de uso

Tabla 35. Perfil Sociodemográfico de personas adultas con discapacidad auditiva usuarias de audífonos estudio $2(\mathrm{n}=137)$

Tabla 36. Promedios de respuestas positivas y negativas obtenidas en el SOTU-C $(n=137)$

Tabla 37. Promedios de respuestas positivas y negativas obtenidas en el SOTU-C en función del rango de edad

Tabla 38. Promedio de respuestas positivas y negativas del instrumento SOTU-C por tipo de audífono

Tabla 39. Puntuaciones globales en la escala PIADS y en sus tres subescalas $(n=137)$

Tabla 40. Puntuaciones globales en la escala PIADS y en sus tres subescalas en función del tipo de audífono $(\mathrm{n}=137)$

Tabla 41. Puntuaciones en la escala PIADS y en sus tres subescalas en función de si el participante había abandonado o no el audífono.

Tabla 42. Puntuaciones globales en la escala PIADS y en sus tres subescalas en función de si el participante había abandonado o no el audífono $(n=137)$

Tabla 43. Puntuación media de las subescalas competencia, adaptabilidad y autoestima por ítem $(\mathrm{n}=137)$. 138

Tabla 44.-Puntuaciones promedio en la escala PIADS y sus tres subescalas por situaciones de uso $(n=137)$.

Tabla 45. Puntuaciones medias en la escala PIADS y sus tres subescalas en función de la frecuencia de uso $(n=137)$

Tabla 46. Puntuaciones medias en la escala PIADS y sus tres subescalas en función del tipo de audífono y la frecuencia de uso $(n=137)$.

Tabla 47. Perfil Sociodemográfico de personas adultas con discapacidad auditiva usuarias de implante coclear estudio $3(n=30)$.

Tabla 48. Puntuaciones promedio positivas y negativas del instrumento SOTU-C en función de variable sociodemográficas.

Tabla 49. Puntuaciones medias obtenidas en el cuestionario SOTU-C en función de la edad $(\mathrm{n}=30)$.

Tabla 50. Puntuaciones medias en la escala PIADS y su tres subescalas en usuarios de IC $(\mathrm{n}=30)$ 
Tabla 51. Puntuaciones promedio de la escala PIADS y sus tres subescalas en función de

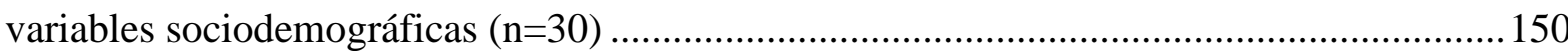

Tabla 52. Puntuaciones promedio de los ítems de la escala PIADS ( $\mathrm{n}=30)$ .151

Tabla 53. Puntuaciones medias en las tres subescalas pertenecientes a la escala PIADS en función del tiempo de implantación.

Tabla 54. Puntuaciones medias obtenidas en la escala PIADS y su tres subescalas en función si el participante abandono o no el I.C $(n=30)$.

Tabla 55. Perfil sociodemográfico de los participantes de los estudios 1,2 y 3 ( $n=291) \ldots . . .156$

Tabla 56. Puntuaciones globales del PIADS y sus tres subescalas $(\mathrm{n}=291)$ 157

Tabla 57. Puntuaciones globales del PIADS y las tres subescalas en función del PA (estudios $1,2$ y $3 ; n=291)$

Tabla 58. Puntuaciones globales del PIADS y sus tres subescalas en función del tipo de PA específico (estudios 1, 2 y 3; $\mathrm{n}=291$ )

Tabla 59. Las puntuaciones medias de los ítems pertenecientes a cada subescala del PIADS

Tabla 60. Puntuaciones medias de positivos, negativos y neutrales del cuestionario SOTU-C por cada grupo de preguntas

Tabla 61.Puntuaciones medias de positivos y negativos del cuestionario SOTU-C por cada tipo de producto de apoyo.

Tabla 62. Consistencia interna del instrumento PIADS y sus tres subescalas en función de tres estudios

Tabla 63. Perfil sociodemográfico de personas sordas y personas con discapacidad auditiva $(\mathrm{n}=15)$

Tabla 64. Perfil sociodemográfico de familiares y profesionales $(\mathrm{n}=21)$

Tabla 65. Preguntas de elaboración propia tomando de base teórica la CIF para los 12 grupos focales

Tabla 66. Descripción de los perfiles de los 3 tipos de grupos focales: personas sordas, familiares y profesionales $(n=36)$

Tabla 67. Duración de los grupos focales: personas sordas, familiares y profesionales $(n=36)$

Tabla 68. Número de citas en función de las dimensiones de la CIF y el tipo de grupo focal

Tabla 69. Códigos de primer nivel de la CIF que aparecen en los diferentes grupos focales y número de citas por tipo de grupo de participantes $(\mathrm{n}=36)$ 
Tabla 70. Número de citas sobre Funciones Corporales (Funciones Mentales) en función del grupo focal

Tabla 71. Ejemplos de citas del primer capítulo de la primera dimensión "Funciones Corporales" 184

Tabla 72. Número de citas sobre Funciones Corporales (Funciones Sensoriales y del dolor) en función del grupo focal 185

Tabla 73. Ejemplos de citas del segundo capítulo de la dimensión "Funciones corporales" 186 Tabla 74. Número de citas sobre Funciones Corporales (Funciones de la voz y el habla) en función del grupo focal 186

Tabla 75. Ejemplos de citas del tercer capítulo de la dimensión "Funciones corporales" .... 188 Tabla 76. Número de citas sobre Funciones Corporales (Capítulo 5: Funciones de los sistemas digestivo, metabólico y endocrino y Capítulo 7: Funciones neuromusculoesqueléticas y relacionadas con el movimiento) en función del grupo focal.189 Tabla 77. Ejemplos de citas del quinto y séptimo capítulo de la dimensión "Funciones corporales".

Tabla 78. Número de citas sobre Actividades y Participación (Aprendizaje y Aplicación del conocimiento) en función del grupo focal

Tabla 79. Ejemplos de citas del primer capítulo de la dimensión "Actividad y Participación"

Tabla 80. Número de citas sobre Actividades y Participación (Tareas y demandas generales) en función del grupo focal

Tabla 81. Ejemplos de citas del segundo capítulo "Tareas y demandas generales"de la dimensión "Actividades y Participación”

Tabla 82. Número de citas sobre Actividades y Participación (Comunicación) en función del grupo focal

Tabla 83. Ejemplos de citas del tercer capítulo "Comunicación”de la dimensión "Actividades y Participación".

Tabla 84. Número de citas sobre Actividades y Participación (Movilidad, autocuidado y vida doméstica) en función del grupo focal

Tabla 85. Ejemplos de citas del cuarto, quinto y sexto capítulos de la dimensión "Actividades y Participación"

Tabla 86. Número de citas sobre Actividades y Participación (Interacciones y relaciones interpersonales) en función del grupo focal. 
Tabla 87. Ejemplos de citas del séptimo capítulo "Interacciones y relaciones interpersonales" de la dimensión "Actividades y Participación" 199

Tabla 88. Número de citas sobre Actividades y Participación (Áreas principales de la vida) en función del grupo focal

Tabla 89. Ejemplos de citas del octavo capítulo “Áreas principales de la vida” de la dimensión "Actividades y Participación"

Tabla 90. Número de citas sobre Actividades y Participación (Vida comunitaria, social y cívica) en función del grupo focal

Tabla 91. Ejemplos de citas del noveno capítulo "Vida comunitaria, social y cívica" de la dimensión “Actividades y Participación”.

Tabla 92. Número de citas sobre Factores ambientales (Productos y Tecnología y Entorno natural y cambios en el entorno derivados de la actividad) en función del grupo focal .......203 Tabla 93. Ejemplos de citas del primer y segundo capítulo de la dimensión "Factores Ambientales".

Tabla 94. Número de citas sobre Factores Ambientales (Apoyo y relaciones y Actitudes) en función del grupo focal

Tabla 95. Ejemplos de citas del tercer y cuarto capítulo de la dimensión "Factores Ambientales". 206

Tabla 96. Número de citas sobre Factores Ambientales (Servicios, sistemas y políticas) en función del grupo focal 206 Tabla 97. Ejemplos de citas del quinto capítulo de la dimensión "Factores Ambientales"..207 Tabla 98. Número de citas sobre Estructuras corporales en función del grupo focal...........208 Tabla 99. Ejemplos de citas del quinto capítulo de la dimensión "Estructuras corporales"..209 Tabla 100. Ejemplos de citas codificadas como factores personales y su quotation personas con hipoacusia y personas sordas 210

Tabla 101. Ejemplos de citas codificadas como factores personales en profesionales 211

Tabla 102. Número de códigos clasificados como Barreras o Facilitadores por tipo de grupo focal.

Tabla 103. Número de factores predictores de abandono o falta de continuidad de productos de apoyo según el modelo de Lauer, Longenecker \& Smith (2006) por tipo de grupo focal 213 Tabla 104. Número de factores predictores de abandono o falta de continuidad expresados en los diferentes grupos focales. 214 Tabla 105. Expresiones codificadas de algunos de los factores de abandono o falta de uso del modelo de Lauer, Longenecker \& Smith (2006) relacionados con la persona. 
Tabla 106. Expresiones codificadas de algunos de los factores de abandono o falta de uso del modelo de Lauer, Longenecker \& Smith (2006) relacionados con el propio producto de apoyo.

Tabla 107. Expresiones codificadas de algunos de los factores de abandono o falta de uso del modelo de Lauer, Longenecker \& Smith (2006) relacionados con el entorno, factores positivo y "otros" 218

Tabla 108. Índice de acuerdo Kappa de Cohen en los códigos citados por los grupos focales y el Conjunto Básico Breve 219

Tabla 109. Índice de acuerdo Kappa de Cohen en los códigos citados por los grupos focales y el Conjunto Básico Completo

Tabla 110. Tabla de comparación entre capítulos con y sin citas presentes entre el core set y el presente estudio 


\section{Índice de figuras}

Figura 1. Número de artículos con la palabra clave "assistive technology" publicados por año de 2000 a 2015. Fuente: Elaboración propia a partir de datos de EBSCO Academic Search.25 Figura 2. Palabras clave en el campo de la investigación en PA y personas con discapacidad

Figura 3. Ejemplo de la norma ISO:9999

Figura 4. Relación entre los factores ambientales de la CIF y el primer nivel de clasificación de la ISO (Tomado de Heerkens, Bougie \& de Kleijn-de Vrankrijker, 2010) ........................36

Figura 5. Modelo Matching Person \& Technology (Scherer, 2003) ......................................43 Figura 6. Proceso de Evaluación de productos de apoyo según el Modelo biopsicosocial de la CIF. El usuario busca una solución para uno o más componentes de la CIF y la solicitud pone en marcha el proceso de Evaluación de productos de apoyo. El usuario recibe la mejor correspondencia entre usuario/cliente y solución de productos de apoyo. El Centro de ayuda técnica verifica la satisfacción y la obtención de beneficios del usuario a través de soporte y seguimiento. El bienestar del usuario prevalece siempre que la solución de productos de apoyo siga constituyendo una buena correspondencia. Tomado de Scherer, Federici, Tiberio,

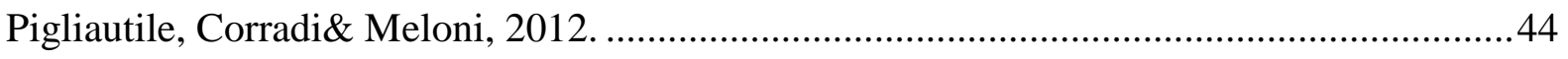

Figura 7. Modelo generado por el proyecto ATOMS de interrupción de PA..........................54

Figura 8. Personas con discapacidad que señalan falta de ayudas personales o técnicas en Castilla y León.

Figura 9. Correlaciones entre las dimensiones de experiencias positivas y negativas con tecnologías (SOTU-C) y el impacto psicosocial (PIADS). El tamaño de los círculos representa la magnitud de la correlación y el color el signo. Las " $\mathrm{x}$ ” señalan las correlaciones no significativas.

Figura 10. Número de factores ambientales de la CIF clasificados como barreras o facilitadores los por tipo de grupo focal 
PARTe I. REvisión TEÓRICA 


\section{PARTE I. REVISIÓN TÉORICA}

\section{Introducción}

Las personas con discapacidad auditiva, cuyos sistemas de comunicación son tanto la lengua oral como la lengua de signos, se enfrentan diariamente a dificultades para el desempeño de sus actividades cotidianas debidas, principalmente, a la presencia de barreras comunicativas. Estas barreras pueden derivar en todo tipo de consecuencias negativas como el aislamiento, los déficit de habilidades académicas y de habilidades sociales, y/o problemas del comportamiento (Saladin \& Hansmann, 2008). Igualmente, algunos estudios también han verificado la existencia de problemas laborales y vocacionales (Kramer, 2008), así como dificultades en el desempeño de actividades de ocio (Van Naardes Braun, Yeargin-Allsopp \& Lollar, 2006). Para mitigar o compensar este tipo de consecuencias, derivadas de las dificultades de comunicación de las personas con discapacidad auditiva, es común el uso de una amplia variedad de tecnologías y productos de apoyo (de ahora en adelante, PA).

Algunos de los PA para la comunicación más utilizados por parte de las personas con discapacidad auditiva son los audífonos (Meyer, et al., 2013), los implantes cocleares (Van Hoesel, 2012), los equipos de frecuencia modulada (FM) (Chisolm, Noe, Mcardle \& Abram, 2008) y los bucles magnéticos. También, todo tipo de servicios de retransmisión de comunicaciones, entre los que destacan aquellos que aprovechan las redes y protocolos de comunicación que ofrece Internet y que están generando nuevos modos de relación y comunicación entre las personas sordas signantes o las personas con problemas de fonación y el resto de los ciudadanos (Keating \& Mirus, 2003).

\section{Propósito}

A pesar de utilizarse con mucha frecuencia, aún se ha investigado muy poco sobre el impacto psicosocial derivado del uso de estos productos o sobre los principales resultados asociados a su utilización, en diferentes contextos y actividades de la vida diaria. Es por ello, que el propósito de esta tesis es indagar el impacto psicosocial de los PA más utilizados por las personas con discapacidad auditiva, así como analizar las medidas de resultados ligadas al uso de los diferentes PA. 


\section{Justificación}

Teniendo en cuenta lo anteriormente expuesto, es necesario realizar estudios para comprobar la efectividad y usabilidad de esos productos mediante medidas de resultados (outcomes) adecuadas en el contexto de las intervenciones con PA. Existe la necesidad de utilizar instrumentos de medida que reflejen tanto las necesidades como los intereses de los usuarios, y que vayan dirigidos a mejorar la calidad de vida y la ejecución de las actividades de la vida diaria. Este hecho hace hincapié en la necesidad de investigación en medidas de resultados y PA, para conocer los resultados de los diferentes PA cuando se utilizan como apoyo a la realización de actividades de la vida diaria. Todo ello no solamente servirá de guía y recomendación para los propios usuarios y los profesionales del ámbito, sino que ayudará al conocimiento científico en el campo de las medidas de resultados y PA, y apoyará las intervenciones basadas en la evidencia tanto en la práctica clínica como en los propios servicios (Harris \& Sprigle, 2008). Este conocimiento es vital para diferentes ámbitos profesionales, como la terapia ocupacional, la logopedia y, en general, cualquier profesión que esté implicada en contextos rehabilitadores. Es importante para los profesionales poder dar respuestas basadas en la evidencia científica a los usuarios de PA, así como conocer las medidas de resultados óptimas para ayudar a la toma de decisiones en el ámbito clínico. También es importante para las administraciones públicas y las entidades privadas, que deben dar respuesta a las necesidades de sus usuarios, desde planteamientos basados en la evidencia, y con una perspectiva de optimización de recursos.

No obstante, no debemos olvidar que las evaluaciones con medidas de resultados pueden variar en función de factores tales como los tipos de actividades, los factores personales y los factores contextuales (Holm, 2000). Y por ello, en esta tesis se ha ahondado en estos factores mediante un estudio cualitativo y un análisis de contenido realizado en base al modelo Clasificación Internacional del Funcionamiento (WHO, 2001). Se necesitan modelos conceptuales como es el de la CIF para completar los elementos asociados al uso de PA en los diferentes contextos (Smith, 1996). Los factores ambientales y personales pueden tener una influencia tanto en el uso de los PA como en el impacto psicosocial derivado de su uso. Igualmente, las intervenciones basadas en evaluaciones con medidas de resultados son necesarias para minimizar la probabilidad de abandono o falta de uso de los PA, otro de los problemas frecuentes en relación a este tipo de intervenciones; y por ello, en esta tesis se lleva a cabo una evaluación de estos factores, no sólo a partir de las opiniones delas personas 
usuarias de los PA (personas sordas y personas con hipoacusia) sino también a partir de la percepción de dichos factores por parte de familiares y profesionales.

Al igual que para la investigación sobre PA, las medidas de resultados son importantes para la decisión del uso y adquisición de un PA (Fuhrer, 2001; Jutai, 2002). Por tanto, este tipo de estudios son de suma importancia para mejorar los procesos de evaluación de los PA, el emparejamiento persona-tecnología y el desarrollo de productos más efectivos para que estos cubran las necesidades de los usuarios finales (Cook \& Hussey, 2003).

\section{Valor y contexto de la investigación}

Esta Tesis Doctoral se centra en una población invisible a los ojos de la sociedad: las personas afectadas de pérdida auditiva usuarias de los diferentes tipos de PA de amplificación y nuevas tecnologías. En concreto, el trabajo empírico tiene como objetivo general analizar el impacto psicosocial de estos productos en el colectivo de personas sordas. En el ámbito de la rehabilitación audiológica, las medidas de resultados se identifican como una prioridad (Cox et al., 2000). Además, el desarrollo de productos auditivos es una de las áreas de investigación sobre rehabilitación audiológica más activas. Desde una perspectiva histórica, las medidas de resultados se han centrado en la mejora específica de la comunicación que sigue a una intervención audiológica. Por ejemplo, las percepciones subjetivas de la capacidad funcional, bienestar y calidad de vida pueden afectar de forma significativa a la adopción y correcto uso de determinados tipos de PA, como los audífonos. Por ello, en este estudio se han utilizado instrumentos que se han empleado en numerosos estudios para evaluar el impacto sobre la calidad de vida debido al uso de un PA, como la escala de Impacto Psicosocial de Productos de Apoyo (PIADS; Psychosocial Impact of Assistive Devices Scale) (Day \& Jutai, 1996; Jutai, 1999). Esta escala ha sido empleada en estudios que investigan la continuidad o el abandono en PA para personas con discapacidad auditiva (Jutai \& Saunders, 2001) y también ha demostrado ser sensible a los factores psicosociales que se relacionan con los beneficios de los PA de amplificación (Jutai, Day \& Strong, 2003).

Estudios como el que se presenta son importantes porque en la literatura científica reciente es posible encontrar muchos ejemplos de investigaciones que muestran cómo la pérdida auditiva puede ser un factor de riesgo asociado al desarrollo de problemas psicosociales. Así, por ejemplo, en personas mayores, es conocida la relación entre la 
prevalencia de pérdida auditiva y los efectos negativos sobre su calidad de vida y el bienestar (Scarinci, Worrall, \& Hickson, 2008) o el impacto que la pérdida auditiva tiene sobre la comunicación y el funcionamiento diario (Boi et al., 2012).

En España, existe poca investigación sobre el desarrollo de estos problemas psicosociales y como afectan al uso y al resultado de un PA. Algunos estudios han demostrado que el uso de la amplificación ha mejorado diversos aspectos psicosociales en la vida de las personas sordas (Kockin \& Rogin, 2000; Mulrow et al, 1990) y por ello, es importante realizar este tipo de estudios en población sorda española. En cuanto a otros PA, los resultados indican que los implantes cocleares deberían ser considerados como una opción para adultos y adolescentes prelocutivos, puesto que la mayoría de los usuarios de estos dispositivos con estas características alegan un beneficio en satisfacción con el dispositivo (Caposecco, Hickson, \& Pedley, 2012). Aunque hay resultados que indican que hay un mayor impacto positivo en personas con un tipo de pérdida profunda postlocutiva (Hallam et al., 2006). Es por ello que en el estudio empírico se ha intentado disponer de muestra con diferentes características tales como el tipo de pérdida y el grado de la misma.

Entre los resultados percibidos por la utilización de otras tecnologías para personas sordas signantes destacan la mejora de la calidad de vida (Götherström, Persson, \& Jonsson, 2004), el bienestar psicológico, y el incremento de la independencia, la autoestima, la sensación de control y la funcionalidad. En general, los hallazgos sugieren un impacto positivo sobre diversos factores psicosociales por el uso de los Sistema de Intermediación por Vídeo (Saladin \& Hansmann, 2008).

\section{Preguntas de investigación}

El campo de las medidas de resultados en PA en personas sordas es un campo reciente y todavía poco abordado. Y si nos centramos en el impacto psicosocial derivado de su uso, aunque en la literatura científica encontramos estudios de esta naturaleza, queda un largo camino por recorrer (Saladin \& Hansman, 2008; Tomita, Mann, \& Welch, 2001). Este hecho puede deberse a que las personas con problemas de audición, usuarias de lengua de signos, suponen un reto debido a las barreras comunicativas y la falta de familiaridad de los investigadores con las personas sordas y su modo de comunicación. Quizás sea este el motivo por el cual existe poca investigación de los problemas que afrontan las personas con discapacidad auditiva en la realización de sus actividades diarias. Es por ello, que nuestras preguntas de investigación van encaminadas a indagar sobre el impacto psicosocial de los 
diferentes PA seleccionados para este estudio (Sistemas de intermediación por vídeo, audífonos e implantes cocleares). Y es por este hecho, que esta Tesis Doctoral esté dividida en 4 estudios; 3 de ellos de naturaleza empírica y el último, de naturaleza cualitativa y siguiendo como modelo la Clasificación Internacional del funcionamiento y los factores de abandono o falta de uso de los PA.

\section{Importancia}

Los resultados de este estudio se vienen a sumar a una base creciente de trabajos en el campo de la medida de resultados tras intervenciones con productos y tecnologías de apoyo $y$, en este sentido, pueden contribuir a mejorar la capacidad de evaluación del impacto que producen los productos de apoyo sobre las vidas de las personas con discapacidad. Esto es un objetivo importante de disciplinas centradas en la intervención con PA, como la terapia ocupacional, y de organizaciones de carácter internacional, como el consorcio para la investigación sobre resultados con productos de apoyo (Consortium for Assistive Technology Outcomes Research, http://www.atoutcomes.com). En este contexto, los resultados de este estudio aportan información adicional y convergente sobre las propiedades métricas del instrumento PIADS. Además, avalan la idea de que el énfasis futuro en este campo debe centrarse en la participación del consumidor en la selección y evaluación de las tecnologías y productos de apoyo, como medio imprescindible para asegurar que las opciones tecnológicas que se ofrecen en el mercado realmente contribuyen a mejorar la calidad de vida de las personas con discapacidad. Además, este estudio indaga sobre los factores que determinan el abandono o falta de uso de los PA, a partir del modelo proporcionado por Lauer, Longenecker \& Smith (2006). Los resultados derivados del análisis de estos factores son de interés tanto para profesionales como para las diferentes entidades relacionadas con el diseño, desarrollo y comercio de estos productos.

\section{Consideraciones éticas}

En todo momento se han seguido los protocolos del Comité de Bioética de la Universidad de Salamanca. Todos los participantes de los 4 estudios han firmado un consentimiento informado y han participado en el estudio de forma voluntaria. Así mismo se ha informado a los participantes sobre la política de protección de datos y los derechos de acceso al mismo. Toda la información recogida de los estudios se encuentra custodiada por el Grupo de Investigación en Tecnología y Discapacidad del Instituto Universitario de Integración a la Comunidad (INICO) de la Universidad de Salamanca (USAL). Todos los 
documentos (cuestionarios y grabaciones) serán destruidos en un periodo de 3 años una vez defendida esta Tesis Doctoral.

\section{Limitaciones}

Entre las limitaciones que encontramos en este estudio podemos destacar que la muestra está compuesta no es totalmente representativa y está formada por un número reducido de participantes. Además, sólo se ha realizado un muestreo de los PA más utilizados tales como los audífonos, implantes cocleares y sistemas de intermediación por vídeo. En el último apartado de esta tesis se desarrollarán las limitaciones de estos productos con más detalle.

\section{Definición de términos}

Producto de apoyo (PA)

La norma UNE-EN ISO 9999 define los productos de apoyo como "cualquier producto (incluyendo dispositivos, equipo, instrumentos y software) fabricado especialmente o disponible en el mercado, para prevenir, compensar, controlar, mitigar o neutralizar deficiencias, limitaciones en la actividad y restricciones en la participación". Los productos de apoyo incluyen desde sillas de ruedas, cubiertos adaptados, software específicos hasta los propios del colectivo de personas con discapacidad auditiva.

Persona con discapacidad auditiva- persona sorda:

Persona con deficiencia auditiva que no se identifica con la comunidad sorda y participa en la cultura y en la comunidad mayoritaria únicamente a través de la utilización de sistemas de comunicación orales.

\section{Persona Sorda:}

Es aquella que posee unas características propias, que hacen que la experiencia visual desarrolle un papel predominante. Este y el hecho de ser minoría social que se enfrente con las barreras de comunicación y haya desarrollado una lengua propia y natural, junto a unas formas de relación y organización social, comportamientos y actitudes, valores, y una cultura propia todo este conjunto da lugar, a la "Comunidad Sorda". 


\section{Comunidad Sorda}

Comunidad sorda se origina en una actitud diferente frente al déficit auditivo ya que no tiene en cuenta el grado de pérdida de sus miembros. La pertenencia a la Comunidad Sorda viene definida por el uso de la lengua de signos, sentimiento de identidad grupal, el autoreconocimiento e identificación como Persona Sorda, los matrimonios endogámicos y por último reconocerse como diferente pero no como deficiente.

\section{Impacto Psicosocial}

Se refiere al cambio efectuado debido a un producto, intervención o programa realizado. El impacto implica una mejora o no, significativa, perdurable o sustentable en el tiempo pero con variaciones personales y contextuales, y depende de las características de la población objetivo.

\section{Medidas de resultados}

Podemos definirlo como los resultados derivados de una intervención y pueden ser expresados de cuatro formas: eficacia, efectividad, utilidad y beneficio. Entendiendo la eficacia como el resultado de una intervención cuando es aplicada en condiciones ideales y la efectividad como el resultado obtenido cuando el procedimiento es aplicado en condiciones habituales. Por otra parte, se han desarrollado instrumentos que miden el resultado de las dos dimensiones (calidad de vida y su duración) que realmente interesan a los pacientes.

\section{Estructura de la tesis}

La siguiente tesis doctoral está dividida en dos partes: parte teórica y parte empírica. En primer lugar la parte teórica está dividida a su vez en tres capítulos con sus correspondientes subcapítulos:

1. Productos de Apoyo.
a. Consideraciones generales.
b. Marcos de referencia y modelos sobre productos de apoyo
c. Herramientas de evaluación
d. Roles y competencias profesionales.
e. Problemas y limitaciones de los Productos de Apoyo.

2. Personas con discapacidad auditiva. 
a. Características generales y definición.

b. Capacidad comunicativa de las personas sordas y su problemática.

c. Comunidad Sorda.

d. Limitaciones comunicativas.

3. Productos de apoyo para la comunicación y acceso a la información en personas sordas.
a. Introducción.
b. Medidas de resultados en Productos de Apoyo para personas sordas.
c. Instrumentos de evaluación.
d. Audífonos.
e. Implante Coclear.
f. Sistemas de intermediación por vídeo.

La segunda parte empírica está distribuida en cuatro estudios empíricos. Los tres primeros estudios se basan en una metodología cuantitativa (con un posterior análisis en conjunto de estos tres estudios debido a sus similitudes) y, el cuarto estudio, se basa en una metodología cualitativa. Cada uno de estos estudios está dividido a su vez en:
a. Introducción.
b. Método.
c. Resultados.
d. Discusión
e. Conclusiones. 


\section{PRODUCTOS DE APOYO.}

\section{Consideraciones generales}

La norma UNE-EN ISO 9999:2007 (European Committee for Standardization, 2011) define los productos de apoyo como "cualquier producto (incluyendo dispositivos, equipo, instrumentos y software) fabricado especialmente o disponible en el mercado, para prevenir, compensar, controlar, mitigar o neutralizar deficiencias, limitaciones en la actividad y restricciones en la participación" (p. 8). Los PA suelen utilizarse distintos contextos vitales de las personas tanto a nivel personal como en el hogar, la educación y el trabajo o el ocio y el esparcimiento (Scherer, 2002).

Los PA y las nuevas tecnologías capacitan y permiten a las personas con discapacidad ocupar el lugar que les corresponde en la toma de decisiones que afectan a su vida. Los informes internacionales de la UNESCO (European Commission, 2014) reconocen que el potencial educativo y cultural de las nuevas tecnologías de la información y bienestar se verán fortalecidos en la medida que las instituciones y la sociedad en general logren captar los progresos tecnológicos y facilitar la capacitación de su uso en personas con discapacidad (Koon \& Vega, 1999). Por ello, es necesario redefinir los problemas de integración de las personas con discapacidad y definir el desarrollo de nuevas tecnologías accesibles a todos sin necesidad de adaptaciones (Bars, Fuentes, Giné, \& Villoira, 2014).

Tradicionalmente, los PA se denominaban con el término“ayudas técnicas” y poco a poco se ha ido incorporando la nueva terminología derivada de la clasificación ISO9999:2007, aunque aún son muchos los términos con los que sehace referencia a estos productos y se podría decir que todavía no existe un claro consenso sobre como denominarlos. Por ejemplo, en la literatura científica se pueden encontrar referencias a los productos de apoyo con términos como: dispositivos de apoyo (DA), tecnologías de apoyo (TA), productos de apoyo (PA) o ayudas técnicas (siendo esta última una de las denominaciones más utilizada). En los países de habla inglesa se hace referencia a estos productos como "assistive technology" (AT) o en algunos casos "assistive devices". Esta denominación fue propuesta en la legislación norteamericana por el Technology-Related Assistance for Individuals with Disabilities Act of 1988 (Assistive Technology Act, 1998), pero el concepto es bastante anterior a la legislación (Scherer, 2002). 
Hay muchas definiciones diferentes de los PA y, entre ellas, cabe destacar algunas. Por ejemplo, la ofrecida por Cook y Polgar (2003) que los definen como "un amplio rango de dispositivos, servicios, estrategia y prácticas que son concebidas y aplicadas para disminuir los problemas experimentados por las personas con algún tipo de discapacidad” (p. 8). O la definición del proyecto europeo de "Horizontal European Activities in Rehabilitation Technology” (HEART), que ofrece una nueva perspectiva de estos productos y sus resultados, estableciendo como objetivo de los productos de apoyo "contribuir a su incorporación efectiva en la vida de las personas con discapacidad y personas mayores, ayudando a superar y resolver sus problemas funcionales, reduciendo la dependencia de otros y contribuyendo a su integración dentro de sus familias y de la sociedad" (Swedish Institute of Assistive Technology, 2010). Con independencia de que estemos de acuerdo con los planteamientos de muchas de las definiciones, en este estudio, emplearemos el término de productos de apoyo para hacer referencia al mismo concepto y definición establecida por la norma ISO 9999:2007 que ya hemos descrito al principio de este apartado. La norma UNEEN ISO 9999 define los productos de apoyo como "cualquier producto (incluyendo dispositivos, equipo, instrumentos y software) fabricado especialmente o disponible en el mercado, para prevenir, compensar, controlar, mitigar o neutralizar deficiencias, limitaciones en la actividad y restricciones en la participación". Los productos de apoyo incluyen desde sillas de ruedas, cubiertos adaptados, software específicos hasta los propios del colectivo de personas con discapacidad auditiva.

La oferta de productos de apoyo es muy amplia y diversa, y cada surgen nuevos productos para cubrir las heterogéneas necesidades de las personas con discapacidad. Estos productos van desde las prótesis y órtesis hasta tecnologías como las aplicaciones informáticas para plataformas móviles (apps), pasando por los dispositivos que facilitan la realización actividades básicas tales como la alimentación, higiene, vestido u otras más complejas, como las actividades instrumentales o avanzadas como son la conducción de un vehículo o la práctica deportiva (Proyecto EASTIN, 2005). Dada esta gran variedad, es difícil estimar el número de productos de apoyo existentes, aunque hay autores y entidades, como por ejemplo la Dirección de Empleo y Asuntos sociales de la Comisión Europea, que estiman la existencia de unos 20.000 productos diferentes; sin embargo, otros autores como Scherer (2002), proponen la existencia de unos 26.000 productos. Con independencia de estas estimaciones, lo que parece claro es que el gran número de productos ha conducido a la 
creación de distintos modos de clasificar los productos. En el siguiente apartado se revisan brevemente las principales clasificaciones y sus características principales.

Al igual que el número de PA aumenta, también aumenta el número de estudios centrados en este campo. Un modo de observar este aumento es analizar la literatura científica de los últimos años, para describir la tendencia en el número de investigaciones que contienen la palabra clave "assistive technology". En la siguiente figura se muestra el resultado de un análisis bibliométrico realizado a partir de todos los artículos indexados en las fuentes recogidas en EBSCO Academic Search desde el año 2000 hasta 2015. Como se puede observar, se verifica una tendencia creciente en el número de investigaciones publicadas que contienen el término "assistive technology".

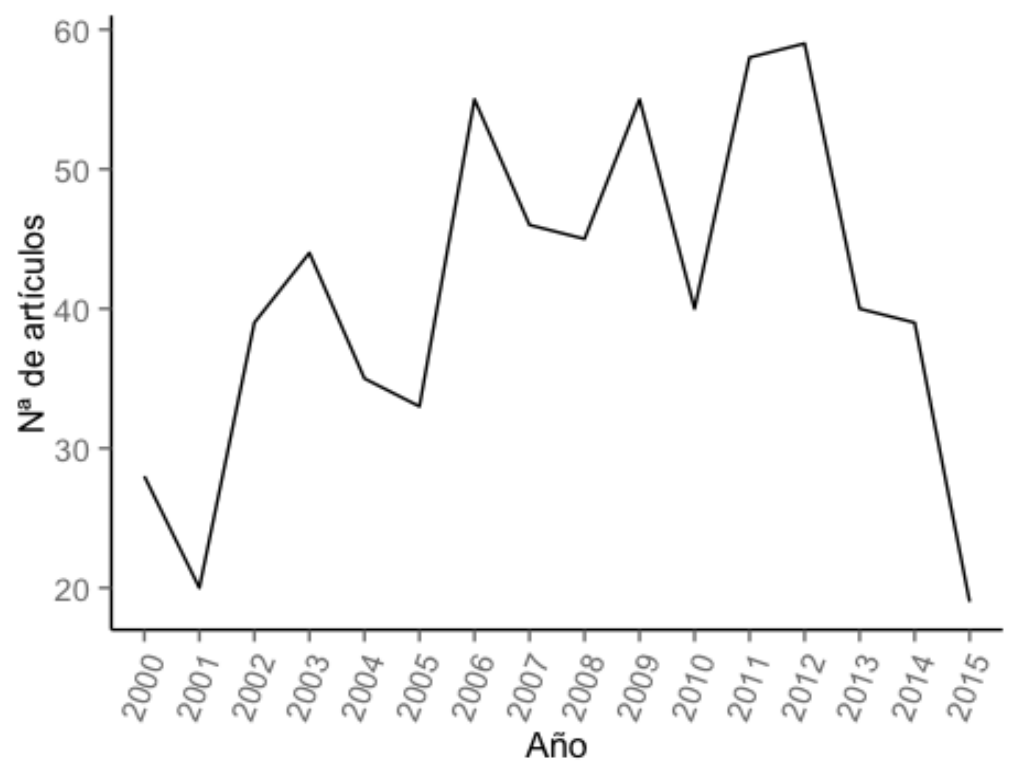

Figura 1.- Número de artículos con la palabra clave "assistive technology" publicados por año de 2000 a 2015. Fuente: Elaboración propia a partir de datos de EBSCO Academic Search

También es de destacar el interés por el tema de los productos de apoyo desde disciplinas variadas. Una forma de ponerlo de manifiesto es observar las revistas que publican trabajos relacionados con el tema. Para ello, se calculó la frecuencia de artículos por revista durante el período seleccionado, con el objeto de mostrar las revistas en las que se publican más estudios. Entre ellas, cabe destacar las mostradas en la siguiente tabla. 
Tabla 1.- Revistas con más de 5 publicaciones que contienen la palabra clave "assistive technology" y número de artículos publicados de 2000 a 2015

\begin{tabular}{lr}
\hline Revista & N $^{\circ}$ de artículos \\
\hline Technology \& Disability & 64 \\
Journal of Visual Impairment \& Blindness & 40 \\
Disability and Rehabilitation: Assistive Technology & 36 \\
Journal of Special Education Technology & 30 \\
Assistive Technology & 25 \\
Assistive Technology Outcomes and Benefits & 15 \\
TEACHING Exceptional Children & 14 \\
Disability and Rehabilitation: An International, Multidisciplinary Journal & 13 \\
Topics in Early Childhood Special Education & 12 \\
Disability \& Rehabilitation & 12 \\
Equipment Services & 12 \\
NeuroRehabilitation & 11 \\
Journal of Disability Policy Studies & 10 \\
Journal of Vocational Rehabilitation & 10 \\
Work: Journal of Prevention, Assessment \& Rehabilitation & 10 \\
Journal of Rehabilitation Research \& Development & 9 \\
American Journal of Physical Medicine \& Rehabilitation & 8 \\
Early Childhood Education Journal & 7 \\
Education and Training in Developmental Disabilities & 7 \\
Reading Research Quarterly & 7 \\
Developmental Disabilities Bulletin & 5 \\
Gerontologist & 5 \\
The British Journal of Occupational Therapy & 5 \\
Eiagnostique & 5 \\
Infants and Young Children & 5 \\
International Journal of Therapy \& Rehabilitation & 6 \\
Sournal of Learning Disabilities & 5 \\
\hline
\end{tabular}

Como se puede apreciar, hay revistas de distintos momentos evolutivos (desde la infancia hasta la edad adulta), de disciplinas variadas (terapia ocupacional, rehabilitación, educación, servicios sociales, etc.) y dedicadas a distintos perfiles de discapacidad.

Otra forma de analizar globalmente la investigación sobre PA es observar las tendencias de las publicaciones atendiendo a las palabras clave utilizadas para describirlas. De acuerdo con Granda et al. (2005), las palabras clave no solo son útiles para la realización de una búsqueda bibliográfica, sino que van más allá y pueden servir para estudiar y analizar trabajos por materia, evidenciando corrientes investigadoras y aspectos de interés de los investigadores. En la Figura 2 se muestra una nube de etiquetas, que representa un análisis de 
frecuencia de palabras clave de las investigaciones sobre productos de apoyo de los últimos años. El tamaño de cada término es proporcional a su frecuencia de aparición.

Figura 2.- Palabras clave en el campo de la investigación en PA y personas con discapacidad

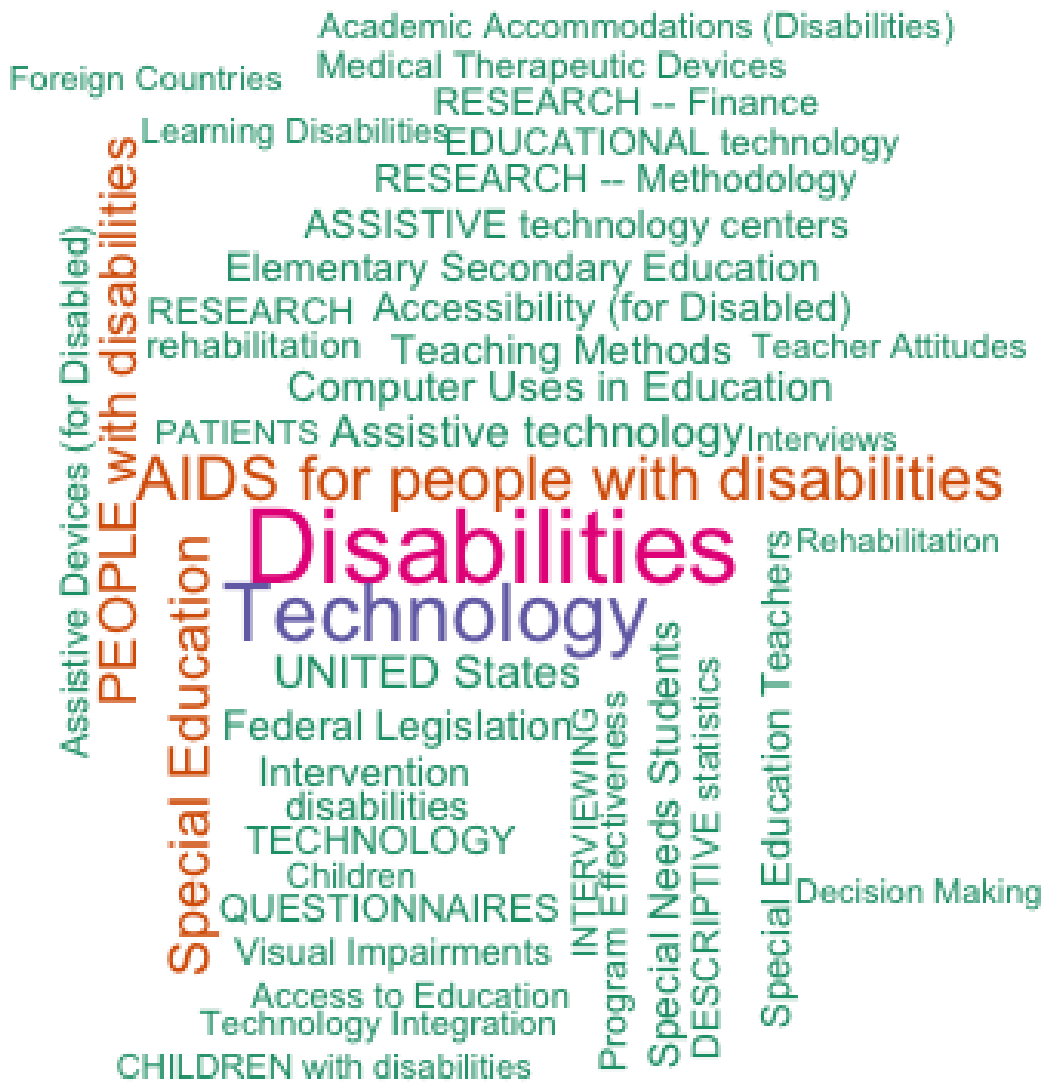

Si prestamos atención a la figura anterior podemos ver que el ámbito predominante en el campo de los PA es el ámbito educativo con palabras clave como: educación, uso del ordenador, dificultades de aprendizaje, alumnos con necesidades educativas especiales, acceso a la educación, efectividad de los programas, actitudes del profesorado, metodología de profesorado, adaptaciones académicas y educación y tecnología. Por ello, a partir de este análisis, podríamos decir que las investigaciones en el campo de los PA predominan las de índole educativo frente a otras. No obstante, también debemos prestar atención a otras palabras clave como integración tecnológica, efectividad de los programas, rehabilitación, accesibilidad y escalas de PA para personas con discapacidad, todas ellas palabras clave más ligadas a la temática de esta Tesis Doctoral. Sin embargo, como se observa en la figura, la discapacidad predominante en el estudio de PA en la visual y en edad infantil, y por el contrario nuestro estudio va enfocado a una población con discapacidad auditiva y adulta. 
Por último, para complementar este breve estudio bibliométrico, se realizó una búsqueda bibliográfica más específica cuyo objetivo era obtener los trabajos pertenecientes a la cúspide de la pirámide de la evidencia científica (i.e., revisiones sistemáticas y metaanálisis). Para ello se utilizaron como términos de búsqueda: assistive technology, disability, sistematic review, metaanalysis and outcomes. En la siguiente tabla se muestran los artículos encontrados por campo de interés. Cabe señalar que no se encontraron revisiones sistemáticas o metaanálisis en medidas de resultados en PA para el colectivo de personas sordas. Sin embargo, si se encontraron revisiones para otras discapacidades, tales como la discapacidad física $(n=18)$, discapacidad cognitiva $(n=4)$, visual $(n=2)$, discapacidad intelectual $(n=2)$, discapacidad adquirida $(\mathrm{n}=1)$ y discapacidad general $(\mathrm{n}=12)$. También se encontraron otras revisiones bibliográficas de otros campos como son el contexto $(n=2)$, herramientas de evaluación $(n=2)$, educación $(n=1)$, enfermería $(n=1)$, modelos conceptuales $(n=1)$, pediatría $(n=1)$ y profesionales $(n=1)$. Las revistas que cuentan con más de 3 artículos de revisión sistemática son las revistas Assistive Technology $(n=5)$, Disability and Rehabilitation $(n=4)$ y Technology and Disability $(n=4)$.

Tabla 2.- Revisiones sistemáticas en el campo de medidas de resultados y PA por ámbito/discapacidad

\begin{tabular}{|c|c|c|c|}
\hline TIPO DE DISCAPACIDAD/ámbito & AUTOR/ES & AÑO & REVISTA \\
\hline Discapacidad adquirida & Alper \& Raharinirina & 2006 & Journal of Special Education Technology \\
\hline Contexto & Ivanoff et al & 2006 & Canadian Journal of Occupational Therapy \\
\hline Contexto & Butterfield \& Ramseur & 2004 & Technology \& Disability \\
\hline D.cognitiva & de Joode & 2010 & Clinical Rehabilitation \\
\hline D.cognitiva & Sauer & 2010 & Disabiliy \& Rehabilitation \\
\hline D.cognitiva & Gillespie & 2012 & $\begin{array}{l}\text { Journal of the International } \\
\text { Neuropsycological Society }\end{array}$ \\
\hline D.cognitiva & Carswell et al & 2009 & Technology and Health Care \\
\hline D.fisica & Rogers \& Holm & 1992 & American Journal of Occupational Therapy \\
\hline D.fisica & Mortenson & 2012 & $\begin{array}{l}\text { American Journal of Physical Medicine \& } \\
\text { Rehabilitation }\end{array}$ \\
\hline D.fisica & Nicolson & 2012 & Assistive Technology \\
\hline D.fisica & Freeman \& Saidoo & 2013 & Brain Injury \\
\hline D.fisica & Harris et al & 2005 & British Journal of Occupational Therapy \\
\hline D.fisica & Davies & 2010 & $\begin{array}{l}\text { Developmental Medicine and child } \\
\text { neurology }\end{array}$ \\
\hline D.fisica & Assucena et al. & 2013 & $\begin{array}{l}\text { Journal of Physical Medicine \& } \\
\text { Rehabilitation Sciences }\end{array}$ \\
\hline D.fisica & O`Neill & 2012 & Neuropsychological Rehabilitation \\
\hline D.fisica & Kirsch & 2004 & Rehabilitation Psychology \\
\hline D.fisica & Desideri et al. & 2013 & Technology \& Disability \\
\hline D.física & Stein & 2013 & Cognitive and Behabioral Neurology \\
\hline D.física & Tuntland & 2010 & $\begin{array}{l}\text { European Journal of Physical and } \\
\text { rehabilitation medicine }\end{array}$ \\
\hline D.física & Manikam & 2014 & Journal of Child and Family Studies \\
\hline D.física & James & 2014 & Journal of Child and Family Studies \\
\hline D.física & Tung et al., & 2015 & $\begin{array}{l}\text { Journal of Rehabilitation Research \& } \\
\text { Development }\end{array}$ \\
\hline
\end{tabular}




\begin{tabular}{|c|c|c|c|}
\hline D.física & Souza & 2010 & $\begin{array}{l}\text { Journal of rehabilitation research and } \\
\text { development }\end{array}$ \\
\hline D.física & Barbosa et al.,2015 & 2015 & Neurosurgical Review \\
\hline D.física & Hoppenbrouwers & 2014 & Technology \& Disability \\
\hline D.física & Cunningham et al & 2009 & Technology and Health Care \\
\hline D.intelectual & Mechling & 2007 & $\begin{array}{l}\text { Education and Training in Developmenal } \\
\text { Disabilities }\end{array}$ \\
\hline D.intelectual & Bryan & 2010 & Exceptionality \\
\hline D.visual & Loux & 2009 & Journal of visual impairment \& Blindness \\
\hline D.visual & Jutai et al & 2009 & Journal of visual impairment \& Blindness \\
\hline Discapacidad & Rodriguez \& Alves & 2013 & Assistive Technology \\
\hline Discapacidad & Burne & 2011 & Assistive Technology \\
\hline Discapacidad & Floyd & 2008 & $\begin{array}{l}\text { Assistive Technology Outcomes and } \\
\text { Benefits }\end{array}$ \\
\hline Discapacidad & Trachtman & 1991 & $\begin{array}{l}\text { Assistive Technology: The Official Journal } \\
\text { of RESNA }\end{array}$ \\
\hline Discapacidad & Chantry \& Dunford & 2010 & British Journal of Occupational Therapy \\
\hline Discapacidad & Dymond \& Potter & 1996 & Clinical Rehabilitation \\
\hline Discapacidad & Harvey-Carter & 2007 & Developmental Disabilities Bulletin \\
\hline Discapacidad & Thornberry & 2004 & Disabiliy \& Rehabilitation \\
\hline Discapacidad & Scherer & 1998 & Disabiliy \& Rehabilitation \\
\hline Discapacidad & Rowe & 2006 & Occupational Therapy in Health Care \\
\hline Discapacidad & Brandt & 2012 & Technology \& Disability \\
\hline Discapacidad & Campbel et al & 2006 & $\begin{array}{l}\text { Topics in Early Childhood Special } \\
\text { Education }\end{array}$ \\
\hline Discapacidad & Ross \& Levitt & 2000 & Volta Voices \\
\hline Educación & Maor et al & 2011 & $\begin{array}{l}\text { European Journal of Special Needs } \\
\text { Education }\end{array}$ \\
\hline Enfermeria & Katsuya & 2011 & CIN: Computers, Informatics, Nursing \\
\hline Factor personal & Pape & 2002 & Disabiliy \& Rehabilitation \\
\hline Herramientas de evaluación & Rust \& Smith & 2005 & $\begin{array}{l}\text { American Journal of Physical Medicine \& } \\
\text { Rehabilitation }\end{array}$ \\
\hline Herramientas de evaluación & Fennema-Jansen & 2000 & Diagnostique \\
\hline Modelos conceptuales & Lenker \& Paquet & 2003 & Assistive Technology \\
\hline Pediatria & Steel \& Gray & 2009 & Assistive Technology \\
\hline Profesionales & Turner-Smith \& Devlin & 2005 & Medical Engineering \& Physics \\
\hline
\end{tabular}




\section{Marcos de referencia y modelos sobre productos de apoyo}

Son pocos las revisiones que encontramos en la literatura científica sobre el desarrollo de modelos de productos de apoyo y discapacidad. En este contexto destaca el trabajo realizado por Hersh y Johnson (2008), los cuales realizaron una división de este campo de estudio y los modelos y metodologías empleadas en el mismo. Es por ello que este apartado esta dividió en base a este trabajo en tres subapartados: metodologías de clasificación, modelos conceptuales y medidas de resultado en productos de apoyo.

\section{Metodologías de clasificación}

En el apartado anterior de consideraciones generales queda patente la dificultad de conocer la cantidad y variedad de productos existentes y es por ello que han surgido diferentes clasificaciones que centran su perspectiva en un criterio concreto; por ejemplo, según su función, contexto o carga tecnológica. Las clasificaciones y taxonomías han sido una estrategia habitual en el desarrollo de modelos sobre productos de apoyo (Hersh \& Johnson, 2008). Y entre todas las clasificaciones, destacamos destaca la ya mencionada clasificación ISO 9999:2007, que realiza su categorización según la función de los productos. Esta clasificación es la adoptada por el Centro de Referencia Estatal de Autonomía Personal (CEAPAT-IMSERSO), tanto en su catálogo de productos como en sus acciones de asesoramiento y desarrollo. Igualmente, la red europea de información sobre las tecnologías para la discapacidad y la autonomía (EASTÍN) toma la norma ISO como modelo de clasificación.

Aunque en esta tesis doctoral tomemos como referencia la norma ISO 9999:2007, existen otras normas dentro del campo de los PA, como por ejemplo la nomenclatura global de dispositivos médicos (GMDN). Esta nomenclatura es un sistema integral de descriptores codificados y reconocidos internacionalmente en el formato de los términos más empleados, junto con las definiciones que se utilizan para identificar y caracterizar genéricamente tipos de dispositivos médicos y productos de cuidado de la salud relacionados. La GMDN incluye productos utilizados en el diagnóstico, prevención, control, tratamiento o alivio de una enfermedad o lesión en los seres humanos. El concepto de un "producto sanitario" es mucho más amplio que el de "producto de apoyo", y por lo tanto el alcance de GMDN es mucho más amplio que el ámbito de aplicación de la norma ISO 9999. Por otro lado, la clasificación SNOMED CT ofrece la terminología general básica para la historia clínica electrónica, y 
contiene más de 311.000 conceptos con significados únicos y sus definiciones. Los PA forman parte de los conceptos de los "objetos físicos". La subdivisión de productos de apoyo en SNOMED CT no es idéntica a la presentada en la norma ISO 9999 ya que muchos de los PA reconocidos en esta son reconocidos en el mercado como productos sanitarios. Además, otros PA (por ejemplo, adaptaciones del hogar o del entorno, dispositivos de comunicación y algunos productos relacionados con la movilidad) no son meros productos de asistencia sino dispositivos médicos a su vez (Heerkens, Bougie \& de Kleijn-de Vrankrijker, 2010).

La clasificación de la norma ISO: 9999 consta de tres niveles jerárquicos y los códigos de cada uno consta de tres pares de dígitos. El primer par de dígitos indica una clase, el segundo par de dígitos una subclase y el tercer par de dígitos una división. Cuando una clase se llama de forma individual, se indica sólo el primer par de dígitos (por ejemplo, la clase 12 en lugar de la clase 120000 ) y subclases se indican con dos pares de dígitos (por ejemplo, la subclase 1203 en lugar de Subclase 1203 00). Los códigos numéricos determinan las posiciones de cada clase, subclase, o división en la clasificación. Por poner un ejemplo ver la siguiente figura

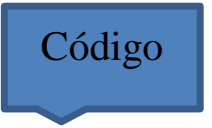

\section{Título}

050603 Productos de apoyo para el aprendizaje de la dactilología

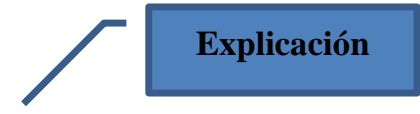

Equipo para el entrenamiento y aprendizaje del deletreo manual, es decir, comunicación táctil para personas sordo-ciegas.

Figura 3.- Ejemplo de la norma ISO: 9999

No obstante, debemos de resaltar que algunos aspectos de la norma ISO han sido muy discutidos y debatidos en algunos estudios de autores experimentados en el campo de los PA por parte de algunos autores (International Standards Organization, ISO 9999, 2005;

Shoemaker, Lenker, Fuhrer, Jutai, Demers \& DeRuyter, 2010) debido, por ejemplo, a que excluye algunos productos y servicios en su definición, tales como los elementos empleados para la instalación de PA, los PA obtenidos gracias a la combinación de dos o más PA -los cuales son clasificados de forma individual en la clasificación-, los medicamentos, los productos e instrumentos auxiliares utilizados exclusivamente por profesionales de la salud o las soluciones y servicios no técnicos (asistentes personales, perros guía o lectura labial). 
Tabla 3.- Dimensiones de clasificación de PA (tomado de Pousada, 2011)

\begin{tabular}{|c|c|c|c|}
\hline Criterio & Autores & Clasificación & Características \\
\hline $\begin{array}{l}\text { Tipo de } \\
\text { apoyo }\end{array}$ & Smith, 1991 & Tecnología de apoyo & $\begin{array}{l}\text { Productos que ayudan a la persona a desarrollar sus actividades } \\
\text { funcionales. }\end{array}$ \\
\hline ofrecido & & $\begin{array}{l}\text { Tecnología de } \\
\text { rehabilitación/educación }\end{array}$ & Productos usados para el desarrollo de capacidades y tratamiento \\
\hline \multirow[t]{2}{*}{$\begin{array}{l}\text { Carga } \\
\text { tecnológica }\end{array}$} & $\begin{array}{l}\text { Propuesto por } \\
\text { Cook \& }\end{array}$ & High Tech & $\begin{array}{l}\text { Alta carga tecnológica: difíciles de conseguir y con dispositivos } \\
\text { eléctricos. }\end{array}$ \\
\hline & Polgar, 2003 & Low Tech & Baja carga tecnológica: fáciles de hacer y conseguir. \\
\hline $\begin{array}{l}\text { Tecnologías } \\
\text { Hard Vs. }\end{array}$ & Odor, 1984 & Tecnologías Hard & $\begin{array}{l}\text { Tangibles, fácilmente disponibles y pueden ser acopladas a } \\
\text { sistemas de apoyo tecnológico. }\end{array}$ \\
\hline Soft & & Tecnologías Soft & $\begin{array}{l}\text { Son servicios, difíciles de definir y dependientes del } \\
\text { conocimiento y experiencia del prescritor }\end{array}$ \\
\hline $\begin{array}{l}\text { Aplicaciones } \\
\text { Vs. }\end{array}$ & $\begin{array}{l}\text { Vanderheiden, } \\
1987\end{array}$ & Aplicaciones & $\begin{array}{l}\text { Dispositivo que proporciona un beneficio al usuario con sus } \\
\text { capacidades funcionales }\end{array}$ \\
\hline Herramientas & & Herramientas & $\begin{array}{l}\text { Dispositivo que requiere el desarrollo de una capacidad } \\
\text { específica por parte del usuario final. }\end{array}$ \\
\hline $\begin{array}{l}\text { Tecnologías } \\
\text { máximas Vs. }\end{array}$ & $\begin{array}{l}\text { Propuesto por } \\
\text { Cook \& }\end{array}$ & Tecnologías máximas & $\begin{array}{l}\text { Dispositivos que sustituyen una capacidad específica que el } \\
\text { usuario final no posee. }\end{array}$ \\
\hline Mínimas & Polgar, 2003 & Tecnologías mínimas & $\begin{array}{l}\text { Dispositivos que proporcionan algún soporte sobre las } \\
\text { capacidades del usuario para desarrollar una tarea. }\end{array}$ \\
\hline \multirow[t]{2}{*}{$\begin{array}{l}\text { Grado de } \\
\text { especificidad }\end{array}$} & $\begin{array}{l}\text { Propuesto por } \\
\text { Cook \& }\end{array}$ & Tecnologías comerciales & $\begin{array}{l}\text { Dispositivos fabricados en masa y comercialmente disponibles } \\
\text { para personas con discapacidad }\end{array}$ \\
\hline & Polgar, 2003 & Tecnologías customizadas & $\begin{array}{l}\text { Dispositivo diseñado especialmente para cubrir una necesidad } \\
\text { concreta. Requiere un mayor nivel de soporte técnico }\end{array}$ \\
\hline $\begin{array}{l}\text { Áreas de } \\
\text { ejecución }\end{array}$ & $\begin{array}{l}\text { Cook \& } \\
\text { Hussey, } 1995\end{array}$ & $\begin{array}{l}\text { Sistemas aumentativos y } \\
\text { alternativos de la comunicación } \\
\text { Tecnologías para la movilidad } \\
\text { personal } \\
\text { Tecnologías para la manipulación } \\
\text { y el control del entorno } \\
\text { Ayudas sensoriales para personas } \\
\text { con discapacidad visual, auditiva } \\
\text { o táctil }\end{array}$ & \\
\hline $\begin{array}{l}\text { Ámbito de } \\
\text { aplicación }\end{array}$ & $\begin{array}{l}\text { Plippo, Inge } \\
\& \text { Barcus, } \\
1995\end{array}$ & $\begin{array}{l}\text { Comunicación aumentativa } \\
\text { Movilidad } \\
\text { Tecnología para personas con } \\
\text { problemas sensoriales } \\
\text { Aplicaciones y estrategias para el } \\
\text { aprendizaje escolar } \\
\text { Adaptaciones del puesto de } \\
\text { trabajo } \\
\text { Ocio, deporte y tiempo libre }\end{array}$ & \\
\hline Función & $\begin{array}{l}\text { Alcantud, } \\
2000\end{array}$ & $\begin{array}{l}\text { Sistemas de habilitación, aprendizaje } \\
\text { y entrenamiento } \\
\text { Sistemas alternativos y aumentativos } \\
\text { de acceso a la información del entorno } \\
\text { Tecnología de acceso al ordenador } \\
\text { Sistemas alternativos y aumentativos } \\
\text { de comunicación } \\
\text { Tecnologías para la movilidad } \\
\text { personal } \\
\text { Tecnologías para la manipulación y el } \\
\text { control del entorno } \\
\text { Tecnologías de la rehabilitación } \\
\text { Tecnologías asistenciales } \\
\text { Tecnologías para el deporte, ocio y } \\
\text { tiempo libre } \\
\text { Tecnologías para la vida diaria }\end{array}$ & \\
\hline \multirow[t]{2}{*}{ Complejidad } & $\begin{array}{l}\text { Basil et al, } \\
1998\end{array}$ & $\begin{array}{l}\text { Ayudas técnicas básicas } \\
\text { Ayudas mecánicas, eléctricas o } \\
\text { electrónicas sencillas, de baja } \\
\text { tecnología }\end{array}$ & $\begin{array}{l}\text { Fácil fabricación y bajo coste } \\
\text { Instrumentos más complejos que los anteriores, pero de fácil } \\
\text { manejo por los usuarios }\end{array}$ \\
\hline & & Ayudas electrónicas complejas & Dispositivos de apoyo que ofrecen amplias posibilidades \\
\hline
\end{tabular}




\section{Modelos conceptuales}

Los modelos conceptuales son empleados por los profesionales de una disciplina porque ofrecen no solo una base teórica, sino que también ayudan a realizar preguntas, interpretar resultados y a guiar a los profesionales en la práctica clínica (incluso tienen un papel importante en la función científica). Rosen (1989) clasificó los modelos conceptuales en:

1. Prototipo que merece imitarse, por ejemplo, un ciudadano modelo o un centro de servicios modelo.

2. Un enfoque común o clásico, que a menudo contrasta con otras maneras de hacer las cosas, por ejemplo, el modelo médico.

3. Una estructura, taxonomía o descripción unificadora de una materia, por ejemplo, el modelo de comunicación aumentativa.

4. Un rasgo equivalente o sustitutivo de otros organismos que muestran características similares a las de un fenómeno humano, por ejemplo, un modelo de ratón para la distrofia muscular de Duchenne.

5. Una hipótesis o explicación conjetural para predecir el comportamiento de un sistema, por ejemplo, el modelo teórico de la espasticidad.

6. Una descripción matemáticamente precisa del comportamiento de un sistema la cual no explica necesariamente la causa subyacente del comportamiento, por ejemplo, la ley de Fitts (Fitts, 1954).

Por poner algunos ejemplos, según Sanders (1976, citado en Lloyd, Quist y Windsor, 1990), los modelos estructuran el conocimiento y ofrecen una perspectiva para examinar nuevos problemas, facilitar la integración de nuevos parámetros y las relaciones, además de aportar una estructura para organizar y evaluar los servicios profesionales. Igualmente, Edyburn (2002) describe los modelos como una ayuda a los trabajadores clínicos e investigadores para atender las variables, relaciones y sistemas que estimulen el avance teórico, la investigación y por tanto al desarrollo de normas y prácticas.

La estructura de los modelos conceptuales en el campo de los PA es muy variada y hay propuestas que van desde modelos de evaluación de los PA, clasificación de los PA, utilización de los PA (Gitlin, 1998; Light, 1999), modelos para evaluar las alternativas de diseño (Staney \& Maxey, 1997) o modelos para analizar los estados, regiones y países (Scherer \& Vitalit, 1997), por citar algunos ejemplos. 
En lo que se refiere a los modelos conceptuales de clasificación de los PA, podemos citar algunos de los principales:1) The Human Activity- Assistive Technolgoy (HAAT) model; (Cook \& Hussey, 2002); 2) The International Classification of Functioning Disability, and health (CIF) model; 3) the Matching Person and Technology (MPT) model (Scherer, 1998); 4) Gitlin's biopsychosocial model of an AT user's “career” (Gitlin, 1998); 5) Social cognition decision-making theories (Ajzen, 2002;Armitage \& Conner,2000;Carter,1990;Roelands, Van Oost Depoorter \& Bysse, 2002); 6) el Perceived Attributes theory for prediction consumer adoption of product innovations (Cass, 1999; Rogers, 1995) o 7) Comprehensive Assistive Technology (CAT)(Hersh \& Johnson, 2008)

Tabla 4. Principales modelos para la selección de productos de apoyo (tomado y adaptado de Pousada, 2011)

\begin{tabular}{|c|c|c|c|}
\hline Modelo & Autor & Características & Instrumentos de medida \\
\hline $\begin{array}{l}\text { Matching Person and } \\
\text { Technology Model } \\
(\text { MPT)(Scherer, 2002) }\end{array}$ & $\begin{array}{l}\text { Scherer, } \\
1998\end{array}$ & $\begin{array}{l}\text { Facilita la selección del PA más adecuado según las } \\
\text { perspectivas y habilidades del usuario, las } \\
\text { características del dispositivo y los factores } \\
\text { contextuales. }\end{array}$ & $\begin{array}{l}\text { Assistive Technology Device } \\
\text { Predisposition Assessments } \\
\text { (ATD PA); } \\
\text { Matching Assistive Technology } \\
\text { and Child (MATCH) }\end{array}$ \\
\hline $\begin{array}{l}\text { Marco de trabajo para un } \\
\text { modelo de selección de } \\
\text { Tecnología de Apoyo (Scherer } \\
\text { et al., 2007) }\end{array}$ & $\begin{array}{l}\text { Scherer et } \\
\text { al., } 2007\end{array}$ & $\begin{array}{l}\text { Línea base conceptual para la organización de todos } \\
\text { los factores relevantes que influyen en la selección de } \\
\text { PA }\end{array}$ & $\begin{array}{l}\text { Se recomienda el uso del ATD } \\
\text { PA. }\end{array}$ \\
\hline $\begin{array}{l}\text { Model of Human Activity } \\
\text { Assistive Technology } \\
\text { (HAAT)(Cook \& Hussey, } \\
\text { 2003) }\end{array}$ & $\begin{array}{l}\text { Cook \& } \\
\text { Hussey, } \\
2002\end{array}$ & $\begin{array}{l}\text { Se centra en la interacción de las habilidades de la } \\
\text { persona para ejecutar una actividad dentro de un } \\
\text { contexto en el que el PA favorece la ejecución }\end{array}$ & $\begin{array}{l}\text { No se ha desarrollado ningún } \\
\text { instrumento de evaluación }\end{array}$ \\
\hline $\begin{array}{l}\text { Model of AT User's Career } \\
\text { (The Institute for Matching } \\
\text { Person \& Technology, 2010) }\end{array}$ & Gitlin, 1998 & $\begin{array}{l}\text { Se basa en las diferentes etapas durante el uso de un } \\
\text { PA y los factores interrelacionados que pueden influir } \\
\text { en el uso o no uso }\end{array}$ & $\begin{array}{l}\text { No se ha desarrollado ningún } \\
\text { instrumento de evaluación }\end{array}$ \\
\hline $\begin{array}{l}\text { Modelo socio-cognitivo de } \\
\text { dispositivos de apoyo } \\
\text { (Roelands, Van Oost, Depoorter } \\
\text { \& Buysse, 2002) }\end{array}$ & $\begin{array}{l}\text { Roelands et } \\
\text { al., } 2002\end{array}$ & $\begin{array}{l}\text { Se centra en el uso de la tecnología de apoyo y } \\
\text { describe los factores que influyen en el mismo }\end{array}$ & $\begin{array}{l}\text { No se ha desarrollado ningún } \\
\text { instrumento de evaluación }\end{array}$ \\
\hline Modelo de la Cognición social & $\begin{array}{l}\text { Carter, } \\
1990\end{array}$ & $\begin{array}{l}\text { Describe la intención de la persona para llevar a cabo } \\
\text { un comportamiento en un espacio definido, sin } \\
\text { centrarse en el contexto físico o habilidades físicas } \\
\text { del usuario }\end{array}$ & $\begin{array}{l}\text { No se ha desarrollado ningún } \\
\text { instrumento de evaluación }\end{array}$ \\
\hline $\begin{array}{l}\text { The perceived attributes Theory } \\
\text { (Lenker \& Paquet, 2003) }\end{array}$ & $\begin{array}{l}\text { Rogers, } \\
1995\end{array}$ & $\begin{array}{l}\text { Describe un proceso de adaptación de la persona } \\
\text { hacia un nuevo producto o práctica para su uso en la } \\
\text { vida diaria }\end{array}$ & $\begin{array}{l}\text { No se ha desarrollado ningún } \\
\text { instrumento de evaluación }\end{array}$ \\
\hline $\begin{array}{l}\text { Lifespace Access Profile for } \\
\text { Individual with Severe or } \\
\text { Multiple Disabilities } \\
\text { (LAP)(Williams, Stemach, } \\
\text { Wolfe \& Stanger, 1995) }\end{array}$ & $\begin{array}{l}\text { Williams et } \\
\text { al., } 1995\end{array}$ & $\begin{array}{l}\text { Tiene un enfoque centrado en el cliente y los datos se } \\
\text { centran en observaciones a través de varios pasos en } \\
\text { un programa comprensivo utilizando la tecnología. }\end{array}$ & $\begin{array}{l}\text { Protocolo LAP: recursos físicos, } \\
\text { recursos cognitivos, recursos } \\
\text { emocionales, recursos de apoyo } \\
\text { y análisis del entorno }\end{array}$ \\
\hline $\begin{array}{l}\text { Student, Environment, Task } \\
\text { and Tools (SETT) }\end{array}$ & $\begin{array}{l}\text { Zabala, } \\
1998\end{array}$ & $\begin{array}{l}\text { Guía para el registro de datos con el fin de tomar } \\
\text { decisiones efectivas en PA. Está orientada a } \\
\text { estudiantes con discapacidad }\end{array}$ & $\begin{array}{l}\text { Cuestionario SETT: Estudiante } \\
\text { (habilidades y necesidades), } \\
\text { entorno (físico e institucional), } \\
\text { tareas (actividades y barreras) y } \\
\text { herramientas (PA y servicios) }\end{array}$ \\
\hline Education Tech Points (ETP) & $\begin{array}{l}\text { Reed and } \\
\text { Bowser, } \\
1998\end{array}$ & $\begin{array}{l}\text { Es una herramienta para ayudar a los equipos de } \\
\text { educación a determinar y satisfacer las necesidades } \\
\text { del estudiante sobre PA y evaluar y mejorar el } \\
\text { servicio de provisión }\end{array}$ & Hojas de evaluación \\
\hline $\begin{array}{l}\text { Wisconsin Assistive } \\
\text { Technology Initiate } \\
\text { (WATI)(Wilconsin Assistive } \\
\text { Technology Initiate, 1998) }\end{array}$ & $\begin{array}{l}\text { WATI, } \\
1998\end{array}$ & $\begin{array}{l}\text { Proporciona un marco comprensivo para el proceso } \\
\text { de evaluación de PA. Está dirigido a niños con } \\
\text { discapacidad }\end{array}$ & $\begin{array}{l}\text { Guía de consideración; guía de } \\
\text { información del estudiante; guía } \\
\text { para la observación del entorno; } \\
\text { guía para la toma de decisiones; } \\
\text { lista de comprobación; guía de } \\
\text { prueba del PA }\end{array}$ \\
\hline
\end{tabular}




\section{Medidas de resultados en productos de apoyo}

Es necesario conocer las medidas de resultados (outcomes) asociadas al uso de los diferentes PA en los diferentes contextos. Pero, ¿cuál es exactamente el significado del término medidas de resultados? La definición más simple sería considerar unresultado como la consecuencia de una intervención que causa un impacto en la vida de los usuarios y su ambiente (Fuhrer, 2001; Scherer, 1998). DeRuyter (1997) lo define de manera más precisa, como el proceso de evaluación diseñado para medir y estabilizar la base del trabajo, cómo se trabaja, cuál es la intervención correcta para unpaciente y el nivel de eficiencia de esa intervención. En la investigación de medidas de resultados es necesario la descripción y medición de los atributos percibidos gracias al uso de PA para poder identificar las relaciones causales entre las variables dependientes e independientes, detección de factores que pueden causar confusión y comparar resultados entre los estudios llevados a cabo mediante unos buenos procedimientos en la práctica clínica cotidiana (Concoran, 2008; Moncher \& Prinz, 1991; Scott \& Sechrest, 1989; Sechrest, West, Phillips, Redner \& Yeaton, 1979; Sharp et al., 2005). Son muchos los autores que han discutido el uso potencial de la CIF en medidas de resultados (Arthanat \& Lenker, 2004; Jutai, Fuhrer, Demers, Scherer, \& DeRuyter, 2005; Lenker \& Jutai, 2002; Scherer \& Jutai, 2007) y son además muchos los instrumentos para la selección de PA que incluyen los componentes de la CIF (Scherer \& Sax, 2005) porque proporciona un esquema sistemático para la organización de necesidades y capacidades de los clientes tales como el de priorizar objetivos porque la CIF presta por un lado atención al funcionamiento y la discapacidad y por otro a los factores contextuales (Cushman \& Scherer, 1996; Jutai, Fuhrer, Demers, Scherer, \& DeRuyter, 2005; Hubert, 2003; Scherer, Jutai, Fuhrer, Scherer \& Glueckauf, 2005), factores no incluidos en otros modelos, incluso describe la relación entre las condiciones de salud, actividades habituales y la participación en la sociedad teniendo en cuenta estos factores (además de los personales) (WHO, 2001). Pero la CIF presenta algunas limitaciones entre las que cabe destacar la falta de componentes temporales y causales (Gray \& Herdershot, 2000) que son ambos necesarios para la predicción del modelo, además de no incluir los factores psicosociales y como estos pueden influir en la medida de resultados es una limitación de esta clasificación (Lenker \& Jutai, 2002). Incluso el mismo proceso de codificación de la CIF reduce la fiabilidad del mismo y por ello ha sido muy criticado (Smith, Jansen, Seitz \& Longenecker, 2007). 
Aunque en la literatura han surgido numerosos modelos de clasificación de PA (Lenker \& Packet, 2003) no existen modelos específicos para la predicción del uso de los PA (Fuhrer, Jutai, Scherer \& DeRuyter, 2003; Jutai, 2002). Los modelos e instrumentos en PA indicados en la literatura buscan la necesidad de práctica basada en la evidencia de (Bernd \& van der Pijl, 2009) tanto en los procedimientos como en la selección y asesoramiento de los mismos para buscar la satisfacción del consumidor y probar su eficacia. Sabemos, gracias a trabajos recientes, que la selección debe estar centrada en el usuario (Craddock, 2002) y ha de tener en cuenta su contexto y el producto en sí mismo (Hoenig et al., 2005; Hoenig, Giacobbi $\&$ Levy, 2007). Fuhrer et al. (2003) identifican cuatro categorías de resultados obtenidos en los estudios analizados: (a) medidas globales y holísticas frente a medidas específicas del dispositivo, (b) medidas objetivas frente a medidas subjetivas, (c) diferentes perspectivas (usuario, familia, profesor) y (d) empleando las definiciones CIF de discapacidad y funcionalidad.

Son muchos los investigadores (DeRuyter, 1997; Gray, Quatrano \& Lieberman; Jutai, Ladak, Schuller, Naumann \& Wright, 1996) que sugieren que el modelo de la CIF es útil en cuanto a medidas de resultados y PA y es el modelo más específico de selección de PA (Lenker \& Paquet, 2003; Ripat \& Booth,2005; Verza et al., 2006). Por ejemplo, las clasificaciones EASTIN (EASTIN, 2010) e ISO 9999:2007 toman la CIF como modelo de referencia (Bernd \& van der Pijl, 2009). Aunque son pocos los autores como Scherer que menciona el uso combinado de la CIF y la ISO 9999 en el proceso de selección de PA (Scherer \& Glueckauf, 2005; Scherer, Sax, Vanbiervliet, Cushman \& Scherer, 2005; Wessels et al., 2000).

CIF

ISO9999
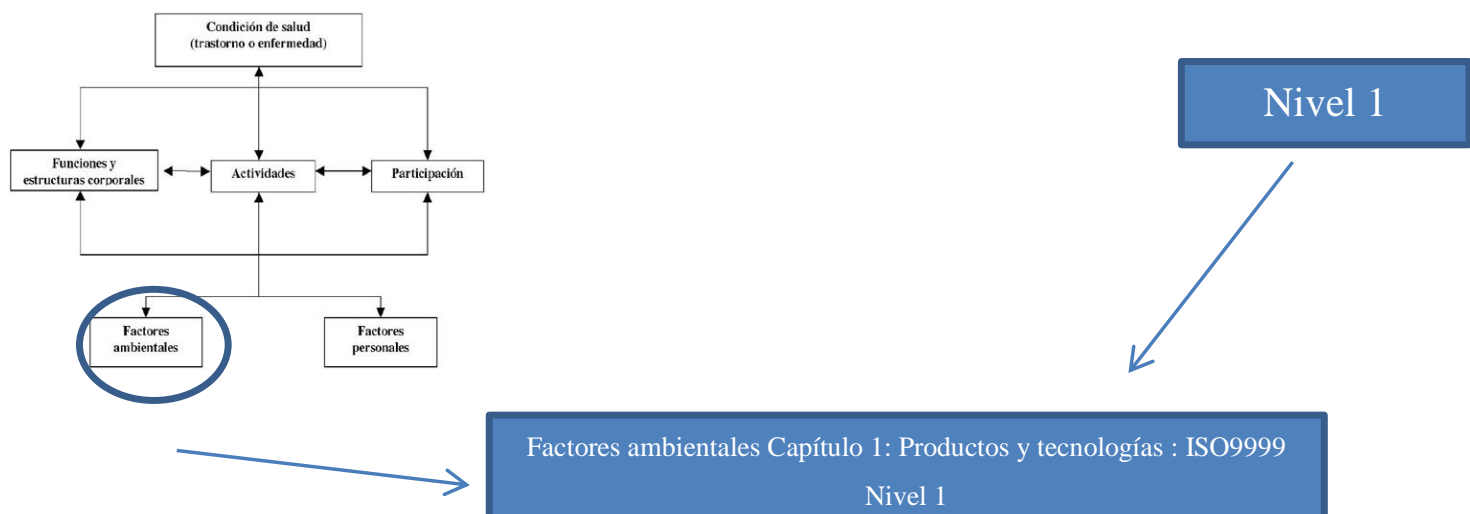

Factores ambientales Capítulo 1: Productos y tecnologías : ISO9999 Nivel 1

Figura 4. Relación entre los factores ambientales de la CIF y el primer nivel de clasificación de la ISO (Tomado de Heerkens, Bougie \& de Kleijn-de Vrankrijker, 2010) 
La consideración de la información de estos dos apartados es fundamental en el diseño, selección, implementación y evaluación de los PA y también en la investigación de diferentes aspectos del desarrollo y uso de la tecnología de apoyo.

La globalización permite acortar las distancias y las barreras comunicativas y representan un papel importante para el desarrollo y el fomento del bienestar en condiciones de equidad social. Debido al cambio del paradigma médico al paradigma bio-psico-social hay una tendencia al enfoque de los derechos humanos (Bickenbach, 2001) estos hacen hincapié en la inclusión y participación en todos los aspectos de la vida como señala el artículo 25 de la ONU en la Convención de los Derechos de las Personas con Discapacidad (United Nations, 2006). Los cambios en los servicios sociales y más en las áreas de rehabilitación son debidos al cambio en la población diana, aumento de la esperanza de vida, mayor envejecimiento y de enfermedades crónicas y multimorbilidad. Por lo que el campo de la rehabilitación se encuentra con dos retos: por un lado proporcionar mejor tratamiento y por otro, reducir los costos de la atención (Scherer, 2002). Por ello la investigación en medidas de resultados y PA es de vital importancia y no sólo por su relevancia científica sino para mejorar los tratamientos y reducir costes.

En 1990 el grupo liderado por Sackett lanzó el concepto de práctica basada en la evidencia (PBE) cuyo objetivo era incrementar la eficiencia y efectividad de los tratamientos. Desde entonces este concepto ha adquirido una gran relevancia dentro de la atención sanitaria y comienza dentro de los servicios sociales. ("Assistive Technology Outcomes Research," 2012). La PBE conduce a un mayor desarrollo y contribuye el razonamiento clínico. Muchos países la usan para establecer prioridades en la intervención por lo que existe la necesidad de que sea confiable y actualizada. Aunque existe muy poca investigación en PBE y PA y sobre todo relacionado con la realización de actividades y participación laboral, hogar y tiempo libre. Son varios los autores que tratan el tema de la investigación en PBE y PA. Por poner algunos ejemplos: Vincent y Routhier (concluyen que los estudios no son adecuados para los profesionales y proponen futuras líneas de investigación), Lenker (discurre sobre la cuestión de que si se desconoce los aspectos de una intervención como las necesidades el usuario, la selección del PA o la inclusión en el servicio del usuario no se puede obtener resultados basados en la PBE), Hoening (abarca el aspecto de la prestación de los servicios de un PA y la predicción de la duración del uso de los mismos) y Anttila y Vincent y Routhier por otra parte concluyeron en sus estudios que una limitación importante de la investigación es la falta de instrumentos estandarizados. (“Assistive Technology Outcomes Research,” 2012). Es 
necesario por tanto incluir la investigación en los servicios ligados con la adquisición de PA y uso de los mismos para poder evaluar la eficacia de los mismos (Fuhrer, Jutai, Scherer \& DeRuyter, 2003). Existen varios estudios que realizan revisiones sobre PA y PBE en diferentes ámbitos tales como en artritis reumatoide (Tuntland et al., 2010), función cognitiva (Gillespie, Best \& O’Neill, 2012), discapacidad intelectual (Mecling, 2007), enfermedad de Parkinson (Cunninghaum, Nugent, Finlay, Moore \& Craig, 2009) pero apenas hay estudios sobre PBE en PA para personas sordas por lo que estudios como el presente son necesarios para mejorar nuestras prácticas profesionales y trabajar en base a la evidencia científica.

Por lo que, podríamos concluir en este apartado que a pesar de que existan numerosos modelos de clasificación y selección de PA, falta todavía mucha investigación en este campo, sobre todo en modelos de predicción de uso de los diferentes PA y en la selección centrada en el usuario, sus diferentes contextos vitales y los diferentes PA. Además podemos concluir también, que son muchos los investigadores del campo que toman el modelo de la CIF en alta consideración como una buena medida de resultados derivados del uso de PA. 
Tabla 5. El modelo de la CIF aplicado a los PA en cuanto a medidas de resultado y práctica (tomado de Lenker \& Jutai, 2002)

\begin{tabular}{|c|c|c|c|c|}
\hline $\begin{array}{l}\text { Dominio } \\
\text { CIF }\end{array}$ & $\begin{array}{l}\text { Función corporal y } \\
\text { estructuras (nivel } \\
\text { corporal) }\end{array}$ & $\begin{array}{l}\text { Actividades } \\
\text { (nivel individual) }\end{array}$ & $\begin{array}{l}\text { Participación } \\
\text { (nivel de role) }\end{array}$ & $\begin{array}{l}\text { Factores contextuales (nivel } \\
\text { social) }\end{array}$ \\
\hline $\begin{array}{l}\text { Ejemplos } \\
\text { de } \\
\text { dominios } \\
\text { relevantes }\end{array}$ & $\begin{array}{l}\text { Integridad funcional y } \\
\text { estructural vs. } \\
\text { Discapacidad. Procesos } \\
\text { psicológico normal y } \\
\text { función de sistemas } \\
\text { orgánicos: cognición, } \\
\text { sensorial, percepción, } \\
\text { motor, psicológico y } \\
\text { proceso psicológico }\end{array}$ & $\begin{array}{l}\text { Actuación de la acción o } \\
\text { actividad (cognitiva, } \\
\text { sensorial, motorico y/o } \\
\text { comportamental) que } \\
\text { facilita la actuación en } \\
\text { roles múltiples: } \\
\text { Inicial, organizar, } \\
\text { secuenciar, juzgar, } \\
\text { atención } \\
\text { Sentarse, levantarse, } \\
\text { subir, alcanzar, agarrar, } \\
\text { contener, soltar } \\
\text { Relacionarse, } \\
\text { interactuar, sobrevivir } \\
\text { Oir, hablar, ver, tocar, } \\
\text { mover } \\
\text { Leer, escribir, aprender, } \\
\text { entender }\end{array}$ & $\begin{array}{l}\text { Desenvolverse en las } \\
\text { situaciones de vida y } \\
\text { actuar según roles } \\
\text { (familia, trabajo, y } \\
\text { educación, autocuidado, } \\
\text { ocio) y tomar parte en } \\
\text { los contextos } \\
\text { específicos (físico, } \\
\text { social, cognitivo) }\end{array}$ & $\begin{array}{l}\text { Características físicas y sociales } \\
\text { que afectan al individuo pero que } \\
\text { no son específicas de las } \\
\text { habilidades o discapacidades del } \\
\text { propio individuo; por ejemplo, } \\
\text { barreras físicas en espacios } \\
\text { públicos, actitudes de los } \\
\text { trabajadores, financiación de los } \\
\text { beneficios de los servicios } \\
\text { sociales, política pública } \\
\text { - Aparatos/productos } \\
\text { - Construcción ambiental } \\
\text { - Personas (amigos, } \\
\quad \text { familiares, colegas) }\end{array}$ \\
\hline $\begin{array}{l}\text { Dominios } \\
\text { relevantes } \\
\text { de } \\
\text { tecnología } \\
\text { de } \\
\text { asistencia }\end{array}$ & $\begin{array}{l}\text { Marcapasos de corazón, } \\
\text { cadera/rodilla } \\
\text { cambiada, implante } \\
\text { coclear, bombona }\end{array}$ & $\begin{array}{l}\text { Ayudas para la movilidad: } \\
\text { sillas de ruedas, bastones, } \\
\text { muletas, andadores; prótesis } \\
\text { de miembro superior; gafas, } \\
\text { ayudas auditivas, aparatos de } \\
\text { comunicación aumentativa y } \\
\text { alternativa }\end{array}$ & $\begin{array}{l}\text { Adaptaciones laborales } \\
\text { ambientales de } \\
\text { Aparatos/ tareas; } \\
\text { adaptaciones del hogar, } \\
\text { adaptaciones del coche, } \\
\text { PA para el ordenador }\end{array}$ & $\begin{array}{l}\text { Lugares públicos accesibles, } \\
\text { construcciones, transporte, } \\
\text { comunicaciones, recreación, } \\
\text { devolución de la tercera parte } \\
\text { para PA servicios y equipos }\end{array}$ \\
\hline $\begin{array}{l}\text { Modelo } \\
\text { funcional }\end{array}$ & Medico & Medico & $\begin{array}{l}\text { Rehabilitación } \\
\text { vocacional } \\
\text { Educación } \\
\text { Empleo } \\
\text { Uso final } \\
\text { Ventaja relativa de } \\
\text { actuación y/o calidad de } \\
\text { vida }\end{array}$ & Valores sociales \\
\hline $\begin{array}{l}\text { Criterio } \\
\text { funcional }\end{array}$ & Necesidad medica & Necesidad médica & $\begin{array}{l}\text { Relevancia vocacional } \\
\text { Relevancia educativa } \\
\text { Ventaja relativa de } \\
\text { actuación y/o calidad de } \\
\text { vida }\end{array}$ & Valores sociales \\
\hline $\begin{array}{l}\text { Evaluació } \\
\mathrm{n} \text { del } \\
\text { dominio } \\
\text { específico }\end{array}$ & $\begin{array}{l}\text { Electrocardiograma, } \\
\text { presión sanguínea, } \\
\text { escala del tono } \\
\text { muscular Ashworth }\end{array}$ & $\begin{array}{l}\text { FIM, agudeza visual, test } \\
\text { audición, producción del } \\
\text { lenguaje }\end{array}$ & $\begin{array}{l}\text { Actuación laboral } \\
\text { (ejemplo, subir, } \\
\text { promocionar) } \\
\text { Actuación educativa } \\
\text { (ejemplo, grados, título) } \\
\text { Role participación } \\
\end{array}$ & $\begin{array}{l}\text { Escala de evaluación de calidad } \\
\text { ambiental }\end{array}$ \\
\hline $\begin{array}{l}\text { Periodo } \\
\text { de } \\
\text { evaluació } \\
\text { n del } \\
\text { dominio }\end{array}$ & $\begin{array}{l}\text { QUEST: Evaluación } \\
\text { Quebec del uso de la } \\
\text { satifacción con PA } \\
\text { (satisfacción del uso } \\
\text { con aparatos y } \\
\text { servicios) } \\
\text { PIADS: Escala de } \\
\text { impacto psicosocial de } \\
\text { PA (Bienestar /Calidad } \\
\text { de vida) } \\
\text { COPM: Evaluación de } \\
\text { actuación de la } \\
\text { ocupación canadiense } \\
\text { ATDPA: Evaluación a } \\
\text { la predisposición de uso } \\
\text { de PA }\end{array}$ & & & \\
\hline
\end{tabular}




\section{Herramientas de evaluación}

Los modelos conceptuales tanto de evaluación como de clasificación han generado distintas herramientas de evaluación, cuya finalidad principal es obtener información importante para la toma decisiones, asesoramiento y medida de resultados en las intervenciones realizadas con PA. Estas herramientas son de vital importancia para realizar intervenciones basadas en la evidencia. Estas herramientas van desde instrumentos generales aplicables en distintos perfiles de discapacidad, como la escala PIADS (Psychosocial Impact of Assistive Devices; Day \& Jutai, 1996), el MPT (Matching Person \& Technology; Scherer \& Craddock, 2002) o la escala QUEST (Evaluation of satisfaction with assistive technology; Demers, Weiss- Lambrou \& Ska, 1996), hasta otros instrumentos de aplicación específica en personas con problemas de audición como el SADL (Satisfaction with Amplification in Daily Life; Cox \& Alexander, 1999) o el ECHO (Cox \& Alexander, 2000; Expected Consequences of Hearing Aid Ownership).

Una de las limitaciones de las herramientas de evaluación es que los nuevos instrumentos suman una tarea de formación más a los profesionales (Edyburn \& Smith, 2004). Por ejemplo el proyecto EUSTAT destacó esta misma limitación y concluía que es de vital importancia para el éxito o fracaso de los PA y además que la metodología a seguir debe ser centrada en el usuario del PA (EUSTAT Consortium, 1998). 
Tabla 6. Principales herramientas de evaluación en productos de apoyo (Tomado y Adaptado de Pousada, 2011).

\begin{tabular}{|c|c|c|c|}
\hline Herramienta & Modelo/Nivel & Dominio & $\begin{array}{l}\text { Constructos/Ámbitos } \\
\text { evaluados }\end{array}$ \\
\hline $\begin{array}{l}\text { Psychosocial Impact of } \\
\text { Assistive Devices Scale } \\
\text { (PIADS) }\end{array}$ & $\begin{array}{l}\text { Psicosocial (medida de } \\
\text { calidad de vida) }\end{array}$ & $\begin{array}{l}\text { Impacto de los PA en la } \\
\text { calidad de vida de los } \\
\text { usuarios }\end{array}$ & $\begin{array}{l}\text { Competencia } \\
\text { Adaptabilidad } \\
\text { Autoestima }\end{array}$ \\
\hline $\begin{array}{l}\text { The Quebec user evaluation } \\
\text { of satisfaction with assistive } \\
\text { technology (QUEST) }\end{array}$ & Satisfacción del usuario & $\begin{array}{l}\text { Evaluación de la efectividad } \\
\text { en la provisión de la } \\
\text { tecnología de apoyo }\end{array}$ & $\begin{array}{l}\text { Autocuidado } \\
\text { Movilidad } \\
\text { Transporte } \\
\text { Tareas domésticas } \\
\text { Seguridad } \\
\text { Actividades de ocio } \\
\text { Comunicación } \\
\text { Rol de actividades } \\
\text { Interacción social }\end{array}$ \\
\hline $\begin{array}{l}\text { Occupational Therapy } \\
\text { Functional Assessment } \\
\text { Compilation Tool } \\
\text { (OTFACT) }\end{array}$ & $\begin{array}{l}\text { Marco de trabajo de terapia } \\
\text { ocupacional (nivel } \\
\text { funcional) }\end{array}$ & $\begin{array}{l}\text { Determinación del impacto } \\
\text { de un producto de apoyo }\end{array}$ & $\begin{array}{l}\text { Integración de roles } \\
\text { Áreas del desempeño } \\
\text { Capacidades del desempeño } \\
\text { Componentes del desempeño } \\
\text { Entorno }\end{array}$ \\
\hline $\begin{array}{l}\text { Assistive Technology } \\
\text { Outcome Measure (ATOM) }\end{array}$ & $\begin{array}{l}\text { Medida de satisfacción del } \\
\text { usuario }\end{array}$ & $\begin{array}{l}\text { Valoración de la usabilidad } \\
\text { de un PA y servicio a corto } \\
\text { plazo }\end{array}$ & $\begin{array}{l}\text { Uso y comunidad } \\
\text { Confort } \\
\text { Molestias } \\
\text { Autopercepción de la función } \\
\text { Asistencia y sobrecarga de } \\
\text { cuidado } \\
\text { Satisfacción con el servicio } \\
\text { Conocimiento del usuario } \\
\text { sobre los recursos en PA }\end{array}$ \\
\hline $\begin{array}{l}\text { Assistive technology device } \\
\text { predisposition assessment } \\
\text { (ATD-PA) } \\
\text { The Educational Technology } \\
\text { Predisposition Assessment } \\
\text { (ET PA) } \\
\text { The Workplace Technology } \\
\text { Predisposition Assessment } \\
\text { (WT PA) } \\
\text { The Health Care Technology } \\
\text { Predisposition Assessment } \\
\text { (HCT PA) }\end{array}$ & $\begin{array}{l}\text { Matching Person and } \\
\text { technology (Medida de } \\
\text { calidad de vida) }\end{array}$ & $\begin{array}{l}\text { Consideración de las } \\
\text { influencias del uso de PA }\end{array}$ & $\begin{array}{l}\text { Áreas funcionales } \\
\text { Aspectos que deben mejorar } \\
\text { Características psicosociales } \\
\text { del usuario } \\
\text { Autopercepción sobre el PA }\end{array}$ \\
\hline
\end{tabular}

De todos los instrumentos de evaluación desarrollados destacamos la escala PIADS, que evalúa el impacto psicosocial de los productos de apoyo, por su interés y aplicación para personas con discapacidad auditiva usuarias de PA. La escala PIADS está compuesta por tres subescalas que evalúan la competencia, la adaptabilidad y la autoestima asociadas al uso o expectativa de uso de un producto de apoyo. La subescala de competencia es sensible al desempeño y la productividad de la persona; la subescala de adaptabilidad evalúa la capacidad de participar en actividades, aceptar cambios y probar cosas nuevas; y la subescala de autoestima evalúa las emociones, felicidad, autoestima y bienestar asociados al uso del PA. Diversos trabajos han abordado el estudio de sus propiedades métricas en distintas poblaciones y en relación a distintos productos de apoyo mostrando que la escala PIADS es 
un instrumento con buenas propiedades psicométricas. Por otra parte las herramientas de la anterior tabla han sido empleadas por diferentes profesionales y con diferentes objetivos y fines, 1) el QUEST es una escala de evaluación de medidas de resultados formada por 12 ítems que evalúan la satisfacción del usuario respecto a PA y servicios. Las propiedades psicométricas han sido realizadas mediante retest, consistencia interna y análisis factorial. Fue creado tanto para uso clínico como de investigación porque provee a los profesionales un conocimiento real sobre los beneficios de los PA y justificar la necesidad de estos, mientras que como herramienta de investigación ha sido empleada para comparar resultados clínicos, calidad de vida, estatus funcional, coste y comodidad (Demers, Weiss-Lambrou, \& Ska, 1996).2) El ATOMS es una medida específica de PA desarrollado para satisfacer la necesidad de una herramienta clínica práctica para

Evaluar la usabilidad y el servicio en un formato fácil de administración corta, y que puede integrarse en un la práctica clínica sin necesidad de altos recursos. Consta de 19 preguntas para medir siete constructos : a) el uso y la comunidad (con qué frecuencia se utiliza un PA dentro y fuera del hogar ) ; b) la comodidad en el de un PA ; c) problemas ( dificultades en el establecimiento, uso y mantenimiento de un dispositivo) ; d) autoevaluación percibidade la función ; e ) la asistencia y la carga de la atención ( asistencia necesaria para la configuración y uso, y la ayuda necesaria con las actividades funcionales de; f) la satisfacción del servicio (rapidez , comunicación , la cortesía, la accesibilidad, la profesionalidad ) y g) el conocimiento del usuario de los recursos de PA (Lauer, Longenecker \& Smith, 2006). 3) OTFACT es un sistema de recopilación de datos basada en software construido sobre tricotómica (Smith, 2002; Edyburn \& Smith, 2004). Su taxonomía consiste en 950 categorías organizadas jerárquicamente en cincodominios que reflejan el enfoque de terapia ocupacional para el desempeño funcional: a) Integración en papel b) actividades de rendimiento, c) habilidades de desempeño, d) componentes de rendimiento e) contexto. Este sistema ofrece la capacidad única para sondear una categoría con una pregunta general, posteriormente se ramifican en preguntas más detalladas cuando las respuestas indican la necesidad de una mayor sensibilidad (Bhasin \& Goodman, 1992; Hammel, Sai \& Heller, 1999; Tinetti, 1999). Y por último, el MPT explora las fortalezas, limitaciones y objetivos en dos niveles: la función corporal y el desempeño. Esto es debido a que Scherer en 1998 en parte quiso preservar la terminología y perspectiva de la CIF. Los componentes relacionados con el entorno y los PA centran todo ello en las pasadas experiencias individuales y los objetivos puestos a un futuro inmediato. Esta herramienta está indicada para el uso/no uso, satisfacción de uso y el funcionamiento subjetivo del usuario. El MPT además ayuda tanto a 
las personas que realizan la propuesta de PA como trabajadores a buscar información sobre la historia de uso de nuevas tecnologías, necesidades actuales, y la disposición a la nueva tecnología. El MPT identifica usabilidad (aunque no todos sus componentes) y los factores psicosociales algo que el modelo de la CIF no tiene. Podemos ver en la literatura que lo que busca el MPT es la existencia ideal como el emparejamiento entre el consumidor y la tecnología (Lenker \& Paquet, 2003).

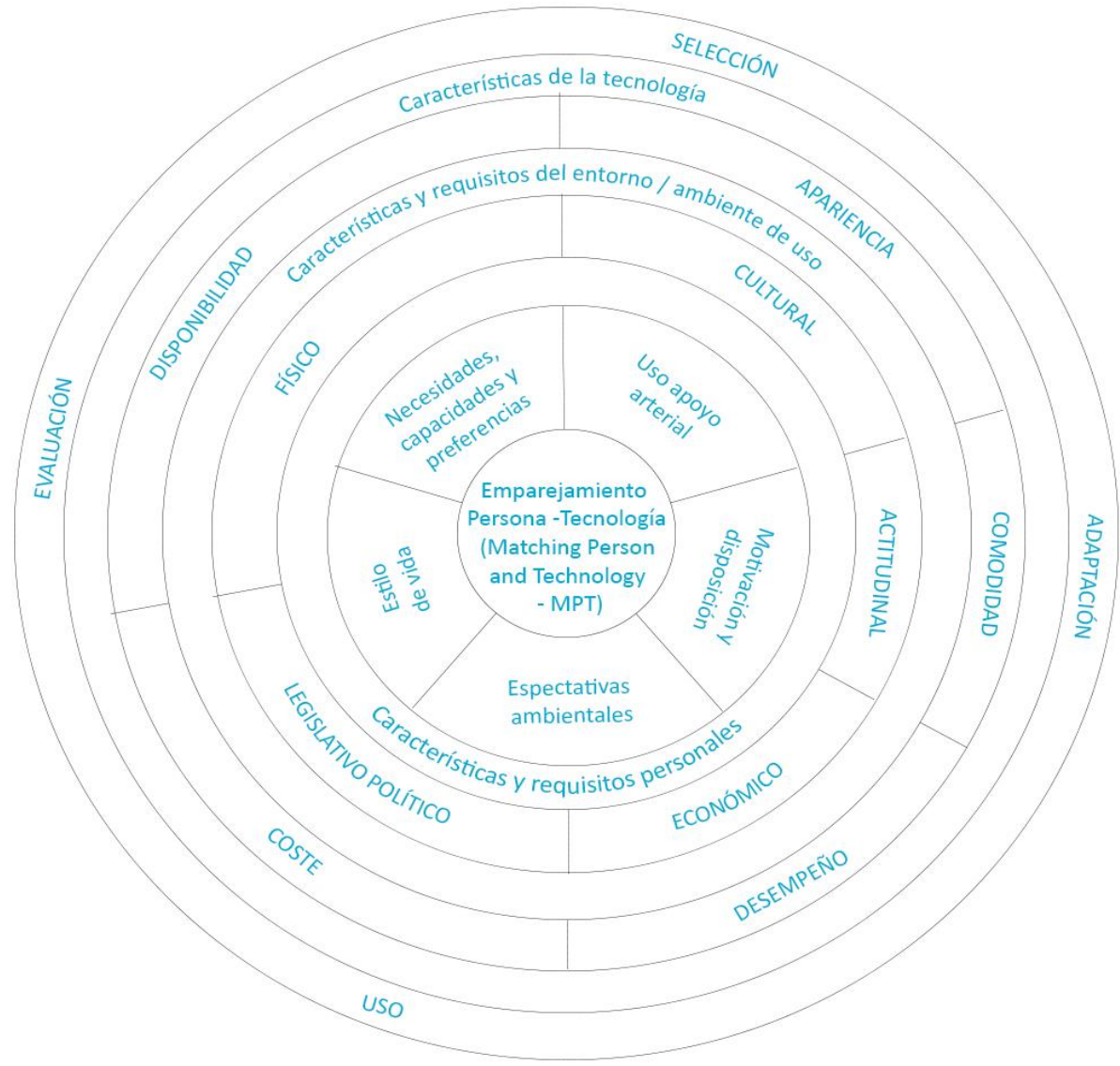

Figura 5.- Modelo Matching Person \& Technology (Scherer, 2003) 
Gracias a la literatura científica sabemos que el modelo Matching Person \& Technology y la CIF son útiles para la selección y seguimiento de los productos de apoyo (Federici \& Scherer, 2012), por ello en esta tesis doctoral hemos empleado ambos modelos en la siguiente figura se puede observar como estos dos modelos están relacionados entre sí. El MPT (Bernd et al., 2009; Scherer \& Craddock, 2002) fue desarrollado teniendo en cuenta los factores ambientales y personales respecto a los PA (tomando estos dominios de la CIF). Este modelo de emparejamiento tecnología-persona utiliza la estructura y secuencia del modelo CIF (Scherer, Sax, Vanbiervliet, Cushman, \& Scherer, 2005) y gracias a la investigación en el campo de los PA y de la salud, sabemos que la CIF ayuda al conocimiento de las capacidades y las limitaciones del usuario de PA tanto en sus actividades como en sus ámbitos de participación. Conocer los factores personales, ambientales y los relacionados con la salud ayuda a comprender los factores que influyen en la capacidad funcional del usuario (Jutai \& Day, 2002). Cuando el MPT no es aplicable o no disponemos del instrumento, el marco de la CIF puede guiar a los diferentes profesionales del campo y a los proveedores en la toma de decisiones de PA y puede ser usado para evaluar las medidas de resultados basados en la evidencia (Adams, 2003), puesto que, los factores ambientales y los personales varían con el tiempo (Scherer, Jutai, Fuhrer, Demmers \& DeRuyter, 2007) y por tanto, la CIF es una herramienta útil para evaluar habilidades del usuario y las necesidades de uso del PA.

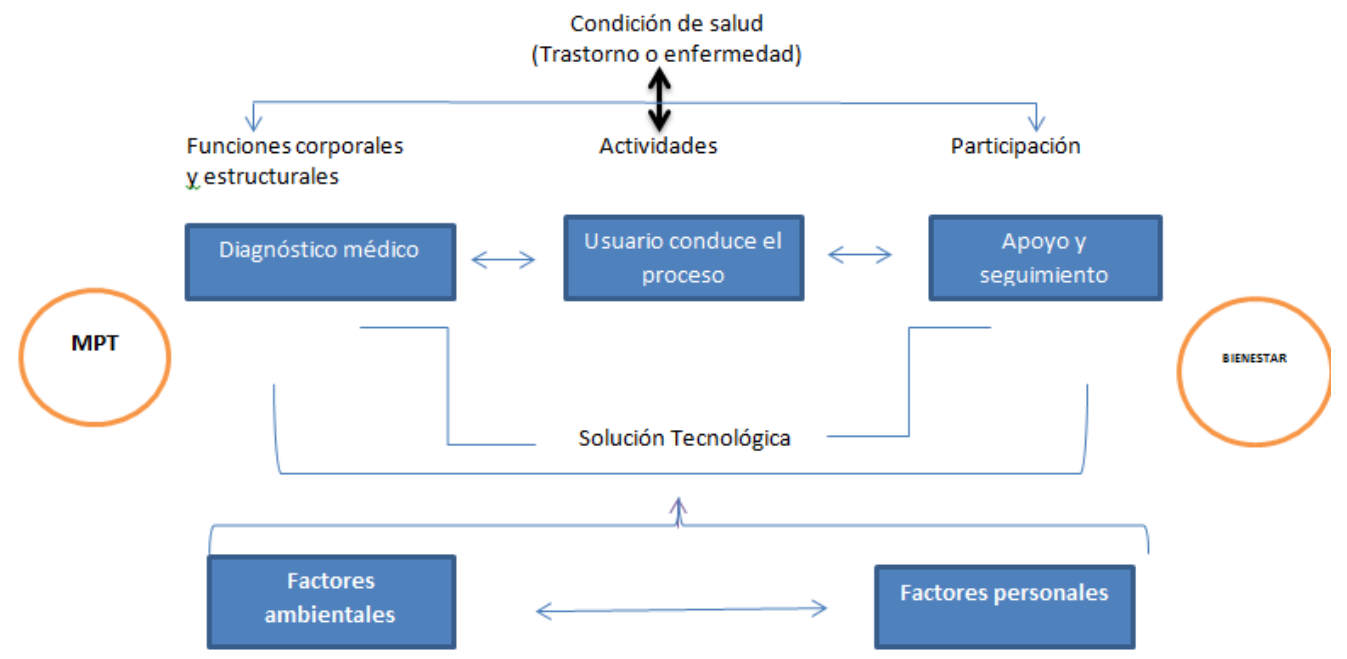

Figura 6.- Proceso de Evaluación de productos de apoyo según el Modelo biopsicosocial de la CIF. El usuario busca una solución para uno o más componentes de la CIF y la solicitud pone en marcha el proceso de Evaluación de productos de apoyo. El usuario recibe la mejor correspondencia entre usuario/cliente y solución de productos de apoyo. El Centro de ayuda técnica verifica la satisfacción y la obtención de beneficios del usuario a través de soporte y seguimiento. El bienestar del usuario prevalece siempre que la solución de productos de apoyo siga constituyendo una buena correspondencia. Tomado de Scherer, Federici, Tiberio, Pigliautile, Corradi\& Meloni, 2012. 
Estas herramientas anteriormente expuestas evalúan de manera global el PA y al usuario de un modo "macro"pero existe otro tipo de herramientas de una índole más funcional. Estas herramientas específicas “micro” incluyen métodos centrados en la evaluación de capacidades concretas mediante registros objetivos como el objeto de seleccionar el PA que más se adapte a las capacidades funcionales reales del individuo. Por poner un ejemplo de estas herramientas tenemos herramientas como 1) etao (Evaluación para el uso de Tecnologías de Ayuda de Acceso al Ordenador), 2) Compass (Koester et al., 2003, 1997) o la herramienta Assessment of Computer Task Performance (Dumont et al., 2001). Estas herramientas tienen varias posibilidades para la evaluación desde evaluar la ejecución con diferentes PA o diagnosticar dificultades de uso o evaluar la efectividad de las intervenciones (Díez, Rodríguez, Velázquez \& Hernández, 2012).En este apartado también debemos de mencionar las conocidas "guías de evaluación de PA" útiles para la práctica clínica diaria de profesionales como los terapeutas ocupacionales que deben de prescribir y adaptar diferentes PA a las necesidades de los usuarios. Necesitamos conocer el uso de la función disponible (componente humano) para la ejecución de aquello que desea (actividad) dentro de un contexto (entorno) (Cook \& Hussey, 2003). Pero en ocasiones la falta de tiempo de los profesionales o la falta de recursos o de formación, no disponen de las herramientas y competencias necesarias para la prescripción y por ello surgieron como necesidad estas “guías de evaluación de PA". Por poner un ejemplo, "Guidelines for the prescription of a seated wheelchair or mobility scooter for people with a traumatic brain injury or spinal cord injury" (EnableNSW, Lifetime Care \& Support Authority, 2011) esta guía surgió para realizar una correcta prescripción de una silla de ruedas para una persona con un traumatismo craneoencefálico o lesión medular para ver los contenidos de la misma ver la siguiente tabla. 
Tabla 7. Ejemplo de las secciones del "Guidelines for the prescription of a seated wheelchair or mobility scooter for people with a traumatic brain injury or spinal cord injury" (EnableNSW, Lifetime Care \& Support Authority, 2011

\begin{tabular}{|c|c|}
\hline Sección & Subsección \\
\hline \multicolumn{2}{|l|}{ Introducción } \\
\hline \multicolumn{2}{|c|}{$\begin{array}{l}\text { Recomendaciones metodológicas y de evidencia } \\
\text { científica }\end{array}$} \\
\hline \multicolumn{2}{|l|}{ Estructura y aproximación } \\
\hline \multicolumn{2}{|l|}{ Aspectos éticos } \\
\hline Objetivos y evaluación & Objetivos y Evaluación en medidas de resultados \\
\hline Evaluación y revisión & $\begin{array}{l}\text { Cuándo y dónde evaluar, Pedir la preinscripción, revisión, } \\
\text { modificaciones para el paciente y razones o factores de no uso }\end{array}$ \\
\hline Capacidad y desempeño & $\begin{array}{l}\text { Capacidad física, Capacidad de toma de decisiones, } \\
\text { Consideraciones psicosociales y de apreciación, cognición y } \\
\text { percepción, Déficit sensorial: visión y audición, Capacidad y } \\
\text { riesgo de lesión en mm.ss } \\
\text { Salud cardiovascular, Comorbilidad, Alcohol, medicación y otras } \\
\text { drogas ilícitas yposibles afectaciones en la salud y la seguridad }\end{array}$ \\
\hline Características de las Sillas de ruedas & $\begin{array}{l}\text { Manejo de presión, agarre y comodidad, basculación, elevador de } \\
\text { mm.ii, elevador de asiento y respaldo }\end{array}$ \\
\hline Propulsión & $\begin{array}{l}\text { Eléctrica o manual, base propulsión, energía asistida, posición de } \\
\text { conducción y productos de control a motor u otros }\end{array}$ \\
\hline \multicolumn{2}{|l|}{ Scooters } \\
\hline Entrenamiento & $\begin{array}{l}\text { Duración, contenido, técnicas de propulsión y modo de } \\
\text { entrenamiento }\end{array}$ \\
\hline Transporte & Transporte público y Normas \\
\hline $\begin{array}{l}\text { Mantenimiento } \\
\text { Recursos }\end{array}$ & $\begin{array}{l}\text { Lista de objetivos, Lista de riesgo de enfermedades o trastornos, } \\
\text { necesidades a larga duración, lista de entrenamientos, prevención } \\
\text { de lesiones, escala de comodidad de uso, bases de datos en } \\
\text { internet de educación e información }\end{array}$ \\
\hline Apéndices & $\begin{array}{l}\text { Revisiones externas, Definiciones y términos, Abreviaturas, CIF } \\
\text { y } \\
\text { Derechos de las personas con discapacidad }\end{array}$ \\
\hline
\end{tabular}

Todavía el desarrollo de este tipo de guías está en curso y centradas mayoritariamente en los PA para la movilidad. Los profesionales del ámbito clínico al comenzar su trayectoria profesional, no tienen una idea muy clara de cómo prescribir los PA a sus usuarios ni de qué información deben de recopilar para realizar una correcta evaluación. Generalmente, los contenidos de la evaluación se centran en el PA pero como se ve en la guía anteriormente dada los usuarios tienen diferentes capacidades y niveles de desempeño al igual que en cada persona varía aspectos de índole psicosocial y sociodemográfico que deben de ser evaluados y debemos de incluir al usuario en este proceso. Debemos de ser conscientes los diferentes profesionales que una ineficaz evaluación puede ser el origen del abandono o 
falta de uso de un PA. Además que una incorrecta revisión o no llevarla a cabo puede acarrear consecuencias negativas para el usuario final.

\section{Roles y competencias profesionales}

Los profesionales con experiencias en el campo de los PA tales como los terapeutas ocupacionales tienen un conocimiento especializado para guiarse en su práctica profesional y requieren de modelos y en particular un modelo común para buscar soluciones individuales en PA (Emily \& Jan, 2011). Para seleccionar un PA el terapeuta ocupacional junto con el equipo multidisciplinar no deben de basarse únicamente en el diagnóstico de la persona como se acostumbraba hacer en base al modelo médico sino en función de las actividades y el contexto que será utilizado por lo que deben de realizar un enfoque centrado en la persona puesto que dará lugar a mejores resultados y reduce el riesgo del uso o no uso de PA. Para evitar el abandono o la falta de uso de los PA los profesionales deben tener claramente definido sus roles además de reciclarse en cuanto a formación en este campo siendo relevante a la formación continua en cuanto a la evaluación y documentación sobre la selección y asesoramiento en PA. En este sentido son varios los modelos que han surgido para minimizar el abandono o falta de uso de PA entre los que cabe destacar el modelo de Lauer, Longenecker \& Smith (2006), el cuál clasifica en 5 apartados los posibles factores de abandono o falta de uso de los productos de apoyo; tres de estos apartados son factores negativos divididos en factores relacionados con la persona, el propio PA y el entorno; otro apartado sobre factores positivos y el último apartado, es el calificado como otros en el que se incluyen los factores neutrales.

Dentro del equipo multidisciplinar, el terapeuta ocupacional domina entre sus competencias las englobadas dentro del asesoramiento y selección de PA pero la pregunta que nos podemos hacer ante esta profesión por muchos desconocida es ¿Qué es la Terapia Ocupacional?

La Terapia Ocupacional (en adelante, TO) empezó en España en 1964 como una profesión sanitaria, socio-sanitaria y enmarcada en las áreas sociales. En la última década la Terapia Ocupacional se ha desarrollado más en los campos de la asistencia, vía académica, investigación y dirección/gerencia de centros y servicios socio-sanitarios. (Santos del Riego, 2005). La base científica de la TO en la ocupación la cual se define como "las actividades 
significativas que las personas realizan como parte de su vida cotidiana en todos los aspectos de la vida que contribuyen a la salud y a la realización del individuo" (McColl et al., 2003). Los trastornos sensoriales, estructurales o funcionales, adquiridos o de nacimiento, pueden generar dificultades en la ejecución de las actividades de la vida diaria por lo que la TO es un componente esencial en la habilitación y trabajo con el colectivo de personas con discapacidad auditiva. Existe muy poca investigación y práctica diaria en personas sordas y su intervención centrada en la ocupación, los pocos estudios publicados tienen como objetivo investigar las actividades de la vida diaria entre personas mayores signantes y personas mayores con pérdida auditiva. Por ejemplo algunos estudios han obtenido que los mayores signantes son más dependientes en actividades de la vida diaria pero al mismo tiempo reportan un mayor bienestar de salud que los mayores con pérdida auditiva.(WerngrenElgström, Iwarsson, Elmståhl, \& Dehlin, 2005).

Las dimensiones psicosociales del comportamiento humano son fundamentales para todos los aspectos de la ocupación y la terapia ocupacional. Y podríamos definir psicosocial según Mosey (1996) como la percepción intrapersonal, interpersonal y experiencias sociales e interacciones que pueden influenciar el comportamiento ocupacional y desarrollo. No hay una única definición del término psicosocial pero es a menudo usado en psicosocial, cognición, social, cultural y espiritual. Además en cuanto psicosocial y ocupación podríamos incluir significado, propósito, motivación, aspecto simbólico de la ocupación, relación, roles y dinámicas inconscientes influenciadas por el comportamiento ocupacional. Los aspectos tales como personalidad, temperamento, energía... pueden afectar en las actividades de la vida diaria (AOTA, 2002).

Los TO iniciamos el proceso de evaluación con la historia de vida del paciente: experiencias, valores, intereses y capacidades. Además de los factores psicosociales han crecido históricamente en nuestra profesión, puesto que, la terapia ocupacional fue fundada por un diverso grupo de profesionales que observaron los efectos de la inactividad individual. Estos fundadores vieron la TO como una profesión holística buscando la interrelación cuerpo-mente y la importancia de la actividad. Estos mismos pensaban que la ocupación es una mezcla entre lo personal, físico y psicosocial todo ello influenciado por lo cultural, social, ambiental y variables políticas. (Kielhofner \& Forsyth, 1997)

Entre las intervenciones de los terapeutas ocupacionales destaca la del uso de PA, nuevas tecnologías y diferentes adaptaciones para mantener, recuperar o mejorar la 
funcionalidad de la persona, por eso tenemos un perfil adecuado para la selección y evaluación de los PA. Aunque, según la Accreditation Council for Occupational Therapy Education (2011), estipula la inclusión de contenido tecnológico tanto de low-tech que englobarían las adaptaciones y high-tech que serían las nuevas tecnologías. Todas las personas con y sin discapacidad deben de aprender de PA y telecomunicaciones y es por ello que los terapeutas ocupacionales debemos de estar preparados para los cambios y avances tecnológicos. La tecnología está ligada a la TO puesto que, es una práctica de la ocupación. Las tecnologías y su práctica se envuelven alrededor de las actividades diarias y los roles de las personas, de esto se deriva la importancia de que estos profesionales tengan formación específica en nuevas tecnologías y PA (Christiansen \& Baum, 1997). Los terapeutas ocupacionales han incluido en su curriculum el aprendizaje tecnológico (Angelo, Buring, Schmeler \& Doster, 1997; Breiner, 1985; Kanny, Anson \& Smith, 1991) además de investigar en tecnologías (Angelo \& Smith, 1993) pero pocos conocen herramientas de evaluación en PA y existe poca investigación en este sentido.

Los trastornos sensoriales, estructurales o funcionales, adquiridos o de nacimiento, pueden generar dificultades en la ejecución de las actividades de la vida diaria por lo que la terapia ocupacional es un componente esencial en la habilitación y trabajo con el colectivo de personas con discapacidad auditiva. Y es necesario estudios que indaguen sobre el impacto psicosocial de los PA en los usuarios de PA, y como estos PA ayudan o no en el desempeño de sus actividades de la vida diaria.

Para que nuestras intervenciones sean eficaces debemos de realizar nuestra labor en base a la evidencia científica y trabajar con un marco de trabajo junto con un modelo estructural. Los terapeutas solemos utilizar y emplear diferentes marcos de trabajo y técnicas derivadas de los modelos teóricos de la ocupación. De forma paralela la OMS (Organización Mundial de la Salud) ha trabajado en un marco común la ya comentada CIF, diseñado para proveer un marco para el análisis sistemático de la relación entre los trastornos de la salud, la capacidad para desempeñarse en una ocupación y la interacción de la persona con el entorno (Grieve \& Gnanasekaran, 2008).

La CIF incluye todas aquellas actividades, tareas y roles que están dentro de las competencias profesionales de terapia ocupacional. El College of Occupational Therapists considera a la CIF un cambio de perspectiva de solo un diagnóstico médico a tener en cuenta los problemas del individuo a partir de su contexto (COT, 2004). La clasificación de la CIF es 
tal que coincide con los conceptos y definiciones actuales de la terapia ocupacional en cuanto el ver a un individuo como un ser ocupacional. Además que muchos de nuestros marcos de trabajo tienen relación con algunas secciones de la CIF. Por ello, este tipo de estudios dan no solo a conocer nuestra profesión sino que lo hacemos basado en un marco teórico adecuado y con evidencia científica en nuestro campo.

La CIF proporciona un marco conceptual que puede ser usado para describir las preguntas de la investigación científica, facilitar la interpretación de la investigación, y construir una intervención desde la perspectiva de la Terapia Ocupacional (Jerosch-Herold, Leite \& Song, 2006). Los terapeutas ocupacionales pueden contribuir a la investigación mediante la publicación de estudios y pruebas relativas a la aplicación de la CIF, y al uso de otras herramientas de evaluación y modelos conceptuales de PA (tratados en la parte teórica de esta Tesis Doctoral) (Farrell et al., 2007; Mortenson, Miller \& Miller-Pogar, 2007). La aplicación de la CIF ha demostrado ser muy útil para los terapeutas ocupacionales en identificar los roles y reflejar el bienestar-calidad de vida de sus usuarios (Dagfinrud et al., 2005), ya que el uso de la CIF facilita una mayor precisión en el registro y control de las condiciones de salud (Hammell, 2004). Es similar a muchos modelos de Terapia Ocupacional en el desarrollo de las tareas y actividades para los usuarios y el reconocimiento de la interacción entre la persona y el medio ambiente (Diamant, 2004; Lenker \& Paquet, 2003; Stewart, 2002)

La CIF puede ser útil para TO en diferentes ámbitos tales como el de la evaluación y asesoramiento de PA. Existen algunos modelos relacionados con los PA: una escala de los factores que afectan a la participación comunitaria para los usuarios de sillas de ruedas (Barker, Reid \& Cott, 2006), modelo para la selección de PA según factores personales como el MPT(Scherer, Jutai, Fuhrer, Demers \& DeRuyter, 2007). Sin embargo, la atención todavía debe dirigirse hacia la selección de las medidas de resultado adecuados las cuales sean capaces de detectar mejoras en la práctica diaria. El componente de la actividad y la participación podría ayudar a los profesionales, en la identificación de las necesidades del servicio, con objeto de optimizar la eficacia y los resultados (Homa, 2007; Royeen, 2002).

Tanto los investigadores como los trabajadores que trabajan en la clínica están interesados en las medidas de resultados y PA. Por poner un ejemplo, los terapeutas ocupacionales utilizan los modelos para describir y predecir la función de los PA (Lenker \& Paquet, 2003). Pero existe escasas investigación en cuanto a la intervención específica de 
algunos PA y las medidas de resultados de los mismos (Fuhrer, 2007; Harris \& Sprigle, 2003; Jutai, Fuhrer, Demers,Lenker, Jutai, Demers, Scherer \& DeRuyter, 2010; Scherer \& DeRuyter, 2005).Y es un conocimiento vital para los profesionales como terapeutas ocupacionales, logopedas y rehabilitadores en general además de las administraciones públicas y servicios privados, y en cierta parte es necesario conocerlo para evitar el abandono o falta de uso de los PA, como comentábamos con anterioridad por tanto los investigadores y los profesionales deben de colaborar para realizar investigación basada en evidencia así como en la educación y formación de los profesionales (Fuhrer, 2007). 


\section{Problemas y limitaciones de los productos de apoyo.}

Aunque los PA son una buena herramienta de intervención son varios los problemas y limitaciones percibimos en la literatura tales como el nivel de satisfacción, el abandono o falta de uso, la aceptación de la discapacidad entre otros.

La determinación del nivel de satisfacción en relación con un PA es fundamental para establecer si el dispositivo responde o no a las necesidades de la persona y condicionará su uso futuro.

Son mucho los autores que han realizado estudios sobre los factores que están ligados al abandono o falta de uso de los PA. Por poner algunos ejemplos, Phillips y Zhao (1993) llevaron a cabo un estudio de 277 usuarios e identificaron 4 factores que pueden derivar en el abandono de los dispositivos (Phillips \& Zhao, 1993); a) Fallo de los proveedores al no tener en cuenta la opinión de los consumidores, b) Dificultad en la obtención del PA, c) Pobre rendimiento del producto y d) Cambios en las prioridades/necesidades de los usuarios. Otro estudio fue el realizado por Riemer-Weiss y Wacker (2000) también examinaron estos factores para predecir el abandono de las tecnologías de apoyo como son las influencias que tienen los diferentes contextos en el uso de las mismas (Riemer-Reiss \& Wacker, 2002). Otros autores concluyeron un factor detonante del abandono de un PA la influencia del contexto (Verza, Carvalho, Battagia, \& Uccelli, 2006). Por otro parte Pape, Kim y Weiner 2002 realizaron una revisión sobre este tema y como las atribuciones personales influyen sobre su integración en la vida diaria del usuario. En particular, las propias expectativas de cómo funcionaría el dispositivo, el coste social derivado de su utilización y la perspectiva de que la discapacidad no define al usuario como persona, son los factores más relevantes que influyen a la integración de los PA en su vida (Pape, Kim \& Weiner, 2002).

Con respecto a este aspecto, destaca la revisión bibliográfica realizada por los investigadores del proyecto ATOMS. El proyecto ATOMS reemplazo la expresión “interrupción" por la de "abandono", ya que esta última implica una explicación más precisa por la que se utiliza o no un PA. Son varios los motivos para conocer los factores del abandono de estos PA, tales como mejorar los servicios de PA tanto para consumidores como familiares, la financiación de los mismos e incluso para apoyar las decisiones de financiación. Encontraron tanto factores negativos como positivos o neutrales para el abandono de los diferentes PA. Su investigación tuvo dos objetivos principales; 1) Identificar y clasificar la 
variedad de factores que influyen tanto en el abandono positivo y negativo y 2) desarrollar métodos innovadores para cuantificar el continuo de la interrupción. En este estudio se identificaron más de sesenta artículos y / o libros de investigadores del campo de los PA. Además de los artículos relativos a PA y “abandono", se analizaron los modelos anteriores y taxonomías para la contribución potencial. (Cook \& Hussey, 2002; Edyburn, 2001; Fuhrer, Jutai, Scherer, \& De Ruyter, 2003; Gitlin, 1998; Lenker \& Paquet, 2003, 2004; Roelands, Van Oost, Depoorter, \& Buysse, 2002; Scherer, 2000; Scherer \& Craddock, 2002). El factor de "abandono" aparecía en la literatura con otras taxonomías tales como: conformidad, incumplimiento, terminación, discontinuación, negativa, insatisfacción e evitación. La muestra de su estudio incluía tanto a los propios usuarios como a sus seres queridos y a los representantes de las agencias de PA. El cuestionario final incluyó 25 preguntas organizas en cinco apartados1) la información del dispositivo, 2) demografía, 3) historia del uso de dispositivos, 4) de formación, y 5) de servicios. La literatura reveló siete diferentes términos que se utilizan indistintamente para discutir la situación de una persona que deja de usar un PA; 1) desuso (Kittel, Di Marco, y Stewart, 2002), 2) no utilización (Bentur, Barnea, y Mizrahi, 1996; Forbes, Hayward, y Agwani, 1993; Geiger, 1990), 3) rechazo (Gitlin, 1995), 4) evitación (Scherer, 1993), 5) incumplimiento (Wielandt \& Strong, 2000), 6) abandono (Hocking, 1999; Kittel et al., 2002; Mann, Granger, Hurren, Tomita, y Charvat, 1995; Phillips y Zhao, 1993; Scherer, 1993), y 7) interrupción (Riemer-Reiss y Wacker, 2000). Concluyeron que de los términos encontrados el de discontinuidad define el proceso por el que un usuario deja de utilizar un PA, por el contrario el resto de términos denotan significados negativos. En la siguiente figura se observa un modelo generado en esta revisión de factores positivos, negativos y "otros" del abandono de PA. Además, en el modelo aparecen aspectos demográficos (es decir, el género, la edad, la ubicación, la educación y la cultura) como factores que varían entre cada individuo y pueden influir en el tipo de discontinuidad de un individuo. Podemos concluir que la revisión llevada a cabo por el proyecto ATOMS fue para aclarar que el término "interrupción” es el más apropiado para describir la interrupción de la no utilización de PA. 
Figura 7.-. Modelo generado por el proyecto ATOMS de interrupción de PA

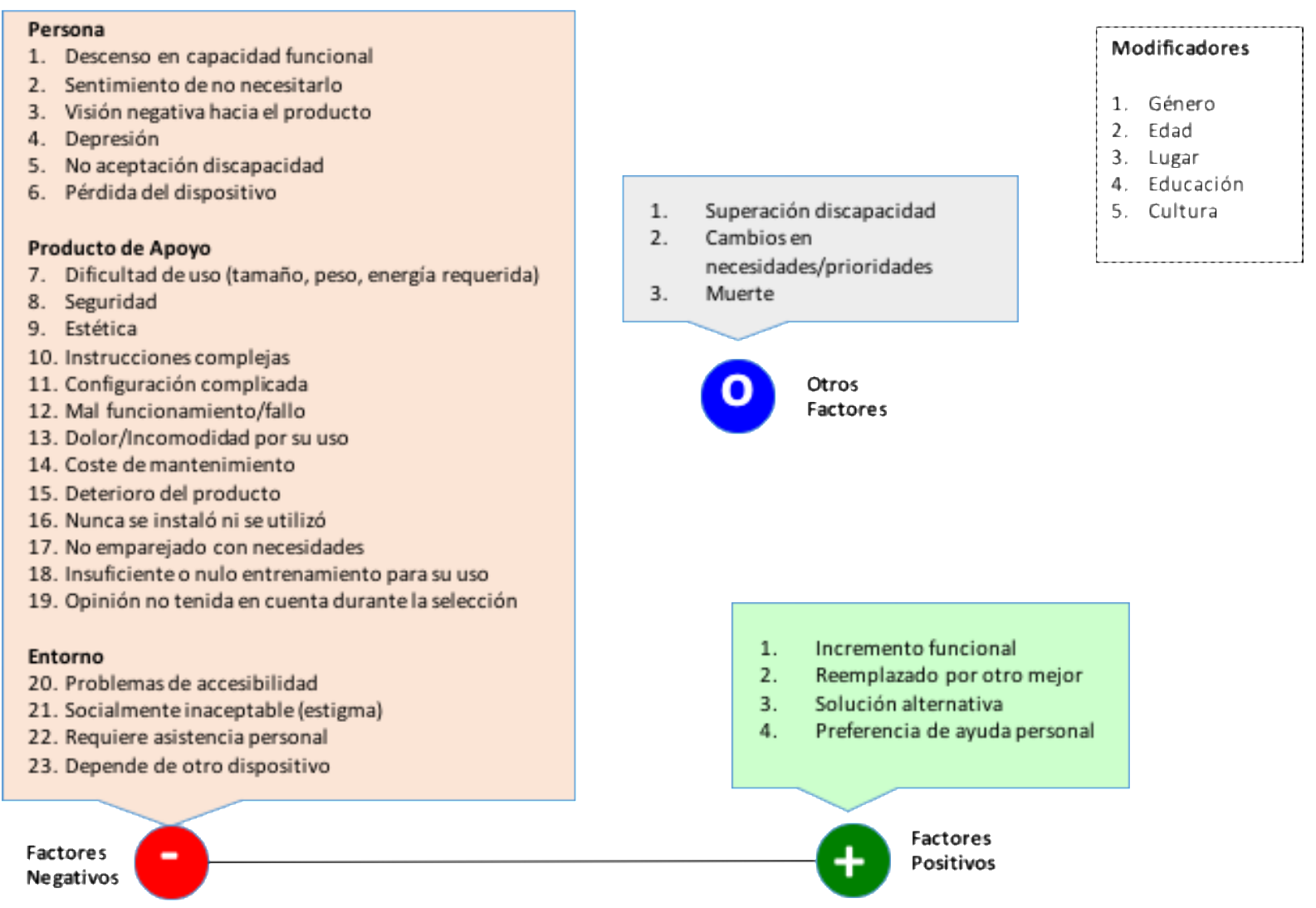

Derivado de la exhaustiva revisión de trabajos realizada por el proyecto ATOMS, hay muchas cuestiones que pueden ser de interés. Las principales conclusiones del proyecto ATOMS son:

En primer lugar, la medida de la satisfacción con PA y los factores relacionados con ésta se relaciona con diferentes disciplinas profesionales, entre ellas, la terapia ocupacional. Como mencionábamos en apartados anteriores existen diferentes herramientas de evaluación y el proyecto ATOMS concluye que cada disciplina utiliza diferentes herramientas de evaluación, pero no existe una medida estándar empleada de una forma común en todas las profesiones. En tercer lugar, los investigadores han centrado sus trabajos en la evaluación de la satisfacción, pero no hay ninguna herramienta para medir la insatisfacción incluyendo también como conclusión que los criterios de fiabilidad y validez son importantes para crear mejores herramientas de evaluación. Para finalizar el proyecto ATOMS concluye que el diseño de los estudios, las técnicas de administración y el período de la investigación se deben considerar como un factor influyente sobre los resultados obtenidos. 
Por una parte la adaptación o la aceptación de la discapacidad es uno de los criterios con mayor influencia en su utilización. Las particularidades relacionadas con el estado de ánimo, la autoestima, la autodeterminación y la motivación, así como las características psicosociales vinculadas al apoyo familiar y de las amistades, son significativos predictores del uso de los productos (Scherer, Sax, Vanbiervliet, Cushman \& Scherer, 2005). Otro factor relevante es el relacionado con las normas psicosociales y culturales, porque aunque los PA puedan permitir la participación en los diferentes contextos vitales de la persona, el éxito de los mismos no está garantizado (Wielandt \& Scherer, 2008).

Son varios los estudios que examinan e indagan como una limitación de los PA, el abandono de los mismos el cuál es un problema muy común y una de las razones es que no consigue mejorar la calidad de vida del adoptante o que tiene un alto coste (tanto el dispositivo como el mantenimiento de este) incluso en algunos casos debido a la apariencia del dispositivo (Day, Jutai, Woolrich, \& Strong, 2001) Además, dentro de este colectivo nos enfrentamos a otras dificultades añadidas para la capacidad del uso de algunos productos debido a las dificultades comunicativas como las de lecto-escritura (Viader \& Pertusa, 1996). Las consecuencias del abandono incluyen la pérdida de habilidades funcionales del usuario, el incremento de los costes asistenciales y de otro tipo de cuidados, así como un uso inefectivo de la financiación por parte de los organismos pagadores (Day, Jutai, Woolrich \& Strong, 2001; Jutai \& Day, 2002).

Por lo que los patrones de uso (incluyendo el no uso) incluyen el impacto en la usabilidad y calidad de vida. Entendemos la usabilidad como " la capacidad de un software de ser comprendido, aprendido, usado y ser atractivo para el usuario, en condiciones específicas de uso"(ISO/IEC 9126:). Esta definición hace énfasis en los atributos internos y externos del producto, los cuales contribuyen a su funcionalidad y eficiencia. La usabilidad depende no sólo del producto sino también del usuario. Por ello un producto no es en ningún caso intrínsecamente usable, sólo tendrá la capacidad de ser usado en un contexto particular y por usuarios particulares. El dominio de la usabilidad no es sólo de suma importancia desde el punto de vista de resultados de investigación sino también que refleja la importancia del producto de apoyo sobre la actividad y participación de las personas con discapacidad auditiva.

Es importante evaluar la usabilidad de un producto de apoyo tanto durante la fase de diseño como durante el ciclo de vida del producto. Se debe investigar la usabilidad no sólo en 
cuanto a aspectos estéticos del producto sino también en cuanto a la satisfacción del usuario con su uso (Ravneberg, 2012). Así, aunque los productos y tecnologías de apoyo facilitan a las personas con discapacidad ocupar el lugar que les corresponde en la toma de decisiones que afectan a su vida también las instituciones y la sociedad en general deben lograr captar los progresos tecnológicos y facilitar la capacitación de su uso a personas con discapacidad. La norma ISO define la usabilidad en términos de facilidad de uso debido que para alcanzar un alto nivel de usabilidad los productos de apoyo deben estar diseñados para reducir física, cognitiva y lingüísticamente el esfuerzo y maximizar la relación entre el usuario y el producto de apoyo (Arthanat, Bauer, Lenker, Nochajski \& Wu, 2007).

Son muchos los estudios que incluyen la usabilidad como un predictor de continuidad de uso de un P.A (Cumming et al., 2002; Gitlin, Levine \& Geiger1993; Gosselin et al., 1993; Wiedlandt \& Strong, 2000). En cuanto a la calidad de vida podemos referirnos a varios conceptos como calidad de salud, estatus, relaciones social y el bienestar subjetivo (Dijkers, 1999; Fuhrer, 2000; Gill \& Feinstein, 1994; Keith, 1994; Ryff, 1995). Jutai, Rigby, Ryan y Stickel (2000) encontraron que el impacto psicosocial anticipado del control ambiental es importante para la continuidad de uso de los PA. Al igual que la adherencia a las adaptaciones en el hogar son predictivas y más estrechamente con los sentimientos que surgen en las recomendaciones (Devor, Wang, Renvel, Feigel \& Ramsdell, 1994) como el valor percibido de los mismos y como su presencia (la de los PA) ayuda a los familiares (Cumming et al., 2001). Incluso el comportamiento puede ser un predictor de continuidad (Ajzen, 1988;1991,2002; Armitage \& Conner, 2000,2001,2002).Pero pueden existir otras dimensiones como la frecuencia de uso (diaria, semanal y mensual;Wieland \& Strong, 2000), duración de uso (minutos o horas de uso en un día; Weiss-Lambrou, Tremblay, LeBlanc, Lacoste \& Danseneau, 1999), y situaciones de uso como las sociales (Murphy, Markov, Collins \& Moodie, 1996) o en la comunidad (Angelo, Jones \& Kokoska, 1995; Treflar\& Crislip, 1985).

Aunque el uso de PA se suele asociar con algo positivo y el desuso con algo negativo, la literatura también muestra estudios de que el abandono puede deberse a una mejora de la capacidad funcional y esto elimina o reduce la necesidad de uso del PA (Clemson \& Martin, 1996; Cushman \& Scherer, 1996; Garber, Bunzel \& Morga, 2002; Phillips \& Zharo, 1993; Wielandt \& Strong, 2000). 


\section{PERSONAS CON DISCAPACIDAD AUDITIVA}

\section{Características generales y definición.}

En España según datos del Instituto Nacional de Estadística (en adelante INE) en su última encuesta realizada en el año 2008 hay un total de 3.787 .400 personas con discapacidad, de las cuales 1.064.600 tienen una discapacidad auditiva.

Tabla 8. Número de personas con dificultades auditivas en función de sus dificultades y el sexo. (Fuente: Encuesta de Discapacidad, Autonomía Personal y Situaciones de Dependencia 2008).

\begin{tabular}{llll}
\hline & \multicolumn{1}{c}{ Total } & & Mujeres \\
\cline { 2 - 4 } Total & Ambos sexos & Varones & 2276,2 \\
\cline { 2 - 3 } & 3787,4 & 1511,3 & 608,5 \\
Recibir cualquier sonido & 1064,6 & 456,1 & 31,4 \\
Audición de sonidos fuertes & 59,7 & 28,3 & 233,6 \\
Escuchar el habla & 397,6 & 163,9 & 563,8 \\
Comunicación & 975,9 & 412 & 398,7 \\
Producir mensajes hablados & 737,2 & 338,5 & 214,7 \\
Recibir mensajes hablados & 410,6 & 195,9 & 209,5 \\
Comunicación de mensajes escritos & 363,7 & 154,2 & 252,9 \\
Comunicación de mensajes de gestos, señales o símbolos & 457,3 & 204,3 & 151,8 \\
Mantener una conversación & 255,4 & 103,5 & 221,1 \\
Comunicación a través de dispositivos y técnicas de comunicación & 409,5 & 188,3 & 294,2 \\
\hline
\end{tabular}

Además, al igual que los datos ofrecidos por el INE, los datos del libro blanco de la $\mathrm{I}+\mathrm{D}+\mathrm{I}$ al servicio de las personas con discapacidad y personas mayores (2003) permiten inferir alguna de las razones de su bajo uso. Por ejemplo: el precio elevado de productos con alto contenido tecnológico, la falta de información de los usuarios y prescriptores sobre dispositivos y sistemas, la presencia de diferencias entre los sistemas de provisión pública, la baja exigencia en el cumplimiento de la legislación sobre accesibilidad, a división y el escaso desarrollo de los mercados relacionados con el suministro de estos productos. Asimismo, en el capítulo 14 del libro Blanco se detallan y explican las líneas prioritarias del I + D, las cuales se presentan en 10 líneas prioritarias. 
Tabla 9 Líneas prioritarias de carácter genérico del libro blanco

\begin{tabular}{|c|c|c|}
\hline & Líneas prioritarias de I+D de carácter genérico & Relación Áreas PN I+D+I \\
\hline 1. & $\begin{array}{l}\text { Desarrollo de productos adaptados a las características de } \\
\text { las personas con discapacidad y de las personas mayores. }\end{array}$ & Diseño y Producción Industrial \\
\hline 2. & Innovación de procesos de fabricación de ayudas técnicas & Diseño y Producción Industrial \\
\hline 3. & $\begin{array}{l}\text { Incorporación de nuevos materiales en las ayudas } \\
\text { técnicas }\end{array}$ & Materiales \\
\hline 4. & $\begin{array}{l}\text { Desarrollo de sistemas de apoyo a la prescripción y } \\
\text { selección de ayudas técnicas }\end{array}$ & Sociedad de la Información, Sociosanitaria \\
\hline 5. & $\begin{array}{l}\text { Innovación de sistemas asistenciales basados en las } \\
\text { Tecnologías de la Sociedad de la Información }\end{array}$ & $\begin{array}{l}\text { Sociedad de la Información. } \\
\text { TIC }\end{array}$ \\
\hline 6. & $\begin{array}{l}\text { Desarrollo de medios que faciliten el acceso a la } \\
\text { información proporcionada por ordenador }\end{array}$ & Sociedad de la información \\
\hline 7. & $\begin{array}{l}\text { Estudio de necesidades tecnológicas asociadas al uso de } \\
\text { Internet por personas con discapacidad y mayores }\end{array}$ & Socioeconomía \\
\hline 8. & $\begin{array}{l}\text { Desarrollo de sistemas de control de entorno que integren } \\
\text { el acceso a servicios de tele-cuidado social y sanitario }\end{array}$ & Sociedad de la Información. TIC \\
\hline 9. & $\begin{array}{l}\text { Desarrollo de pasarelas residenciales con acceso a } \\
\text { Internet de banda ancha para aplicaciones en } \\
\text { Teledomótica }\end{array}$ & Sociedad de la Información. TIC \\
\hline 10. & $\begin{array}{l}\text { Desarrollo de sistemas de orientación y navegación } \\
\text { urbana y rural }\end{array}$ & Sociedad de la Información \\
\hline
\end{tabular}

Dentro del ámbito que nos ocupa, el citado libro nos da también información sobre los PA para la comunicación y acceso a la información para personas con discapacidad auditiva tales como el desarrollo de medios de acceso a la información vía telemática y desarrollo de sistemas domóticos de control del entorno y acceso a servicios sanitarios. Dentro de las 36 líneas prioritarias de carácter subsectorial entre las que cabe destacar las ayudas técnicas para la audición (prótesis auditivas) y la accesibilidad a la información y a la comunicación

En la encuesta del INE también se incluyeron preguntas sobre el nivel de satisfacción de los usuarios con alguna discapacidad respecto a las ayudas técnicas. Podemos concluir que más de medio millón de españoles opinan que las ayudas son insuficientes y más de otro medio millón cree que no recibe las ayudas técnicas necesarias aunque las necesite.

Tabla 10.- Población (miles) con discapacidad según su satisfacción respecto a las ayudas técnicas que recibe para su discapacidad.

\begin{tabular}{llll}
\hline & Total & & \\
& Ambos sexos & Varones & Mujeres \\
\hline Total & 3787,4 & 1511,3 & 2276,2 \\
Satisfecho con las ayudas & 860,5 & 328 & 532,5 \\
No satisfecho con las ayudas, son insuficientes & 533,5 & 191,6 & 341,8 \\
No recibe o utiliza ayudas técnicas, aunque las necesita & 554 & 199,8 & 354,1 \\
No necesita ayudas técnica & 1472,8 & 625 & 847,8 \\
No consta & 366,7 & 166,7 & 199,9 \\
\hline
\end{tabular}


En España, la financiación para la adquisición de productos de apoyo proviene de los servicios sanitarios y de los servicios sociales. Hay determinados productos de apoyo que son financiados y proporcionados por las diferentes Comunidades Autónomas. Estos dispositivos están relacionados con productos de apoyo para la movilidad, órtesis y adaptaciones del hogar.

El catálogo de material ortoprotésico está regulado por el Real Decreto 1030/2006, de 15 de septiembre, por el que estable la cartera de servicios comunes del Sistema Nacional de Salud y el procedimiento para su actuación definiéndolos como "la utilización de productos sanitarios, implantables o no, cuya finalidad es sustituir total o parcialmente una estructura corporal, o bien modificar, corregir o facilitar su función”. En la Comunidad Autónoma de Castilla y león, en el Boletín Oficial de Castilla y León de 03 de Noviembre de 2014 aparecen las cuantías máximas subvencionadas para productos de apoyo apareciendo las de: movilidad y comunicación (adaptación de vehículos de motor y obras de adaptación de útiles en la vivienda habitual como adaptación del baño, habitaciones accesibles, rampas o eliminación de peldaños, pasamanos, puertas y puertas automáticas, cocina y salva-escaleras) y otras ayudas técnicas como ascensores, camas y somieres portátiles articulados, colchón antiescaras, grúa con arnés, adaptación de ordenadora, plataforma salva-escaleras, rampa telescópica, silla de baño, teléfono con adaptaciones, carro de ducha, oruga salva-escaleras, bipedestador. Para el colectivo de personas con discapacidad auditiva encontramos ayudas para la adquisición y recambios para audífonos, procesador de palabras o mobil speak, sistemas y dispositivos (ordenadores de sobremesa, portátiles, PDA) informáticos o adaptaciones que faciliten la accesibilidad, generadores de voz o comunicadores".

Estas últimas ayudas están dotadas con 1000 euros de subvención. No obstante, los servicios sanitarios financian la implantación de un implante coclear con su posterior rehabilitación logopédica. Los implantes cocleares están incluidos en el anexo VI del ReaL Decreto 1030/2006, como implante quirúrgico. Sin embargo, esta norma no detalla expresamente la renovación de los componentes externos, que resultan imprescindibles para el funcionamiento del implante coclear. Esta ausencia ha sido señalada por las asociaciones de pacientes que demandan mayor concreción normativa con el fin de evitar posibles desigualdades en la interpretación de la misma.

El INE también realizó la encuesta por Comunidad Autónoma y la falta de ayuda técnica y/o asistencia personal. 
El concepto de discapacidad se ha relacionado históricamente con la discriminación y la exclusión social, es decir, este tema es una cuestión socio-política cuyos efectos van más allá de la salud del individuo. El modelo basado en los derechos sociales y humanos de la discapacidad ha abierto nuevos caminos para promover el bienestar y la salud. Los factores claves para la no discriminación de las personas sordas es aceptar su cultura, educación bilingüe, intérpretes de lengua de signos y el acceso a la información y a la comunicación. La discapacidad auditiva no es una "tragedia personal" sino un producto social que nace de la interacción entre las características personales y las condiciones sociales del contexto que circunda a las personas. Estas condiciones actúan de forma de auténticas "barreras" que cristalizan en forma de actitudes, comportamientos, prácticas y políticas sociales discriminatorias hacia los “discapacitados” (Domínguez y Alonso, 2004)

Históricamente, la sordera y la hipoacusia han sido incomprendidas. En cuanto a la educación de personas sordas, el medio de comunicación y el remedio de la sordera produce un debate entre profesionales y personas sordas (Sneed \& Joss, 1999). Entre los campos más investigados en personas sordas, además de la lectoescritura (Domínguez, Pérez, \& Alegría, 2012; Domínguez, Alegría, Carrillo, \& Soriano, 2013; Gough, \& Tunmer, 1986; Hoover \& Gough ,1990; Leybaert,1993; Mayberry, Giudice, \& Lieberman,2011; Protopapas, Simos, Sideridis \& Mouzaki, 2012), encontramos el de la salud mental (Rogers, Evans, Campbell, Young, \& Lovell, 2014). Las personas sordas han sido marcadas como diferentes y tratadas de manera discriminatoria. La literatura describe la sordera como una patología, centrándose en la cura o mitigación de las desventajas percibidas. Actualmente, los estudios sobre sordera adoptan unas perspectivas socioculturales más complejas, planteando cuestiones de identidad de la comunidad, formación y lenguaje. Por poner un ejemplo, los antropólogos abordan el estudio de la Comunidad Sorda desde 3 ángulos útiles: el centrado en la historia de estas Comunidades seguido de las perspectivas de los propios miembros y, por último, las cuestiones linguísticas y como estas influyen en la sociedad oyente (Senghas \& Monaghan, 2002).

Se debe analizar a las personas sordas desde diferentes planos o dimensiones. En primer lugar, el plano audiológico, por ejemplo, considerando los grados de pérdida auditiva, o la localización del déficit y la necesidad de uso de PA. En segundo lugar, el plano de la discapacidad, entendida esta como las limitaciones funcionales que esos déficits originan y 
que se sitúan principalmente, en el ámbito del desarrollo del lenguaje oral y escrito. Y por último, desde la dimensión sociocultural, donde lo importante es que las personas sordas comparten una lengua, una historia y una cultura propia, aspectos todos que les confiere una "identidad" que debe ser aceptada y reconocida en una sociedad que abogue por la "igualdad en la diversidad" (Domínguez \& Alonso, 2004).

En España es difícil determinar la población de personas sordas usuarias de lengua de signos debido, principalmente, a la dificultad del sondeo. Pero según la Encuesta de Discapacidad, Autonomía personal y Situaciones de Dependencia del año 2008 realizada por el INE, hay un total de 13.300 personas sordas usuarias de la lengua de signos española, entre los que encontramos 7.000 hombres frente a las 6.300 mujeres. Aunque según esta misma encuesta en España hay 1.064.600 personas con problemas de audición. España ha sido uno de los primeros países en establecer medidas legislativas y acciones para hacer efectivos algunos de los derechos reconocidos en ella relativos a la comunidad sorda. Por ejemplo, la Ley 27/2007 y la Ley 17/2010 reconocen el derecho de las personas sordas al aprendizaje, el conocimiento, el uso, la investigación y la interpretación de dos lenguas de signos en España, la española y la catalana, incluyendo el acceso a la salud en lengua de signos española. Estas medidas, unidas a la Ley 51/2003, al I Plan Nacional de Accesibilidad 2004-2012, y al reciente Plan Nacional de Derechos Humanos, suponen un importante avance en la promoción y la protección de los derechos de las personas sordas usuarias de lenguas de signos en España, pero por sí solas no pueden eliminar las barreras actitudinales, físicas, políticas, de prácticas o de recursos creadas por la sociedad. Por poner un ejemplo, el acceso a una educación bilingüe en lengua de signos y lengua oral es todavía muy limitado en España, donde menos del 1\% de las escuelas de educación primaria usan una lengua de signos como medio de comunicación con niños y niñas sordos, y el 92\% de toda la población sorda (usuaria o no de la lengua de signos española) no tiene formación que la habilite para el ejercicio de una profesión y carece de competencias profesionales adquiridas mediante enseñanza reglada. Todo ello tiene consecuencias directas sobre los niveles de actividad económica (el 56,6\% de las personas sordas en edad de trabajar están en situación de inactividad económica) y de ocupación laboral (el 20\% están desempleadas frente al 11\% del conjunto de la población), y la situación todavía es peor en el caso de las mujeres sordas (67,2\% de inactividad económica y 30\% de tasa de paro) (Muñoz-Baell et al., 2011).

En general, tanto investigadores como profesionales prestan particularmente atención al apego, autoestima y competencia social (Zand \& Pierce, 2011). Pero la verdad es que las 
personas con discapacidad auditiva se enfrentan diariamente a dificultades para el desempeño de sus actividades cotidianas (Brennan \& Bally, 2007; Kvam et al., 2007) debidas, principalmente, a la presencia de barreras comunicativas, y es necesario que los profesionales pertenecientes al equipo multidisciplinar tengan una formación específica en este colectivo debido a que estas barreras pueden derivar en todo tipo de consecuencias negativas como el aislamiento, los déficit de habilidades académicas y de habilidades sociales y/o problemas del comportamiento (Saladin \& Hansmann, 2008). De igual modo, otros estudios han verificado la existencia de problemas en el desempeño de AVD avanzadas como las requeridas para desempeñar un trabajo (Kramer, 2008) o para participar del ocio (Van Naardes Braun, Yeargin-Allsopp \& Lollar, 2006) limitando así su participación social (Whiteneck, 2009). En términos de la Clasificación Internacional del Funcionamiento y la Discapacidad (WHO, 2001), se podría afirmar que las barreras comunicativas que encuentran las personas sordas signantes pueden llegar a limitar su capacidad para realizar ciertas actividades y restringir su participación en la comunidad. Por poner un ejemplo, las personas con discapacidad auditiva encuentran muchas dificultades cuando asisten a los servicios comunitarios. Las dificultades de comunicación son evidentes, además del miedo, la desconfianza y la frustración de los participantes que acuden, por ejemplo, a los servicios sociales. Aunque las experiencias positivas en estos servicios se caracterizan por la presencia de un intérprete y de otros profesionales de la salud con cocimientos de lengua de signos, y otros profesionales que hacen esfuerzos por mejorar la comunicación, toda esta problemática se podría mejorar mediante el uso de PA, por ejemplo. La realidad es que las personas sordas viven en minoría frente a la población oyente, y son estos últimos los que dirigen y programan todos los ámbitos de su vida diaria., aunque de forma lenta esto va cambiando de forma paulatina, gracias a la labor y lucha diaria de las diferentes asociaciones de personas sordas.

Las personas con problemas de audición usuarias de lengua de signos suponen un reto para el resto de la sociedad y para los investigadores. Quizás uno de los motivos por los que existe poca investigación de los problemas que afrontan las personas con discapacidad auditiva en la realización de sus actividades diarias tiene que ver con estas barreras comunicativas y la falta de familiaridad de muchos investigadores con la población. Una estrategia empleada en el campo de la investigación es el marketing social ya que es efectivo en el alcance de poblaciones difíciles de alcanzar tales como las personas pertenecientes a la Comunidad Sorda. Y podría emplearse en este colectivo e indagar más es sus problemáticas y la intervención a través de los PA para paliar estas barreras comunicativas. Pero para cumplir 
esto las personas sordas necesitan el reconocimiento de su diversidad cultural y lingüística, geografía y sistemas de intercambio de información (Kobayashi, Boudreault, Hill,

Sinsheimer \& Palmer, 2013). Puesto que son muchos los contextos en los que se encuentran con barreras para poder usar la lengua de signos, incluso en ámbitos oficiales tales como en ámbitos legislativos a pesar como hemos mencionado con anterioridad es una lengua oficial en nuestro país (Lucas, 2003).

En España hay un gran movimiento asociativo en favor de las personas sordas. Así, podemos encontrar la Confederación Estatal de Personas Sordas (CNSE), que en el ámbito nacional representa a las personas sordas usuarias de la lengua de signos española y defiende sus intereses, liderada por personas sordas usuarias de esta lengua. La CNSE trabaja desde 1936 para lograr la plena ciudadanía y la igualdad de oportunidades de las personas sordas en toda España y está integrada por 17 federaciones autonómicas, 135 asociaciones provinciales y locales de personas sordas, además de las distintas asociaciones de familias.

\section{Capacidad comunicativa de las personas sordas y su problemática}

Son varios los factores que hacen que una persona se considere sorda (refiriéndonos a una persona perteneciente a la Comunidad Sorda) o una persona con discapacidad auditiva tales factores son: la edad en la que se produce la sordera, ya que esta puede ser (a) congénita (las personas afectadas se les conoce como sordos prelocutivos y aunque depende de otros factores individuales y contextuales este grupo suele ser usuario de la lengua de signos); o (b) adquirida, normalmente tras los 3 años de edad o después de la adquisición del lenguaje (las personas afectadas se les conoce como sordos postlocutivos y pueden usar lengua de signos y/o lengua oral); el grado de pérdida auditiva es un factor importante y este se puede dividir en leve (26-45 dB), moderada (46-70 dB), severa (71-90 dB) y profunda (91 o más dB).

Las personas que presentan una sordera prelocutiva con un grado de pérdida profundo se les suele conocer como "sordomudos", aunque hemos de aclarar que este término de sordomudos es erróneo; y aunque coloquialmente sean llamados así, es un término incorrecto y peyorativo hacia las personas sordas, el término correcto es persona sorda y así es como las personas pertenecientes a la Comunidad Sorda lo ven correcto. 
Las lenguas de signos son lenguajes naturales que se han desarrollado independientemente del lenguaje hablado. No se corresponden lingüísticamente con él, teniendo además sus propias estructuras sintácticas y organizativas. Durante mucho tiempo, las lenguas de signos se consideraron formas inferiores de comunicación. En la actualidad se considera que la lengua de signos es una lengua con su propia gramática, con un proceso de adquisición al igual que la lengua oral. Aunque durante mucho tiempo las lenguas de signos han estado infravaloradas calificándose de "mímica", "dibujos en el aire" o "gestos naturales". Los primeros estudios de la lengua de signos fueron realizados por Stokoe hace y más de medio siglo, lingüista norteamericano que publicó "Sign Language Structure”. Es el primer trabajo que profundiza en el análisis de las lenguas de signos basándose en los conocimientos de la lingüística moderna. Esta obra supuso una revolución del concepto que se tenía sobre las lenguas de signos hasta ese momento, puesto que el concepto anterior se limitaba a una sencilla descripción de la lengua como un conjunto de gestos pactados a partir de las reglas de la lengua oral (que esta definición es la del bimodal y no la de la lengua de signos). Posteriormente a esta publicación, que Stockoe complementó años más tarde con “A Dictionary of American Sign Language on Linguistic Principles", Stokoe (1974) presentó una clasificación de los lenguajes de signos, diferenciando dos tipos. El primero, de carácter artificial y basado en el lenguaje oral, al igual que la escritura y la lectura (dactilológico o morfemas, palabras). Y el segundo, el que reconocemos como lengua de signos, que no está basado en la lengua oral, y con léxico y sintaxis independientes a los de la comunidad oyente.

Son pioneros en el estudio de la lengua de signos los autores Klima y Bellugi (1972), que presentaron la obra de "The Signs of Language", centrada en los aspectos arbitrarios e icónicos de los signos y en su estructura interna. Estos autores definieron la lengua de signos como sistemas lingüísticos complejos que cuentan con los tradicionales niveles fonológico, morfológico y sintáctico, además de con sus propias reglas gramaticales. En España, por otra parte, fueron Perelló y Frigola los que definieron la lengua de signos como el medio de comunicación espontáneo y natural de 70 millones de personas en el mundo, basado en ademanes y gestos realizado principalmente con las manos. A raíz de investigaciones como las citadas aumentó el número de investigaciones psicolingüísticas y existe un consenso al afirmar que los niños expuestos a la lengua de signos en su medio familiar adquieren dicha lengua a un ritmo madurativo idéntico al de adquisición del lenguaje oral. Por poner un ejemplo, Amate y Giménez (2000) realizaron un estudio donde comparaban los campos semánticos utilizados por niños sordos y oyentes. Los resultados mostraron que entre los 11- 
14 meses son similares: alimentos, animales... Su adquisición puede iniciarse a través de los primeros gestos naturales con palabras en los oyentes significación. Se trata de gestos comparables, por características y función, a las primeras. Su adquisición puede iniciarse a través de los primeros gestos naturales con palabras en los oyentes significación. Se trata de gestos comparables, por características y función, a las primeras.

El aprendizaje de la Lengua de Signos Española (LSE) exige tiempo y dedicación para el oyente. Son muchos los oyentes que no son conscientes de la dificultad de aprender un idioma visual. No se trata sólo aprender una serie de signos y realizar signo-palabra sino que se debe de estructurar la mente para poder signar y usar la lengua de signos pura, y no rebajarla al lenguaje bimodal porque ya no hablaríamos de lengua de signos. Se trata de aprender a pensar en otra lengua y aprender a estructurar el pensamiento siguiendo reglas diferentes a las habituales. La lengua de signos es un lenguaje que se ve, no se oye, y la información se transmite tanto con el cuerpo como con las manos y la expresión facial. Las personas oyentes estamos acostumbrados a recibir la información por el canal auditivo y nos es costoso cambiar este canal al visual. Es una lengua minoritaria, poco extendida. Son pocas las personas que conocen este lenguaje con nivel suficiente para mantener una comunicación fluida y fuerte en contenido, salvo profesionales directos como los intérpretes de lengua de signos o profesiones afines y, los propios familiares de las personas sordas. Se ha venido insistiendo en la enseñanza de la lectura por medio del movimiento de los labios, labiolectura, que no es sino un modo anormal de percibir el lenguaje verbal, cuyo modo de percepción es acústico. Sobre todo, se ha tenido mucho más en cuenta la emisión de palabras que su comprensión (Rodríguez, 1992). Las lenguas de signos permiten a las personas sordas comunicarse y acceder a la información, el cometido de esta lengua es el de facilitar el desempeño de las actividades de la vida diaria. (Antunes, Guimaraes, Garcia, Oliveira, \& Fernandes, 2011).

Por otra parte, hay que considerar la confluencia de los dos sistemas, lenguaje de signos y lenguaje verbal, que se da en la persona sorda, en mayor o menor grado, en función de la edad en la que sobreviene la pérdida de audición y también según el grado de pérdida de la misma. El lenguaje de signos no es universal; como toda lengua (aunque la mayoría de la población así lo piense), presenta variantes geográficas, que se manifiestan dentro del mismo entorno geográfico como en España que conviven la LSE y la LSC, y también es diferente en los distintos países. Existe un Sistema de Signos Internacional (SSI), que no es un lenguaje y toma los signos más visuales de las diferentes lenguas de signos haciendo una "mezcla" de 
todas ellas. Es como el esperanto en las lenguas orales, considerado una lengua auxiliar artificial y, al igual que esta, el SSI es poco utilizado salvo en encuentros internacionales y con un intérprete. Este sistema surgió debido a que cada Comunidad Sorda de los diferentes países vive sujeta a unos factores históricos, políticos, económicos, sociales y culturales que determinan la evolución de la lengua de signos. 


\section{Comunidad sorda}

Las personas que se ven a sí mismos como personas sordas son aquellas que, aunque con problemas en su capacidad de oír, se han adherido a la sociedad oyente y se perciben con una cultura diferente. Cada vez se extiende más la comprensión de la sordera como un fenómeno sociocultural, y se considera a las personas sordas como un grupo social minoritario con una lengua, una historia y una cultura propia. Las personas que se hacen llamar sordos definen la sordera como una identidad cultural y no como un impedimento para algunos propósitos, sino que insisten en que su cultura y su identidad separada deben de ser nutridos y mantenidos. En 1972, Woodward propuso unas definiciones recogidas tanto por la Unión Europea de Sordos (European Union of the Deaf, E.U.D) como por la Federación Mundial de Sordos (World Federation of the Deaf, W.F.T). Así, la Guía de la E.U.D dice "Sordo (con S mayúscula) se refiere a una persona que utiliza la Lengua de Signos como modo de comunicación primario, se identifica a sí misma con otras personas sordas y usualmente no oye". Consecuentemente, la EUD ofrece una segunda definición de sordo (con s minúscula) para referir a una persona que simplemente no oye, bien porque sea prelocutiva o congénita o por ser postlocutiva. Por ello, podríamos decir que la teoría de la cultura sorda se basa en su lengua de signos. Según la NAD (National Association of the Deaf) Las personas sordas quieren ser sordos y están orgullosos de su sordera. En resumen, afirman el derecho de nacimiento del silencio. Otros muchos individuos no están de acuerdo en que estos hechos dan lugar a una verdadera cultura(Tucker \& Poitras, 1998). No obstante, la Comunidad Sorda vive un periodo histórico de reconocimiento de los derechos sociales que le han sido negados durante más de un siglo. Uno de los motivos por los que las personas sordas se unieron fue porque eran miembros de sus asociaciones locales, donde compartían y comparten su tiempo de ocio con otras personas con las mismas experiencias, intereses y puntos de vista o similares. Estas asociaciones sirvieron como centros sociales y culturales de la Comunidad Sorda, lo que les permite a las personas sordas formar apegos personales y comunales. Además, estas mismas asociaciones permiten la transmisión de la cultura, lengua, tradición y por tanto su historia (Atherton, 2009). Según Hale (2004), "la comunidad sorda ha crecido cada vez más cohesionada y orgullosa de su cultura y lengua”. Aunque según Schowe (1979), "es la incertidumbre acerca de la propia pertenencia lo que crea un conflicto psicológico", debido a que se encuentran con múltiples dificultades en el acceso a la información y a la comunicación derivados del uso de su lengua, pero todo ello puede ser mitigado usando los PA y las nuevas tecnologías. Las Comunidades Sordas identifican sus 
lenguas de signos como un indicador de posición social. Si se reconociera y respetara la lengua de signos, ayudaría a reducir la falsa creencia de que las lenguas de signos son meros instrumentos de compensación (Conama, 2013). Los temas de justicia social para estas Comunidades son: el acceso a los medios de comunicación, reconocimiento de su lengua y la educación.

El nivel de igualdad de la lengua de signos se observa mediante la evidencia de la investigación y de la literatura, poniendo a dicha lengua en una posición en desventaja frente a la lengua oral. Por ello, es importante desarrollar nuevas tecnologías en las que la lengua de signos sean el medio de comunicación, entre otros PA para cubrir las necesidades específicas de este colectivo, además de respetar sus diferencias y diseñar herramientas que mitiguen sus barreras comunicativas y promuevan el acceso al conocimiento social y a su inclusión (Trindade et al., 2013). La comunicación siempre ha sido un área discutida cuando nos referimos a las personas sordas, y ya no solo en cuanto a la equiparación de la lengua de signos a la lengua oral, sino en cuanto al grado de interacción y comprensión de la comunicación en lengua de signos dentro de la Comunidad Sorda (Glickman, 2003; Hauser \& Marschark, 2008). Todo ello debido a que la comunicación no deja de ser una forma de compromiso social y muchas interacciones entre personas sordas y oyentes se vuelven tensas y con una gran pérdida de información (Foster, 1998), lo que lleva a una exclusión de este colectivo y que sus experiencias vitales se vean reducidas a las personas que conocen la lengua de signos. Esto, junto a las perspectivas negativas sobre la sordera, que están influenciadas también por factores históricos, médicos e incluso religiosos. Dependiendo del modelo que sigamos, como por ejemplo el tradicional modelo médico, el cual considera la sordera como una minoría lingüística con una discapacidad, o si tomamos el modelo biopsico-social entenderíamos que algunas personas sordas tienen una identidad sorda considerándola como normal y con una cultura y lengua propias. Y en este trabajo tomamos como modelo la perspectiva bio-psico-social, con lo cual creemos que las personas con discapacidad auditiva usuarias de lengua de signos tienen una identidad propia y son pertenecientes a la Comunidad Sorda.

Si la persona es prelocutiva (adquisición de la discapacidad auditiva antes de los 3 años o de la adquisición del lenguaje) y signante, la pérdida de comunicación oral en un mundo oyente es difícil. Mientras que si se trata de un tipo de pérdida postlocutiva (adquisición de la discapacidad auditiva después de los 3 años o de la adquisición del lenguaje) puede influir en la personalidad del individuo y su capacidad para adaptarse a la 
pérdida. Las personas sordas y con dificultades auditivas desarrollan sus identidades dentro de los ambientes que transmiten y refuerzan las hipótesis preconcebidas de la discapacidad y de la sordera. Estos supuestos influyen en la evolución de su identidad y a su vez en su bienestar psicológico (Leigh, 2009). Por ello es importante realizar estudios en medidas de resultados de los PA entre otras intervenciones al igual que es vital indagar sobre el impacto psicosocial del uso de PA en la vida de las personas sordas.

La falta de experiencias vitales acarrea una serie de consecuencias a este colectivo, tales como: menor conocimiento sobre la salud (Margellos-Anast, Estarziau, \& Kaufman, 2006), mayor número de visitas médicas que las personas oyentes (Mann, Zhou, McKee, \& McDermott, 2007), problemas para salir de relaciones insanas o abusivas (Merkin \& Smith, 1995), presentan frustración e aislamiento en los diferentes contextos de la escuela, hogar y barrio (Foster, 1989), problemas para adquirir su propio autoconcepto (MaxwellMcCaw,2001), problemas laborales de lo que se deriva la falta de experiencias vitales como identidad, cohesión de grupo, competencia y autoestima (Bagga-Gupta \& Domfors, 2003) entre otros. Son muchas las personas sordas que debido a su pérdida ven afectadas sus interacciones sociales, aunque esto depende mucho del entorno social, pero la sordera se asocia a bajas tasas de matrimonio y de natalidad (Carlsson, Danermark, \& Borg, 2004). Aunque se han desarrollo enfoques únicos para comprender, por ejemplo, otros aspectos tales como la teología, sin uso alguno de la palabra (Morris, 2008). En otras líneas de investigación sobre dificultades que encuentran las personas sordas encontramos, por poner algunos ejemplos, los problemas de salud de las mujeres sordas (Schlehofer, \& Ross, 2010), los problemas de violencia doméstica y sexual en la Comunidad sorda (Rems-Smario, 2007), discapacidad y violencia de pareja (Rems-Smario, 2007). Y el hecho de que no hayan sido estudiados, no implica que no ocurran estos hechos (Mason, 2010) o que no sean relevantes, al igual que sucede con otras líneas de investigación tales como la medición de resultados en el uso de PA en personas sordas.

En cuanto a la problemática de la investigación en PA y las personas pertenecientes a la Comunidad Sorda se debe señalar que los miembros y partidarios de la cultura sorda se oponen vigorosamente a los implantes, ya que los perciben como un tratamiento invasivo de dudosa eficacia.(Achiques et al., 2010). Además, las personas sordas tienen una serie de conflictos con sus creencias sociales, culturales y lingüísticas de las comunidades signantes (Hyde \& Power, 2000). Puesto que muchas personas sordas pertenecientes a la Comunidad Sorda piensan que una persona con un implante coclear deja de ser una persona sorda, aunque 
esto no podría estar más alejado de la realidad. Sin embargo, a pesar de estas creencias y problemas socioculturales a los que se enfrentan las personas sordas implantadas, son numerosos los estudios que muestran tanto la capacidad de las personas con sordera profunda de oír el habla con los implantes cocleares como la capacidad de los niños sordos implantados para desarrollar el lenguaje apropiado. Aunque el futuro en cuanto a la utilización de los implantes cocleares es incierto, las investigaciones sobre este producto son numerosas, sobre todo las centradas en optimizar la calidad de la señal auditiva (Sarget, 2005). 


\section{Limitaciones comunicativas}

Las personas sordas prelocutivas tienen una serie de dificultades, tanto en el desarrollo del lenguaje como en la cognición y en el ámbito psicosocial. Las barreras comunicativas limitan el acceso al conocimiento y la participación en la sociedad, aunque el uso de la lengua de signos conecta a las personas sordas socio-culturalmente, solo pueden comunicarse con los miembros pertenecientes a la Comunidad Sorda o personas que conozcan la lengua de signos. Otro de los problemas debido a las barreras comunicativas es el acceso a los servicios comunitarios, aunque los servicios con profesionales especializados como los intérpretes pueden mejorar en acceso a los diferentes servicios (Fellinger \& Fellinger, 2014). Además, frecuentemente, las personas sordas o discapacidad auditiva tienen problemas para entender y leer los labios de otras personas, y muchas veces se sienten excluidos de las conversaciones, por ejemplo, en el acceso a servicios tales como los servicios médicos; incluso, a veces, en realidad son ignoradas por otras personas y profesionales. Existe una gran variedad de sistemas y medios para comunicarse y acceder a la información tanto mediante PA como mediante medios humanos. Por ejemplo, Equipos de frecuencia modulada (FM), Bucle Magnético, Servicios de Intermediación por Vídeo (Video Relay Services), e intérpretes (Talha, Wan, Za'ba, Razlan, \& Shahriman, 2013). Y en el próximo apartado se caracterizarán algunas de estas ayudas a la comunicación.

Son muchos los servicios y las actividades diarias donde la presencia del intérprete de lengua de signos es necesaria para el éxito de la comunicación y para facilitar la igualdad en el acceso a los diferentes servicios en los que los pacientes no comparten un lenguaje común (Brämberg \& Sandman, 2013). Los profesionales como los médicos, entre otros, deben reconocer las dificultades inherentes a las medidas de evaluación en personas con problemas de audición, al igual que las dificultades de accesibilidad al colectivo. En futuras investigaciones se debería de analizar y validar instrumentos de evaluación para este colectivo teniendo en cuenta sus necesidades (Reesman et al., 2014).

En el ámbito académico cada vez es mayor la presencia de personas sordas y son muchas las que no disponen de PA u otras tecnologías para el acceso a la información. Algunas tecnologías, como la plataforma de gestión de aprendizaje Moodle, se han utilizado como método alternativo de aprendizaje a los utilizados en las clases tradicionales, incluyendo un video con un intérprete además del subtitulado (Debevc, Stjepanovič, \& Holzinger, 2014). Además, en este sentido, está demostrado por ejemplo entre los hábitos 
televisivos de los espectadores sordos se centran en primer lugar en el intérprete y en segundo lugar en el material gráfico, pero hacen muy poco uso de los subtítulos o de la lectura labial (Naccari \& Mrak, 2013). Algunos estudios confirman que la figura del intérprete como fuente de información principal para los espectadores sordos sino que además, algunos estudios ponen en duda la eficacia de subtitulado como fuente de información alternativa (Wehmeyer, 2014).

En cuanto a las actividades de la vida diaria en el colectivo de personas sordas, se suele encontrar una dificultad para realizar determinadas actividades instrumentales de la vida diaria aunque no parece extenderse esta limitación a lo que se refiere a la participación social dentro de la Comunidad Sorda, ya que, este colectivo acostumbra a realizar actividades de ocio por poner un ejemplo que tengan en cuenta sus preferencias comunicativas. Sin embargo las personas con discapacidad auditiva usuarias de lengua oral si encuentra limitadas tanto sus actividades instrumentales y avanzadas como su participación social(Yamada, Nishiwaki, Michikawa, \& Takebayashi, 2012). En algunos estudios, como en el de Zahedi et al. (2001) , concluyeron que las personas con pérdida auditiva moderada-severa tenían más probabilidades que las personas sin pérdida de tener una disminución en la ejecución de sus actividades básicas e instrumentales de la vida diaria. Además, el grado de pérdida no sólo se asocia a la disminución de la función mental y física, sino también a la reducción de la calidad de vida (Ciorba et al., 2012). El no corregir la pérdida de audición puede resultar en una disminución en la participación de actividades sociales, que a su vez puede afectar a la calidad de vida así como la salud y el bienestar mental. Incluso con la audición disminuida y sin una estimulación intelectual, pueden dar lugar a cambios en el sistema nervioso central (Seniors Research Group, 1999). Por ello, los profesionales de la terapia ocupacional, encargados de la intervención en las actividades de la vida diaria, deben encaminar sus intervenciones tanto a PA como a las actividades instrumentales y avanzadas. 


\section{3.- PRODUCTOS DE APOYO PARA LA COMUNICACIÓN Y ACCESO A LA INFORMACIÓN EN PERSONAS SORDAS}

\section{Introducción}

Este capítulo tiene por objetivo caracterizar algunos de los PA para la comunicación y acceso a la información de personas sordas y personas con discapacidad auditiva. Esto es importante en el contexto de esta Tesis Doctoral puesto que, posteriormente, en el trabajo empírico, se indagará sobre los resultados asociados a 3 de estos productos de uso habitual en personas sordas o con discapacidad auditiva: audífonos, implantes cocleares y sistemas de intermediación por vídeo. El capítulo comenzará con una breve descripción de los productos de apoyo para la comunicación y acceso a la información en personas con discapacidad auditiva tal y como aparecen caracterizados en la norma ISO 9999. Posteriormente, revisaremos las principales medidas de resultados que se han utilizado para evaluar la eficacia de estos PA.

Son muchos los PA y tecnologías que existen para mitigar, compensar o neutralizar las limitaciones comunicativas que sufren las personas con discapacidad auditiva, independientemente del grado y tipo de pérdida, o del lenguaje que empleen para la comunicación diaria. También son numerosas las clasificaciones de PA para personas con discapacidad auditiva, entre las que encontramos la ya citada norma ISO 9999:2007. En la siguiente tabla se presenta la clasificación de PA para la comunicación y acceso a la información de personas con discapacidad auditiva tal y como se recoge en dicha clasificación.

Tabla 11.- Clasificación de PA para la comunicación y acceso a la información de personas con discapacidad auditiva (tomado de la norma ISO 9999)

\begin{tabular}{|c|c|c|}
\hline Código & Nombre & Descripción \\
\hline ISO 2145 & $\begin{array}{l}\text { Ayudas para la } \\
\text { audición }\end{array}$ & Audífonos, ayudas táctiles y ayudas con implante \\
\hline ISO 2139 & $\begin{array}{l}\text { Sistemas de } \\
\text { transmisión de sonido }\end{array}$ & $\begin{array}{l}\text { En este apartado se recogen las ayudas que facilitan escuchar con } \\
\text { más claridad la televisión, el aparato de música, el ordenador o la } \\
\text { radio. Auriculares, altavoces, micrófonos, amplificadores, unidades } \\
\text { de conexión para receptores de radio y televisión; amplificadores } \\
\text { de bucle, receptores de bucle y bucles; sistemas de FM (frecuencia } \\
\text { modulada); sistemas de IR (infrarrojos). }\end{array}$ \\
\hline ISO 2136 & $\begin{array}{l}\text { Comunicación } \\
\text { telefónica, teléfonos y } \\
\text { ayudas para } \\
\text { telefonear }\end{array}$ & $\begin{array}{l}\text { teléfonos estándares, teléfonos móviles y para coches, teléfonos } \\
\text { con entrada y/o salida en texto, videófonos, contestadores } \\
\text { automáticos, teléfonos con amplificación, fax, amplificadores de } \\
\text { sonido. }\end{array}$ \\
\hline ISO 2148 & $\begin{array}{l}\text { Sistemas de } \\
\text { información }\end{array}$ & Indicadores de sonido y avisadores \\
\hline ISO 0951 & Relojes despertadores & \\
\hline
\end{tabular}


Además, la norma ISO 9999:2007 tiene una clasificación más exhaustiva de los PA para

personas sordas, como se muestra en la siguiente tabla.

Tabla 12 Clasificación de PA para personas sordas según la norma ISO 9999:2007

\begin{tabular}{|c|c|c|}
\hline Código ISO & Nombre & Descripción \\
\hline 0503 & $\begin{array}{l}\text { Productos de apoyo para terapia y } \\
\text { entrenamiento/aprendizaje de la comunicación }\end{array}$ & $\begin{array}{l}\text { Equipo para mejorar las aptitudes de comunicación en la } \\
\text { lengua hablada y escrita. }\end{array}$ \\
\hline 050303 & $\begin{array}{l}\text { Productos de apoyo para el } \\
\text { entrenamiento/aprendizaje de la lengua hablada }\end{array}$ & $\begin{array}{l}\text { Equipo para el entrenamiento y desarrollo del uso de la } \\
\text { voz y de la palabra particularmente en relación a la } \\
\text { producción y conocimiento de sonidos. Productos de } \\
\text { apoyo para el entrenamiento/aprendizaje de la lengua } \\
\text { hablada, }\end{array}$ \\
\hline 050306 & $\begin{array}{l}\text { Material de entrenamiento/aprendizaje para } \\
\text { desarrollar la capacidad lectora }\end{array}$ & $\begin{array}{l}\text { Equipo para el aprendizaje y desarrollo de la capacidad } \\
\text { lectora, particularmente estrategia, planteamiento e } \\
\text { interpretación. }\end{array}$ \\
\hline 050309 & $\begin{array}{l}\text { Materiales de entrenamiento/aprendizaje para } \\
\text { desarrollar las habilidades para la escritura }\end{array}$ & $\begin{array}{l}\text { Equipo para el aprendizaje y desarrollo de la capacidad de } \\
\text { escritura, particularmente estrategia, planteamiento, } \\
\text { interpretación y creatividad. }\end{array}$ \\
\hline 0506 & $\begin{array}{l}\text { Productos de apoyo para el } \\
\text { entrenamiento/aprendizaje en comunicación } \\
\text { alternativa y aumentativa }\end{array}$ & $\begin{array}{l}\text { Productos de apoyo para el entrenamiento/aprendizaje en } \\
\text { técnicas de comunicación alternativa y vocabulario para } \\
\text { permitir la comunicación interpersonal. } \\
\text { Braille, lengua de signos, lengua Bliss, etc., incluidos. }\end{array}$ \\
\hline 050603 & $\begin{array}{l}\text { Productos de apoyo para el aprendizaje de la } \\
\text { dactilología }\end{array}$ & $\begin{array}{l}\text { Equipo para el entrenamiento y aprendizaje del deletreo } \\
\text { manual, es decir, comunicación táctil para personas } \\
\text { sordo-ciegas. }\end{array}$ \\
\hline 050606 & $\begin{array}{l}\text { Productos de apoyo para el aprendizaje de la } \\
\text { lengua de signos }\end{array}$ & $\begin{array}{l}\text { Equipo para el entrenamiento y aprendizaje de la lengua } \\
\text { de signos, es decir, lenguaje visual para personas sordas. }\end{array}$ \\
\hline 050609 & $\begin{array}{l}\text { Productos de apoyo para el aprendizaje de la } \\
\text { lectura labial }\end{array}$ & $\begin{array}{l}\text { Equipo para el entrenamiento y aprendizaje de la lectura } \\
\text { labial. Productos de apoyo para el aprendizaje de } \\
\text { personas sordas y con deficiencia auditiva para entender } \\
\text { lo que otras personas dicen mirando los labios. }\end{array}$ \\
\hline 050612 & $\begin{array}{l}\text { Productos de apoyo para el aprendizaje del } \\
\text { lenguaje cued speech }\end{array}$ & $\begin{array}{l}\text { Equipo para el entrenamiento y aprendizaje de lengua } \\
\text { vocal complementada por la lengua de signos }\end{array}$ \\
\hline
\end{tabular}

Aunque existe un gran número de personas con discapacidad auditiva, muchas de ellas no utilizan ningún PA, según la encuesta realizada en 2008 por INE (véase siguientes tablas).

Tabla 13.- Población con discapacidad auditiva en función del tipo de pérdida auditiva por rango de edad

\begin{tabular}{|c|c|c|c|}
\hline Franja edad & $6-64$ & $65-79$ & $80+$ \\
\hline & $\begin{array}{l}\text { Ambos } \\
\text { géneros }\end{array}$ & $\begin{array}{l}\text { Ambos } \\
\text { géneros }\end{array}$ & $\begin{array}{l}\text { Ambos } \\
\text { géneros }\end{array}$ \\
\hline Audición de sonidos fuertes: Total & 105 & 122 & 170,8 \\
\hline Sin ayudas & 50 & 48,2 & 89,9 \\
\hline Sólo ayudas técnicas & 49 & 67,5 & 68,9 \\
\hline No consta & 6,3 & 5,9 & 11,9 \\
\hline
\end{tabular}


Tabla 14.- Población con discapacidad auditiva que no puede recibir mensajes hablados por rango de edad

\begin{tabular}{|c|c|c|c|}
\hline Franja de edad & $6-64$ & $65-79$ & $80+$ \\
\hline & 151 & 78,3 & 134,9 \\
\hline $\begin{array}{l}\text { Recibir mensajes hablados: Tota } \\
\text { Sin ayudas }\end{array}$ & 69 & 39,7 & 56,6 \\
\hline Sólo asistencia o ayuda personal & 76 & 35,6 & 70,8 \\
\hline No consta & 5,5 & 3 & 7,5 \\
\hline
\end{tabular}

Tabla 15.- Población con discapacidad auditiva que emplea para la comunicación dispositivos y técnicas de comunicación

\begin{tabular}{lrrr}
\hline Franja de edad & $6-64$ & $65-79$ & $80+$ \\
\hline & & & \\
Comunicación a través de & & & 229,1 \\
dispositivos y técnicas de & & & 116,7 \\
comunicación: Total & 166 & 60,3 & 84,8 \\
Sin ayudas & 80 & 45,8 & 5,9 \\
Sólo asistencia o ayuda personal & 61 & 7,7 & 9,6 \\
Sólo ayudas técnicas & 10 & 5,7 & 12,2 \\
Ambos tipos de ayuda & 6,6 & 5,7 & \\
No consta & 7,8 & & \\
\hline
\end{tabular}

Tabla 16.- Población con discapacidad auditiva que produce mensajes hablados con/sin ayudas/ayudas técnicas

\begin{tabular}{|c|c|c|c|}
\hline Franja de edad & $6-64$ & $65-79$ & $80+$ \\
\hline Producir mensajes hablados: Total & 187 & 92,1 & 131,7 \\
\hline Sin ayudas & 164 & 82,9 & 122 \\
\hline Sólo ayudas técnicas & 15 & 4,6 & 3,4 \\
\hline No consta & 8 & 4,6 & 6,3 \\
\hline
\end{tabular}

Observando las tablas anteriores se podría afirmar que en España existe un bajo uso de los PA en el colectivo de personas con discapacidad auditiva.

Figura 8.- Personas con discapacidad que señalan falta de ayudas personales o técnicas en Castilla y León.

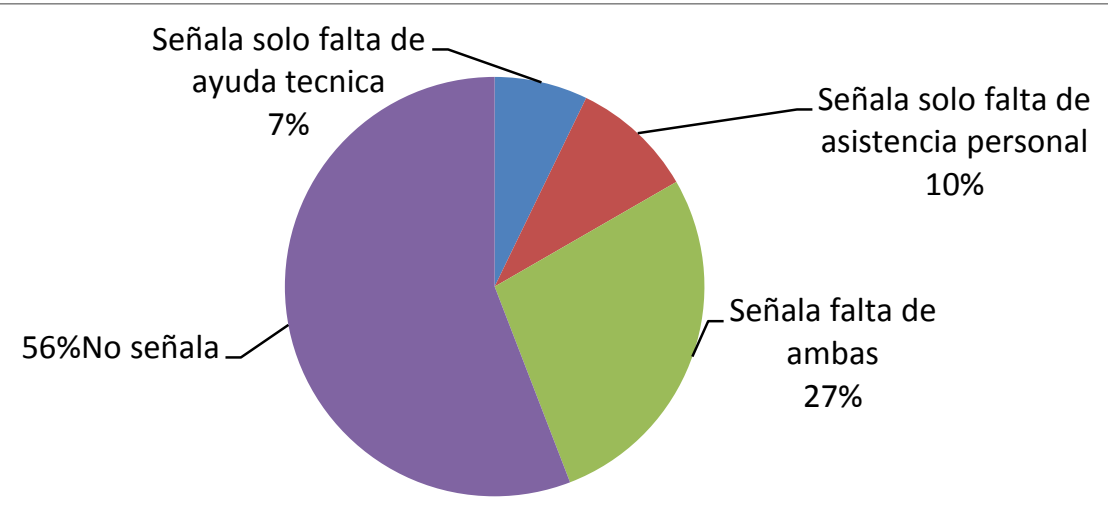


A modo de ejemplo, en la siguiente tabla se listan algunos PA para personas con discapacidad auditiva actuales (tomado del catálogo del CEAPAT). No obstante, debemos mencionar algunos de los PA tradicionales que han sido utilizados por las personas con discapacidad auditiva, antes del surgimiento de nuevas tecnologías y de PA como los implantes cocleares (Schwartzman, 2002) tales como: los dispositivos telefónicos para sordos (DTS) que sustituyeron al Amper (Dubuisson \& Daigle, 1998; Dubuisson, Machab’ee \& Parisot, 1997), tableros de comunicación, comunicadores (Marín \& Pérez, 2003), teléfonos de amplificación (de-Gómez, Solís-Rábago, Méndez-Martínez, Medina-Vega, \& Martínez-Consuegra, 200), entre otros. Tampoco se debe olvidar que diariamente se proponen y desarrollan nuevos productos de interés para el colectivo de personas con discapacidad auditiva tales como: productos para la síntesis y reconocimiento de voz (Hotton, 2004), avatares que reproducen la lengua de signos (Elliott, 2008; San-Segundo, 2008), traductores de lengua de signos a lengua oral y viceversa (Al-Jarrah \& Halawani, 2001), sistemas de comunicación alternativa (pictogramas, dibujos, mapas conceptuales)(Peluso \& Viera, 2014), guantes que traducen la lengua de signos a lengua hablada (o dispositivos cuyo objetivo es avisar a la persona con discapacidad auditiva de las señales acústicas de su entorno, por citar algunos ejemplos. 
Tabla 17. Principales PA para personas con discapacidad auditiva (elaboración propia a partir de CEAPAT) .

\begin{tabular}{|c|c|c|c|}
\hline Clasificación & Producto & Clasificación & Tipos \\
\hline $\begin{array}{l}\text { Productos para el } \\
\text { aprovechamiento de } \\
\text { restos auditivos }\end{array}$ & 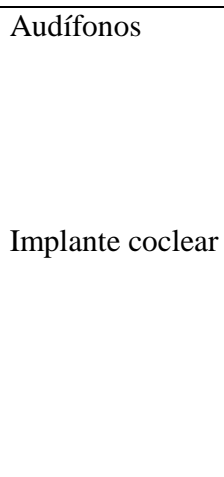 & $\begin{array}{l}\text { Implantes osteointegrado } \\
\text { Audífonos implantados de } \\
\text { conducción aérea } \\
\text { Implantes de oído medio } \\
\text { Implantes cocleares } \\
\text { Implantes de tronco } \\
\text { cerebral }\end{array}$ & $\begin{array}{l}\text { Retroauriculares } \\
\text { Intracraneales } \\
\text { Audífonos de bolsillo } \\
\text { Prótesis ósea o de } \\
\text { diadema } \\
\text { Audífonos adaptado a } \\
\text { gafas } \\
\text { CIC }\end{array}$ \\
\hline
\end{tabular}

acústica

Receptores de infrarrojos

Productos para entornos amplios

Productos específicos para entornos

educativos

Productos informáticos para la estimulación lingüística

Productos para la comunicación a distancia

Acceso a los medios de comunicación

Productos para el acceso a la información en los lugares públicos

Algunos ejemplos

Algunos ejemplos

Productos para el hogar Algunos ejemplos
SUVAG

ESTIMULADORES

VIBROTÁCTILES

Sistema VISHA

VISUALIZADOR FONÉTICO

DE IBM (SPEECHVIEWER

LAOS

PHONOS

INTELEX (12000 TÉRMINOS

EN LENGUA DE SIGNOS)

¡A Signar!

SIMICOLE.

Despertadores

VIBROTÁCTILES

Relojes despertadores

vibradores o luminosos de

pulsera

Intercomunicadores o avisadores del hogar

Fax, Teléfono de texto,

Móvil:apps,Skype, Oovoo,

Sistemas de intermediación por vídeo, Videoteléfono y

Videoconferencia

Subtitulado de programas,

Programas con intérprete de lengua de signos y Teletexto

Paneles de información
TÁCTIL

Electroacústicas,Videoportero y Sistemas de alerta y ayuda

visual
Amplificadores de bucle Aros magnéticos Sistemas FM 


\section{Medidas de resultados en productos de apoyo para personas sordas}

El campo de medidas de resultados en PA para personas sordas es uno de los campos más activos dentro de la investigación en la rehabilitación audiológica (Cox, Hyde \& Gatehouse, 2000). Dentro del campo de las medidas de resultados y los PA para personas sordas podemos encontrar varios estudios donde se examinan las medidas genéricas y específicas en cuanto al rendimiento de los PA, como por ejemplo en el estudio realizado por Saunders y Jutai (2004) donde determinaron la sensibilidad al uso de PA y examinaron la relación entre expectativas previas al uso y los resultados posteriores a su utilización.

Las ventajas del uso de medidas de resultados en PA para personas sordas son variadas. Por ejemplo, los foniatras y otorrinolaringólogos pueden obtener resultados sobre el proceso de rehabilitación auditiva y el estado mental-físico de los usuarios, analizar el costebeneficio de la asignación de un PA y planificar así una mejor asignación de recursos en base a las medidas de resultados, y también llevar a cabo comparaciones entre diferentes PA.

En general, en el campo de las medidas de resultados y PA para personas sordas, la investigación se ha centrado en examinar los cambios que se producen con las intervenciones médicas y no existen grandes diferencias en las puntuaciones entre el pre- y el post derivado del uso del propio PA para personas sordas (Crandell, 1998; Hedley-Williams et al., 1998; Mulrow et al., 1990).

No obstante, también existen varios estudios en los que se analiza el impacto psicosocial de PA de amplificación como los audífonos (Kochkin \& Rogin, 2000; Mulrow et al.,1990) debido a que existe una clara evidencia respecto a cómo las percepciones subjetivas sobre el nivel de funcionamiento y la calidad de vida afectan significativamente en la adopción y éxito de los PA para la comunicación en personas sordas. No obstante, hay muy poca investigación del impacto en las AVD derivado del uso de PA de este tipo, al igual que es escasa la investigación en medidas de resultados en PA (Saunders \& Jutai, 2003). Muchas personas que necesitarían utilizar un PA de amplificación no lo hacen (Kochkin \& Rogin, 2000); y en otras muchas personas, su uso no mejora su calidad de vida (Kochkin \& Rogin, 2000; Mann, Hurren \& Tomita, 1994; Salamon, Vesterager \& Jagd, 1988) y ello puede ser debido a factores psicosociales (Kochkin,1993). 


\section{Instrumentos de evaluación para el uso de PA en personas sordas o con discapacidad auditiva}

Entre las escalas específicas de evaluación de PA para personas sordas encontramos al menos cinco instrumentos que se han utilizado de manera frecuente en la literatura (tabla 18)

Tabla 18.- Instrumentos de evaluación de resultados de PA específicos para personas sordas

\begin{tabular}{|c|c|c|c|}
\hline Cuestionario & Autor & Descripción & PA \\
\hline $\begin{array}{l}\text { APHAB (Abbreviated } \\
\text { Profile of Hearing Aid } \\
\text { Benefit) }\end{array}$ & $\begin{array}{l}\text { Cox and } \\
\text { Alexander, } \\
1995\end{array}$ & $\begin{array}{l}\text { Formado por } 24 \text { ítems. Se compone de cuatro } \\
\text { subescalas: (1) facilidad } \\
\text { de Comunicación (CE), (2) La reverberación } \\
\text { V), (3) Ruido de fondo (BN), (4) La aversión } \\
\text { de Sonidos (AV). }\end{array}$ & Para audífonos \\
\hline $\begin{array}{l}\text { ECHO (Expected } \\
\text { Consequences of Hearing } \\
\text { Aid Ownership) }\end{array}$ & $\begin{array}{l}\text { Cox and } \\
\text { Alexander, } \\
2000\end{array}$ & $\begin{array}{l}\text { Formado por } 15 \text { ítems y cuatro subescalas: } \\
\text { Efectos positivos (PE), Servicio y Coste } \\
\text { (SC), } \\
\text { Imagen Personal (PI), y rasgos negativos } \\
\text { (NF). }\end{array}$ & Prótesis auditivas en general \\
\hline $\begin{array}{l}\text { SADL (Satisfaction with } \\
\text { Amplification }\end{array}$ & $\begin{array}{l}\text { Cox and } \\
\text { Alexander, } \\
1999\end{array}$ & $\begin{array}{l}\text { Formado por } 15 \text { ítems y cuatro subescalas: } \\
\text { Efectos positivos (PE), Servicio y Coste } \\
\text { (SC),Imagen Personal (PI), y rasgos negativos } \\
\text { (NF). }\end{array}$ & Prótesis auditivas \\
\hline $\begin{array}{l}\text { PIADS (Psychosocial } \\
\text { Impact of Assistive Devices } \\
\text { Scale) }\end{array}$ & $\begin{array}{l}\text { Day and } \\
\text { Jutai, } 1996\end{array}$ & $\begin{array}{l}\text { Es un cuestionario de } 26 \text { ítems } \\
\text { con tres subescalas: competencia, adaptabilidad } \\
\text { y autoestima }\end{array}$ & $\begin{array}{l}\text { En PA para personas sordas se } \\
\text { ha empleado con audífonos y } \\
\text { sistemas de intermediación } \\
\text { por vídeo }\end{array}$ \\
\hline $\begin{array}{l}\text { The Hearing Technology } \\
\text { Predisposition Assessment } \\
\text { (HTPA) }\end{array}$ & $\begin{array}{l}\text { Scherer, } \\
\text { Medwetsky } \\
\text { \& Frisina, } \\
2005\end{array}$ & $\begin{array}{l}\text { El HTPA consiste en } 50 \text { items (tipo escala } \\
\text { Liker) y dividido en dos escalas (estado actual } \\
\text { con } 11 \text { ítems, estado personal y psicosocial con } \\
29 \text { items y expectativas ( } 10 \text { items). }\end{array}$ & $\begin{array}{l}\text { El HTPA fue diseñado para } \\
\text { evaluar la predisposición de } \\
\text { las personas para usar ayudas } \\
\text { auditivas y ayudar a anticipar } \\
\text { sus medidas de resultados }\end{array}$ \\
\hline
\end{tabular}

Como se puede apreciar, el objetivo de estos instrumentos es muy variado. Desde instrumentos centrados en PA específicos y que evalúan aspectos concretos de la interacción con ese PA hasta instrumentos de carácter general, aplicables a cualquier PA y centrados en la evaluación de cambios en constructos de carácter general, como el impacto psicosocial. La literatura muestra que estas escalas tienen una aplicación diferente, según la información que se desee obtener. Así, por ejemplo, el APHAB es la mejor herramienta para la adaptación al audífonos, el SADL para saber el conocimiento que tiene el usuario sobre los PA de amplificación y de la audición en general, y el PIADS tiene unas buenas propiedades psicométricas en cuanto a sensibilidad con lo que sería un instrumento adecuado para evaluar el cambio con cualquier PA (Day \& Jutai, 1996; Saunder \& Jutai, 2004,) y fiabilidad (Day \& Jutai, 1996). 
En este apartado también debemos citar otros modelos, que si bien no se configuran como instrumentos específicos de evaluación, si proponen pautas para la selección de PA específico para personas sordas en ámbitos concretos. Por ejemplo, el modelo WATI (Wisconsin Assistive technology Initiative, 2005), que se configura como una guía para tomar la decisión de que PA utilizar específicamente dentro del ámbito académico. Este modelo tiene en cuenta varios aspectos a la hora de la evaluación y la evaluación se centra en 8 aspectos: 1) evalúa tanto las habilidades como las dificultades del estudiante con discapacidad auditiva (beneficios de PA de amplificación, profesorado, acceso a alarmar o avisos, teléfono, programas y material audiovisual, actividades grupales, toma de apuntes); 2) factores ambientales (ruido, acústica, distancia, acceso visual, luminosidad, tecnología de apoyo); 3) tareas (accede a la misma información que los estudiantes oyentes); 4) consideraciones sensoriales (visual, auditiva y táctil); 5) focaliza e identifica las tareas; 5) generación de herramientas y estrategias; 6) selección de herramientas y estrategias; 7) implementa y organiza planes; y 8) sigue los planes

Este modelo propone una serie de consideraciones relativas al uso y selección de PA para el ámbito educativo, desde PA tales como productos de amplificación y equipos FM, bucles magnéticos e infrarrojos, a dispositivos de alerta como monitores para bebes, relojes, ordenadores, timbres, detectores de monóxido de carbono y teléfono. También considera los apoyos para la comunicación, entre los que encontraríamos: dispositivos de telecomunicación (móvil, TDT, SIV, cámara web ...), subtítulos, apoyos personales o dispositivos de texto. (Heckendorf, 2009).

Esta Tesis Doctoral tiene como objetivo analizar el impacto psicosocial de los PA para la comunicación y acceso a la información empleados por personas con discapacidad auditiva y personas sordas. A continuación se presentan los PA que serán objeto de estudio en la parte empírica de esta Tesis: audífonos, implante coclear y sistemas de intermediación por vídeo. Para cada PA se expondrán los factores psicosociales ligados al uso de cada uno de los PA expuestos, a partir de la revisión de la literatura y en base al modelo de los factores de abandono o falta de uso de Lauer, Longenecker \& Smith (2006).

\section{Audífonos}

El audífono es un dispositivo electroacústico que amplifica los sonidos del entorno, y potencia los sonidos del habla por encima de los ambientales. Desde el punto de vista audiológico se pueden definir como prótesis auditivas a cualquier instrumento capaz de paliar 
artificialmente una pérdida auditiva. El funcionamiento de este tipo de prótesis es simple. El dispositivo recibe la señal sonora a través de un micrófono y transforma las variaciones de presión acústica en señal eléctrica, la cual es amplificada y transformada de nuevo en señal acústica para su emisión al oído. Las personas con sorderas obtienen habitualmente buena respuesta auditiva con el audífono en las frecuencias del habla hasta 80-90 db.

Hay muchos tipos diferentes de audífonos y, normalmente, deben ser ajustados para adaptarse mejor a la pérdida específica de cada persona. El audífono es un aparato que necesita un mantenimiento metódico, es necesario realizar a menudo la limpieza de los moldes y hay que renovarlos cuando hay cambios en el grado de pérdida, entre otros factores. Para garantizar su ajuste, se recomienda renovarlo cada 5-6 años. Los gabinetes audioprotésicos, donde habitualmente se adquieren estos PA, hacen las recomendaciones oportunas sobre averías, mantenimiento, uso y colocación.

\section{Factores relacionados con la persona}

Las medidas de resultados han sido designadas como una prioridad de la rehabilitación audiológica (Cox et al., 2000). Existe evidencia que avala que el estatus funcional, bienestar y calidad de vida están significativamente ligadas al uso y al éxito de las ayudas auditivas. Jutai observó que las escalas de calidad de vida relacionada con la salud (en adelante CVRS) tienen deficiencias cuando se aplican a los audífonos. En general, muchos autores consideran que las escalas CVRS sufren limitaciones similares cuando se aplican a prácticamente todos los tipos de productos de apoyo (Jutai, 1999). Esto no se traduce necesariamente en que las medidas subjetivas que no se han desarrollado específicamente para la hipoacusia y los audífonos no resulten útiles. A cierto nivel analítico, las características subjetivas de una buena o mala calidad de vida son las mismas tanto para un usuario de producto auditivo como para usuarios de silla de ruedas o de ayudas para personas con visión reducida. Sería de gran utilidad comprobar si los audífonos tienen un impacto sobre la calidad de vida comparable con el de otros dispositivos de apoyo, especialmente cuando los individuos evaluados utilizan más de un tipo de dispositivo.

Podemos definir y entender la calidad de vida según muchas perspectivas y modelos. por poner algún ejemplo el modelo proporcionado por Verdugo y Schalock (2003;2007), que definen la calidad de vida como "un concepto identificado con el movimiento de avance, innovación y cambio en las prácticas profesionales y en los servicios, permitiendo promover actuaciones a nivel de la persona, de la organización y del sistema social”. Además, en el 
modelo proporcionado por estos dos autores clasifican en ocho dimensiones la calidad de vida con sus respectivos indicadores, lo cual ha sido estudiado y revisado en la literatura científica (Schalock \&Verdugo, 2007; Verdugo \&Schalock, 2003)

Tabla 19. Dimensiones y sus Indicadores del modelo de Calidad de Vida (tomado de Verdugo \& Schalock, 2003)

\begin{tabular}{|c|c|}
\hline Dimensiones & Indicadores \\
\hline Bienestar emocional & 1. Satisfacción, 2. Autoconcepto, 3. Ausencia de estrés \\
\hline Relaciones interpersonales & 4. Interacciones, 5.Relaciones, 6. Apoyos \\
\hline Bienestar material & 7. Estatus económico, 8. Empleo, 9. Vivienda \\
\hline Desarrollo personal & 11. Educación, 11. Competencia personal, 12. Desempeño \\
\hline \multirow[t]{2}{*}{ Bienestar físico } & 13. Salud, 14. Actividades de la vida diaria, 15. Atención sanitaria, \\
\hline & 16. Ocio \\
\hline \multirow[t]{2}{*}{ Autodeterminación } & 17. Autonomía/Control Personal, 18. Metas y valore personales, 19. \\
\hline & Elecciones \\
\hline \multirow[t]{2}{*}{ Inclusión Social } & 20. Integración y participación en la comunidad, 21. Roles \\
\hline & comunitarios, 22. Apoyos sociales \\
\hline Derechos & 23. Derechos humanos, 24. Derechos legales \\
\hline
\end{tabular}

Por otra parte, las medidas de los resultados de los productos auditivos es una de las áreas de investigación sobre rehabilitación audiológica más activas. En términos históricos, las medidas de resultados se han centrado en la mejora específica de la comunicación que sigue a una intervención audiológica. Por ejemplo, existen evidencias claras de que las percepciones subjetivas de la capacidad funcional, el bienestar y la calidad de vida pueden afectar de forma significativa a la adopción y correcto uso de audífonos (Jutai \& Saunders, 2003).

En muchos casos, los factores psicosociales, y no tanto los auditivos, son los que podrían explicar la falta de uso de productos auditivos (Jutai \& Bortolussi, 2003). Algunos estudios han demostrado que el uso de la amplificación ha mejorado diversos aspectos psicosociales de la vida (Kockin \& Rogin, 2000; Mulrow et al, 1990). Por ejemplo, la reducción de síntomas depresivos se observa desde el principio de uso de los dispositivos auditivos y es un factor psicosocial a tener en cuenta (Boi et al., 2012). Así mismo, el éxito de PA y nuevas tecnologías implica el reconocimiento de los problemas de audición (Southall, 
Gagné, \& Leroux, 2006), por ello es necesario que los profesionales del campo tengan formación específica en los aspectos psicosociales derivados del uso de estos PA

Se han realizado al menos dos estudios (Saunders \& Forsline, 2012; Saunders, Lewis $\&$ Forsline, 2009) en los que se comparan las formas de asesoramiento, haciendo especial hincapié entre el asesoramiento informativo y el asesoramiento en el desempeño perceptivo (medir y comprender la percepción del habla). Los resultados derivados del uso de técnicas de asesoramiento son, entre otros: incremento de uso de los audífonos, mayor comprensión y aceptación de la pérdida auditiva, y utilización de un mayor número de estrategias de comunicación. Por poner un ejemplo concreto, en el estudio de Saunders \& Forsline (2012), se compararon dos formas de asesoramiento en audífonos: el asesoramiento informativo y el asesoramiento en el desempeño perceptual. El primero se centró en la discusión de estrategias de comunicación y consejos para el uso de audífonos. Mientras que el segundo se dirigió a la discrepancia entre la medida y la capacidad de entender el habla. La medida de resultados se tomó de ocho a diez semanas después de la sesión, por ello, emplearon varios instrumentos entre los cuales, se encontraba la escala PIADS. Se verificó que las puntuaciones en la escala PIADS mejoraron, y la entrevista semiestructurada reveló un mayor uso de audífonos, mejor comprensión y aceptación de la pérdida de audición. La conclusión de estos autores fue la necesidad de incluir al menos una sesión de asesoramiento antes del uso del audífono. Por ello, escuchar las demandas auditivas o el estilo de vida son un factor importante a tener en cuenta al seleccionar un audífono del mismo modo que se deben de conocer las características de amplificación del dispositivo auditivo.

Por otra parte, los factores relacionados con la propia persona sugieren que si se tienen altas expectativas respecto a la audición, los PA conducen a mejores resultados, además de tener un importante efecto en el bienestar psicosocial. Por el contrario, las expectativas excesivamente altas podrían dar lugar a decepción respecto al PA (Saunders, Lewis, \& Forsline, 2009). Por tanto, los resultados de la investigación alientan a apoyar las expectativas positivas con el fin de motivar a las personas con hipoacusia a usar audífonos (Meister, Walger, Brehmer, von Wedel, \& von Wedel, 2008). Por ello, la tarea de asesoramiento y evaluación del PA debe de realizarse en equipo multidisciplinar que incluya profesionales que consideren factores no solamente técnicos.

Como propusieron Lauer, Longenecker \& Smith (2006), uno de los factores que puede conducir al abandono de un PA es la no aceptación de la discapacidad por parte de la 
persona y, de hecho, una de las problemáticas más relevante respecto al uso de audífonos tiene que ver con la aceptación de la pérdida auditiva (Rawool, 2000). Por ejemplo, muchas personas mayores niegan su pérdida auditiva o sus problemas auditivos (Hétu, 1996; Maxwell, 1999). De hecho, en personas mayores, la pérdida auditiva sí que puede contribuir a una disfunción cognitiva, y existen estudios previos que han demostrado una asociación entre audición-cognición (Lin et al., 2011). Por ejemplo, Uhlman et al. (1989) realizaron un estudio de 100 casos en personas con Alzheimer y 100 casos en personas sin demencia. Como resultado principal cabe resaltar que las personas con Alzheimer presentaron mayor grado de pérdida auditiva que los casos sin demencia. Además, esta pérdida auditiva correlacionaba con la severidad en la disfunción cognitiva, evaluado con el Mini Examen del Estado Mental. Resultados como estos pueden indicar una asociación entre pérdida auditiva y demencia. (Uhlman et al., 1989). Otro estudio fue el realizado por Meister et al. (2015), en el que utilizaron medidas objetivas y subjetivas para analizar los beneficios de las ayudas para la audición. Además emplearon pruebas neuropsicológicas para evaluar funciones cognitivas generales, tales como la atención, memoria y la inteligencia. Entre los resultados obtenidos en este estudio cabe señalar que los usuarios con puntuaciones menores de inteligencia fluida también mostraban mayor pérdida auditiva. Y de mucho interés fue la relación positiva, verificada en un análisis de regresión, entre el estado cognitivo y el beneficio objetivo derivado del uso de la ayuda auditiva. Sin embargo, el beneficio subjetivo no se pudo predecir a partir de ninguna variable.

En general, lo que parece derivarse de la literatura científica es que la pérdida auditiva en personas mayores es importante porque es incapacitante y potencialmente tratable, aunque son muchas las personas usuarias de audífonos que no los usan con regularidad y, aunque usen los audífonos, muchos están deshabilitados socialmente. Además, hay que tener en cuenta que una fuente importante de morbilidad en las personas de edad avanzada puede ser aliviado por mejoras de detección y manejo de la pérdida auditiva (Smeeth et al., 2002).

La revisión de la literatura también muestra otros factores que afectan en el reconocimiento de la pérdida auditiva tales como las habilidades de afrontamiento (Popelka, Wiley, Cruicksharks, Nondehl \& Tweed, 2000), el afrontamiento de la pérdida es percibido de forma diferente entre hombres y mujeres (Garstecki \& Erler, 1999) y en función de la edad, aunque el estigma asociado a la pérdida auditiva es mayor en las personas jóvenes que en las personas mayores (Erler \& Garstecki, 2002). Las pérdida auditiva severa se asocia con una significativa disminución de la función, y una mayor gravedad de la pérdida se asocia 
con una menor calidad de vida en los adultos mayores(Ciorba, Bianchini, Pelucchi, \& Pastore, 2012). Por tanto, la pérdida auditiva puede ocasionar un riesgo en el desarrollo de problemas psicosociales debido a que la prevalencia de pérdida auditiva en las personas mayores y sus efectos negativos sobre su calidad de vida y el bienestar es conocido (Scarinci, Worrall, \& Hickson, 2008). Incluso la pérdida auditiva tiene un fuerte impacto no solo en la comunicación sino en el funcionamiento diario y en la ejecución de sus actividades diarias (Boi et al., 2012).

\section{Factores relacionados con el producto de apoyo}

Entre los problemas asociados al uso del audífono, además de la dificultad de acoplamiento, encontramos que, en situaciones ruidosas (ruido ambiental, conversaciones de más de 3 emisores...), las personas con hipoacusia oyen igual con y sin el dispositivo auditivo (Billari, 2009). Además, existen ventajas gracias al uso de audífonos digitales avanzados frente a los analógicos lineales, tanto en resultados objetivos como subjetivos (Wood \& Lutman, 2004). Los problemas comunicativos generados de la pérdida de audición, tanto el reconocimiento del habla en ambientes ruidosos como la localización e identificación del sonido, afectan tanto a la persona como a los miembros de su entorno familiar y/o compañeros de trabajo, y estos no conocen las consecuencias derivadas de la pérdida auditiva. Además, estas personas que se encuentran en contacto con la persona con déficit auditivo deberían esforzarse más en la comunicación con la persona afectada adaptándose al situación en cuestiones como por ejemplo hablar más despacio y con una mejor articulación, girar la cabeza hacia la persona para permitir la lectura-labial, y acercarse más hacia la persona (Johansson \& Arlinger, 2003).

Otros trabajos señalan que los adultos mayores tienen un estilo de vida menos activo por lo que sus exigencias respecto al audífono son menores (Wu \& Bentler, 2012). Al igual que los usuarios con experiencia en el uso de audífonos tienen un excelente conocimiento de su uso (Desjardins \& Doherty, 2009).

\section{Factores relacionados con el entorno}

Existe un alto riesgo que las personas del entorno tengan un menor contacto con la persona con pérdida auditiva haciendo que esta se encuentre más aislada. A menudo, la persona con discapacidad auditiva no es consciente de todas las consecuencias de la pérdida, lo que puede explicarse por el propio progreso de la pérdida, puesto que la persona puede no 
ser consciente de todos los sonido que se han convertido en inaudibles (Johansson \&Arlinger, 2003).

Uno de los factores que pueden influir en el reconocimiento de la pérdida auditiva es el estigma social (Erler \& Garstecki, 2002), puesto que las personas que presentan pérdida auditiva son a menudo percibidos por los otros como con un estado cognitivo deteriorado/disminuido, menor capacidad y socialmente incompetentes (Southall, Gagné, \& Jennings, 2010).

En nuestro país es escasa la investigación en el campo de los audífonos pero cabe señalar, el Instituto de Neurociencias de Castilla y León, perteneciente a la Universidad de Salamanca, en el que entre sus estudios destacan los dedicados a la investigación de casos clínicos de personas con discapacidad auditiva y el desarrollo de PA tales como los audífonos. Por otra parte en otros países existen entidades dedicadas en exclusiva a la investigación en PA, entre las cuales cabe destacar el Centro de Investigación Eriksholm con más de 100 investigaciones en el campo de los PA para personas con discapacidad auditiva, el centro MRC (vinculado a la Universidad de Nottingham, y con sede en Reino Unido, China y Malasia) especializado en varias áreas dentro del campo de los PA para personas con discapacidad auditiva, UPMC (cuenta con más de 15 centros repartidos por EE.UU) entre sus competencias investigadoras destaca desarrollo de pruebas estandarizadas y PA para la educación. 


\section{Implantes cocleares.}

El implante coclear es un producto de apoyo que sirve para recuperar la audición en algunos casos de sordera profunda bilateral, y se basa en la transformación del sonido en energía eléctrica estimulando el nervio auditivo. Por tanto, es un dispositivo eléctrico diseñado para reproducir la función de la cóclea y mejorar la comunicación de personas sordas. El implante coclear cuenta con unos componentes internos y otros externos. Las partes internas se colocan mediante cirugía clínica, con anestesia general, y están compuestas por el estimulador/receptor y los electrodos que se introducen en la cóclea (caracol). Para ser candidato a un implante, hay que cumplir con una serie de requisitos, tales como padecer de sordera total o profunda con un grado de comprensión pobre, y que los audífonos hayan fracasado. Existe un consenso generalizado entre teóricos, investigadores y profesionales a la hora de definir los criterios generales que permitan seleccionar a las personas candidatas a un IC: (1) Los implantes cocleares están indicados para pacientes que presentan una hipoacusia neurosensorial bilateral severa o profunda, es decir, pérdidas superiores a $90 \mathrm{Db}$. (2) Cuando no pueden obtener beneficios de los audífonos y no pueden adquirir el lenguaje oral. (3) Cuando el candidato no tenga ninguna contraindicación médica. (4) Es importante que el candidato y sus familiares estén motivados y tengas expectativas realistas del IC. (5) En el caso de los niños/as, que tengan posibilidades de acceder a la educación y seguimiento en la rehabilitación. (6) Se recomienda la implantación a una edad temprana debido a que la audición es de vital importancia para el desarrollo del lenguaje y porque las investigaciones han demostrado obtener mejores resultados en los niños implantados a temprana edad. (7) Los niños de mayor edad, los adolescentes y los adultos con un desarrollo del habla y del lenguaje previo, generalmente funcionan mejor con un IC (Goffi et al., 2004).

El equipo médico multidisciplinar de un centro implantador tiene que valorar el caso individualmente y, después de una serie de pruebas, comunicar a la persona en cuestión en caso de ser mayor de edad o a sus familiares si se trata de un menor. Mientras otros PA proporcionan un sonido más intenso y más claro, los implantes cocleares proporcionan sonido útil por estimulación directa de las fibras nerviosas dañadas en el oído interno que a su vez envían la información a la zona cerebral responsable de la audición. Pero debemos de tener en cuenta que la "implantación" no restaura la audición normal (Christiansen \& Leigh, 2002). El dispositivo necesita un mantenimiento y una atención diaria para su correcto funcionamiento. Además, el procesador se puede dañar, por ejemplo, por una descarga electroestática (Hedley-Williams, Sladen \& Tharpe, 2003). Por tanto, la persona implantada 
durante periodos en que estará en contacto directo con humedad como la ducha, nadar... deberá adoptar una serie de medidas de seguridad, como quitarse el dispositivo, y es en estos momentos donde la persona deberá usar otros medios para asegurar la comunicación.

En España, el coste del implante coclear se financia a través de la Seguridad Social, así como la intervención quirúrgica y el posterior tratamiento rehabilitador. La Seguridad Social cubre por tanto la colocación del implante y del primer procesador, pero no financia los sucesivos gastos de mantenimiento o de sustitución del procesador por uno nuevo. Las marcas que más se implantan actualmente son: Med-El, Cochlear y Advanced bionics.

Si tenemos en cuenta la pérdida de audición se debe tener en cuenta la parte del sistema auditivo que no está funcionando normalmente. Dependiendo si el problema se encuentra en una de las tres partes del oído: externa (pérdida conductiva), medio (pérdida conductiva) o interna (pérdida neurosensorial). Solamente en estas dos últimas el implante coclear es eficaz.

\section{Factores relacionados con la persona}

Hay mucha evidencia que sugiere que, al principio de la vida, la información auditiva y la comunicación son esenciales para el desarrollo normal del lenguaje, cognición y comportamiento. Los implantes cocleares pueden tener muy buena perspectiva en la restauración de la información auditiva y mejorar en el reconocimiento de voz y de la producción, siempre y cuando se trabajen adecuadamente y la persona sea candidato al implante (Quittner, Leibach, \& Marciel, 2004).

En las dos últimas décadas, el número de personas, sobre todo niños, que han recibido un implante coclear ha aumentado. La etapa infantil y adolescente está caracterizada por un rápido desarrollo psicosocial y social (Harter, 2003; Kroger, 1996; Noller, Feeney \& Peterson, 2001). Por ello, el IC puede afectar a su estado de "normalizar" su status y negar su discapacidad (Ladd, 2003; Preisler, 2007). Sin embargo, otros autores argumentan que el IC puede servir como vehículo para la vía académica y para el ajuste psicosocial, ya que supone una mejora sustancial en el acceso a la lengua oral (Fagan, Pisoni, Horn \& Dillon, 2007; Geers, 2006; Spencer \& Marschark, 2003; Wheeler, Archbold, Gregory \& Skipp, 2007). La integración social de los adolescentes sordos con IC puede ser positiva, siempre y cuando presenten una seguridad emocional y participen frecuentemente en actividades sociales (Leigh \& Stinson, 1991; Stinson, Chase \& Kluwin, 1990; Stinson \& Kluwin, 2003). Sin 
embargo, esta participación social puede verse afectada por las barreras comunicativas presentes entre personas sordas y oyentes (Bat-Chava \& Deignan, 2001; Eriks-Brophy et al., 2007; Stinson \& Kluwin, 2003). Por esta razón, muchos estudiantes sordos reportan sentimientos de soledad, pocas amistades y falta de contactos sociales (Leigh \& Stinson, 1991; Stinson \& Lang, 1994; Stinson \& Whitmire, 1992; Stinson, Whitmire \& Kluwin, 1996). Incluso hay estudios que concluyen que jóvenes sordos manifiestan insatisfacción al interaccionar con personas oyentes (Boyd, Knutson \& Dahlstrom, 2000). Por tanto, la literatura científica revela que existe una preocupación en cuanto al ajuste psicosocial de los jóvenes sordos implantados(Leigh, Maxwell-McCaw, Bat-Chava, \& Christiansen, 2008).

Los implantes cocleares proporcionan a los niños sordos acceso a la lengua oral a través de la audición y, por lo tanto, facilitan el desarrollo del lenguaje hablado. Durante los últimos 20 años, su uso se ha vuelto cada vez más extendido y, hoy en día, es una opción aceptada para los niños con sordera profunda. Eso significa que hay un considerable cohorte de niños que han tenido un implante coclear desde hace varios años y hay muchas investigaciones que evalúan su progreso. Por ejemplo, en un estudio en el que se investigó la competencia en lengua oral entre un grupo de niños sordos implantados y otro grupo de niños sin IC, se comprobó que los niños sordos con implante coclear tienen un desarrollo del lenguaje similar al de los niños oyentes; y que, además, este desarrollo del lenguaje oral con el IC es más rápido que con audífonos (Svirsky, Robbins, Kirk, Pisoni, Miyamoto, 2000).

El factor más importante para determinar el desarrollo exitoso de la lengua hablada después del implante parece ser la edad de implantación. Cuánto menor es la edad de implantación, más posibilidades de entender el lenguaje hablado y usar un lenguaje hablado inteligible para la comunicación cotidiana (McDonald, Hieber, Arts \& Zwolan, 2000; Nikolopoulos, O’Donoghue \& Archbold, 1999; Nikolopoulos, Archbold, Lutman \& O’Donoghue, 2000). En España, en general, las personas sordas suelen tener un único IC y de ser el caso, emplean un audífono en el otro oído (Phillips et al., 2009). A pesar de que no existe revisiones sistemáticas y/o meta-análisis que comparen los IC frente a los audífonos en pérdidas profundas (Fitzpatrick et al., 2012), son muchos los estudios demuestran los beneficios de los implantes cocleares en los niños (Anderson, Weichbold, D'Haese, 2004; Osberger, Maso \& Sam, 1993; Spencer, Barker \& Tomblin, 2003; Tye-Murray, Spencer \& Woodworth, 1995; Young \& Killen, 2002). 
Investigaciones anteriores han demostrado los beneficios del implante coclear, como la disminución significativa de las dificultades psicológicas y emocionales. La personalidad y otros factores psicológicos pueden influir en el resultado de la rehabilitación (Scheetz, 2004). En este sentido, cabe describir el estudio realizado por Knutson, Johnson, y Murray (2006), en el que examinaron si las personas usuarias de IC en los últimos años difieren psicológicamente de los implantados en la década de 1980. Además, como segundo objetivo, exploraron los mecanismos por los que la sordera profunda podría contribuir a las dificultades psicológicas y emocionales para los candidatos de implantes y sus cónyuges. La muestra contaba con un total de 178 candidatos a los cuales se les evaluó mediante medidas objetivas psicosociales y emocionales, además de evaluar la participación social. Los resultados mostraron que no había diferencias significativas temporales, sin embargo, las personas implantadas revelaron altas puntuaciones en depresión, introversión social, desconfianza, ansiedad social y soledad. Además las personas con mayor grado de pérdida reportaron una menor participación social.

El implante coclear permite, además, la mejora en la comunicación y la calidad de vida en las personas con edad avanzada con un grado de pérdida severo-profundo y un tipo de pérdida neurosensorial. Hay factores médicos y psicosociales que plantean retos adicionales que pueden afectar a los resultados deseados con el implante coclear. Los riesgos asociados con los implantes cocleares no se incrementan significativamente con la edad. Así, los profesionales debemos tener en cuenta las necesidades pre-operacionales de esta población y los riesgos adicionales asociados con el proceso de recuperación (Yeagle, Ceh, \& Francis, 2010).

En las personas mayores es necesario, además, tener en cuenta otros factores para ser candidatos a IC, tales como la edad y el sistema auditivo, duración de la sordera, el grado de deterioro de las habilidades comunicativas y la coexistencia de problemas médicospsicosociales (Buchman, Fucci, \& Luxford, 1999). La duración de la sordera, junto con el porcentaje de vida que se vive siendo sordo, son predictivos del no abandono del PA, lo que demuestra que los restos auditivos y las habilidades de lenguaje pueden ser la clave para el éxito (Leung et al., 2005). Se ha demostrado que los adultos postlocutivos generan una perspectiva positiva después de recibir un implante. Y se ha informado de que estos adultos han mejorado en autoestima, independencia, competencia y se ha disminuido los sentimientos de soledad, depresión y aislamiento social. Se debe comenzar a estratificar el riesgo-beneficio de los implantes cocleares en personas mayores (Eshraghi et al., 2012), puesto que la esperanza de vida ha aumentado en las últimas décadas. 
Los implantes cocleares en adultos mayores están asociados, además, con un aumento en la salud, las mejoras en las audición y aumento en la calidad de vida, por lo que los IC tienen un impacto significativo en las personas sordas de más edad y son una intervención costeefectiva en esta población (Francis, et al., 2002). Además, se han encontrado beneficios en la audición en candidatos de edad avanzada (Chatelin et al., 2004; Francis et al., 2002; Vermeire et al., 2005) Esta mejora en la calidad de vida se obtiene, principalmente, en los primeros meses después de la implantación, y una menor duración de la sordera y un mayor nivel educativo son predictores de una positiva satisfacción con el implante (Klop et al., 2008). Para algunos autores (Klop et al., 2008; Zhao, Bai, \& Stephens, 2008)), esta mejora en la calidad de vida es debida no solo a la capacidad para comunicarse, sino por su faceta facilitadora en el uso de otros dispositivos, como el teléfono, o su capacidad para generar mayor autoconfianza, menor sensación de aislamiento, o permitir el disfrute de la música y/o la televisión. Y otros autores (Mo, Lindbaek \& Harris; 2005) concluyen que la mejora en la calidad de vida se debe, principalmente, a los componentes de comunicación, sensación de ser una carga, aislamiento y relación con amigos-familiares. Incluso se asocia a una reducción significativa en la depresión y la ansiedad. En general, ha habido muchos estudios que intentan evaluar los cambios en la calidad de vida en los pacientes después de la cirugía de implantación y han demostrado que lleva a una mejora sustancial de la misma (Mo, Lindbaek \& Harris; 2005).

Así, los resultados confirman la utilidad indiscutible del implante coclear y proporcionan evidencia de que los pacientes de edad avanzada obtienen un beneficio sustancial en la calidad de vida, como lo demuestra el estado de salud, el éxito en actividades comunes y la satisfacción percibida después del procedimiento (Di Nardo, Anzivino, Giannantonio, Schinaia, \& Paludetti, 2014). Por todo ello podríamos afirmar que el implante coclear es un procedimiento rentable (Klop et al., 2008). Sin embargo, los candidatos también deben estar informados acerca de las complicaciones asociadas con el procedimiento (Migirov, Taitelbaum-Swead, Drendel, Hildesheimer, \& Kronenberg, 2010). Las decisiones sobre la relación costo-efectividad de los implantes cocleares bilaterales deberían tener en cuenta el alto grado de incertidumbre en relación con el aumento de la utilidad (Bond et al., 2009). El uso de implantes cocleares en ancianos ha sido limitado, posiblemente, por la idea errónea de que los pacientes de edad avanzada tendrán un mal desempeño (Labadie, Carrasco, Gilmer, \& Pillsbury, 2000).

La mayoría de resultados muestran que es un tratamiento exitoso y efectivo para las personas con deficiencia auditiva severa y profunda en términos de proporcionar una mejora 
en el rendimiento auditivo. Pero, sin embargo, estos resultados se obtienen en contextos clínicos y no representan la facilidad o dificultad que un individuo tiene en su vida diaria. Uno de los objetivos de la implantación es minimizar cualquier discapacidad que un individuo experimente como resultado de la pérdida de audición profunda junto con la mejora de la calidad de vida. Por lo tanto, es esencial evaluar cambios en las limitaciones de las actividades, restricción en la participación y la calidad de vida, según la percepción de los pacientes con implante coclear, con el fin de definir la eficacia del implante coclear (Zhao, Bai, \& Stephens, 2008).

Las personas usuarias de implante coclear obtienen una mayor satisfacción de vida gracias al uso. Además de sentirse a gusto, tanto con personas sordas como con personas oyentes, y perciben una mayor inclusión con el mundo oyente (Spencer, Tomblin, \& Gantz, 2012). Además, muchos usuarios reportan una disminución de los acúfenos (fenómeno perceptivo que consiste en notar golpes o sonidos en el oído, que no proceden de ninguna fuente externa) y una mayor calidad de vida relacionada con la salud, e incluso una menor percepción de estrés derivada de uso del dispositivo (Olze et al., 2012). También, otros estudios muestran una gran dependencia de la lectura labial y un efecto grave de tinnitus (Hallam, Ashton, Sherbourne, \& Gailey, 2006).

El estrés de afrontamiento y las estrategias utilizadas entre personas sordas postlocutivas y personas oyentes son muy diferentes. Los sordos postlocutivos rara vez utilizan estrategias eficaces tales como el afrontamiento activo, planificación y humor, y tienden más al uso a la negación. En algunos estudios se muestra que las personas implantadas presentan una salud mental y social peor, además de peor funcionamiento físico (Kobosko, Pankowska, \& Skarżyński, 2012). Aunque otros estudios concluyen que el bienestar psicológico mejora gracias al uso del dispositivo (Rembar, Lind, Arnesen \& Helvik, 2009). En numerosos estudios, la salud mental es comparada entre personas con un tipo de pérdida profunda adquirida y personas con pérdida adquirida en general. Los resultados señalan mayor dependencia de lectura labial y efecto grave de acúfenos (conocidos en la literatura científica también como tinnitus) para la pérdida profunda. Además, apoyan la conclusión de que el impacto psicosocial es mayor en pérdidas profundas (Hallam, Ashton, Sherbourne, \& Gailey, 2006).

La literatura también señala que los implantes cocleares deberían ser considerados como una opción para adultos y adolescentes prelocutivos, puesto que la mayoría de los usuarios de estos dispositivos con estas características alegan un beneficio en satisfacción con 
el dispositivo (Caposecco, Hickson, \& Pedley, 2012). Aunque también hay resultados que indican que hay un mayor impacto positivo en personas con un tipo de pérdida profunda postlocutiva (Hallam et al., 2006).

La cirugía del implante coclear es un acontecimiento vital por lo que suponer la forma en la que el individuo responde en situaciones estresantes podría predecir cómo el individuo se adaptará al implante (pesimista-optimista, expectativas realistas-no realistas y el tipo de sistema de apoyo) tiene un impacto directo en el éxito del implante coclear. Los usuarios de implante coclear deben someterse a una terapia post-quirúrgica extensa en la que se pueden incluir habla, reconocimiento audiológico y el mantenimiento del propio implante. Faltan por realizar estudios que se centren en las actitudes y las percepciones del implante coclear en los diferentes contextos. La disponibilidad permanente de apoyo psicológico para estos pacientes es esencial, así como el conocimiento de sus problemas (Kobosko et al., 2012). Hay consultas para la evaluación de la pérdida, pero no hay demasiados servicios para hacer frente a las necesidades psicosociales, solamente para las audiológicas (Claesen \& Pryce, 2012).

Comprender el impacto en la calidad de vida ayuda a los profesionales en la comprensión de las limitaciones prácticas de estos dispositivos y también permite aconsejar a los pacientes futuros en consecuencia (Buhagiar \& Lutman, 2011). Además, un enfoque multidisciplinar para la evaluación es necesario para minimizar los riesgos de la intervención y desarrollar expectativas adecuadas por el paciente y sus familiares (Yeagle et al., 2010).

Hay estudios que demuestran que una de las prestaciones de los implantes cocleares es la de reducir la limitación en la actividad (Tye-Murray et al.,1992). Dado que son los terapeutas ocupacionales los encargados de las actividades de la vida diaria, su presencia en este ámbito junto al equipo multidisciplinar debería asegurarse. Entre los beneficios del implante coclear podemos encontrar la realización de una actividad instrumental de la vida diaria ( en adelante AVD) como es el uso del teléfono (Clinkard et al., 2011), mejoras en las AVD en el uso de nuevas tecnologías como uso de reproductores de música y televisiones y mejoras en general en las actividades de la vida diaria (Zhao et al., 2008). Además de un mayor acceso a variedad de actividades (Spencer \& Marschank, 2003).

\section{Factores relacionados con el producto de apoyo}

Diversos estudios muestran resultados que indican un mal funcionamiento de los IC en cuanto al reconocimiento de voz y la calidad de recepción de los sonidos por parte de las personas implantadas (Park, Shipp, Chen, Nedzelski, \& Lin, 2011; Sladen \& Zappler, 2015; 
Zohdi, AbdelMessih, El Shennawy, Badreldin, \& Ashour, 2014). Además de existir estudios específicos respecto al mal funcionamiento del implante externo (Belle, 2005).

Como con cualquier otro PA, se debe tener en cuenta como los candidatos a un implante eligen el IC. En este sentido, cabe destacar el estudio realizado por Migirov et al. (2009), que analizaron los factores que influyen en la decisión de elección de un IC. Para ello realizaron un cuestionario que incluía preguntas sobre aspectos estéticos del PA, sobre consideraciones técnicas y sobre la calidad de funcionamiento del mismo. La muestra total estaba formada por 184 participantes. Los resultados de este estudio se dividieron por el tipo de IC. Los candidatos al IC Nucleus manifestaron que su decisión de optar por este IC estuvo más influenciada por el funcionamiento del mismo que por su estética. Sin embargo, los usuarios del $\mathrm{ABC}$ estuvieron más influenciados por los aspectos estéticos; y los usuarios de MED-EL señalaron estar igualmente influenciados por los aspectos técnicos que con los estéticos. Existieron diferencias en cuanto a los factores dependiendo del género, siendo las mujeres más influenciadas por la opinión de la familia que los varones, al igual que por la calidad del funcionamiento del dispositivo. Los autores concluyeron que la elección del IC es un proceso altamente dependiente de los factores personales, sociales y culturales. En este mismo sentido, destaca el estudio realizado por Muzaffar, Davis y Meyer (2012), en el cual realizaron una investigación en base a las motivaciones e influencias que rodean a la selección de un IC. Los resultados reportados fueron que el 79\% de los usuarios buscaron información en la red, seguido de un $66 \%$ en folletos y guías de fabricantes, un $61 \%$ en foros específicos y, por último, un $37 \%$ consultaron a un profesional de la salud como primera fuente de información. La conclusión principal de este estudio fue que los usuarios de IC de todas las edades, independientemente del lugar de residencia, emplean los recursos en línea para la toma de decisiones para elegir el IC más adecuado.

Uno de los factores relacionados con el IC es su alto coste. Son varios los estudios que investigan el coste-beneficio del uso de estos PA, por ser ésta una de las causas de la no adopción del propio PA o del abandono (e.g, por el coste del mantenimiento) (Cheng et al., 2000; Cheng \& Niparko, 1999). Por otra parte, otro de los factores influyentes en el uso de estos PA es la propia apariencia o estética del IC, y de hecho algunos usuarios de IC terminan por abandonarlo por este factor (Pollard, 1996). 


\section{Factores relacionados con el entorno}

Las personas sordas manifiestan una gran preocupación por los implantes cocleares, puesto que los ven como una amenaza, tanto para la cultura sorda como para la lengua de signos. Además, son muchas las personas sordas que manifiestan una actitud escéptica sobre la rehabilitación después de la cirugía. Estas ideas han atraído poco la atención de los investigadores, pero podrían representar cuestiones éticas pertinentes de las cuales los profesionales y los investigadores en el campo de la implantación son conscientes y son un factor para no adoptar el IC (Kermit, 2012), además del estigma social por parte de las personas oyentes asociado a su uso (Zola, 1993). 


\section{Sistemas de intermediación por vídeo. VRS}

Los Servicios de Intermediación en Vídeo (o Video Relay Services; en adelante SIV) permiten la comunicación en tiempo real entre una persona usuaria de lengua de signos y una persona usuaria de lengua oral, a través de un intermediario intérprete de lengua de signos y con el apoyo de videoteléfonos o tecnologías similares. El intérprete es la única persona vinculada a los dos individuos que quieren comunicarse y su función es la de administrar y coordinar la conversación. Para utilizar un SIV se necesita disponer de un receptor de vídeo (pantalla de teléfono móvil o tableta, televisión o pantalla de ordenador), una pequeña cámara de video y una conexión de datos de alta velocidad.

Los SIV son productos desarrollados a partir de la evolución de los Servicios de Telecomunicación conocidos como TRS o IP-Relay. En un principio, estos productos fueron diseñados para ser conectados a través de un TDD (TTY) u otro dispositivo telefónico de asistencia. Pero, gracias al auge en las nuevas tecnologías, hoy en día, estos productos pueden ser conectados a un ordenador, portátil, móvil, PDA y a otros muchos dispositivos. El primero de estos productos fue establecido por Converse Comunicaciones de Connecticut en 1974. Actualmente, los SIV están disponibles en muchos países y su uso se ha extendido bastante, sobre todo en Europa y EE.UU (Warnicke \& Plejert, 2012), conduciendo a la creación de nuevos contextos de interacción social y el uso del lenguaje entre sordos y oyentes (Keating, Edwards \& Mirus, 2008; Omnitor, 2005; Polycom, 2005; SingTalk America LLC, 2005; Sorenson, 2005).

\section{Factores relacionados con la persona}

La literatura muestra muchos resultados derivados del uso de SIV entre los que destacan la mejora de la calidad de vida el bienestar psicológico, y el incremento de la independencia, la autoestima, la sensación de control y la funcionalidad (Götherström, Persson, \& Jonsson, 2004). En general, los hallazgos sugieren un impacto positivo sobre diversos factores psicosociales por el uso de los SIV. Saladin y Hansmann (2008) realizaron un estudio con SIV, empleando la escala PIADS, cuyo objetivo era indagar acerca de la adopción del PA y el impacto psicosocial derivado de su uso. En el estudio emplearon un análisis discriminante múltiple, cuyos resultados mostraron que las subescalas del PIADS (competencia, adaptabilidad y autoestima) eran buenas predictoras de la adopción de un SIV. Además, realizaron un análisis para comprobar si otras variables demográficas (modo de 
comunicación, nivel de audición, entrenamiento en el uso del SIV, uso del SIV en el trabajo, uso del SIV en el hogar, nivel educativo y sexo) podían discriminar entre distintos perfiles de adopción del PA sin encontrar ningún resultado concluyente. Aunque sí e verificó una relación entre la competencia y la adaptabilidad de la escala PIADS y el entrenamiento en el uso de SIV, lo cual enfatiza la importancia de considerar cuestiones relativas al entrenamiento en el uso de PA incluso en productos que a priori parecen no tener una excesiva complejidad de uso.

En la literatura no hay muchos más estudios sobre SIV. Por ello, el realizado en esta Tesis Doctoral será un contribución de interés en este campo.

\section{Factores relacionados con el producto de apoyo}

Aunque el uso de SIV se asocie a resultados positivos, también se han identificado algunos problemas. Por ejemplo, los SIV mediante telefonía móvil podrían no ser tan eficientes para la comunicación debido a que, en ocasiones, se producen errores de compensación de los movimientos que distraen a la persona signante; o decrementos de la velocidad de la conexión que podrían interrumpir la coherencia temporal del vídeo (Ciaramello \& Hemami, 2009). Aun así, son muchos los usuarios de lengua de signos que lo emplean debido a la libertad y comodidad comunicativa que genera el uso de vídeo a través de un dispositivo de fácil acceso como el teléfono móvil.

Por ejemplo, los móviles se han convertido en un dispositivo muy popular entre las personas sordas teniendo en cuenta su utilidad para este colectivo. Sin embargo, son pocos los móviles accesibles para las personas sordas o con dificultades para oír, y hoy en día suponen un desafío. Actualmente, existen móviles con amplificación especial del volumen pero si se trata de una persona sorda profunda, los móviles son, o bien imposibles de usar, o al menos complejos. No obstante, para las pérdidas profundas existen teléfonos con vídeomensajes que están muy extendidos entre la población sorda pero necesitan de un mayor nivel de competencia en aspectos tecnológicos (Miesenberger, Klaus, Zagler, \& Karshmer, 2008).

\section{Factores relacionados con el entorno}

Las personas sordas, como tales, están excluidas del uso del teléfono común como medio de comunicación para fines personales, sociales y profesionales. Ello ha provocado que las personas sordas acojan con entusiasmo la llegada de los mensajes de texto y otros 
medios visuales de comunicación a través de internet. Las personas sordas emplean Internet para los fines habituales, al igual que hacemos los oyentes: socialización, entretenimiento, aprendizaje, negocios, etc. (Power, Power \& Rehling, 2009). También utilizan servicios de mensajes cortos (SMS), email, fax y teléfono para comunicarse dentro de la comunidad, tanto sorda como oyente. Este uso va dirigido a sociabilizar, aunque existe también un uso instrumental (mantener un contacto para negocios, citas o simplemente obtener información) (Power, Power, \& Rehling, 2007). Las comunidades en línea son útiles y tienen muchas ventajas para las personas sordas, ya que éstas utilizan la lengua de signos, es por ello que las personas sordas suelen tener problemas para desenvolverse en las páginas web, chats...(Zahedi, Mashal, \& Salehi, 2011). Este colectivo está unido en un "Deaf-World" que trasciende fronteras tanto nacionales como geográfica (Lane, Harlan, Hoffmeister \& Bahan, 1996)

En general, sabemos muy poco acerca de la participación social con el uso de productos de apoyo y sabemos aún menos de la comunicación entre sordos signantes y oyentes gracias a PA (Vincent, Deaudelin \& Hotton, 2007). Hoy en día, las tecnologías Web son una forma muy eficaz para garantizar la comunicación entre un público amplio y heterogéneo. Pero uno de los problemas de acceso de las personas sordas a la información Web es que esta está basada principalmente en contenido textual. Este problema se debe a la falta de servicios que faciliten el aprendizaje de la lengua de signos para personas oyentes o la traducción de los textos a la lengua de signos (Boulares \& Jemni, 2012). Así, en la mayor parte de los foros sobre tecnologías virtuales se puede observar que las personas sordas afirman la existencia de dificultades técnicas, un mal ajuste de los productos de apoyo, problemas en la accesibilidad y dificultades tanto en la comunicación como en el reconocimiento de sus derechos (Shoham \& Heber, 2012).

Aunque en España los SIV aún están poco desarrollados, en el ámbito internacional se puede encontrar un enorme abanico de productos. En la siguiente tabla se citan diferentes SIV o sistemas que permiten la intermediación. Sin duda, ellos demuestra el interés por esta tecnología. 
Tabla 20.- Clasificación de sistemas de intermediación por vídeo para personas con y sin discapacidad auditiva

\begin{tabular}{|c|c|}
\hline Tipo de Producto & Clasificación \\
\hline $\begin{array}{l}\text { Video } \\
\text { Telecomunicación }\end{array}$ & $\begin{array}{l}\text { IVèS: Live Video Plugin } \\
\text { Mirial s.u.r.l.: Mirial Softphone } \\
\text { swyMe }\end{array}$ \\
\hline $\begin{array}{l}\text { Sistemas para } \\
\text { videoconferencias }\end{array}$ & $\begin{array}{l}\text { Audisoft Technologies : Frontline HD, Fronline Communicator FC03, AudiSee, } \\
\text { Audisoft Medical Cart (Canada) } \\
\text { IOCOM: Visimeet (United States) } \\
\text { IVèS: Total conversation solution (video, voice and real-time text) for Video } \\
\text { Relay Services (VRS), Video Remote Interpreting (VRI), Text Relay and } \\
\text { telemedecine. } \\
\text { Librestream: Onsight (Canada) } \\
\text { Mirial s.u.r.l. } \\
\text { Polycom }\end{array}$ \\
\hline Video-mensajería & $\begin{array}{l}\text { AOL Instant Messenger (AIM) } \\
\text { Appear.in (HTML5 videconferencing) } \\
\text { Camfrog } \\
\text { CU-SeeMe } \\
\text { Ekiga } \\
\text { FilmOn } \\
\text { Gmail } \\
\text { Google Talk } \\
\text { iCall } \\
\text { iChat } \\
\text { IOCOM: Visimeet } \\
\text { Jitsi (encrypted chat and VOIP) } \\
\text { Pidgin Pidgin } \\
\text { MeBeam } \\
\text { Meetings.io } \\
\text { Videolink2.me } \\
\text { Microsoft: Windows Live Messenger } \\
\text { Microsoft: Windows Live Video Messages } \\
\text { ooVoo } \\
\text { Paltalk (now PaltalkScene) } \\
\text { SightSpeed } \\
\text { Skype } \\
\text { Stickam } \\
\text { Tinychat } \\
\text { TrueConf } \\
\text { Vinnect } \\
\text { Yahoo! Messenger }\end{array}$ \\
\hline
\end{tabular}




\section{Otros productos de apoyo para personas sordas y personas con discapacidad auditiva}

\section{Bucles magneticos}

El bucle magnético es uno de los productos más útiles para las personas con discapacidad auditiva usuarias de audífonos o implantes cocleares. Este producto posibilita la comunicación y las relaciones interpersonales en espacios y/o situaciones con ruido ambiental, y/o en situaciones en las que la distancia con el interlocutor o la presencia de varios interlocutores dificulta o impide dicha comunicación y el acceso a la información. Su funcionamiento es simple, es un sistema de sonido que transforma una señal de audio en un campo magnético, que es recibido por los audífonos dotados de posición “T”, puesto que, la bobina de estos audífonos transforma el campo magnético de nuevo en sonido en el canal auditivo del usuario de una forma aislada y sin ruido ambiental, por lo que el sonido recibido es más limpio y nítido.

Este sistema acerca y mejora la señal auditiva y ofrece mejor calidad de sonido evitando las interferencias producidas por el ruido de fondo. El bucle ofrece dos aplicaciones:

- Uso individual: El alumno con prótesis auditiva puede colocarse el bucle alrededor del cuello y adaptarlo al sistema de FM.

- De uso colectivo: Varios alumnos con prótesis auditiva pueden beneficiarse simultáneamente del bucle. En este caso, el cable se coloca alrededor del área que se quiere adaptar como por ejemplo el aula, el salón de actos y el usuario de audífono o implante dentro del perímetro adaptado, podrá moverse libremente y situarse en cualquier punto del mismo (Velasco \& Perez, 2009).

Algunos autores como Amador (2016), han realizado estudios en nuestro país de los beneficios del uso de este producto de apoyo en lugares públicos para que las personas usuarias de audífonos se beneficien de dicha amplificación, algunos de estos lugares que señala con mayor hincapié el autor son los cines puesto que este dispositivo es necesario para tener una correcta escucha del visionado. Otros autores como Acaro y Lucila (2015) señalan la importancia de uso de este dispositivo en otros lugares públicos de índole cultural tales como museos, ya que, como se mencionó en el anterior capitulo muchas personas sordas ven 
reducida su participación social por no contar con accesibilidad en los diferentes contextos y actividades.

\section{Equipos de Frecuencia Modulada (FM)}

Los equipos de FM son sistemas de amplificación de uso individual, inalámbrico, sin equipos de instalación, que trasmiten a través de ondas de alta frecuencia (FM), la voz del interlocutor (profesor) mediante un micrófono, directamente al receptor o receptores (alumno o alumnos). El sistema de FM permite, por ejemplo a un alumno sordo, escuchar sólo la voz del profesor/a. Pero además, cuando lo necesite o prefiera, podrá escuchar la voz de sus compañeros o los sonidos del ambiente. Hoy en día prácticamente todos los audífonos e implantes tienen una "entrada directa de audio", esto permite que la señal de FM entre directamente en el audífono, proporcionando una señal de audio de alta calidad.

Si se utilizan varios sistemas FM uno cerca del otro, es importante que cada uno este sintonizado en una frecuencia diferente para evitar que uno interfiera con el otro. Los Sistemas Personales FM son comúnmente utilizados por niños con pérdidas auditivas bilaterales, pero sería recomendable su uso también con niños con pérdida de audición unilateral, perdidas de audición fluctuantes o conductivas (del oído medio) y algunos tipos de problemas de aprendizaje. El receptor del sistema de FM puede estar conectado a un bucle magnético, que el usuario se coloca alrededor del cuello, y esto mejoraría la calidad de la escucha en los diferentes contextos en los que se desenvuelve una persona con discapacidad auditiva (Velasco \& Perez, 2009).

Los sistemas FM son bastante utilizados por las personas con discapacidad auditiva (Chisolm, Noe, Mcardle and Abram, 2008) y entre sus resultados encontramos una mejora en la participación en diferentes contextos como el educativo (Jacob et al., 2014), además de una mejora en el reconocimiento de habla (Wolfe et al., 2013). Existen algunos estudios experimentales sobre la eficacia del equipo FM y sus medidas de resultados (Boothroyd, 2004; Lewis, Crandell, Valente \& Enrietto, 2004; Lewis, Valente, Horn \& Crandall, 2005). Además de existir estudios de la ayuda que este dispositivo ofrece al reconocimiento del habla (Schafer, Huynh, Romine \& Jimenez, 2013; Schafer \& Thibodeau, 2006) . No obstante es necesaria mayor investigación en medidas de resultados de los equipos de frecuencia modulada (Lemos et al., 2012), en este sentido cabe resaltar el estudio realizado por Saunders 
y compañeros en el año 2014 del uso de este PA en población veterana (Saunders et al., 2014)

Por ejemplo, es de interés el estudio de Chisolm, Colleen, Noe, McArdle y Abrahams (2007) sobre la evidencia del uso de este PA en personas con discapacidad auditiva adultas, del que cabe destacar las conclusiones del mismo como la efectividad del uso del equipo FM en la vida diaria para una gran cantidad de contextos de uso, cuando el equipo FM va directo a la prótesis auditiva la escucha es mejor que si van por separado, es percibido como más fiable que otros PA y mayor insatisfacción con la visibilidad de otros PA que la del equipo FM.

No debemos de olvidar que las tecnologías de la comunicación están en constante resurgimiento y más cuando hacen referencia a tecnologías cuya población diana son las personas con discapacidad, puesto que, son en su mayoría un colectivo que las emplea de manera diaria y su uso puede ayudar a mitigar o al menos a compensar los déficits. Dentro del colectivo de personas sordas están surgiendo en los últimos meses tecnologías tales como: software de reconocimiento de las diferentes lenguas de signos mediante el uso de sensores de movimiento, avisadores luminosos en el hogar manejados mediante los smarthphone o simplemente equipos FM similares a una radio.

En el apartado de esta Tesis Doctoral que se trataron las limitaciones de los productos de apoyo se mencionó el modelo de Lauer, Longeneck y Smith (2006) el cual se trata de un modelo de los factores que pueden producir que un usuario de un producto de apoyo abandone o interrumpa su uso. Es por ello, que en la siguiente tabla se hace un pequeño resumen de aquellos trabajos y estudios que abarcan cada uno de los diferentes factores de abandono: 1) los relacionados con la persona; 2) relacionados con el propio producto de apoyo y 3) relacionados con el entorno. En cada uno de estos apartados podemos encontrar trabajos relacionados con cada uno de los productos de apoyo que han sido objeto de estudio en la parte empírica de esta Tesis Doctoral: audífonos, implante coclear y sistemas de intermediación por vídeo. 
Tabla 21.- Algunos de los factores de interrupción del uso de PA identificados según el modelo de Lauer \& Smith (2006)

\begin{tabular}{|c|c|c|c|}
\hline Factor & Audífono & Implante coclear & SIV \\
\hline Persona & $\begin{array}{l}\text { Mejora de la calidad de } \\
\text { vida, bienestar y } \\
\text { capacidad funcional (Jutai } \\
\text { \& Saunders, 2003) } \\
\text { Visión negativa del } \\
\text { producto o expectativas } \\
\text { altas (Saunders, Lewis \& } \\
\text { Forsline, 2009; Meister, } \\
\text { Walger, Brehmer, von } \\
\text { Wedel \& von Wedel, } \\
\text { 2008) } \\
\text { No aceptación de la } \\
\text { discapacidad (Rawool, } \\
\text { 2000) } \\
\text { Depresión (Kockin \& } \\
\text { Rogin, 2000; Mulrow et } \\
\text { al., 1990; Boi et al., 2012) }\end{array}$ & $\begin{array}{l}\text { Mejora de calidad de } \\
\text { vida, bienestar y } \\
\text { capacidad funcional } \\
\text { Scheetz, 2004 } \\
\text { Knutson, Johnson \& } \\
\text { Murray, 2006 } \\
\text { Klop et al., 2008 } \\
\text { Caposecco, Hickson \& } \\
\text { Pedley, 2012 } \\
\text { Hallam et al., 2006 } \\
\text { Kobosko et al., 2012 } \\
\text { Buhagiar \& Lutman, 2011 } \\
\text { Yeagle et al., 2010 } \\
\text { Zhao et al., 2008 }\end{array}$ & $\begin{array}{l}\text { Mejora de la calidad de } \\
\text { vida, bienestar } \\
\text { psicológico, } \\
\text { independencia, } \\
\text { autoestima y desempeño } \\
\text { Götherström, Persson, \& } \\
\text { Jonsson, } 2004 \\
\text { Saladin \& Hansmann, } \\
2008\end{array}$ \\
\hline Producto de apoyo & $\begin{array}{l}\text { Mal funcionamiento/fallo } \\
\text { (Billari, 2009; Wood } \\
\text { Lutman, 2004) } \\
\text { Configuración } \\
\text { complicada (Desjardins \& } \\
\text { Doherty, 2009) } \\
\text { No emparejado con } \\
\text { necesidades (Jutai \& } \\
\text { Bortolussi, 2003) }\end{array}$ & $\begin{array}{l}\text { Estética(Belle, 2005; } \\
\text { Pollard, 1996) } \\
\text { Coste(Eshraghi et al., } \\
\text { 2009;Francis, Chee, } \\
\text { Yeagle, Cheng \& } \\
\text { Niparko, 2002) } \\
\text { Utilidad (Bond et al., } \\
\text { 2009) }\end{array}$ & $\begin{array}{l}\text { Mal funcionamiento } \\
\text { (Ciaramello \& Hemami, } \\
\text { 2009) } \\
\text { Configuración } \\
\text { complicada } \\
\text { (Miesenberger, Klaus, } \\
\text { Zagler \& Karshmer, } \\
\text { 2008) }\end{array}$ \\
\hline Entorno & $\begin{array}{l}\text { Socialmente inaceptable } \\
\text { (estigma)(Erler \& } \\
\text { Garstecki, 2002; Southall, } \\
\text { Gagné \& Jennings, 2010) }\end{array}$ & $\begin{array}{l}\text { Socialmente inaceptable } \\
\text { (Kermit, 2012; } \\
\text { Zola, 1993) }\end{array}$ & $\begin{array}{l}\text { Accesibilidad (Shoham \& } \\
\text { Heber, 2012) }\end{array}$ \\
\hline
\end{tabular}


PARTE II. ESTUDIO EMPÍRICO 


\section{PARTE II. ESTUDIO EMPÍRICO}

\section{Justificación}

A lo largo de la primera parte de esta Tesis Doctoral se ha mostrado que la investigación, el desarrollo y la innovación en el campo de los PA y las nuevas tecnologías han crecido de manera importante durante la última década. No obstante, aún existe poca investigación respecto a las medidas de resultados en PA para personas con discapacidad auditiva (Fuhrer, 2001; Fuhrer, 2007; Jutai, Fuhrer, Demers, Scherer \& DeRuyter, 2005; Jutai, 2002). Dentro de las pocas investigaciones sobre medidas de resultados, también se constata un bajo número de trabajos interesados por el impacto psicosocial derivado del uso de PA en personas sordas, empleando instrumentos y herramientas de evaluación de resultados. Por ejemplo, la escala PIADS ha sido empleada para evaluar el impacto psicosocial derivado del uso de audífonos (Jutai \& Saunders, 2003) y los SIV (Saladin \& Hansman, 2008), pero no hay investigación empleando este instrumento en otros PA para personas sordas tales como los IC. De todo ello se deriva el primer objetivo de esta Tesis Doctoral: indagar sobre el impacto psicosocial de los tres PA elegidos por los investigadores: audífonos, Implantes Cocleares y Sistemas de Intermediación por Video, empleando una herramienta de evaluación propia de medidas de resultados como la escala PIADS.

Por otra parte, son escasas las investigaciones realizadas en cuanto a la intervención específica de algunos PA y de su efectividad (Fuhrer, 2007; Harris \& Sprigle, 2003; Jutai, Fuhrer, Demers, Scherer \& DeRuyter, 2005; Lenker, Fuhrer, Jutai, Demers, Scherer \& DeRuyter, 2010), o como estos PA influyen en las AVD de las personas y en su participación social (Arthanat, Nochajsk \& Stone, 2004; Fortnum, Marshall, Bamford \& Summerfield, 2002; Fougeyrollas, Cloutier, Bergeron, C`ote \& Stmichel, 1999; Fuhrer, Jutai, Scherer \& DeRuyter, 2005; Knutson, Johnson, \& Murray, 2006; Lenker et al., 2010; Lenker, Scherer, Fuhrer, Jutai \& DeRuyter, 2001; Scheetz, 2004; Vincent, Deaudelin \& Hotton, 2007). Y aún menos las que utilizan metodologías de carácter cualitativo, como por ejemplo grupos focales, como medio para obtener información sobre las percepciones de las personas sordas respecto a los PA.

Teniendo en cuenta la escasa literatura existente en este campo, esta Tesis Doctoral pretende, de manera general, aportar nuevos trabajos empíricos que puedan complementar algunos de los resultados previos y que proporcionen nuevos resultados en los que basar los 
sistemas de toma de decisión sobre uso de PA en personas sordas o con discapacidad auditiva. Así, en la primera parte se realizaron tres estudios empíricos sobre el impacto psicosocial de tres de los productos de apoyo de uso más frecuente entre personas sordas y con discapacidad auditiva. En la segunda parte, con el objetivo de complementar el enfoque cuantitativo se llevó a cabo un estudio mediante grupos focales con el objetivo de indagar el impacto de los PA en las personas sordas, personas con discapacidad auditiva, familiares y profesionales. Además en estos grupos focales se realizaron una aproximación del impacto que tienen los PA en las AVD y en la participación social de este colectivo.

Todo ello se ha realizado empleando la CIF como enfoque general y guía de codificación. Ello permitirá, también, aportar resultados de interés para la validación del Conjunto Básico de la CIF desarrollado por la Organización Mundial de la Salud para personas con discapacidad auditiva. Esta comparativa permitirá, además de ofrecer datos sobre la validez al estudio, observar aquellas categorías de la CIF que están más relacionadas con los PA, que pueden no estar presentes en el Conjunto Básico, pero que seguramente se relacionen con temas recurrentes en el colectivo de personas sordas. Recordemos, que las personas sordas presentan unas características personales, sociales, culturales y actitudinales diferentes a las personas que presentan un tipo de pérdida postlocutiva y son ajenas a la Comunidad Sorda. Esto sentaría las bases para la propuesta de un Conjunto Fundamental de la CIF específico para personas sordas.

Además, el estudio cualitativo permitió indagar sobre los factores de abandono o falta de uso de los PA en personas sordas y personas con discapacidad auditiva, siguiendo uno de los modelos más exhaustivos sobre factores de abandono: el modelo de Lauer, Longenecker \& Smith (2006), descrito en el capítulo 1 de este trabajo.

El estudio de las medidas de resultados de los PA es un conocimiento vital para los profesionales, como terapeutas ocupacionales, logopedas y rehabilitadores en general además de las administraciones públicas y servicios privados, y en cierta parte es necesario conocerlo para que las tomas decisiones reduzcan la probabilidad de abandono o falta de uso de los PA. Así, consideramos que estudios como el desarrollado en esta Tesis Doctoral, son muy necesarios para que las intervenciones con PA se realicen en base a la evidencia científica. A la vez, este tipo de estudios no son solo útiles para profesionales, sino que aportan un mayor conocimiento a los propios usuarios para evitar el abandono o falta de uso de los PA (Fuhrer, 2007). 
Por último, y no por ello menos importante, de estudios como el planteado en este trabajo, ser derivan resultados sobre instrumentos y herramientas de evaluación específicas para evaluar resultados asociados al uso de PA para personas sordas. La disponibilidad de resultados sobre las cualidades métricas y sobre la validez de los instrumentos es de enorme importancia, dado que los instrumentos son la base de los protocolos de evaluación. En los tres primeros estudios empíricos se empleó la escala PIADS (Lenker \& Jutai, 2002; Lenker \& Paquet, 2003), que ya había sido usada en esta población (Saladin \& Hansman, 2008; Saunders \& Jutai, 2004). No obstante, también es necesario disponer de instrumentos adecuados para esta población con sus características socioculturales y linguiísticas, ya que las personas sordas pertenecientes a la Comunidad Sorda necesitan instrumentos adaptados a su lengua (Hoenig, 2005; Lenker \& Paquet, 2003; Scherer, Jutai, Fuhrer, Demers \& DeRuyter, 2007) y que tengan en cuenta los factores personales, contextuales y culturales de los usuarios de los PA (Hoenig, 2005; Ripat \& Booth, 2005; Scherer, Jutai, Fuhrer, Demers \& DeRuyter, 2007; Scherer \& Gluckauf, 2005). Es por ello, que el estudio de los SIV fue traducido y adaptado a la lengua de signos española, ya que, la muestra diana eran personas sordas usuarias de lengua de signos y/o lengua oral. En resumen, la obtención de resultados sobre instrumentos de evaluación de resultados es muy necesaria, no solo para mejorar sus propiedades cuando se utilizan en la evaluación y selección de los PA (Gitlin, 2002; Scherer, Jutai, Fuhrer, Demers \& DeRuyter, 2007), sino también para que puedan utilizarse con garantías en el análisis del impacto psicosocial de los PA.

A continuación se presentan los objetivos general y específicos de esta Tesis Doctoral.

\section{Objetivos.}

\section{Objetivo general}

Analizar el Impacto psicosocial derivado del empleo de los productos de apoyo para la comunicación y acceso a la información en personas con discapacidad auditiva y personas sordas.

\section{Objetivos específicos}

- Ofrecer información sobre las características sociodemográficas de las personas con discapacidad auditiva usuarias de productos de apoyo para la comunicación y/o acceso a la información (estudios 1, 2, 3 y 4). 
- Indagar sobre los factores de abandono o falta de uso de los PA en personas sordas y personas con discapacidad auditiva (estudios 2, 3 y 4).

- Establecer la predisposición general de las personas con discapacidad auditiva hacia el uso de las nuevas tecnologías (estudios 1, 2 y 3 ).

- Contribuir a la mejora y desarrollo de la Clasificación Internacional del Funcionamiento de la Discapacidad y la Salud así como al Conjunto Básico (Core Set) desarrollado para personas con discapacidad auditiva (estudio 4).

- Ofrecer información sobre la percepción de los profesionales directos del colectivo sobre el acceso a la información y comunicación del mismo: intérpretes de lengua de signos, logopedas, psicólogos, terapeutas ocupacionales, trabajadores sociales y educadores sociales. Así como de los familiares y personas con discapacidad auditiva (estudio 4).

- Ofrecer información de familiares y profesionales de personas sordas y personas con discapacidad auditiva respecto a los resultados derivados del uso de PA (estudio 4).

- Ofrecer información acerca del desempeño de las AVD y participación social derivado del uso de PA en personas sordas y personas con discapacidad auditiva (estudio 4).

- Contribuir a la obtención de información sobre las propiedades psicométricas de la escala PIADS en personas sordas y personas con discapacidad auditiva y respecto a los productos de apoyo-tecnologías estudiados (estudios 1, 2 y 3 ).

- Contribuir al conocimiento de la discapacidad auditiva en nuestro país (estudios 1, 2,3 y 4). 


\section{Estudio 1. Impacto psicosocial derivado del uso de sistemas de intermediación por vídeo (SIV)}

\section{Introducción}

Actualmente, existen diversas tecnologías y productos específicos para personas sordas signantes cuyo objetivo es permitir la comunicación entre personas sordas usuarias de lengua de signos y personas usuarias de lengua oral. Entre estos productos destacan los ya mencionados SIV. Conocemos, gracias a la literatura científica, que entre los resultados derivados de su uso cabe destacar un aumento de la calidad de vida, independencia, sensación de bienestar y felicidad (Saladin \& Hansman, 2008). No obstante, existe poca investigación sobre este tipo de productos, y mucha menos en nuestro país, donde, en general, es difícil encontrar trabajos que analicen el impacto psicosocial derivado del uso de estos u otros productos de apoyo. Aunque se pueden encontrar algunos trabajos en el ámbito internacional, estas son muy concretas y escasas, y además no incluyen variables de interés, como la problemática del entrenamiento o los factores de abandono o falta de uso de estos productos.

Los SIV están disponibles en muchos países y su uso se ha extendido bastante, sobre todo Europa y EE.UU (Warnicke \& Plejert, 2012), aunque en nuestro país estos productos no están muy extendidos y no sean divulgados de manera adecuada. Las personas sordas utilizan estos y otros productos, como los servicios de mensajes cortos (SMS), email, fax y teléfono, para comunicarse tanto dentro de la Comunidad Sorda como con oyentes que desconozcan la lengua de signos. En el caso de emplearse como un medio para poder comunicarse con personas oyentes, su uso va dirigido, principalmente, a sociabilizar aunque existe también un uso de carácter instrumental, como mantener un contacto para negocios, citas o simplemente obtener información (Power, Power, \& Rehling, 2007). Y de este uso se deriva la importancia de realizar estudios en medidas de resultados y del impacto psicosocial de estos productos en el ámbito español.

Como se ha comentado en la parte teórica de esta Tesis Doctoral, existen estudios que revelan que gracias al uso de SIV mejora la calidad de vida, el bienestar psicológico, y el incremento de la independencia, la autoestima, la sensación de control y la funcionalidad (Götherström, Persson, \& Jonsson, 2004). Pero en nuestro país no existen estudios que investiguen los aspectos psicosociales derivados del uso de estos productos, así como si las personas sordas conocen y usan este tipo de PA. Entre los objetivos de este estudio cabe 
destacar, en primer lugar, indagar sobre el impacto psicosocial derivado del uso de estos productos. Para ello se empleó la escala PIADS, al igual que en el estudio llevado a cabo por Saladin y Hansmann (2008), cuyos resultados sugerían un impacto psicosocial positivo debido al uso de SIV. No obstante, estos resultados no son generalizables a la población sorda española, por lo que un objetivo específico de este estudio es conocer el uso o no uso de estos PA y, de forma paralela, se perseguía conocer las diferencias en el impacto psicosocial en función de los diferentes productos de comunicación por vídeo utilizados por las personas sordas en nuestro país, entre los que se encuentran Oovoo, Skype y móvil.

Dado que se trata de un colectivo con una cultura y lengua propia se llevó a cabo una adaptación de la escala PIADS y del SOTU-C, en su lengua natural, la lengua de signos española por lo que esto es un objetivo específico en sí mismo. Parte del interés de este estudio era obtener información sobre las características sociodemográficas de las personas con discapacidad auditiva usuarias de productos de SIV. Por otra parte, se empleó el instrumento SOTU-C (Survey of Technology Use-Consumer, perteneciente al Matching Person \& Technology) para indagar sobre la predisposición general de las personas con discapacidad auditiva hacia el uso de las nuevas tecnologías y conocer la tendencia al uso de estas en función de variables sociodemográficas. Este estudio además tiene como objetivo específico contribuir a la obtención de información sobre las propiedades psicométricas de la escala PIADS. De manera general, además, el estudio contribuye a disponer de información actualizada sobre el uso de productos de apoyo en personas sordas.

\section{Método}

\section{Participantes.}

La muestra de este estudio se seleccionó por medio de un muestreo de conveniencia no probabilístico. El trabajo se ha realizado con usuarios de diferentes asociaciones de personas con discapacidad auditiva. Por lo que el ámbito de aplicación de este trabajo se extiende a comunidades autónomas de España (Castilla y León, Castilla la Mancha, País Vasco, Andalucía, Murcia, Extremadura, Comunidad Valenciana y Madrid), centrándose en las personas sordas signantes usuarias de sistemas de intermediación por vídeo.

Además, se optó por establecer un conjunto de criterios de inclusión y exclusión con el objeto de mejorar la homogeneidad de la muestra. 
Criterios de inclusión:

- Personas con un diagnóstico de pérdida auditiva

- Personas mayores de 18 años.

- Personas que tengan/utilicen diferentes PA y otras tecnologías para la comunicación.

- Personas con un lengua oral y/o lengua de signos.

Criterios de exclusión:

- Personas con un diagnóstico adicional al de pérdida auditiva.

- Personas afectadas por pérdida auditiva menores de 18 años.

Una vez definidos los criterios de inclusión, otras 6 personas fueron excluidas por presentar una discapacidad física además de la discapacidad auditiva.

El contacto se realizó mediante entrevista presencial y/o telemática, en diferentes asociaciones y mediante profesionales de intervención directa con personas con discapacidad auditiva y/o personas sordas. Se ofreció, tanto a las asociaciones como a los profesionales, una información detallada del estudio y de los objetivos del mismo y se solicitó colaboración. Si la respuesta era afirmativa, se proponían fechas para aplicar el cuestionario de forma presencial en las diferentes asociaciones, o bien mediante en enlace Web existente para los diferentes productos de apoyo.

Finalmente, la muestra quedó formada por 124 personas, 73 mujeres y 51 hombres, con una edad media de 36,5 años $(S D=15,5)$. En la tabla 14 se resumen las principales características demográficas de los participantes. 
Tabla 22.- Perfil sociodemográfico de personas adultas con discapacidad auditiva usuarias de sistemas de intermediación por vídeo u otras tecnologías de la comunicación $(n=124)$

\begin{tabular}{ll}
\hline VARIABLE & $\mathrm{N}(\%)$ \\
\hline Edad & $M=36,55 ; S D=15,12$ \\
Género & $51(41,1)$ \\
Varón & $73(58,9)$ \\
Mujer & $36(29)$ \\
Lengua & $0(0,0)$ \\
Lengua de signos & $88(71)$ \\
Lengua oral & \\
Ambas & $26(21)$ \\
Zona residencial & $98(79)$ \\
Rural & $72(58,1)$ \\
Urbano & $52(41,9)$ \\
Momento pérdida & \\
Prelocutivo & $80(64,5)$ \\
Postlocutivo & $44(35,5)$ \\
Tipo de pérdida & \\
Hipoacusia & $46(37,1)$ \\
Cofósis & $27(21,8)$ \\
Nivel de estudios & $11(8,9)$ \\
Elemental & $7(5,6)$ \\
Bachillerato & $17(13,7)$ \\
Ciclo grado medio & $1(0,8)$ \\
Ciclo grado superior & $15(12,1)$ \\
Universidad & $3(2,4)$ \\
Máster & $83(66,9)$ \\
Otros & $38(30,6)$ \\
Grado de discapacidad &
\end{tabular}

Todas las personas participantes recibieron información detallada sobre las características del estudio y tuvieron que firmar un consentimiento informado (véase Anexo VI) según modelo del Comité de Bioética de la Universidad de Salamanca.

\section{Instrumentos}

\section{Escala del impacto psicosocial de productos de apoyo (PIADS, Psychosocial}

\section{Impact of assistive devices scale; Jutai \& Day, 1996)}

La escala PIADS fue creada a través de exploración empírica e investigación cualitativa mediante grupos focales (Jutai \& Day, 2002) y ha sido utilizada en trabajos que investigan la continuidad o el abandono en productos de apoyo para personas con discapacidad, incluyendo personas con discapacidad auditiva. Está compuesta por 26 ítems divididos en tres subescalas: competencia (desempeño y la productividad), adaptabilidad (capacidad de participar en actividades, aceptar cambios y probar cosas nuevas) y autoestima (emociones, felicidad, autoestima y bienestar asociados al uso del PA). La escala se contesta mediante una 
escala de -3 a +3 señalando, para cada ítems, si el aspecto concreto que se describe en ese ítem ha disminuido (-3), no ha cambiado $(0)$ o ha aumentado $(+3)$ tras comenzar a utilizar un producto de apoyo. En la siguiente tabla se muestran, de manera resumida, los aspectos que se deben valorar en cada ítem. La aplicación contempla la aclaración, mediante una descripción mucho más detallada, de cada uno de estos aspectos.

Tabla 23. Composición de los ítems de la escala PIADS por subescala

\begin{tabular}{lll}
\hline Competencia (12 ítems) & Adaptabilidad (6 ítems) & Autoestima (8 ítems) \\
\hline $\begin{array}{l}\text { Competencia } \\
\text { Independencia }\end{array}$ & $\begin{array}{l}\text { Bienestar } \\
\text { Dispuesto a darse oportunidades } \\
\text { Centirse a la altura de las } \\
\text { circunstancias } \\
\begin{array}{l}\text { Confusión } \\
\text { Eficacia }\end{array}\end{array}$ & $\begin{array}{l}\text { Felicidad para participar } \\
\text { Autoestima } \\
\text { Seguridad }\end{array}$ \\
$\begin{array}{l}\text { Deseoso de probar cosas nuevas } \\
\text { Capacidad para adaptarse a las } \\
\text { actividades cotidianas } \\
\text { Capacidad para aprovechar las } \\
\text { oportunidades }\end{array}$ & $\begin{array}{l}\text { Frustración * } \\
\text { Confianza en sí mismo }\end{array}$ \\
$\begin{array}{l}\text { Sentirse útil } \\
\text { Pericia } \\
\text { Aptitud } \\
\text { Sentirse capaz } \\
\text { Calidad de vida } \\
\text { Realización }\end{array}$ & Sensación de poder \\
* Una puntuación alta en estos ítems indica un impacto negativo & $\begin{array}{l}\text { Sensación de control } \\
\text { Sentirse a disgusto * }\end{array}$ \\
\hline
\end{tabular}

Desde el punto de vista métrico, la escala PIADS es una herramienta fiable y válida, que parece tener un poder muy importante para predecir el abandono y retención de productos de apoyo. Se puede y debe usar tanto deductivamente e inductivamente para construir, descubrir y teóricamente sobre el impacto psicosocial de los productos de apoyo (Day, Jutai \& Campbell, 2002). El PIADS resulta ser una herramienta clínicamente útil para explorar las interacciones persona-medio ambiente y parece ser muy adecuada a los objetivos y valores de la terapia ocupacional (Devitt, Chau \& Jutai, 2003).

En la mayor parte de los estudios se ha observado que las puntuaciones de la escala PIADS correlacionan de manera positiva con el uso de productos de productos de apoyo de aplicación habitual en personas sordas, como los audífonos. Además, su mayor uso y aceptación mejora la comprensión, la aceptación de la pérdida de audición y favorece el incremento del uso de estrategias comunicativas (Jutai \& Saunders, 2001). Asimismo, se ha demostrado que la escala PIADS es sensible a los factores psicosociales que se relacionan con los beneficios de los productos de apoyo de amplificación en personas sordas (Jutai, Day \& Strong, 2003). La escala PIADS también se ha utilizado para mejorar las evaluaciones y la medición de los resultados del audífono en la persona (Jutai \& Day, 1999). En este contexto, 
la finalidad de la escala PIADS es determinar las variables que influyen sobre la continuidad en el uso o el abandono de un producto de apoyo y su aplicación tiene el objetivo de conocer los factores asociados a la persona que influyen en la selección de un producto de apoyo (Day \& Jutai, 1996).

La escala PIADS se ha utilizado con distintos objetivos en relación al uso de productos de apoyo. Se ha utilizado como medida de resultados para evaluar el impacto sobre la calidad de vida debido al uso de un producto de apoyo (Jutai, 1999), o como instrumento de evaluación para analizar las expectativas asociadas al futuro uso de productos de apoyo, como audífonos (Saunders, Lewis \& Forsline, 2009), ayudas electrónicas (Jutai, Rigby, Ryan \& Stickel, 2000), sillas de ruedas (Devitt, Chau \& Jutai, 2004; Pousada, 2011) e incluso en productos de apoyo para la incontinencia urinaria (Jutai, Fowler, Southall, Van Den Heuvel \& Long, 2013). Incluso hay estudios donde se investiga el impacto psicosocial de los actuales servicios de salud electrónica basados en Web y aplicaciones móviles (Axelsson, Nyberg, Näslund, \& Wikman, 2013), el acceso a la comunicación y a la tecnología en los viajes (Palmer \& Jepson, 2012) y para el reconocimiento de voz (DeRosier \& Farber, 2005). También es una escala de interés para los servicios de PA que buscan mejorar sus protocolos de evaluación. Al ser una escala reconocida internacionalmente y fácil de poner en práctica puede ser un valioso instrumento para medir impacto de una intervención (Zahid \& Boyle, 2013). 


\section{Emparejando persona y tecnología- Cuestionario sobre uso de tecnología- usuario (MPT-SOTU-C, Matching Person \& Technology-Survey of Technology use-Consumer, Scherer, 2005)}

El instrumento MPT (Matching Person \& Technology) fue desarrollado para identificar el producto de apoyo que mejor se adecua a una persona, teniendo en cuenta sus cualidades, necesidades, preferencias personales y estilo de vida. Aunque el MPT está formado por 7 instrumentos que ofrecen una amplia gama de herramientas en función del cliente y el tipo de tecnología, en este estudio se ha empleado únicamente el cuestionario Survey of Technology Use - Consumer versión (SOTU-C), debido a que en trabajos previos (e.g., Scherer\& Glueckauf, 2005) sus puntuaciones han mostrado relaciones de interés con otros instrumentos de evaluación derivados del modelo de la CIF, como el WHO DAS II, en concreto con las dimensiones de comunicación, interacción con otras personas y vida social.

El Cuestionario Sobre el Uso de Tecnologías - Consumidor (SOTU-C) examina, de manera general, las influencias que tienen más impacto sobre el usuario de productos y tecnologías de apoyo en general. En concreto, el SOTU-C examina, mediante una escala diferencial semántica de 3 categorías (positivo, neutral y negativo), las tecnologías más utilizadas, las experiencias con las tecnologías, las perspectivas sobre el uso de nuevos productos y las actividades típicas y características personales/sociales del usuario de productos de apoyo. En cuanto a sus propiedades psicométricas sabemos que es un instrumento con fiabilidad adecuada (Federici et al., 2003; Scherer \& Craddock, 2002 Scherer, Jutai, Fuhrer, Demers \& DeRuyter, 2007; Scherer \& Glueckauf, 2005).Al igual que es un instrumentoválido para separar necesidades subjetivas y objetivas de un determinado PA para predecir su uso o no..

\section{Procedimiento}

El proceso de recogida de datos se ha realizado con la aplicación de un cuestionario sociodemográfico de elaboración propia, la escala PIADS y el cuestionario SOTU-C del MPT. Ambos instrumentos tienen la posibilidad de ser administrados a través de entrevista personal o telefónica (Day \& Campbell, 2003; Day \& Jutai, 1996; Scherer, 1998) o de forma auto-administrada con las indicaciones adecuadas (Day \& Jutai, 2003; Scherer \& Craddock, 2002). En este estudio la recogida de datos se realizó por medio de dos procedimientos alternativos: 
- Entrevista individual. Debido a las características comunicativas de los usuarios esta fue la forma mayoritaria de recogida de datos (98 personas). La duración de cada entrevista osciló entre los 15 minutos y la hora y media, dependiendo de las características de los usuarios. Puesto que, muchos de los participantes tenían un nivel bajo de comprensión de los ítems y/o problemas en la lectoescritura. A pesar de ofrecer una explicación y traducir los ítems a la lengua de signos española, para algunos participantes era difícil aprehender el concepto que se les pedía evaluar.

- Cuestionario electrónico accesible a través de página Web. Algunos usuarios procedentes de comunidades autónomas distintas a Castilla y León, y que por tanto eran difíciles de contactar de manera presencial, realizaron los cuestionarios vía online. Para ello, las preguntas se ofrecían tanto en formato escrito como en lengua de signos española. El instrumento se realizó en una página Web donde se encontraba alojado el cuestionario y por cada uno de los ítems se podía acceder a un vídeo traducido a lengua de signos.

Las personas sordas a menudo presentan dificultades en la lectoescritura (Domínguez, Pérez \& Alegría, 2012). Este hecho fue una de las mayores dificultades a la hora de realizar este estudio y por ello se tuvieron en cuenta las necesidades comunicativas de las personas sordas y se llevó a cabo una adaptación de los instrumentos en su lengua natural, la lengua de signos, ya que esta es la lengua que la mayor parte de las personas de este colectivo emplea tanto para su comunicación como para el acceso a la información (Antunes, Guimarães, García, Oliveira \& Fernande, 2011). La persona que realizó la adaptación a lengua de signos española fue la investigadora principal de esta Tesis Doctoral, puesto que es conocedora de esta lengua. Al mismo tiempo, para las entrevistas en las que fue necesario emplear la lengua de signos fue la entrevistadora-investigadora principal de este estudio la que se encargó de actuar como intérprete.

El estudio de campo (realización de las entrevistas, aplicación de los cuestionarios y recogida de datos) se llevó a cabo en 9 meses.

El diseño planteado es un diseño no experimental transversal correlacional.

\section{Resultados}

Las respuestas a las preguntas del cuestionario de características demográficas, de la escala PIADS y del cuestionario SOTU-C fueron registradas en una hoja de cálculo Excel. 
Posteriormente, se calcularon los diferentes estadísticos tanto en el programa SPSS 21 y en el software "R" (R Core Team, 2015).

Comenzaremos por describir los resultados generales derivados de las respuestas de los participantes al cuestionario inicial de datos socio-demográficos y los resultados globales relativos al uso de productos y tecnologías de apoyo. Dado que el principal interés de este trabajo es la comparación del grupo de personas que usan sistemas SIV con las que utilizan otros sistemas de comunicación, los resultados se mostrarán agrupados por esta variable siempre que sea relevante.

En primer lugar, en relación al uso de productos de apoyo para la comunicación por vídeo, del total de 124 participantes el 53\% afirmaron utilizar sistemas SVI y el $47 \%$ restante manifestó utilizar otros sistemas, como, el teléfono móvil (21\%), una aplicación gratuita de chat en vídeo llamada Oovoo (14\%) o el software de mensajería Skype (12\%). Cabe destacar que entre los participantes que no utilizan SIV, un 52\% manifestó no conocer este tipo de sistemas.

La mayoría de los participantes, usuarios o no de sistemas SVI, manifestaron utilizar 4 o 5 tecnologías distintas de manera habitual (véase siguiente tabla). Entre las tecnologías más utilizadas se encuentra el teléfono móvil $(n=122)$, Internet $(n=115)$, ordenador de sobremesa $(n=113)$, ordenador portátil $(n=60)$, tableta $(n=43)$, PDA $(n=14)$ y videojuegos $(n=9)$. Y en cuanto a los contextos de uso de los SIV y el resto de sistemas de comunicación por vídeo, el $85,5 \%$ afirman utilizarlos para comunicarse con amigos y/o familiares, el 32,3\% lo emplean para utilizar servicios sanitarios, un 29,8 \% lo usan en contextos educativos y el 29,8\% que los utiliza para asuntos laborales.

Tabla 24.- Número de tecnologías empleadas en función del uso o no de los SIV

\begin{tabular}{|c|c|c|}
\hline \multirow{2}{*}{$\begin{array}{r}\mathrm{N}^{\circ} \text { de nuevas tecnologías } \\
\text { empleadas }\end{array}$} & \multicolumn{2}{|c|}{$\mathrm{N}^{\circ}$ de participantes que usan SIV } \\
\hline & Sí $\left(n^{\circ}\right)$ & No $\left(n^{\circ}\right)$ \\
\hline 1 & 3 & 1 \\
\hline 2 & 6 & 4 \\
\hline 3 & 14 & 7 \\
\hline 4 & 26 & 15 \\
\hline 5 & 23 & 15 \\
\hline 6 & 1 & 2 \\
\hline 7 & 1 & 6 \\
\hline
\end{tabular}

Entre los productos y tecnologías que los usuarios empleaban antes del surgimiento de los SIV y otros sistemas de comunicación por vídeo, encontramos que un 37,9\% pedían ayuda a otra persona para realizar la llamada, un 34,7\% empleaba un teléfono de texto, un 
13,7\% usaban dispositivos telefónicos para sordos (DTS) y un 12,9\% usaba un intérprete de lengua de signos para mediar la conversación (ver siguiente tabla).

Tabla 25.- Número de participantes usuarios de sistemas de intermediación de video y otras tecnologías de vídeo en función del producto utilizado anteriormente

\begin{tabular}{clrrrr}
\hline & & \multicolumn{4}{c}{ Sistema utilizado actualmente } \\
& & SIV & Oovoo & Skype & Móvil \\
\hline \multirow{4}{*}{ Anterior dispositivo } & Teléfono de texto & 23 & 3 & 9 & 8 \\
de uso & DTS & 12 & 3 & 0 & 2 \\
& Otra persona & 25 & 7 & 5 & 10 \\
& Intérprete & 5 & 4 & 1 & 6 \\
& Otro & 1 & 0 & 0 & 0 \\
\hline
\end{tabular}

Diversos contrastes Chi-cuadrado de Pearson permitieron verificar la ausencia de relación entre las variables demográficas que caracterizaban la muestra y el uso y no uso de sistemas SIV; en concreto, la lengua utilizada (lengua de signos $v s$ lengua de signos + lengua oral), el momento de adquisición de la discapacidad auditiva (precolutivo vs postlocutivo), el tipo de pérdida (hipoacusia vs cofosis), el grado de discapacidad (leve, moderada, severa), el lugar de residencia (rural vs urbano) o el nivel estudios no mostraron relación con el uso/no uso de SIV(en todos los casos, valores de probabilidad de $\left.\chi^{2}>0,05\right)$.

Para avanzar en la caracterización de los usuarios de sistemas SIV, se calcularon los promedios de respuestas positivas, negativas y neutras en los cinco apartados del SOTU-C. En la siguiente tabla se pueden ver los resultados de los promedios del SOTU-C en sus cinco apartados de todos los participantes en el estudio $1(n=124)$

Tabla 26.- Puntuaciones promedio (positivas, negativas y neutrales) del cuestionario SOTU-C por apartado del instrumento $(n=124)$

\begin{tabular}{lc}
\hline APARTADO DEL CUESTIONARIO SOTU-C & Media $(S D)$ \\
\hline Experiencias globlales con las tecnologías utilizadas._POSITIVAS & $4,08(1,40)$ \\
Experiencias globlales con las tecnologías utilizadas_NEUTRALES & $0,59(0,95)$ \\
Experiencias globlales con las tecnologías utilizadas_NEGATIVAS & $0,310, .85)$ \\
Perspectivas sobre tecnologías_POSITIVAS & $4,72(1,69)$ \\
Perspectivas sobre tecnologías_NEUTRALES & $1,23(1,48)$ \\
Perspectivas sobre tecnologías_NEGATIVAS & $2,05(1,69)$ \\
Actividades típicas_POSITIVAS & $2,20(1,47)$ \\
Actividades típicas_NEUTRALES & $0,83(1,05)$ \\
Actividades típicas_NEGATIVAS & $0,97(1,37)$ \\
Algunas características personales/sociales_POSITIVAS & $7,53(3,67)$ \\
Algunas características personales/sociales_NEUTRALES & $3,14(2,82)$ \\
Algunas características personales/sociales_NEGATIVAS & $2,32(3,03)$ \\
SOTU GLOBAL_POSITIVAS & $18,53(6,64)$ \\
SOTU GLOBAL_NEUTRALES & $5,78(4,44)$ \\
SOTU_GLOBAL NEGATIVO & $5,65(5,9)$ \\
\hline
\end{tabular}

Los contrastes de diferencias de medias con corrección de Bonferroni sobre esas puntuaciones revelaron que las personas que utilizan sistemas SIV se caracterizan por tener 
más respuestas positivas sobre sus experiencias globales con las tecnologías $(M=4,35)$ en comparación a las que no usan $\operatorname{los} \operatorname{SIV}(M=3,68), p<0,05$, considerando, por ejemplo, que las tecnologías son satisfactorias, apoyan la creatividad, les acercan a la gente o apoyan su autoestima. Aunque ninguna otra diferencia resultó ser significativa, globalmente, los usuarios de SIV mostraron más respuestas positivas $(M=19,03)$ que el grupo que no usa SIV $(M=17,8), p<0,05$, considerando más positivas las experiencias con las tecnologías en la niñez o en la escuela y manifestando, en general, bienestar asociado al uso de tecnologías. . En la siguiente tabla se muestran los promedios en SOTU-C en función del uso de SIV.

Tabla 27.- Puntuaciones promedio de las respuestas positivas y negativas por apartado del instrumento SOTU-C en función de si usan o no SIV

\begin{tabular}{lcc}
\hline & No usa SIV & Si usa SIV \\
APARTADO DEL CUESTIONARIO SOTU-C & Media & Media \\
\hline Experiencias globlales con las tecnologías utilizadas._POSITIVAS * & 3,68 & 4,35 \\
Experiencias globlales con las tecnologías utilizadas_NEGATIVAS & 0,48 & 0,20 \\
Perspectivas sobre tecnologías_POSITIVAS & 4,34 & 4,97 \\
Perspectivas sobre tecnologías_NEGATIVAS & 2,14 & 1,99 \\
Actividades típicas_POSITIVAS & 2,06 & 2,30 \\
Actividades típicas_NEGATIVAS & 1,22 & 0,80 \\
Algunas características personales/sociales_POSITIVAS & 7,72 & 7,41 \\
Algunas características personales/sociales_NEGATIVAS & 2,66 & 2,09 \\
SOTU GLOBAL_POSITIVAS* & 17,8 & 19,03 \\
SOTU_GLOBAL NEGATIVO & 6,5 & 5,08 \\
\hline
\end{tabular}

En la anterior tabla 27 podemos observar que las personas que usan SIV tienen unas puntuaciones más positivas en el cuestionario SOTU-C, no obstante, cabe resaltar que la puntuación en el apartado de algunas características personales/sociales es mayor en las personas no usuarias de SIV que las que si lo emplean.

En cuanto a la relación entre la edad y las experiencias con el uso de tecnologías, en la siguiente tabla se muestran los promedios en función del grupo de edad. En general se observa un patrón que indica relación inversa entre las experiencias positivas y la edad, y un relación directa entre las experiencias negativas y la edad. Un análisis de correlación verificó este aspecto mostrando una $r=-0,42(p<, 01)$ entre la edad y las experiencias positivas globales y una $\mathrm{r}=0,50(p<, 01)$ entre la edad y las experiencias negativas con las tecnologías. 
Tabla 28.- Puntuaciones promedio (positivas y negativas) en relación al instrumento SOTU-C y la edad

\begin{tabular}{lccc}
\hline APARTADO DEL CUESTIONARIO SOTU-C & \multicolumn{3}{c}{ EDAD } \\
\hline & $16-39$ & $40-77$ & $78-98$ \\
\cline { 2 - 4 } Experiencias globlales con las tecnologías utilizadas._POSITIVAS & 4,39 & 3,31 & 2,50 \\
Experiencias globlales con las tecnologías utilizadas_NEGATIVAS & 0,10 & 0,88 & 1 \\
Perspectivas sobre tecnologías_POSITIVAS & 5,21 & 3,47 & 2,50 \\
Perspectivas sobre tecnologías_NEGATIVAS & 1,56 & 3,25 & 5 \\
Actividades típicas_POSITIVAS & 2,61 & 1,16 & 0,50 \\
Actividades típicas_NEGATIVAS & 0,52 & 2,1 & 3 \\
Algunas características personales/sociales_POSITIVAS & 8,20 & 5,97 & 2,50 \\
Algunas características personales/sociales_NEGATIVAS & 1,52 & 4,16 & 9 \\
SOTU GLOBAL_POSITIVAS & 20,41 & 13,91 & 8 \\
SOTU_GLOBAL_NEGATIVO & 3,70 & 10,38 & 18 \\
\hline
\end{tabular}

En cuanto a la relación entre las distintas variables demográficas y las experiencias con las tecnologías, en la siguiente tabla se muestran los resultados. No se verificaron diferencias significativas para ninguna de las variables.

Tabla 29.- Diferencias en las puntuaciones promedio (positivas y negativas) en relación al instrumento SOTU-C y diferentes variables sociodemográficas.

\begin{tabular}{llll}
\hline Variable sociodemográfica & Clasificación & SOTU-C POSITIVAS & SOTU-C NEGATIVAS \\
\hline Género & Mujer & 18,38 & 5,75 \\
& Varón & 18,75 & 5,82 \\
Momento de la pérdida & Postlocutivo & 20,65 & 4,71 \\
& Prelocutivo & 17 & 6,56 \\
Tipo de pérdida & Cofosis & 17,36 & 6,80 \\
& Hipoacusia & 19,18 & 5,03 \\
Lengua empleada & Ambas lenguas & 19,67 & 5,66 \\
& Lengua de signos & 15,75 & 6,08 \\
Zona de residencia & Rural & 14,66 & 9,12 \\
& Urbano & 19,56 & 4,73 \\
Nivel de estudios & Elemental & 16,70 & 7,5 \\
& Ciclo Grado Medio & 20,82 & 3,18 \\
& Ciclo Grado Superior & 22,57 & 2,71 \\
& Bachillerato & 20,15 & 4,26 \\
& Otros & 13,07 & 8,80 \\
& Universidad & 22,35 & 3,24 \\
\hline
\end{tabular}

Uno de los objetivos principales de este estudio era analizar el impacto psicosocial derivado del uso de productos de apoyo para la comunicación, con especial interés en la comparación entre los sistemas de intermediación en vídeo y otros productos de apoyo en personas adultas sordas signantes. Para ello, se calcularon los promedios de la escala PIADS global, y de sus tres subescalas, para el grupo de participantes que utilizan sistemas SIV y para aquellos que utilizan otros sistemas (véase Tabla 30). 
Tabla 30.- Puntuaciones globales en la escala PIADS y en sus tres subescalas en función del uso de SIV.

\begin{tabular}{lll}
\hline & \multicolumn{2}{c}{ USO SIV } \\
& Sí $(\mathbf{n = 7 4})$ & No $(\mathbf{n = 5 0})$ \\
\hline PIADS TOTAL & $1,30(, 86)$ & $0,57(0,96)$ \\
Competencia & $1,34(0,88)$ & $0,54(0,98)$ \\
Adaptabilidad & $1,61(0,98)$ & $0,72(1,21)$ \\
Autoestima & $1,02(1)$ & $0,48(0,94)$ \\
\hline
\end{tabular}

Con el objeto de comprobar si había diferencias en el impacto psicosocial en función del uso de SIV se llevó a cabo un análisis de varianza de un factor (uso de SIV) tomando como variable dependiente la puntuación global de PIADS. De esta manera se verificó que el grupo de participantes que utilizan sistemas SIV obtuvo una puntuación más positiva en la escala PIADS $(M=1,30)$ que el grupo de participantes que no utilizan sistemas $\operatorname{SIV~}(M=$ $0,57),\left[F(1,122)=19,984, p<.001, \eta^{2}=, 141\right]$.

Con el objetivo de observar el origen de estas diferencias, se llevó a cabo un análisis de varianza multivariado, tomando como variables dependientes las puntuaciones en las tres subescalas de PIADS (competencia, adaptabilidad y autoestima) y como variable independiente el tipo de producto de apoyo para la comunicación utilizado por los participantes (Oovoo, Skype, Móvil y SVisual). El análisis multivariado mostró la existencia de diferencias significativas en la subescala de competencia $\left[F(3,120)=9,115, p<.001, \eta^{2}=\right.$ ,186], en la de adaptabilidad $\left[F(3,120)=8,033, p<.001, \eta^{2}=, 167\right]$ y en la de autoestima [ $F$ $\left.(3,120)=3,396, p<.05, \eta^{2}=, 078\right]$, en función del tipo de producto de apoyo utilizado. Tal y como muestra la siguiente tabla las pruebas post-hoc (Tukey HSD) mostraron, en general, que los usuario de SVisual tuvieron puntuaciones más altas en competencia y adaptabilidad, en relación a los usuarios de Skype y Móvil pero no respecto a los usuarios del chat de video Oovoo. Sin embargo, en la subescala de autoestima sólo se observó una diferencia significativa entre los usuarios de SVisual $(M=1,036 ; S D=1,01)$ y los usuarios de teléfono móvil $(M=0,36 ; S D=1,08)$. 
Tabla 31.- Puntuaciones de las tres subescalas pertenecientes a la escala PIADS por tipo de producto de apoyo $(\mathrm{n}=124)$

\begin{tabular}{ccc}
\hline Subescala PIADS & Producto de apoyo $(\mathbf{n})$ & M $(\boldsymbol{S D})$ \\
\hline Competencia & Móvil $(\mathrm{n}=26)$ & $0,40(1,06)$ \\
& Oovoo $(\mathrm{n}=17)$ & $0,90(0,76)$ \\
& Skype $(\mathrm{n}=15)$ & $0,56(0,88)$ \\
& Svisual $(\mathrm{n}=66)$ & $1,4(0,9)$ \\
Adaptabilidad & Móvil $(\mathrm{n}=26)$ & $0,49(1,3)$ \\
& Oovoo $(\mathrm{n}=17)$ & $1,44(0,86)$ \\
& Skype $(\mathrm{n}=15)$ &, $77(1,02)$ \\
& Svisual $(\mathrm{n}=66)$ & $1,6(1,02)$ \\
Autoestima & Móvil $(\mathrm{n}=26)$ &, $35(1,1)$ \\
& Oovoo $(\mathrm{n}=17)$ &, $88(, 95)$ \\
& Skype $(\mathrm{n}=15)$ &, $52(, 72)$ \\
& Svisual $(\mathrm{n}=66)$ & $1,04(1,01)$ \\
\hline
\end{tabular}

Aunque el análisis de cada uno de los ítems no se planteó como objetivo específico de este estudio, en las dos siguientes tablas podemos observar las puntuaciones medias por ítem y por subescala para toda la muestra y en función del uso de SIV.

Tabla 32.- Puntuaciones por las subescalas de competencia, adaptabilidad y autoestima de la escala PIADS

\begin{tabular}{|c|c|c|}
\hline Competencia (12 ítems) & Adaptabilidad (6 ítems) & Autoestima (8 ítems) \\
\hline Competencia; $M=1,44$ & Bienestar; $M=1,31$ & Felicidad; $M=1,26$ \\
\hline Independencia; $M=1,38$ & $\begin{array}{l}\text { Dispuesto a darse oportunidades; } M \\
=0,91\end{array}$ & Autoestima; $M=1,09$ \\
\hline $\begin{array}{l}\text { Sentirse a la altura de las } \\
\text { circunstancias; } M=0,95\end{array}$ & Capacidad para participar; $M=1,40$ & Seguridad; $M=0,86$ \\
\hline Confusión *; $M=1,06$ & $\begin{array}{l}\text { Deseoso de probar cosas nuevas; } M \\
=1,48\end{array}$ & Frustración $* ; M=-0,15$ \\
\hline Eficacia; $M=0,98$ & $\begin{array}{l}\text { Capacidad para adaptarse a las } \\
\text { actividades cotidianas; } M=1,23\end{array}$ & Confianza en sí mismo; $M=1,30$ \\
\hline Productividad; $M=1,28$ & $\begin{array}{l}\text { Capacidad para aprovechar las } \\
\text { oportunidades; } M=1,27\end{array}$ & Sensación de poder; $M=1,09$ \\
\hline Sentirse útil; $M=0,85$ & & Sensación de control; $M=0,97$ \\
\hline Pericia; $M=1,23$ & & Sentirse a disgusto $* ; M=0,30$ \\
\hline \multicolumn{3}{|l|}{ Aptitud; $M=1,34$} \\
\hline \multicolumn{3}{|l|}{ Sentirse capaz; $M=1,21$} \\
\hline \multicolumn{3}{|l|}{ Calidad de vida; $M=1,36$} \\
\hline Realización; $M=1,30$ & & \\
\hline
\end{tabular}

Como se puede apreciar en al siguiente tabla, las diferencias entre los usuarios de SIV y los que no los utilizan se originan principalmente en los ítems de competencia, independencia, sentirse a la altura de las circunstancias, eficacia, capacidad para participar y capacidad para adaptarse a las actividades de la vida diaria. 
Tabla 33.- Puntuación por ítem de la escala PIADS en función de si usa SIV o no usa SIV (n=124)

\begin{tabular}{lcc}
\hline & No usa SIV & Sí usa SIV \\
\hline Competencia & 0,80 & 1,86 \\
Felicidad & 0,72 & 1,62 \\
Independencia & 0,68 & 1,85 \\
Sentirse a la altura de las circunstancias & 0,30 & 1,39 \\
Confusión & 0,40 & 1,51 \\
Eficacia & 0,26 & 1,47 \\
Autoestima & 0,36 & 1,58 \\
Productividad & 0,56 & 1,77 \\
Seguridad & 0,40 & 1,18 \\
Frustración & $-0,40$ & 0,01 \\
Sentirse útil & 0,38 & 1,16 \\
Confianza en sí mismo & 0,94 & 1,54 \\
Pericia & 0,68 & 1,59 \\
Aptitud & 0,88 & 1,65 \\
Bienestar & 0,90 & 1,59 \\
Sentirse capaz & 0,66 & 1,58 \\
Calidad de vida & 0,82 & 1,73 \\
Realización & 0,90 & 1,57 \\
Sensación de poder & 0,62 & 1,41 \\
Sensación de control & 0,50 & 1,28 \\
Sentirse a disgusto & 0,06 & 0,46 \\
Dispuesto a darse oportunidades & 0,54 & 1,16 \\
Capacidad para participar & 0,70 & 1,88 \\
Deseoso de probar nuevas cosas & 0,92 & 1,85 \\
Capacidad para adaptarse a las actividades de la vida diaria & 0,64 & 1,64 \\
Capacidad para aprovechar las oportunidades & 0,64 & 1,53 \\
\hline
\end{tabular}

Por último, resultaba de interés comprobar la relación entre la frecuencia de uso de los productos de apoyo para la comunicación y el impacto psicosocial percibido. En la siguiente tabla se muestran los valores globales de PIADS en función de la frecuencia de uso y del tipo de sistema utilizado. 
Tabla 34.- Impacto psicosocial percibido en función del uso o no de SIV y de la frecuencia de uso

\begin{tabular}{cccc}
\hline & \multicolumn{2}{c}{ Uso de SIV } & \\
Frecuencia de uso & SI & NO & Dif significativa \\
\hline Diario (n=83) & & & Sí $(\mathrm{p}<0,05)$ \\
Competencia & 1,42 & 0,49 & \\
Autoestima & 1,03 & 0,36 & \\
Adaptabilidad & 1,6 & 0,64 & No \\
& & & \\
Semanal (n=25) & 1,32 & 0,97 & \\
Competencia &, 88 & 1,02 & \\
Autoestima & 1,56 & 1,02 & \\
Adaptabilidad & & & \\
& & & No \\
Mensual (n=16) & & & \\
Competencia & 1,05 & 0,47 & \\
Autoestima & 1,2 & 0,77 & \\
Adaptabilidad & 1,8 & 0,94 & \\
\hline
\end{tabular}

Como puede apreciarse, la diferencia en el impacto psicosocial a favor de los usuarios de SIV es significativa en el grupo de usuarios que utiliza estos sistemas a diario mientras que no lo es en los grupos de usuarios que los utilizan con menor frecuencia.

\section{Discusión y conclusiones}

Muchos autores han señalado la importancia de la utilización de productos de apoyo para superar los problemas de comunicación (Fortnum, Marshall, Bamford \& Summerfield, 2002; Johnston, 2004). Aunque exista mucha variedad de productos y tecnologías de apoyo para la comunicación "a distancia" entre sordos y oyentes, los beneficios derivados de los distintos productos no son percibidos de manera homogénea para todos los productos. Pero gracias a la evolución tecnológica y al desarrollo de diferentes tipos de comunicación como la interpretación en línea se logra un aumento en la participación social gracias a su uso (Vincent, Deaudelin \& Hotton, 2007).

Los resultados obtenidos muestran que las personas sordas de nuestro país, al menos los participantes en el estudio, utilizan algún tipo de sistema de comunicación, siendo el SIV el más usado (seguido del dispositivo móvil) respecto a otros sistemas, aunque no parece haber un perfil claro del usuario de SIV. Se han verificado diferencias en las experiencias con las tecnologías de uso gracias a las puntuaciones obtenidas en el instrumento SOTU-C, existiendo una relación entre experiencias positivas con las tecnologías y el uso de los SIV, este resultado indica que tiene relación el uso de nuevas tecnologías en general para emplear esta tecnología en particular por lo que su no uso puede derivarse de la falta de experiencias en el uso estas tecnologías emergentes, y es por ello que en investigaciones futuras sobre 
estos productos debería plantearse indagar sobre la predisposición o no a usar este tipo de tecnologías en personas poco familiarizadas con este tipo de software. Además, con las puntuaciones del SOTU-C se puede deducir que los factores personas/características personales no están vinculadas al uso de estas tecnologías (Scherer \& Glueckauf, 2005), no obstante sí parece subyacer diferencias en cuanto a características sociodemográficas se refiere los participantes postlocutivos obtienen unas puntuaciones más positivas derivados del uso de tecnologías que los participantes con un tipo de pérdida prelocutivo, lo mismo ocurre con los participantes usuarios de ambas lenguas (lengua oral y lengua de signos) frente a los que emplean únicamente la lengua de signos como lengua para comunicarse. Por último, a mayor nivel académico mayor promedio de respuestas positivas en el instrumento SOTU-C.

Entre las personas que no utilizan los SIV, hay un 52\% que no los conocen, por lo que su difusión y la creación de programas específicos para su entrenamiento debería ser una prioridad para, por ejemplo, las asociaciones de personas sordas. Además, el uso de estos PA requiere de un entrenamiento previo, por lo que se podrían impartir talleres y sesiones de entrenamiento por parte de, por ejemplo, terapeutas ocupacionales. En las zonas rurales no suele hacerse difusión de este tipo de tecnologías, dadas las respuestas de los participantes que residen en el ámbito rural, por lo que se debe de implicar a los residentes de estas zonas en el uso y difusión de estos productos.

En este estudio se ha comprobado que el impacto psicosocial derivado del uso de productos de apoyo es mayor en las personas usuarias de los SIV que en los que utilizan otros productos y tecnologías de apoyo para la comunicación. Este impacto se ve reflejado con una mayor puntuación en los ítems de competencia, independencia y calidad de vida en la subescala de competencia; en los ítems que reflejan el deseo de probar cosas nuevas, la capacidad para participar y el bienestar, en la subescala adaptabilidad y; en cuanto a la subescala de autoestima, en los ítems que reflejan la confianza en sí mismo y la felicidad. Cabe señalar que todos los ítems de las tres subescalas pertenecientes a la escala del PIADS obtuvieron una mayor puntuación en las personas usuarias de SIV, sin embargo, no hay una diferencia en el ítem "sentirse a disgusto", por lo que, en futuras investigaciones sería oportuno indagar sobre si existe estigma asociado al uso de estas tecnologías. Otros estudios habían demostrado, con este instrumento y en este colectivo, que el uso de productos de apoyo de amplificación mejoraba diversos aspectos psicosociales de la vida (e.g., Bridges \& Bentler, 1998; Kochkin \& Rogin, 2000; Mulrow et al., 1990). En general, todos los sistemas de intermediación por vídeo han generado un impacto positivo en sus usuarios, aunque el 
móvil es el producto más utilizado tras los SIV, y es el que obtuvo una menor puntuación en la escala global PIADS y en sus tres subescalas. Al igual que en el estudio de Butussi, Carchietti, Chittaro y Coppo (2010), el teléfono móvil es una de las tecnologías de uso más frecuente en personas sordas, aunque su impacto psicosocial es menor, por lo que en investigaciones futuras debería de plantearse como objetivo indagar sobre el teléfono móvil como producto de apoyo con el objetivo de mejorar aquellos aspectos de diseño, funcionamiento o servicio que pudieran dar cuenta de este impacto menor respecto a los SIV.

Por último, en cuanto a la relación impacto psicosocial y frecuencia de uso del producto de apoyo, Saunders y Jutai (2004) ya encontraron que los participantes que usaban con mayor frecuencia los productos de amplificación tenían un mayor impacto positivo en el PIADS. En este estudio se ha obtenido un resultado similar ya que las personas que usan los SIV a diario también tienen una puntuación mayor en la escala PIADS. 


\section{Estudio 2. Impacto psicosocial derivado del uso de audífonos}

\section{Introducción}

El audífono es uno de los PA para personas con discapacidad auditiva más extendido y usado en todo el mundo. Como se mencionó con anterioridad, existen evidencias claras de que las percepciones subjetivas de la capacidad funcional, el bienestar y la calidad de vida pueden verse afectadas de forma significativa y positiva con posterioridad a la adopción y correcto uso de un audífono. Son muchas las personas con una pérdida auditiva que podrían beneficiarse del uso de un audífono y no cuentan con uno en la actualidad (Kockin \& Rogin, 2000), mientras que una amplia proporción de las personas que tienen un producto auditivo o bien no lo usan, o bien no aprovechan todas sus ventajas para mejorar su calidad de vida (Kockin \& Rogin, 2000; Mann, Hurren \& Tomita, 1994; Salamon, Verterages \& Jagal, 1988). Gracias a la revisión de la literatura realizada en la primera parte de la tesis, sabemos que los factores psicosociales, y no tanto los auditivos, parecen subyacer bajo muchos casos de falta de uso de este tipo de productos de apoyo (Jutai \& Bortolussi, 2003).

Tal y como se describió en la parte teórica de esta Tesis Doctoral, se ha demostrado que estos productos mejoran algunos resultados en el ámbito psicosocial (Kockin \& Rogin, 2000; Mulrow et al, 1990). En la literatura científica aparece además que la hipoacusia en adultos mayores se asocia significativamente a dificultades en la comunicación, disminución de la actividad social, alteraciones emocionales (presentan un mayor riesgo de depresión), menor capacidad de autocuidado, deterioro cognitivo y alteraciones de memoria (Muirow et al., 1990; Rabbitt, 1990), por lo que es necesario realizar intervenciones que minimicen estas posibles dificultades, y una intervención habitual en este contexto es utilizando PA como el audífono. No obstante, muchas personas que necesitarían utilizar un PA de amplificación no lo hacen (Kochkin \& Rogin, 2000); e incluso, otras muchas, aunque usen un PA, este no se asocia a una en mejora su calidad de vida (Kochkin \& Rogin, 2000; Mann, Hurren \& Tomita, 1994; Salamon, Vesterager \& Jagd, 1988). Esto podría suceder, entre otros factores, debido a la influencia de distintas variables de carácter psicosocial que se asocian a la adherencia de uso a un PA (Kochkin, 1993). De aquí se deriva el primer objetivo de este estudio: indagar sobre el impacto psicosocial derivado del uso de diferentes audífonos.

Existe literatura científica previa que revela la existencia de un impacto psicosocial variable según el tipo de audífono (Wood \& Lutman, 2004). Y por ello resulta de interés 
comprobar si esto es aplicable a los usuarios de audífonos de nuestro país y hasta qué punto los resultados entre estudios realizados en distintos contextos son comparables.

Otro asunto de interés es indagar sobre el abandono o falta de uso de este tipo de productos de apoyo de amplificación. Algunos autores han estimado que la interrupción en el uso de audífonos en pacientes adultos mayores llega al 30 \% (Oyegard \& Ramstrom, 1994). En un estudio realizado en Alemania, consultados los pacientes sobre las razones para no usar audífonos, aparecía en primer lugar el disconfort auditivo, seguido de cuestiones relativas a la comodidad y la apariencia de los aparatos (Meister, Lausberg, Von Wedel \& Walger, 2004). En otro estudio, realizado en U.S.A. (O'Neill, 1999), las razones reportadas para no usar audífonos fueron el costo, un 50\%; la apariencia, un 20\%; y el que estos dispositivos no le resolvían su problema, un $30 \%$. Y en otro estudio, realizado también en ese país, se encontró que el no uso de audífonos estaba asociado con la edad, severidad de la hipoacusia y el nivel académico (Popelka et al., 1998). Sin embargo, existe poca investigación respecto a las medidas de resultados de los audífonos (Saunders \& Jutai, 2004), y aún menos en España. Por otra parte, la evidencia apunta a que el estatus funcional, bienestar y calidad de vida están significativamente ligadas al uso y al éxito de los audífonos (Jutai \& Saunders, 2003). Por ello, en este estudio se ha empleado el instrumento PIADS, puesto que permite evaluar tanto el impacto psicosocial como la calidad de vida percibida derivada del uso de un PA.

Un objetivo específico de este estudio ha sido evaluar la predisposición al uso de nuevas tecnologías de usuarios de audífonos empleando el instrumento SOTU-C, y evaluar si existe diferencias según características sociodemográficas tales como la edad, género, nivel de estudio o lugar de residencia (Scherer \& Glueckauf, 2005). La literatura sugiere que existen diferencias en el uso de tecnologías en función de la edad y, aunque en estudios anteriores han examinado las habilidades de estos usuarios con ordenadores y otras tecnologías, existen pocos estudios que examinen los efectos de los problemas de audición en las perspectivas y experiencias con el uso de nuevas tecnologías (Henshaw, Clark, Kang, \& Ferguson, 2012). Paralelamente, el SOTU-C evalúa características personales y sociales que se relacionan con la predisposición a usar tecnologías, y de aquí se deriva el objetivo específico de analizar la relación entre las características personales, sociales y sociodemográficas y el uso de nuevas tecnologías. 


\section{Método}

\section{Participantes}

La muestra de este estudio se seleccionó por medio de un muestreo de conveniencia no probabilístico.

El trabajo se ha realizado en diferentes centros y asociaciones tanto de personas con discapacidad auditiva como residencias de personas mayores de Castilla y León. Además, se optó por establecer un conjunto de criterios de inclusión y exclusión con el objeto de mejorar la homogeneidad de la muestra.

Criterios de inclusión:

- Personas con un diagnóstico de pérdida auditiva

- Personas afectadas, mayores de 18 años.

- Personas afectadas, usuarias de audífonos

- Personas con una lengua oral y/o lengua de signos.

- Personas que no presenten un deterioro cognitivo (en el caso de las personas mayores residentes de diferentes centros)

Criterios de exclusión:

- Personas con un diagnóstico adicional a la pérdida auditiva.

- Personas afectadas por pérdida auditiva menores de 18 años.

- Personas que, cumpliendo los criterios de inclusión y habiendo recibido una completa información sobre el estudio, no deseen participar en el mismo.

- Personas con deterioro cognitivo.

Una vez definidos los criterios de inclusión, fueron excluidos del estudio 4 participantes por presentar discapacidad visual en diferentes grados. Para poder acceder a los participantes de este estudio, se realizó el contacto mediante la asociación SADAP (Asociación de personas con discapacidad postlocutiva). En primer lugar, se les proporcionó información detallada sobre el estudio y los objetivos del mismo para pedir así su colaboración en la realización del estudio. Si la respuesta era afirmativa, se proponían fechas para realizar el cuestionario de forma presencial tanto en la asociación SADAP como otros entornos tales como la Universidad de Salamanca (USAL), hogares y centros de trabajo. 
Finalmente la muestra quedó formada por 137 personas, 82 mujeres y 55 hombres, con una edad media de 75,29 años $(S D=17,6)$. En la siguiente tabla se resumen las principales características demográficas de los participantes.

Tabla 35.- Perfil Sociodemográfico de personas adultas con discapacidad auditiva usuarias de audífonos estudio 2 $(\mathrm{n}=137)$

\begin{tabular}{ll}
\hline VARIABLE & $\mathrm{N}(\%)$ \\
\hline Edad & $M=75,29 ; S D=17,61$ \\
Género & $55(40,1)$ \\
Varón & $82(59,9)$ \\
Mujer & $2(1,5)$ \\
Lengua & $126(92)$ \\
Lengua de signos & $9(6,6)$ \\
Lengua oral & \\
Ambas & $29(21,2)$ \\
Zona residencial & $108(78,8)$ \\
Rural & \\
Urbano & $8(5,8)$ \\
Momento pérdida & $129(94,2)$ \\
Prelocutivo & \\
Postlocutivo & $121(88,3)$ \\
Tipo de pérdida & $16(11,7)$ \\
Hipoacusia & \\
Cofósis & $98(71,5)$ \\
Nivel de estudios & $10(7,3)$ \\
Elemental & $8(5,8)$ \\
Bachillerato & $1(0,7)$ \\
Ciclo grado medio & $18(13,1)$ \\
Ciclo grado superior & $2(1,5)$ \\
Universidad & $0(0)$ \\
Máster & $12(8,8)$ \\
Otros & $30(21,9)$ \\
Grado de pérdida & $59(43,1)$ \\
Pérdida leve & $36(26,3)$ \\
Pérdida moderada &
\end{tabular}

Todas las personas participantes recibieron información detallada sobre las características del estudio y tuvieron que firmar un consentimiento informado según modelo del Comité de Bioética de la Universidad de Salamanca (véase Anexo VI). 


\section{Instrumentos}

Los instrumentos empleados en este estudio fueron los mismos que los utilizados en el estudio 1.

\section{Procedimiento}

El proceso de recogida de datos se ha realizado con la aplicación del cuestionario sociodemográfico propio, el PIADS y el cuestionario SOTU-C perteneciente al MPT. Estos instrumentos tienen una aplicabilidad de evaluación que permite que sean administrados a través de entrevista personal o telefónica y de forma auto-administrada con las indicaciones adecuadas. Todos los participantes rellenaron el cuestionario de forma individual. Esto ha sido debido a las características comunicativas de los usuarios y el posible sesgo derivado de respuestas realizadas de forma grupal.

La recogida de datos fue realizada mediante dos procedimientos alternativos

Entrevista individual: (La entrevista por teléfono fue descartada debido a los problemas comunicativos que presenta el colectivo). Fue el medio mayoritario de recogida de muestra $(n=125)$. La duración de cada entrevista osciló entre los 25 minutos y 60 minutos dependiendo de las características del usuario.

Cuestionario electrónico, accesible a través de página Web para personas residentes fuera de la provincia de Salamanca $(n=12)$.

La duración del estudio en cuanto al trabajo de campo (realización de las entrevistas, aplicación de los cuestionarios y recogida de datos) ha sido de un total de 12 meses.

El diseño planteado es un diseño no experimental transversal correlacional.

\section{Resultados}

Los resultados de los cuestionarios se fueron incorporando a una hoja de cálculo diseñada en Microsoft Excel y posteriormente los datos fueron analizados mediante IBM SPSS v 21 y R.

Comenzaremos ofreciendo un resumen sobre el tipo de tecnologías empleadas por los participantes: móvil $(n=67)$, ordenador $(n=33)$, internet $(n=26)$, tableta $(n=24)$, cajero 
automático $(n=22)$, portátil $(n=9)$, netbook $(n=10)$, reproductor música $(n=15)$, teléfono específico para personas con hipoacusia $(n=3)$, nintendo DS $(n=7)$, kinect $(n=3)$, Xbox $(n=3)$ y proyector $3 \mathrm{D}(\mathrm{n}=1)$. Los promedios de puntuaciones positivas y negativas respecto al cuestionario SOTU-C: respuestas positivas $(M=13,88 ; S D=7,3)$ y respuestas negativas $(M=8,8 ; S D=5,8)$

Para avanzar en la caracterización de los usuarios de audífono se calcularon los promedios de respuestas positivas y negativas según características sociodemográficas en la puntuación total de SOTU-C y en los distintos apartados (ver siguiente tabla).

Tabla 36.- Promedios de respuestas positivas y negativas obtenidas en el SOTU-C $(n=137)$

\begin{tabular}{|c|c|c|c|}
\hline Variable & & SOTU POSITIVO & SOTU NEGATIVO \\
\hline \multirow[t]{2}{*}{ Género } & Hombre & 14 & 8 \\
\hline & Mujer & 13 & 10 \\
\hline \multirow[t]{2}{*}{ Lengua empleada } & Lengua de signos & 15 & 8 \\
\hline & Lengua oral & 13 & 9 \\
\hline \multirow[t]{2}{*}{ Momento de pérdida } & Postlocutivo & 14 & 9 \\
\hline & Prelocutivo & 16 & 4 \\
\hline \multirow[t]{2}{*}{ Tipo de pérdida } & Cofosis & 14 & 7 \\
\hline & Hipoacusia & 14 & 9 \\
\hline \multirow[t]{2}{*}{ Zona residencia } & Rural & 15 & 5 \\
\hline & Urbano & 14 & 10 \\
\hline \multirow[t]{6}{*}{ Nivel de estudios } & Elemental & 12 & 10 \\
\hline & Ciclo Grado Medio & 18 & 3 \\
\hline & Ciclo Grado Superior & 11 & 6 \\
\hline & Bachillerato & 15 & 7 \\
\hline & Universidad & 18 & 6 \\
\hline & Máster/Doctorado & 26 & 2 \\
\hline
\end{tabular}

En la anterior tabla 36 podemos observar las diferencias en las puntuaciones positivas y negativas obtenidas en el cuestionario SOTU-C en función de diferentes variables. Cabe señalar que las personas con un mayor nivel educativo obtuvieron puntuaciones más altas respecto a personas con un nivel de educación elemental. Por otra parte resulta de interés que parece no existir una diferencia en cuanto al tipo de pérdida para las puntuaciones positivas pero si para el momento de la pérdida, presentando un mayor número las personas 
prelocutivas. Para finalizar las personas usuarias de lengua de signos presentan mayor número de puntuaciones positivas que las personas usuarias de lengua oral.

También se calcularon los promedios de respuestas positivas y negativas en todos los apartados del SOTU-C en función del grupo de edad, tal y como se muestra en la tabla siguiente:

Tabla 37.- Promedios de respuestas positivas y negativas obtenidas en el SOTU-C en función del rango de edad

\begin{tabular}{|c|c|c|c|}
\hline \multirow[t]{2}{*}{ APARTADO DEL CUESTIONARIO SOTU-C } & \multicolumn{3}{|c|}{ EDAD } \\
\hline & 16-39 años & 40-77 años & $78-98$ años \\
\hline Experiencias globlales con las tecnologías utilizadas._POSITIVAS & 3,92 & 2,75 & 2,80 \\
\hline Experiencias globlales con las tecnologías utilizadas_NEGATIVAS & 0,23 & 0,67 & 0,60 \\
\hline Perspectivas sobre tecnologías_POSITIVAS & 5,69 & 3,25 & 3,20 \\
\hline Perspectivas sobre tecnologías_NEGATIVAS & 1 & 2,92 & 4 \\
\hline Actividades típicas_POSITIVAS & 3 & 2 & 2 \\
\hline Actividades típicas_NEGATIVAS & 0,31 & 1,42 & 1,60 \\
\hline Algunas características personales/sociales_POSITIVAS & 10,38 & 7,42 & 6,20 \\
\hline Algunas características personales/sociales_NEGATIVAS & 0,85 & 3,83 & 5,20 \\
\hline SOTU GLOBAL_POSITIVAS & 23 & 15,42 & 14,20 \\
\hline SOTU_GLOBAL NEGATIVO & 2,4 & 8,8 & 11,4 \\
\hline
\end{tabular}

La anterior tabla hace referencia a las puntuaciones obtenidas en el SOTU-C por franja de edad, podemos observar que a menor franja de edad existe un mayor número de respuestas positivas. 
Respecto al SOTU-C, también se calcularon las puntuaciones en los apartados en función del tipo de audífono utilizado. Los tipos de audífonos utilizados por los participantes de la muestra fueron, principalmente, cuatro: 1) gafas auditivas su característica principal son sus circuitos insertados en el interior de las varillas de las propias gafas, al tener, los circuitos dentro de la varilla de su estructura, este tipo de audífono resulta prácticamente invisible, cuidando así la estética del paciente; 2)inserción profunda son aquellos que se adaptan al canal auditivo más profundamente para que sean menos visibles además de reducir el problema de ruido provocado por el viento y la retroalimentación del teléfono; 3 ) intracanal son los audífonos que se introducen más profundamente en el canal auditivo que otros audífonos y 4) retroauricular son los audífonos con mayor potencia y suelen emplearse para pérdidas severas y profundas, van colocados detrás del oído y se ajustan al pabellón auditivo mediante un molde a medida.

Tabla 38.- Promedio de respuestas positivas y negativas del instrumento SOTU-C por tipo de audífono

\begin{tabular}{|c|c|c|c|c|}
\hline APARTADO DEL CUESTIONARIO SOTU-C & $\begin{array}{c}\text { Gafas } \\
\text { auditivas }\end{array}$ & $\begin{array}{l}\text { Inserción } \\
\text { profunda }\end{array}$ & Intracanal & Retroauricular \\
\hline $\begin{array}{l}\text { Experiencias globlales con las tecnologías } \\
\text { utilizadas._POSITIVAS }\end{array}$ & 2,5 & 1,2 & 1,7 & 2,34 \\
\hline $\begin{array}{l}\text { Experiencias globlales con las tecnologías utilizadas } \\
\text { _NEGATIVAS }\end{array}$ & 0 & 0,2 & 0,69 & 0,32 \\
\hline Perspectivas sobre tecnologías_POSITIVAS & 2,5 & 1,8 & 2,14 & 2,6 \\
\hline Perspectivas sobre tecnologías_NEGATIVAS & 3,5 & 4,2 & 3,72 & 2,9 \\
\hline Actividades típicas_POSITIVAS & 2 & 1,8 & 1,89 & 1,9 \\
\hline Actividades típicas_NEGATIVAS & 1 & 1,2 & 1,67 & 1,4 \\
\hline Algunas características personales/sociales_POSITIVAS & 11,5 & 8,6 & 6,53 & 7,6 \\
\hline $\begin{array}{l}\text { Algunas características personales/sociales } \\
\text { _NEGATIVAS }\end{array}$ & 1 & 2,8 & 5,2 & 3,4 \\
\hline SOTU GLOBAL_POSITIVAS & 18,50 & 13,40 & 12,25 & 14,41 \\
\hline SOTU_GLOBAL NEGATIVO & 5,5 & 8,40 & 11,25 & 8,1 \\
\hline
\end{tabular}


Dado que el objetivo principal de este estudio era indagar sobre el impacto psicosocial derivado del uso del uso de audífonos, se calcularon los promedios de puntuaciones en la escala PIADS. En la tabla siguiente, se puede observar los promedios de la escala PIADS global y de sus tres subescalas (competencia, autoestima y adaptabilidad) de todos los participantes (véase tabla 39)

Tabla 39.- Puntuaciones globales en la escala PIADS y en sus tres subescalas $(\mathrm{n}=137)$

\begin{tabular}{|lllll|}
\hline PA (audífono) & PIADS TOTAL & Competencia & Adaptabilidad & Autoestima \\
\hline Audífono & $1,39(0,93)$ & $1,37(0,92)$ & $1,41(0,97)$ & $1,42(1,1)$ \\
& & & & \\
\hline
\end{tabular}

Como puede apreciarse, el impacto global es positivo, siendo todas las puntuaciones positivas y mayores de 1.

También se calcularon los promedios en PIADS en función del tipo de audífono (véase tabla 40).

Tabla 40.- Puntuaciones globales en la escala PIADS y en sus tres subescalas en función del tipo de audífono (n=137)

\begin{tabular}{lcccc}
\hline & PIADS TOTAL $($ SD $)$ & Competencia & Adaptabilidad & Autoestima \\
\cline { 2 - 4 } Retroauricular $(\mathrm{n}=84)$ & $1,39(0,96)$ & $1,37(0,92)$ & $1,43(0,98)$ & $1,42(1,14)$ \\
Intracanal $(\mathrm{n}=36)$ & $1,33(0,89)$ & $1,3(0,92)$ & $1,32(0,98)$ & $1,39(1,01)$ \\
Inserción profunda $(\mathrm{n}=5)$ & $1,32(0,66)$ & $1,28(0,75)$ & $1,27(0,8)$ & $1,43(0,56)$ \\
Gafas auditiva $(\mathrm{n}=2)$ & $2,77(0,11)$ & $2,79(0,18)$ & $2,5(0,7)$ & $2,94(0,88)$ \\
\hline
\end{tabular}

Un análisis de varianza multivariado mostró que no había ninguna diferencia significativa en las puntuaciones de competencia, adaptabilidad y autoestima en función del tipo de audífono, $[\mathrm{F}(3,133)=0.694, \mathrm{p}=.714$; Wilk's $\Lambda=0.954$, partial $\eta 2=.02$.

Finalmente, como modo de indagar sobre el abandono de los audífonos, un año después de realizar la encuesta inicial se contactó de nuevo con todos los participantes para preguntar si seguían o no utilizando el audífono. En un total de 25 casos el audífono había sido abandonado. 
Con esta nueva variable de abandono se realizó un una comparación en la escala global PIADS y sus tres subescalas en función de si el participante había abandonado el PA. Los resultados se muestran en la siguiente tabla:

Tabla 41.- Puntuaciones en la escala PIADS y en sus tres subescalas en función de si el participante había abandonado o no el audífono

\begin{tabular}{lllll}
\hline Abandono & PIADS TOTAL $(S D)$ & Competencia & Adaptabilidad & Autoestima \\
\hline $\begin{array}{l}\text { No abandono } \\
(\mathrm{n}=112)\end{array}$ & $1,67(0,80)$ & $1,62(0,81)$ & $1,66(0,88)$ & $1,75(0,9)$ \\
Si abandono $(\mathrm{n}=25)$ & $0,16(0,25)$ & $0,23(0,32)$ & $0,27(0,45)$ & $-0,4(0,51)$ \\
\hline
\end{tabular}

Tabla 42.- Puntuaciones globales en la escala PIADS y en sus tres subescalas en función de si el participante había abandonado o no el audífono $(\mathrm{n}=137)$

\begin{tabular}{|c|c|c|c|c|c|}
\hline $\begin{array}{l}\text { Tipo de producto de } \\
\text { amplificación }\end{array}$ & Abandono & PIADS $(S D)$ & $\begin{array}{c}\text { Competencia } \\
(S D)\end{array}$ & $\begin{array}{l}\text { Adaptabilidad } \\
\text { (SD) }\end{array}$ & $\begin{array}{l}\text { Autoestima } \\
\qquad(S D)\end{array}$ \\
\hline \multirow[t]{2}{*}{ Gafas auditivas } & No abandono & $2,77(0,11)$ & $2,79(0,18)$ & $2,50(0,71)$ & $2,94(0,09)$ \\
\hline & $\mathrm{Si}$ abandono & - & - & - & - \\
\hline \multirow[t]{2}{*}{$\begin{array}{l}\text { Audífonos de } \\
\text { inserción profunda }\end{array}$} & No abandono & $1,55(0,50)$ & $1,56(0,48)$ & $1,46(0,77)$ & $1,59(0,48)$ \\
\hline & $\mathrm{Si}$ abandono & 0,42 & 0,17 & 0,50 & 0,75 \\
\hline \multirow[t]{2}{*}{$\begin{array}{l}\text { Audífonos } \\
\text { intracanal }\end{array}$} & No abandono & $1,59(0,78)$ & $1,55(0,84)$ & $1,55(0,92)$ & $1,70(0,84)$ \\
\hline & Si abandono & $0,24(0,28)$ & $0,29(0,34)$ & $0,36(0,52)$ & $0,09(0,50)$ \\
\hline \multirow[t]{2}{*}{ Petaca } & No abandono & 1,54 & 1,33 & 1,50 & 1,88 \\
\hline & Si abandono & - & - & - & - \\
\hline \multirow[t]{2}{*}{$\begin{array}{l}\text { Audífono } \\
\text { retroauricular }\end{array}$} & No abandono & $1,68(0,81)$ & $1,62(0,81)$ & $1,70(0,87)$ & $1,74(0,95)$ \\
\hline & $\mathrm{Si}$ abandono & $0,11(0,24)$ & $0,21(0,32)$ & $0,23(0,44)$ & $-0,13(0,50)$ \\
\hline
\end{tabular}


Cabe destacar, que la escala que ha obtenido una menor puntuación de aquellas personas que han abandono el PA, es la de autoestima obteniendo incluso puntuaciones negativas tanto en la puntuación general de todos los PA como la puntuación específica por tipo de audífono como sucede en el audífono tipo retroauricular. Por otra parte, cabe destacar que el resto de puntuaciones fueron superiores a 0 por lo que el impacto psicosocial fue positivo; aunque, si comprobamos las puntuaciones tanto de la escala global como de las tres subescalas, las puntuaciones obtenidas en los participantes que abandonaron el audífono son muy inferiores y cercanas a $0 \mathrm{y}$, por el contrario, las puntuaciones de las personas que continúan empleando el audífono tienen promedios cercanos a 2, por lo que se puede considerar que el impacto psicosocial percibido por el uso del audífono es mayor. Además, este resultados avala las cualidades predictivas de la escala PIADS y de sus tres dimensiones como constructos que puede contribuir a determinar en el futuro la probabilidad de abandono de un producto de apoyo. No obstante, este es un resultado preliminar y habría que realizar estudios a mayor escala sobre la relación del impacto psicosocial con el abandono de audífonos. 
Tabla 43.- Puntuación media de las subescalas competencia, adaptabilidad y autoestima por ítem (n=137).

\begin{tabular}{|c|c|c|c|c|}
\hline & Gafas auditivas & Inserción Profunda & Intracanal & Retroauricular \\
\hline Competencia & $\mathrm{N}=3,00$ & $\mathrm{~N}=1,00$ & $\mathrm{~N}=1,64$ & $\mathrm{~N}=1,65$ \\
\hline Felicidad & $\mathrm{N}=3,00$ & $\mathrm{~N}=1,60$ & $\mathrm{~N}=1,89$ & $\mathrm{~N}=1,72$ \\
\hline Independencia & $\mathrm{N}=3,00$ & $\mathrm{~N}=1,20$ & $\mathrm{~N}=1,31$ & $\mathrm{~N}=1,56$ \\
\hline $\begin{array}{l}\text { Sentirse a la altura de las } \\
\text { circunstancias }\end{array}$ & $\mathrm{N}=3,00$ & $\mathrm{~N}=1,20$ & $\mathrm{~N}=1,14$ & $\mathrm{~N}=1,26$ \\
\hline Confusión & $\mathrm{N}=-3,00$ & $\mathrm{~N}=-1,20$ & $\mathrm{~N}=-1,33$ & $\mathrm{~N}=-, 95$ \\
\hline Eficacia & $\mathrm{N}=3,00$ & $\mathrm{~N}=1,60$ & $\mathrm{~N}=1,36$ & $\mathrm{~N}=1,30$ \\
\hline Autoestima & $\mathrm{N}=3,00$ & $\mathrm{~N}=1,60$ & $\mathrm{~N}=1,69$ & $\mathrm{~N}=1,62$ \\
\hline Productividad & $\mathrm{N}=3,00$ & $\mathrm{~N}=, 80$ & $\mathrm{~N}=, 89$ & $\mathrm{~N}=, 99$ \\
\hline Seguridad & $\mathrm{N}=3,00$ & $\mathrm{~N}=1,40$ & $\mathrm{~N}=1,78$ & $\mathrm{~N}=1,91$ \\
\hline Frustración & $\mathrm{N}=-3,00$ & $\mathrm{~N}=-2,00$ & $\mathrm{~N}=-1,47$ & $\mathrm{~N}=-1,16$ \\
\hline Sentirse útil & $\mathrm{N}=3,00$ & $\mathrm{~N}=1,20$ & $\mathrm{~N}=1,36$ & $\mathrm{~N}=1,52$ \\
\hline Confianza en sí mismo & $\mathrm{N}=3,00$ & $\mathrm{~N}=1,00$ & $\mathrm{~N}=1,44$ & $\mathrm{~N}=1,57$ \\
\hline Pericia & $\mathrm{N}=2,50$ & $\mathrm{~N}=, 40$ & $\mathrm{~N}=, 83$ & $\mathrm{~N}=1,10$ \\
\hline Aptitud & $\mathrm{N}=2,00$ & $\mathrm{~N}=1,40$ & $\mathrm{~N}=1,36$ & $\mathrm{~N}=1,44$ \\
\hline Bienestar & $\mathrm{N}=3,00$ & $\mathrm{~N}=2,00$ & $\mathrm{~N}=1,89$ & $\mathrm{~N}=1,71$ \\
\hline Sentirse capaz & $\mathrm{N}=3,00$ & $\mathrm{~N}=1,80$ & $\mathrm{~N}=1,39$ & $\mathrm{~N}=1,49$ \\
\hline Calidad de vida & $\mathrm{N}=3,00$ & $\mathrm{~N}=2,40$ & $\mathrm{~N}=1,81$ & $\mathrm{~N}=1,81$ \\
\hline Realización & $\mathrm{N}=2,00$ & $\mathrm{~N}=1,20$ & $\mathrm{~N}=1,19$ & $\mathrm{~N}=1,33$ \\
\hline Sensación de poder & $\mathrm{N}=3,00$ & $\mathrm{~N}=, 60$ & $\mathrm{~N}=1,28$ & $\mathrm{~N}=1,30$ \\
\hline Sensación de control & $\mathrm{N}=2,50$ & $\mathrm{~N}=1,80$ & $\mathrm{~N}=1,08$ & $\mathrm{~N}=1,39$ \\
\hline Sentirse a disgusto & $\mathrm{N}=-3,00$ & $\mathrm{~N}=-1,40$ & $\mathrm{~N}=-, 44$ & $\mathrm{~N}=-, 53$ \\
\hline Dispuesto a darse oportunidades & $\mathrm{N}=2,50$ & $\mathrm{~N}=1,00$ & $\mathrm{~N}=, 97$ & $\mathrm{~N}=1,13$ \\
\hline Capacidad para participar & $\mathrm{N}=2,50$ & $\mathrm{~N}=1,00$ & $\mathrm{~N}=1,47$ & $\mathrm{~N}=1,72$ \\
\hline Deseoso de probar nuevas cosas & $\mathrm{N}=2,00$ & $\mathrm{~N}=1,20$ & $\mathrm{~N}=, 75$ & $\mathrm{~N}=, 94$ \\
\hline $\begin{array}{l}\text { Capacidad para adaptarse a las } \\
\text { actividades de la vida diaria }\end{array}$ & $\mathrm{N}=2,50$ & $\mathrm{~N}=1,00$ & $\mathrm{~N}=1,64$ & $\mathrm{~N}=1,76$ \\
\hline $\begin{array}{l}\text { Capacidad para aprovechar las } \\
\text { oportunidades }\end{array}$ & $\mathrm{N}=2,50$ & $\mathrm{~N}=1,40$ & $\mathrm{~N}=1,19$ & $\mathrm{~N}=1,31$ \\
\hline
\end{tabular}

En la anterior tabla podemos observar que el audífono tipo retroauricular ha presentado una mayor puntuación seguido del intracanal y por último, el de inserción profunda, aunque este último presentó una puntuación mayor en la subescala de autoestima esto puede deberse a la estética del mismo, puesto que, este tipo de audífonos no son visuales a simple vista y esto puede derivar un mayor autoestima en personas que no tengan aceptada su pérdida auditiva, por lo que en futuras investigaciones se debe de indagar sobre este aspecto Los ítems de la escala PIADS y de las diferentes subescalas que presentaron puntuaciones promedio mayores fueron: subescala de competencia en los ítems de competencia, eficacia, 
calidad de vida y aptitud; subescala de adaptabilidad en los ítems de bienestar, capacidad para adaptarse a las actividades diarias y felicidad; y por último, la subescala de autoestima los ítems con mayor puntuación fueron autoestima, seguridad y sensación de control

Tabla 44.- Puntuaciones promedio en la escala PIADS y sus tres subescalas por situaciones de uso (n=137)

\begin{tabular}{|c|c|c|c|c|c|}
\hline Situación & & PIADS & Competencia & Adaptabilidad & Autoestima \\
\hline \multirow[t]{2}{*}{$\begin{array}{l}\text { Hablar con amigos y/o } \\
\text { familiares }\end{array}$} & $\mathrm{Si}(\mathrm{n}=110)$ & 1,46 & 1,45 & 1,66 & 1,34 \\
\hline & No $(n=27)$ & 1,6 & 1,54 & 1,5 & 1,75 \\
\hline \multirow[t]{2}{*}{ Asuntos laborales } & $\mathrm{Si}(\mathrm{n}=30)$ & 2 & 1,89 & 2,1 & 2,1 \\
\hline & No $(n=107)$ & 1,42 & 1,4 & 1,6 & 1,3 \\
\hline \multirow[t]{2}{*}{ Asuntos educativos } & Sí (n= 39) & 1,9 & 1,95 & 2,24 & 1,55 \\
\hline & No $(n=98)$ & 1,34 & 1,3 & 1,5 & 1,3 \\
\hline \multirow[t]{2}{*}{ Servicios sanitarios } & Sí (n=113) & 1,52 & 1,52 & 1,72 & 1,4 \\
\hline & No $(n=24)$ & 0,69 & 0,54 & 0,67 & 0,94 \\
\hline \multirow[t]{2}{*}{ Actividades de ocio } & Sí $(n=110)$ & 1,44 & 1,41 & 1,64 & 1,33 \\
\hline & No $(n=27)$ & 2,54 & 2,75 & 2 & 2,63 \\
\hline \multirow[t]{2}{*}{ Otros } & Sí (n= 21) & 2,42 & 2,25 & 2,83 & 2,38 \\
\hline & No $(n=116)$ & 1,44 & 1,43 & 1,61 & 1,33 \\
\hline
\end{tabular}

En la anterior tabla podemos observar que parece existir una diferencia en el impacto psicosocial percibido por los usuarios de audífonos en función de la situación de uso, siendo las situaciones de uso con una puntuación más favorable las relaciones con asuntos laborales 
y educativos. Sin embargo parece que en lo referente a las actividades de ocio las personas que emplean el audífono tienen una puntuación menor.

También resultaba de interés comprobar si había diferencias en el impacto psicosocial en función de la frecuencia de uso del audífono. En la siguiente tabla se muestran dichos resultados.

Tabla 45.- Puntuaciones medias en la escala PIADS y sus tres subescalas en función de la frecuencia de uso (n=137)

\begin{tabular}{cccc}
\hline Escala & \multicolumn{2}{c}{ Frecuencia de uso } \\
PIADS & Todos los días & Semanalmente & Mensualmente \\
\hline Global PIADS & 1,62 & 0,19 & 0,22 \\
Competencia & 1,57 & 0,21 & 0,39 \\
Adaptabilidad & 1,60 & 0,44 & 0,37 \\
Autoestima & 1,71 & $-0,3$ & $-0,14$ \\
\hline
\end{tabular}

Tal y como se observa en la anterior tabla las personas que emplean con mayor frecuencia de uso el producto de apoyo obtienen una mayor puntuación respecto a las personas que lo emplean con una frecuencia semanal y mensual. Cabe señalar que en las personas que no lo emplean a diario en la subescala de autoestima obtuvieron una puntuación negativa de lo que se deriva un impacto negativo.

Tabla 46.- Puntuaciones medias en la escala PIADS y sus tres subescalas en función del tipo de audífono y la frecuencia de uso $(n=137)$

\begin{tabular}{|c|c|c|c|c|c|c|c|c|c|c|c|c|c|c|c|}
\hline & Gaf & $s$ auc & ivas & & ción Pr & unda & & Intracan & & & Petaca & & & etroaricul & \\
\hline & $\begin{array}{l}\text { Todos } \\
\text { los } \\
\text { días }\end{array}$ & $\begin{array}{l}\text { Se } \\
\text { ma } \\
\text { nal } \\
\text { me } \\
\text { nte }\end{array}$ & $\begin{array}{l}\text { Mens } \\
\text { ualme } \\
\text { nte }\end{array}$ & $\begin{array}{l}\text { Todos } \\
\text { los } \\
\text { días }\end{array}$ & $\begin{array}{l}\text { Sema } \\
\text { nalme } \\
\text { nte }\end{array}$ & $\begin{array}{l}\text { Mensual } \\
\text { mente }\end{array}$ & $\begin{array}{l}\text { Todos } \\
\text { los } \\
\text { días }\end{array}$ & $\begin{array}{l}\text { Semanal } \\
\text { mente }\end{array}$ & $\begin{array}{l}\text { Mensual } \\
\text { mente }\end{array}$ & $\begin{array}{l}\text { Todos } \\
\text { los } \\
\text { días }\end{array}$ & $\begin{array}{l}\text { Sema } \\
\text { nalme } \\
\text { nte }\end{array}$ & $\begin{array}{l}\text { Mensual } \\
\text { mente }\end{array}$ & $\begin{array}{l}\text { Todos } \\
\text { los días }\end{array}$ & $\begin{array}{l}\text { Semanal } \\
\text { mente }\end{array}$ & $\begin{array}{l}\text { Mensual } \\
\text { mente }\end{array}$ \\
\hline 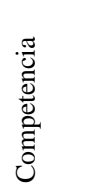 & 2,8 & - & - & 1,28 & - & - & 1,55 & 0,14 & 0,3 & 1,33 & - & - & 1,58 & 0,23 & 0,15 \\
\hline 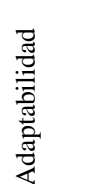 & 2,5 & - & - & 1,27 & - & - & 1,6 & 0,11 & 0,3 & 1,5 & - & - & 1,6 & 0,53 & 0,3 \\
\hline 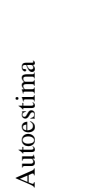 & 2,9 & - & - & 1,4 & - & - & 1,8 & 0,04 & $-0,16$ & 1,88 & - & - & 1,66 & $-0,05$ & $-0,06$ \\
\hline PIADS & 2,77 & - & - & 1,32 & - & - & 1,65 & 0,1 & 0,18 & 1,54 & - & - & 1,6 & 0,21 & 0,11 \\
\hline
\end{tabular}


La anterior tabla nos muestra las diferencias en las puntuaciones de la escala PIADS y sus tres subescalas en función tanto de la frecuencia de uso como por tipo de audífono. Se puede observar que para todos los tipos de audífono (aunque no hay otra frecuencia diferente al uso de todos los días para las gafas auditivas como para el de inserción profunda y el de tipo petaca), las personas que lo emplean con una frecuencia diaria obtienen un impacto mayor respecto a las que lo emplean de manera semanal o mensual.

\section{Discusión y Conclusiones}

Los resultados de este estudio alientan el uso de productos de apoyo de amplificación dado que, globalmente, los diferentes tipos de audífonos conducen a resultados de impacto psicosocial positivo tanto en la escala global como en sus tres subescalas. Así, al igual que en estudios anteriores, se deriva un alto nivel de satisfacción y mejora de la calidad de vida (Billari, 2009; Jutai \& Saunders, 2003) por el uso de audífonos. De igual modo, se verifica una mejora de la autoestima derivada de su uso (Boi et al., 2012).

En segundo lugar, la escala PIADS ofrece ventajas para mejorar la prescripción y el seguimiento en la evaluación de audífonos, y los resultados señalan que podría ser un instrumento sensible a diferentes tipos de audífonos (Jutai \& Day, 1999). En este sentido, el tipo de audífono que obtuvo una puntuación mayor fueron las gafas auditivas, seguido del audífono tipo retroauricular no obstante este dato no es extrapolable a la población en general española puesto que la muestra era muy reducida.

No se verificaron diferencias estadísticamente significativas respecto a variables demográficas y el impacto psicosocial tales como género, edad, nivel de estudios, tipo y momento de la pérdida al igual que en otros estudios previos (Cox et al., 2000; Solheim, Kværner, \& Falkenberg, 2011). Pero si se verificaron diferencias en las puntuaciones promedio de respuestas positivas y negativas del cuestionario SOTU-C, entre las cuales cabe destacar que existe un mayor promedio de respuestas positivas en el uso de nuevas tecnologías en hombres que mujeres, además parece existir una diferencia en cuanto a la lengua de uso ya que las personas usuarias de lengua de signos tienen puntuaciones más positivas que las personas usuarias de lengua oral. Paralelamente parece subyacer una diferencia con el tipo y momento de pérdida siendo las personas con una pérdida prelocutiva . 
En cuanto a la frecuencia de uso, al igual que en el estudio de Jutai \& Day (1999), los resultados muestran que a mayor frecuencia de uso también se obtiene una puntuación de impacto psicosocial más positiva. Así mismo, las puntuaciones en el presente estudio son similares a las encontradas por estos autores, y aunque globalmente se observe una puntuación positiva, coincide que la subescala de autoestima obtuvo una puntuación menor respecto a las subescalas de competencia y adaptabilidad. Lo mismo sucede en las puntuaciones obtenidas del abandono del PA en la subescala de autoestima, aunque en otros estudios, el uso no regular de los audífonos o abandono se asoció significativamente con la edad, género, lengua, tipo de audífono y dificultad de uso (Bertoli, 2009) y en el presente estudio no se verificaron estas relaciones.

Las personas que emplean el audífono de forma diaria obtuvieron puntuaciones más altas respecto a las personas que lo empleaban semanalmente y mensualmente, al igual que se ha encontrado en otros estudios realizados únicamente con personas mayores (e.g., Williger \& Lang, 2015). El impacto psicosocial se ve afectado por las situaciones de uso de los diferentes audífonos. Así, las personas usuarias de audífonos perciben un mayor impacto psicosocial derivado de estos productos cuando lo emplean en situaciones laborales, educativas y/o sanitarias. Sin embargo, las personas usuarias de estos PA perciben un menor impacto empleando el producto en situaciones donde se realicen actividades de ocio o hablar con amigos y/o familiares, este tipo de conclusiones ya se habían recogido en otros estudios (Cox \& Alexander, 1995; Dillon, 2001).

También se han verificado diferencias en el uso de tecnologías respecto a la edad, existiendo una relación en la que menor edad existe un mayor número de respuestas positivas en experiencias y uso en tecnologías. Existe poca investigación en lo referente al impacto en el uso de nuevas tecnologías como ordenadores y otro tipo de hardware afines como las tabletas en personas que presentan déficit auditivo. Es por ello que en futuras investigaciones debe de indagarse si la discapacidad auditiva puede influir en el uso de estos dispositivos (Henshaw, Clark, Kang, \& Ferguson, 2012).

Por último, entre las principales conclusiones que pueden derivarse en este estudio, cabe resaltar que la escala PIADS es suficientemente sensible para realizar una evaluación subjetiva y clínicamente útil para el uso de audífonos, al igual que concluyeron otros estudios ya mencionados. Paralelamente, desde el punto de vista del impacto psicosocial, cabe mencionar que tanto las gafas auditivas como los audífonos tipo retroauricular son los más 
recomendables en este colectivo, frente a los intracanales y los de inserción profunda, a pesar de que son los más empleados.

Entre las limitaciones que presenta este estudio, destacamos el reducido número de participantes, además de que algunos productos, como las gafas auditivas, son empleadas únicamente por dos participantes, por lo que los resultados obtenidos difícilmente pueden generalizarse más allá de la muestra.

Respecto a las futuras líneas de investigación, se destacan las relativas a la evaluación con medidas de resultados durante todo el proceso de selección y adquisición del producto. Así mismo, sería adecuado realizar un estudio a nivel nacional sobre los factores de abandono o falta de uso de audífonos. Y también se deberían realizar estudios que avalen el uso de los audífonos de alta gama y realizar un análisis coste-beneficio teniendo en cuenta las variables personales relacionadas con la adquisición y uso del audífono, por ejemplo, mediante estudios longitudinales. Además, se debería estudiar el efecto del audífono en el estado de ánimo, calidad de vida y carga del cuidador, en el caso que fuera necesario.

Existen consecuencias en el desempeño de las AVD y en la participación derivados de la pérdida auditiva y hay una gran prevalencia de la misma en personas mayores. Los resultados indican que los aspectos psicosociales deben ser enfatizados y evaluados como parte natural en los procesos de recomendación de productos de apoyo. Son varios los factores personales y ambientales que limitan el funcionamiento y desempeño de las AVD, y por ello es importante realizar una correcta evaluación del audífono, entrenar en su uso, tener en cuenta la opinión, necesidades y actividades típicas del usuario así como emparejarlo con sus necesidades. Si no se realiza una correcta evaluación, los usuarios no usarán con frecuencia el audífono o lo terminarán por abandonar, negándose a sí mismos los beneficios comprobados en comunicación, participación social y la satisfacción vital en general. Willigan \& Lang (2015) concluyeron que los audífonos ayudan al desempeño de las personas en distintos contextos y que el éxito de la ayuda depende de cómo esta ayude a manejar las AVD, por lo que el uso de audífonos es recomendable a personas que presenten déficit auditivo y tengan resto auditivo, aunque todavía se requiera más investigación para mejorar su funcionamiento. Dado que la pérdida de audición tiene un fuerte impacto en la comunicación y en el funcionamiento diario de las personas con déficit auditivo, consideramos que todos los resultados obtenidos en este estudio son de claro interés. 


\section{Estudio 3. Impacto psicosocial derivado del uso de implante coclear}

\section{Introducción}

El implante coclear (IC) ha sido uno de los PA más investigados en los últimos años, debido, sobre todo, a su capacidad para mejorar la audición de personas con pérdidas auditivas profundas y prelocutivas. Aunque la temática más investigada en relación a los IC han sido las medidas de resultados en el ámbito estrictamente audiológico, también se han abordado otras, como por ejemplo su repercusión en el ámbito educativo o sus efectos sobre las capacidades de lectoescritura. En el caso de medidas de resultados sobre el impacto psicosocial derivado del uso de implante cocleares, también hay algunas investigaciones de interés; principalmente, trabajos sobre el ajuste psicosocial necesario para su uso, así como trabajos que buscan relacionar su uso con el aumento de la calidad de vida, participación social y estatus funcional (Knutson, Johnson, \& Murray, 2006; Scheetz, 2004). En cualquier caso, en España existe muy poca investigación al respecto. En nuestro país la mayoría de implantados son niños y jóvenes pero son pocos los adultos mayores que reciben este producto. Y es por este motivo que la investigación centrada en medidas de resultados en población mayor y el uso de implantes cocleares es necesaria, tanto para analizar los costesbeneficios derivados del uso del producto (e.g., Eshraghi et al., 2009), como para evaluar el efecto negativo que tiene la pérdida auditiva en la calidad de vida y otros aspectos psicosociales. Principalmente, dado el escenario en el que la esperanza de vida ha aumentado notablemente y son muchas las personas mayores en nuestro país que presentan pérdida auditiva y presbiacusia.

En la literatura científica encontramos evidencia de que existe una mejora en ámbito psicosocial derivada del uso de IC (Fagan, Pisoni, Horn \& Dillon, 2007; Geers, 2006; Spencer \& Marschark, 2003; Wheeler, Archbold, Gregory \& Skipp, 2007). No obstante, no hay estudios que evalúen este impacto empleando instrumentos específicos de evaluación de medidas de resultados en PA y, por ello, el objetivo principal de este estudio es indagar sobre el impacto psicosocial derivado del uso del IC, empleando el instrumento PIADS, tal y como hemos realizado en los dos anteriores estudios. Cabe señalar que el PIADS sí ha sido empleado en estudios de audífonos y de SIV. Sin embargo, no hay estudios con IC y la escala PIADS, por lo que este estudio será una aportación novedosa y de interés al campo las medidas de resultados con PA para personas con discapacidad auditiva. Además, en nuestro 
país tampoco hemos encontrado estudios que indaguen sobre el impacto psicosocial de los PA en personas adultas mayores.

La literatura sugiere que el impacto psicosocial puede verse alterado por el tipo de pérdida (prelocutiva o postlocutiva), el grado de pérdida (Caposecco, Hickson, \& Pedley, 2012; Hallam et al., 2006), el nivel académico (Leigh \& Stinson, 1991; Stinson \& Lang, 1994; Stinson \& Whitmire, 1992; Stinson, Whitmire \& Kluwin, 1996), el tiempo de implantación (siendo mayor impacto psicosocial positivo en los primeros meses) (Klop et al., 2008) y la edad avanzada (como se trató en el capítulo tres en el apartado del IC la mayoría de implantados son niños) (Chatelin et al., 2004; Francis et al., 2002; Vermeire et al., 2005; ) o durante la adolescencia (Chatelin et al., 2004; Francis et al., 2002; Vermeire et al., 2005; Francis et al., 2002). Por ello, en este estudio se pretende verificar si todas estas variables también tienen importancia en el caso de una población de usuarios de IC española

Así mismo, entre los beneficios del IC se encuentra la mejora en el desempeño de AVD, tanto instrumentales como avanzadas (Clinkard et al., 2011), y la mejora en el uso de sistemas de comunicación y nuevas tecnologías como televisores, reproductores de música o móviles (Spencer \& Marschank, 2003; Zhao et al., 2008). Por este motivo, se ha empleado el instrumento SOTU-C para evaluar la predisposición al uso de nuevas tecnologías por parte de personas implantadas y analizar el impacto psicosocial en función del perfil de uso de tecnologías.

\section{Método}

\section{Participantes}

El trabajo se ha realizado en la asociación de personas postlocutivas de Salamanca (SADAP). Por lo que el ámbito de aplicación de este trabajo se extiende a personas usuarias de IC y residentes en Salamanca.

Se optó por establecer un conjunto de criterios de inclusión y exclusión con el objeto de optimizar la homogeneidad de la muestra. 
Criterios de inclusión:

- Personas con un diagnóstico de pérdida auditiva

- Personas afectadas mayores de 18 años.

- Personas afectadas que tengan/utilicen implante coclear.

- Personas con un lengua oral y/o lengua de signos.

- Personas que hayan dado su consentimiento a participar en el mismo.

Criterios de exclusión:

- Personas con un diagnóstico adicional a la pérdida auditiva.

- Personas afectadas por pérdida auditiva menores de 18 años.

- Personas que, cumpliendo los criterios de inclusión y habiendo recibido una completa información sobre el estudio, no deseen participar en el mismo

Una vez definidos los criterios de inclusión, fueron excluidos dos participantes, por ser menores de edad. Posteriormente, se contactó de manera presencial con los profesionales para ofrecerles una información detallada del estudio y de los objetivos del mismo y solicitar la colaboración. Si la respuesta era afirmativa se proponían fechas para aplicar los instrumentos de forma presencial. La aplicación se llevó a cabo en el servicio de logopedia de la UPSA, en centros de trabajo y en la asociación SADAP.

Finalmente la muestra quedó formada por 30 personas, 21 mujeres y 9 hombres, con una edad media de 50,10 años $(S D=21,63)$. En la siguiente tabla se resumen las principales características demográficas de los participantes. 
Tabla 47. Perfil Sociodemográfico de personas adultas con discapacidad auditiva usuarias de implante coclear estudio $3(n=30)$

\begin{tabular}{ll}
\hline VARIABLE & $\mathrm{N}(\%)$ \\
\hline Edad & $M=50,10 ; S D=21,634$ \\
Género & $9(30,0)$ \\
Varón & $21(70,0)$ \\
Mujer & \\
Lengua & $1(3,3)$ \\
Lengua de signos & $20(66,7)$ \\
Lengua oral & $9(30,0)$ \\
Ambas & $5(16,7)$ \\
Zona residencial & $25(83,3)$ \\
Rural & $14(46,7)$ \\
Urbano & $16(53,3)$ \\
Momento pérdida & $12(40,0)$ \\
Prelocutivo & $18(60,0)$ \\
Postlocutivo & $8(26,7)$ \\
Tipo de pérdida (Oído izquierdo) & $22(73,3)$ \\
Hipoacusia & \\
Cofósis & $19(63,3)$ \\
Tipo de pérdida (Oído derecho) & $1(3,3)$ \\
Hipoacusia & $3(10,0)$ \\
Cofosis & $2(6,7)$ \\
Nivel de estudios & $3(10,0)$ \\
Elemental & $2(6,7)$ \\
Bachillerato & $0(0,0)$ \\
Ciclo grado medio & \\
Ciclo grado superior & \\
Universidad & \\
Máster & \\
Otros & \\
&
\end{tabular}

Todas las personas participantes recibieron información detallada sobre las características del estudio y tuvieron que firmar un consentimiento informado (véase Anexo V) según modelo del Comité de Bioética de la Universidad de Salamanca.

\section{Instrumentos}

Los instrumentos empleados en este estudio son los mismos que los utilizados y descritos en el estudio 1.

\section{Procedimiento}

El proceso de recogida de datos se ha realizado con la aplicación del cuestionario sociodemográfico propio, el PIADS y el cuestionario SOTU-C perteneciente al MPT. Estos instrumentos tienen una aplicabilidad de evaluación que permiten que sean administrados a través de entrevista personal o telefónica y de forma auto-administrada con las indicaciones 
adecuadas debido a las características de los usuarios se determinó realizarla por entrevista individual.

La duración del estudio en cuanto al trabajo de campo (realización de las entrevistas, aplicación de los cuestionarios y recogida de datos) se extendió por un total de 10 meses.

El diseño planteado es un diseño no experimental transversal correlacional

\section{Resultados}

A medida que se realizaron las entrevistas, éstas eran incorporadas a una hoja de registro. Los análisis estadísticos posteriores se llevaron a cabo con el software libre $\mathrm{R}$ y con SPSS. Se utilizó un nivel alfa de 0,05 para todos los contrastes estadísticos.

La mayoría de los participantes manifestaron utilizar varias tecnologías distintas de manera habitual. Entre las tecnologías más utilizadas se encuentra el teléfono móvil (86.7\%), ordenador de sobremesa (56.7\%), ordenador portátil (36.7\%), tableta (43.3\%), videojuegos tipo Xbox (13.3\%), cajero automático (20\%), PDA (3.3\%), sistemas de intermediación por vídeo $(3.3 \%)$ y otros software específicos $(3.3 \%)$. Cabe destacar, que un total de 5 participantes utilizan los audífonos de forma simultánea junto al implante coclear. Respecto al uso de tecnologías, las puntuaciones del cuestionario SOTU-C mostraron que los participantes de este estudio se caracterizaban por tener muchas más experiencias positivas con las tecnologías que experiencias negativas o neutras $[F(2,58)=31,14 ; p<, 001]$. Un análisis correlacional mostró, además, que existía una relación positiva de carácter moderado entre el impacto en adaptabilidad y las respuestas positivas en el apartado de características personales/sociales ( $r$ $=, 39 ; p<, 05)$. Igualmente, se verificó una relación negativa de carácter moderado entre la edad de los participantes y las dimensiones de perspectivas en tecnologías $(r=-, 58 ; p<, 001)$, actividades típicas $(r=-, 50 ; p<, 001)$ y características personales/sociales $(r=-, 56 ; p<, 01)$. 
Tabla 48.- Puntuaciones promedio positivas y negativas del instrumento SOTU-C en función de variable sociodemográficas.

\begin{tabular}{llcc}
\hline Variable & Clasificación & SOTU-C POSITIVAS & SOTU-C NEGATIVAS \\
\hline Sociodemográfica & & & 6,48 \\
& Mujer & 17,95 & 6,44 \\
Momento de la pérdida & Varón & 19,78 & 9,69 \\
& Postlocutivo & 14,50 & 2,79 \\
Lengua empleada & Prelocutivo & 23,07 & 5,66 \\
& Ambas lenguas & 19,67 & 6,08 \\
Zona de residencia & Lengua de signos & 15,75 & 3,00 \\
& Rural & 21,40 & 7,16 \\
Nivel de estudios & Urbano & 17,92 & 8 \\
& Elemental & 17,11 & 6 \\
& Ciclo Grado Medio & 19,67 & 2,5 \\
& Ciclo Grado Superior & 22,00 & 9 \\
& Bachillerato & 19 & 0 \\
& Otros & 28,5 & 3,33 \\
\hline
\end{tabular}

Tabla 49.- Puntuaciones medias obtenidas en el cuestionario SOTU-C en función de la edad ( $\mathrm{n}=30$ )

\begin{tabular}{lccc}
\hline APARTADO DEL CUESTIONARIO SOTU-C & \multicolumn{2}{c}{ EDAD } \\
\hline Experiencias globlales con las tecnologías utilizadas._POSITIVAS & 3,91 & 2,42 & $78-98$ años \\
Experiencias globlales con las tecnologías utilizadas & 0,27 & 0,42 & 0,40 \\
_NEGATIVAS & & $40-77$ años & 1,86 \\
Perspectivas sobre tecnologías_POSITIVAS & 5,55 & 2,97 & 3,82 \\
Perspectivas sobre tecnologías_NEGATIVAS & 1,36 & 2,19 & 1,80 \\
Actividades típicas_POSITIVAS & 2,36 & 2 & 1,69 \\
Actividades típicas_NEGATIVAS & 0,27 & 1,16 & 7,33 \\
Algunas características personales/sociales_POSITIVAS & 8,91 & 7,61 & 4,32 \\
Algunas características personales/sociales_NEGATIVAS & 0,64 & 3,39 & 12,80 \\
SOTU GLOBAL_POSITIVAS & 20,73 & 15,00 & 10,23 \\
SOTU_GLOBAL_NEGATIVO & 2,55 & 7,16 & \\
\hline
\end{tabular}

Respecto a la puntuaciones de impacto psicosocial, tanto la puntuación global $(M=$ $1,47)$ como las puntuaciones de las subescalas de competencia $(M=1,45)$, Adaptabilidad $(M=$ $1,65)$ y Autoestima $(M=1,37)$ mostraron valores mayores de cero, mostrando que el uso de IC se asocia a un impacto psicosocial positivo. Aunque se observó una puntuación ligeramente mayor en la dimensión de adaptabilidad, un análisis de varianza intrasujeto mostró que no existía ninguna diferencia entre las puntuaciones de las 3 subescalas de PIADS $[F(2,58)=$ $2,37 ; p=, 10]$. 
Tabla 50.- Puntuaciones medias en la escala PIADS y su tres subescalas en usuarios de IC ( $\mathrm{n}=\mathbf{3 0}$ )

\begin{tabular}{ccccc}
\hline & COMPETENCIA & ADAPTABILIDAD & AUTOESTIMA & PIADS TOTAL \\
\hline $\mathrm{M}(S D)$ & $1,45(1,16)$ & $1,65(1,15)$ & $1,37(1,28)$ & $1,47(1,13)$ \\
\hline
\end{tabular}

Para responder a la preguntas de si existen o no diferencias en el impacto psicosocial percibido de los usuarios de implante coclear según sus características personales se llevaron a cabo análisis de varianza mixtos con las subescalas de PIADS como factor intrasujeto y distintas variables como factor entre-sujetos. Ninguna de las variables mostró efectos significativos de grupo o interacciones mostrando, por tanto, que el impacto parece ser independiente de distintas características como el género (hombre y mujer), el momento de adquisición de la discapacidad auditiva (precolutivo vs postlocutivo), el tipo de pérdida (hipoacusia vs cofosis), la edad, el tiempo de implantación o el nivel estudios (elemental, bachillerato, ciclo grado medio, ciclo grado superior, universidad y otros).

Tabla 51.- Puntuaciones promedio de la escala PIADS y sus tres subescalas en función de variables sociodemográficas $(\mathrm{n}=\mathbf{3 0})$

\begin{tabular}{llllll}
\hline Variable & Tipo & PIADS TOTAL & Competencia & Adaptabilidad & Autoestima \\
\hline Género & Hombre & 1,31 & 1,23 & 1,57 & 1,24 \\
\multirow{2}{*}{ Lengua } & Mujer & 1,54 & 1,55 & 1,68 & 1,43 \\
& Lengua de signos & $-0,96$ & $-1,08$ & $-0,33$ & $-1,25$ \\
\multirow{2}{*}{ Momento de la pérdida } & Lengua oral & 1,64 & 1,60 & 1,81 & 1,58 \\
& Ambas lenguas & 1,37 & 1,40 & 1,52 & 1,21 \\
Zona de residencia & Prelocutivo & 1,34 & 1,30 & 1,39 & 1,37 \\
& Rural & 1,62 & 1,62 & 1,95 & 1,38 \\
& Urbano & 1,69 & 1,75 & 1,97 & 1,40 \\
& Elemental & 1,43 & 1,39 & 1,59 & 1,37 \\
& Ciclo Grado Medio & 0,95 & 1,31 & 1,44 & 1,28 \\
\multirow{2}{*}{ Nivel de estudios } & Bachillerato & 2,77 & 0,75 & 1,44 & 0,88 \\
& Ciclo Grado Superior & 1,75 & 2,75 & 3 & 2,63 \\
& Universidad & 2,17 & 1,92 & 2 & 1,31 \\
\hline
\end{tabular}

Al igual que en los estudio 1 y 2 , también se calcularon los promedios de todos los ítems de la escala PIADS. Tal y como muestra la tabla 51, los ítems que presentaron una mayor puntuación fueron la subescala de competencia; calidad de vida, competencia, independencia y sentirse útil siendo los ítems de productividad y pericia positivos pero con una menor puntuación promedio; en la subescala de adaptabilidad los ítems con mayor puntuación fueron bienestar, dispuesto a darse oportunidades y capacidad para participar y el 
ítem con menor puntuación aunque positiva deseoso de probar cosas nuevas. En cuanto a la subescala de autoestima los ítems que presentaron una puntuación mayor fueron confianza en sí mismo, autoestima y felicidad y, los que obtuvieron una menor puntuación aun siendo esta positiva se encuentra la sensación de control.

Tabla 52.- Puntuaciones promedio de los ítems de la escala PIADS ( $\mathrm{n}=30$ )

\begin{tabular}{ll}
\hline Items escala PIADS & Implante Coclear \\
\hline Competencia & $\mathrm{N}=1,60$ \\
Felicidad & $\mathrm{N}=1,83$ \\
Independencia & $\mathrm{N}=1,73$ \\
Sentirse a la altura de las & $\mathrm{N}=1,27$ \\
circunstancias & $\mathrm{N}=-0,50$ \\
Confusión & $\mathrm{N}=1,37$ \\
Eficacia & $\mathrm{N}=1,77$ \\
Autoestima & $\mathrm{N}=1,23$ \\
Productividad & $\mathrm{N}=1,50$ \\
Seguridad & $\mathrm{N}=-0,20$ \\
Frustración & $\mathrm{N}=1,50$ \\
Sentirse útil & $\mathrm{N}=1,93$ \\
Confianza en sí mismo & $\mathrm{N}=1,20$ \\
Pericia & $\mathrm{N}=1,53$ \\
Aptitud & $\mathrm{N}=1,97$ \\
Bienestar & $\mathrm{N}=1,73$ \\
Sentirse capaz & $\mathrm{N}=2,10$ \\
Calidad de vida & $\mathrm{N}=1,67$ \\
Realización & $\mathrm{N}=1,57$ \\
Sensación de poder & $\mathrm{N}=1,23$ \\
Sensación de control & $\mathrm{N}=-0,93$ \\
Sentirse a disgusto & $\mathrm{N}=1,77$ \\
Dispuesto a darse oportunidades & $\mathrm{N}=1,77$ \\
Capacidad para participar & $\mathrm{N}=1,23$ \\
Deseoso de probar nuevas cosas & $\mathrm{N}=1,63$ \\
Capacidad para adaptarse a las & \\
actividades de la vida diaria & $\mathrm{N}=1,53$ \\
Capacidad para aprovechar las & \\
oportunidades &
\end{tabular}

Otra variable de interés que podría tener relación con el impacto psicosocial es el tiempo pasado desde la implantación. En la tabla siguiente se muestran los promedios en PIADS en función del tiempo de implantación transcurrido tras el proceso quirúrgico de implantación.

Tabla 53. Puntuaciones medias en las tres subescalas pertenecientes a la escala PIADS en función del tiempo de implantación.

\begin{tabular}{llll}
\hline & \multicolumn{3}{c}{ Tiempo de Implantación } \\
\cline { 2 - 4 } PIADS & De 1 a 4 años & De 5 a 10 años & Más de 10 años \\
Competencia & 1,05 & 2,14 & 1,26 \\
Adaptabilidad & 1,18 & 2,5 & 1,36 \\
Autoestima & 1,24 & 1,85 & 1,10 \\
\hline
\end{tabular}

Finalmente, como modo de indagar sobre el abandono de los implantes cocleares, un año después de realizar la encuesta inicial se contactó de nuevo con todos los participantes 
para preguntar si seguían o no utilizando el audífono. En un total de 6 casos el implante coclear había sido abandonado.

Para comprobar las diferencias en función de variables de interés tales como la edad, género, tipo de pérdida, momento de la pérdida, años implantados, nivel de estudios, estado civil y si el participantes terminó por abandonar el IC, se llevaron a cabo MANOVAS mediante pruebas post-hoc.

Tabla 54.- Puntuaciones medias obtenidas en la escala PIADS y su tres subescalas en función si el participante abandono o no el I.C $(n=30)$

\begin{tabular}{lrrrr}
\hline & $\begin{array}{c}\text { COMPETENCIA } \\
\mathrm{M}(S D)\end{array}$ & $\begin{array}{c}\text { ADAPTABILIDA } \\
\mathrm{D}\end{array}$ & $\begin{array}{c}\text { AUTOESTIMA } \\
\mathrm{M}(S D)\end{array}$ & $\begin{array}{c}\text { PIADS_TOTAL } \\
\mathrm{M}(S D)\end{array}$ \\
\cline { 2 - 5 } No abandono $(\mathrm{N}=24)$ & $1,66(1)$ & $1,83(1,05)$ & $1,62(1,1)$ & $1,69(0,96)$ \\
Si abandono $(\mathrm{N}=6)$ & $-0,44(0,55)$ & $0(0,44)$ & $-0,83(0,62)$ & $-0,46(0,50)$ \\
\hline
\end{tabular}

En la anterior tabla se puede observar las puntuaciones tanto en la escala global del PIADS como sus tres subescalas en función del abandono o no del I.C. Así mismo, podemos observar que las puntuaciones obtenidas tanto en la escala global del PIADS como sus tres subescalas para las personas que abandonaron el producto fueron negativas o cercanas a cero (en el caso de la subescala de adaptabilidad).

En estos resultados se puede percibir que el impacto psicosocial percibido por las personas usuarias de IC puede verse modificado por factores y características sociales y personales. Por poner algún ejemplo, entre los participantes de este estudio las personas usuarias de lengua oral con un tipo de pérdida prelocutiva obtuvieron un mayor impacto positivo. Por otra parte, en las personas que no abandonaron el IC este (en función de los ítems de la escala PIADS) tiene un impacto más positivo en la calidad de vida, confianza en sí mismos, autoestima, felicidad, independencia y capacidad para adaptarse a las AVD. 


\section{Discusión y Conclusiones}

El uso de IC se asocia con una alta satisfacción con el mismo, mejora en la calidad de vida y aumento en el bienestar psicológico. Y ello queda reflejado tanto en la puntuación global del PIADS como en sus tres subescalas, que muestran un impacto psicosocial positivo (Huarte, Lezaun, \& Manrique, 2014; Olze et al., 2011; Park et al., 2011; Rembar, Lind, Arnesen, \& Helvik, 2009; Spencer, Tomblin, \& Gantz, 2012).

En estudios anteriores ya se había demostrado el beneficio psicológico de los IC, aunque algunos resultados indicaban que existen diferencias según estado civil, tipo y grado de sordera, y participación en actividades. En el estudio actual no se encontraron diferencias significativas en lo referente a factores personales y sociodemográficos, salvo en el apartado de uso y experiencias con las tecnologías en los que existen diferencias en cuanto a la edad de los participantes (a menor edad hay un mayor número de respuestas positivas) y en lo referente a las actividades típicas de los participantes. Del mismo modo, estudios previos asociaban mayor aumento en la calidad de vida a una menor duración de la sordera y un mayor nivel educativo (Klop et al., 2008) pero estos resultados no fueron obtenidos de manera significativa con nuestros participantes. En el estudio llevado a cabo por Klop et al. (2008) concluyeron que el impacto psicosocial era mayor a partir de los 4 años, resultados que también se ha observado en el presente estudio. Por otra parte, al igual que en otros estudios (e.g., Clinkard et al., 2011; Di Nardo et al., 2014; Zhao, Bai, \& Stephens, 2008), en el presente estudio se ha encontrado evidencia de que personas de edad más avanzada pueden beneficiarse de este tipo de productos, tanto en la mejora de la calidad de vida como en el éxito de ejecución de actividades de la vida diaria tales como las actividades instrumentales de la vida diaria donde se encuentra el uso del teléfono (o actividades avanzadas como ocio entre las que se observa disfrute de la música u visualización de programas.

Respecto a la capacidad de PIADS para predecir el abandono, recordemos que fueron 6 los participantes que abandonaron el producto una vez finalizada la recogida de datos, y los resultados obtenidos gracias a este instrumento fueron negativos o cercanos a cero por lo que el PIADS es efectivo en la predicción de abandono de estos dispositivos. Este abandono puede estar causado por múltiples motivos tales como: una visión negativa hacia el producto, la no aceptación de la discapacidad, el mal funcionamiento, un entrenamiento insuficiente, etc. No debemos olvidar que la cirugía del IC es un acontecimiento estresante, en el que se debería tener en cuenta la opinión de la persona, sus expectativas, el sistema de comunicación 
elegido, el estigma asociado a su uso e intereses personales (Bell, 2005). No obstante, dada las puntuaciones positivas en la escala PIADS y sus tres subescalas, el IC es un producto adecuado para esta población tanto las puntuaciones generales como las obtenidas por ítems obtuvieron puntuaciones positivas en la calidad de vida, competencia, independencia, bienestar, autoestima y confianza en sí mismo por lo que, aunque los resultados no son extrapolables a la población sorda en general sí que nos da una idea aproximada para recomendar la implantación en personas sordas adultas.

Consideramos, al igual que Claesen y Pryce (2012), que conocer las necesidades psicosociales de las personas que buscan PA para la pérdida de audición es una prioridad y los equipos multidisciplinares deben prestar atención tanto a las demandas audiológicas como a las psicosociales, porque son varias las consecuencias que se derivan de una evaluación insuficiente como el abandono del producto o que este no conduzca a mejoras sustanciales de la calidad de vida. El IC permite la mejora de la comunicación pero hay factores médicos y psicosociales que plantean retos adicionales que pueden afectar al resultado del IC. Debemos de tener en cuenta en la evaluación las necesidades pre-operacionales de este colectivo y los riesgos adicionales asociados con el proceso de rehabilitación. Por tanto, es indispensable un enfoque multidisciplinar de evaluación para minimizar los riesgos de abandono y desarrollar expectativas adecuadas para el paciente y los familiares

Este estudio presenta algunas limitaciones, entre las que debemos señalar el escaso número de participantes o la ausencia de un muestreo probabilístico. En lo referente a futuras líneas de investigación caben destacar en primer lugar, que aunque la mayoría de resultados en investigación muestran que el IC es un tratamiento exitoso y efectivo para pérdidas severas-profundas, estos resultados se obtienen en contextos clínicos y no representan la facilidad o dificultad que un individuo tiene en la ejecución de sus AVD. Por ello, en futuras investigaciones, deben analizarse esos cambios en el contexto natural de funcionamiento de la persona. En esta misma línea, es esencial evaluar los cambios en las limitaciones de las actividades, restricciones en la participación y calidad de vida según la propia percepción de los pacientes con el fin de definir la eficacia del IC, algo ya recomendado por otros autores con anterioridad (Zhao et al., 2008). Así mismo, aunque en este estudio no contáramos con participantes bi-implantados, es necesario realizar estudios que comprueben el impacto en la calidad de vida después de recibir un segundo implante, ya que ayudaría tanto a profesionales como futuros usuarios a incrementar la comprensión sobre las limitaciones prácticas de estos dispositivos y aconsejar a los pacientes futuros en consecuencia. También, en estudios 
anteriores (e.g., Knutson, Johnson, \& Murray, 2006), se ha demostrado que pacientes mayores de 65 años obtuvieron buenos resultados tanto audiológicos como en medidas de resultados en calidad de vida, por lo que una futura investigación sería realizar un estudio similar en nuestro país y compararlo con diferentes ámbitos geográficos. Estudios como el que acabamos de plantear sería necesario realizarlo a corto plazo puesto que con el aumento de la esperanza de vida, los servicios y sistemas sanitarios-sociales deben comenzar a valorar los beneficios coste-efectivo de la implantación en personas mayores. Una de las grandes dificultades para continuar con estas líneas de investigación es la escasez de herramientas de evaluación tanto en medidas de resultados como en evaluación de la ejecución de tareas y restricción en participación validadas al castellano y lamentablemente ninguna a la lengua de signos española (Tye-Murray, Tyler, Woodworth, \& Gantz, 1992). 


\section{Impacto psicosocial en función de los productos de apoyo (análisis conjunto de los resultados de los estudios 1, 2 y 3).}

Dado que en los tres estudios anteriores se utilizó un mismo instrumento para analizar el impacto psicosocial asociados al uso de los distintos PA, y de que todos los PA seleccionados para su estudio en esta Tesis Doctoral tenían en común su objetivo de mejora de la comunicación, en este apartado se ha querido abordar un análisis conjunto de los resultados con un doble objetivo. Por un lado, comparar el impacto psicosocial de los distintos PA y las experiencias con las tecnologías de todos los participantes en los 3 primeros estudios. Y, por otro lado, obtener información respecto a las cualidades métricas de la escala PIADS cuando se utiliza con PA en personas sordas o con discapacidad auditiva.

Globalmente, el perfil sociodemográfico de los participantes de los tres estudios (n=291) se presenta en la siguiente tabla.

Tabla 55.- Perfil sociodemográfico de los participantes de los estudios 1, 2 y 3 (n=291)

\begin{tabular}{ll}
\hline VARIABLE & $\mathrm{N}(\%)$ \\
\hline Edad & $M=56,12 ; S D=25.11$ \\
Género & $115(39,5)$ \\
Varón & $176(60,5)$ \\
Mujer & $39(13,4)$ \\
Lengua & $146(50,2)$ \\
Lengua de signos & $106(36,4)$ \\
Lengua oral & \\
Ambas & $60(20.6)$ \\
Zona residencial & $231(79,4)$ \\
Rural & \\
Urbano & $94(32,3)$ \\
Momento pérdida & $197(67,7)$ \\
Prelocutivo & \\
Postlocutivo & $200(68,7)$ \\
Tipo de pérdida & $91(31,3)$ \\
Hipoacusia & \\
Cofósis & $163(56)$ \\
Nivel de estudios & $38(13,1)$ \\
Elemental & $22(7,6)$ \\
Bachillerato & $10(3,4)$ \\
Ciclo grado medio & $38(13.1)$ \\
Ciclo grado superior & $3(1)$ \\
Universidad & $17(5,8)$ \\
Máster & \\
Otros &
\end{tabular}

En primer lugar se llevó a cabo un análisis conjunto de los resultados en la escala PIADSS. En la siguiente tabla se reflejan la puntuación global de la escala y la de las 3 subescalas. Como puede apreciarse, globalmente el promedio de impacto es positivo, 
oscilando entre 1,15 para la dimensión de autoestima y 1,37 para la de adaptabilidad. Por tanto, se podría concluir que el uso de productos de apoyo para la comunicación en personas sordas y con discapacidad auditiva tiene un impacto psicosocial positivo que se manifiesta principalmente en mejoras de la adaptabilidad, la competencia y la autoestima, en ese orden.

Tabla 56.- Puntuaciones globales del PIADS y sus tres subescalas $(\mathrm{n}=291)$

\begin{tabular}{llll}
\hline PIADS GLOBAL & Competencia & Adaptabilidad & Autoestima \\
\hline $1,24(S D=0,99)$ & $1,23(S D=1)$ & $1,37(S D=1,1)$ & $1,15(S D=1,12)$
\end{tabular}

Aunque estos resultados ya se han presentado de manera separada, en la siguiente tabla de han compilado las puntuaciones de los distintos PA en los tres estudios. Los valores más altos de impacto se observan en el implante coclear, si bien las diferencias entre los distintos productos en las distintas dimensiones son muy pequeñas (y no significativas)

Tabla 57.- Puntuaciones globales del PIADS y las tres subescalas en función del PA (estudios 1, 2 y 3; n= 291)

\begin{tabular}{|c|c|c|c|c|c|}
\hline & & PIADS TOTAL & COMPETENCIA & ADAPTABILIDAD & AUTOESTIMA \\
\hline & SIV & $1,30(0,86)$ & $1,34(0,88)$ & $1,61(0,98)$ & $1,02(1)$ \\
\hline PA & Audífonos & $1,39(0,93)$ & $1,37(0,92)$ & $1,41(0,97)$ & $1,42(1,1)$ \\
\hline & $\begin{array}{l}\text { Implante } \\
\text { coclear }\end{array}$ & $1,47(1,13)$ & $1,45(1,16)$ & $1,65(1,15)$ & $1,37(1,28)$ \\
\hline
\end{tabular}

También resultaba de interés observar de manera conjunta las puntuaciones de cada uno de los ítems de la escala PIADS. En la siguiente tabla se muestran dichos resultados.

Tabla 58.- Puntuaciones globales del PIADS y sus tres subescalas en función del tipo de PA específico (estudios 1, 2 y $3 ; \mathrm{n}=291$ )

\begin{tabular}{|c|c|c|c|c|c|c|c|c|c|c|}
\hline & $\begin{array}{c}\text { Gafas } \\
\text { auditivas }\end{array}$ & $\begin{array}{l}\text { Implante } \\
\text { Coclear }\end{array}$ & $\begin{array}{l}\text { Inserción } \\
\text { profunda }\end{array}$ & Intracanal & Móvil & Oovoo & Petaca & Retroauricular & Svisual & Skype \\
\hline COMPETENCIA & 2,79 & 1,45 & 1,3 & 1,3 & 0,40 & 0,9 & 1,3 & 1,37 & 1,4 & 0,56 \\
\hline ADAPTABILIDAD & 2,50 & 1,6 & 1,2 & 1,32 & 0,49 & 1,4 & 1,5 & 1,4 & 1,6 & 0,77 \\
\hline AUTOESTIMA & 2,9 & 1,4 & 1,4 & 1,4 & 0,4 & 0,83 & 1,9 & 1,4 & 1,03 & 0,52 \\
\hline PIADS_TOTAL & 2,8 & 1,47 & 1,3 & 1,3 & 0,41 & 1 & 1,5 & 1,4 & 1,34 & 0,6 \\
\hline
\end{tabular}

En la anterior tabla 58 se puede observar que las gafas auditivas, el audífono tipo petaca y retroauricular y el implante coclear fueron los PA con una mayor puntuación en la escala global del PIADS. En lo referente a las subescalas, en la subescala de competencia las gafas 
auditivas, el implante colear, el Svisual y el audífono tipo retroauricular fueron los que obtuvieron una mayor puntuación; en la subescala de adaptabilidad los PA que obtuvieron las puntuaciones más altas fueron las gafas auditivas, implante coclear, y el Svisual $(>1,5)$ y, por último, en la subescala de autoestima los PA con mayor puntuación fueron las gafas auditivas, implante coclear y los diferentes audífonos (retroauricular, inserción profunda, intracanal y petaca)

Tabla 59.- Las puntuaciones medias de los ítems pertenecientes a cada subescala del PIADS

\begin{tabular}{|c|c|c|}
\hline Competencia $(M / S D)$ & Adaptabilidad $(M / S D)$ & Autoestima $(M / S D)$ \\
\hline Competencia $(M=1,55 ; S D=1,4)$ & $\operatorname{Bienestar}(M=1,6 ; S D=1,4)$ & Felicidad $(M=1,6 ; S D=1,4)$ \\
\hline Independencia $(M=1,47 ; S D=1,4)$ & $\begin{array}{l}\text { Dispuesto a darse oportunidades } \\
(M=1,1 ; S D=1,5)\end{array}$ & Autoestima $(M=1,4 ; S D=1,6)$ \\
\hline $\begin{array}{l}\text { Sentirse a la altura de las } \\
\text { circunstancias }(M=1,12 ; S D=1,43)\end{array}$ & $\begin{array}{l}\text { Capacidad para participar }(M=1,55 \text {; } \\
S D=1,4)\end{array}$ & Seguridad $(M=1,4 ; S D=1,6)$ \\
\hline Confusión $(M=-0,11 ; S D=2)$ & $\begin{array}{l}\text { Deseoso de probar cosas nuevas } \\
(M=1,2 ; S D=1,4)\end{array}$ & Frustración $(M=-0,7 ; S D=1,9)$ \\
\hline Eficacia $(M=1,20 ; S D=1,47)$ & $\begin{array}{l}\text { Capacidad para adaptarse a las } \\
\text { actividades cotidianas }(M=1,5 \text {; } \\
S D=1,3)\end{array}$ & $\begin{array}{l}\text { Confianza en sí mismo }(M=1,5 \text {; } \\
S D=1,4)\end{array}$ \\
\hline Productividad $(M=1,14 ; S D=1,4)$ & $\begin{array}{l}\text { Capacidad para aprovechar las } \\
\text { oportunidades }(M=1,3 ; S D=1,3)\end{array}$ & $\begin{array}{l}\text { Sensación de poder }(M=1,23 ; S D= \\
1,4)\end{array}$ \\
\hline Sentirse útil $(M=1,22 ; S D=1,48)$ & & $\begin{array}{l}\text { Sensación de control }(M=1,17 \text {; } \\
S D=1,5)\end{array}$ \\
\hline Pericia $(M=1,13 ; S D=1,3)$ & & $\begin{array}{l}\text { Sentirse a disgusto }(M=-0,24 ; S D= \\
\text { 2) }\end{array}$ \\
\hline Aptitud $(M=1,4 ; S D=1,3)$ & & \\
\hline Sentirse capaz $(M=1,4 ; S D=1,4)$ & & \\
\hline Calidad de vida $(M=1,7 ; S D=1,3)$ & & \\
\hline Realización $(M=1,3 ; S D=1,3)$ & & \\
\hline
\end{tabular}


De todos los ítems, únicamente se observó una puntuación negativa en un ítem de la escala de competencia (confusión) y en dos ítems de la subescala de autoestima (frustración y sentirse a disgusto). Por tanto, si bien el impacto global de los PA para la comunicación es positivo, habría que atender a algunas características de los productos que podrían empeorar los resultados alcanzados por su uso. Así, la confusión se refiere a la sensación de "no poder pensar claramente o no poder actuar con decisión" tras empezar a utilizar el PA. La frustración se refiere al "sentimiento de desilusión e irritación por la falta de progreso en la consecución de los deseos; sentirse decepcionado" y sentirse a disgusto implica sentirse "más torpe, incómodo o avergonzado" tras comenzar a utilizar el PA. Sería de interés indagar de manera más concreta en estos aspectos. Es por ello que en el próximo estudio se abordará un análisis más detallado de las circunstancias de rodean el uso de PA desde una perspectiva más cualitativa.

En lo referente al instrumento SOTU-C, mediante el que se han analizado las experiencias con las tecnologías de todos los participantes, en la siguiente tabla se pueden observar las puntuaciones medias positivas, negativas y neutrales por grupo de preguntas en los participantes de los 3 estudios realizados.

Tabla 60.- Puntuaciones medias de positivos, negativos y neutrales del cuestionario SOTU-C por cada grupo de preguntas

\begin{tabular}{llll}
\hline & Positivos & Negativos & Neutrales \\
\hline Total & $16,3(7,3)$ & $7,25(6,03)$ & $6,39(5,1)$ \\
$\begin{array}{l}\text { Experiencias globales con } \\
\text { las tecnologías utilizadas }\end{array}$ & $3,1(2)$ & $0,37(0,82)$ & $1,5(1,86)$ \\
$\begin{array}{l}\text { Perspectivas sobre } \\
\text { tecnologías }\end{array}$ & $3,59(2,3)$ & $2,6(1,96)$ & $1,8(1,9)$ \\
$\begin{array}{l}\text { Actividades típicas } \\
\begin{array}{l}\text { Características } \\
\text { personales/sociales }\end{array}\end{array}$ & $2,1(1,3)$ & $0,7(1)$ & $1,2(1,3)$ \\
& $7,6(3,7)$ & $3,1(3,4)$ & $2,3(2,7)$ \\
\hline
\end{tabular}

Globalmente se verificó un mayor número de experiencias positivas que negativas o neutras en todos los apartados del SOTU-C, así como en la puntuación global. 
Tabla 61.- .-Puntuaciones medias de positivos y negativos del cuestionario SOTU-C por cada tipo de producto de apoyo.

\begin{tabular}{|c|c|c|c|c|c|c|c|c|c|}
\hline & $\begin{array}{c}\text { Gafas } \\
\text { auditivas }\end{array}$ & $\begin{array}{r}\text { Implante } \\
\text { Coclear }\end{array}$ & $\begin{array}{l}\text { Inserción } \\
\text { profunda }\end{array}$ & Intracanal & Móvil & Oovoo & $\begin{array}{c}\text { Retroau } \\
\text { ricular }\end{array}$ & Skype & Svisual \\
\hline 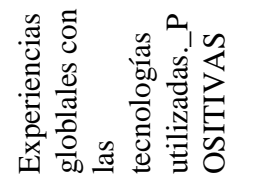 & 2,5 & 3,3 & 1,2 & 1,7 & 3,2 & 4,2 & 2,3 & 4,2 & 4,4 \\
\hline 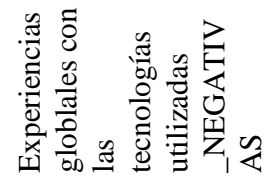 & 0,0 & 0,5 & 0,2 & 0,7 & 0,9 & 0,2 & 0,3 & 0,1 & 0,2 \\
\hline 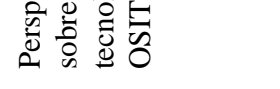 & 2,5 & 4,3 & 1,8 & 2,1 & 3,8 & 4,9 & 2,6 & 4,9 & 5 \\
\hline 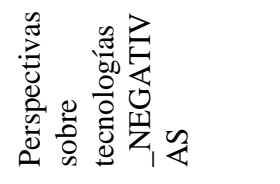 & 3,5 & 2,3 & 4,2 & 3,7 & 2,9 & 1,2 & 3 & 1,5 & 2 \\
\hline 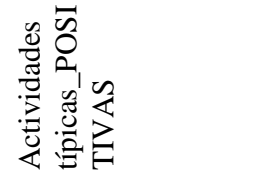 & 2 & 2,4 & 1,8 & 1,9 & 1,8 & 2,4 & 1,9 & 2,4 & 2,3 \\
\hline 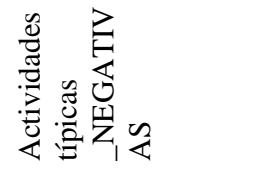 & 1 & 0,9 & 1,2 & 1,7 & 1,6 & 0,6 & 1,4 & 0,7 & 0,9 \\
\hline 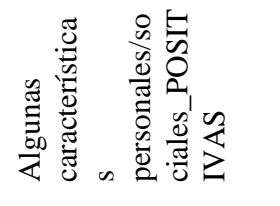 & 11,5 & 8,5 & 8,6 & 6,5 & 6,4 & 9,3 & 7,6 & 8,3 & 7,3 \\
\hline 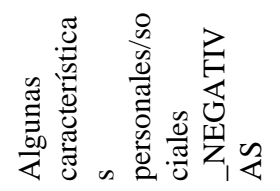 & 1 & 2,8 & 2,8 & 5,2 & 4,1 & 1 & 3,4 & 1,5 & 2,2 \\
\hline 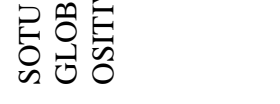 & 18,5 & 18,5 & 13,4 & 12,25 & 15,3 & 20,9 & 14,4 & 19,9 & 18,9 \\
\hline 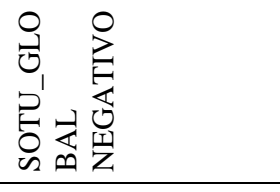 & 5,5 & 6,5 & 8,4 & 11,3 & 9,5 & 3 & 8,1 & 3,9 & 5,2 \\
\hline
\end{tabular}


De la anterior tabla 60 cabe señalar que las usuarios de gafas auditivas, móvil, audífono tipo retroauricular y Skype son los que obtuvieron un mayor número de respuestas positivas. Por el contrario el audífono tipo intracanal fue el producto de apoyo que obtuvo una mayor puntuación negativa en la escala SOTU-C. Cabe resaltar, que las personas usuarias de móvil obtuvieron una puntuación más negativa en el apartado de experiencias con la tecnología que el resto de usuarios sin embargo estos mismos usuarios de móvil obtuvieron una puntuación más positiva en el apartado de características personales.

Para indagar sobre las relaciones entre las experiencias con las tecnologías y el impacto psicosocial, se realizó un estudio correlacional de las puntuaciones escala PIADS y las respuestas positivas y negativas del SOTU-C. En al siguiente figura se presenta un correlograma que representa estas relaciones.

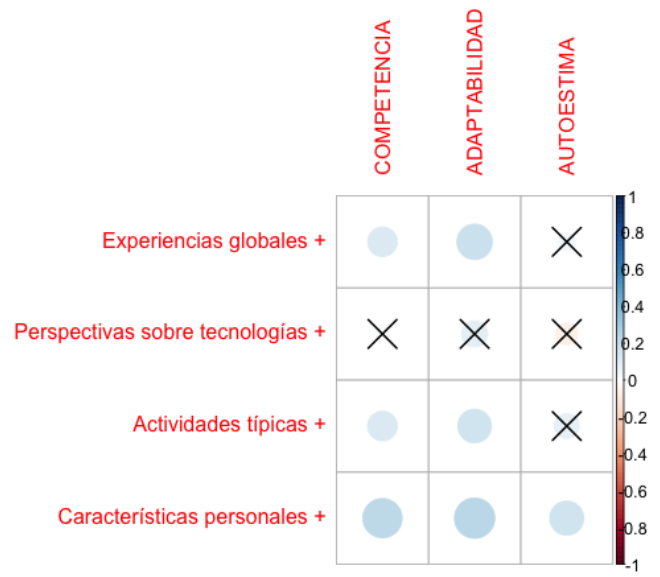

Positivas (SOTU-C)

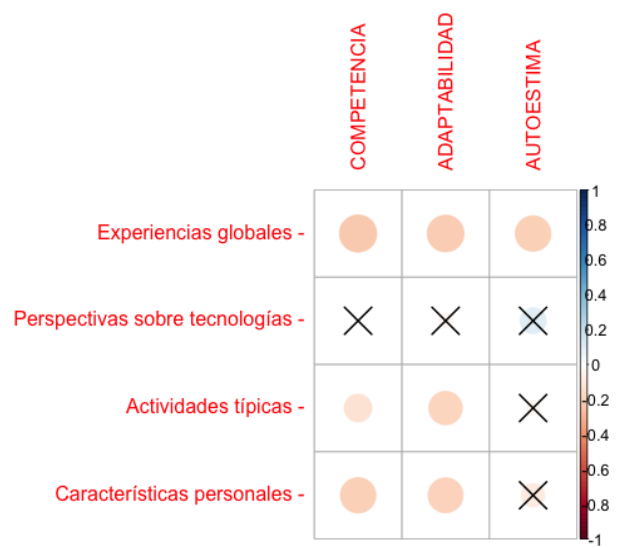

Negativas (SOTU-C)

Figura 9.- Correlaciones entre las dimensiones de experiencias positivas y negativas con tecnologías (SOTU-C) y el impacto psicosocial (PIADS). El tamaño de los círculos representa la magnitud de la correlación y el color el signo. Las "x" señalan las correlaciones no significativas.

Como puede apreciarse en esta figura, las relaciones positivas de mayor magnitud (tamaño mayor de los círculos) se verificaron entre las puntuaciones positivas en el apartado de características personales y las dimensiones de la escala PIADS. Parece que las características personales pudieran ser un factor importante que determina el impacto psicosocial positiva tras el uso de un PA. Globalmente, la escala de autoestima es la que mostró menor relación con los distintos apartados del SOTU-C. En cuanto a las experiencias 
negativas on las tecnologías, las experiencias globales podrían ser uno de los factores de importancia para anticipar menor impacto psicosocial. De manera general, el patrón de relaciones

Por último, el segundo objetivo de este análisis conjunto tenía que ver con la obtención de resultados respecto a las cualidades métricas de la escala PIADS cuando es aplicada a personas sordas o con discapacidad auditiva en relación a productos de apoyo para la comunicación. Para ello, se realizó un análisis de fiabilidad mediante el cálculo de la consistencia interna (alfa de Cronbach) de la escala PIADS y sus tres subescalas, en los tres estudios. A modo de datos de contraste, en la siguiente tabla se añadieron, además, las puntuaciones de consistencia interna obtenidas por otros autores en estudios previos como el de los creadores del PIADS y los resultados obtenidos en el estudio de Saladin y Hansman que usaron la escala PIADS con SIV, al igual que en el estudio 1 de esta Tesis Doctoral.

Tabla 62.- Consistencia interna del instrumento PIADS y sus tres subescalas en función de tres estudios

\begin{tabular}{lllll}
\hline ESTUDIO & PIADS GLOBAL & Competencia & Adaptabilidad & Autoestima \\
\hline Day \& Jutai (1996) & 0,95 & 0,92 & 0,88 & 0,87 \\
Saladin \& Hansman (2008) & 0,89 & 0,92 & 0,88 & 0,87 \\
Estudio 1 (SIV) & 0,95 & 0,91 & 0,87 & 0,78 \\
Estudio 2 (Audífonos) & 0,91 & 0,86 & 0,86 & 0,42 \\
Estudio 3 (Implante Coclear) & 0,93 & 0,91 & 0,93 & 0,31 \\
\end{tabular}

En general el patrón de resultados es similar en todos los estudios mostrados. La escala de competencia es la de mayor consistencia interna, seguida de la escala de adaptabilidad y en último lugar la de autoestima. Las diferencias se verifican en la magnitud del valor de consistencia interna de la escala de autoestima que, en el caso de los estudios 2 y 3 de esta tesis, mostraron valores bastante bajos. Aunque no tengamos una explicación totalmente satisfactoria se podría hipotetizar (a) que la subescala de autoestima es la de menor consistencia interna en la escala PIADS con independencia del tipo de usuarios. De hecho en todos los estudios es la que menores valores presenta. Y (2) que probablemente es el constructo de autoestima en usuarios de audífonos e implante coclear donde mayor 
variabilidad de respuestas se genera. Esto podría tener que ver con la muestra más pequeña en estos dos grupos, pero también con la imagen de sí mismos de los usuarios de dichos dispositivos. En cualquier caso, habría que poner en marcha otras investigaciones para indagar sobre este resultado. Y de hecho, en el siguiente capítulo se aborda el análisis de la problemática de uso de PA en personas sordas y con discapacidad auditiva desde una perspectiva cualitativa como modo de complementar los resultados cuantitativos ofrecidos en los 3 primeros estudios de esta Tesis Doctoral. 


\section{Estudio 4.- Estudio cualitativo sobre factores relacionados con el uso de productos de apoyo: grupos focales de personas sordas, familiares y profesionales.}

\section{Introducción}

En los primeros tres estudios de esta tesis doctoral se ha abordado el estudio del impacto psicosocial derivado del uso de productos de apoyo para la mejora de la comunicación en personas sordas y con discapacidad auditiva desde una perspectiva, sobre todo, cuantitativa. La perspectiva cuantitativa permite un abordaje bastante objetivo en el estudio de un problema de investigación, facilita la generalización de resultados desde una muestra a una población y, se podría afirmar, que es una de las estrategias más habituales entre los investigadores.

A pesar de las ventajas de la perspectiva cuantitativa, la investigación sobre resultados en usuarios de productos de apoyo se debería complementar con información obtenida mediante técnicas cualitativas (Odom et al., 2005). Por un lado, las técnicas cualitativas podrían conducir a un conocimiento más profundo sobre las razones y motivaciones subyacentes en las decisiones de uso o no uso de un producto. Y por otro, el abordaje cualitativo, al incluir también a personas del contexto de los propios usuarios, facilita la obtención de información que se origina en distintos puntos de vista y perspectivas. Por ello, este cuarto estudio tuvo como objetivo indagar sobre la opinión acerca de los productos de apoyo no sólo de las personas sordas sino también de sus familiares y de los profesionales que trabajan con ellos a diario. Nuestro propósito era el de enriquecer esta tesis doctoral a partir de las opiniones y visión de los productos de apoyo y los factores a tener en cuenta para su uso de los propios usuarios y su entorno. Además, paralelamente, queríamos indagar sobre los factores relacionados con la falta de continuidad o abandono de los PA en personas sordas/personas con discapacidad auditiva. La necesidad de completar esta tesis con un enfoque cualitativo se origina en su facilidad para permitir conocer la opinión de los usuarios de una forma más exhaustiva (Gillis \& Jackson, 2002). Además, empleando ambos enfoques, el cualitativo y el cuantitativo, se pueden obtener resultados más consistentes y por ello las posibles conclusiones de este trabajo podrían ser de mayor valor para la práctica. Además, teniendo en cuenta las características socio-culturales del colectivo estudiado, parece clara la 
necesidad de mejorar la calidad de los resultados mediante preguntas y experiencias directas con los participantes (Gibson et al., 2010).

De entre todas las técnicas "no cuantitativas", los grupos focales son técnicas bien conocidas en la investigación cualitativa y en el ámbito de la discapacidad. El objetivo de los grupos focales es el de generar opiniones, poner de manifiesto puntos de vista y evocar experiencias sobre un tema específico (Bloor, 2001). Algunos de estos métodos se usan habitualmente en investigación sobre PA y en este contexto pueden proporcionar información de mucho interés así como un enfoque para comprender los resultados de las intervenciones mediante PA.

El uso de grupos focales en personas sordas plantea bastantes dificultades debido a las barreras comunicativas que presenta el colectivo. No obstante, hay estudios que han empleado esta herramienta en personas perteneciente a la Comunidad Sorda usuarias de lengua de signos (Cavender \& Ladner, 2008; Spicer, 2009) y en personas usuarias tanto de lengua de signos como de lengua oral (Spicer, Schmidt, Ward \& Pinnington, 2005). Son diversas las cuestiones a tener en cuenta cuando se organizan grupos focales con personas sordas tales como: recurrir a personas competentes en lengua de signos mejor que participantes con buena lectura labial, ya que es lo que sugiere la evidencia, puesto que estos últimos comprenden un $30 \%$ del mensaje, contar con intérprete de lengua de signos (aunque siempre es mejor disponer de dos por si uno de estos no comprende algún mensaje) y disponer a los participantes de forma circular para facilitar el contacto visual. Además se debe tener en cuenta que las personas sordas no se ven a sí mismas con una discapacidad y no les gusta la terminología de persona con discapacidad auditiva sino persona sorda, con su propia identidad. En este estudio se tuvieron en cuenta todos estos aspectos para organizar distintos grupos focales de personas sordas, familiares y profesionales.

Como técnica de análisis y método para extraer conclusiones a partir del discurso derivado de los grupos focales, se utilizó el análisis de contenido mediante la aplicación de categorías deductivas. En concreto, se partió de dos modelos bien conocidos y con mucha utilidad a la hora de extraer conclusiones sobre el funcionamiento de las personas derivado del uso de productos de apoyo: la clasificación internacional del funcionamiento, la discapacidad y la salud (CIF) y el modelo de factores relacionados con el uso/falta de uso de productos de apoyo de Lauer, Longenecker \& Smith (2006). 
La CIF ya ha sido utilizada en otros estudios como sistema de categorías a partir del que llevar a cabo análisis de contenido. Por ejemplo, Federicci, Meloni, Brogioni y Lo Presti (2008) llevaron a cabo un análisis de contenido del discurso mediante la CIF, como modo de obtención de información relativa a las representaciones y modelos subyacentes de la discapacidad de 90 profesores, padres y educadores de personas con necesidades especiales. En dicho estudio, el análisis de contenido a partir de la CIF permitió inferir la perspectiva sobre la discapacidad de distintos grupos (e.g., padres de niños con discapacidad versus padres de niños sin discapacidad); y, al margen de los resultados concretos, es un buen ejemplo de cómo inferir representaciones mentales de grupos de personas respecto a algún asunto concreto. Estas representaciones son el origen de las emociones y conductas, y conocerlas es importante para planificar e implementar programas de intervención adecuados, en este caso, en el ámbito de los resultados con PA.

Paralelamente, el uso de la CIF como herramienta para codificar el discurso derivado de los diferentes grupos focales, además de permitir la organización y estructuración de la información, también puede aportar información de interés para validar conjuntos básicos de la CIF (core set). La CIF contiene más de 1400 categorías y, por ello, para facilitar su implementación, la Organización Mundial de la Salud y la CIF Research Branch se plantearon el desarrollo de conjuntos básicos de las categorías de la CIF para colectivos y propósitos específicos. Así, un conjunto básico o core set (en adelante, CIF-CS) es una selección de las categorías esenciales de la clasificación completa de la CIF que son consideradas relevantes para describir el funcionamiento de una persona con una condición de salud específica o en un contexto socio-sanitarioespecífico. Cada conjunto básico está especialmente orientado a un colectivo, y constituye una versión reducida que tiene mucha aplicabilidad en la práctica diaria de los profesionales. Los conjuntos básicos han sido desarrollados para diversas aplicaciones, incluyendo la gestión específica de patologías, además de servir de guía para los profesionales sanitarios, cuidadores o los propios pacientes. Los conjuntos básicos de la CIF son, por tanto, conjuntos de categorías que proporcionan los estándares mínimos para la evaluación, la presentación de informes y la comunicación de los factores relacionados con el funcionamiento y la salud. Estos factores pueden figurar en los estudios clínicos, informes clínicos, y la evaluación y la gestión de los equipos multiprofesionales. Por el momento se han desarrollado 34 conjuntos básicos, y para todos ellos hay una versión breve y una ampliada. Y únicamente hay un CIF-CS para personas con 
discapacidad auditiva (comprehensive and brief Core Set for hearing loss), aunque no para personas sordas.

Normalmente, los conjuntos básicos se desarrollan mediante un proceso de toma de decisiones y de consenso, en el que la evidencia de estudios preliminares se integra con la opinión de expertos (Cieza et al., 2004; Cieza et al., 2010; Kirschneck, Rauch, Stucki \& Cieza, 2011; Stucki, Ewert \& Cieza, 2002; Stucki, Üstün \& Melvin, 2005; Yen et al., 2014).. Los estudios preliminares incluyen revisiones sistemáticas y la recopilación de datos empíricos, y este proceso conduce a la identificación de las categorías relevantes de la CIF en un colectivo o ámbito determinado. Como es lógico, parte del proceso de creación y validación de los CIF-CS incluye también la obtención de información sobre la perspectiva del paciente. Así, los estudios destinados a la exploración de la perspectiva del paciente facilitan la exploración de su perspectiva de un problema de salud, como es el caso que nos ocupa, la pérdida auditiva y el uso de productos de apoyo como medio para mejorar sus resultados. Los enfoques cualitativos permiten, además, explorar como las personas entienden e interpretan su mundo social.

Por tanto, en este estudio nos planteamos, primero, contrastar las categorías emergentes del discurso de las personas sordas y con discapacidad auditiva mediante el CIF-CS existente para personas con pérdida auditiva. En cierto modo, este análisis permitiría extender las validez del CIF-CS a ámbitos específicos como el del uso de PA. Segundo, también nos planteamos que, dado que existe un CIF-CS para personas con discapacidad auditiva, aunque no para personas sordas, los resultados de un análisis de estas características podrían servir para avanzar en la definición de un futuro CIF-CS para personas sordas. Pudiera ser que el CIF-CS ya existente no tenga en cuenta las particularidades de las personas sordas ni su perspectiva de la sordera y por tanto resultaba de interés plantearnos este objetivo.

Otro de los objetivos principales de este estudio tiene que ver con la exploración, mediante técnicas cualitativas, de las razones de uso o no uso de PA en personas sordas y con discapacidad auditiva. Como se ha mencionado en la parte teórica de esta tesis doctoral, una de las limitaciones en el uso de los PA es el abandono o falta de uso de los PA. Por ello, de manera paralela al uso de la CIF, en la codificación del discurso de los diferentes grupos focales también se usaron como categorías deductivas los factores de abandono o interrupción del modelo de Lauer, Longenecker \& Smith (2006). Estos factores están divididos, tal y como se explicó en la parte teórica de esta tesis doctoral, en cinco apartados: 
1) factores relacionados con la persona (6 factores), 2) factores relacionados con el producto de apoyo (13 factores), 3) factores del entorno (4 factores), 4) factores positivos (4 factores) y, por último, 5) los factores considerados como "otros" (3 factores). Los resultados derivados de este análisis serán relevantes para conocer con mayor detalle las cuestiones relativas al uso de PA en la población analizada y también como sistema de validación del propio modelo de Lauer, Longenecker \& Smith.

En resumen, el objetivo principal de este estudio es complementar los hallazgos obtenidos en los estudios anteriores, de carácter cuantitativo, con metodologías cualitativas que nos permitan profundizar en los aspectos subjetivos que se relacionan con el uso y abandono de productos de apoyo en personas sordas y con discapacidad auditiva. Ello se traduce en una serie de objetivos específicos:

Analizar el discurso de personas sordas y con discapacidad auditiva, para indagar sobre los aspectos de funcionamiento relacionados con el uso y abandono de productos de apoyo, a partir de las dimensiones de la clasificación CIF. De manera indirecta, obtener información específica que complemente y ayude a validar el actual conjunto básico de la CIF para personas con pérdida auditiva (ICF Core Set for Hearing Loss).

Analizar el discurso de personas sordas y con discapacidad auditiva, familiares y profesionales, para explorar su percepción acerca de los factores de abandono o falta de uso de PA, a partir de un modelo de factores de abandono basado en la evidencia. De manera indirecta, aportar información para la validación de dicho modelo en personas con dificultades auditivas.

\section{Método}

\section{Participantes}

Participaron 36 personas, 6 eran personas sordas, 9 con discapacidad auditiva, 8 familiares y 13 profesionales. Todos eran previamente conocidos de la entrevistadora (la investigadora principal y conocedora de la Comunidad Sorda). La selección de la muestra se realizó a través de la asociación SADAP Salamanca. La investigadora principal se puso en contacto con las personas sordas vía telemática y con los familiares y profesionales vía 
telefónica, telemática y cara a cara. Ninguna persona con las que se contactó se negó a participar en el estudio.

Criterios de inclusión:

- Personas con discapacidad auditiva prelocutiva o postlocutiva.

- Personas con discapacidad auditiva mayores de 18 años de edad.

- Personas con discapacidad auditiva usuarias o no de productos de apoyo.

- Familiares directos de personas con discapacidad auditiva, hasta $2^{\circ}$ grado.

- Profesionales directos de personas con discapacidad auditiva.

- Personas que hayan dado su consentimiento para participar en el mismo.

Criterios de exclusión:

- Personas con algún otro diagnóstico adicional a la discapacidad auditiva

- Personas con discapacidad auditiva menores de 18 años.

- Personas que cumpliendo con los requisitos de inclusión y habiendo recibido una completa información sobre el estudio, no deseen participar en el mismo.

En la siguiente tabla se muestra el perfil de los participantes sordos y con discapacidad auditiva

Tabla 63.- Perfil sociodemográfico de personas sordas y personas con discapacidad auditiva $(\mathrm{n}=15)$

\begin{tabular}{ll}
\hline VARIABLE & $\mathrm{N}(\%)$ \\
\hline Edad & $M=47.27 ; S D=14,81$ \\
Género & $12(80,0)$ \\
$\quad$ Varón & $3(20,0)$ \\
Mujer & \\
Lengua & $5(33,3)$ \\
$\quad$ Lengua de signos & $10(66,7)$ \\
$\quad$ Lengua oral & $0(0,0)$ \\
Ambas & \\
Momento pérdida & $8(53,3)$ \\
$\quad$ Prelocutivo & $7(46,7)$ \\
Postlocutivo & \\
Grado de pérdida & $12(80,0)$ \\
$\quad$ Profunda & $3(20,0)$ \\
Moderada & \\
& \\
\hline
\end{tabular}

El perfil del resto de participante, familiares y profesionales, se muestra en la siguiente tabla. 
Tabla 64.- Perfil sociodemográfico de familiares y profesionales( $\mathrm{n}=21)$

\begin{tabular}{ll}
\hline VARIABLE & $\mathrm{N}(\%)$ \\
\hline Edad & $M=34.10 ; S D=14.1$ \\
Género & \\
Mujer & $18(85.7)$ \\
Varón & $3(14.3)$ \\
&
\end{tabular}

\section{Instrumentos}

\section{Cuestionario de elaboración propia}

Para la realización de los grupos focales la investigadora principal de este estudio diseñó un cuestionario formado por 10 preguntas. Se tomaron como base las dimensiones de la CIF: funciones corporales, factores ambientales, actividad y participación y factores personales; en cuanto a la dimensión de estructuras corporales, no se incluyeron preguntas específicas, dado que el interés del trabajo está estaba más enfocado hacia cuestiones relacionadas con aspectos no médicos. En la tabla 58 se muestran las diez preguntas que se formulaban a los diferentes grupos focales, junto con la dimensión de la CIF a la que pertenece. En resumen, se creó una pregunta acerca de las funciones corporales, cuatro sobre actividades y participación, tres sobre factores ambientales y dos sobre factores personales. 
Tabla 65.- Preguntas de elaboración propia tomando de base teórica la CIF para los 12 grupos focales

\begin{tabular}{|c|c|}
\hline Pregunta & Dimensiones de la clasificación internacional del funcionamiento. \\
\hline $\begin{array}{l}\text { ¿Cuál es su opinión acerca de los productos de apoyo de } \\
\text { amplificación para las personas con discapacidad } \\
\text { auditiva? }\end{array}$ & Factores ambientales, productos y tecnologías. \\
\hline $\begin{array}{l}\text { ¿Cree que los productos de apoyo ayudan al desarrollo } \\
\text { de funciones psicosociales, es decir, a obtener } \\
\text { habilidades personales necesarias para establecer } \\
\text { interacciones sociales? }\end{array}$ & $\begin{array}{l}\text { Actividades y participación. Interacciones y relaciones } \\
\text { interpersonales. }\end{array}$ \\
\hline $\begin{array}{l}\text { ¿En qué cree que los productos de apoyo pueden } \\
\text { favorecer en la comunicación-recepción de mensajes } \\
\text { hablados, no verbales, lengua de signos u otros? }\end{array}$ & Actividades y participación: comunicación \\
\hline $\begin{array}{l}\text { ¿Cree que los productos de apoyo ayudan a la } \\
\text { percepción de los sonidos y a la discriminación de su } \\
\text { localización, volumen y calidad de la misma? }\end{array}$ & Funciones corporales. Funciones auditivas y vestibulares. \\
\hline $\begin{array}{l}\text { ¿Qué opina acerca de los productos de apoyo y cómo } \\
\text { interfieren estos en la participación de actividades } \\
\text { educativas, laborales o de ocio? }\end{array}$ & Actividades y participación. Vida comunitaria, social y cívica. \\
\hline $\begin{array}{l}\text { ¿Cree que los productos de apoyo ayudan al acceso y } \\
\text { uso de tecnologías de la comunicación? }\end{array}$ & Factores ambientales. Productos y de tecnologías. \\
\hline $\begin{array}{l}\text { ¿Consideras la sordera una discapacidad o piensas que } \\
\text { las personas sordas son un colectivo con una lengua y } \\
\text { cultura diferentes a la oralista? }\end{array}$ & Factores ambientales. Actitudes. \\
\hline $\begin{array}{l}\text { ¿Cree que los factores personales pueden influir en el } \\
\text { uso de productos de apoyo? Tales como la autoestima, la } \\
\text { motivación, la adaptabilidad... }\end{array}$ & Factores personales \\
\hline $\begin{array}{l}\text { ¿Cree que los factores sociodemográficos influyen en el } \\
\text { uso de productos de apoyo? Tales como el género, la } \\
\text { edad, el nivel socio-cultural, el nivel socio-económico, } \\
\text { estudios }\end{array}$ & Factores personales \\
\hline $\begin{array}{l}\text { ¿Cree que los productos de apoyo ayudan a la } \\
\text { realización de actividades instrumentales de la vida } \\
\text { diaria por ejemplo: capacidad de usar el teléfono, } \\
\text { movilidad en la comunidad, manejo de las actividades } \\
\text { del hogar...? }\end{array}$ & Actividades y participación \\
\hline $\begin{array}{l}\text { ¿Y en cuanto a las actividades avanzadas de la vida } \\
\text { diaria: educación, trabajo y ocio? }\end{array}$ & \\
\hline
\end{tabular}

\section{Procedimiento}

Los requisitos para el envío de manuscritos a revistas biomédicas publicadas por el Comité Internacional de Editores de Revistas Médicas no proporcionan directrices para los estudios cualitativos. Es por ello, que para llevar a cabo este estudio empírico se tomó como criterio la lista de comprobación/checklist COREQ (Consolidated criteria for reporting qualitative research; Tong, Sainsbury \& Craig, 2007). Esta lista de comprobación fue desarrollada para promover la información explícita y exhaustiva sobre los detalles metodológicos en los estudios cualitativos. Se compone de elementos específicos para la 
presentación de informes de estudios cualitativos y se opone a los criterios genéricos que son aplicables a todos los tipos o informes de investigación. COREQ es una lista de preguntas formada por 32 items (dividido en tres dominios: temas de investigación y reflexividad, diseño de estudio y análisis y recomendaciones) que cubre los componentes necesarios del diseño del estudio, que deben incluirse en un estudio con metodología cualitativa. Los criterios incluidos en la lista de verificación pueden ayudar a los investigadores a la hora de redactar y exponer los aspectos importantes del procedimiento, métodos empleados, contexto del estudio, los resultados, el análisis y la interpretación. De ahí que se haya utilizado como elemento de organización del trabajo en este estudio cualitativo.

El investigador principal de este estudio fue al mismo tiempo el entrevistador de los 12 grupos focales, tratándose de un terapeuta ocupacional con experiencia en el campo de la discapacidad y con entrenamiento en la evaluación de personas con discapacidad auditiva. El entrevistador empleo como guía para las preguntas el cuestionario de elaboración propia, que se utilizó para todos los grupos focales. Los grupos focales se desarrollaron en diferentes emplazamientos: aula de la asociación SADAP, sala de usos múltiples de la Universidad de Salamanca y en domicilios particulares. Para el registro de las sesiones se empleó una grabadora de voz para los profesionales, familiares y las personas sordas usuarias de lengua oral, y dos videocámaras para las personas usuarias de lengua de signos. En cuanto a la duración de los diferentes grupos, osciló entre los 19 minutos y los 90 minutos, siendo los grupos focales de los profesionales los que tuvieron una mayor duración. En la tabla 58 se muestra la duración total de cada grupo focal. No se devolvió feedback a los participantes de sus transcripciones, puesto que ninguno de los participantes manifestó obtener un reporte del resultado de las sesiones. Ninguno de los participantes tomó notas durante la duración de los grupos focales, aunque a todos los participantes se les facilitó útiles de escritura y papel por si deseaban hacerlo. Así mismo, los participantes conocían las razones por las que se realizaba el estudio y todas las personas con las que se contactó por las diferentes vías (teléfono, email, SMS y SIV) colaboraron en el estudio.

Los grupos focales estaban formados por 12 grupos en total, cuatro de profesionales, dos personas con hipoacusia, tres grupos de personas sordas prelocutivas y tres grupos de familiares. En la tabla siguiente se resumen las características de los participantes en los distintos grupos. 
Tabla 66.- Descripción de los perfiles de los 3 tipos de grupos focales: personas sordas, familiares y profesionales $(\mathrm{n}=36)$

\begin{tabular}{|c|c|c|}
\hline Grupo Focal & $\mathrm{N}^{\circ}$ PARTICIPANTES & Participantes \\
\hline Grupo 1 Familiares & \multirow[t]{3}{*}{8 Participantes } & $\begin{array}{l}1 \text { Persona hija de una persona con una pérdida severa usuaria } \\
\text { de audífono y con un tipo de pérdida postlocutiva. } \\
1 \text { Persona hija de una persona con hipoacusia moderada } \\
\text { usuaria de audífono. } \\
1 \text { Persona nieta de una persona con una hipoacusia profunda } \\
\text { y postlocutiva }\end{array}$ \\
\hline Grupo 2 Familiares & & $\begin{array}{l}3 \text { Personas (Padres y hermana de la madre) familiares de una } \\
\text { persona con un tipo de pérdida prelocutiva y con una } \\
\text { hipoacusia profunda. }\end{array}$ \\
\hline Grupo 3 Familiares & & $\begin{array}{l}2 \text { Personas (Cónyuge e hija) de una persona con una } \\
\text { hipoacusia profunda postlocutiva. }\end{array}$ \\
\hline Grupo 1 Personas sordas & \multirow{3}{*}{6 Participantes } & 2 Personas sordas tipo prelocutiva usuarias de IC \\
\hline Grupo 2 Personas sordas & & $\begin{array}{l}\text { 1 Persona sorda prelocutiva sin PA usuaria de LSE } \\
1 \text { Persona sorda prelocutiva usuaria de IC }\end{array}$ \\
\hline Grupo 3 Personas sordas & & 2 Personas sordas prelocutivas usuarias de audífonos \\
\hline $\begin{array}{l}\text { Grupo } 1 \text { personas con } \\
\text { hipoacusia }\end{array}$ & \multirow{2}{*}{9 Participantes } & $\begin{array}{l}6 \text { Personas con hipoacusia con un tipo de pérdida } \\
\text { postlocutiva usuarios de audífonos }\end{array}$ \\
\hline $\begin{array}{l}\text { Grupo } 2 \text { personas con } \\
\text { hipoacusia }\end{array}$ & & $\begin{array}{l}2 \text { Personas con hipoacusia usuarias de audífonos } \\
1 \text { Persona sorda prelocutiva no usuaria de PA }\end{array}$ \\
\hline Grupo 1 Profesionales & \multirow{4}{*}{13 Participantes } & $\begin{array}{l}1 \text { Trabajadora social e ILSE } \\
1 \text { Logopeda e ILSE } \\
1 \text { ILSE } \\
\end{array}$ \\
\hline Grupo 2 Profesionales & & $\begin{array}{l}1 \text { Logopeda } \\
1 \text { ILSE y Filóloga }\end{array}$ \\
\hline Grupo 3 Profesionales & & $\begin{array}{l}\text { 1 Educadora social e ILSE } \\
1 \text { ILSE y técnico de atención socio-sanitaria } \\
1 \text { ILSE } \\
1 \text { Psicóloga e ILSE }\end{array}$ \\
\hline Grupo 4 Profesionales & & $\begin{array}{l}1 \text { Terapeuta Ocupacional } \\
1 \text { Psicóloga e ILSE } \\
1 \text { Logopeda } \\
1 \text { Psicopedagoga e ILSE }\end{array}$ \\
\hline
\end{tabular}

Los grupos focales fueron desarrollados bajo un guion de conducción en el que se establecían las líneas generales a ser tratadas durante las sesiones. Se tomaron en consideración las sugerencias de Corbetta (2003) y Viedma (2009) en cuanto al lugar de realización de la entrevista, en el sentido de evitar lugares donde hubiera contaminación acústica, estímulos distractores, posibilidad de interrupciones ajenas al estudio, así como espacios que pudieran restringir la veracidad de las respuestas. Los grupos focales fueron convenidos previamente entre el investigador y los participantes, en el momento de contactar y explicar para qué se quería el encuentro y lo que sería idealmente buscado para no entorpecer los resultados y sentirse confortables. Antes de la realización de los grupos focales, se explicaba a los diferentes participantes que se requería que explicaran sus contestaciones lo más posible, ya que no se trataba de una encuesta sino de un grupo para debatir y opinar sobre un mismo tema. Se pidió su consentimiento para grabar los grupos focales, manteniendo la grabadora y/o videocámara (dependiendo de la lengua empleada: 
lengua oral o lengua de signos) fuera de la vista de los participantes, por lo que después de unos minutos los participantes no tomaban en consideración su presencia. Se ha tenido especial interés que los lugares tuvieran buena luminosidad, tanto para la adecuada percepción de lengua de signos como para la lectura labial y, en la medida de lo posible, con poco ruido exterior para no viciar la recepción. Como se ha comentado con anterioridad, los participantes contaban con hojas de papel y lapiceros para las situaciones que requerían de estos recursos, para puntualizar algo o recordarlo para su posterior explicación. En todos los grupos, tanto de las personas con discapacidad como de sus familiares y profesionales, se administró un consentimiento informado, según modelo del Comité de Bioética de la Universidad de Salamanca, con anterioridad al desarrollo de la sesión en grupo.

El trabajo se desarrolló en la ciudad de Salamanca y se centra en las personas con discapacidad auditiva, personas sordas, familiares y profesionales de los mismos. La duración del trabajo de campo (realización de los grupos focales y grabación de los mismos) ha sido un total de 7 meses desde el 16 de mayo hasta el 19 de diciembre del 2014.

El diseño planteado es un diseño no experimental transversal correlacional. Mediante una metodología cualitativa para realizar un análisis en mayor profundidad mediante el marco conceptual de la CIF y el marco conceptual de Lauer, Longenecker \& Smith (2006) sobre el abandono o falta de uso de los productos de apoyos. 


\section{Resultados}

En primer lugar, en la siguiente tabla se ofrecen los datos de la duración de los diferentes grupos focales.

Tabla 67.- Duración de los grupos focales: personas sordas, familiares y profesionales $(\mathrm{n}=36)$

\begin{tabular}{|c|c|c|c|}
\hline Grupo Focal & $\mathrm{N}^{\circ}$ PARTICIPANTES & Duración & $\begin{array}{l}\mathrm{N}^{\mathrm{o}} \mathrm{de} \\
\text { palabras }\end{array}$ \\
\hline Grupo 1 Familiares & \multirow{3}{*}{ \& } & $25: 06$ & 3715 \\
\hline Grupo 2 Familiares & & $19: 38$ & 1470 \\
\hline Grupo 3 Familiares & & $19: 44$ & 2766 \\
\hline Grupo 1 Personas sordas & \multirow{3}{*}{ 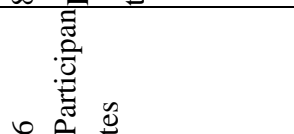 } & $33: 45$ & 2129 \\
\hline Grupo 2 Personas sordas & & $36: 01$ & 1358 \\
\hline Grupo 3 Personas sordas & & $26: 01$ & 334 \\
\hline Grupo 1 personas con hipoacusia & \multirow{2}{*}{ 吢 } & $50: 15$ & 6637 \\
\hline Grupo 2 personas con hipoacusia & & $35: 49$ & 2543 \\
\hline Grupo 1 Profesionales & \multirow{4}{*}{$n$ : } & $1: 26: 33$ & 14013 \\
\hline Grupo 2 Profesionales & & $50: 58$ & 7913 \\
\hline Grupo 3 Profesionales & & $37: 31$ & 6779 \\
\hline Grupo 4 Profesionales & & $40: 28$ & 6060 \\
\hline
\end{tabular}

En la anterior tabla podemos observar las diferencias en cuanto a la duración de los grupos focales y el número de palabras transcritas en los mismos. Cabe resaltar que los grupos de los profesionales fueron los que obtuvieron un mayor número de palabras y de duración, sin embargo los familiares fueron los que obtuvieron una menor duración pero fueron los grupos de personas sordas los que acumularon un menor número de palabras.

\section{Transformación de las entrevistas a datos primarios}

El primer paso realizado fue la transcripción de la información grabada a documentos de texto (documentos primarios). La transcripción se realizó de manera manual por parte de la investigadora principal. Posteriormente, se llevó a cabo un análisis de contenido de los documentos primarios asignando códigos a las distintas ideas manifestadas por los participantes (quotations). Tanto el registro como la categorización del discurso producido en los grupos focales se llevó a cabo mediante el software Atlas ti 6.2.

Como ya se había explicado en la introducción, el análisis de contenido se llevó a cabo de dos maneras distintas: mediante la CIF y mediante un modelo de factores de abandono de PA. La CIF ofrece un lenguaje unificado y estandarizado, y un marco conceptual para la 
descripción de la salud y los estados "relacionados con la salud". Además la CIF es utilizada por varias disciplinas y diferentes sectores con múltiples propósitos como permitir la comparación de datos entre países, entre disciplinas sanitarias y entre los servicio (Campo, Saneiro \& Roca, 2002). La CIF proporciona un esquema de codificación sistematizado para ser aplicado en los sistemas de información estadística de distintos campos así como herramienta para desarrollar políticas públicas como las medidas de resultados en PA. En resumen, la CIF nos proporciona un marco de referencia conceptual que es aplicable tanto a la atención médica como a la social, y las dimensiones incluidas en la CIF pueden ser considerados como dominios de la salud y dominios "relacionados con la salud". La CIF por tanto adopta una posición neutral respecto a la etiología de manera que quedan como objeto de estudio los determinantes o factores de riesgo como una aportación en la comprensión conceptual de la discapacidad.

El proceso de codificación también fue llevado a cabo por la autora de esta tesis doctoral. El proceso consistía en la lectura del discurso codificado de cada grupo focal para identificar los fragmentos de los documentos primarios que tenían significado para el objetivo de la investigación (i.e., citas o quotations). Una vez identificada cada cita, se asignaba a alguno de los códigos CIF. En primer lugar se identificaba la dimensión (código de 1 dígito) a la que pertenecía la idea a codificar y posteriormente se identificaba el capítulo correspondiente (código de 2 dígitos). En el caso en el que hubiera información suficiente se concretaba la codificación en niveles inferiores con mucho más detalle (3 y 4 dígitos).

Posteriormente, tras el proceso de codificación, se realizó un sumatorio de los diferentes códigos en función de capítulo, dimensión y tipo de participante por grupo focal. El objetivo final de este proceso era poder comprobar el número de citas por dimensión de la CIF (funciones corporales, actividades y participación, estructuras corporales, factores ambientales y factores personales) y por grupo focal (personas sordas, personas con discapacidad auditiva, familiares y profesionales). Además, cabe señalar que los factores ambientales se clasificaron tal y como señala la CIF en barreras o facilitadores, lo que permitió realizar un registro de ambos según el tipo de grupo focal.

De forma paralela, en este estudio se realizó una codificación de los factores de abandono o falta de uso de los PA, según el modelo de Longenecker, Lauer \& Smith (2006). Este modelo clasifica en 5 apartados los posibles factores de abandono o falta de uso de los productos de apoyo; tres de estos apartados son factores negativos divididos en factores 
relacionados con la persona, el propio PA y el entorno; otro apartado sobre factores positivos y el último apartado, es el calificado como otros en el que se incluyen los factores neutrales.

Para realizar la categorización de los diferentes factores de abandono se analizaron las diferentes transcripciones del discurso de los diferentes grupos focales. Si durante el análisis del discurso se presentaba alguna cita relacionada con el tema, se registraba el factor de abandono que correspondía, seleccionándolo entre los 30 factores de abandono englobados del modelo de Longenecker, Lauer \& Smith. Tras este proceso se realizaba un sumatorio de los diferentes factores de los cinco apartados del modelo y se clasificaba por grupo de participante.

Como modo de estimar la fiabilidad en la asignación de citas a códigos CIF se utilizó un procedimiento consistente en seleccionar al azar 39 citas que habían sido asignadas a los distintos capítulos de la CIF por el codificador original, y se administraron a dos jueces independientes, conocedores de la clasificación CIF y que fueron instruidos para la codificación en el colectivo de personas con discapacidad auditiva, ambos jueces emplean la CIF en su labor profesional diaria, el juez 1 es un terapeuta ocupacional e fisioterapeuta y ha desarrollado tu trayectoria profesional en el campo de la rehabilitación en física en personas con daño cerebral mientras que el juez 2 es una profesional de la logopedia con amplia experiencia en el colectivo de las personas sordas pertenecientes a la Comunidad Sorda y emplea la CIF para la evaluación de los mismos. Los jueces asignaron un código CIF a las citas y se calculó un porcentaje de concordancia, considerando la concordancia como la coincidencia en la asignación de códigos entre el codificador original y las codificaciones de los dos jueces. Hay que destacar que algunos de los jueces utilizaron codificaciones con más dígitos que la original y estos casos también fueron considerados como concordancias dado que los códigos CIF de 4 dígitos, por ejemplo, están contenidos en el código jerárquicamente superior de 3 dígitos.

El análisis de concordancia mostró un acuerdo del 97\% en la asignación de códigos a citas. 


\section{Análisis de citas en función de la CIF}

En primer lugar, se presentarán los resultados obtenidos de los sumatorios de citas en las 5 dimensiones de la CIF por tipo de participante (véase Tabla XX).

Tabla 68.- Número de citas en función de las dimensiones de la CIF y el tipo de grupo focal

\begin{tabular}{|c|c|c|c|c|}
\hline Dimensión/ Grupo & Familiares & Profesionales & $\begin{array}{l}\text { Personas con } \\
\text { hipoacusia }\end{array}$ & Personas sordas \\
\hline Actividades y participación & 374 & 467 & 194 & 151 \\
\hline Estructuras corporales & 1 & 14 & 4 & 3 \\
\hline Factores ambientales & 198 & 640 & 138 & 232 \\
\hline Funciones corporales & 125 & 236 & 152 & 121 \\
\hline Factores personales & 69 & 337 & 105 & 129 \\
\hline TOTAL & 767 & 1694 & 593 & 636 \\
\hline
\end{tabular}

En la tabla anterior se puede observar como los profesionales son los que mayor número de citas producen en todas las dimensiones, en especial citas sobre los factores ambientales ( $\mathrm{n}=640)$ y también en actividades y participación (467). Tras los profesionales, los familiares fueron los que obtuvieron un mayor número de citas. Debemos puntualizar en este grupo que la mayor parte de sus citas corresponden a la dimensión de actividades y participación probablemente reflejo de la percepción de que sus allegados con discapacidad encuentran una limitación en el desarrollo de sus actividades y su participación social, debida en gran parte a los factores ambientales considerados como barreras en su mayor parte. En cuanto a las personas sordas, durante su discurso los factores ambientales suscitaron un mayor número de citas, haciendo referencia en su mayoría a los PA, puesto que, la mayor parte de este grupo fueron personas usuarias de los mismos, entre los cuales también se encontraba una persona sorda totalmente en contra al implante coclear. Sin embargo, dos de los participantes implantados cocleares avalaron en uso de dicho dispositivo. La dimensión de actividades y participación obtuvo también un número mayor de códigos que el resto de dimensiones pero en menor proporción que los profesionales y familiares. No obstante, en el grupo de personas con discapacidad auditiva se verificó un mayor número de citas en la dimensión de actividades y participación puesto que esta se había visto reducida y mermada a raíz de la adquisición de su discapacidad. En este grupo la mayor parte de los participantes tenían un tipo de pérdida postlocutiva y de aquí se puede derivar, también, que la dimensión que obtuvo un mayor número de citas seguida de actividades y participación fuera la de 
funciones corporales, porque a diferencia de la mayor parte de las personas sordas, las personas con discapacidad auditiva quiere restaurar la función de la audición, mientras que la mayor parte de las personas sordas se sientes miembros de la Comunidad Sorda y tienen una cultura y lengua diferente a la oyente como se explicó en la parte teórica de esta Tesis Doctoral.

El análisis global de citas es complejo y por ello también se calcularon las citas en función de los códigos CIF para cada grupo focal. Dado el elevado número de resultados que surgen de un análisis de estas características, solo se expondrán las tablas con códigos de hasta 3 dígitos.

En primer lugar, en la siguiente tabla podemos observar el número total de citas de primer nivel de la CIF en función de los 4 tipos participantes de los grupos focales: familiares, personas con hipoacusia, profesionales y personas sordas. 
Tabla 69.- Códigos de primer nivel de la CIF que aparecen en los diferentes grupos focales y número de citas por tipo de grupo de participantes $(n=36$ )

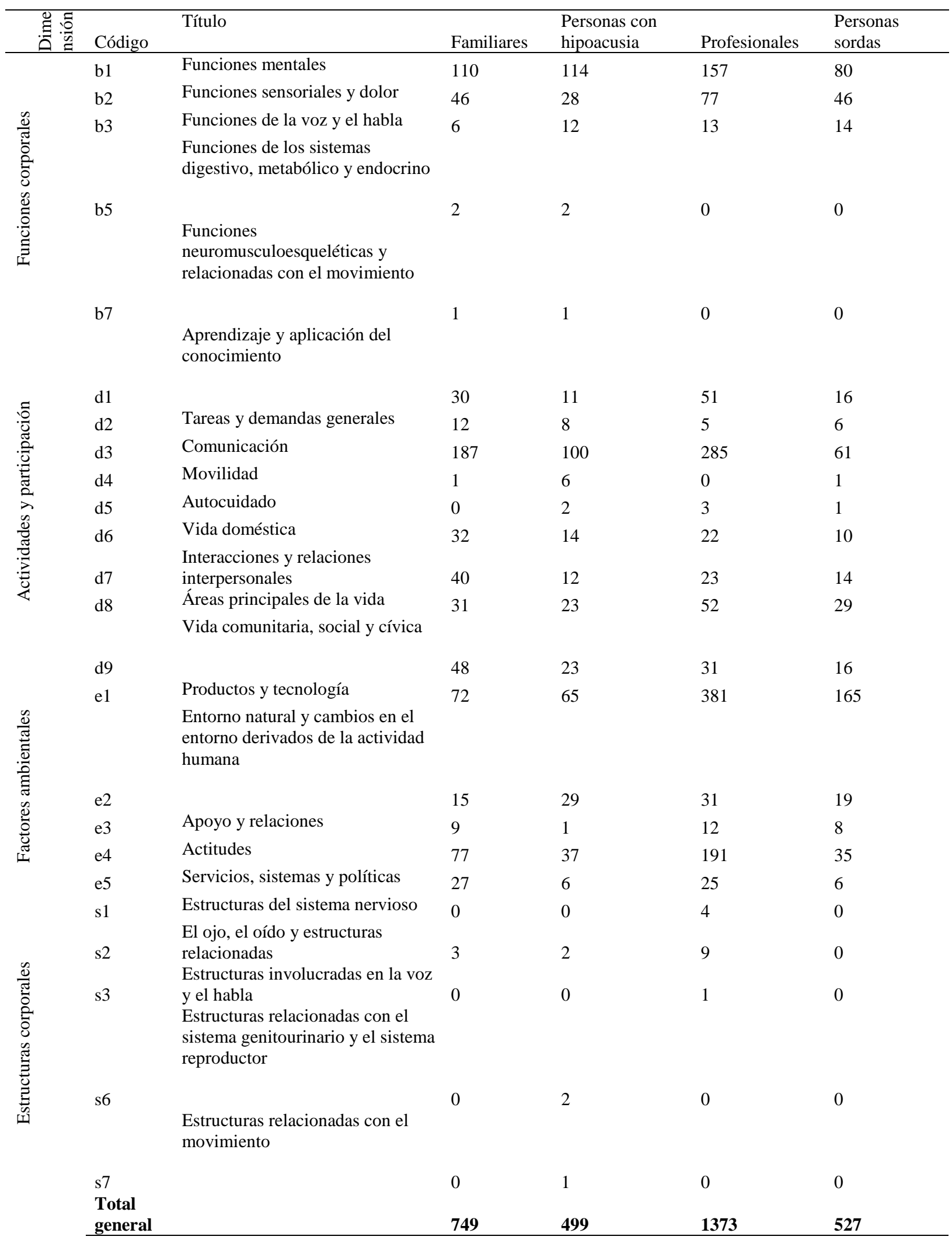


En la primera dimensión de la CIF, funciones corporales, cabe destacar que los profesionales producen un mayor número de citas en los capítulos de funciones mentales y funciones sensoriales y dolor; sin embargo, son las personas sordas las que presentan un mayor número en las funciones de la voz y el habla, seguidos de profesionales y personas con hipoacusia. Cabe resaltar que los familiares son los que presentan un menor número de citas en este último capítulo. Este resultado podría derivar de que la mayor parte de las personas sordas signantes tienen dificultades y limitaciones en sus funciones de la voz y el habla. El hecho de este resultado no se muestre en sus familiares podría parecer contradictorio según la literatura, ya que una de las mayores preocupaciones de los familiares es la limitación en el lenguaje oral que presentan algunas personas sordas, y es por ello, que son muchos los progenitores de personas sordas que optan por el implante coclear (Gregory, Sheldon, \& Bishop, 1995; Hyde \& Power, 2006; Peterson, 2004). En el caso de los familiares de los grupos focales de este estudio parece que no manifiestan tanta preocupación como las propias personas sordas por aspectos relacionados con las actividades de la vida diaria tales como el autocuidado.

En la segunda dimensión de la CIF, Actividad y Participación, cabe resaltar que son los profesionales, junto con los familiares, los que presentan un mayor número de citas en el capítulo de comunicación ( $\mathrm{n}=285$ y $n=187$ respectivamente) frente a las personas sordas $(\mathrm{n}$ $=61$ ). Este resultado puede derivar del hecho de que las personas sordas usuarias de lengua de signos no perciben su discapacidad como lo hacen los profesionales del campo y sus familiares. De hecho, existen estudios previos que muestran que la opinión de las personas sordas y sus preocupaciones psicosociales son pocas veces abordadas tanto por profesionales como familiares en comparación con otras limitaciones percibidas por estos (Grenness, Hickson, Laplante-Lévesque, Meyer, \& Davidson, 2015). Otro resultado que cabe señalar es el capítulo "aprendizaje y aplicación del conocimiento", donde tanto los profesionales como los familiares presentan un mayor número de citas. Ello puede deberse a la preocupación que ha habido, y existe hoy en día, respecto a la educación de las personas sordas. Aunque la educación reglada actual se basa (en algunos centros pioneros en nuestro país) en un enfoque bicultural y bilingüe, sigue siendo una de las mayores barreras que presenta el colectivo de personas sordas (Marchesi, 1987; Torrijo, 2005). Según los resultados, parece que los familiares prestan mayor preocupación a las interacciones y relaciones interpersonales como a la vida comunitaria, social y cívica y a la vida doméstica respecto a los otros grupos, esto puede deberse que los familiares presentan una mayor preocupación porque perciben una 
carencia en la participación y el desempeño de actividades instrumentales y avanzadas (Backenroth, 1995; Harris \& Bamford, 2001; Hindley \& Kitson, 2000; Power \& Hyde, 2002).

En tercer lugar, en la dimensión Factores Ambientales cabe destacar que los profesionales son los que presentan un mayor número de citas en comparación con los otros grupos y en mayor proporción en los capítulos de productos y tecnología y actitudes. También las personas sordas presentan un alto número de citas en el capítulo de productos y tecnologías. Esto puede deberse que en la última década las nuevas tecnologías desarrolladas para las personas sordas incluyen el uso de las lenguas de signos. Además con la inclusión de la telefonía móvil y los mensajes de texto, incluyendo aplicaciones móviles específicas tales como WhatsApp, Telegram o Messenger, son muchas las personas sordas que emplean estos dispositivos para la comunicación (Goggin, 2004; May \& Hearn, 2005; Power, Power, \& Horstmanshof, 2007). Los resultados revelan que las actitudes sociales son uno de los factores ambientales más destacados de esta dimensión (Bebout \& Arthur, 1992; Coryell, Holcomb, \& Scherer, 1992; Deal, 2003). Puede deberse a que existe una percepción social de la sordera equívoca en la sociedad occidental porque, en general, las personas oyentes consideran a las personas sordas y personas con discapacidad auditiva como personas afectadas en su desarrollo intelectual e incluso su capacidad psíquica (Corvera \& González, 2000). Además, son pocos los oyentes que entienden lo que significa la identidad sorda (Mottez, 1995) y la pertenencia a la Comunidad Sorda es percibida a menudo por los oyentes con una actitud negativa hacia la misma (Gallardo, 1999).

En lo referente a la dimensión "Estructuras corporales", es la dimensión con un menor número de citas por parte de todos los grupos focales, aunque parece que existe un mayor número de citas en lo que refiere a las estructuras propias del oído y las relacionadas con el sistema nervioso.

A continuación se expondrán los resultados de citas tomando como unidad de análisis los códigos de 3 dígitos y, al igual que en tablas anteriores, en función del tipo de participante de los grupos focales.

Así, la tabla 70 hace referencia a las funciones mentales y cabe señalar que los códigos que obtuvieron un mayor número de citas fueron las funciones de la percepción, funciones mentales del lenguaje y funciones del temperamento y la personalidad. Siendo los profesionales y los familiares los que tienen un mayor número de citas. Dentro del colectivo de personas sordas y con discapacidad auditiva debemos tener en cuenta que las dificultades 
de comunicación verbal y no verbal se suman a las funciones mentales afectadas tales como la rigidez, el egocentrismo, la falta de control sobre sí mismo y la impulsividad (Corvera \& González, 2000). Existen estudios previos que tratan sobre el estrés que causa la discapacidad auditiva y los problemas mentales y de personalidad (e.g., Fellinger, Holzinger \& Pollard, 2012). Al igual de que existe evidencia científica que sugiere que el principio de la vida, la información auditiva y la comunicación son esenciales para el desarrollo normal del lenguaje, cognición y comportamiento (Quittner, Leibach \& Marciel, 2004)

Tabla 70.- Número de citas sobre Funciones Corporales (Funciones Mentales) en función del grupo focal

\begin{tabular}{|c|c|c|c|c|c|}
\hline $\begin{array}{l}\text { Código } \\
\text { CIF }\end{array}$ & Título & Familiares & $\begin{array}{l}\text { Personas con } \\
\text { hipoacusia }\end{array}$ & Profesionales & $\begin{array}{l}\text { Personas } \\
\text { sordas }\end{array}$ \\
\hline b122 & Funciones psicosociales globales & 7 & 0 & 1 & 0 \\
\hline b126 & Funciones del temperamento y la personalidad & 10 & 18 & 3 & 1 \\
\hline b130 & Funciones relacionadas con la energía y los impulsos & 3 & 5 & 2 & 1 \\
\hline b134 & Funciones del sueño & 0 & 0 & 0 & 1 \\
\hline b140 & Funciones de la atención & 0 & 2 & 4 & 0 \\
\hline b144 & Funciones de la memoria & 0 & 0 & 3 & 0 \\
\hline b147 & Funciones psicomotoras & 0 & 0 & 1 & 0 \\
\hline b152 & Funciones emocionales & 1 & 1 & 0 & 0 \\
\hline b156 & Funciones de la percepción & 38 & 44 & 73 & 43 \\
\hline b160 & Funciones del pensamiento & 2 & 0 & 0 & 0 \\
\hline b164 & Funciones cognitivas superiores & 1 & 12 & 7 & 0 \\
\hline b167 & Funciones mentales del lenguaje & 45 & 32 & 61 & 34 \\
\hline b180 & Experiencias relacionadas con uno mismo y con el tiempo & 3 & 0 & 1 & 0 \\
\hline b189 & $\begin{array}{r}\text { Funciones mentales específicas, otras específicas y no } \\
\text { específicas }\end{array}$ & 0 & 0 & 1 & 0 \\
\hline
\end{tabular}

A modo de resumen de las cuestiones planteadas por los participantes en los grupos focales, en esta parte de los resultados describiremos un conjunto de citas de cada uno de los apartados que se van a ir analizando. En la siguiente tabla se muestran ejemplos de citas de la dimensión funciones corporales. 
Tabla 71.- Ejemplos de citas del primer capítullo de la primera dimensión "Funciones Corporales"

\begin{tabular}{|c|c|}
\hline $\begin{array}{l}\text { Personas } \\
\text { hipoacúsica } \\
\text { postlocutiva }\end{array}$ & $\begin{array}{l}\text { "Para la vida social para estas siempre y si voy y no entiendo y si voy y no oigo y si estas } \\
\text { constantemente ahí en un que tienes límites. Hay veces que no sabes si te comportas bien o } \\
\text { no, algo que yo no me doy cuenta... al masticar no sabía que hacia ruido... sino me lo dicen } \\
\text { no lo sé yo no lo percibo como un mal comportamiento pero lo es" }\end{array}$ \\
\hline Profesional & $\begin{array}{l}\text { "El colectivo de sordos tiene una cultura y una lengua propia igualmente respetables pero sí } \\
\text { que hay que decir que ellos mismos son excluyentes sí que es verdad que tienen asociaciones y } \\
\text { demás pero nosotros somos sordos y vosotros sois oyentes y hay una barrera que yo creo que } \\
\text { hoy por hoy no todo el mundo sabe superar" }\end{array}$ \\
\hline $\begin{array}{l}\text { Persona } \\
\text { hipoacúsica }\end{array}$ & $\begin{array}{l}\text { "pero no todo el mundo sirve para hacer eso no todo el mundo tiene un carácter te vuelves } \\
\text { más sensible igual que más solidario te vuelves más sensible con la discapacidad" }\end{array}$ \\
\hline Profesional & $\begin{array}{l}\text { "A mí no me vale con lo de la señora de } 80 \text { años no es que tú tienes que decirlo otra vez se lo } \\
\text { dices tres veces y se lo vuelves a repetir igual y es más que tú crees que hablas alto pero } \\
\text { hablas a voces y a una persona que le hablan a voces no le gusta entonces no te lo va a volver } \\
\text { a preguntar y es que ya te da igual lo que diga y hay un momento que se va encerrando o sea } \\
\text { yo creo que sí que es hay interfiere muchas capacidades, y habilidades sociales y en } \\
\text { depresión, y muchas historias por no tener recursos para comunicarte con esa persona y que } \\
\text { necesita, y puede ser que esa persona debiera tener esos conomientos pero mi abuela con } 80 \\
\text { años o la abuela de mi prima con } 80 \text { años creo que no es culpa suya no tener esas habilidades } \\
\text { es que vive en un cortijo entonces le da vergüenza llevar el audífono mucha, le da vergüenza } \\
\text { preguntarle a su nieta } 3 \text { veces que ha dicho mucha, muchísima porque es ella la que nos cuida } \\
\text { entonces le da vergüenza sentirse discapacitada muchísima por lo cual pregunta, con lo cual } \\
\text { está metido ya en su mundo y si si si sabiendo todos que no se está enterando de nada, y si le } \\
\text { preguntas el nombre de alguien y ese quien es y a veces recuerda quien es pero a veces no } \\
\text { sabe ni de quien hablamos porque no lo ha oído previamente y te ha dicho que si entonces yo } \\
\text { que sé lo que decía C y la conversación que tenías en la panadería con toda la naturalidad ya } \\
\text { no la tienes y que tu como hablas tan bien porque si tu pierdes la audición con } 80 \text { años tu voz } \\
\text { no cambia, es que esta mayor no perdona puede estar mayor y todo lo que tú quieras pero mis } \\
\text { capacidades están perfectas y no te oigo, entonces el problema está que nosotros no tenemos } \\
\text { recursos para comunicarnos con ella." }\end{array}$ \\
\hline $\begin{array}{l}\text { Persona } \\
\text { hipoacúsica }\end{array}$ & $\begin{array}{l}\text { "Las nuevas tecnologías depende de lo sociable que seas supongo que eso es cuestión de la } \\
\text { persona de lo sociable que sea ayudar por supuesto q ayudan más facilidades tienes he tenido } \\
\text { un WhatsApp y un Facebook puedes hacerlo por palabras es más fácil pero hacer amigos } \\
\text { nuevos depende de la persona y no sé yo no soy muy sociable pero a mis años ya es difícil } \\
\text { jajaja encontrar gente conocida nueva" }\end{array}$ \\
\hline Persona sorda & $\begin{array}{l}\text { "yo con personas sordas que usan lengua de signos estuve mucho tiempo una temporada con } \\
\text { ellos pero cuando estas con ellos pierdes totalmente el habla no puedo y mucho no entienden } \\
\text { mi manera de hablar yo convivir no puedo porque pierdo de todo, me cambia la persona mía" }\end{array}$ \\
\hline Persona sorda & $\begin{array}{l}\text { "Yo pienso que la sordera afecta a la persona, la sociedad no ayudan que es las personas } \\
\text { sordas las que deben de colaborar. El audífono o el i.c no hacen nada si tú eres una persona } \\
\text { que puedes hacerlo y punto. El i.c o el audífono da igual tu si te los quitas puedes hacerlo. Por } \\
\text { ejemplo si a mí me apetece jugar un partido de fútbol y te quitas el i.c da igual." }\end{array}$ \\
\hline Familiar & $\begin{array}{l}\text { "Yo creo que ella se puede desarrollar más como persona con oyentes se abre más al mundo a } \\
\text { otras opiniones porque hay a veces que están hablando varios y hay varias opiniones pues ella } \\
\text { absorbe más opiniones yo pienso" }\end{array}$ \\
\hline $\begin{array}{l}\text { Persona } \\
\text { hipoacúsica }\end{array}$ & $\begin{array}{l}\text { "Vamos a ver todo esto es según la persona las personas que somos con mucho } \\
\text { temperamento o nos hacemos a la idea tiramos para adelante pero yo conozco personas que } \\
\text { son muy acopadas y a lo mejor no vienen ni a estas reuniones el hecho de que estemos aquí es } \\
\text { que ya somos personas que estamos intentando entender al otro intentando mejorar } \\
\text { intentando ser positivos pero hay personas que se hunden y es verdad es que esto va en la } \\
\text { persona yo me enfado a mí me sienta mal no me gusta ver a esas personas como dices que se } \\
\text { hunden" }\end{array}$ \\
\hline
\end{tabular}


Respecto al capítulo de funciones corporales, en la tabla 72 podemos observar que el código que más citas ha acumulado es el relativo a las funciones auditivas, siendo los profesionales y las personas sordas las que tienen un mayor número de citas. Esto puede ser debido a que una de las mayores preocupaciones de los profesionales es reestablecer la función auditiva mediante el uso de técnicas y procedimientos tales como el uso de PA (Tucker, 1998). Para las personas sordas y personas con discapacidad auditiva es la función auditiva el motivo de su discapacidad por lo cual resulta obvio que tenga un mayor número de citas este código respecto a los otros.

Tabla 72.- Número de citas sobre Funciones Corporales (Funciones Sensoriales y del dolor) en función del grupo focal

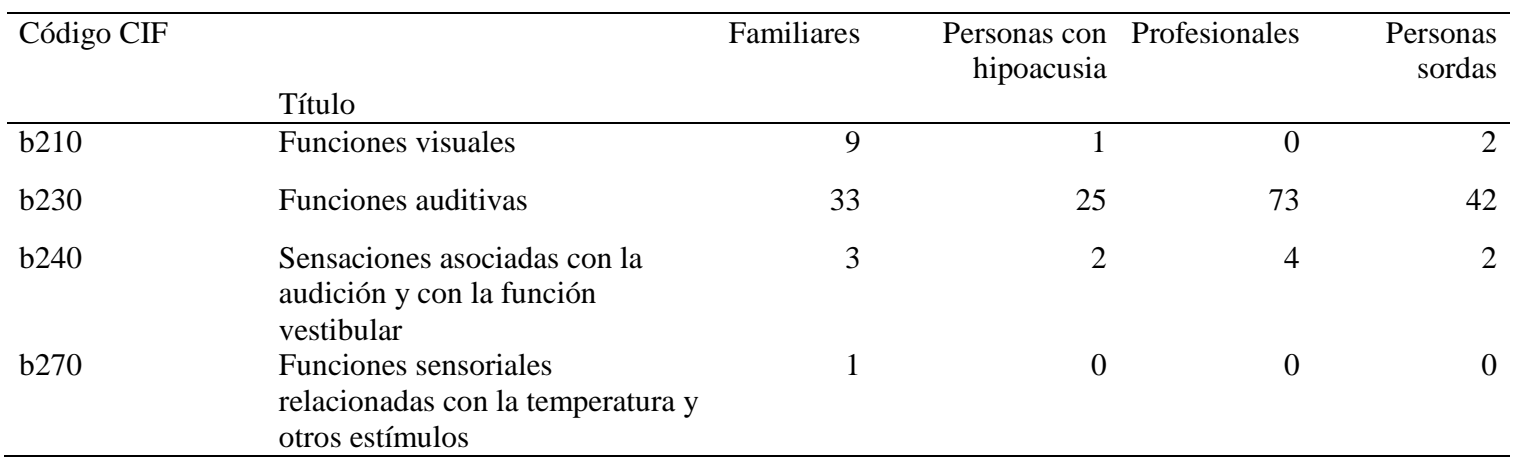


Tabla 73.-Ejemplos de citas del segundo capítulo de la dimensión "Funciones corporales"

\begin{tabular}{|c|c|}
\hline Familiar & $\begin{array}{l}\text { "es que tenemos que pensar que XXXXXX tiene una pérdida total de uno no tiene nada y del otro solo restos } \\
\text { entonces estamos hablando de una perdida que yo no sé si los audífonos en otras pérdidas serán vitales en esta } \\
\text { de Esther no tanto" }\end{array}$ \\
\hline $\begin{array}{l}\text { Persona } \\
\text { con } \\
\text { hipoacusia }\end{array}$ & $\begin{array}{l}\text { "yo creo que hay diferencias hay diferencias en la edad si la pérdida auditiva te coge en una edad mediana } \\
\text { edad yo creo que es más fácil el adaptarte a los audífonos. Yo conozco personas mayores que son muy } \\
\text { reticentes a ponerse los audífonos otros que lo han intentado y tienen los audífonos en casa porque no soportan } \\
\text { claro las primeras sensaciones que tienes al principio de utilizar el audífono pues son diferentes, te sientes } \\
\text { diferente, oyes diferente y todo es diferente" }\end{array}$ \\
\hline $\begin{array}{l}\text { Persona } \\
\text { con } \\
\text { hipoacusia }\end{array}$ & $\begin{array}{l}\text { "pues que me limitan me limitan es decir yo pensaba que yo iba a tener más autonomía y no tengo tanta } \\
\text { autonomía también me limita mucho. En conversaciones pues a veces oigo las palabras así sueltas pero no cojo } \\
\text { la conversación completa."” yo de lo que dices o sea de los ruidos del ordenador y tal yo es que creo que } \\
\text { muchos de los que oímos mal encima nos molesta mucho más el ruido nos sentimos muchos más molestos ante } \\
\text { el ruido más que incluso que el que oye normalmente a mí a mi particularmente a mi he notao que me pasa eso } \\
\text { aparte de eso a mí con lo que dicen de los estudios a mis veintitantos yo no era consciente de que de que yo no } \\
\text { oía bien pero me da la impresión ahora de que ya tenía empezaba a no oír bien porque yo ahora me doy cuenta } \\
\text { de que tenía un compañero que siempre le andaba preguntando que ha dicho y yo creía que yo era muy } \\
\text { distraído bueno pero que lo soy no es que soy un distraído y todo lo achacaba a ello pero posiblemente ahora } \\
\text { me doy cuenta que algo era de falta de oído." }\end{array}$ \\
\hline $\begin{array}{l}\text { Persona } \\
\text { sorda }\end{array}$ & $\begin{array}{l}\text { "es muy buena, muy buena pongamos el ejemplo del mar yo con el audífono yo oía el mar escandaloso vaya por } \\
\text { dios si el mar se oye como una moto es que oirá el ese del mar como una moto me parecía desagradable oír el } \\
\text { mar me levantaba dolor de cabeza con el audífono todo metálico todo artificial todo angoso no sé hasta las } \\
\text { personas las oía también raras y con el i.c no con el i.c captas mejor el sonido del mar oyes eso un susurro } \\
\text { notas como golpea la roca, como cae el agua a la roca si luego también oyes los pájaros el pio el piar de los } \\
\text { pájaros el romper las leñas cuando queman que se chascan que hacen crash que antes no se oía con el audífono } \\
\text { son muchas cosas y ha sido muy buena la discriminación ha sido muy buena y en palabras también sobre todo } \\
\text { en mi misma yo he notado que hablo mejor porque me controlo mejor la voz yo con el audífono no sabía si } \\
\text { controlaba si hablaba alto o hablaba bajo no sabía la gente me decía cállate o hablas más alto claro no sabía } \\
\text { eso con el i.c lo controlas más" }\end{array}$ \\
\hline $\begin{array}{l}\text { Persona } \\
\text { sorda }\end{array}$ & $\begin{array}{l}\text { "Yo por ejemplo antes cuando tenía los audífonos no diferenciaba los sonidos por ejemplo de una ambulancia o } \\
\text { de la sirena de una policía. Ahora con el i.c diferencio muchas cosas yo voy por la calle y oigo una sirena y sé } \\
\text { que es la de policía y miro y digo ah es la de policía. La voz la diferencio pero si es agudo o grave no lo noto } \\
\text { mucho" }\end{array}$ \\
\hline Familiar & $\begin{array}{l}\text { "depende de la situación porque si te pones de frente te leen los labios a pesar de que lleven audífonos si te } \\
\text { tapas la boca te buscan ellos la forma de colocarse para ello pero ellos son más de leer los labios y su mundo es } \\
\text { ese luego yo creo que oyen mejor por detrás pero bueno eso es por mi experiencia personal y lateral también } \\
\text { oyen mejor que de frente o así como oír si estas de frente te ven mejor por los labios" }\end{array}$ \\
\hline
\end{tabular}

Tabla 74.- Número de citas sobre Funciones Corporales (Funciones de la voz y el habla) en función del grupo focal

\begin{tabular}{lrrrrr}
\hline Código CIF & Título & Familiares & $\begin{array}{r}\text { Personas con } \\
\text { hipoacusia }\end{array}$ & $\begin{array}{r}\text { Profesionales } \\
\text { b310 }\end{array} \quad \begin{array}{r}\text { Personas } \\
\text { sordas }\end{array}$ \\
b320 & Funciones de la articulación & 1 & 3 & 4 & 6 \\
b330 & $\begin{array}{r}\text { Funciones relacionadas con } \\
\text { la fluidez y el ritmo del } \\
\text { habla }\end{array}$ & 4 & 4 & 0 & 1 \\
b340 & $\begin{array}{r}\text { Funciones alternativas de } \\
\text { vocalización }\end{array}$ & 1 & 2 & 9 & 5 \\
& & & & 0 & 0 \\
\hline
\end{tabular}

Las personas sordas junto con los profesionales son los que han acumulado un mayor número de citas en este capítulo perteneciente a la dimensión de las funciones corporales. Esto puede derivarse del hecho que una de las principales estrategias de intervención con el colectivo de las personas sordas tienen el objetivo principal de mejorar y trabajar las funciones de la voz, articulación, vocalización y las relacionadas con la fluidez y 
ritmo del habla (Blamey et al., 2001; Erber, 1975; Monsen, 1983). Para las personas sordas oralistas y para las personas con discapacidad auditiva tales como las postlocutivas, emplean la lengua oral como medio de comunicación, por lo que puede ser razonable que acumulen un mayor número de citas. En la literatura científica encontramos que una de las mayores preocupaciones de las personas sordas prelocutivas es la articulación y vocalización dado que su voz en ocasiones es de difícil comprensión para personas oyentes, mientras que para las personas con discapacidad auditiva postlocutiva el tono de voz y el ritmo es una de sus mayores limitaciones en la expresión comunicativa oral (Atkinson, 2006; Barnett, 2002; Perfetti \& Sandak, 2000; Sloboda, Wise \& Peretz, 2005). 
Tabla 75.- Ejemplos de citas del tercer capítulo de la dimensión "Funciones corporales"

\begin{tabular}{|c|c|}
\hline $\begin{array}{l}\text { Persona } \\
\text { sorda }\end{array}$ & $\begin{array}{l}\text { "Luego probé con el i.c a llamar y mucho mejor bueno yo no entiendo a todo el mundo solo a la } \\
\text { gente de confianza mi madre mi hermano porque ellos saben cómo deben de vocalizar y hacer con } \\
\text { la voz para que yo les entienda. Pero la verdad es que a mí el i.c me ayuda muchísimo" }\end{array}$ \\
\hline $\begin{array}{l}\text { Persona } \\
\text { sorda }\end{array}$ & $\begin{array}{l}\text { "yo creo que el i.c ayuda muchísimo porque además puedes manejar el teléfono hablando pero cada } \\
\text { persona tiene una voz distinta hay personas que hablan deprisa hay personas que hablan bajo hay } \\
\text { personas que hablan alto y no se entiende muy bien, es normal como toda persona que oye y yo } \\
\text { puedo escuchar perfectamente por teléfono a quien sea porque antes era presidente de la comunidad } \\
\text { de vecinos y me apañe yo solo llamando a un fontanero, a un pintor, a un trabajador para que } \\
\text { regara las flores del portal y muy bien sin ningún problema" }\end{array}$ \\
\hline $\begin{array}{l}\text { Persona } \\
\text { hipoacusica }\end{array}$ & $\begin{array}{l}\text { "no sabía si controlaba si hablaba alto o hablaba bajo no sabía la gente me decía cállate o hablas } \\
\text { más alto claro no sabía eso" }\end{array}$ \\
\hline $\begin{array}{l}\text { Persona } \\
\text { hipoacúsica }\end{array}$ & $\begin{array}{l}\text { "Yo oigo totalmente por todas las direcciones normalmente sé por dónde viene un ruido con los } \\
\text { audífonos pero me gusta más hablar de frente porque me ayudo con los labios y con los gestos y me } \\
\text { entero muchísimo mejor." }\end{array}$ \\
\hline $\begin{array}{l}\text { Persona } \\
\text { con } \\
\text { hipoacusia }\end{array}$ & $\begin{array}{l}\text { "algo creo que genera al menos a mí un poco de tensión al menos a mí me genera un poco de } \\
\text { tensión es él lo voy a oír no lo voy a oír y sobre todo sobre todo cuando estas en ese término le oigo } \\
\text { no le oigo y coges el teléfono y ya lo coges un poquito con ese temor a ver si cuando a lo mejor ya } \\
\text { están hablando por teléfono bajo y le tienes que decir por favor puede hablar un poco más alto o } \\
\text { arrimarse más al teléfono a mi es algo que por experiencia sé que habrá personas más tranquilas } \\
\text { que yo a mi es lo que más me fastidia en las relaciones sociales porque te las vas quitando te vas } \\
\text { retirando de ellas" }\end{array}$ \\
\hline $\begin{array}{l}\text { Persona } \\
\text { sorda }\end{array}$ & $\begin{array}{l}\text { "bueno pues yo el audífono capto más información tanto escrita porque no entiendo lo que dice } \\
\text { pues voy a leer la prensa lo que dice o voy a leer con atención los subtitulados por ejemplo antes } \\
\text { era así, ahora con el implante capto más oigo más y leo más capto mucho más la información y me } \\
\text { he dado cuenta que en la tv cuando dice una cosa los subtítulos dice otra cosa para tenerlo en } \\
\text { cuenta faltan palabras faltan frases falta preposiciones falta artículos falta tal y del subtitulo lo } \\
\text { deduces. Dan información muy pobre para sordos" }\end{array}$ \\
\hline Profesional & $\begin{array}{l}\text { "vale, desde el punto de vista logopédico sí que nos apoyamos mucho en las prótesis auditivas tanto } \\
\text { los i.c como los audífonos porque ayudan a que el niño escuche hable bien y mientras aprende habla } \\
\text { entienda bien los fonemas y el objetivo de la logopedia es que los niños hablen por así decirlo la } \\
\text { lengua de signos queda en un segundo puesto entonces el objetivo es que el niño hable y si escucha } \\
\text { es la única forma de que pueda hablar bien, la entonación, la prosodia entonces sí que estamos de } \\
\text { acuerdo en las ayudas técnicas y creo que la mayoría de los logopedas sí que aconsejan que o } \\
\text { pongan i.c a sus hijos o al menos audífonos si tiene restos" }\end{array}$ \\
\hline
\end{tabular}

Son muchas las personas sordas y con discapacidad auditiva que recurren al uso de productos de apoyo tales como los implantes cocleares para mejorar la calidad de la recepción de la voz y otros sonidos (Park, Shipp, Chen, Nedzelski, \& Lin, 2011; Sladen \& Zappler, 2015; Zohdi, AbdelMessih, El Shennawy, Badreldin, \& Ashour, 2014). Por otra parte, ayudas para la comprensión del lenguaje oral tales como los subtítulos tienen a menudo fallos en la redacción y es uno de los ámbitos que las personas sordas suelen acusar mayor queja (Heckendorf, 2009). 
Tabla 76.- Número de citas sobre Funciones Corporales (Capítulo 5: Funciones de los sistemas digestivo, metabólico y endocrino y Capítulo 7: Funciones neuromusculoesqueléticas y relacionadas con el movimiento) en función del grupo focal

\begin{tabular}{|c|c|c|c|c|c|}
\hline $\begin{array}{l}\text { Código } \\
\text { CIF }\end{array}$ & Título & Familiares & $\begin{array}{r}\text { Personas con } \\
\text { hipoacusia } \\
\end{array}$ & Profesionales & $\begin{array}{r}\text { Personas } \\
\text { sordas } \\
\end{array}$ \\
\hline b510 & Funciones relacionadas con la ingestión & 0 & 3 & 4 & 6 \\
\hline b540 & Funciones metabólicas generales & 1 & 0 & 0 & 1 \\
\hline b710 & $\begin{array}{r}\text { Funciones relacionadas con la movilidad de las } \\
\text { articulaciones }\end{array}$ & 4 & 4 & 9 & 5 \\
\hline b730 & Funciones relacionadas con la fuerza muscular & 1 & 2 & 0 & 0 \\
\hline
\end{tabular}

Tabla 77.- Ejemplos de citas del quinto y séptimo capítulo de la dimensión "Funciones corporales"

\begin{tabular}{|l|l|}
\hline Persona sorda & $\begin{array}{l}\text { "Mira yo creo mira yo soy diabético yo soy sordo yo muchas veces me tengo que ir al clínico } \\
\text { porque tengo el riñón un poco mal y tengo que irme y me tienen que meter cosas y todo. Pero yo } \\
\text { nunca me agobio porque esa persona que se ríe porque los demás estamos un poco mal" }\end{array}$ \\
\hline Familiar & $\begin{array}{l}\text { "las empresas no están ahora mismo capacitadas para para hacerlo se debería trabajar más ese } \\
\text { aspecto porque al igual que cualquier tipo de discapacidad del más del 33\% se pueden obtener con lo cual una persona con discapacidad auditiva puede tener muchísima } \\
\text { fuerza física y no requerir de otro tipo de tareas y puede hacerlo muy bien se debería de trabajar } \\
\text { un poco más" }\end{array}$ \\
\hline
\end{tabular}

La siguiente tabla hace referencia al capítulo de "Aprendizaje y Aplicación del conocimiento" de la dimensión Actividades y Participación. Como se puede observar, los códigos que obtuvieron un mayor número de citas son los referentes a leer. El campo de la lecto-escritura ha sido y es actualmente uno de los campos de investigación sobre las personas sordas/ personas con discapacidad auditiva más investigado. En el estudio de Alegría y Domínguez aclaran que la causa de que sea una de las áreas más investigadas es debido que los niños sordos, al inicio de la educación primaria, tienen un vocabulario muy limitado e insuficiente para leer y escribir, y este hecho añadido a las dificultades lingüísticas (léxicas y morfo-sintácticas) y pragmáticas, hacen de la lectoescritura un ámbito con limitaciones en el desempeño para este colectivo (Alegría \& Domínguez, 2009). 
Tabla 78.- Número de citas sobre Actividades y Participación (Aprendizaje y Aplicación del conocimiento) en función del grupo focal

\begin{tabular}{|c|c|c|c|c|c|}
\hline $\begin{array}{l}\text { Código } \\
\text { CIF }\end{array}$ & Título & Familiares & $\begin{array}{r}\text { Personas con } \\
\text { hipoacusia }\end{array}$ & Profesionales & $\begin{array}{r}\text { Personas } \\
\text { sordas } \\
\end{array}$ \\
\hline $\mathrm{d} 115$ & Escuchar & 0 & 1 & 0 & 0 \\
\hline d120 & $\begin{array}{r}\text { Otras experiencias sensoriales } \\
\text { intencionadas }\end{array}$ & 2 & 0 & 0 & 0 \\
\hline d130 & Copiar & 1 & 0 & 0 & 0 \\
\hline d140 & Aprender a leer & 1 & 0 & 8 & 0 \\
\hline d145 & Aprender a escribir & 1 & 0 & 7 & 0 \\
\hline d150 & Aprender a calcular & 1 & 0 & 0 & 0 \\
\hline d155 & Adquisición de habilidades & 4 & 3 & 9 & 1 \\
\hline d159 & $\begin{array}{r}\text { Aprendizaje básico, otro especificado } \\
\text { y no especificado }\end{array}$ & 1 & 0 & 0 & 0 \\
\hline d160 & Centrar la atención & 2 & 0 & 0 & 0 \\
\hline d166 & Leer & 5 & 2 & 15 & 12 \\
\hline d 170 & Escribir & 6 & 0 & 6 & 0 \\
\hline d175 & Resolver problemas & 1 & 2 & 0 & 0 \\
\hline d177 & Tomar decisiones & 1 & 0 & 1 & 0 \\
\hline d179 & $\begin{array}{r}\text { Aplicación del conocimiento, otra } \\
\text { especificada y no especificada }\end{array}$ & 1 & 0 & 1 & 0 \\
\hline d198 & $\begin{array}{l}\text { Aprendizaje y aplicación del } \\
\text { conocimiento, otro especificado }\end{array}$ & 3 & 2 & 3 & 2 \\
\hline
\end{tabular}


Tabla 79.- Ejemplos de citas del primer capítulo de la dimensión "Actividad y Participación"

\begin{tabular}{|c|c|}
\hline Familiar & $\begin{array}{l}\text { "a los oyentes no los admiten y es que no quieren introducirlos en su mundo y es la única forman } \\
\text { de que ellos aprendan y no sé qué aprendan del mundo normal y esto es juntarse con gente de todo } \\
\text { tipo pues no ellos se meten en su mundo de sordera y su mundo de signos y no quieren saber más } \\
\text { son muy cerrados muy cerrados" }\end{array}$ \\
\hline Profesional & $\begin{array}{l}\text { "el área del lenguaje es el área del lenguaje y tú puedes aprender lengua de signos y lengua oral, } \\
\text { dependiendo del acceso que tengas tú en ese momento a la información, por qué vía, porque a lo } \\
\text { mejor adquieres antes el lenguaje por lengua de signos y luego poco a poco gracias al apoyo del } \\
\text { implante, del audífono, poco a poco se van mejorando características auditivas que te van } \\
\text { mejorando el acceso al lenguaje oral o te facilitan la lengua escrita, porque al fin y al cabo la } \\
\text { lengua de signos no es mmmm no es suficiente para acceder a una lectoescritura porque no tiene } \\
\text { una lectoescritura es una pena, que debería tenerla, pero no la tiene. La lectoescritura es la lengua } \\
\text { española es oral y claro pues si estas aprendiendo un lenguaje la lengua de signos, y luego te vas al } \\
\text { oral, pues yo también pienso de aquí va el debate de a qué edad los niños aprenden a leer y a } \\
\text { escribir en España, comparándolo con otros países, que sistema y que tipo de enseñanza a la hora } \\
\text { de la lectoescritura se utiliza con los niños, en fin." }\end{array}$ \\
\hline Profesional & $\begin{array}{l}\text { "No se tienen las ayudas técnicas vamos los productos estos auditivos sí que al escuchar entienden } \\
\text { la estructura semántica de la oración entonces a la hora de escribir saben que el sujeto va el } \\
\text { primero luego el verbo los complementos. Vamos ayuda a la estructura de la frase y esto ayuda a la } \\
\text { hora de seguir. Sí que es cierto que los sordos que no tienen así una lengua muy rica sí que fallan } \\
\text { en ese aspecto y sí que cometen errores en la sintaxis y en la estructura de las oraciones que son } \\
\text { raras para las personas que leen en estructura de castellano porque ellos escriben en estructura de } \\
\text { lengua de signos entonces a los profesores les lleva error porque no saben que está escribiendo } \\
\text { bien solo que con estructura de lengua de signos. Que cambia en cuanto a la estructura de la } \\
\text { lengua oral. Sí que es importante" }\end{array}$ \\
\hline Familiar & $\begin{array}{l}\text { "yo creo que eso de que sean incultas como dice mi padre no, a lo mejor ha sido porque a nivel } \\
\text { educativo no se les ha estimulado ni se les ha entendido su discapacidad desde hace bien poco que } \\
\text { vamos que se entendian como que tuvieran un retraso mental y no una discapacidad auditiva que } \\
\text { les impedía comunicarse entonces no se les ha estimulado no se ha trabajado con ellos y por tanto } \\
\text { no saben ni leer ni escribir porque se les apartaba precisamente de todo esto y bueno creo que no } \\
\text { ha sido culpa de ellos sino ha sido culpa que en general no se ha entendido bien esa discapacidad" }\end{array}$ \\
\hline $\begin{array}{l}\text { Persona } \\
\text { sorda }\end{array}$ & $\begin{array}{l}\text { "bueno pues yo el audífono capto más información tanto escrita porque no entiendo lo que dice } \\
\text { pues voy a leer la prensa lo que dice o voy a leer con atención los subtitulados por ejemplo antes } \\
\text { era así, ahora con el implante capto más oigo más y leo más capto mucho más la información y me } \\
\text { he dado cuenta que en la tv cuando dice una cosa los subtítulos dice otra cosa para tenerlo en } \\
\text { cuenta faltan palabras faltan frases falta preposiciones falta artículos falta tal y del subtitulo lo } \\
\text { deduces. Dan información muy pobre para sordos" }\end{array}$ \\
\hline $\begin{array}{l}\text { Persona } \\
\text { sorda }\end{array}$ & $\begin{array}{l}\text { "El i.c no te hace nada y el audífono tampoco si tu naces sordo y no te enseñan técnicas de cómo } \\
\text { escuchar si no te entrenan a oír no te ayuda para nada. El WhatsApp por ejemplo si siempre y } \\
\text { cuando sepas leer claro está. Por ejemplo en clase puedes ir leyendo las cosas pero no escuchando } \\
\text { si eres sordo." }\end{array}$ \\
\hline $\begin{array}{l}\text { Persona } \\
\text { sorda }\end{array}$ & $\begin{array}{l}\text { "Es que yo creo que ni los i.c ni los audífonos hacen milagros porque si tu naces no naces no } \\
\text { porque si tú de pequeño no te interesa estudiar no te gusta leer hay muchos niños sordos que no les } \\
\text { gusta leer pero hay a otros muchos que si igual que a los oyentes hay diversidad lo que pasa que el } \\
\text { colectivo sordo es muy reducido y hay a una gran mayoría que no les gusta leer y la sociedad ya da } \\
\text { por hecho que a los sordos no les gusta leer. Pero yo pienso que si a un niño no le gusta leer por } \\
\text { mucho que le pongas audífono o i.c no va a decir ala me encanta leer pues no. Si alguien no le } \\
\text { gusta leer o estudiar habrá que darle otro camino otra salida no se algo un mínimo no sé cómo un } \\
\text { ciclo. No por el hecho de llevar un audífono o un i.c es como ala tú tienes que seguir estudiando y } \\
\text { avanzando pues no depende de las capacidades de la persona depende de su interés y de su } \\
\text { motivación e incluso del apoyo de la familia. Yo si estoy en un aula siempre con tratamiento } \\
\text { logopédico pierdo el interés y la motivación" }\end{array}$ \\
\hline
\end{tabular}

A continuación se muestran las citas sobre actividades y participación (Tareas y demandas generales). 
Tabla 80.- Número de citas sobre Actividades y Participación (Tareas y demandas generales) en función del grupo focal

\begin{tabular}{|c|c|c|c|c|c|}
\hline Código CIF & Título & Familiares & Personas con hipoacusia & Profesionales & Persona sorda \\
\hline $\mathrm{d} 210$ & Llevar a cabo una única tarea & 1 & 0 & 1 & 0 \\
\hline $\mathrm{d} 220$ & Llevar a cabo múltiples tareas & 4 & 0 & 2 & 1 \\
\hline $\mathrm{d} 230$ & Llevar a cabo rutinas diarias & 1 & 1 & 1 & 0 \\
\hline $\mathrm{d} 240$ & $\begin{array}{l}\text { Manejo del estrés y otras demandas } \\
\text { psicológicas }\end{array}$ & 3 & 5 & 0 & 1 \\
\hline $\mathrm{d} 298$ & $\begin{array}{l}\text { Tareas y demandas generales, otras } \\
\text { especificadas }\end{array}$ & 3 & 2 & 1 & 4 \\
\hline
\end{tabular}

En la tabla anterior podemos observar el número de citas pertenecientes al capítulo tareas y demandas generales de la dimensión Actividades y Participación. Podemos observar que los que tienen un mayor número de citas son las personas con hipoacusia (en "manejo del estrés y otras demandas psicológicas" con cinco citas) seguido de personas sordas (en tareas y demandas generales, otras específicas con cuatro citas) y los familiares (llevar a cabo múltiples tareas). Existen estudios previos que indagan sobre el estrés y otros trastornos del estado anímico en el colectivo de personas sordas. Este aspecto es más notable en las personas con discapacidad auditiva postlocutiva, puesto que deben de adquirir habilidades y destrezas para hacer frente a su nueva situación, al igual que ocurre con sus familiares (Hintermair, 2006). Los resultados muestran que el alto estrés de los familiares se asocia con problemas socioemocionales frecuentes en los hijos, enfatizando así la importancia de un apoyo psicológico, ya que el acceso de los familiares a los recursos personales y sociales se asocia con un número significativamente menor de experiencias estresantes. En cuanto a las personas sordas, cabe señalar que estudios previos plantean que algunos adultos sordos pueden tener niveles más altos de estrés percibido en comparación a la población general. Estos estudios concluyen que las personas sordas presentan mayor presencia de síntomas emocionales y comportamentales, tienen menores niveles de calidad de vida, y presentan una mayor vulnerabilidad al desarrollo de trastornos de ansiedad y del estado de ánimo, en comparación con las personas oyentes. Todo ello se deriva de las tareas y demandas generales que no están adaptadas al colectivo sordo ni a su lengua. (Casas, Linares, Lemos \& Restrepo, 2011; Kang, Ouellette, \& Jones, 2006) 
Tabla 81.- Ejemplos de citas del segundo capítulo “Tareas y demandas generales” de la dimensión "Actividades y Participación"

\begin{tabular}{|c|c|}
\hline Profesional & $\begin{array}{l}\text { "depende mucho del usuario de la pérdida depende mucho de todo pero si es verdad que quizás } \\
\text { sea una pérdida que si le puede ayudar igual esa persona ya puede tener cierta independencia a } \\
\text { la hora por ejemplo de ir a comprar algo pero claro hay entramos ya hasta qué punto es la } \\
\text { ayuda o la lectura labial entonces no" }\end{array}$ \\
\hline Familiar & $\begin{array}{l}\text { "yo creo que ha sido un problema de la sociedad y del sistema educativo y en general de las } \\
\text { administraciones públicas que no han sabido profundizar en el tema de esta discapacidad es } \\
\text { una gran desconocida la ONCE durante muchos años ha trabajado con las personas invidentes } \\
\text { y se ha progresado un montón y son personas que pueden hacer una vida totalmente } \\
\text { normalizada sin embargo los sordos no han progresado tanto porque no ha habido instituciones } \\
\text { no ha habido apoyo no ha habido recursos pero bueno es mi opinión." }\end{array}$ \\
\hline Profesional & $\begin{array}{l}\text { "claro que eso te puede ayudar es que a su autonomía sí que ayuda y a sus actividades diarias } \\
\text { pues supongo que también si quieres favorecer que esa persona sea autónoma pues claro } \\
\text { siempre y cuando como llevamos diciendo toda la tarde depende de las características } \\
\text { personales depende es que igual no hace falta un apoyo tecnológico un audífono para hacer la } \\
\text { compra que a lo mejor una persona que no es capaz que no admite un audífono o no puede por } \\
\text { mil razones le puedes hacer un panel de comunicación le puedes hacer sabes se pueden hacer } \\
\text { un millón de recursos que si tú ahora mismo vas a una tienda te viene en la esta lo que valen } \\
\text { quiero decir es entrenamiento y saber que en esta sociedad hay personas de todo tipo y que hay } \\
\text { de todas las clases" }\end{array}$ \\
\hline Persona sorda & $\begin{array}{l}\text { "Yo si he notado la diferencia de antes a ahora porque yo hago muchas más cosas de las que } \\
\text { hacía antes" }\end{array}$ \\
\hline $\begin{array}{l}\text { Persona con } \\
\text { discapacidad } \\
\text { auditiva } \\
\text { postlocutiva }\end{array}$ & $\begin{array}{l}\text { "Yo creo que sí que la personalidad es decisiva y por eso creo que a veces las personas que } \\
\text { tienen que tener una acogida y un apoyo en ese momento quizás todos al principio lo hemos } \\
\text { pasado mal pero hemos pasado el duelo hemos remontado ese duelo hemos levantado vuelo. } \\
\text { Nos hemos habilitado de estrategias comunicativas para seguir funcionando normalmente en la } \\
\text { vida y sin perder el pleno derecho a la información a la comunicación y tener una vida } \\
\text { totalmente como cualquier otro ciudadano. Pero si nosotras tenemos experiencia en nuestro } \\
\text { propio grupo gente y no tiene que ver la formación, gente con formación muy alta de } \\
\text { licenciatura que realmente abandona el grupo porque no se siente no se quiere reconocer yo } \\
\text { creo que tenemos que adquirir una nueva identidad a veces lo asimilo a lo que es la } \\
\text { adolescencia tenemos que madurar ahí nuestra nueva forma de ser y estar y que no es muy } \\
\text { diferente a la otra sino como te he dicho auxiliarte en una serie de herramientas de estrategias } \\
\text { y es definitivo claro el ser una persona con esperanza, con motivación, positiva... pues claro } \\
\text { que hace porque si no te lleva mucho al aislamiento al apartarte y no puede ser eso. Por eso es } \\
\text { muy necesario que existan grupos de ayuda mutuo tu primer acercamiento a tu propia } \\
\text { problemática conozcas a otras personas que han pasado por lo tuyo y digas uff si aquí no se } \\
\text { acaba" }\end{array}$ \\
\hline
\end{tabular}


En la siguiente tabla se muestran las citas sobre Actividades y Participación (Comunicación).

Tabla 82.- Número de citas sobre Actividades y Participación (Comunicación) en función del grupo focal

\begin{tabular}{|c|c|c|c|c|c|}
\hline \multirow[t]{2}{*}{$\begin{array}{l}\text { Código } \\
\text { CIF }\end{array}$} & & Familiares & $\begin{array}{r}\text { Personas con } \\
\text { hipoacusia }\end{array}$ & Profesionales & $\begin{array}{r}\text { Personas } \\
\text { sordas }\end{array}$ \\
\hline & Título & & & & \\
\hline $\mathrm{d} 310$ & Comunicación-recepción de mensajes hablados & 18 & 10 & 30 & 2 \\
\hline $\mathrm{d} 315$ & Comunicación-recepción de mensajes no verbales & 35 & 11 & 32 & 0 \\
\hline d320 & $\begin{array}{r}\text { Comunicación-recepción de mensajes en lenguaje } \\
\text { de signos convencional }\end{array}$ & 23 & 4 & 76 & 9 \\
\hline $\mathrm{d} 325$ & Comunicación-recepción de mensajes escritos & 13 & 6 & 8 & 0 \\
\hline d329 & $\begin{array}{r}\text { Comunicación-recepción, otra especificada y no } \\
\text { especificada }\end{array}$ & 10 & 2 & 11 & 0 \\
\hline $\mathrm{d} 330$ & Hablar & 7 & 7 & 12 & 9 \\
\hline d335 & Producción de mensajes no verbales & 1 & 0 & 0 & 0 \\
\hline d340 & $\begin{array}{r}\text { Producción de mensajes en lenguaje de signos } \\
\text { convencional }\end{array}$ & 1 & 0 & 0 & 0 \\
\hline d345 & Mensajes escritos & 5 & 0 & 2 & 0 \\
\hline d349 & $\begin{array}{r}\text { Comunicación-producción, otra especificada y no } \\
\text { especificada }\end{array}$ & 6 & 0 & 2 & 0 \\
\hline d350 & Conversación & 8 & 13 & 1 & 0 \\
\hline d 355 & Discusión & 0 & 1 & 7 & 1 \\
\hline d 360 & $\begin{array}{r}\text { Utilización de dispositivos y técnicas de } \\
\text { comunicación }\end{array}$ & 54 & 43 & 101 & 37 \\
\hline d369 & $\begin{array}{r}\text { Conversación y utilización de dispositivos y } \\
\text { técnicas de comunicación }\end{array}$ & 6 & 2 & 2 & 2 \\
\hline
\end{tabular}

Como se ha comentado en el apartado teórico de esta tesis doctoral, dentro del colectivo de personas con discapacidad auditiva podemos encontrar personas que se consideran a sí mismas personas sordas pertenecientes a una comunidad, la comunidad sorda; mayoritariamente su lengua para la comunicación es la lengua de signos, y de manera general son personas con un tipo de pérdida elocutivo. Y por otro lado, las personas con discapacidad auditiva generalmente usuarias de la lengua oral y con un tipo de pérdida postlocutivo. Es por ello, que en la anterior tabla perteneciente al capítulo "Comunicación" la producción de mensajes en lengua oral y lengua de signos son los que tienen un mayor número de citas por estos códigos, lo mismo ocurre con el código de utilización de dispositivos y técnicas de comunicación. Un alto porcentaje de personas sordas y con discapacidad auditiva son usuarias de algún tipo de PA y, también, un alto porcentaje emplea algún dispositivo, sobre todo nuevas tecnologías para la comunicación. 
Tabla 83.- Ejemplos de citas del tercer capítulo "Comunicación" de la dimensión "Actividades y Participación"

\begin{tabular}{|c|c|}
\hline Familiar & $\begin{array}{l}\text { "hombre yo creo que si porque esto les facilita la comunicación por tanto si lo llevan y hacen } \\
\text { un buen uso tendrán una buena comunicación otra cosa es como dice M que tengan } \\
\text { prejuicios o les de vergüenza llevarlo y entonces lo oculten y eso impida por no llevarlo no } \\
\text { relacionarse porque no quieren que les asocien con la discapacidad pero a priori si" }\end{array}$ \\
\hline $\begin{array}{l}\text { Persona con } \\
\text { discapacidad } \\
\text { auditiva }\end{array}$ & $\begin{array}{l}\text { "los mensajes hablados claro que ayuda el tener audífonos es que de otra manera muchas } \\
\text { veces no podríamos de hecho nos ponemos los audifonos cuando ya es una necesidad cuando } \\
\text { de otra manera no puedes entender al interlocutor." }\end{array}$ \\
\hline Persona sorda & $\begin{array}{l}\text { "claro para mí las tres cosas son muy importantes y mensajes y el hablar porque esto ayuda } \\
\text { bastante (se señala los audífonos) tanto para las expresiones y todo eso sí." }\end{array}$ \\
\hline Persona sorda & $\begin{array}{l}\text { "yo con personas sordas que usan lengua de signos estuve mucho tiempo una temporada con } \\
\text { ellos pero cuando estas con ellos pierdes totalmente el habla no puedo y mucho no entienden } \\
\text { mi manera de hablar yo convivir no puedo porque pierdo de todo" }\end{array}$ \\
\hline $\begin{array}{l}\text { Persona con } \\
\text { discapacidad } \\
\text { auditiva }\end{array}$ & $\begin{array}{l}\text { "Supongo que dependerá mucho de la pérdida de agudos o graves para entender y oír mejor } \\
\text { en las conversaciones pero que a veces no somos conscientes de nosotros mismos de lo que } \\
\text { oímos o no oímos creemos que nos hemos quedado con toda la conversación y luego ya a } \\
\text { agua pasada dices ahh pero habían dicho esto pero habían comentado ah pues yo no lo oí y } \\
\text { no sé hasta qué punto al final te has quedado con la conversación que sé que se ha quedado } \\
\text { en el tintero que no se ha quedado en el tintero yo creo que nos yo particularmente nooo no } \\
\text { me entero de todo creo que sí pero luego cuando recapitulas o vuelven a hablar de la } \\
\text { conversación dices ah pues es que no me entere" }\end{array}$ \\
\hline Profesional & $\begin{array}{l}\text { "Yo creo que bueno por un lado dependo un poco de toda la heterogeneidad que existe } \\
\text { dentro de las personas sordas que es de lo que estamos hablando pero si es verdad que por un } \\
\text { lado si lo mejoran bajo mi punto de vista porque es cierto que hay un grupo de personas que } \\
\text { solamente amplificando el sonido y escuchando mejor se rompe esa barrera que existe entre } \\
\text { esa persona u otra y se puede producir la comunicación y al producirse la comunicación ya } \\
\text { tienes ese contacto sin embargo hay personas que por mucho que tu amplifiques el sonido o } \\
\text { por muchos subtítulos que tenga pues por su pérdida auditiva y su falta de adquisición de } \\
\text { lectoescritura y por desconocimiento siguen teniendo esa barrera. " }\end{array}$ \\
\hline Profesional & $\begin{array}{l}\text { "Muchísimos niños sordos que tienen una lectura de loro que no sirve para nada no saben de } \\
\text { la vida tu aprendes de lo que has vivido, pero a veces vives cosas que no comprendes o no le } \\
\text { das significado por falta de comunicación eso se lo están perdiendo por el mero hecho de } \\
\text { cuando naces te estoy dando comunicación igual que al niño se le dice ea ea ea o se le dice } \\
\text { mama eso se puede hacer mediante la lengua de signos y demostrado esta antes el niño } \\
\text { comprende antes que produce eso en cualquier lengua pero con la lengua de signos se } \\
\text { empieza a producir antes, entonces sea sordo o no porque te voy a negar eso. Y a parte lo que } \\
\text { ha dicho Cel niño con i.c que se va a la piscina y tal, pero incluso un niño o un joven con i.c } \\
\text { es sordo porque nunca nunca va a tener la misma audición que un oyente porque el profesor } \\
\text { o en una conferencia yo tengo pues también niños, usuarios no sé cómo llamarlos que están } \\
\text { implantados que tienen una lengua super buena, una lectoescritura súper buena pero que en } \\
\text { una conversación de dos o tres personas se pierden y necesitan un intérprete y ellos se } \\
\text { comunican y te pueden explicar muchas cosas porque ellos tienen mucho conocimiento } \\
\text { gracias a la audición que han tenido eso es cierto pero también hay ciertas ocasiones que se } \\
\text { las perdería sino fuera gracias a la lengua de signos" }\end{array}$ \\
\hline
\end{tabular}


Tabla 84.- Número de citas sobre Actividades y Participación (Movilidad, autocuidado y vida doméstica) en función del grupo focal

\begin{tabular}{|c|c|c|c|c|c|}
\hline $\begin{array}{l}\text { Código } \\
\text { CIF }\end{array}$ & Título & Familiares & $\begin{array}{r}\text { Personas con } \\
\text { hipoacusia }\end{array}$ & Profesionales & $\begin{array}{r}\text { Personas } \\
\text { sordas }\end{array}$ \\
\hline $\mathrm{d} 460$ & $\begin{array}{r}\text { Desplazarse por distintos } \\
\text { lugares }\end{array}$ & 0 & 2 & 0 & 0 \\
\hline d470 & $\begin{array}{r}\text { Utilización de medios de } \\
\text { transporte }\end{array}$ & 0 & 4 & 0 & 0 \\
\hline d475 & Conducción & 0 & 0 & 0 & 1 \\
\hline d489 & $\begin{array}{r}\text { Desplazarse utilizando medios } \\
\text { de transporte, otro especificado } \\
\text { y no especificado }\end{array}$ & 1 & 0 & 0 & 0 \\
\hline d5 510 & Lavarse & 0 & 0 & 1 & 0 \\
\hline d570 & Cuidado de la propia salud & 0 & 2 & 2 & 1 \\
\hline d620 & $\begin{array}{r}\text { Adquisición de bienes y } \\
\text { servicios }\end{array}$ & 14 & 4 & 6 & 2 \\
\hline d630 & Preparar comidas & 3 & 1 & 1 & 0 \\
\hline d640 & $\begin{array}{r}\text { Realizar los quehaceres de la } \\
\text { casa }\end{array}$ & 1 & 2 & 0 & 1 \\
\hline d649 & $\begin{array}{r}\text { Tareas del hogar, otras } \\
\text { especificadas y no } \\
\text { especificadas }\end{array}$ & 2 & 0 & 0 & 0 \\
\hline d650 & $\begin{array}{r}\text { Cuidado de los objetos del } \\
\text { hogar }\end{array}$ & 1 & 0 & 5 & 0 \\
\hline d660 & Ayudar a los demás & 8 & 7 & 10 & 7 \\
\hline d669 & $\begin{array}{r}\text { Cuidado de los objetos del } \\
\text { hogar y ayudar a los demás, } \\
\text { otro especificado }\end{array}$ & 1 & 0 & 0 & 0 \\
\hline d698 & $\begin{array}{r}\text { Vida doméstica, otras } \\
\text { especificadas }\end{array}$ & 2 & 0 & 0 & 0 \\
\hline
\end{tabular}

En la tabla anterior se especifican las citas sobre movilidad, autocuidado y vida doméstica. Una de las limitaciones en el desempeño ocupacional que se encuentran el colectivo de personas sordas/personas con discapacidad auditiva, cuando salen de su entorno más próximo, es el de actividades englobadas dentro de las actividades instrumentales de la vida diaria, como la realización de compras y adquisición de bienes, principalmente por las barreras comunicativas. Probablemente este sea el motivo por el que los códigos de estos capítulos presentan un mayor número de citas. De igual modo ocurre con las ayudas a los demás. A muchas personas sordas usuarias de lengua de signos o con dificultades en la expresión-recepción de mensajes hablados les resulta muy complicado poder interaccionar con una persona ajena a su lengua para poder prestarle ayuda. 
Tabla 85.- Ejemplos de citas del cuarto, quinto y sexto capítulos de la dimensión "Actividades y Participación"

\begin{tabular}{|c|c|}
\hline $\begin{array}{l}\text { Persona con } \\
\text { discapacidad } \\
\text { auditiva }\end{array}$ & $\begin{array}{l}\text { "yo opino también que viajar en tren es un poco complicado porque si te dicen por megafonía } \\
\text { está llegando usted a Madrid pero tú no oyes" }\end{array}$ \\
\hline Persona sorda & $\begin{array}{l}\text { "A mí me han pillado cuando iba a conducir con el coche me ha parado la guardia civil en } \\
\text { una glorieta y me pregunto que no se puede llevar cascos, perdone es que yo llevo un i.c, ah } \\
\text { perdón siga usted circulando" }\end{array}$ \\
\hline Profesional & $\begin{array}{l}\text { "hombre en ese sentido si simplemente por cuestiones técnicas pues si lo malo es evidente las } \\
\text { actividades acuáticas emmm pues tienes que prescindir. Bueno y ya no actividades acuáticas } \\
\text { en tu vida cotidiana para darte un baño o bañar a tu hijo si es sordo tienes que quitarte el } \\
\text { audífono porque obviamente tiene componentes electrónicos que es algo que no son muchas } \\
\text { familias conscientes cuando lo que decían antes le pongo un implante a mi hijo y ya no es } \\
\text { sordo emmm se puede quedar sin pilas se puede mojar entonces sí que" }\end{array}$ \\
\hline Persona sorda & $\begin{array}{l}\text { "por ejemplo yo quiero ir al médico y necesito ilse, y que ocurre si es una urgencia... pues } \\
\text { que tengo un problema si es de noche o fin de semana, pero claro esto la gente no lo piensa" }\end{array}$ \\
\hline $\begin{array}{l}\text { Persona con } \\
\text { discapacidad } \\
\text { auditiva }\end{array}$ & $\begin{array}{l}\text { "de la consulta y paso pero de verdad es que no no no no que la propia sanidad y a personas } \\
\text { con nuestra problemática que te estén poniendo una barrera para poder acudir a tu propio } \\
\text { medico es vamos es impresionante no se ni como calificarlo francamente" }\end{array}$ \\
\hline $\begin{array}{l}\text { Persona con } \\
\text { discapacidad } \\
\text { auditiva }\end{array}$ & $\begin{array}{l}\text { "Yo no tengo vamos en el momento que tenga más perdida probablemente tendré que utilizar } \\
\text { N.T pero vuelvo a lo mismo es un presupuesto que ahora mismo no dispone nadie la mayoría } \\
\text { de las personas no disponen y yo me he encontrado en mi trabajo personas que pierden el } \\
\text { trabajo por no ponerse audífonos y no pueden comprarse los audífonos porque no tienen } \\
\text { trabajo o sea un círculo vicioso que realmente es impresionante que alguien no pueda vivir } \\
\text { como un ciudadano de a pie porque no pueda ponerse unos audífonos es no sea a mí me } \\
\text { parece totalmente de justicia social" }\end{array}$ \\
\hline Profesional & $\begin{array}{l}\text { "si una persona de repente se encuentra que es sorda y encima tiene que usar un aparato que } \\
\text { es raro para la Sociedad aunque tenga } 50 \text { años eso le puede llegar a afectar dependiendo del } \\
\text { carácter de la persona pero es que no es solo la cuestión de usar una ayuda externa que es } \\
\text { visible para los demás sino que tu estas sintiendo por dentro, porque ya no oyes, no te es fácil } \\
\text { comunicarte con tus amigos, igual ya no vas a comprar a la panadería porque no le puedes } \\
\text { llamar a la señora que tal va tu vida? Porque simplemente no la oyes." }\end{array}$ \\
\hline Profesional & $\begin{array}{l}\text { "como decía al principio para una comunicación diaria de un uso cotidiano como ir a hacer } \\
\text { la compra o hablar con tu vecino sobre algún problema o algo pues es fundamental sobre } \\
\text { todo en la ciudad en las ciudades que tú tienes que salir ir hacer la compra tienes que } \\
\text { comunicarte con el dependiente de una tienda de ropa o cualquier tipo de local y me parece } \\
\text { fundamental sobre todo en la ciudad" }\end{array}$ \\
\hline
\end{tabular}

En la siguiente tabla, se especifican las citas del capítulo siete, Interacciones y relaciones interpersonales, perteneciente a la dimensión Actividades y Participación. Una de las mayores preocupaciones a nivel social dentro del colectivo de personas que presentan déficit auditivo, se engloba las relaciones sociales. Tal y como se puede observar, el código relaciones sociales informales es el que presenta un mayor número de citas. Cabe señalar que los familiares son los que presentan un mayor número de citas en este capítulo seguido de profesionales, personas sordas y personas con discapacidad auditiva. Muchas personas sordas usuarias de lengua de signos se ven forzadas a mantener relaciones personales con personas que dominen la lengua de signos, y estas en ocasiones están limitadas a familiares y profesionales. De manera paralela, muchas personas con discapacidad auditiva postlocutiva usuarias de lengua oral, tienden a aislarse y disminuir en número sus relaciones interpersonales así como limitar éstas a relaciones formales. Esto deriva de la falta de 
herramientas y estrategias comunicativas además del sentimiento de vergüenza y no aceptación de su discapacidad (Erler \& Garstecki, 2002; Lane, Hoffmeister \& Bahan, 1996; Tambs, 2004).

Tabla 86.- Número de citas sobre Actividades y Participación (Interacciones y relaciones interpersonales) en función del grupo focal.

\begin{tabular}{|c|c|c|c|c|c|}
\hline \multirow[t]{2}{*}{$\begin{array}{l}\text { Código } \\
\text { CIF }\end{array}$} & & Familiares & $\begin{array}{r}\text { Personas con } \\
\text { hipoacusia }\end{array}$ & Profesionales & \multirow[t]{2}{*}{$\begin{array}{r}\text { Personas } \\
\text { sordas }\end{array}$} \\
\hline & Título & & & & \\
\hline $\mathrm{d} 710$ & Interacciones interpersonales básicas & 4 & 0 & 0 & 1 \\
\hline $\mathrm{d} 720$ & Interacciones interpersonales complejas & 3 & 0 & 0 & 0 \\
\hline d730 & Relaciones con extraños & 1 & 0 & 0 & 0 \\
\hline d740 & Relaciones formales & 3 & 3 & 2 & 1 \\
\hline d750 & Relaciones sociales informales & 18 & 8 & 16 & 10 \\
\hline d760 & Relaciones familiares & 4 & 0 & 5 & 1 \\
\hline $\mathrm{d} 770$ & Relaciones íntimas & 1 & 0 & 0 & 0 \\
\hline d798 & $\begin{array}{r}\text { Interacciones y relaciones interpersonales, otras } \\
\text { especificadas }\end{array}$ & 5 & 1 & 0 & 0 \\
\hline
\end{tabular}


Tabla 87.- Ejemplos de citas del séptimo capítulo “Interacciones y relaciones interpersonales" de la dimensión “Actividades y Participación"

\begin{tabular}{|c|c|}
\hline Familiar & $\begin{array}{l}\text { "Completamente si porque al no oír le margina y no puede entrar en conversación con otras } \\
\text { personas o sea que sí que estoy de acuerdo que mejora las relaciones, la calidad humana } \\
\text { también" }\end{array}$ \\
\hline Persona sorda & $\begin{array}{l}\text { "Yo desde pequeña siempre he aceptado mi sordera y mis audífonos y jamás me dio vergüenza } \\
\text { yo siempre he estado segura pero el primer día que siempre he ido algún lado de temas } \\
\text { educativos yo me los cubría porque yo sabía que si me veían los audífonos se alejaban de mi } \\
\text { entonces el llevar aparato afecta al estigma que se tiene y al desconocimiento se van, afecta a la } \\
\text { iniciación de relaciones porque saben que soy sorda si lo llevo y si no lo llevo me vocalizan } \\
\text { también más y me llaman tocándome el hombro eso sí es cierto lo intentan más la primera vez } \\
\text { es" }\end{array}$ \\
\hline $\begin{array}{l}\text { Persona con } \\
\text { discapacidad } \\
\text { auditiva }\end{array}$ & $\begin{array}{l}\text { "Es cierto que aunque tengo mis limitaciones sí que me han dado una cierta autonomía para } \\
\text { poder dedicar un poco más al tema social no porque me estaba aislando por el tema de que iba } \\
\text { a una cafetería pufff y no me enteraba de na y desde luego que aburrimiento me voy para mi } \\
\text { casa no? iEntonces hay sí que he notado una cierta diferencia lo otro no lo sé porque si no hay } \\
\text { bucles! Yo ya en mi trabajo ya he dicho a mi jefa porque estamos muchos quiero decir que en mi } \\
\text { trabajo hay } 5 \text { personas con problemas de audición no sola } 1 \text { eh y estamos en un sitio publico } \\
\text { donde nos tenemos que relacionar directamente con las personas entonces hemos pedido bucles } \\
\text { pero como no hay dinero pues no hay bucle”" }\end{array}$ \\
\hline Profesional & $\begin{array}{l}\text { "la favorecen en el sentido de que la gente es oyente y para interaccionar con la gente tiene que } \\
\text { ser oyente porque su círculo es muy cerrado se limita a las personas que saben lengua de signos } \\
\text { ya sean intérpretes o amigos y familiares que sepan entonces para relacionarse con otro tipo de } \\
\text { gente como compañeros de clase si lo van a necesitar pero es porque la mayor parte de la } \\
\text { comunidad es oyente" }\end{array}$ \\
\hline Profesional & $\begin{array}{l}\text { "El colectivo de sordos tiene una cultura y una lengua propia igualmente respetables pero sí } \\
\text { que hay que decir que ellos mismos son excluyentes sí que es verdad que tienen asociaciones y } \\
\text { demás pero nosotros somos sordos y vosotros sois oyentes y hay una barrera que yo creo que } \\
\text { hoy por hoy no todo el mundo sabe superar" }\end{array}$ \\
\hline Familiar & $\begin{array}{l}\text { "pero yo creo que porque la sociedad no les entiende porque no saben tratar con una persona } \\
\text { sorda porque no tienen conocimiento de sus limitaciones o sea no es un problema de ellos solos } \\
\text { que puede ser también pero pueden que tengan problemas de autoestima o problemas de que se } \\
\text { van inseguros a la hora de relacionarse sino que también no se les ha entendido porque también } \\
\text { durante mucho tiempo se les decía que eran sordomudos cuando sabemos que no es que sean } \\
\text { sordomudos sino que son sordos y por eso no reproducen sonidos pero yo creo que ha sido un } \\
\text { problema de la sociedad" }\end{array}$ \\
\hline Persona sorda & $\begin{array}{l}\text { "Eso cuando yo antes cuando era jovencita me escondía antes para que no viera que era sorda } \\
\text { para que yo pueda estar con el grupo la gente pero ahora me pongo prefiero que me vean y que } \\
\text { se den cuenta de que soy sorda y me pueda comunicar y cuando la gente se da cuenta de que soy } \\
\text { sorda ja (signo apartar)" }\end{array}$ \\
\hline $\begin{array}{l}\text { Persona con } \\
\text { discapacidad } \\
\text { auditiva }\end{array}$ & $\begin{array}{l}\text { "algo creo que genera al menos a mí un poco de tensión al menos a mí me genera un poco de } \\
\text { tensión es él lo voy a oír no lo voy a oír y sobre todo sobre todo cuando estas en ese término le } \\
\text { oigo no le oigo y coges el teléfono y ya lo coges un poquito con ese temor a ver si cuando a lo } \\
\text { mejor ya están hablando por teléfono bajo y le tienes que decir por favor puede hablar un poco } \\
\text { más alto o arrimarse más al teléfono a mi es algo que por experiencia sé que habrá personas } \\
\text { más tranquilas que yo a mi es lo que más me fastidia en las relaciones sociales porque te las vas } \\
\text { quitando te vas retirando de ellas" }\end{array}$ \\
\hline Profesional & $\begin{array}{l}\text { "si pienso que le ayuda en las interacciones sociales pienso también que hay que matizar no sé } \\
\text { si después hay alguna pregunta al respecto me guardo para el final pero también es distinto una } \\
\text { interacción individual tu a tu a la interacción grupal donde empiezan a sentirse perdidos no les } \\
\text { llega la información y eso muchas veces les hace echarse para atrás en reuniones en actos más } \\
\text { sociales que haya más de un interlocutor depende un poco yo haber tengo un punto de vista } \\
\text { positivo con respecto a las ayudas pero siempre hay casos delicados" }\end{array}$ \\
\hline
\end{tabular}

La tabla 87 hace referencia al octavo capítulo Áreas principales de la vida, perteneciente a la dimensión Actividades y Participación. Los códigos que obtuvieron un mayor número de citas son los relativos a la autosuficiencia económica observándose un número de citas similar para personas sordas, personas con hipoacusia y familiares. La educación parece ser un tema de mayor interés para profesionales que para el resto de grupos 
focales, y debemos de señalar que la actividad laboral parece tener mayor interés y preocupación por parte de los familiares, que las propias personas con discapacidad (Alleyne, Dufresne, Kanji \& Reesal, 1989; Meyer, Chen, McDonald \& Cherry, 2002; Ricao \& de Gracia, 2004).

Tabla 88.- Número de citas sobre Actividades y Participación (Áreas principales de la vida) en función del grupo focal

\begin{tabular}{|c|c|c|c|c|c|}
\hline $\begin{array}{l}\text { Código } \\
\text { CIF }\end{array}$ & Título & Familiares & $\begin{array}{r}\text { Personas } \\
\text { con } \\
\text { hipoacusia } \\
\end{array}$ & Profesionales & $\begin{array}{r}\text { Personas } \\
\text { sordas }\end{array}$ \\
\hline $\mathrm{d} 810$ & Educación no reglada & 1 & 2 & 6 & 0 \\
\hline $\mathrm{d} 815$ & Educación preescolar & 0 & 0 & 2 & 0 \\
\hline $\mathrm{d} 820$ & Educación escolar & 3 & 0 & 7 & 4 \\
\hline $\mathrm{d} 825$ & Formación profesional & 0 & 0 & 1 & 0 \\
\hline $\mathrm{d} 830$ & Educación superior & 1 & 3 & 2 & 5 \\
\hline $\mathrm{d} 840$ & Aprendizaje (preparación para el trabajo) & 1 & 0 & 0 & 0 \\
\hline $\mathrm{d} 845$ & Conseguir, mantener y finalizar un trabajo & 5 & 2 & 2 & 1 \\
\hline $\mathrm{d} 850$ & Trabajo remunerado & 2 & 1 & 4 & 2 \\
\hline $\mathrm{d} 855$ & Trabajo no remunerado & 0 & 0 & 0 & 1 \\
\hline d859 & $\begin{array}{r}\text { Trabajo y empleo, otro especificado y no } \\
\text { especificado }\end{array}$ & 1 & 0 & 0 & 0 \\
\hline $\mathrm{d} 870$ & Autosuficiencia económica & 15 & 15 & 27 & 16 \\
\hline d898 & Áreas principales de la vida, otras especificadas & 1 & 0 & 0 & 0 \\
\hline $\mathrm{d} 899$ & Áreas principales de la vida no especificadas & 1 & 0 & 0 & 0 \\
\hline
\end{tabular}


Tabla 89.- Ejemplos de citas del octavo capítulo "Áreas principales de la vida" de la dimensión "Actividades y Participación"

\begin{tabular}{|c|c|}
\hline $\begin{array}{l}\text { Persona con } \\
\text { discapacidad } \\
\text { auditiva }\end{array}$ & $\begin{array}{l}\text { "cuando he participado en algún grupo en alguna acción formación que algunos son por } \\
\text { videoconferencia. Y en las conferencias a veces depende de la calidad de la calidad de propio } \\
\text { aparato porque a veces que... y del medio porque no todos los medios están acústicamente } \\
\text { preparados para poder entender de una manera clara si estamos en un medio adecuado pues } \\
\text { estupendo la videoconferencia si estoy en un medio que es todo pared no hay nada de cortinaje } \\
\text { nada de cocina y hay una ververancia acústica imponente pues la verdad por mucho medio } \\
\text { tecnológico el medio no ayuda" }\end{array}$ \\
\hline $\begin{array}{l}\text { Persona con } \\
\text { discapacidad } \\
\text { auditiva }\end{array}$ & $\begin{array}{l}\text { "luego lo de estudiar ahora lo que hago es por internet los cursos bueno los cursillos de estos } \\
\text { son por internet bueno hice uno presencial que fue hace dos años que ese era presencial y lo que } \\
\text { conseguí es que me pusieran en primera fila para entender y que me dieran con un día de } \\
\text { antelación los apuntes que iban a dar para yo leérmelos antes y saber de lo que iba porque jijij } \\
\text { pero siempre el profesor que iba lo daba justo en el día o sea yo el primer día que iba con ... } \\
\text { porque no podía salir a decírselo pero vamos luego ya el resto de los días los apuntes me } \\
\text { enteraba de las cosas" }\end{array}$ \\
\hline Familiar & $\begin{array}{l}\text { "se está viendo en los últimos años que se está trabajando y se está viendo mucho más con los } \\
\text { niños que son sordos porque ahora mismo en cualquier escuela pública puedes encontrarte un } \\
\text { niño que sea sordo y que tengan una persona intérprete con ellos y eso antiguamente pues no se } \\
\text { les excluía de la escuela porque no podían continuar las clases con normalidad y no había ese } \\
\text { tipo de recursos y de apoyos con lo cual sí que ahora mismo cuanto más joven más se trabaja } \\
\text { desde el nacimiento porque de hecho te hacen una prueba cuando eres recién nacido con } 3 \text { días } \\
\text { de detección precoz de la sordera en la que un poco lo que vienen a hacer es a trabajar la } \\
\text { estimulación desde bebé con lo cual estará mucho más estimulado ahora mismo un niño que una } \\
\text { persona que tenga } 30 \text { años" }\end{array}$ \\
\hline $\begin{array}{l}\text { Persona con } \\
\text { discapacidad } \\
\text { auditiva }\end{array}$ & $\begin{array}{l}\text { "porque cuando yo estudie me costó muchísimo ir tomando apuntes estar pendiente de la } \\
\text { explicación y fue todo a base de trabajar mis apuntes no tenían sentido todo aquello era } \\
\text { incompleto pues como puedo estar ahora mismo estar tomando apuntes pero no sé si los estoy } \\
\text { tomando bien o mal a mí por ejemplo el estudiar me supuso mucho esfuerzo y desde luego para } \\
\text { todo para todo te limita para todo" }\end{array}$ \\
\hline Persona sorda & $\begin{array}{l}\text { "en todo por ejemplo mi trabajo es accesible yo tengo ilse, svisual, webcam o sea mis } \\
\text { compañeras bueno mi compañera saben LSE" }\end{array}$ \\
\hline Familiar & $\begin{array}{l}\text { "las personas que quizás estén en una ciudad en un nivel socio-económico importante y demás } \\
\text { pues podrán acceder mejor a los recursos incluso podrá tener un intérprete o pagar } \\
\text { determinadas cosas que una persona que no lo tenga como todo en la vida osea quien tiene un } \\
\text { poco más de dinero se puede permitir más cosas yo desconozco cuánto vale un implante coclear } \\
\text { y cuanto subvenciona la seguridad social y todo lo que es el mantenimiento pero yo entiendo } \\
\text { que son cosas que no son fáciles de mantener con lo cual como todo en la vida quien más dinero } \\
\text { tiene más facilidad y acceso va a tener" }\end{array}$ \\
\hline $\begin{array}{l}\text { Persona con } \\
\text { discapacidad } \\
\text { auditiva }\end{array}$ & $\begin{array}{l}\text { "Me parecen estupendos pero realmente si quieres tener un buen equipo tienes que tener un } \\
\text { buen recurso económico y creo que por ahí es donde puede venir la solución que nos apoyaran } \\
\text { más para obtener mejores ayudas tecnológicas que s u vez mejoraran nuestro bienestar de vida" }\end{array}$ \\
\hline
\end{tabular}


Tabla 90.- Número de citas sobre Actividades y Participación (Vida comunitaria, social y cívica) en función del grupo focal

\begin{tabular}{|c|c|c|c|c|c|}
\hline Código CIF & Título & Familiares & $\begin{array}{r}\text { Personas } \\
\text { con } \\
\text { hipoacusia } \\
\end{array}$ & Profesionales & $\begin{array}{r}\text { Personas } \\
\text { sordas }\end{array}$ \\
\hline d910 & Vida comunitaria & 21 & 8 & 14 & 8 \\
\hline d920 & Tiempo libre y ocio & 21 & 14 & 17 & 8 \\
\hline d940 & Derechos Humanos & 1 & 1 & 0 & 0 \\
\hline d998 & $\begin{array}{r}\text { Vida comunitaria, social y cívica, otra } \\
\text { especificada }\end{array}$ & 3 & 0 & 0 & 0 \\
\hline
\end{tabular}

La tabla 90 hace referencia al noveno capítulo, vida comunitaria, social y cívica de la dimensión Actividades y Participación. Los códigos que obtuvieron un mayor número de citas fueron tiempo libre y ocio y vida comunitaria. Las personas que presentan algún tipo de discapacidad encuentran dificultades en el desempeño de sus actividades avanzadas tales como el ocio o el trabajo. Dentro de este colectivo la falta de información y conocimiento de esta discapacidad hace todavía más difícil la accesibilidad a actividades de ocio. Son muchas las actividades que las personas desean realizar, pero son pocas las que están adaptadas a sus necesidades; esto, añadido al gran desconocimiento de su discapacidad, hace difícil el acceso a actividades en la comunidad (Backenroth, 1995; Backenroth, 1993; Carr, 2004; Lieberman \& Stuart, 2002; Tsai \& Fung, 2005). 
Tabla 91.- Ejemplos de citas del noveno capítulo "Vida comunitaria, social y cívica" de la dimensión “Actividades y Participación"

\begin{tabular}{|c|c|}
\hline Profesional & $\begin{array}{l}\text { "hay algún cine que está adaptado pero no hay en edificios o si te toca ir a un Congreso y tienes } \\
\text { que ir a un taller no existe como tal ese acceso a la información que sí que podrían conectarse a } \\
\text { él que sí que son muy útiles que están muy bien el problema que no está sensibilizada la gente } \\
\text { para poder usarlos como se debería esa es mi opinión." }\end{array}$ \\
\hline Familiar & $\begin{array}{l}\text { "Yo creo que tienen una discapacidad y que tienden a asociarse con otras personas sordas } \\
\text { porque se sienten arropados y que la comunicación es más fácil con ellos porque ni la sociedad } \\
\text { está preparada para comunicarse con una persona sorda ni un sordo se siente a veces capaz de } \\
\text { explicarse ante una persona que no pues que en este caso escuche" }\end{array}$ \\
\hline Familiar & $\begin{array}{l}\text { "si tienes ocio y haces con asociaciones que están sensibilizadas pues si pero si no hay muchas } \\
\text { actividades que evidentemente no pueden ir porque no tienen acceso entonces hay sí creo que } \\
\text { falta todo el camino o sea el normalizar la vida falta muchísimo " }\end{array}$ \\
\hline $\begin{array}{l}\text { Persona con } \\
\text { discapacidad } \\
\text { auditiva }\end{array}$ & $\begin{array}{l}\text { "te puede divertir de otra manera que no es yendo al cine y la tv y otras cosas que entran por el } \\
\text { oúdo pues aparte de esto tienes otras alternativas que puedes ponerte cascos y oír ya con el } \\
\text { casco que mejora muchísimo la audición nuestra porque se oye mucho más nítido que por } \\
\text { ejemplo oyendo directamente en la tv después todo esto del Messenger que ya no se utiliza pero } \\
\text { el Skype y todo esto pues puedes hablar con la gente también con cascos si quieres o a través } \\
\text { del teclado o sea que ayuda y mucho además" }\end{array}$ \\
\hline $\begin{array}{l}\text { Persona con } \\
\text { discapacidad } \\
\text { auditiva }\end{array}$ & $\begin{array}{l}\text { "yo para el cine para ser honesta si me lo subtitulan. El teatro no voy porque no me entero de } \\
\text { nada fui hace poco un musical la musiquilla un poco pero apenas me enteraba de lo que decían. } \\
\text { Nos hemos habilitado de estrategias comunicativas para seguir funcionando normalmente en la } \\
\text { vida y sin perder el pleno derecho a la información a la comunicación y tener una vida } \\
\text { totalmente como cualquier otro ciudadano pero hay cosas que es necesario adaptarlas" }\end{array}$ \\
\hline Persona sorda & $\begin{array}{l}\text { "puedes hacer actividades de ocio pero no de alto riesgo no puedes tirar puenting no puedes } \\
\text { tirarte a lo mejor a dos metros a un metro y pico de una piscina a tirarte de cabeza hay cosas } \\
\text { que no pero puedes hacer todo tipo de deporte." }\end{array}$ \\
\hline Familiar & "yo creo que el ocio ahora mismo en general no está planteado para personas sordas." \\
\hline Persona sorda & $\begin{array}{l}\text { "si vas al cine no entiendo en el caso de que hay subtítulos, si voy a un teatro... lo mismo, e ir a } \\
\text { cosas culturales como museo muy esporádico, yo digo porque no guía aunque sea por móvil en } \\
\text { lengua de signos" }\end{array}$ \\
\hline
\end{tabular}

Tabla 92.- Número de citas sobre Factores ambientales (Productos y Tecnología y Entorno natural y cambios en el entorno derivados de la actividad) en función del grupo focal

\begin{tabular}{|c|c|c|c|c|c|}
\hline $\begin{array}{l}\text { Código } \\
\text { CIF }\end{array}$ & Título & Familiares & $\begin{array}{r}\text { Personas con } \\
\text { hipoacusia }\end{array}$ & Profesionales & Personas sordas \\
\hline e110 & $\begin{array}{l}\text { Productos o sustancias } \\
\text { para el consumo personal }\end{array}$ & 3 & 2 & 0 & 0 \\
\hline e115 & $\begin{array}{r}\text { Productos y tecnología } \\
\text { para uso personal en la } \\
\text { vida diaria }\end{array}$ & 9 & 0 & 19 & 0 \\
\hline e120 & $\begin{array}{r}\text { Productos y tecnología } \\
\text { para la movilidad y el } \\
\text { transporte personal }\end{array}$ & 3 & 4 & 5 & 0 \\
\hline e125 & $\begin{array}{l}\text { Productos y tecnología } \\
\text { para la comunicación }\end{array}$ & 56 & 59 & 357 & 165 \\
\hline e210 & Geografía física & 0 & 0 & 6 & 0 \\
\hline e215 & Población & 13 & 3 & 0 & 0 \\
\hline e240 & Luz & 0 & 2 & 1 & 1 \\
\hline $\mathrm{e} 245$ & $\begin{array}{r}\text { Cambios relacionados con } \\
\text { el paso del tiempo }\end{array}$ & 0 & 0 & 0 & 2 \\
\hline e250 & Sonido & 2 & 20 & 24 & 16 \\
\hline e255 & Vibración & 0 & 2 & 0 & 0 \\
\hline e298 & $\begin{array}{r}\text { Entorno natural y cambios } \\
\text { en el entorno derivados de } \\
\text { la actividad }\end{array}$ & 0 & 2 & 0 & 0 \\
\hline
\end{tabular}


La anterior tabla hace referencia a la dimensión Factores ambientales y a los capítulos de Productos y Tecnología y Entorno natural y cambios en el entorno derivados de la actividad. Los códigos que presentan un mayor número de citas son productos y tecnología para la comunicación, seguido por sonido y productos y tecnología para uso personal en la vida diaria. Es lógico que los PA para la comunicación hayan recibido un mayor número de citas, puesto que son el objeto de esta tesis doctoral y en el cuestionario de elaboración propia las preguntas realizadas estaban englobadas dentro de los PA. Aunque es llamativo el elevado número de citas de los profesionales comparado con los otros grupos focales. Las personas sordas presentan un mayor número de citas que las personas con hipoacusia, lo cuál es, hasta cierto punto, lógico dado que hoy en día existen muchos PA y nuevas tecnologías para este colectivo, tal y como se expuso en la parte teórica. Las personas con pérdida auditiva postlocutiva son poco conocedores de PA específicos puesto que muchos de ellos niegan su pérdida auditiva y únicamente emplean los audífonos como PA para la comunicación.

Tabla 93.- Ejemplos de citas del primer y segundo capítulo de la dimensión "Factores Ambientales".

\begin{tabular}{|c|c|}
\hline Profesional & $\begin{array}{l}\text { "un PA salva algunas de las barreras de comunicación que existen pero mmm pero el producto } \\
\text { técnico como tal no es el que hace que esa persona esté más integrada en la comunidad o necesita } \\
\text { de un factor humano" }\end{array}$ \\
\hline Profesional & $\begin{array}{l}\text { "La participación social tampoco existe con esos p.a. o sea no acerca a esa persona a la Sociedad } \\
\text { y además por ejemplo con los del avatar tu cuando tienes una comunicación existe un contacto } \\
\text { dentro de un contexto comunicativo que un p.a. no te da, te amplifica sonido, te pone subtítulos te } \\
\text { puede intentar ayudar de cierta forma pero no es suficiente solo el p.a. siempre necesitas recursos } \\
\text { humanos para la participación social y para la comprensión completa del mensaje yo creo" }\end{array}$ \\
\hline Familiar & $\begin{array}{l}\text { "si la persona vive en una Sociedad y en un entorno y es triste pero el entorno tendrá que cambiar } \\
\text { un poco para que todas esas ayudas técnicas sean realmente útiles y le faciliten la vida" }\end{array}$ \\
\hline Profesional & $\begin{array}{l}\text { "pues a mí desde mi punto de vista los p.a. de amplificación me parecen indispensables para } \\
\text { mantener no solo el desarrollo de las interacciones sociales sino para mantener la conexión con lo } \\
\text { que es la comunidad de las personas. Una de las capacidades que tiene el ser humano es el } \\
\text { lenguaje son capaces de comunicarse si contamos sin la parte de la audición el aislamiento sería } \\
\text { completo entonces vemos a la persona limitada a relacionarse con personas que únicamente hablen } \\
\text { lengua de signos no es únicamente la comunidad sorda sino también el resto de participantes" }\end{array}$ \\
\hline $\begin{array}{l}\text { Persona } \\
\text { sorda }\end{array}$ & $\begin{array}{l}\text { "Pues yo del implante no estoy muy conforme porque soy casi de nacimiento y me han dicho que no } \\
\text { congenita no se puede. Y el aparato o sea el audífonos, son muy importantes porque como tengo } \\
\text { bastante pérdida necesito mucha amplificación y me cuesta entenderlo y es bueno que investiguen } \\
\text { que miren y todo esto económicamente también que tenga ayudas." }\end{array}$ \\
\hline $\begin{array}{l}\text { Persona con } \\
\text { discapacidad } \\
\text { auditiva }\end{array}$ & $\begin{array}{l}\text { "los mensajes hablados claro que ayuda el tener audífonos es que de otra manera muchas veces no } \\
\text { podríamos de hecho nos ponemos los audífonos cuando ya es una necesidad cuando de otra manera } \\
\text { no puedes entender al interlocutor" }\end{array}$ \\
\hline $\begin{array}{l}\text { Persona con } \\
\text { discapacidad } \\
\text { auditiva }\end{array}$ & $\begin{array}{l}\text { "yo la calidad de la escucha siempre me situó en conferencias que en ningún sitio esta con su bucle } \\
\text { magnético a veces hay audífonos que tienen una posición T que pasas a oúr directamente al ponente } \\
\text { que pasa que muchos sitios no tienen instalado lo de la posición T que es justo donde está instalado } \\
\text { el bucle magnético yo me siento adelante" }\end{array}$ \\
\hline $\begin{array}{l}\text { Persona con } \\
\text { discapacidad } \\
\text { auditiva }\end{array}$ & $\begin{array}{l}\text { "Yo oigo totalmente por todas las direcciones normalmente se por dónde viene un ruido con los } \\
\text { audífonos pero me gusta más hablar de frente porque me ayudo con los labios y con los gestos y me } \\
\text { entero muchísimo mejor." }\end{array}$ \\
\hline $\begin{array}{l}\text { Persona con } \\
\text { discapacidad } \\
\text { auditiva }\end{array}$ & $\begin{array}{l}\text { "Yo estoy trabajando y mi temor era tener que dejar de trabajar porque además en mi caso me } \\
\text { dedico mucho a la orientación e intervención social y se basa todo en la escucha. En la escucha } \\
\text { activa y en el contacto con otras personas entonces a la hora de ponerme los audífonos yo pude } \\
\text { mantener y he mantenido mi trabajo a veces el tener audífonos y tener reconocida la discapacidad } \\
\text { me ha dado oportunidad de trabajar" }\end{array}$ \\
\hline
\end{tabular}


Tabla 94.- Número de citas sobre Factores Ambientales (Apoyo y relaciones y Actitudes) en función del grupo focal

\begin{tabular}{|c|c|c|c|c|c|}
\hline $\begin{array}{l}\text { Código } \\
\text { CIF }\end{array}$ & Título & Familiares & $\begin{array}{r}\text { Personas con } \\
\text { hipoacusia }\end{array}$ & Profesionales & $\begin{array}{r}\text { Personas } \\
\text { sordas } \\
\end{array}$ \\
\hline e310 & Familiares cercanos & 1 & 0 & 0 & 0 \\
\hline e325 & $\begin{array}{l}\text { Conocidos, compañeros, colegas, vecinos } \\
\text { y miembros de la comunidad }\end{array}$ & 1 & 0 & 1 & 1 \\
\hline e330 & Personas en cargos de autoridad & 1 & 0 & 0 & 0 \\
\hline e355 & Profesionales de la salud & 0 & 0 & 9 & 0 \\
\hline e360 & Otros profesionales & 3 & 0 & 1 & 6 \\
\hline e398 & Apoyo y relaciones, otros especificados & 3 & 1 & 1 & 1 \\
\hline e410 & $\begin{array}{l}\text { Actitudes individuales de miembros de la } \\
\text { familia cercana }\end{array}$ & 19 & 0 & 4 & 0 \\
\hline e415 & Actitudes individuales de otros familiares & 1 & 0 & 0 & 0 \\
\hline e425 & $\begin{array}{l}\text { Actitudes individuales de conocidos, } \\
\text { compañeros, colegas, vecinos y miembros } \\
\text { de la Comunidad }\end{array}$ & 19 & 0 & 1 & 0 \\
\hline e430 & $\begin{array}{l}\text { Actitudes individuales de personas en } \\
\text { cargos de autoridad }\end{array}$ & 2 & 0 & 0 & 0 \\
\hline e445 & Actitudes individuales de extraños & 1 & 0 & 0 & 0 \\
\hline e450 & $\begin{array}{l}\text { Actitudes individuales de profesionales de } \\
\text { la salud }\end{array}$ & 2 & 1 & 10 & 2 \\
\hline e455 & $\begin{array}{l}\text { Actitudes individuales de profesionales } \\
\text { "relacionados con la salud" }\end{array}$ & 0 & 0 & 5 & 0 \\
\hline e460 & Actitudes sociales & 13 & 23 & 106 & 26 \\
\hline e465 & Normas, costumbres e ideologías sociales & 12 & 5 & 53 & 6 \\
\hline e498 & Actitudes, otras especificadas & 3 & 8 & 12 & 1 \\
\hline e499 & Actitudes, no especificadas & 4 & 0 & 0 & 0 \\
\hline
\end{tabular}

La tabla 94 hace referencia a los capítulos de apoyo y relaciones y actitudes de la dimensión Factores ambientales. La discapacidad auditiva es una de las discapacidades más desconocidas en nuestra Sociedad, en general, la población oyente no es consciente de la problemática del déficit auditivo, limitándolo únicamente al habla. Es por ello que los códigos que recibieron un mayor número de citas fueron actitudes sociales dado que la discapacidad auditiva es invisible y normas, costumbres e ideología social. Como se ha descrito con anterioridad, las personas sordas tienen su propia cultura y lengua, y forman parte de lo que denominamos como comunidad sorda, la cual tiene sus propias costumbres y normas. En muchas ocasiones las personas con discapacidad y sus familiares reportan una mala actitud por parte no solo de la sociedad, sino de los propios profesionales, en mayor medida los profesionales de la salud. De manera paralela, existe una gran falta de apoyo social a este colectivo. 
Tabla 95.- Ejemplos de citas del tercer y cuarto capítulo de la dimensión "Factores Ambientales".

\begin{tabular}{|c|c|}
\hline Profesional & $\begin{array}{l}\text { "si esa clase, si esos amigos, si esa familia, si todo el contexto todas tus redes de apoyo tienen } \\
\text { realmente sensibilización en cuanto a esos p.a. y que tú eres una persona sorda sí o no porque si tú en } \\
\text { tus redes de apoyo no sientes ese autoestima de manera de poder llevarlo libremente fuera no lo vas a } \\
\text { hacer" }\end{array}$ \\
\hline Persona sorda & "yo es que quiero a los oyentes porque me ayudan" \\
\hline Familiar & "le costó muchísimo aceptarlo pero luego lo ha llevado muy bien siempre muy bien" \\
\hline Profesional & $\begin{array}{l}\text { "Lo que sea, que haces tú a ese niño hay que tenerlo en cuenta lo que dicen los profesionales a los } \\
\text { padres cuando de repente se encuentran con una discapacidad que desconocen y tienen que hacerle } \\
\text { frente y tienen que asumir toda esa información que les llega de lengua de signos si lengua de signos } \\
\text { no porque con el implante va a oír, no porque." }\end{array}$ \\
\hline Familiar & $\begin{array}{l}\text { "tienen esa doble vertiente doble vertiente tanto ellos que ese como asociación siempre están juntos y } \\
\text { casi ni permiten la entrada de gente del exterior que sea oyente y por nuestra parte nuestra parte } \\
\text { también que tampoco es que hagamos mucho ademán de conocer ese lenguaje ese lenguaje que } \\
\text { quieras que no siempre podría ayudar en la comunicación en algunos casos" }\end{array}$ \\
\hline Profesional & $\begin{array}{l}\text { "los niños pueden ser bastante crueles en el colegio y es verdad y yo no sé cómo meter mano porque } \\
\text { yo trabajo con niños y muchas veces se discriminan entre sí, se pelean y todo lo demás y yo me } \\
\text { esfuerzo para que sean amigos, y tú no sabes nada de inglés y el otro pues si es verdad pero tú eres } \\
\text { tonto. Yo me esfuerzo pero tú realmente es muy difícil tal ese contexto es muy complicado porque hace } \\
\text { parte de la identidad del niño, de hacer una identidad sentirse que pertenece al grupo y tener un } \\
\text { audífono le hace ser diferente y ya es como no se quizás los fabricantes puedan hacer algo quizás en } \\
\text { unos años podrían hacerlo más pequeño o normalizarlo, pero aun así yo lo veo el tema de la } \\
\text { vergüenza y el de la no aceptación de la sordera a mí me parece muy importante en estas cosas." }\end{array}$ \\
\hline Profesional & $\begin{array}{l}\text { "Y con una persona sorda no ocurre o sea a mí me ha pasado de llegar a la revisión de un i.c en un } \\
\text { hospital y que me digan no pasa solo y decir no mira es que soy el intérprete, y que me digan ahh es } \\
\text { que no entiende. Perdona es que estamos en un hospital estamos haciendo la revisión de un i.c o sea } \\
\text { por favor, es que ni siquiera la misma gente del propio ámbito de la sordera tiene conocimientos al } \\
\text { respecto. O que un otorrino diga sordomudez o sea estamos hablando de una exageración entonces la } \\
\text { educación va desde los propios profesionales, y somos los propios profesionales que tratamos la } \\
\text { sordera los que tienen que preocuparse de hacer llegar a la Sociedad que no tienen por qué saberlo } \\
\text { sino les ha tocado en su vida que la sordera es una discapacidad con unas características propias y } \\
\text { que tienes que tratarlos de cierta manera." }\end{array}$ \\
\hline
\end{tabular}

Tabla 96.- Número de citas sobre Factores Ambientales (Servicios, sistemas y políticas) en función del grupo focal

\begin{tabular}{|c|c|c|c|c|c|}
\hline $\begin{array}{l}\text { Código } \\
\text { CIF }\end{array}$ & Título & Familiares & $\begin{array}{r}\text { Personas con } \\
\text { hipoacusia }\end{array}$ & Profesionales & Personas sordas \\
\hline e510 & $\begin{array}{l}\text { Servicios, sistemas y políticas de } \\
\text { producción de artículos de } \\
\text { consumo }\end{array}$ & 2 & 0 & 0 & 0 \\
\hline e515 & $\begin{array}{l}\text { Servicios, sistemas y políticas de } \\
\text { arquitectura y construcción }\end{array}$ & 0 & 0 & 1 & 0 \\
\hline e530 & $\begin{array}{l}\text { Servicios, sistemas y políticas de } \\
\text { utilidad pública }\end{array}$ & 1 & 0 & 0 & 0 \\
\hline e550 & $\begin{array}{l}\text { Servicios, sistemas y políticas } \\
\text { legales }\end{array}$ & 0 & 0 & 2 & 0 \\
\hline e555 & $\begin{array}{l}\text { Servicios, sistemas y políticas de } \\
\text { asociación y organización }\end{array}$ & 4 & 0 & 0 & 0 \\
\hline e565 & $\begin{array}{l}\text { Servicios, sistemas y políticas } \\
\text { económicas }\end{array}$ & 8 & 0 & 0 & 0 \\
\hline e570 & $\begin{array}{l}\text { Servicios, sistemas y políticas de } \\
\text { seguridad social }\end{array}$ & 6 & 1 & 7 & 2 \\
\hline e575 & $\begin{array}{l}\text { Servicios, sistemas y políticas de } \\
\text { apoyo social general }\end{array}$ & 2 & 4 & 0 & 1 \\
\hline e580 & $\begin{array}{l}\text { Servicios, sistemas y políticas } \\
\text { sanitarias }\end{array}$ & 2 & 0 & 10 & 2 \\
\hline e585 & $\begin{array}{l}\text { Servicios, sistemas y políticas de } \\
\text { educación y formación }\end{array}$ & 0 & 0 & 5 & 1 \\
\hline e590 & $\begin{array}{l}\text { Servicios, sistemas y políticas } \\
\text { laborales y de empleo }\end{array}$ & 0 & 1 & 0 & 0 \\
\hline e595 & $\begin{array}{l}\text { Servicios, sistemas y políticas de } \\
\text { gobierno }\end{array}$ & 2 & 0 & 0 & 0 \\
\hline
\end{tabular}


La tabla 96 hace referencia al capítulo de Servicios, sistemas y políticas de la dimensión Factores ambientales. Podemos observar en la tabla que los profesionales tienen un mayor número de citas para el código servicios, sistemas y política sanitaria seguida de servicios, sistemas y políticas de seguridad social. Sin embargo, para los familiares servicios, sistemas y políticas económicas, son las que en este capítulo han tenido un mayor número de citas lo cual puede derivarse del elevado coste de los PA para este colectivo además de su mantenimiento, es una de las mayores preocupaciones de los familiares de las personas con discapacidad. Por último, servicios sistemas y políticas de apoyo social general ha recibido un mayor número de citas para personas con hipoacusia. Son muchas las personas con discapacidad que creen que debería de haber más ayudas económicas por lo que las políticas deberían de cambiar, así mismo, es un debate continuo dentro de la comunidad sorda los servicios sociales, laborales, sanitarios y de educación (Malo, 2015; Moreno, 2007; Muñoz-Baell et al., 2011; Palacios, 2008).

Tabla 97.- Ejemplos de citas del quinto capítulo de la dimensión "Factores Ambientales".

\begin{tabular}{|c|c|}
\hline Profesional & $\begin{array}{l}\text { "la mayor barrera sea quizás el tema monetario el precio tan excesivo que tienen aquí en España en } \\
\text { comparación con otros sitios pero también a la falta de implantación por ejemplo el bucle } \\
\text { magnético da la sensación de que es lo raro cuando es algo que debería de estar ya implantado en } \\
\text { toda institución pública" }\end{array}$ \\
\hline Profesional & $\begin{array}{l}\text { "discriminados y son discapacitados porque no pueden acceder a la información y quién impide ese } \\
\text { acceso a la información la mayoría, podemos acceder de forma superfácil y porque en el colegio } \\
\text { tienen que hacerle una adaptación de acceso a la comunicación, si la lengua de signos es un } \\
\text { lenguaje si yo me pongo por narices es que mi niño tiene una educación bilingüe por ley lo que pasa } \\
\text { que como la mayoría no pues es una broma todo entonces creo que me voy a la discapacidad } \\
\text { auditiva pero como si me voy a otro tipo de discapacidades incluso a la discapacidad intelectual, } \\
\text { nosotros somos los que hacemos el mundo difícil para ellos no son discapacitados no somos } \\
\text { discapacitados es mi opinión y es el contexto quien discapacita." }\end{array}$ \\
\hline Familiar & "que grado de discapacidad tengas, todo depende de eso, debería de cambiarse esas politicas" \\
\hline Familiar & $\begin{array}{l}\text { "se debe trabajar paralelamente lo que son las asociaciones que trabajan con estas personas con } \\
\text { este tipo de discapacidad, la administración pública y las empresas. Para poder normalizar a estas } \\
\text { personas porque las ayudas que hay ahora mismo por discapacidad, las pensiones que hay son muy } \\
\text { bajas con lo cual estamos haciendo que una persona con este tipo de discapacidad no pueda } \\
\text { acceder a un mercado laboral normal y podrían hacerlo perfectamente" }\end{array}$ \\
\hline Familiar & $\begin{array}{l}\text { "las empresas muchas veces se aprovechan de eso se aprovechan para recibir las subvenciones y } \\
\text { luego en realidad cuando no valoran ese trabajo o no ven lo que pueden llegar a hacer" }\end{array}$ \\
\hline Profesional & $\begin{array}{l}\text { "creo que falta mucho camino porque como ha dicho ella que necesitan mucho apoyo y se les da } \\
\text { una infinita parte de lo que necesitan a lo largo de la semana para estudiar o para lo que sea pues } \\
\text { les falta mucho camino para integrarse y puedan vivir una vida más o menos independiente porque } \\
\text { al fin y al cabo ellos quieren necesitan independencia pero por ejemplo en ámbito laboral el día a } \\
\text { día es imposible muy duro y si ya en si tienen una barrera no pueden escuchar te pones algo para } \\
\text { poder escuchar y no hay más mecanismos para que puedas tener una calidad entonces no te vas a } \\
\text { poder integrar en ningún momento" }\end{array}$ \\
\hline Profesional & $\begin{array}{l}\text { "haria falta hacer mucha más presión de colegios profesionales tanto de ilses, en fin todas las } \\
\text { personas que están en contacto un poco con la comunidad sorda de cara a instituciones o sea al } \\
\text { final un poco el agente de cambio social es gobiernos, ministerios, instituciones que van a marcar a } \\
\text { instar un poco a estimular tanto el desarrollo de estas aplicaciones que gracias a dios ya se van } \\
\text { desarrollando pero luego lo que decimos es implantarlas y que se usen bien tanto para instituciones, } \\
\text { en el ayuntamiento que pues eso que adapte su página web todos sus procedimientos administrativos } \\
\text { para hacerlos accesibles para personas sordas este tipo de cosas también nos falta ese empuje" }\end{array}$ \\
\hline
\end{tabular}


Tabla 98.- Número de citas sobre Estructuras corporales en función del grupo focal

\begin{tabular}{|c|c|c|c|c|c|}
\hline $\begin{array}{l}\text { Código } \\
\text { CIF }\end{array}$ & Título & Familiares & $\begin{array}{l}\text { Personas } \\
\text { con } \\
\text { hipoacusia }\end{array}$ & Profesionales & $\begin{array}{l}\text { Personas } \\
\text { sordas }\end{array}$ \\
\hline s110 & Estructura del cerebro & 0 & 0 & 4 & 0 \\
\hline s240 & Estructura del oído externo & 1 & 0 & 0 & 0 \\
\hline $\mathrm{s} 250$ & Estructura del oído medio & 1 & 0 & 7 & 0 \\
\hline s260 & Estructura del oído interno & 1 & 2 & 2 & 0 \\
\hline s340 & Estructura de la laringe & 0 & 0 & 1 & 0 \\
\hline s610 & Estructura del sistema urinario & 0 & 1 & 0 & 0 \\
\hline s630 & Estructura del sistema reproductor & 0 & 1 & 0 & 0 \\
\hline s750 & Estructura de la extremidad inferior & 0 & 1 & 0 & 0 \\
\hline
\end{tabular}

La tabla 98 hace referencia a la dimensión "Estructuras Corporales", que fue la dimensión que obtuvo un menor número de citas. Podemos observar en la tabla que el grupo con mayor número de citas fue el de los profesionales, con mayor número en las relativas a la estructura del oído medio, seguido de las personas con hipoacusia, con dos citas para el código estructura del oído interno. Para los familiares las citas están compensadas en una cita para las diferentes estructuras del oído: externo, medio e interno. Finalmente, llama la atención que para las personas sordas no hay ninguna cita. 
Tabla 99.- Ejemplos de citas del quinto capítulo de la dimensión "Estructuras corporales".

\begin{tabular}{|l|l|}
\hline Profesional & $\begin{array}{l}\text { "las estructuras cerebrales que ya no pueden evolucionar mucho más entonces una educación } \\
\text { auditiva a los } 70 \text { años a los } 50 \text { años si has oído previamente puede pero si eres sordo y llevas la } \\
\text { identidad sorda y tu lengua de signos lo veo más dificil." }\end{array}$ \\
\hline Profesional & $\begin{array}{l}\text { "Una persona que ya ha oído se queda sorda digamos por un accidente o una enfermedad profunda } \\
\text { y digamos que pierde totalmente la audición y vuelve a recuperarla con la el audifono yo creo que } \\
\text { es más fácil generar los circuitos neuronales que ya tenían volver a identificar volver a buscar esos } \\
\text { matices que tiene cada sonido" }\end{array}$ \\
\hline Profesional & $\begin{array}{l}\text { "la corteza cerebral el área del lenguaje se especializa en lo visual, eso es una tontería el área del } \\
\text { lenguaje es el área del lenguaje y tú puedes aprender lengua de signos y lengua oral, dependiendo } \\
\text { del acceso que tengas tú en ese momento a la información" }\end{array}$ \\
\hline Profesional & $\begin{array}{l}\text { "con un intérprete también va apoyando de forma inconsciente el oído y va trabajando también el } \\
\text { oído para poder escuchar le va dando más información" }\end{array}$ \\
\hline
\end{tabular}

Como hemos comentado en la parte teórica de esta Tesis Doctoral, los factores personales no se encuentran codificados en la CIF, por ello en las siguientes tablas se ponen algunos ejemplos de citas codificadas como factores personales. 
Tabla 100.- Ejemplos de citas codificadas como factores personales y su quotation personas con hipoacusia y personas sordas

\begin{tabular}{ll}
\hline Sujeto & Cita \\
\hline Familiar-Cónyuge persona & que tengan prejuicios o les de vergüenza llevarnos y entonces lo oculten \\
sorda & \\
Familiar-Hijo persona sorda & problemas de autoestima o problemas de que se van inseguros \\
Persona con hipoacusia & desde que me los he puesto me han dado mucha seguridad y autoestima \\
Persona con hipoacusia & es definitivo claro el ser una persona con esperanza, con motivación, positiva \\
Persona con hipoacusia & $\begin{array}{l}\text { Tiendes a distraerte y a encerrarte en ti mismo, muchas veces por vergüenza a no } \\
\text { enterarte de las conversaciones y tener que repetir ¿Qué ha dicho? Yl final te } \\
\text { excluyes tu solo }\end{array}$ \\
Persona con hipoacusia & $\begin{array}{l}\text { Puedas pasar a tener una pequeña depresión, que te retraigas, que seas más } \\
\text { tímido de ahí sí creo porque lo he visto por experiencia a gente muy allegada a mí. } \\
\text { no hay que tener vergüenza ni ponerse nervioso }\end{array}$ \\
Persona sorda usuaria de IC & $\begin{array}{l}\text { Mi sueño es que las personas sordas se unan aunque sea implantado aunque sea } \\
\text { signado aunque sea oralista, todos juntos todos tenemos el mismo problema y } \\
\text { tenemos que luchas para eliminar este problema y estas barreras, porque si no } \\
\text { vamos a seguir teniendo el mismo problema y no lo vamos a eliminar nunca }\end{array}$ \\
Persona sorda & $\begin{array}{l}\text { nos ven a nosotros como si fuéramos personas normales y agradecidos que } \\
\text { estamos pero no somos personas normales, tenemos nuestra sordera hasta que nos } \\
\text { muramos } \\
\text { Yo pienso que yo no necesito estos productos para ser igual a un oyente. Yo estoy } \\
\text { a gusto con ser sorda }\end{array}$
\end{tabular}

Persona sorda

Clarísimamente las dos porque por desgracia hay como dos mundos las personas con discapacidad y las personas sin discapacidad, dentro de las personas sin discapacidad hay mucha heterogeneidad y dependiendo de la discapacidad hay diferentes barreras. Las personas que tienen la misma discapacidad se arreglan haciendo cosas juntos yo con mis amigos sordos me no se desahogó pues estoy molesta con la intérprete porque fijate lo que me ha hecho y las personas sordas me entienden saben de lo que estoy hablando. Yo se lo cuento a una persona oyente y no lo entiende me dice no pasa nada tienes que intentar entenderlo no nos ponemos de acuerdo básicamente. Pero una persona sorda me entiende y creo que es porque sabe las barreras que tenemos y como que intentamos arreglarlas juntos nos entendemos. Está claro que tenemos una discapacidad nos falta un sentido la audición eso está clarísimo pero la discapacidad auditiva te da una cultura unas habilidades da muchas cosas

Persona sorda usuaria de audífonos

Persona sorda usuaria de IC

Persona sorda
Yo antes por ejemplo con los audífonos me daba vergüenza llevarlos y los tapaba con el pelo simplemente porque no aceptaba mi sordera.

yo me siento muy orgullosa porque he evolucionado muchísimo y me da igual que haya gente en contra de los implantados porque yo sé quién soy

Yo hablo del primer día que lo ven y se separan se alejan luego ya el segundo, tercer, cuarto día se dan cuenta que eres una persona normal y ya bien toman contacto yo hablo del primer día. Yo desde bien pequeña he sentido el rechazo es como cuando ven a una persona ciega que dicen uy como hago y se alejan después ya se acercan y no pasa nada hay relación yo pienso que pasa con todas las discapacidades 
Tabla 101.- Ejemplos de citas codificadas como factores personales en profesionales

\begin{tabular}{|c|c|}
\hline Participante & Cita \\
\hline $\begin{array}{l}\text { Profesional-ILSE y Trabajadora } \\
\text { social }\end{array}$ & $\begin{array}{l}\text { obviamente va en el carácter de cada uno pero a una cierta edad cuando } \\
\text { tienes ya un carácter o una personalidad formada con un autoestima más o } \\
\text { menos positiva o demás, unos audífonos o demás desde mi punto de vista o lo } \\
\text { que yo he conocido, es como al que le toca ponerse gafas o dentadura postiza }\end{array}$ \\
\hline
\end{tabular}

Profesional-ILSE

Profesional-ILSE

Profesional-ILSE y trabajadora social

Profesional-ILSE

Profesional-ILSE y logopeda

Profesional-ILSE y logopeda

Profesional-ILSE y psicóloga

Profesional-Terapeuta Ocupacional

Profesional- ILSE

Profesional- ILSE y psicóloga

Profesional- ILSE y logopeda
Además de eso mi experiencia social me lleva a que yo conozco bastantes personas sordas que les da vergüenza que les da muchísima vergüenza llevar los audífonos y se los quitan, yo pregunto pero porque te los quitas, porque no me gusta, porque al fin y al cabo se sienten discriminados

\section{depresión}

yo creo que siempre hablamos de la heterogeneidad en la sordera, y la heterogeneidad no está ligada a la sordera como tal está ligada a cada persona cada persona asume y afronta su vida y lo que en su vida ocurre de forma diferente

parece que estas despistado que este niño es un despistado y un vago

creo que tiene que haber mucho trabajo de la persona como no se adapte bien no le va a servir de nada

afecta mucho los tipos de motivos y afectan por supuesto los motivos de vergüenza, el qué dirán, de la opinión social, sentirte marcado es al final sentirte señalado

Nos adaptamos mucho más a las circunstancias, somos más valientes y le echamos lo que hay que echarle a la vida, yo creo que a los hombres a veces les cuesta mucho y creo que son un poco cobardes y prefieren quedarse ahí y de ahí no le sacas. Nosotras somos más valientes

en realidad a cada persona puede que le vaya bien o puede que su calidad de vida sea peor porque no se siente cómodo con las ayudas

el problema que las expectativas no son realistas no tiene nada que ver con lo que en realidad hace

tú tienes una visión negativa de esas ayudas, sentir que es algo que te rebaja o si lo vas a negar incluso si te pudiera resultar muy útil y ayudar y facilitar las cosas en muchos sentidos lo vas a rechazar para que no afecte a tu autoconcepto

tu autoestima tampoco porque no te ves bien a los ojos de los demás ya no solo a tus ojos es como que vas por ahí y tienes la necesidad de tapártelo o algo porque sientes la sensación de que los demás te están juzgando tu autoestima disminuye

Como ya hemos expuesto anteriormente una de las ventajas del uso de la CIF en la clasificación de los factores ambientales y como estos son barreras o facilitadores. Los facilitadores son todos aquellos factores ambientales en el entorno de una persona que mejoran el funcionamiento y reducen la discapacidad, y pueden prevenir que el déficit auditivo no limite la actividad de la persona sorda. Por otra parte, las barreras son todos aquellos factores ambientales en el entorno de una persona que cuando están presentes, limitan el funcionamiento y generan discapacidad. Entre ellos se incluyen la inaccesibilidad al ambiente físico, productos de apoyo inadecuados o falta de ellos, falta de apoyo o 
presencia de actitudes negativas de la población respecto a la discapacidad. En la siguiente figura podemos observar el número de factores ambientales ya sean barreras o facilitadores por los 4 tipos de grupos focales.

Figura 10. Número de factores ambientales de la CIF clasificados como barreras o facilitadores los por tipo de grupo focal

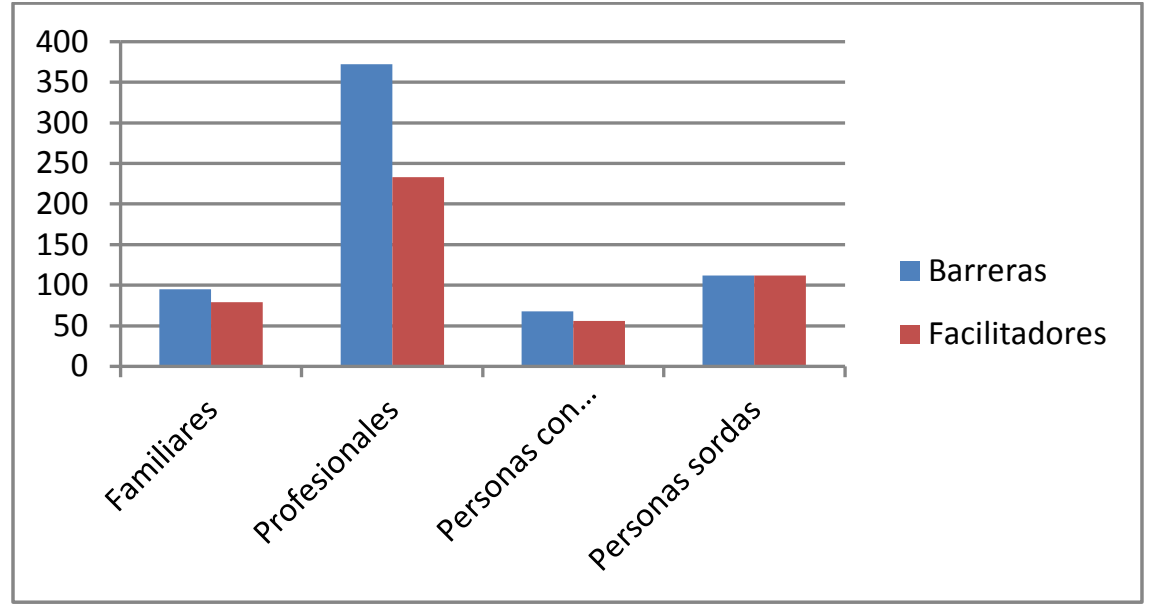

Tabla 102.- Número de códigos clasificados como Barreras o Facilitadores por tipo de grupo focal

\begin{tabular}{llllll}
\hline & Familiares & Profesionales & Personas con hipoacusia & Personas sordas & Total \\
Barreras & 95 & 372 & 68 & 112 & 647 \\
Facilitadores & 79 & 233 & 56 & 112 & 480 \\
\hline Total & 174 & 504 & 124 & 224 & 1127 \\
\hline
\end{tabular}

Uno los objetivos específicos de este estudio era el de indagar sobre los factores que provocan abandono o falta de continuidad de los productos de apoyo en personas sordas y con discapacidad auditiva. Para ello, tal y como se ha mencionado con anterioridad, se codificaron las partes del discurso que hacían referencia a cada uno de los 30 factores que forman parte del modelo sobre factores de abandono de productos de apoyo de Lauer, Longenecker \& Smith (2006). Dado que el modelo organiza los factores en 5 dimensiones, en la siguiente figura se puede consultar la distribución de citas en función de la dimensión y del tipo de participante. 
Tabla 103.- Número de factores predictores de abandono o falta de continuidad de productos de apoyo según el modelo de Lauer, Longenecker \& Smith (2006) por tipo de grupo focal

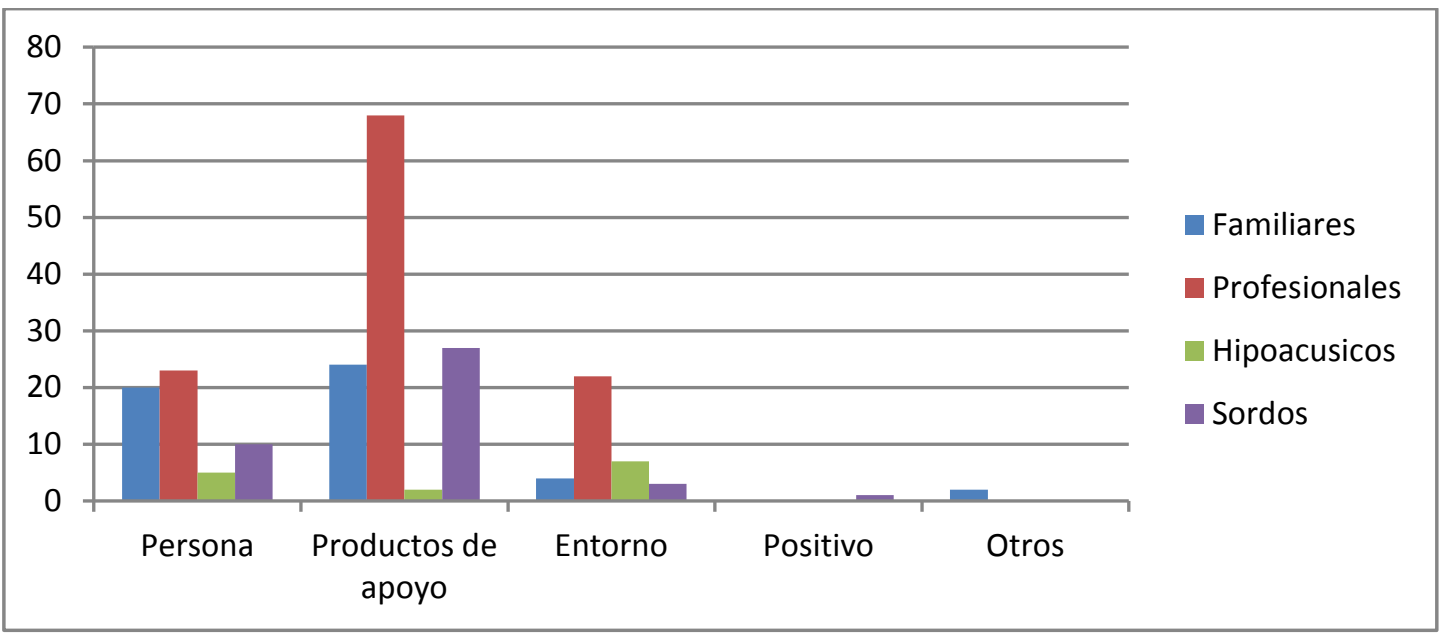


Y en la tabla siguiente se muestra el detalle de citas de cada uno de los factores por grupo de participantes.

Tabla 104.- Número de factores predictores de abandono o falta de continuidad expresados en los diferentes grupos focales

\begin{tabular}{|c|c|c|c|c|c|c|c|}
\hline $\begin{array}{l}\text { Tipo de } \\
\text { factor }\end{array}$ & Título & Códigos & Total & $\begin{array}{l}\text { Total } \\
\text { familiares }\end{array}$ & $\begin{array}{l}\text { Total } \\
\text { hipoacúsicos }\end{array}$ & $\begin{array}{l}\text { Total } \\
\text { profesionales }\end{array}$ & $\begin{array}{l}\text { Total } \\
\text { sordos }\end{array}$ \\
\hline Otros & $\begin{array}{l}\text { Cambios en } \\
\text { necesidades/prioridades }\end{array}$ & $\mathrm{O} 2$ & 2 & 2 & 0 & 0 & 0 \\
\hline \multirow[t]{5}{*}{ Persona } & $\begin{array}{l}\text { Descenso en capacidad } \\
\text { funcional }\end{array}$ & P1 & 1 & 1 & 0 & 0 & 0 \\
\hline & $\begin{array}{l}\text { Sentimiento de no } \\
\text { necesitarlo }\end{array}$ & $\mathrm{P} 2$ & 5 & 2 & 0 & 1 & 2 \\
\hline & $\begin{array}{l}\text { Visión negativa hacia el } \\
\text { producto }\end{array}$ & P3 & 32 & 11 & 4 & 12 & 5 \\
\hline & Depresión & P4 & 3 & 1 & 1 & 1 & 0 \\
\hline & $\begin{array}{l}\text { No aceptación } \\
\text { discapacidad }\end{array}$ & P5 & 17 & 5 & 0 & 9 & 3 \\
\hline \multirow{13}{*}{$\begin{array}{l}\text { Producto } \\
\text { de apoyo }\end{array}$} & Dificultad de uso & PA7 & 4 & 1 & 2 & 1 & 0 \\
\hline & Seguridad & PA8 & 1 & 0 & 0 & 1 & 0 \\
\hline & Estética & PA9 & 10 & 3 & 0 & 4 & 3 \\
\hline & Instrucciones complejas & PA10 & 9 & 2 & 2 & 5 & 0 \\
\hline & Configuración complicada & PA11 & 2 & 2 & 0 & 0 & 0 \\
\hline & Mal funcionamiento/ fallo & PA12 & 38 & 4 & 9 & 14 & 11 \\
\hline & $\begin{array}{l}\text { Dolor/incomodidad por su } \\
\text { uso }\end{array}$ & PA13 & 7 & 0 & 2 & 3 & 2 \\
\hline & Coste de mantenimiento & PA14 & 28 & 5 & 3 & 7 & 8 \\
\hline & Deterioro de producto & PA15 & 5 & 0 & 1 & 4 & 0 \\
\hline & $\begin{array}{l}\text { Nunca se instaló ni se } \\
\text { utilizó }\end{array}$ & PA16 & 7 & 0 & 0 & 5 & 2 \\
\hline & $\begin{array}{l}\text { No emparejado con } \\
\text { necesidades }\end{array}$ & PA17 & 13 & 3 & 2 & 8 & 0 \\
\hline & $\begin{array}{l}\text { Insuficiente o nulo } \\
\text { entrenamiento }\end{array}$ & PA18 & 18 & 2 & 0 & 15 & 1 \\
\hline & $\begin{array}{l}\text { Opinión no tenida en } \\
\text { cuenta selección }\end{array}$ & PA19 & 3 & 2 & 0 & 1 & 0 \\
\hline \multirow[t]{4}{*}{ Entorno } & Problemas de accesibilidad & PA20 & 15 & 0 & 3 & 11 & 1 \\
\hline & $\begin{array}{l}\text { Socialmente inaceptable } \\
\text { (estigma) }\end{array}$ & PA21 & 18 & 4 & 3 & 9 & 2 \\
\hline & $\begin{array}{l}\text { Requiere asistencia } \\
\text { personal }\end{array}$ & PA22 & 1 & 0 & 0 & 1 & 0 \\
\hline & $\begin{array}{l}\text { Depende de otro } \\
\text { dispositivo }\end{array}$ & PA23 & 2 & 0 & 1 & 1 & 0 \\
\hline Positivo & Reemplazo por otro mejor & $\mathrm{PO} 2$ & 1 & 0 & 0 & 0 & 1 \\
\hline
\end{tabular}

En la tabla anterior cabe destacar aquellos factores que tienen una mayor número de citas: (1) mal funcionamiento/fallo ( $\mathrm{n}=38$ ) al igual que en el estudio de Phillips y Zhao (1993) que concluyeron como primer factor de abandono el pobre rendimiento del producto; (2) visión negativa hacia el producto $(\mathrm{n}=32)$ ligado, probablemente, a su mal funcionamiento; (3) coste de mantenimiento $(n=28)$ como concluyeron Day, Jutai, Woolrich \& Strong (2001) como uno de los principales factores de abandono o falta de uso; (4) insuficiente o nulo entrenamiento $(n=18)$, que denota el hecho de que muchas personas usuarias de PA específicos para la comunicación no reciben un entrenamiento en las mismas; de hecho, en el 
estudio 1 de esta tesis doctoral recordemos que el $52 \%$ de las personas que no empleaban los SIV no conocían el dispositivo ni han sido entrenados para su uso; (5) el estigma $(n=18)$ es otro de los problemas asociados al uso de PA. Tal y como han concluido varios autores, que consideran este factor como principal causa de abandono o falta de uso de un PA (LouiseBender, Kim \& Weiner, 2002; Verza, Carvallo, Battagia \& Ucelli, 2006); (6) no aceptación de la discapacidad $(n=17)$, y de hecho son muchas las personas con discapacidad auditiva que no aceptan su discapacidad; (7) problemas de accesibilidad $(n=15)$, un factor importante a tener en cuenta en el campo de los PA; (7) no emparejamiento con necesidades ( $\mathrm{n}=13$ ), por lo que es necesario realizar una correcta evaluación antes de la adquisición del producto y emplear instrumentos adecuados en medidas de resultados como el empleado en este estudio, el MPT puesto que el objetivo principal de este instrumento no es otro que conocer el emparejamiento entre una persona y el PA; y (8) cuestiones estéticas $(n=10)$, que también son un factor que suele dar lugar a un gran número de abandono de PA (Day, Jutai, Woolrich \& Strong, 2001; Ravneberg, 2012).

También fueron citados otros factores, aunque en menor proporción, pero entre estos cabe destacar los relacionados con la usabilidad de los PA tales como instrucciones complejas $(n=9)$, dificultad de uso $(n=4)$ y deterioro del producto $(n=5)($ Arthanat et al., 2007); y por otro lado son de destacar los relacionados con factores psicosociales como sentimiento de no necesitarlo $(n=5)$, depresión $(n=3)$ o no tener en cuenta la opinión del usuario en la adquisición del PA (n=3) (Day, Jutai, Woolrich \& Strong, 2001). Cabe mencionar que son varias las citas en las que aparece el dolor o la incomodidad del uso de audífonos (n=7) (Kochkin, 2000).

A modo de ejemplo de las citas que corresponden a los factores de abandono, en al siguiente tabla se ofrecen algunos ejemplo por tipo de participante. 
Tabla 105.- Expresiones codificadas de algunos de los factores de abandono o falta de uso del modelo de Lauer, Longenecker \& Smith (2006) relacionados con la persona.

\section{Dimensión de}

\section{Expresión}

\section{factores}

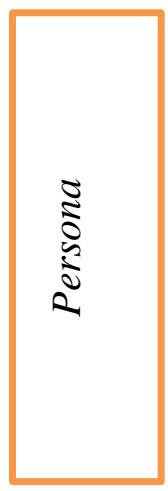

(P3: Visión negativa hacia el producto)"la persona que tiene la perdida mas tarde es lo que tú has intentado esconder hasta entonces en el momento que tú te lo pones es cuando todo el mundo ya lo sabe". "que incluso hay ahora un movimiento que yo no sé si es incluso a nivel mundial o que pero hay un movimiento en contra de los implantados que eso tiene ya tela"." si yo creo que si porque eso te condiciona mucho o sea el concepto que tú tienes de lo que implica esas ayudas frente a tu auto valía claro que influye para vamos que no sé cómo explicarlo para alargarlo un poco más te condiciona en el sentido de que si tú tienes una visión negativa de esas ayudas, sentir que es algo que te rebaja o si lo vas a negar incluso si te pudiera resultar muy útil y ayudar y facilitar las cosas en muchos sentidos lo vas a rechazar para que no afecte a tu autoconcepto entonces si claro que si"

(P4: Depresión)" ese es el problema que las expectativas no son realistas no tiene nada que ver con lo que en realidad hacer hombre no todas los casos pero es lo que comentan ellos que luego muchas veces la experiencia es muy negativa e incluso para alguna gente traumática entonces habría que tener muchas precauciones en ese sentido si" (P5: No aceptación discapacidad)" porque no aceptaba mi sordera" 
Tabla 106.- Expresiones codificadas de algunos de los factores de abandono o falta de uso del modelo de Lauer, Longenecker \& Smith (2006) relacionados con el propio producto de apoyo.

Dimensión

\section{de factores}

Expresión

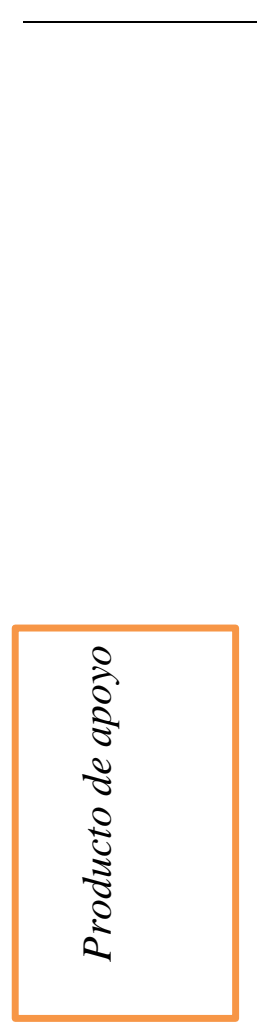

(PA 18,10,8 y 7): “yo creo que en parte el problema es que muchos de estos apoyos, ayudas técnicas, tecnologías y todo lo demás son muy nuevas y creo que estamos en una Sociedad que actualmente tenemos personas que son nativos digitales y los que no son, y la gran mayoría no lo es. Y cuanto más nos alejamos cuanto más mayor es la persona que es introducida en el mundo digital peor porque es mucho más difícil adaptarse y aprender, entonces pensar que los apoyos electrónicos son lo mejor de todo o que van a ayudar a todo el mundo es una quimera. Porque sirve para algunos. Dentro de 50 años, este problema ya no existe probablemente o 60 años, porque ya todos seremos nativos digitales y tendremos otro tipos de problemas, pero ahora mismo no podemos pensar que eso es la solución, no que estas descartando a un gran colectivo que no pueda acceder por sus limitaciones personales porque no pueden una persona mayor pues no no entiende cómo va a ir un ordenador"

(PA 10):”El problema que si yo quiero aprender a utilizarlas me tienen que enseñar porque no tengo ni idea".

(PA12) "un gran problema es que por ejemplo los usuarios de la lengua de signos, es que la lengua de signos se apoya en la expresión facial y ya eso un avatar tiene que mejorar muchísimo para llegar hasta poder porque existen muchos signos que son iguales en sus parámetros formativos pero necesitan la diferencia entre un signo u otro es la expresión y eso todavía un avatar no lo puede dar"," teniendo ya la experiencia del audífono te estanca mucho te estanca mucho porque no te capta todo", "pero hay otras personas que no y que se ha demostrado que no ha funcionado o que la rehabilitación que se ha llevado con ellos no ha llegado a un buen puerto el i.c no era para sus necesidades no era lo que necesitaba"

(PA13: Incomodidad por su uso)" yo lo he usado alguna vez pero no me siento cómoda" (PA14: Coste de mantenimiento)" y lo que cuesta tienes presupuesto para toda la vida para pagar"' el i.c muy mal tanto gasto para nada"' Me parecen estupendos pero realmente si quieres tener un buen equipo tienes que tener un buen recurso económico y creo que por ahí es donde puede venir la solución que nos apoyaran más para obtener mejores ayudas tecnológicas que s u vez mejoraran nuestro bienestar de vida"' si bueno también hay que reconocer que esto antes bueno ahora entra por la Seguridad Social pero bueno las pilas son muy caras y los audífonos son también bastante caros sí que tienen ciertas ayudas no estoy segura estoy hablando sin saber pero si no conozco el precio si me dijo una chica el precio pero no recuerdo el cual pero sí que eran caros te dejabas un pastón en pilas para los implantes y para los audífonos"' El dinero es básico también eso es que a veces aunque quieran puedan eso hay a veces que también la pila, el otro día por ejemplo porque yo ahora estoy viendo todavía más cosas, y ya no son solo las pilas es que los audífonos hay que limpiarlos y hay un aparatito especial para limpiarlos que vale no se cuánto el recambio o sea es que es una pasada y lo que cuestan es una pasada "si te pagan la operación y la rehabilitación pero el mantenerlo no"

(PA15: Deterioro del producto)" el niño corre, el niño se le cae el implante, el niño se lo quita rompe el cable ah pues ya no oye ah pues, quien te paga eso, eso no te lo paga nadie"' el implante se estropea"

(PA16: nunca se instaló ni se utilizó)" y tengas esa facilidad de acceso, falta ya lo que dice ella que las instituciones lo cojan y digan vamos a ver si esto está bien y está funcionando vamos a implantarlo como hay que implantarlo falta mucho trabajo de muchos sitios "sacan productos muy interesantes pero si la gente no sabe que es lo que tiene que instalar"

(PA17: las cosas pueden funcionar pero realmente no preguntan a quién va dirigido no miran las necesidades que tiene la persona es sordo toma implante y no miran nada más)

(PA18: Insuficiente o nulo entrenamiento) "yo creo que al acceso si pero al uso no, o sea a mí no me vale que tú me des pues no es un portátil, me lio a regalar portátiles para que las personas sordas puedan usar el Svisual pero y yo que hago con esto si a mí no me estas enseñando a usar el portátil"' preocuparte en enseñarle a los miembros de la asociación, incluido junta directiva, como se utiliza el aparato"' gente que le puede valer PA pero no se le da un entrenamiento previo"'” Es vital una formación en el PA Al menos que puedan acceder y darle uso"'”, (PA19: Opinión no tenida en cuenta)" debe de haber una buena no sé cómo decir un buen asesoramiento por parte del establecimiento que miren que es lo que necesito no darme lo primero que vean, ah! Tiene presbiacusia toma audífono retroauricular" 
Tabla 107.- Expresiones codificadas de algunos de los factores de abandono o falta de uso del modelo de Lauer, Longenecker \& Smith (2006) relacionados con el entorno, factores positivo y "otros"

\section{Dimensión}

\section{de factores}

\section{Expresión}

(PA20: Problemas de accesibilidad)" el FM sobre todo cine, conferencias, teatro como no lo hay sería una buena ayuda pero como no lo hay nos fastidiamos y nos quedamos sin ir a mí por ejemplo me encanta el teatro pues y es más yo hacía teatro y lo tuve que dejar porque no me enteraba entonces pues es un problema el que todavía no está como muy desarrollado a nivel de calle"'si existiera en realidad un bucle magnético en tiendas y establecimientos, cines... se enterarían mejor incluso pero en realidad todo eso es mentira es falso no hay accesibilidad" (PA21: Socialmente inaceptable)" tener un audífono le hace ser diferente y ya es como no se quizás los fabricantes puedan hacer algo quizás en unos años podrían hacerlo más pequeño o normalizarlo"

" está en el entorno y el entorno pasa por la educación de la sociedad en general pero a lo que iba de la pregunta misma yo creo que el hecho de usar este tipo de ayudas que son tan visuales puede afectar muchísimo al usuario

" claro volvemos a lo mismo a la cultura de la sociedad que tú puedes decir bueno yo los uso y tal pero tu autoestima tampoco porque no te ves bien a los ojos de los demás ya no solo a tus ojos es como que vas por ahí y tienes la necesidad de tapártelo o algo porque sientes la sensación de que los demás te están juzgando o algo entonces yo creo que sí que afecta un montón el autoestima y todo eso a la hora de usarlos los apoyos"

"Les choca, chocan, te miran al principio que tienes ahí y tal. Eso fue cuando nos pusieron recientemente el i.c, claro a mí me cortaron el pelo, me rapo y yo y mucha gente choco mucho conmigo, me miraban mucho, fíjate R. que tiene el pelo cortito y se le ve, yo estoy ahora con el pelo largo y no se me ve pero con coleta si y me da igual si es que me da igual pero te da rabia jobar que te miran mucho y que te digan y que no te quita el ojo encima a ver que tienes ahí puesto encima de la oreja"

Positivo

(PO2: Reemplazo por otro mejor)" Yo primero lleve audífonos en ambos oídos y después me puse un i.c. Yo con el i.c he notado un gran avance un gran progreso.'”

(O2: yo me los quite porque mis necesidades eran otras los audífonos no me hacían nada) 


\section{Análisis de correspondencia con el conjunto básico de la CIF}

El tercer objetivo de este estudio era aportar información para validar el actual conjunto básico de la CIF para personas con pérdida auditiva. Además, este estudio podría aportar información para la realización de un conjunto básico específico para personas sordas

Con el objeto de estimar el grado de acuerdo entre los códigos citados por los participantes de los grupos focales (hipoacusia y personas sordas) y los códigos que componen los conjuntos básicos de la CIF, se calculó un índice kappa de Cohen para dos jueces, tomando como juez 1 al propio conjunto básico y como juez 2 el listado de códigos que describen el discurso de las personas sordas y con discapacidad aditiva que participaron en los grupos focales.

En primer lugar, en la tabla 108 se muestran los índices kappa de Cohen para el Conjunto Básico Breve. Como se puede apreciar, los índices de acuerdo alcanzaron valores moderados, siendo menor el acuerdo del grupo de personas sordas $(\kappa=0,40)$ que el de personas con hipoacusia $(\kappa=0,51)$.

Tabla 108. Índice de acuerdo Kappa de Cohen en los códigos citados por los grupos focales y el Conjunto Básico Breve

\begin{tabular}{lcc}
\hline & Core Set Breve & Grupo Sordera \\
\cline { 2 - 3 } Grupo Hipoacusia & 0,51 & 0,53 \\
Grupo Sordera & 0,40 & \\
\hline
\end{tabular}

En segundo lugar, en la tabla 109 se muestran los índices kappa de Cohen para el Conjunto Completo. Como se puede apreciar, los índices de acuerdo alcanzaron valores moderados, siendo menor el acuerdo del grupo de personas sordas $(\kappa=0,40)$ que el de personas con hipoacusia $(\kappa=0,42)$.

Tabla 109.- Índice de acuerdo Kappa de Cohen en los códigos citados por los grupos focales y el Conjunto Básico Completo

\begin{tabular}{lcc}
\hline & Core Set Completo & Grupo Sordera \\
\cline { 2 - 3 } Grupo Hipoacusia & 0,42 & 0,65 \\
Grupo Sordera & 0,40 & \\
\hline
\end{tabular}

Es de especial interés señalar algunos de los códigos de la CIF que aparecen en el conjunto básico breve pero no fueron citados por los participantes de nuestro estudio: 1) 
(b144) funciones de la memoria, (b210) funciones visuales, (b240) sensaciones asociadas con la audición y con la función vestibular, (e310) familiares cercanos, (e355) profesionales de la salud, (e410) actitudes individuales de miembros de la familia, (e580) servicios, sistemas y políticas sanitarias, (s110) estructura del cerebro, (s240) estructura del oído externo y (s250) estructura del oído medio. La razón por la que estos códigos no aparecen en los discursos de las personas con discapacidad auditiva y personas sordas podría tener que ver con que los ítems del cuestionario tenían como objeto indagar sobre productos de apoyo y desempeño diario y no tanto con lo relacionado a las estructurales corporales y daños concretos en el nivel físico. No obstante, en el grupo de profesionales sí se encuentran estos códigos, por lo que es un aspecto a explorar en futuras investigaciones sobre los conjuntos básicos.

Además, resulta de interés que no se hayan encontrado citas relacionadas con función vestibular y de la memoria y con las actitudes de los profesionales de la salud porque tal y como se desarrolló en la parte teórica de esta Tesis Doctoral las personas sordas presentan dificultades en estas dimensiones. Tales como las dificultades comunicativas a las que se enfrentan las personas sordas debido a las actitudes que muestran algunos profesionales de la salud en cuanto a los factores contextuales y en lo relativo a las funciones corporales, en la parte teórica se mencionó algunos estudios que relacionan la pérdida auditiva con limitaciones en la memoria así como las limitaciones en las actividades dado al tinnitus o como marca el código de la CIF, (b240) sensaciones asociadas con la audición y con la función vestibular.

En la siguiente tabla aparecen los capítulos incluidos en las cinco dimensiones de la CIF y una comparación entre el conjunto básico y el estudio actual de los que se encuentran incluidos en el presente estudio y los que no. 
Tabla 110.- Tabla de comparación entre capítulos con y sin citas presentes entre el core set y el presente estudio

\begin{tabular}{|l|l|}
\hline CORE SET & \multicolumn{1}{c|}{$\begin{array}{c}\text { CAPÍTULOS SIN CITAS EN EL PRESENTE } \\
\text { ESTUDIO }\end{array}$} \\
\hline & $\begin{array}{l}\text { Funciones corporales. Capítulo 2 Funciones sensoriales } \\
\text { y dolor } \\
\text { Actividades y participación. Capítulo 4 Movilidad }\end{array}$ \\
\hline ESTUDIO 4 & CAPÍTULOS NO PRESENTES EN EL CORE SET \\
\hline & $\begin{array}{l}\text { Actividades y Participación. Capítulo 2 Tareas y } \\
\text { demandas generales }\end{array}$ \\
& $\begin{array}{l}\text { Actividades y Participación. Capítulo } 5 \text { Autocuidado } \\
\text { Estructuras corporales. Capítulo 3 Estructuras } \\
\text { involucradas en la voz y el habla }\end{array}$ \\
Estructuras corporales. Capítulo 7 Estructuras para la \\
movilidad
\end{tabular}

\section{Discusión}

Son muchos los autores que han destacado la importancia del uso de PA para los problemas en la comunicación derivados de la discapacidad auditiva (Beaulieu, Noreau \& Fougeyrollas, 1998; Fortnum, Marshall, Bamford \& Summerfield, 2002; Hotton, 2004; Johnston, 2004) y por ello nuestro objetivo de indagar sobre el resultado del uso de PA en esta población. Además, muchas disciplinas han investigado la comunicación y las personas que presentan alguna limitación de índole comunicativo, tales como las personas sordas, empleando la CIF (O'Halloran, Hickson, \& Worrall, 2008). Algunos de estos campos son la foniatría (Kagan, 1995; McKooey-O`Halloran et al., 2004; Yorkston, 1992); audiología (Potl \& Hickson, 1990) o enfermería (Happ, 2005). Pero no existen estudios desde la perspectiva de la terapia ocupacional. Muchos de estos estudios fueron realizados mediantes metodología cualitativa, mediante cuestionarios (Hines, 2000; Royal National Institute for the Deaf, 2004) o, como en el estudio actual, mediante grupos focales (Ierzzoni et al., 2004; Witte \& Kuzel, 2000). Muchos se han centrado en las actitudes negativas (Iezzoni et al., 2004; Witte \& Kuzel, 2000) y las actitudes de los familiares (Cumella \& Martin, 2004; Hemsley, Balandin \& Without, 2004; Iacono \& Davis, 2003) pero ninguno se había centrado en las medidas de resultados de los PA.

En este estudio, la CIF se ha empleado como marco conceptual y base para el análisis de contenido, debido a su universalidad y a su visión inclusiva e integral en el 
funcionamiento humano. A nivel práctico, la CIF puede emplearse para cuantificar el impacto en la limitación de la capacidad de una persona tanto para actuar en su entorno y para evaluar las intervenciones para reducir al mínimo el impacto de la discapacidad y maximizar su funcionamiento (Martins, 2015). Sin embargo, existe poca literatura respecto al uso de la CIF como herramienta en población con discapacidad auditiva (Moller, 2003). Algunos autores remarcan la dificultad de realizar cuestionarios y entrevistas personales, al igual que existe un gran abanico de factores personales y ambientales no contemplados en la clasificación de esta población tan heterogénea,lo cual hace complicado el desarrollo y aplicación de la CIF en dicho colectivo (Möller, 2003). No obstante, si existen estudios sobre la elección de no realizar ciertas actividades de la vida diaria a causa de una condición de salud empleando esta herramienta o las dificultades para la participación social dependiendo de los factores personales y los factores ambientales (Fortnum, Marshall, Bamford \& Summerfield, 2002; Fougeyrollas, Cloutier, Bergeron, C`ote \& Stmichel, 1999).

En este sentido cabe señalar que todos los perfiles de participantes obtuvieron su mayor número de citas en las dimensiones de actividades y participación y en factores ambientales. A pesar de que la CIF no categorice los factores personales, en este colectivo es un aspecto muy importante porque, recordemos, muchas de las personas que se ven a sí mismo como "Persona Sorda" no consideran que tengan una discapacidad. En esta misma línea, las dificultades en el desempeño de las actividades parece ser un tema a abordar en este colectivo, puesto que todos los perfiles han hecho hincapié en ello, y debería ser responsabilidad del Terapeuta Ocupacional dado que es el profesional responsable de las intervenciones en la mejora de la ejecución ocupacional en actividades de la vida diaria. Como se ha mencionado con anterioridad, los factores ambientales junto con la dimensión de actividades y participación han sido los que obtuvieron un mayor número de citas. Debemos recordar que, entre las ventajas de la CIF, encontramos que estos factores se dividen a su vez en barreras y en facilitadores. En todos los perfiles de los participantes se obtuvo un mayor número de barreras que de facilitadores, salvo en el grupo de personas sordas que obtuvieron el mismo número de citas en ambas categorías $(\mathrm{n}=112)$; y cabe resaltar que entre los códigos que obtuvieron un mayor número de citas fueron los relacionados con las actitudes sociales (Iezzoni et al., 2004; Witte \& Kuzel, 2000).

La evaluación del impacto de los PA y las tecnologías especializadas en la vida diaria y en la participación social representan un dominio importante de investigación en las estrategias de intervención llevadas a cabo por profesionales de la salud, tales como los 
terapeutas ocupacionales y en lo referente a la investigación en medidas de resultados (Arthanat, Nochajsk \& Stone, 2004; Fuhrer, Jutai, Scherer \& DeRuyter, 2005; Lenker et al., 2010; Lenker, Scherer, Fuhrer, Jutai \& DeRuyter, 2001). El uso de PA en el colectivo de personas sordas y con discapacidad auditiva es vital para realizar las AVD y participar socialmente, por ello es importante que en el proceso de selección de un PA para una persona, se describa de forma uniforme y transparente su funcionamiento, y la CIF puede ser empleada para este proceso, ya que, la CIF se utiliza (algunos de sus componentes) en todos los modelos o marcos para la selección, prescripción y asesoramiento en PA. Y como hemos podido comprobar en el presente estudio, la CIF realiza una buena descripción del funcionamiento de la persona y, aunque no es una herramienta perfecta, sí es bastante completa para la selección de un PA (Queiros, Alvarelhao, Cerqueira, \& Rocha, 2014). Al igual que otros estudios, como el realizado por Vincent, Deaudelin y Hotton (2007), la discapacidad auditiva se ve ligada a los factores personales en cuanto al desempeño de las AVD y a los roles sociales. En la misma línea a este estudio, las personas sordas que viven en un entorno diseñado por oyentes tienen dificultades en la integración social y ocupacional, especialmente si estos se comunican mediante la lengua de signos únicamente (Nadeau, Vercaingne-M`enard, Dubuisson, Leclerc \& De Maisonneuve, 1994).

A pesar de las dificultades comunicativas que presenta el colectivo, si se desarrolló un conjunto básico de la CIF para personas con discapacidad auditiva, cuyo objetivo fue explorar las áreas de funcionamiento y los factores ambientales de los adultos con pérdida de audición mediante el uso de la CIF como herramienta para determinar y documentar cada elemento. En este conjunto básico, en su versión extendida, hay 143 categorías de nivel 0 identificadas y en el presente estudio han sido un total de 119 categorías de nivel 0 y 159 de nivel 1, pero debemos de tener en cuenta que el cuestionario de elaboración propia iba encaminado al uso de los PA y las actividades de la vida diaria. En el conjunto básico la mayor parte de las categorías pertenecen al componente de Actividad y Participación seguido por factores ambientales al igual que ocurre en el presente estudio: 1) Actividades y Participación, 2) Factores ambientales, 3) Funciones corporales, 4) Factores personales y 5) Estructuras corporales. Al igual que en el conjunto básico, en este estudio los participantes también mencionaron categorías específicas relacionadas con la comunicación y la interacción; y por otra parte, los PA, apoyo y actitudes de los demás en el entorno se consideraron de gran influencia para el funcionamiento y la discapacidad. No obstante, el conjunto básico de la CIF ya publicado incluye a todas las personas que presentan 
discapacidad auditiva pero no realiza una división entre personas con discapacidad auditiva y personas sordas. Es por ello, que en este estudio realizamos una concordancia con las citas reportadas por nuestros participantes y las que se incluyen en dicho conjunto básico, para aportar información para una futura línea de investigación, un conjunto básico para personas sordas.

Los resultados de este estudio ponen de manifiesto la necesidad de utilizar una herramienta multidimensional como la CIF para clasificar el funcionamiento y la salud de las personas que presentan déficit auditivo. También, la CIF se ha empleado para vincular medidas de resultados utilizadas en investigación audiológica y, en este contexto, fueron identificadas 285 categorías, siendo las más prevalentes las relacionadas con la escucha, funciones auditivas, percepción auditiva y el entorno físico. En este estudio también fueron halladas varias categorías relacionadas con las funciones de la percepción, funciones mentales del lenguaje y funciones de la voz y el habla. No obstante el uso de la CIF en medidas de resultados audiológicos presentan una prevalencia más baja en las categorías relacionadas con la comunicación, el entorno social y actitudinal, hecho que no sucede en el presente estudio, puesto que hay una alta frecuencia de citas en categorías que tienen que ver con la comunicación y las actitudes (Grangberg et al., 2014).

Las personas con discapacidad auditiva y personas sordas, a pesar de que presentan una misma discapacidad, presentan unas limitaciones diferentes y estas son categorizadas no solamente por los usuarios con discapacidad, sino por sus familiares y los profesionales del campo. La diversidad existente entre las personas que presentan el mismo tipo de discapacidad queda patente dentro de la discapacidad auditiva, por la diversidad y heterogeneidad de este colectivo. Así, las diferencias encontradas en este estudio se definen tanto por sus preferencias individuales y por las capacidades y limitaciones propias de cada uno de ellos, y de ello depende el éxito y uso de los PA.

\section{Limitaciones}

Antes de llegar a las conclusiones, debemos exponer las limitaciones más notables de los cuatro estudios llevados a cabo. Probablemente, una de las más notables tiene que ver con el sistema de muestreo, no probabilístico y de conveniencia. Esto, lógicamente, limita la generalidad de las conclusiones que se han extraído de cada uno de los estudios. Aun así, debemos reconocer que la investigación en este campo es escasa y las muestras alcanzadas en 
algunos de los estudios, a pesar del método de selección, tienen tamaños que si bien podrían ser más grandes, son bastante adecuados para los objetivos planteados.

En segundo lugar, podríamos hablar de las limitaciones de los instrumentos de medida utilizados. Así, los instrumentos empleados evalúan, principalmente, la percepción subjetiva de los participantes. Además, la propia aplicación de los instrumentos, al no estar adaptados a las personas sordas, supuso una barrera en la aplicación. Aunque el PIADS demuestra ser una herramienta de evaluación con buenas propiedades psicométricas y válida como medida de resultados en PA, el instrumento tuvo que ser adaptado para personas sordas. De esta dificultad se deriva otra futura línea de investigación: la de adaptar y validar instrumentos estandarizados al colectivo de personas sordas signantes. Por otro parte, en el estudio cuatro con una metodología cualitativa, la codificación y asignación de discurso a códigos podrían haberse realizado con más jueces, pero las dificultades, principalmente temporales, impidieron implicar a más jueces en la ardua tarea de registrar y codificar el resultado de las discusiones de los grupos focales.

En tercer lugar, los productos de apoyo que se han explorado en este estudio no representan todos los tipos de productos disponibles para personas sordas y con discapacidad aditiva y, por ejemplo, hubiera sido adecuado plantear la medida de resultados con otras tecnologías emergentes en el campo de los problemas de audición.

En cuarto lugar, en el estudio cuatro el proceso de codificación fue llevado por una única persona y esto supone en sí una limitación del mismo.

Por último, en este estudio no se adoptó a priori una perspectiva longitudinal para indagar sobre el efecto tanto en el impacto psicosocial como en el desempeño ocupacional derivado del uso de los productos de apoyo. De esta limitación surge otra posible línea de investigación, la cual es realizar estudios longitudinales de los diferentes PA para comprobar la eficacia de las herramientas de evaluación y para indagar sobre los factores de abandono de los mismos, todo ello para optimizar los recursos; puesto que por poner algún ejemplo los IC son costeados por la Seguridad Social, y su abandono supone un alto coste. Aun así, se indagó a posteriori sobre el abandono de algunos productos con resultados que consideramos de mucho interés. 


\section{Conclusiones}

Esta Tesis Doctoral ha profundizado en una temática y en un colectivo sobre el que hay muy poca investigación. De los estudios con medidas de resultados en productos de apoyo para la comunicación en personas con discapacidad auditiva/personas sordas realizados en esta Tesis se pueden derivar posibles recomendaciones, resultados y futuras líneas de investigación.

En primer lugar, y de manera general, podemos extraer las siguientes conclusiones:

1. El uso de la escala PIADS, como medida de resultados, ha permitido considerar la perspectiva de las personas con discapacidad auditiva y personas sordas contribuyendo a la práctica centrada en el cliente desde un modelo bio-psico-social como el planteado por la CIF.

2. El instrumento PIADS ha demostrado un buen funcionamiento en personas con discapacidad auditiva/personas sordas, mostrando una adecuada consistencia interna tanto en la puntuación total como en las puntuaciones de las subescalas de competencia y adaptabilidad.

A continuación se resumirán las conclusiones de cada uno de los estudios realizados.

\section{ESTUDIO 1}

3. Los SIV tienen un impacto psicosocial con puntuaciones más positivas en las personas con discapacidad auditiva/personas sordas que los demás dispositivos que utilizan el vídeo.

4. Los dispositivos móviles tienen un impacto psicosocial positivo, pero menor que el de los SIV.

5. Las personas con discapacidad auditiva postlocutiva y usuarias de ambas lenguas tienen un historia de uso de tecnologías más positivo, tal y como muestran las puntuaciones en el cuestionario SOTU-C.

\section{ESTUDIO 2}

6. Los audífonos tienen un impacto psicosocial positivo sobre la competencia, adaptabilidad y autoestima de las personas con discapacidad auditiva/personas sordas.

7. Las gafas auditivas y el audífono tipo retroauricular proporcionan una mayor competencia y adaptabilidad. 
8. Las personas usuarias de gafas auditivas y audífonos tipo retroauricular presentan puntuaciones más altas en la escala PIADS.

9. Las personas jóvenes parecen tener experiencias y perspectivas tecnológicas más positivas.

10. La escala PIADS es una herramienta válida para la evaluación del abandono o falta de uso de los productos de apoyo de amplificación.

11. Las situaciones de uso del audífono influyen en el impacto psicosocial, derivándose en un impacto positivo gracias a su uso en situaciones tales como asuntos laborales, educativos y sanitarios. No obstante, en determinadas situaciones como conversaciones con familiares y amigos parece subyacer un impacto psicosocial menor.

12. La frecuencia de uso influyen en el impacto psicosocial, teniendo un impacto más positivo en aquellas personas que lo emplean a diario.

\section{ESTUDIO 3}

13. Las características personales como género, edad y el tipo/momento de la pérdida auditiva no tienen un efecto significativo sobre el impacto psicosocial derivado del uso de IC.

14. El IC es el producto de apoyo con mayor impacto psicosocial en la persona con discapacidad auditiva/persona sorda, verificándose el mayor impacto en el componente de adaptabilidad.

15. El IC puede ser un producto recomendable para personas adultas y mayores puesto que su uso en personas de esa edad se asocia con un impacto psicosocial positivo.

16. En las personas usuarias de IC cuyo sistema de comunicación es la lengua de signos se verificó un impacto psicosocial negativo.

\section{ESTUDIO 4}

17. En el proceso de selección del PA y en su prescripción, el equipo multidisciplinar debe considerar no sólo a la persona sino los factores ambientales y personales.

18. Las dimensiones de la CIF que más citan tanto en las personas afectadas de déficit auditivo como en familiares y profesionales son los factores ambientales, seguidos de actividades y participación.

19. Los factores ambientales son considerados como barreras más que como facilitadores salvo en las personas sordas en los que se consideran por igual. 
20. Los factores de abandono más frecuentes en el colectivo de personas con discapacidad auditiva/sordas son: una visión negativa hacia el producto, mal funcionamiento/fallo, coste de mantenimiento, insuficiente o nulo entrenamiento sobre su uso y el estigma asociado a su uso/socialmente inaceptable.

21. Los factores que causan con mayor frecuencia el abandono o falta de uso de los PA son aquellos englobados en los factores propios del PA y los relacionados con la propia persona.

22. Es fundamental que en la prescripción y selección de un PA se tengan en cuenta los factores personales.

23. El conjunto básico breve diseñado para personas con pérdida auditiva puede ser empleado para personas sordas pertenecientes a la Comunidad Sorda puesto que los códigos que lo conforman parecen ser los mismos. 
El desarrollo de esta Tesis Doctoral buscaba mostrar las dificultades que las personas sordas y con discapacidad auditiva tienen a diario. Su discapacidad no solo afecta a la comunicación sino al desempeño diario y a su participación social. Pero también tenía como objetivo visibilizar esta discapacidad, puesto que es una de las más desconocidas y considerada a nivel social como "invisible". La mayor parte de la población desconoce por completo las dificultades que se encuentran a diario las personas sordas y con discapacidad auditiva, y todavía se siguen empleando términos erróneos entre los propios profesionales tales como el calificativo de "sordomudo". Asimismo, este estudio tenía como objetivo principal conocer el impacto psicosocial que los productos de apoyo tienen en las personas afectadas de déficit auditivo. Este tipo de estudios son necesarios, no solo para conocer el uso y la satisfacción respecto a los productos de apoyo y nuevas tecnologías, sino también para indagar sobre las limitaciones asociadas a su uso (e.g., el abandono o falta de uso de los mismos y sus factores determinantes).

Es indispensable que estos estudios se sigan ampliando y sean adoptados por los propios profesionales. La escala PIADS, Psychosocial Impact of Assistive Devices Scale, ha demostrado ser válida y predictiva del abandono o falta de uso de los audífonos y los implantes cocleares, pero es necesario seguir investigando sobre su aplicabilidad y la mejora de las condiciones de aplicación (e.g, mejora de la adaptación a lengua de signos).

De igual modo, los profesionales deben basar su práctica en la evidencia y adoptar y realizar sus intervenciones en base a la misma. Es por ello que se recomienda el uso de la CIF, herramienta válida para su uso en el ámbito clínico; y por este motivo que en el presente estudio pretende mostrar la validez de su uso en la categorización de las preocupaciones de un colectivo. Además se ha aportado información relevante para validar un futuro conjunto básico para personas sordas signantes, dado que actualmente existe el conjunto básico abreviado y el conjunto básico para problemas de audición pero no uno para personas de la Comunidad Sorda.

En esta misma línea, creemos a ver reflejado en este estudio la importancia de saber diferenciar entre personas pertenecientes a la Comunidad Sorda y las personas ajenas a la misma. Si adoptamos los modelos biopsicosociales en nuestra práctica es necesario saber que las Personas Sordas se consideran a sí mismas ajenas a la Comunidad oyente, cuyo medio de socialización es la comunicación oral y escrita, y para ellos las lenguas de signos son su 
lenguaje natural y debemos de considerar su cultura a la hora de planificar y evaluar una intervención.

Todo ello conduce a reconocer la importancia de la investigación en medidas de resultados en intervenciones con productos de apoyo, para poder trabajar en base a la evidencia y evitar las limitaciones en el uso de PA, como el abandono prematuro o el mal emparejado entre personas y tecnologías. Aunque en nuestro país parece que es una temática poco tratada y con escasa literatura e investigación, en otros países cada vez existen más estudios que abordan esta temática. Cabe destacar que, dentro de las diferentes discapacidades, las personas sordas son uno de los colectivos menos representados en el campo de la investigación y menos aún en lo relativo a los productos de apoyo. Por ello, creemos que esta tesis doctoral es una valiosa contribución a la promoción del uso de los productos de apoyo y al conocimiento de la problemática de uso de PA en este colectivo

En la literatura científica es manifiesto que las investigaciones que tratan sobre implantes cocleares están centradas, en mayor medida, en población infantil y desde una perspectiva médica. Por otra parte, existen estudios, que van en aumento, sobre la problemática de las personas sordas y sus dificultades en lectoescritura, por ejemplo. Pero son pocos los estudios que indagan sobre las dificultades en el uso de los productos de apoyo o sus limitaciones. En este sentido, uno de los objetivos de esta tesis es mostrar una herramienta de valoración válida, la escala PIADS, que se podría utilizar en estos contextos. En esta misma línea, la CIF se revela como un modelo útil para analizar las cuestiones que se derivan el uso de productos de apoyo en las personas con discapacidad. El uso de estas herramientas en los equipos multidisciplinares sería un aporte para la formación de equipos transdisciplinares que trabajen persiguiendo los mismos objetivos desde diferentes disciplinas y perspectivas. Así, los resultados obtenidos en esta tesis pueden resultar de interés no solo a Terapeutas Ocupacionales sino también a otros profesionales como médicos, psicólogos, logopedas y, en general cualquier persona interesada en este campo de medidas de resultados y productos de apoyo.

Con los resultados derivados de esta tesis doctoral, esperamos contribuir, de algún modo, a mejorar las condiciones que rodean la evaluación para el uso de productos de apoyo en personas sordas y con discapacidad auditiva. Dado que los productos de apoyo son un medio demostrado de mejora de la calidad de vida de las personas con discapacidad, estaríamos contribuyendo también a que algunas personas se sientan más independientes 
(competencia), tengan más capacidad para participar (adaptabilidad) y sean, en definitiva, un poco más felices (autoestima). 


\section{Referencias}

Acaro, B., \& Lucila, P. (2015). La lengua de señas y su influencia en la guianza turística del Centro Histórico de Quito de las personas sordas asociadas a la ASOP durante el año 2013. http://www.dspace.uce.edu.ec/handle/25000/6032

ACT (2008). Advanced care technologies programme definition of terms assistive technology. Available from: http://www.actprogramme.org.uk/content/51/definition-ofterms.

Achiques, M. T., Morant, A., Muñoz, N., Marco, J., Llópez, I., Latorre, E., \& Pitarch, I. (2010). Cochlear implant complications and failures. Acta Otorrinolaringologica (English Edition), 61(6), 412-417.

Adam, R., Carty, B., \& Stone, C. (2011). Ghostwriting: Deaf translators within the Deaf community. Babel, 57(4), 375-393. doi:10.1075/babel.57.4.01ada

Adams, E. (2003). Optical devices for adults with low vision: A systematic review of published studies of effectiveness: VA Technology Assessment Program: Office of Patient Care Services. Recuperado del National Institute for Health Research http://www.crd.york.ac.uk/crdweb/ShowRecord.asp?LinkFrom=OAI\&ID=3200300016 3

Ajzen, I. (1988). Attitudes, personality and behaviour. Milton Keynes, UK: Open University Press.

Ajzen, I. (1991). The theory of planned behaviour. Organizational Behaviour and Human Decision Processes, 50, 179-211.

Ajzen, I. (2002). Perceived behavioral control, self-efficacy, locus of control, and the theory of planned behavior. Journal of Applied Social Psychology, 32(32), 1-20.

Al-Jarrah, O., \& Halawani, A. (2001). Recognition of gestures in Arabic sign language using neuro-fuzzy systems. Artificial Intelligence, 133(1), 117-138.

Alegría, J. (2003). Deafness and Reading. En T. Nunes \& P. Bryant (Eds.). Handbook of Children's Literacy. Dordrescht: Kluwer Academic Publishers.

Alegría, J., \& Domínguez, A. B. (2009). Los alumnos sordos y la lengua escrita Deaf students and the written language. Revista Latinoamericana de Educación Inclusiva, 3(1), 95111. 
Alleyne, B. C., Dufresne, R. M., Kanji, N., \& Reesal, M. R. (1989). Costs of workers' compensation claims for hearing loss. Journal of Occupational and Environmental Medicine, 31(2), 134-138.

Alcantud, F. (2000). Nuevas tecnologías, viejas esperanzas. VVAA. Nuevas Tecnologías, Viejas Esperanzas: las nuevas tecnologías en el ámbito de la discapacidad y las necesidades educativas especiales. Murcia: Consejería de Educación y Universidades.

Alper, S., \& Raharinirina, S. (2006). Assistive Technology for Individuals with Disabilities: A Review and Synthesis of the Literature. Journal of Special Education Technology, 21(2), 47-64.

Alvarelhao, J., Queiros, A., Cerqueira, M., \& Rocha, N. P. (2014). AAL systems and services for end users: Are the AT models and frameworks suitable for prescription and selection?. In Information Systems and Technologies (CISTI), 9th Iberian Conference on (pp. 1-6). doi: 10.1109/CISTI.2014.6876912

Amate, G., \& Giménez, L.(2000). “Adquisición del lenguaje”, En F. Martínez et al. (eds.): Apuntes de lingüística de la lengua de signos española (pp. 193-217), Madrid: CNSE.

American Occupational Therapy Association. (2011). Accreditation Council for Occupational Therapy Education (ACOTE®) standards. American Journal of Occupational Therapy, 66(6), 1-45.

Amieva, H., Ouvrard, C., Giulioli, C., Meillon, C., Rullier, L., \& Dartigues, J. F. (2015). SelfReported Hearing Loss, Hearing Aids, and Cognitive Decline in Elderly Adults: A 25Year Study. Journal of the American Geriatrics Society, 63(10), 2099-2104. doi:10.1111/jgs.13649

Anderson, I., Weichbold, V., \& D'Haese, P. (2004) Three-year follow up of children with open-set speech recognition who use the MED-EL cochlear implant system. Cochlear Implants International , 5(2): 45-57. doi: 10.1002/cii.125.

Angelo, D., Jones, S., \& Kokoska, S.(1995). Family perspective on augmentative and alternative communication: Families of Young children. Augmentative \& Alternative Communication, 11, 193-202.

Angelo, J., Buning, M., Schmeler, M., \& Doster, S. (1997). Identifying best practice in the occupational therapy assistive technology evaluation: An analysis of three focus groups. American Journal of Occupational Therapy, 51(10), 916-920.

Angelo, J., \& Smith, R. (1993). An analysis of computer-related articles in occupational therapy periodicals. The American Journal of Occupational Therapy.: Official Publication of the American Occupational Therapy Association, 47(1), 25-29 
Antunes, D., Guimaraes, C., Garcia, L., Oliveira, L., \& Fernandes, S. (2011). A framework to support development of Sign Language human-computer interaction: Building tools for effective information access and inclusion of the deaf (pp. 1-12). IEEE. doi:10.1109/RCIS.2011.6006832

Anzola, M., León, A., \& Rivas, P. (2006). Educación superior para sordos. Educere, 10(33), 357-360.

Armitage, C., \& Conner, M. (2000). Social cognition models and health behaviour: A structured review. Psychology and Health, 15, 173-189.

Armitage, C., \& Conner, M. (2001). Efficacy of the theory of planned behaviour: A metaanalytic review. British Journal of Social Psychology, 40, 471-499.

Armitage, C., \& Conner, M. (2002). Reducing fat intake: Interventions based on the theory of planned behaviour. In D. Rutter \& L. Quine (Eds.), Changing health behaviour: Intervention and research with social cognition models (pp. 87-104). Buckingham, UK: Open University Press

Arthanat, S., Bauer, s., Lenker, J., Nochajski, S., \& Wu, Y. (2007). Conceptualization and measurement of assistive technology usability. Disability and Rehabilitation: Assistive Technology, 2 (4) 235-248.doi: 10.1080/1748310001343665

Arthanat, S., \& Lenker, J. (2004). Evaluating the ICF as a Framework for Clinical Assesment of Persons for Assistive Technology Devise Recommendaion, 10 North American Collaborating Centre (NACC). Conference on ICF, Halifax.ASEM.

ASEM (2008). Guía de Enfermedades Neuromusculares: Información y apoyo a las familias. Jaen: Formación Alcalá

Brandt, A., Denmark, A., \& Alwin, J. (2012). Assistive Technology Outcomes Research: Contributions to Evidence-Based Assistive Technology Practice. Technology and Disability, 24, 5-7. doi:10.3233/TAD-2012-0338

Assucena, A., Wu, S. S. H., \& Pradas, J. (2013). Amyotrophic lateral sclerosis diseasemodifying therapy and assistive technology: Review and update... ......12th Congress of European Forum for Research in Rehabilitation / XXX. Journal of Physical Medicine \& Rehabilitation Sciences / Fiziksel Tup ve Rehabilitasyon Bilimleri Dergisi, 13-13.

Atherton, M. (2009). A feeling as much as a place: leisure, deaf clubs and the British deaf community. Leisure Studies, 28(4), 443-454. doi:10.1080/02614360902951690

Atkinson, J. R. (2006). The perceptual characteristics of voice-hallucinations in deaf people: insights into the nature of subvocal thought and sensory feedback loops. Schizophrenia bulletin, 32(4), 701-708. doi: 10.1093/schbul/sbj063 
Audit Commission (2004). Older people and well-being: the challenge for public services. Audit Commission. London.

Axelsson, S. , Nyberg, L., Näslund, A., \& Wikman, A. M. (2013). The anticipated positive psychosocial impact of present web-based e-health services and future mobile health applications: an investigation among older swedes. International Journal of Telemedicine and Applications, Article ID 509198.

Backenroth, G.A. (1995). Deaf people's perception of social interaction in working life. International Journal of Rehabilitation Research, 18(1), 76-81.

Backenroth, G. A. (1993). Loneliness in the deaf community: a personal or an enforced choice?. International Journal of Rehabilitation Research, 16(4), 331-336

Bagga-Gupta, S., \& Domfors, L. Å. (2003). Pedagogicalissues in Swedish Deaf education. Balandin S., Hemsley B., Sigafoos J.,\& Green, V.(2007). Communicating with nurses: the experiences of 10 adults with cerebral palsy and complex communication needs. Applied Nursing Research; 20, 56-62. doi: 10.1016/j.apnr.2006.03.001

Barbosa, B. J., Mariano, E. D., Batista, C. M., Marie, S. K. N., Teixeira, M. J., Pereira, C. U., . \& Lepski, G. A. (2015). Intraoperative assistive technologies and extent of resection in glioma surgery: a systematic review of prospective controlled studies. Neurosurgical Review, 38(2), 217-226. doi: 10.1007/s 10143-014-0592-0

Barker, D. J., Reid, D., \& Cott, C. (2006). The experience of senior stroke survivors: factors in community participation among wheelchair users. Canadian Journal of Occupational Therapy, 73(1), 18-25.doi: 10.2182/cjot.05.0002

Barnett, S. (2002). Communication with Deaf and Hard-of-hearing People: A Guide for Medical Education. Academic Medicine, 77(7), 694-700.

Bars, I., Fuentes, S. , Giné, C. G., \& Villoira, E. (2014). Análisis de los distintos enfoques del paradigma del diseño universal aplicado a la educación.Revista latinoamericana de educación inclusiva, 8(1), 143-152.

Bat-Chava, Y. (1993). Antecedents of self-esteem in deaf people: A meta-analytic review. Rehabilitation Psychology, 38(4), 221-234. doi:10.1037/0090-5550.38.4.221

Bat-Chava, Y., \& Deignan, E. (2001). Peer relationships of children with cochlear implants. Journal of Deaf Studies and Deaf Education, 6, 186-199.

Baum, C. M., \& Christiansen, C. (Eds.). (1997). Occupational therapy: Enabling function and well-being. Thorofare: Slack.

Bavelier, D., Dye, M. W., \& Hauser, P. C. (2006). Do deaf individuals see better? Trends in Cognitive Sciences, 10 (11), 512-518. doi:10.1016/j.tics.2006.09.006 
Beaulieu, L., Noreau, L., \& Fougeyrollas, P. (1998). Inter-rater reliability of LIFE-H among individuals who have been discharged home after stroke rehabilitation. Unpublished data, Institut de réadaptation en déficience physique de Québec.

Bebout, L., \& Arthur, B. (1992). Cross-cultural attitudes toward speech disorders. Journal of Speech, Language, and Hearing Research, 35(1), 45-52.

Belle, M.,B. (2005). The Psychological/Social Impact of Cochlear Implants. National Technical Institute for the Deaf. Rochester Institute of technology.

Bentur, N., Barnea, T., \& Mizrahi, I. (1996). A follow-up study of elderly buyers of an assistive chair. Physical \& Occupational Therapy in Geriatrics, 14(3), 51-60.

Bernd, T., \& Van der Pijl, D.(2009). Existing models and instruments for the selection of assistive technology in rehabilitation practice. Scandinavian Journal of Occupational Therapy, 16(3), 146-158. doi: 10.1080/11038120802449362

Bertoli, S., Staehelin, K., Zemp, E., Schindler, C., Bodmer, D., \& Probst, R. (2009). Survey on hearing aid use and satisfaction in Switzerland and their determinants. International journal of audiology, 48(4), 183-195. doi: 10.1080/14992020802572627

Bhasin, C., \& Goodman, G. (1992). The use of OT FACT categories to analyze activity configurations of individuals with multiple sclerosis. Occupational Therapy Journal of Research, 12(2), 67-79.

Bickenbach, J. (2001). Disability human rights, law, and policy. In G. L. Albrecht GL, K. D. Seelman \& M. Bury (Eds.): Handbook of disability studies (pp. 565-584). Thousand Oaks, CA: Sage Publications.

Billari, S. L. (2009). Outcome Assessment of Audient Foundation Hearing Aids at the James Madison University Clinic. ProQuest.

Brämberg, E. , \& Sandman, L. (2013). Communication through in-person interpreters: a qualitative study of home care providers' and social workers' views. Journal of Clinical Nursing, 22(1-2), 159-167. doi:10.1111/j.1365-2702.2012.04312.x

Blamey, P. J., Sarant, J. Z., Paatsch, L. E., Barry, J. G., Bow, C. P., Wales, R. J., \& Tooher, R. (2001). Relationships among speech perception, production, language, hearing loss, and age in children with impaired hearing. Journal of Speech, Language, and Hearing Research, 44(2), 264-285.

Blanco, I. L. (2003). I+ D+ I al Servicio de las Personas con Discapacidad y las Personas Mayores. IMSERSO, Dirección General de Política Tecnológica y Comité Español de Representantes de Minusválidos. Valencia.

Bloor, M. (2001). Focus groups in social research. Sage. 
Bowser, G., \& Reed, P. R. (1998). Education tech points: A framework for assistive technology planning. Coalition for Assistive Technology in Oregon.

Brämberg, E. B., \& Sandman, L. (2013). Communication through in-person interpreters: a qualitative study of home care providers' and social workers' views. Journal of Clinical Nursing, 22(1-2), 159-167.

Brandt, Å., Alwin, J., Anttila, H., Samuelsson, K., \& Salminen, A.,L. (2012). Quality of evidence of assistive technology interventions for people with disability: An overview of systematic reviews. Technology \& Disability, 24(1), 9-48.

Breines, E. (1985). Computers and the private practitioner in occupational therapy. Occupational Therapy in Health Care, 2, 103-115.

Breines, E. B. (2002). Occupational therapy education in a technological world. American Journal of Occupational Therapy, 56(4), 467-469.

Boi, R., Racca, L., Cavallero, A., Carpaneto, V., Racca, M., Dall'Acqua, F., \& Odetti, P. (2012). Hearing loss and depressive symptoms in elderly patients.Geriatrics \& Gerontology International, 12(3), 440-445.

Bryant, B. R., Bryant, D. P., Shih, M., \& Seok, S. (2010). Assistive Technology and Supports Provision: A Selective Review of the Literature and Proposed Areas of Application. Exceptionality: A Special Education Journal, 18(4), 203-213.

Bonet, J. (1620) Reducción de las letras y arte para enseñar a hablar a los mudos. Madrid. Francisco Abarca de Angulo. Adaptación de Jacabo Garrido y Lorenzo Gascón.

Bond, M., Mealing, S., Anderson, R., Elston, J., Weiner, G., \& Taylor, R. (2009). The effectiveness and cost-effectiveness of cochlear implants for severe to profound deafness in children and adults: a systematic review and economic model. Health Technology Assessment, 13(44).

Boothroyd, A. (2004). Hearing aid accessories for adults: the remote FM microphone. Ear Hearing, 25, 22-33.

Boulares, M., \& Jemni, M. (2012, April). Mobile sign language translation system for deaf community. In Proceedings of the International Cross-Disciplinary Conference on Web Accessibility (p. 37). ACM. doi:10.1145/2207016.2207049

Boyd, R., Knutson, J., \& Dahlstrom, A., (2000). Social interaction of pediatric cochlear implant recipients with agematched peers. Annals of Otology, Rhinology \& Laryngology, 12(2), 105-109. 
Brennan, M., \& Bally, S., K. (2007). Psychosocial adaptations to dual sensory loss in middle and late adulthood. Trends in Amplification, 11, 281-300. doi: $10.1177 / 1084713807308210$

Bridges, J. A., \& Bentler, R. A. (1998). Relating hearing aid use to well-being among older adults. The Hearing Journal, 51(7), 39-42.

Buchman, C. A., Fucci, M. J., \& Luxford, W. M. (1999). Cochlear implants in the geriatric population: benefits out weigh risks. Ear, Nose \& Throat Journal, 78(7), 489.

Buhagiar, R., \& Lutman, M. (2011). Development of a quality-of life measure for adult patients with sequential bilateral cochlear implants. Cochlear implants international, 12(s2), 44-46.doi:10.1179/146701011X13074645127559

Burne, B., Knafelc, V., Melonis, M., \& Heyn, P. C. (2011). The use and application of assistive technology to promote literacy in early childhood: a systematic review. Disability and Rehabilitation. Assistive Technology, 6(3), 207-213. doi: $10.3109 / 17483107.2010 .522684$

Butterfield, T. M., \& Ramseur, J. H. (2004). Research and case study findings in the area of workplace accommodations including provisions for assistive technology: a literature review. Technology \& Disability, 16(4), 201-210.

Buttussi, F., Chittaro, L., Carchietti, E., \& Coppo, M. (2010, September). Using mobile devices to support communication between emergency medical responders and deaf people. In Proceedings of the 12th international conference on Human computer interaction with mobile devices and services (pp. 7-16). ACM.

Callejo, J., \& Viedma, A. (2006). Proyectos y estrategias de investigación: la perspectiva de la intervención. Madrid: Mc Graw Hill.

Campbell, P. H., Milbourne, S., Dugan, L. M., \& Wilcox, M. J. (2006). A Review of Evidence on Practices for Teaching Young Children to Use Assistive Technology Devices. Topics in Early Childhood Special Education, 26(1), 3-13. doi: 10.1177/02711214060260010101

Campo, M. E., Saneiro, M., \& Roca, J. (2002). Metodología para la aplicación de la CIF a una población específica. Madrid: Sanz y Torres.

Caposecco, A., Hickson, L., \& Pedley, K. (2012). Cochlear implant outcomes in adults and adolescents with early-onset hearing loss. Ear and Hearing, 33(2), 209-220.doi: 10.1097/AUD.0b013e31822eb16c 
Carlsson, P., Danermark, B., \& Borg, E. (2004). Marital status and birthrate of deaf people in two Swedish counties: the impact of social environment in terms of deaf community. American Annals of the Deaf, 149(5), 415-420.

Carr, L. (2004). Leisure and disabled people. Disabling barriers-enabling environments, 183188

Carswell, W., McCullagh, P. J., Augusto, J. C., Martin, S., Mulvenna, M. D., Zheng, H., Jeffers, W. P. (2009). A review of the role of assistive technology for people with dementia in the hours of darkness. Technology And Health Care: Official Journal Of The European Society For Engineering And Medicine, 17(4), 281-304. doi: 10.3233/THC-2009-0553

Carter, W. B. (1990). Health behavior as a rational process: Theory of reasoned action and multiattribute theory. In K. Glanz, F. Lewis \& Rimer, B.: Health behavior and health education: Theory, research, and practice, (pp. 36-92). San Francisco: JosseyBossCass.

Castro, C. (2009) Desarrollo de estrategias sintácticas y semánticas en lectura a través de lector en personas sordas adultas en Castilla y León. Tesis Doctoral no publicada. Disponible en http://hdl.handle.net/10366/76435.

Casas, D. A., Linares, M. S., Lemos, M., \& Restrepo, D. A. (2011). Depresión y ansiedad en personas con deficiencia auditiva: revisión de literatura. Revista Virtual Universidad Católica del Norte, 1(28), 1-15.

Cavender, A., \& Ladner, R. (2008) Hearing Impairments. Chapter 3 in Harper and Yesilada (Eds.), Web Accessibility: A Foundation for Research. New York: Springer, 25-36.

CEN workshop agreement (2010). Guidelines to standardisers of ICT products and services in the CEN ICT domain. Available from: ftp://cenftp1.cenorm.be/PUBLIC/CWAs/eEurope/DFA/cwa14661-00-2003-Feb.pdf.

Chantry, J., \& Dunford, C. (2010). How do computer assistive technologies enhance participation in childhood occupations for children with multiple and complex disabilities? A review of the current literature. British Journal of Occupational Therapy, 73(8), 351-365. doi: 10.4276/030802210X12813483277107

Chapman, A., R., (1994). Health care reform: A human rights approach. Washington, DC: Georgetown University Press.

Chatelin, V., Kim, E. J., Driscoll, C., Larky, J., Polite, C., Price, L., \&Lalwani, A. K. (2004). Cochlear implant outcomes in theelderly. Otology \& Neurotology, 25(3), 298-301. 
Cheng, A. K., \& Niparko, J. K. (1999). Cost-utility of thecochlearimplant in adults: a metaanalysis. Archives of Otolaryngology-Head \&Neck Surgery, 125(11), 1214-1218.

Cheng, A. K., Rubin, H. R., Powe, N. R., Mellon, N. K., Francis, H. W., \& Niparko, J. K. (2000). Cost-utility analysis of thecochlear implant in children. The Journal of the American Medical Association - JAMA, 284(7), 850-856.

Chisolm, T. H., Noe, C. M., McArdle, R., \& Abrams, H. (2007). Evidence for the use of hearing assistive technology by adults: The role of the FM system. Trends in Amplification, 11(2), 73-89. doi: 10.1177/1084713807300879

Christiansen, J. B., \& Leigh, I. (2002). Cochlearimplants in children: Ethics and choices. Gallaudet University Press.

Christiansen, C., Backman, C., Little, B., \& Nguyen, A. (1999). Occupations and well-being: A study of personal projects. American Journal of Occupational Therapy, 53(1), 91100.

Christiansen, J. B., \& Leigh, I. W. (2002). Cochlear Implants in Children: Ethics and Choices.

Ciaramello, L. \& Hemami, S. (2009). Quantifying the Effect of Disruptions to Temporal Coherence on the Intelligibility of Compressed American Sign Language Video. In B. E. Rotowitz \& T. N. Pappas (Eds). Proceedings of the International Society for Optics and Photonics, (7240).

Cieza, A., Ewert, T., Ustun, T. B., Chatterji, S., Kostanjsek, N., \& Stucki, G. (2004). Development of ICF Core Sets for patients with chronic conditions. Journal of Rehabilitation Medicine, 44 Suppl, 9-11.

Cieza, A., Kirchberger, I., Biering-Sørensen, F., Baumberger, M., Charlifue, S., Post, M. W., \& Kostanjsek, N. (2010). ICF Core Sets for individuals with spinal cord injury in the long-term context. Spinal Cord, 48(4), 305-312. doi:10.1038/sc.2009.183

Ciorba, A., Bianchini, C., Pelucchi, S., \& Pastore, A. (2012). The impact of hearing loss on the quality of life of elderly adults. Clinical Interventions in Aging, 7, 159. Doi: 10.2147/CIA.S26059

Claesen, E., \& Pryce, H. (2012). An exploration of the perspectives of help-seekers prescribed hearing aids. Primary Health Care Research \& Development, 13(3), 279284.

Clemson, L., \& Martin, R. (1996). Usage and effectiveness of rails, bathing and toileting aids. Occupational Therapy in Health Care, 10(1),42-59 
Clinkard, D., Shipp, D., Friesen, L. M., Stewart, S., Ostroff, J., Chen, J. M., ... \& Lin, V. Y. (2011). Telephone use and the factors influencing it among cochlear implant patients. Cochlear implants international, 12(3), 140-146.

College of Occupational Therapist (2004). Guidance for the Use of the International Classification of Functioning, Disability and Health (ICF) and the Ottawa Charter for Health Promotion in Occupational Therapy Services. London: College of Occupational Therapist.

Collins, M.P., Souza, P.E., O`Neill, S., \& Yueh, B. (2007). Effectiveness of group versus individual hearing aids visits. Journal of Rehabilitation Research \& Development, 44(5), 739-750.

Conama, J. B. (2013). Situating the socio-economic position of Irish Deaf community in the equality framework. Equality, Diversity and Inclusion: An International Journal, 32(2), 173-194. doi:10.1108/02610151311324406

Concoran, M. (2008). Five years in review: Clinical scholarship revisited. American Journal of Occupational Therapy, 62(3), 263-264.

Cook, A. \& Hussey, S. (2002). Assistive Technologies: Principles and Practice (2 ${ }^{\text {nd }}$ ed.). St. Louis, MO: Mosby.

Cook, A. M., \& Hussey, S. M. (1995). Seating and positioning systems as extrinsic enablers for assistive technologies. Assistive Technology: Principles and Practice, 235-310.

Corbetta, P. (2003). Metodología y Técnicas de Investigación Social. Madrid: McGrawHill.

Corvera, J., \& González, F. (2000). Psicodinamia de la Sordera. Gaceta Medica de Mexico, 136(2),139-151.

Coryell, J., Holcomb, T. K., \& Scherer, M. (1992). Attitudes toward deafness: A collegiate perspective. American Annals of the Deaf, 137(3), 299-302.

Cox, R. M., \& Alexander, G. C. (1995). The abbreviated profile of hearing aid benefit. Ear and hearing, 16(2), 176-186.

Cox, R. M., \& Alexander, G. C. (1999). Expectations about hearing aids and their relationship to fitting outcome. Journal of the American Academy of Audiology, 11(7), 368-82.

Cox, R. M., \& Alexander, G. C. (1999). Measuring satisfaction with amplification in daily life: The SADL scale. Ear and hearing, 20(4), 306-320.

Cox, R., Hyde, M., Gatehouse, S., Noble, W., Dillon, H., Bentler, R., \& Hallberg, L. (2000). Optimal outcome measures, research priorities, and international cooperation. Ear and Hearing, 21(4), 106-115. 
Craddock, G. (2002). Partnership and assistive technology in Ireland. In M. J. Scherer (Ed.). Assistive technology: Matching device and consumer for successful rehabilitation (pp. 253-266). Washington, DC: American Psychological Association.

Crandell, C. C. (1998). Hearingaids: Their effects on functional health status. The Hearing Journal, 51(2), 22-24.

Cumella, S., \& Martin, D. (2004). Secondary Health care and Learning Disability Results of Consensus Development Conferences. Journal of Learning Disabilities, 8(1), 30-40.

Cumming, R.G., Thomas, M., Szonyi, G., Frampton, G., Salked, G, \& Clemson, L.(2001). Adherence to occupational therapist recommendations for home modifications for falss prevention. American Journal of Occupational Therapy, 55, 641-648.

Cunningham, L. M., Nugent, C. D., Finlay, D. D., Moore, G., \& Craig, D. (2009). A review of assistive technologies for people with Parkinson's disease. Technology And Health Care: Official Journal Of The European Society For Engineering And Medicine, 17(3), 269-279. doi: 10.3233/THC-2009-0547

Cushman, L.A., \& Scherer, M.J. (1996). Measuring the relationship of assistive technology use, functional status over time, and consumer-therapist perceptions of ATs. Assistive Technology, 8, 130-109.

Dagfinrud, H., Kjeken, I., Mowinckel, P., Hagen, K. B., \& Kvien, T. K. (2005). Impact of functional impairment in ankylosing spondylitis: impairment, activity limitation, and participation restrictions. The Journal of Rheumatology, 32(3), 516-523.

Davies, T. C., Mudge, S., Ameratunga, S., \& Stott, N. S. (2010). Enabling self-directed computer use for individuals with cerebral palsy: a systematic review of assistive devices and technologies. Developmental Medicine And Child Neurology, 52(6), 510516. doi: 10.1111/j.1469-8749.2009.03564.x

Day, H., \& Campbell, K. (2003). Is telephone assessment a valid tool in rehabilitation research and practice?. Disability \& Rehabilitation, 25(19), 1126-1131.

Day, H., \& Jutai, J. (1996). Measuring the psychosocial impact of assistive devices: the PIADS. Canadian Journal Rehabilitation, 9, 159-168.

Day, H., Jutai, J., \& Campbell, K. A. (2002). Development of a scale to measure the psychosocial impact of assistive devices: lessons learned and the road ahead. Disability \& Rehabilitation, 24(1-3), 31-37.

Day, H., Jutai, J., Woolrich, W., \& Strong, G. (2001). The stability of impact of assistive device. Disability Rehabilitation. 23(9), 400-404. 
Deal, M. (2003). Disabled people's attitudes toward other impairment groups: a hierarchy of impairments. Disability \& society, 18(7), 897-910.

Debevc, M., Stjepanovič, Z., \& Holzinger, A. (2014). Development and evaluation of an elearning course for deaf and hard of hearing based on the advanced Adapted Pedagogical Index method. Interactive Learning Environments, 22(1), 35-50. doi:10.1080/10494820.2011.641673

DeCaro, J. J., Feuerstein, M., \& Hurwitz, T. A. (1992). Cumulative trauma disorders among educational interpreters. contributing factors and intervention. American Annals of the Deaf, 137(3), 288-292. doi: 10.1353/aad.2012.0483

de-Gómez, A. C., Solís-Rábago, M. L., Méndez-Martínez, D., Medina-Vega, F. A., \& Martínez-Consuegra, N. (2007). El auxiliar auditivo eléctrico y el teléfono celular. Acta Pediátrica de México, 28(2).

De Jonge, D., Scherer, M. J., \& Rodger, S. (2007). Assistive technology in the workplace. CIUDAD: Elsevier Health Sciences.

de Joode, E., van Heugten, C., Verhey, F., \& van Boxtel, M. (2010). Efficacy and usability of assistive technology for patients with cognitive deficits: a systematic review. Clinical Rehabilitation, 24(8), 701-714. doi: 10.1177/0269215510367551

de Luna, M. A. C. (2004). Discapacidad y aspectos sociales: la igualdad de oportunidades, la no discriminación y la accesibilidad universal como ejes de una nueva política a favor de las personas con discapacidad y sus familias. Algunas consideraciones en materia de protección social. Revista del Ministerio de Trabajo e Inmigración, (50), 21-46.

Demers, L., Weis-Lambrou, R., \& Ska, B. (1996). Development of the Quebec User Evaluation of Satisfaction with assistive Technology (QUEST). Assistive Technology, $8(1), 3-13$.

DeRosier, R., \& Farber, R. S. (2004). Speech recognition software as an assistive device: a pilot study of user satisfaction and psychosocial impact. Work (Reading, Mass.), 25(2), 125-134.

DeRuyter, F.(1997). The importance of outcome measures for assistive technology service delivery systems. Technology and Disability, 6, 89-104.

Desideri, L., Roentgen, U., Hoogerwerf, E.-J., \& de Witte, L. (2013). Recommending assistive technology (AT) for children with multiple disabilities: A systematic review and qualitative synthesis of models and instruments for AT professionals. Technology \& Disability, 25(1), 3-13. 
Desjardins, J. L., \&Doherty, K. A. (2009). Do experienced hearing aid users know how to use their hearing aids correctly?. American Journal of Audiology,18(1), 69-76.

Devitt, R., Chau, B., \& Jutai, J. W. (2004). The effect of wheelchair use on the quality of life of persons with multiple sclerosis. Occupational Therapy in Health Care, 17(3-4), 6379.

Devor, M., Wang, A., Renvel, M., Feigal, D., \& Ramsdell, J. (1994). Compliance with social and safet recommendations in an outpatient comprehensive geriatric assessment program. Journal of Gerontology, 49(4), 168-173.

Diamant, R. B. (2004). Integration of occupational therapy practice framework and international classifications of functioning concepts: Application of role performance in client-centered practice. World Federation of Occupational Therapists Bulletin, 50(1), 24-40.

Díez, E., Rodríguez, N., Velázquez, D. \& Hernández, R. (2012). eTAO: Evaluación funcional para el uso de productos de apoyo en el acceso al ordenador. En L. Nieto, B. Broba, T. Pousada \& J. Pereira (Eds.). Aplicación de la Tecnologías de la Información y las Comunicaciones en la vida diaria de las personas con discapacidad (pp. 69-94). A Coruña: Universidad da Coruña, Servicio de Publicaciones y Fundación Orange.

Digiovine, C., Hobson, D. A., \& Cooper, R. A. (2007). Clinical practice of rehabilitation engineering. In: Cooper, R., Ohnabe, H., \& Hobson, D. An Introduction to Rehabilitation Engineering, 19-45.

Dijkers, M. (1999). Measuring quality of life: Methodological issues. American Journal of Pshycal Medicine and Rehabilitation, 78, 286-300.

Dillon, H. (2001). Hearing aids. New York: Thieme.

Di Nardo W, Anzivino R. Giannantonio S, Schinaia L, \& Paludetti G.(2014) The effects of cochlear implantation on quality of life in the elderly. European Archives Of OtoRhino-Laryngology, 271(1), 65-73. doi: 10.1007/s00405-013-2396-1.

Dominguez, A. B. \& Alonso, P. (2004). La educación de los alumnos sordos hoy. Perspectivas y respuestas educativas. Madrid: Ediciones Aljibe.

Domínguez, A. B., Pérez, M. I., \& Alegría, J. (2012). La lectura en los alumnos sordos: aportación del implante coclear. Infancia y Aprendizaje: Journal for the Study of Education and Development, 35(3), 327-341. doi:10.1174/021037012802238993

Domínguez, A.B., Alegría, J., Carrillo, M., y Soriano, J. (2013). PEALE. Pruebas de Evaluación Analítica de Lengua Escrita. Universidad de Salamanca. Número de asiento registral: 00/2013/4067. 
Dorman, M.F., Basham, K., \& McCandless, G. (1991) Speech understanding and music appreciation with the Ineriad cochlear implant. Hearing Journal, 44, 34-35.

Donner, A., Marshall, M., \& Mozrall, J. (2013). Biomechanical Comparison of American Sign Language Interpretation and Conversation. Proceedings of the Human Factors and Ergonomics Society Annual Meeting, 57(1), 384-388. doi:10.1177/1541931213571083

Dorziat, A., \& Araújo, J. R. de. (2012). O intérprete de língua de sinais no contexto da educação inclusiva: o pronunciado e o executado. Revista Brasileira de Educação Especial, 18(3), 391-410. doi:10.1590/S1413-65382012000300004

Dubuisson, C. \& Daigle, D. (1998). Lecture, 'ecriture et surdit`e: visions actualles et nouvelles perspectives. Revue des sciences de l"education XVII, 229-234.

Dubuisson, C., Machab`ee, D., \& Parisot, A. (1997). L`enseignement du français aux sourds: ce que des Sourds ont a en dire. Revue de linguistique et de didactique des langues, 15, 5381.

Dumont, C., Vincent, C., \& Mazer, B. (2002). Development of a Standardized Instrument to Assess Computer Task Performance. The American Journal of Occupational Therapy, $56,60-68$.

Dymond, E., \& Potter, R. (1996). Controlling assistive technology with head movements -- a review. Clinical Rehabilitation, 10 (2), 93-103.

EASTIN, 2010. EASTIN, European Assistive Technology Information Network

Edyburn, D.L.(2002). Models, theories, and frameworks: Contributions to understanding special education technology. Special Education Technology Practice, 4, 16-24.

Edyburn, D.,L., \& Smith, R., O., (2004). Creating an Assistive Technology Outcomes Measurement System: Validating the components. Assistive Technology Outcomes and Benefits, 1(1), 8-15.

Elliott, R., Glauert, J. R., Kennaway, J. R., Marshall, I., \& Safar, E. (2008). Linguistic modelling and language-processing technologies for Avatar-based sign language presentation. Universal Access in the Information Society, 6(4), 375-391.

Enable NSW and Lifetime Care \& Support Authority (2011). Guidelines for the prescription of a seated wheelchair or mobility scooter for people with a traumatic brain injury or spinal cord injury. Sydney: EnableNSW and LTCSA Editor.

Erber, N. P. (1975). Auditory-visual perception of speech. Journal of Speech and Hearing Disorders, 40 (4), 481-492. 
Eriks-Brophy, A., Durieux-Smith, A., Olds, J., Fitzpatrick, E., Duquette, C., \& Wittingham, J. (2007). Facilitators and barriers to the integration of orally educated children and youth with hearing loss into their families and communities. The Volta Review, 107, 536.

Erler, S. F., \& Garstecki, D. C. (2002). Hearing Loss-and Hearing Aid-Related Stigma Perceptions of Women with Age-Normal Hearing. American Journal of Audiology, 11(2), 83-91.

Eshraghi, A. A., Nazarian, R., Telischi, F. F., Rajguru, S. M., Truy, E. \& Gupta, C. (2012), The Cochlear Implant: Historical Aspects and Future Prospects. Anatomical Record, 295, 1967-1980. doi: 10.1002/ar.22580

EUSTAT Consortium.(1998). Critical Factors involved in End-Users`'Education in relation to Assistive Technology. Empowering Users Through Assistive Technology, EUSTAT Consortium.

Fagan, M., Pisoni, D., Horn, D., \& Dillon, C. (2007). Neuropsychological correlates of vocabulary, reading, and working memory in deaf children with cochlear implants. Journal of Deaf Studies and Deaf Education, 12, 461-471.

Farrell, J., Anderson, S., Hewitt, K., Livingston, M. H., \& Stewart, D. (2007). A survey of occupational therapists in Canada about their knowledge and use of the ICF. Canadian Journal of Occupational Therapy, 74(5 suppl), 221-232.

FAST1 (2008). Definition of the term 'assistive Technology'. Available from: http://www.fastuk.org/about/definitionofat.php

Federici, S., Meloni, F., Brogioni, A., \& Lo Presti, A. (2008). The disability models in the perspective of parents, teachers, and special needs educators: a qualitative data analysis. Open Educational Journal, 1, 37-48.

Federici, S., \& Scherer, M. (2012). Assistive technology assessment handbook. CRC Press.

Federici, S., Scherer, M., Micangeli, A., Lombardo, C., \& Belardinelli, M. O. (2003). A cross-cultural analysis of relationships between disability self-evaluation and individual predisposition to use assistive technology. Assistive Technology, 1, 941-946.

Fellinger, M., \& Fellinger, J. (2014). Gehörlose Patienten im psychiatrischen Kontext. neuropsychiatrie, 28(1), 19-26. doi:10.1007/s40211-013-0088-0

Fellinger, J., Holzinger, D., \& Pollard, R. (2012). Mental health of deaf people.The Lancet, 379(9820), 1037-1044.doi:10.1016/S0140-6736(11)61143-4

Fennema-Jansen, S. (2000). Review of Volume I: RESNA resource guide for assistive technology outcomes: Measurement tools, Volume II: RESNA resource guide for 
assistive technology outcomes: Assessment instruments, tools, \& checklists from the field and Volume III: RESNA resource guide for assistive technology outcomes: Developing domains of need and criteria of services. Diagnostique, 25(4), 353-359. Ferguson-Pell, M., Nicholson, G., Bain, D., Call, E., Grady, J. \& deVries, J. The role of wheelchair seating standars in determining clinical practices and funding policy. Assistive Technology, 17, 1-6.

Fernández-López, J. A., Fernández-Fidalgo, M., \& Cieza, A. (2010). Los conceptos de Calidad de Vida, Salud y Bienestar analizados desde la perspectiva de la Clasificación Internacional del Funcionamiento (CIF). Revista Española de Salud Pública, 84, 169184.

Fischer, S. L., Marshall, M. M., \& Woodcock, K. (2012). Musculoskeletal disorders in sign language interpreters: a systematic review and conceptual model of musculoskeletal disorder development. Work (Reading, Mass.), 42(2), 173-184. doi:10.3233/WOR2012-1342

Fitts, P.M (1954). The information capacity of the human motor system in controlling the amplitudes of movement. Journal of Experimental Psychology, 47, 381-391.

Fitzpatrick, E. M., Olds, J., Gaboury, I., McCrae, R., Schramm, D., \&Durieux-Smith, A. (2012). Comparison of outcomes in children with hearing aids and cochlear implants. Cochlear Implants International, 13(1), 5-15.

Floyd, K. K., Smith Canter, L. L., Jeffs, T., \& Judge, S. A. (2008). Assistive Technology and Emergent Literacy for Preschoolers: A Literature Review. Assistive Technology Outcomes and Benefits, 5(1), 92-102.

Forbes, W. F., Thompson, M. E., Agwani, N., \& Hayward, L. M. (1993). A log-linear relationship between reported impairments and age: implications for the multistage hypothesis. Journal of Gerontology, 48(1), 33-40.

Fortnum, H., Marshall, D., Bamford, J. \& Summerfield, A. (2002). Hearing impaired children in the UK: education setting and communication approach. Deafness and Education International, 4, 123-141.

Foster, S. (1998). Communication as social engagement: implications for interactions between deaf and hearing persons. Scandinavian Audiology, 27(4), 116-124.

Fougeyrollas, R., Cloutier, R., Bergeron, H., C`ote, J. \& StMichel, G. (1999). The disability creation process. The Quebec Classification. Ciudad: Editorial. 
Francis, H. W., Chee, N., Yeagle, J., Cheng, A., \& Niparko, J. K. (2002). Impact of cochlear implants on thef unctional health status of older adults. The Laryngoscope, 11 2(8), 1482-1488.

Freeman, M., \& Saidoo, K. (2013). Review of Assistive technologies and other support for people with brain impairment. Brain Injury, 27(9), 1090-1091. doi: $10.3109 / 02699052.2013 .794976$

Frishberg, N. (1975). Arbitrariness and iconicity. Historical change in American Sign Language. Language, 51, 696-719.

Fuhrer, M. J. (2000). Subjectifying quality of life as a medical rehabilitation outcome. Disability and Rehabilitation, 22, 481-189.

Fuhrer, M. J. (2001). Assistive technology outcomes research: Challenges met and unmet. American Journal of Physical Medicine and Rehabilitation, 8, 528-535.

Fuhrer, M. J., (2007). Assessing the efficacy, effectiveness, and cost-effectiveness of assistive technology interventions for enhancing mobility. Disability and Rehabilitation: Assistive Technology, 2(3), 149-158.

Fuhrer, M. J, Jutai, J. W., Scherer, M. J., \& DeRuyter, F. (2003) A framework for the conceptual modeling of assistive technology device outcomes. Disability and Rehabilitation, 25, 1243-1251.

Gagné, J., Jennings, M., \& Southall, K. (2009). The ICF: A Classification System and Conceptual Framework Ideal for Audiological Rehabilitation. Perspectives on Aural Rehabilitation and Its Instrumentation (16), 8-14.

Gallardo, B. T. (1999). La comunidad sorda. Barcelona: ISEP - Edicions Universitat de Barcelona..

Garber, S. L., Bunzel, R., \& Monga, T. N.(2002). Wheelchair utilization and satisfaction following cerebral vascular accident. Journal of Rehabilitation Research and Development, 39, 521-534.

García, M., \& Giménez, A. I. (2000). Adquisición del lenguaje. Martínez Sánchez, Francisco et al, 193-217.

Garstecki, D. C., \& Erler, S. F. (1999). Older Adult Performance on the Communication Profile for the Hearing Impaired Gender Difference. Journal of Speech, Language, and Hearing Research, 42(4), 785-796.

Gascón, A. R., Storch, J. G., \& Asensio, (2004). Historia de la educación de los sordos en España y su influencia en Europa y América. Madrid: Centro de Estudios Ramón Areces. 
Geers, A. (2006). Spoken language in children with cochlear implants. In P. Spencer \& M. Marschark: Advances in the spoken language development of deaf and hard of hearing children (pp. 244-270). New York: Oxford University Press.

Geiger, C. (1990). The utilization of assistive devices by patients discharged from an acute rehabilitation setting. Physical and Occupational Therapy in Geriatrics, 9, 3-25.

Gibson, F., Aldiss, S., Horstman, M., Kumpunen, S., \& Richardson, A. (2010). Children and young people's experiences of cancer care: a qualitative research study using participatory methods. International Journal of Nursing Studies, 47(11), 1397-1407.

Gill, T.M., \& Feinstein, A.R. (1994). A critical appraisal of the quality of quality-of-lifemeasurements. JAMA, 272, 24-31.

Gillespie, A., Best, C., \& O`Neill, B. (2012). Cognitive Function and Assistive Technology for cognition: A Systematic Review. Journal of the International Neuropsychological, 18, 1-19. doi:10.1017/S1355617711001548

Gillis, A and Jackson, W. (2002). Research for nurses: Methods and interpretation. Philadelphia: F.A Davis Company.Gitlin, L. (1995). Issuing assistive devices to older patients in rehabilitation: an exploratory study. The American Journal of Occupational Therapy, 49(10), 994-1000.

Gitlin, L., N. (2002) Assistive technology in the home and community for older people: Psychological and social considerations. In M. J. Scherer (Ed.): Assistive technology: Matching device and consumer for successful rehabilitation (pp. 109-122) . Washington, DC: American Psychological Association.

Gitlin, L. N., Levine, R., \& Geiger, C. (1993). Adaptative device use in the home by older adults with mixed disabilities. Archives of Physical Medicine and Rehabilitation, 74, 149-152.

Gitlin, L. N. (1998a) From hospital to home: Individual variations in experience with assistive devices among older adults. In D.B. Gray, L.A. Quatrano \& M.L. Lieberman: Designing and using assistive technology (pp. 117-135). Baltimore, MD: Paul H. Brookes.

Gitlin, L. N. (1998b) The role of social science research in understanding technology use among older adults. In M.G. Ory \& G.H. DeFriese: Self-care in later life: Research program and policy issues, (pp. 142-169). New York: Springer.

Gitlin, L. N., (2002). Assistive technology in the home and community for older people: Psychological and social considerations. American Psychological Association, VOL, 109-122. 
Glanz, K., Basil, M., Maibach, E., Goldberg, J., \& Snyder, D. A. N. (1998). Why Americans eat what they do: taste, nutrition, cost, convenience, and weight control concerns as influences on food consumption. Journal of the American Dietetic Association, 98(10), 1118-1126.

Glickman, N. S., \& Gulati, S. (Eds.). (2003). Mental healthcare of deaf people: A culturally affirmative approach. CIUDAD: Routledge.

Goffi, M. V. S., Gomez, M. C., Guedes, S. B. G., Sant Anna, C. G., Peralta, O., \& KojiTsuji, R. (2004). Critérios de seleção e avaliação médica e audiológica dos candidatos ao implante coclear: Protocolo HCFMUSP. Arquivos Internacionais de Otorrinolaringologia, 8, 197-204.

Goggin, G. (2004). Mobile text. M/C - A Journal of Media and Culture, 7(1), 1-4.

Gosselin, C., Robitaille, Y., Trickey, F., \& Maltais, D. (1993). Factors predicting the implementation of home modifications among elderly people with loss of independence. Physical and Occupational Therapy in Geriatrics, 12, 15-27.

Götherström, U. C., Persson, J., \& Jonsson, D. (2004). A socioeconomic model for evaluation of postal and telecommunication services for disabled persons.Technology and Disability, 16(2), 91-99.

Gough, P. B., \& Tunmer, W. E. (1986). Decoding, reading, and reading disability. Remedial and Special Education, 7(1), 6-10.

De Granda Orive, J. I., Río, F. G., Vázquez, F. R., Sacristán, J. E., Jiménez, T. G., \& Sánchez, L. C. (2005). Las palabras clave como herramientas imprescindibles en las búsquedas bibliográficas. Análisis de las áreas del sistema respiratorio a través de Archivosde Bronconeumología. Archivos de Bronconeumología, 41(2), 78-83.

Granberg, S., Pronk, M., Swanepoel, D. W., Kramer, S. E., Hagsten, H., Hjaldahl, J.\& Danermark, B. (2014). The ICF core sets for hearing loss project: Functioning and disability from the patient perspective. International journal of audiology, 53(11), 777786. doi: $10.3109 / 14992027.2014 .938370$

Granberg, S., Swanepoel, D. W., Englund, U., Möller, C., \& Danermark, B. (2014). The ICF core sets for hearing loss project: International expert survey on functioning and disability of adults with hearing loss using the international classification of functioning, disability, and health (ICF). International Journal of Audiology, 53(8), 497-506.doi:10.3109/14992027.2014.900196

Gray, J.M. (2001). Discussion of the ICIDH-2 in relation to occupational therapy and occupational science. Scandinavian Journal of Occupational Therapy, 8(1), 19-30. 
Gray, D.B., Quatrano, L.A., \& Lieberman, M.L.(1998). Moving to the next stage of assistive technology development. In D. B. Gray, L. A. Quatrano, \& M. L. Lieberman (Eds.): Designing and using assistive technology: The human perspective (pp. 299-309). Ciudad: Editorial.

Gray, D.B., \& Hendershot, G.E. (2000). The ICIDH-2: Defelopments for a new era of outcomes research. Archives of Physical Medicine and Rehabilitation, 81, 10-14 .

Gregory, S., Sheldon, L., \& Bishop, J. (1995). Deaf young people and their families: Developing understanding. Ciudad: Cambridge University Press.

Grenness, C., Hickson, L., Laplante-Lévesque, A., Meyer, C., \& Davidson, B. (2015). The nature of communication throughout diagnosis and management planning in initial audiologic rehabilitation consultations. Journal of the American Academy of Audiology, 26(1), 36-50. doi:10.3766/jaaa.26.1.5

Grieve, J. \& Gnanasekaran, L. (2009). Neuropsychology for occupational therapists: Cognition in Occupational Performance. Oxford: Blackwell Publishing.

Grill, E., Zochling, J., Stucki, G., Mittrach, R., Scheuringer, M., Liman, W., \& Braun, J. (2007). International Classification of Functioning, Disability and Health (ICF) Core Set for patients with acute arthritis. Clinical and Experimental Rheumatology, 25(2), 252-258.

Hale, M. (2004). An Exploratory Study of Identity Formation of Adolescents with Cochlear Implants. Unpublished raw data, Smith College School for Social Work, Northampton, MA. A project based upon an independent investigation submitted in partial fulfillment of the requirements for the degree of Masters of Social Work.

Hallam, R., Ashton, P., Sherbourne, K., \& Gailey, L. (2006). Acquired profound hearing loss: Mental health and othercharacteristics of a largesample: Hipoacusia adquirida profunda: Salud mental y otras características de una muestra grande. International Journal of Audiology, 45(12), 715-723.

Hallam, R.S., Rachman, S., \& Hinchcliffe, R. (2006). Psychological aspects of tinnitus. In: Rachman (Ed.): Contribution to Medical Psychology. Vol.3, (pp.. 31-34). Oxford: Pergamon Press.

Hammel, J., \& Luebben, A. J. (1996). Assistive technology in occupational therapy: What is it, why do I need to know it, and what do I need to know? In J. Hammel (Ed.): Technology and Occupational Therapy: A Link to Function. Bethesda, MD: AOTA. 
Hammel, J., Sai, J. S., \& Heller, T. (1999). Functional outcomes of assistive technology for adults with developmental disabilities. Proceedings of the 22nd Annual RESNA Conference, Long Beach, CA, 22, 195-197.

Hammell, K. W. (2004). Deviating from the Norm: A Sceptical Interrogation of the Classificatory Practices of the ICF. The British Journal of Occupational Therapy, 67(9), 408-411.

Hamill, A. C., \& Stein, C. H. (2011). Culture and empowerment in the Deaf community: An analysis of internet weblogs. Journal of Community \& Applied Social Psychology, 21(5), 388-406. doi:10.1002/casp.1081

Happ, T. (2005). U.S. Patent Application 11/086,997.

Harris, J., \& Bamford, C. (2001). The uphill struggle: services for deaf and hard of hearing people-issues of equality, participation and access. Disability \& Society, 16(7), 969-97.

Harris, A., Pinnington, L. L., \& Ward, C. D. (2005). Evaluating the impact of mobilityrelated assistive technology on the lives of disabled people: a review of outcome measures. The British Journal of Occupational Therapy, 68(12), 553-558.

Harris, F. \& Sprigle, S. (2003). Cost analyses in assistive technology research. Assistive Technology, 15, 16-27.

Harris, F., \& Sprigle, S. (2008). Outcomes measurement of a wheelchair intervention. Disability Rehabilitation Assistive Technology, 3(4), 171-180.

Harter, S. (2003). The development of self representations during childhood and adolescence. In M. Leary \& J.P. Tangney. Handbook of self and identify. New York: Guilford.

Harvey-Carter, L. (2007). The Lenovo X-60 Convertible Notebook Tablet PC: An Assistive Technology Tool Review. Developmental Disabilities Bulletin, 35(1-2), 29-43.

Hauser, P.C., Willss, K. \& Isquith, P.K. (2005). Hard of hearing, deafness, and being deaf. Neurodevelopmental disabilities: Clinical research and practice, VOL, 119-131.

Hedley-Williams, A. J., Sladen, D. P., \& Tharpe, A. M. (2003). Programming, care, and troubleshooting of cochlear implants for children. Topics in Language Disorders, 23(1), 46-56.

Heckendorf, S. (2009). Assistive technology for individuals who are deaf or hard of hearing. In J. Gierach (Ed.): Assessing Students' Needs for Assistitive Technology. Assistive Technology (ASNAT) A Resource manual for school district teams (5 $5^{\text {th }} \mathrm{ed}$.). Washington: WATI. 
Hedley-Williams, A. J., Sladen, D. P., \& Tharpe, A. M. (2003). Programming, care, and troubleshooting of cochlear implants for children. Topics in Language Disorders, 23(1), 46-56.

Heerkens, Y.,F., Bougie, T., \& de Kleijn-de Vrankrijker, M.,W. (2010). Classification and terminology of assistive products. In: J. H. Stone \& M. Blouin (Eds.): International Encyclopedia of Rehabilitation. Available online: http://cirrie.buffalo.edu/encyclopedia/en/article/265/

Henshaw, H., Clark, D. P., Kang, S., \& Ferguson, M. A. (2012). Computer skills and internet use in adults aged 50-74 years: influence of hearing difficulties. Journal of Medical Internet Research, 14(4), e133. doi:10.2196/jmir.2036

Hemsley, B., Balandin, S., \& Without, A. C. (2004). The stories of unpaid carers of adults with cerebral palsy and complex communication needs in hospital. Augmentative and Alternative Communication, 20(4), 243-258.

Hersh, M. A., \& Johnson, M. A. (2008). On modelling assistive technology systems-Part I: Modelling framework. Technology and Disability, 20(3), 193-215.

Hétu, R. (1996). The stigma attached to hearing impairment. Scandinavian Audiology Supplement, 43, 12-24.

Hines, J. (2000) Communication problems of hearing-impaired patients. Nursing Standard, 14(19), 33-37.

Hindley, P., \& Kitson, N. (2000). Mental health and deafness. CIUDAD: Wiley.

Hintermair, M. (2006). Parental resources, parental stress, and socioemotional development of deaf and hard of hearing children. Journal of Deaf Studies and Deaf Education, 11(4), 493-513.

Hocking, C. (1999). Function or feelings: Factors in abandonment of assistive devices. Technology and Disability, 11(1/2), 3-11.

Hoenig, H., Giacobbi, P., \& Levy, C., E (2007). Methodological challenges confronting researchers of wheeled mobility aids and other technologies. Disability Rehabilitation Assistive Technology,(2),159-168. doi:10.1080/17483100701374405

Hoenig, H., Landerman, L., R, Shipp, K.,M, Pieper. C,, Richardson, M., Pahel, N., \& George, L.(2005) A clinical trial of a rehabilitation expert clinician versus usual care for providing manual wheelchairs. Journal American Geriatric Social, 53, 1712-1720.

Holm, M.B (2000). Our mandate for the new millennium: Evidence-based practice. The American Journal of Occupational Therapy, 54, 575-585. 
Homa, D. B. (2007). Using the International Classification of Functioning, Disability and Health (ICF) in job placement. Work, 29(4), 277-286.

Hoover, W. A., \& Gough, P. B. (1990). The simple view of reading. Reading and writing, 2(2), 127-160.

Hoppenbrouwers, G., Stewart, H., \& Kernot, J. (2014). Assistive technology assessment tools for assessing switch use of children: A systematic review and descriptive analysis. Technology \& Disability, 26(2/3), 171-185. doi: 10.3233/TAD-140405

Hotton, M. (2004). Le comit'e sur les nouvelles technologies en d'eficience auditive de I'I.R.D.P.Q.: projet de recherché sur les appareils de t’el communications pour les personnes sourdes et malentendantes differences. Magazine de l'Institut de readaptation en defiance physique de Quebec, 5, 3238.

Huarte, A., Lezaun, R., \& Manrique, M. (2014). Quality of Life Outcomes for Cochlear Implantation in the Elderly. Audiology and Neurotology, 19(Suppl. 1), 36-39. doi:10.1159/000371608

Huber, M. (2003). Die Praxis der Bedarfsermittlung zur Hilfsmittelversorgung in den Niederlanden [The practice of needs assessment for the supply of technical aids in the Netherlands]. Die Rehabilitation (Stuttg), 42, 52-59.

Hyde, M., \& Power, D. (2000). Informed parental consent for cochlear implantation of young deaf children: social and other considerations in the use of the'bionic ear'. The Australian Journal of Social Issues, 35(2), 117.

Hyde, M., \& Power, D. (2006). Some ethical dimensions of cochlear implantation for deaf children and their families. Journal of Deaf Studies and Deaf Education, 11(1), 102111.

Iacono, T., \& Davis, R.(2003) The experience of people with developmental disability in emergency departments and hospital wards. Research in Developmental Disabilities, 24, 247-264.

Iezzoni, L., O'Day, B., Killeen, M., \& Harker, H. (2004). Communicating about health care: Observations from persons who are deaf or hard of hearing. Annals of Internal Medicine, 140(5), 356-362.

Imrie, R. (2004). Demystifying disability: A review of the international classification of functioning, disability and health. Sociology of Health \& Illness, 26(3), 287-305. International Standards Organization, ISO 9999 (2005): Technical aids for people with disabilities-classification and terminology. Geneva. Switzerland: ISO. 
International Standards Organization (ISO). (2007). ISO 9999:2007: Assistive Products for Persons with Disability —Classification and Terminology. Geneva, Switzerland: ISO.

ISO/IEC 9126-1 (2001). Software engineering-Product quality-Part 1: Quality model. ISO. ISO/IEC 9126-3 (2002). Software engineering -Product quality-Part3: Internal metrics. ISO.

ISO/IEC 9126-2 (2002). Software engineering -Product quality-Part2: External metrics. ISO

ISO/IEC 9126-4 (2002). Software engineering -Product quality-Part4: Quality In Use metrics. ISO.

Ivanoff, S. D., Iwarsson, S., \& Sonn, U. (2006). Occupational therapy research on assistive technology and physical environmental issues: A literature review. Canadian Journal of Occupational Therapy / Revue Canadienne D'Ergothérapie, 73(2), 109-119. doi:10.1177/000841740607300203

Jacob, R. T., Alves, T., Moret, A., Morettin, M., Santos, L. G. D., \& Mondelli, M. (2014). Participation in regular classroom of student with hearing loss: frequency modulation System use. In CoDAS.. Sociedade Brasileira de Fonoaudiologia, 26(4), 308-314. doi:10.1590/2317-1782/201420130027

James, S. E. (2014). Review of Assistive technology: Interventions for individuals with severe/profound and multiple disabilities. Journal of Child and Family Studies, 23(1), 169-171. doi: 10.1007/s10826-013-9723-4

James, J. R., \& Gabriel, K. I. (2012). Student interpreters show encoding and recall differences for information in english and american sign language. Translation and Interpreting, 4(1), 21-37.

Jerosch-Herold, C., Leite, C. D. C. J., \& Song, F. (2006). A systematic review of outcomes assessed in randomized controlled trials of surgical interventions for carpal tunnel syndrome using the International Classification of Functioning, Disability and Health (ICF) as a reference tool. BMC musculoskeletal disorders,7(1), 1.

Johansson, M. S., \& Arlinger, S. D. (2003). Prevalence of hearingimpairment in a population in Sweden: Prevalencia de las pérdidas auditivas en una población de Suecia. International Journal of Audiology, 42(1), 18-28.

Johnston, T. (2004). W(h)ither the Deaf Community? Population, Genetics, and the Future of Australian Sign Language. American Annals of the Deaf, 148, 358-375.

Jutai, J. (1999). Quality of life impact of assistive technology. Rehabilitation Engineering, $14,2-7$. 
Jutai, J., \& Bortolussi, J. (2003). Psychosocial impact of assistive technology: development of a measure for children (pp. 935-940). Amsterdam: IOS Press

Jutai, J., \& Day, H. (2002). Psychosocial impact of Assistive Devices Scale (PIADS). Technology \& Disability, 14, 107-111.

Jutai, J., Day, H., Woolrich, W., \& Strong, G. (2003). The predictability of retention and discontinuation of contact lenses.Optometry, 74, 299-308.

Jutai, J. W., Fuhrer, M. J., Demers, L., Scherer, M. J., \& DeRuyter, F. (2005). Toward a taxonomy of assistive technology device outcomes. American Journal of Physical Medicine \& Rehabilitation, 84(4), 294-302.

Jutai, J., Ladak, N., Schuller, R., Naumann, S., \& Wright, V. (1996). Outcomes measurement of assistive technologies: An institutional case study. Assistive Technology, 8(2), 110120.

Jutai, J. \& Saunders, H. (2001). Psychosocial Impact of Hearing Aids with a Generic Scale. Paper presented at the American Academy of Audiology, San Diego, CA, April 19-22. Jutai, J.W. (2002). Occupational therapy and assistive technology: The research challenge. Israel Journal of Occupational Therapy, 11(1), 3-22.

Jutai, J., Rigby, P., Ryan, S., \& Stickel, S. (2000). Psychosocial impact of electronic aids to daily living. Assistive Technology, 12(2), 123-131.

Jutai, J., \& Day, H. (2002). Psychosocial Impact of Assistive Devices Scale (PIADS). Technology and Disability, 14(3), 107-111.

Jutai, J.W., Fuhrer, M.J., Demers, L., Scherer, M.J., \& DeRuyter, F. (2005). Toward a taxonomy of assistive technology device outcomes. American Journal of Physical Medicine \& Rehabilitation, 84(4), 294-302. doi:10.1097/01.PHM.0000157313.88732.DC

Jutai, J. W., Strong, J. G., \& Russell-Minda, E. (2009). Effectiveness of assistive technologies for low vision rehabilitation: a systematic review. Journal of Visual Impairment \& Blindness, 103(4), 210-222.

Kagan, A. (1995) Revealing the competence of aphasic adults through conversation: a challenge to health professionals. Topics in Stroke Rehabilitation, 2(1), 15-28.

Kang, Y., Ouellette, S. E., \& Jones, E. (2006). Perceived stress among deaf adults. American Annals of the Deaf, 151(1), 25-31.

Kanny, E. M., Anson, D. K., \& Smith, R. O. (1991). A survey of technology education in entry-level curricula: Quantity, quality, and barriers. Occupational Therapy Journal of Research, 11(5), 311-319. 
Katsuya, K., \& Kelemen, A. (2011). A systematic review of intelligent patient care assistive technology: toward a revolution of nursing practice. CIN: Computers, Informatics, Nursing, 29(8), 441-442. doi: 10.1097/NCN.0b013e3182305d5a

Keating, E., Edwards, T., \& Mirus, G. (2008). Cybersign and new proximities: Impacts of new communication technologies on space and language. Journal of Pragmatics, 40(6), 1067-1081.

Keating, E. \& Mirus, G. (2003). American Sign Language in virtual space: Interactions between deaf users of computer-mediated video communication and the impact of technology on language practices. Language in Society, 32, 693-714. doi: $10.1017 / \mathrm{s} 00474404503325047$

Keith, R. (1994). Functional health and health status. Archives of Pshycal Medicine and Rehabilitation, 75, 478-483.

Kercher, K., \& Rowe, D. C. (2012). Improving the learning experience for the deaf through augment reality innovations (pp. 1-11). IEEE.Engineering, Technology and Innovation (ICE), 18th International ICE Conference on. doi:10.1109/ICE.2012.6297673

Kermit, P. (2012). Enhancement technology and outcomes: What professionals and researchers can learn from thoses keptical about cochlear implants. Health Care Analysis, 20(4), 367-384. doi: 10.1007/s10728-012-0225-0

Khan, F., \& Pallant, J. F. (2007). Use of the International Classification of Functioning, Disability and Health (ICF) to identify preliminary comprehensive and brief core sets for multiple sclerosis. Disability and rehabilitation, 29(3), 205-213. doi:10.1080/09638280600756141

Kielhofner, G. (2002). A Model of Human Occupation theory and application. ( $3^{\text {rd }}$ ed.). Baltimore: Lippincott Williams \& Wilkins.

Kielhofner, G., \& Forsyth, K. (1997). The model of human occupation: An overview of current concepts. The British Journal of Occupational Therapy, 60(3), 103-110.

Kirsch, N. L., Shenton, M., Spirl, E., Rowan, J., Simpson, R., Schreckenghost, D., \& LoPresti, E. F. (2004). Web-Based Assistive Technology Interventions for Cognitive Impairments After Traumatic Brain Injury: A Selective Review and Two Case Studies. Rehabilitation Psychology, 49(3), 200-212. doi: 10.1037/0090-5550.49.3.200

Kirschneck, M., Rauch, A., Stucki, G., \& Cieza, A. (2011). How to Apply the International Classification of Functioning, Disability and Health (ICF) for Rehabilitation Management in Clinical Practice. Physikalische Medizin, Rehabilitationsmedizin, Kurortmedizin, 21(01), 11-21. 
Kirchberger, I., Cieza, A., \& Stucki, G. (2008). Validation of the Comprehensive ICF Core Set for rheumatoid arthritis: The perspective of psychologists. Psychology and Health, 23(6), 639-659. doi:10.1080/14768320701244076

Kittel, A., Marco, A. D., \& Stewart, H. (2002). Factors influencing the decision to abandon manual wheelchairs for three individuals with a spinal cord injury. Disability and Rehabilitation, 24(1-3), 106-114.

Klima, E. \& Bellugi, U. (1979). The signs of language. Cambridge: Harvard University Press. Klop, W. M., Boermans, P. P., Marciano, B., van den Hout, W. B., Stiggelbout, A. M, \& Frijns, J. H. (2008). Clinical Relevance of Quality of Life Outcome in Cochlear Implantation in Postlingually Deafened Adults. Otology \& Neurology, 29(50), 615-621.

Knutson, J.F., Johnson, A., \& Murray, K.T. (2006). Social and emotional characteristics of adults seeking a cochlear implant and their spouses. British Journal of Health Psychology, 11(2), 279-292. doi:10.1348/135910705X52273

Kobayashi, Y., Boudreault, P., Hill, K., Sinsheimer, J. S., \& Palmer, C. G. (2013). Using a social marketing framework to evaluate recruitment of a prospective study of genetic counseling and testing for the deaf community. BMC Medical Research Methodology, 13(1), 145. doi:10.1186/1471-2288-13-145

Kobosko, J., Pankowska, A., \& Skarżyński, H. (2012). Strategieradzeniasobiezestresem u osóbdorosłychpostlingwalnieogłuchłychkorzystających z implantuślimakowego, w porównaniu z populacjąogólnąsłyszących. OtolaryngologiaPolska, 66(2), 132-137.

Kockin, S. \& Rogin, M. (2000). Quantifying the obvious: the impact of hearing instruments on the quality of life. The Hearing Review, 7, 6-30.

Kochkin, S. (2000). MarkeTrak V:" Why my hearing aids are in the drawer": The consumers' perspective. The Hearing Journal, 53(2), 34-36.

Kochkin, S. (1993). MarkeTrak III: Why 20 Million In US Don't Use Hearing Aids For Their Hearing Loss-Part 1. The Hearing Journal, 46, 20-20.

Koester, H., \& McMillan, W. (1997). Software for Assessing Computer Usage Skill. Preedings of RESNA “97 Annual Conference. Pittsburgh, Arlington, VA: RESNA Press"

Koester, H., LoPresti, E., Ashlock, G., McMillan, W., Moore, P., \& Simpson, R. (2003). Compass: Software for Computer Skills Assessment. Proceedings of CSUN 2003 International Conference on Technology and Persons with disabilities. Los Angeles, CA. 
Koon, A., \& Vega, E. (1999). El impacto tecnológico en las personas con discapacidad. La Habana-Cuba: Instituto Superior Pedagógico.

Kramer, S.E. (2008). Hearing impairment, work and vocational enablement. International Journal of Audiology, 47, 124-130. doi:10.1080/14992020802310887

Kritzinger, J., Schneider, M., Swartz, L., \& Braathen, S. H. (2014). “I just answer 'yes' to everything they say": Access to health care for deaf people in Worcester, South Africa and the politics of exclusion. Patient Education and Counseling, 94(3), 379-383. doi:10.1016/j.pec.2013.12.006

Kroger, J. (1996). Identity in adolescence: The balance between self and other. New York: Routledge.

Krueger, R. \& Casey, M. (2000). Focus groups. A Practical Guide for Applied Research. Thousand Oaks CA: Sage Publications.

Kukkonen, P. (2013). The translating and signifying subject as homo interpres and homo significans: Victoria Welby's concept of translation - a polyfunctional tool. Semiotica, 2013(196), 261-281. doi:10.1515/sem-2013-0059

Kvan, M. H., Loeb, M., \& Tambs, K. (2007). Mental health in deaf adults: Symptoms of anxiety and depression among hearing and deaf individuals. Journal Deaf Studies Deaf Education, 12, 1-7.

Labadie, R. F., Carrasco, V. N., Gilmer, C. H., \& Pillsbury, H. C. (2000). Cochlear implant performance in senior citizens. Otolaryngology--Head and NeckSurgery, 123(4), 419424.

Ladd, P. (2003). Understanding Deaf Culture. Clevedon, UK: Multilingual Matters.

Lane, H. (2005). Ethnicity, Ethics, and the Deaf-World. Journal of Deaf Studies and Deaf Education, 10(3), 291-310. doi:10.1093/deafed/eni030

Lane, H., Hoffmeister, R., \& Bahan, B. J. (1996). A journey into the deaf-world. San Diego, CA: DawnSignPress.

Lara, A. J., \& García, A. H. (2010). Políticas públicas sobre discapacidad en España. Hacia una perspectiva basada en los derechos. Politica y Sociedad,47(1), 137-152.

Lauer, A., Longenecker R. K., \& Smith, R. O. (2006, August 18). ATOMS Project Technical Report-Factors in Assistive Technology Device Abandonment: Replacing “Abandonment" with "Discontinuance." Retrieved from http://www.r2d2.uwm.edu/atoms/archive/technicalreports/tr-discontinuance.html

Law, M. (2002). Participation in the occupations of everyday life. The American Journal of Occupational Therapy, 56(6), 640-649. 
Leigh, I. (2009). A lens on deaf identities. Oxford University Press, USA.

Leigh, I. W., Maxwell-McCaw, D., Bat-Chava, Y., \& Christiansen, J. B. (2009). Correlates of psychosocial adjustment in deaf adolescents with and without cochlear implants: A preliminary investigation. Journal of Deaf Studies and Deaf Education, 14(2), 244-259. doi:10.1093/deafed/enn038

Leigh, I.W., \& Stinson, M.S. (1991). Social environments, self-perceptions, and identity of hearing-impaired adolescents. The Volta Review, 93, 7-22.

Lemos, I. C. C., Jacob, R. T. D. S., Gejão, M. G., Bevilacqua, M. C., Feniman, M. R., \& Ferrari, D. V. (2009). Frequency modulation (FM) system in auditory processing disorder: an evidence-based practice?. Pró-Fono Revista de Atualização Científica, 21(3), 243-248.

Lenker, J.A., Fuhrer, M.J., Jutai, J.W., Demers, L., Scherer, M.J. \& DeRuyter, F. (2010). Treatment theory, intervention specification, and treatment fidelity in assistive technology outcomes research. Assistive Technology, 22(3), 129-138. doi:10.1080/10400430903519910

Lenker, J.A., \& Jutai, J.W. (2002). Assistive technology research and practice: What role for ICF? Paper presented at the 8 th North American Collaboratin Center (NACC) Conference on ICF, Toronto, ON.

Lenker, J.A., \& Paquet, V.L. (2003). A review of conceptual models for assistive technology outcomes research and practice. Assistive Technology, 15(1), 1-15.

Leung, J., Wang, N., \& Yeagle, J.D. (2005).Predictive Models for Cochlear Implantation in Elderly Candidates. Archives of Otolaryngology Head \& Neck Surgery, 131(12), 10491054. doi:10.1001/archotol.131.12.1049.

Lewis, M.,S., Crandell, C.,C., Valente, M., \& Enrietto, J.,E. (2004). Speech perception in noise: directional microphones versus frequency modulation (FM) systems. Journal American Academy Audiology, 15, 426-439.

Lewis, M.,S., Valente, M., Horn, J.,E., \& Crandall, C. (2005). The effect of hearing aids and frequency modulation technology on results from the Communication Profile for the Hearing Impaired. Journal American Academy Audiological, 16, 250-261.

Ley 27/2007, de 23 de octubre, por la que se reconocen las lenguas de signos españolas y se regulan los medios de apoyo a la comunicación oral de las personas sordas, con discapacidad auditiva y sordociegas.

Ley 17/2010, de 3 de junio, de la lengua de signos catalana. 
Ley 51/2003, de 2 de diciembre, de igualdad de oportunidades, no discriminación y accesibilidad universal de las personas con discapacidad.

Leybaert, J. (1993). Reading in the deaf: The roles of phonological codes. Psychological Perspectives on Deafness, 1, 269-308.

Lieberman, D., \& Scheer, J. (2002). AOTA's evidence-based literature review project: An overview. The American Journal of Occupational Therapy, 56(3), 344-349.

Lieberman, L., \& Stuart, M. (2002). Self-determined recreational and leisure choices of individuals with deaf-blindness. Self, 96(10), 724-735.

Light, J. (1999). Do augmentative and alternative communication interventions really make a difference?: The challenges of efficacy research. Augmentative and Alternative Comunication, 15, 13-24.

Lin, F. R., Ferrucci, L., Metter, E. J., An, Y., Zonderman, A. B., \& Resnick, S. M. (2011). Hearing loss and cognition in the Baltimore Longitudinal Study of Aging. Neuropsychology, 25(6), 763. doi:10.1037/a0024238

Lincoln, Y. S., \& Denzin, N. K. (2000). The seventh moment: Out of the past. Handbook of qualitative research, 2, 1047-1065.

Lockey, K., Jennings, M. B., \& Shaw, L. (2010). Exploring hearing aid use in older women through narratives. International Journal of Audiology, 49(8), 542-549. doi: $10.3109 / 14992021003685817$

Louise-Bender, P.T., Kim, J., \& Weiner, B. (2002). The shaping of individual meanings assigned to assistive technology: a review of personal factors. Disability and Rehabilitation. 24(1-3),5-20.

Loux, K. (2009). Assistive technology for students who are blind or visually impaired: a guide to assessment. Journal of Visual Impairment \& Blindness, 103(6), 379-380.

Lucas, C. (Ed.). (2003). Language and the law in deaf communities. Washington, D.C: Gallaudet University Press.

Lupsakko, T.A., Kautiainen, H.J., \& Sulkava, R. (2005). The non-use of hearing aids in people aged 75 years and over in the city of Kuoplo in Finland. Eur Arch Otorhinolaryngol, 262, 165-169.

Lloyd, L.L., Quist, R.W., \& Windsor, J.(1990). A proposed augmentative and alternative communication model. Augmentative and Alternative Communication,6, 172-183.

Malo, M. Á. (2015). La definición de la discapacidad en la investigación económica: Una reflexión necesaria sobre qué características debería cumplir. Estudios de Economía Aplicada, 25, 407-427. 
Manikam, R. (2014). Review of Assistive Technologies for People withDiverse Abilities. Journal of Child and Family Studies, 23(7), 1310-1312. doi: 10.1007/s10826-0140017-2

Mann, W. C., Granger, C., Hurren, D., Tomita, M., \& Charvat, B. (1995). An analysis of problems with canes encountered by elderly persons. Physical and Occupational Therapy in Geriatrics, 13(1/2), 25-49.

Mann, J. R., Zhou, L., McKee, M., \& McDermott, S. (2007). Children With Hearing Loss and Increased Risk of Injury. The Annals of Family Medicine, 5(6), 528-533. doi:10.1370/afm.740

Mann, W., Hurren, D. \& Tomita, M. (1994). Assistive device needs of home-based elderly persons with hearing impairments. Technology and Disability, 3, 47-61.

Maor, D., Currie, J., \& Drewry, R. (2011). The Effectiveness of Assistive Technologies for Children with Special Needs: A Review of Research-Based Studies. European Journal of Special Needs Education, 26(3), 283-298. doi:10.1080/08856257.2011.593821

Marchesi, A. (1998). El desarrollo cognitivo y lingüístico de los niños sordos. Alianza Psicología.

Margellos-Anast, H., Estarziau, M., \& Kaufman, G. (2006). Cardiovascular disease knowledge among culturally Deaf patients in Chicago. Preventive Medicine, 42(3), 235-239. doi:10.1016/j.ypmed.2005.12.012

Marín, F. A., \& Pérez, F. J. (2003). Tecnologías de ayuda en personas con trastornos de comunicación. CIUDAD: Nau Llibres.

Marschark, M., \& Hauser, P. C. (Eds.). (2008). Deaf Cognition: Foundations and outcomes: Foundations and outcomes. Oxford University Press. doi: 10.1093/acprof:oso/9780195368673.001001.0001

Martínez, E. (2016). Los sordos no van al cine: la accesibilidad de las personas con discapacidad auditiva en las salas de cine españoles. Journal of Communication, 12, 130-144.

Martins, A. C. (2015). Using the international classification of functioning, disability and health (ICF) to address facilitators and barriers to participation at work. Work, 50(4), 585-593.

Mason, T. C. (2010). Does knowledge of dating violence keep Deaf college students at Gallaudet University out of abusive relationships?. Journal of the American Deafness \& Rehabilitation Association (JADARA), 43(2), 74-91. 
Maxwell, J. M. (1999). Centers for older people, guide for the programs and facilities: A report of a National Council on the Aging project. National Council on the Aging.

Maxwell-McCaw, D. L. (2001). Acculturation and psychological well-being in deaf and hard-of-hearing people. Tesis Doctoral no publicada. University of Hong Kong.

May, H., \& Hearn, G. (2005). The mobile phone as media. International Journal of Cultural Studies, 8(2), 195-211.

Mayberry, R. I., del Giudice, A. A., \& Lieberman, A. M. (2011). Reading achievement in relation to phonological coding and awareness in deaf readers: A meta-analysis. Journal of Deaf Studies and Deaf Education, 16(2), 164188. doi:10.1096/deafed/eng049

McColl, M.,A., Law, M., Stewart, D., Doubt, L., Pollock, N. \& Krupa, T. (2003). Theoretical Basis of Occupational Therapy. Second edition. New Jersey: Thorofare, NJ: Slack Inc.

McCooey-O'Halloran R., Worrall L., \& Hickson L.(2004) Evaluating the role of speechlanguage pathology with patients with communication disability in the acute care hospital setting using the ICF. Journal of Medical Speech-Language Pathology, 12(2),49-58

McDonald Connor C, Hieber, S., Arts, H.,A., \& Zwolan, T.,A. (2000) Speech, vocabulary, and the education of children using cochlear implants: oral or total communication? Journal of Speech, Language, and Hearing Research, 43(5), 1185-1204.

McGuire, R. M., Hernandez-Rebollar, J., Starner, T., Henderson, V., Brashear, H., \& Ross, D. S. (2004, May). Towards a one-way American sign language translator. In Automatic Face and Gesture Recognition, 2004. Proceedings. Sixth IEEE International Conference on (pp. 620-625). IEEE

Mechling, L. (2007). Assistive Technologies as a Self-Management Tool for Prompting Students with Intellectual Disabilities to Initiate and Complete Daily Tasks: A Literature Review. Education and Training in Developmental Disabilities, 42(3), 252269.

Meister, H., Lausberg, I., Von Wedel, H., \& Walger, M. (2004) Identifying factors before the provision of hearing aids. Results from a pilot study. HNO, 52, 790-7.

Meister, H., Rählmann, S., Walger, M., Margolf-Hackl, S., \& Kießling, J. (2015). Hearing aid fitting in older persons with hearing impairment: the influence of cognitive function, age, and hearing loss on hearing aid benefit. Clinical Interventions in Aging, 10, 435443. doi:10.2147/CIA.S77096 
Meister, H., Walger, M., Brehmer, D., von Wedel, U. C., \& von Wedel, H. (2008). The relationship between pre-fitting expectations and willingness to use hearing aids. International Journal of Audiology, 47(4), 153-159. doi:10.1080/14992020701843111

Merkin, L., \& Smith, M. J. (1995). A community based model providing services for deaf and deaf-blind victims of sexual assault and domestic violence. Sexuality and disability, 13(2), 97-106.

Meyer, J. D., Chen, Y., McDonald, J. C., \& Cherry, N. M. (2002). Surveillance for workrelated hearing loss in the UK: OSSA and OPRA 1997-2000. Occupational Medicine, 52(2), 75-79.

Meyer, A., Sie, K., Skalicky, A., Edwards, T. C., Schick, B., Niparko, J., \& Patrick, D. L. (2013). Quality of Life in Youth With Severe to Profound Sensorineural Hearing Loss. JAMA Otolaryngology-Head \& Neck Surgery, 139(3), 294-300. doi:10.1001/jamaoto.2013.35

Migirov, L., Taitelbaum-Swead, R., Drendel, M., Hildesheimer, M., \& Kronenberg, J. (2010). Cochlear implantation in elderly patients: surgical and audiologicaloutcome. Gerontology, 56(2), 123-128. doi:10.1159/000235864

Miesenberger, K., Klaus, J., Zagler, W., \& Karshmer, A. (Eds.). (2008). Computers Helping People with Special Needs(Vol. 5105). Berlin, Heidelberg: Springer Berlin Heidelberg. doi:10.1007/978-3-319-08599-9

Mo, B., Lindbaek M. \& Harris, S. (2005) Cochlear implants and quality of life: a prospective study. Ear Hear, 26, 186-194.

Molin, M. (2004). Delktighet inmo handikappomeradet- En begreppsanalys (Participation in the disability area- A conceptual analysis). In A. Gustavsson (Ed.): The language of participation. Stockholm: Studentlitteratur.

Möller, K. (2003). Deafblindness: a challenge for assessment-is the ICF a useful tool?. International Journal of Audiology, 42(S1), 140-142.

Moncher, F. J., \& Prinz, R. J. (1991). Treatment fidelity in outcome studies.Clinical Psychology Review, 11(3), 247-266.

Monsen, R. B. (1983). The oral speech intelligibility of hearing-impaired talkers. Journal of Speech and Hearing Disorders, 48(3), 286-296.

Moreno, L. (2007). Europa Social, Bienestar en España y la" Malla de Seguridad". La experiencia Europea. Madrid, Fundación Carolina/Siglo XXI. 
Morris, W. (2008). Theology without Words. Theology in the Deaf Community. UK: Routledge

Mortenson, W. B., Demers, L., Fuhrer, M. J., Jutai, J. W., Lenker, J., \& DeRuyter, F. (2012). How Assistive Technology Use by Individuals with Disabilities Impacts Their Caregivers: A Systematic Review of the Research Evidence. American Journal of Physical Medicine \& Rehabilitation, 91(11), 984-998. doi:

10.1097/PHM.0b013e318269eceb

Mortenson, W. B., Miller, W. C., \& Miller-Pogar, J. (2007). Measuring wheelchair intervention outcomes: development of the wheelchair outcome measure. Disability and Rehabilitation: Assistive Technology, 2(5), 275-285. doi:

10.1080/17483100701475863

Mosey, A. (1996). Applied scientific inquiry in health professions: An epistemological orientation. (2nd edition). Bethesda, MD: The American Occupational Therapy Association, Inc.

Mottez, B. (1995). Identidad sorda. El Bilingüismo de los Sordos, 1(1), 32-36.

Mulrow, C., Aguilar, C., Endicott, J., Tuley, M., Velez, R., Charlip, W., Rhodes,M., Hill, S. \& De Nino, L. (1990). Quality-of-life changes and hearing impairment: randomized trial. Annals of Internal Medicine, 113, 188-194. doi:10.7326/0003-4819-113-3-188

Muirow, C., Aguilar, C., Endicott, J.E., Velez, R., Tuley, M.R, Charlip, W.S, Hill, J.A.(1990) Association between hearing Impairment and the quality of life of elderly Individuals. Journal American Geriatric Social, 38, 45-50.

Mulrow, C. D., Aguilar, C., Endicott, J. E., Tuley, M. R., Velez, R., Charlip, W. S., ...\& DeNino, L. A. (1990). Quality-of-lifechanges and hearingimpairment: a randomized trial. Annals of Internal Medicine, 113(3), 188-194.

Murphy, J., Markov, I., Collins, S., \& Moodie, E. (1996). ACC systems: Obstacles to effective use. European Journal of Disorders of Communication, 31, 31-44.

Muñoz-Baell, I. M., Ruiz-Cantero, M. T., Álvarez-Dardet, C., Ferreiro-Lago, E., \& ArocaFernández, E. (2011). Comunidades sordas: ¿pacientes o ciudadanas?. Gaceta Sanitaria, 25(1), 72-78.

Muzaffar, W., Davis, K. S., \& Meyer, T. A. (2012).The Role of Social Media in Patient Motivation and Decision Making in Cochlear Implant Device Selection. Self, 76, 77-6. Naccari, M., \& Mrak, M. (2013). Binary alpha channel compression for coding of supplementary video streams (pp. 200-205). IEEE. doi:10.1109/MMSP.2013.6659288 
Nadeau, M., Vercaingne-Ménard, A., Leclerc, S., de Maisonneuve, S., \& Dubuisson, C. (1994). à chaque problème sa solution: les difficultés des Sourds de niveau postsecondaire en français écrit. Élargir les horizons-Perspectives scientifiques sur l'intégration sociale.(oPHQ), 909-916.

Nicolson, A., Moir, L., \& Millsteed, J. (2012). Impact of assistive technology on family caregivers of children with physical disabilities: a systematic review. Disability \& Rehabilitation: Assistive Technology, 7(5), 345-349. doi:

$10.3109 / 17483107.2012 .667194$

Nikolopoulos, T, O’Donoghue, G, \& Archbold, S. (1999) Age at implantation is important in paediatric cochlear implantation. Laryngoscope, 109, 595-599.

Nikolopoulos, T. P., Archbold, S. M., Tait, M., O'donoghue, G. M., Lutman, M. E., \& Gregory, S. (2000). Approach to communication, speech perception and intelligibility after paediatric cochlear implantation. British Journal of Audiology, 34(4), 257-264.

Noller, P., Feeney, J., \& Peterson, C. (2001). Personal relationships across the life span. Philadelphia. Taylor \& Francis

Nordenfelt, L. (2003). Action theory, disability and ICF: Disability \& Rehabilitation, 25(18), 1075-1079.

Occupational Therapy Practice Framework: domain and process (2002). American Journal Occupational Therapy, 56(6), 609-639.

Odom, S. L., Brantlinger, E., Gersten, R., Horner, R. H., Thompson, B., \& Harris, K. R. (2005). Research in special education: Scientific methods and evidence-based practices. Exceptional children, 71(2), 137-148.

Odor, P. (1984). Hard and soft technology for education and communication for disabled people. Proceedings of the International Computer Conference, Perth, Australia.

O'Halloran, R., Hickson, L., \& Worrall, L. (2008). Environmental factors that influence communication between people with communication disability and their healthcare providers in hospital: A review of the literature within the International Classification of Functioning, Disability and Health (ICF) framework. International Journal of Language \& Communication Disorders, 43(6), 601-632.

Olze, H., Szczepek, A. J., Haupt, H., Zirke, N., Graebel, S., \& Mazurek, B. (2011). The impact of cochlear implantation on tinnitus, stress and quality of life in postlingually deafened patients. Audiology \& Neuro-otology, 17(1), 2-11. doi:10.1159/000323847 
O'Neill, B. (2012). Review of Assistive technologies and other supports for people with brain impairment. Neuropsychological Rehabilitation, 22(6), 948-950. doi: 10.1080/09602011.2012.703801

O'Neill, G. (1999) Hearing loss. A growing problem that affects quality of life. Challenges for the $21^{\text {st }}$ century: Chronic and disabling conditions. National Academy on an Aging Society, 2.

Omnitor (2005). Communication for all. http://www.omnitor.es

Orden SPI/573/2011, de 11 de marzo, por la que se modifican los Anexos III y VII del Real Decreto 1030/2006, de 15 de septiembre, por el que se establece la cartera de servicios comunes del Sistema Nacional de Salud y el procedimiento para su actualización

Osberger, M., Maso, M.,\& Sam, L. (1993) Speech intelligibility of children with cochlear implants, tactile aids, or hearing aids. Journal of Speech and Hearing Researc, 36, 186203.

Oyegard, A., \& Ramstrom, A.B. (1994) Individual follow-up of hearing aid fitting. Scandinavian Audiology, 23, 57-63.

Palacios, A. (2008). El modelo social de discapacidad: orígenes, caracterización y plasmación en la Convención Internacional sobre los Derechos de las Personas con Discapacidad. CERMI.

Palmer, P., \& Jepson, J. (2012). The search for a suitable outcome measure for use in evaluating the outcome of provision of an environmental control system. Journal of Assistive Technologies, 6(1), 66-70. doi:10.1108/17549451211214373

Pape, T. L., Kim, J., \& Weiner, B. (2002). The shaping of individual meanings assigned to assistive technology: a review of personal factors. Disability and rehabilitation, 24(13), 5-20.

Park, E., Shipp, D. B., Chen, J. M., Nedzelski, J. M., \& Lin, V. Y. (2011). Postlingually deaf adults of all ages derive equal benefits from unilateral multichannel cochlear implant. Journal of the American Academy of Audiology, 22(10), 637-643. doi: 10.3766/jaaa.22.10.2

Pasha, M., \& Pasha, S. (2006), Let's Redefine Assistive Technology Discussion Paper, http://222.cartuk.org/?q=node/33.

Peluso, L., \& Viera, A. (2014). Tecnologías de la lengua y la comunicación aplicadas a las lenguas habladas por sordos y personas con parálisis cerebral: consideraciones lingüísticas y educativas. Revista diálogos e perspectivas em educação especial, 1(1), $85-98$. 
Perelló, J., \& Frigola, J. (1987). Lenguaje de signos manuales. Barcelona. Editorial: Científico-médica.

Perello, J. \& Tortosa, F. (1978). Sordomudez. Barcelona. Científico-médica.

Perfetti, C. A., \& Sandak, R. (2000). Reading optimally builds on spoken language: Implications for deaf readers. Journal of Deaf Studies and Deaf Education, 5(1), 32-50.

Peterson, C. C. (2004). Theory-of-mind development in oral deaf children with cochlear implants or conventional hearing aids. Journal of child psychology and psychiatry, 45(6), 1096-1106.

Phillips, J., Toiviainen, P., Gosselin, N., Piché, O., Nozaradan, S., Palmer, C., \& Peretz, I. (2009). Born to dance but beat deaf: a new form of congenitalamusia. Neuropsychologia, 49(5), 961-969.

Philips, B., \& Zhao, H. (1993). Predictors of assistive technology abandonment. Assistive Technology, 5, 36-45.

Pier Luigi Emiliani. (2006) Assistive Technology (AT) versus Mainstream Technology (MST): The research perspective. Technology and Disability, Volume 18(1), 19-29.

Polycom Inc. (2005). Polycom Worldwide: where voice, video and data meet. http://www.polycom.com

Pollard, R. Q., \& Barnett, S. (2009). Health-related vocabulary knowledge among deaf adults. Rehabilitation Psychology, 54(2), 182-185. doi:10.1037/a0015771

Pollard, R. (1996). Conceptualizing and Conducting Preoperative Psychological Assessments of Cochlear Implant Candidates. Journal of Deaf Studies and Deaf Education , 1, 1428.

Popelka, M.,M., Cruickshanks, K.J., Wiley, T.L., Tweed, T.S., Klein, B.E., \& Klein, R. (2000). Moderate alcohol consumption and hearingloss: a protectiveeffect. Journal of the American Geriatrics Society, 48, 1273 -1278

Popelka, M.M., Cruickshanks, K.J., Wiley, T.L., Tweed, T.S., Klein, B.E, Klein, R. (1998) Low prevalence of hearing aid use among older adults with hearing loss: The epidemiology of hearing loss study. Journal of the American Geriatrics Society, 46, 1075-1078.

Potl, S., \& Hickson, L. (1990). Hearing status of elderly hospital inpatients. Australian Journal of Audiology, 12, 79-83.

Pousada T. (2011). The psychosocial impact of wheelchair in life of people with neuromuscular disorders. Thesis. University of A Coruna. 
Pousada, T., Groba, B. \& Nieto, L. (2011). Assistive technologies, tools and resources for the Access and use of information and communication technologies by people with disabilities. In J. Pereira: Handbook of research on personal autonomy technologies and disability informatics (pp. 1-15). Hershey, PA : Medical Information Science Reference

Power, D., \& Hyde, M. (2002). The characteristics and extent of participation of deaf and hard-of-hearing students in regular classes in Australian schools. Journal of Deaf Studies and Deaf Education, 7(4), 302-311.

Power, M. R., Power, D., \& Horstmanshof, L. (2007). Deaf people communicating via SMS, TTY, relay service, fax, and computers in Australia. Journal of Deaf Studies and Deaf Education, 12 (1), 80-92. doi: 10.1093/deafed/en1016

Power, D., Power, M. R., \& Rehling, B. (2007). German deaf people using text communication: short message service, TTY, relay services, fax, and e-mail. American Annals of the Deaf, 152(3), 291-301. doi:10.1353/aad.2007.0030

Preisler, G. (2007). The psychosocial development of deaf children with cochlear implants. In L. Komesaroff (Ed.): Surgical consent: Bioethics and cochlear implants (pp. 120-136). Washington, DC: Gallaudet University Press

Protopapas, A., Simos, P.G., Sideridis, G., \&Mouzaki, A. (2012). The components of the simple view of Reading: A confirmatory factor analysis. Reading Psychology, 33, 217240. doi:10.1080/02702711.2010.507626

Proyecto EASTIN (2005). Minusval,153,17.

Queirós, A., Cerqueira, M., Martins, A. I., Silva, A. G., Alvarelhão, J., \& Rocha, N. P. (2014). Personas and Scenarios Based on Functioning and Health Conditions. Human Factors in Software Development and Design, 274.

Quinteiro, M. V. (2011). Impacto de las ayudas técnicas de acceso al ordenador en el aprendizaje de materias informáticas mediante cursos de enseñanza asistida por ordenador (E.A.O.) de alumnos con discapacidad en los miembros superiores. Tesis Doctoral no publicada, Universidad Pontificia Comillas. Madrid.

Quittner, A. L., Leibach, P., \& Marciel, K. (2004). The impact of cochlear implants on young deaf children: new methods to assess cognitive and behavioral development. Archives of Otolaryngology-Head \&Neck Surgery, 130(5), 547-554.

Rabbitt, P. (1990). Mild hearing loss can cause apparent memory failures which Increase with age and reduce with IQ. Acta Oto-Laryngologica Suppl, 476,167-175. 
Raggi, A., Leonardi, M., Ajovalasit, D., Carella, F., Soliveri, P., Albanese, A., \& Romito, L. (2010). Functioning and disability in Parkinson's disease. Disability and Rehabilitation, 32(1), 33-41.

Ravneberg, B. (2012). Usability and abandonment of assistive technology. Journal of Assistive Technologies, 6(4), 259-269. doi:10.1108/17549451211285753

Rawool, V. W.(2010) Invisible Hearing Loss Among Obvious Multiple Disabilities, Part 1: Ensuring Auditory Care. Hearing Review, 17(1), 18-21.

Real Decreto 1030/2006, de 15 de septiembre, por el que se establece la cartera de servicios comunes del Sistema Nacional de Salud y el procedimiento para su actualización.Boletín Oficial del Estado. Madrid, 17 de Septiembre de 2006, núm. 222.

Reesman, J. H., Day, L. A., Szymanski, C. A., Hughes-Wheatland, R., Witkin, G. A., Kalback, S. R., \& Brice, P. J. (2014). Review of intellectual assessment measures for children who are deaf or hard of hearing. Rehabilitation Psychology, 59(1), 99-106. doi:10.1037/a0035829

Reid, D.T. \& Renwick, R.M (2001). Relating familiar stress to the psychosocial adjustement of adolescents with Duchenne muscular dystrophy. Journal of Rehabilitation, 24(2), 83-93.

Rembar, S., Lind, O., Arnesen, H., \& Helvik, A. S. (2009). Effects of cochlear implants: a qualitative study. Cochlear Implants International, 10(4), 179-197.

Rems-Smario, J. (2007). Domestic violence: We can't ignore it any more. NADmag, March/April, 16-18.

Renwick, R., \& Brown, I. (1996). The Centre for Health Promotion's conceptual approach to the quality of life. In R. Renwick, I. Brown, \& M. Nagles: Quality of life in health promotion and rehabilitation: Conceptual approaches, issues, and applications.

Thousand Oaks, CA: Sage.

Research Triangle Institute (2000). National Classification System for Assistive Technology Devices and Services (Revised). Washington DC.

Ricao, A. G., \& de Gracia, J. G. S. (2004). Historia de la educación de los sordos en España y su influencia en Europa y América. Centro de Estudios Ramón Areces.

Richardson, L. \& Pierre, A. S. (2000). Writing: A method of inquiry. In Handbook of qualitative research (pp. 923-948). 
Riemer-Reiss, M.L., Wacker, R.R. (2000) Factors associated with assistive technology discontinuance among individuals with disabilities. Journal of Rehabilitation, 66(3), 44-50.

Ripat, J., \& Booth, A. (2005). Characteristics of assistive technology service delivery models: stakeholder perspectives and preferences. Disability and Rehabilitation, 27, 1461-1470.

Rodrigues, P. R., \& Gama Alves, L. R. (2013). Tecnologia assistiva - uma revisão do tema. (Portuguese). Assistive Technology - A REVIEW. (English), 29(6), 170-180.

Rodriguez, G. M. (1992). Lenguaje de signos. Fundación CNSE. Barcelona.

Roelands, M., Van Oost, P., Depoorter, A. \& Buysse, A. (2002). A social-cognitive model to predict the use of assistive devices for mobility and self-care in elderly people. Gerontologist, 42(1), 39-50.

Rogers, E., M. (1995). Diffusion of innovations (4 ed.). New York: Simon \& Schuster Rogers, K., Evans, C., Campbell, M., Young, A., \& Lovell, K. (2014). The reliability of British Sign Language and English versions of the Clinical Outcomes in Routine Evaluation - Outcome Measure with d/Deaf populations in the UK: an initial study. Health \& Social Care in the Community, 22(3), 278-289. doi:10.1111/hsc.12078

Rogers, J. C., \& Holm, M. B. (1992). Assistive Technology Device Use in Patients With Rheumatic Disease: A Literature Review. The American Journal of Occupational Therapy, 46(2), 120-127.

Rosen, M. (1989). Editorial. Assistive Technology, 1, 49-50Ross, M., \& Levitt, H. (2000). Developments in research and technology. Assistive listening systems: a review and update. Volta Voices, 7(1), 30-34.

Rouse, W.B. (1980). Systems engineering models of human machine interaction. New York: North Holland.

Ross, M., \& Levitt, H. (2000). Developments in Research and Technology: Implantable Hearing Aids, Part I. VOLTA VOICES, 7(6), 32-32

Rowe, J. (2006). DVD review. Assistive technology in the workplace: case study videos. Occupational Therapy in Health Care, 20(2), 107-109.

Royal National Institute for the Deaf (RNID). A Simple Cure, et al. RNID, London Royeen, C. B. (2002). Occupation reconsidered. Occupational Therapy International, 9(2), 111-120.

Rust, K. L., \& Smith, R. O. (2005). Assistive technology in the measurement of rehabilitation and health outcomes: a review and analysis of instruments. American Journal of Physical Medicine \& Rehabilitation, 84(10), 780-793. 
Ryff, C.D. (1995). Psychological well-being in adult life. Current Directions in Psychological Science, 4(4), 99-104

Sacket, D. L. (1998). Evaluation of health services. Mosley-Rosenau's public health and preventive medicine.

Saladin, S. P., \& Hansmann, S. E. (2008). Psychosocial variables related to the adoption of video relay services among deaf or hard-of-hearing employees at the Texas school for the deaf. Assistive Technology, 20, 36-47.doi: 10.1080/10400435.2008.10131930.

Salamon, G., Verterages, V. \& Jagal, M. (1988). Age-related hearing difficulties, I. Hearing impairment, disability and handicap- a controlled study. Audiology, 27, 146-178.

San-Segundo, R., Barra, R., Córdoba, R., D’Haro, L. F., Fernández, F., Ferreiros, J., \& Pardo, J. M. (2008). Speech to sign language translation system for Spanish. Speech Communication, 50(11), 1009-1020.

Sarget, C. (2005). Hearing impairment: a population study of age at diagnosis, severity, and language outcomes at 7-8 years. Archives of Disease in Childhood, 90(3), 238-244.

Sarmento-Henrique, R. \& Giménez-Dasí M. (2013) Emotional development in deaf children: a proposal of intervention. International Journal on Mental Health and Deafness, 3.

Santos del Riego, S. (2005). Terapia ocupacional: del siglo XIX al XXI. Historia y concepto de ocupación. Rehabilitación, 39(4), 179-184. doi:10.1016/S0048-7120(05)74343-7

Sauer, A. L., Parks, A., \& Heyn, P. C. (2010). Assistive technology effects on the employment outcomes for people with cognitive disabilities: a systematic review. Disability \& Rehabilitation: Assistive Technology, 5(6), 377-391. doi: $10.3109 / 17483101003746360$

Saunders, G. H., \& Forsline, A. (2012). Hearing-aidcounseling: Comparison of singlesessioninformationalcounselingwith single-session performance-perceptual counseling. International Journal of Audiology, 51(10), 754-764.

Saunders, G., Frederick, M., Chisolm, T., Silverman, S., Arnold, M., \& Myers, P. (2014). Use of a frequency-modulated system for veterans with blast exposure, perceived hearing problems, and normal hearing sensitivity. Seminars in Hearing, 35(03), 227238

Saunders, G. H., Lewis, M. S., \& Forsline, A. (2009). Expectations, prefittingcounseling, and hearingaidoutcome. Journal of the American Academy of Audiology, 20(5), 320-334.

Scarinci, N., Worrall, L., \& Hickson, L. (2008). The effect of hearing impairment in older people on the spouse. International Journal of Audiology, 47(3), 141-151. 
Scott, A.G., \& Sechrest, L.B. (1989). Strengh of theory and theory of strength. Evaluation and Program Planning, 12, 329-336.

Schafer, E. C., Huynh, C., Romine, D., \& Jimenez, R. (2013). Speech recognition and subjective perceptions of neck-loop FM receivers with cochlear implants. American Journal of Audiology, 22(1), 53-64. doi.:10.1044/1059-0889(2012/11-0032)

Schafer, E. C., \& Thibodeau, L. M. (2006). Speech recognition in noise in children with cochlear implants while listening in bilateral, bimodal, and FM-system arrangements. American Journal of Audiology, 15(2), 114-126. doi:10.1044/1059-0889(2006/015)

Schalock, R. L., \& Verdugo, M. Á. (2007). El concepto de calidad de vida en los servicios y apoyos para personas con discapacidad intelectual. Siglo Cero, 38, 21-36.

Schalock, R. L., \& Verdugo, M. A. (2003). Calidad de vida: manual para profesionales de la educación, salud y servicios sociales. Madrid: Alianza editorial.

Scherer, M. (1993). What we know about women's technology, use, avoidance, and abandonment. Women and Therapy, 14(3/4), 117-132.

Scherer, M. J. (1998). Matching Person \& Technology. A Series of Assessments for Evaluating Predispositions to and Outcomes of Technology Use in Rehabilitation, Education, the Workplace \& Other Settings. Webster, NY: The Institute for Matching Person \& Technology, Inc.

Scherer, M. J. (1998). Characteristics of a meaningful outcome assessment. RESNA resource guide for assistive technology outcomes: Measurement tools, 1, 50-59.

Scherer M., J., (2002). Assistive technology: Matching deviceand consumer for successful rehabilitation. Washington, DC: American Psychological Association.

Scherer, M. J. (2005). The matching person \& technology (MPT) model manual and assessments [CD-ROM]. The Institute for Matching Person \& Technology, Webster, NY, b4.

Scherer, M. J. (2007). A framework for modeling the selection of assistive technology devices (ATDs). Assistive technology, 2(1), 1-8.

Scherer, M., J., \& Craddock, G., (2002). Matching Person \& Technology (MPT) assessment process. Technology Disability, (14), 125-131.

Scherer, M. J., \& Cushman, M. (2001). Measuring subjective quality of life following spinal cord injury: a validation study of the assistive technology device predisposition assessment. Disability and Rehabilitation, 23(9), 387-393. 
Scherer, M. J., Federici, S., Tiberio, L., Pigliautile, M., Corradi, F., \& Meloni, F. (2012). ICF core set for matching older adults with dementia and technology.Ageing International, 37(4), 414-440. doi:10.1007/s12126-010-9093-9

Scherer, M. J. \& Glueckauf, R. (2005). Assessing the benefits of assistive technology for activities and participation. Rehabitation Psychology, 50,132-141. doi:10.1037/00905550.50 .2 .132

Scherer, M., \& Jutai, J. (2007). A framework for modeling the selection of assistive technology devices (ATDs). Disability and Rehabilitation. Assistive technology, 2(1), $1-8$.

Scherer, M. J., Medwetsky, L., \& Frisina, R. D. (2005) The Hearing Technology Predisposition Assessment (HTPA). Recuperado desde http://www.audiologyonline.com/articles/hearing-technology-predispositionassessment-htpa-1025

Scherer, M. J., Sax, C. L., \& Glueckauf, R. L. (2005). Activities and Participation: The Need to Include Assistive Technology in Rehabilitation Counselor Education. Rehabilitation Education, 19(2-3), 177-190.

Scherer, M. J., Sax, C., Vanbiervliet, A., Cushman, L.A., \& Scherer, J.V. (2005). Predictors of assistive technology use: the importance of personal and psychosocial factors. Disability and Rehabilitation, 27(21), 1321-1331.

Scherer, M. J., \& Vitaliti, L. T. (1997). A functional approach to technological factors and their assessment in rehabilitation. In S.S. Dittmar \& G.E. Gresham: Functional assessment and outcome measures for the rehabilitation professional. Gaithersburg, MD: Aspen.

Scheetz, N. A. (2004). Psychosocial aspects of deafness. Deafness \& Education International. 7 (4), 224-225.

Scheetz, N. A. (2004). Psychosocial Aspects of Deafness. Boston: Allyn and Bacon.

Scheuringer, M., Stucki, G., Huber, E. O., Brach, M., Schwarzkopf, S. R., Kostanjsek, N., \& Stoll, T. (2005). ICF Core Set for patients with musculoskeletal conditions in early post-acute rehabilitation facilities. Disability and Rehabilitation, 27(7-8), 405-410.

Schlehofer, D., Ross, D.S.(2010) Presented at Women's Health 2010: The 18th Annual Congress, Washington, DCMarch.

Schowe, B. M. (1979). Identity Crisis in Deafness - A humanistic perspective. Tempe, Arizona: The Scholars Press.

Schwartzman, J.A. (2002). Historia del implante coclear. Revista Integración, 22. 
Sechrest, L.B., West, S.G., Phillips, M.A., Redner R., \& Yeaton, W. (1979). Some neglected problems in evaluation research: Strengh and integrity of treatments. In L. Sechrest, S. G. West, M. A. Philips, R. Redner \& W. Yeaton (Eds.): Evaluation studies: Review Annual (Vol. 4) (pp. 15-35). Beverly Hills: Sage.

Seniors ResearchGroup. (1999). The consequences of untreated hearing loss in older persons. Washington, DC: The National Council on the Aging.

Senghas, R. J., \& Monaghan, L. (2002). SIGNS OF THEIR TIMES: Deaf Communities and the Culture of Language. Annual Review of Anthropology, 31(1), 69-97. doi:10.1146/annurev.anthro.31.020402.101302

Sneed, S. \& Joss, D. (1999). Deafness and hearing loss - a global health problem. Work: A Journal of Prevention, Assessment and Rehabilitation, 12, 93-101.

Sharp, D.L., Borelli, B., Sepinwall, D., Bellg, A.J., Breger, R., \& DeFrancesco, C. (2005). A new tool to assess treatment fidelity and evaluation of treatment fidelity across 10 years of health behavior research. Journal of Consulting and Clinical Psychology, 73(5), 852860.

Shinn, M. M. (2013). Parent-Child Interaction Therapy With a Deaf and Hard of Hearing Family. Clinical Case Studies, 12(6), 411-427. doi:10.1177/1534650113500065

Shoham, S., \& Heber, M. (2012). Characteristics of a virtual community for individuals who are d/deaf and hard of hearing. American Annals of the Deaf, 157(3), 251-263. doi:10.1353/aad.2012.1625

Shoemaker, L. L., Lenker, J. A., Fuhrer, M. J., Jutai, J. W., Demers, L. \& DeRuyter, F. (2009). Development and evaluation of a new taxonomy of mobility-related assistive technology devices. American Journal of Physical Medicine \& Rehabilitation, 89(10), 795-808. doi:10.1097/PHM.0b013e3181f1bbcd

SingTalk America LLC. (2005). Helping the deaf communicate. http://www.signtalkamerica.com

Sladen, D. P., \& Zappler, A. (2015). Older and YoungerAdultCochlearImplantUsers: SpeechRecognition in Quiet and Noise, Quality of Life, and Music Perception. American journal of audiology, 24(1), 31-39.

Sloboda, J. A., Wise, K. J., \& Peretz, I. (2005). Quantifying tone deafness in the general population. Annals of the New York Academy of Sciences, 1060(1), 255-261. doi:10.1196/annals.1360.018

Smith, O.(1996). Measuring the outcome of assistive technology: Challenge and innovation. Assistive Technology, 8, 71-81. 
Smeeth, L., Fletcher, A., Stirling, S., Nunes, M., Breeze, E., \& Tulloch, A. (2002). Reduced hearing, ownership, and use of hearing aids in elderly people in the UK-the MRC Trial of the Assessment and Management of Older People in the Community: a crosssectional survey. The Lancet, 359(9316), 1466-1470.

Smith, R. (2002). OTFACT: Multi-level performance-oriented software with an assistive technology outcomes assessment protocol. Technology and Disability, 14, 133 - 139.

Smith, R.O, Jansen, C.J., Seitz, J., \& Longenecker, K (2007). ATOMS Project Technical Report: The ICF in the context of assistive technology (AT) interventions and outcome [Online] Available at:http://www.r2d2.uwm.edu/atoms/archive/icf.html

Sneed, S., \& Joss, D. (1999). Deafness and hearing loss-a global health problem. Work, 12(1), 93-101.

Sofaer, S. (2002). Qualitative research methods. International Journal for Quality in Health Care, 14(4), 329-336.

Solheim, J., Kværner, K. J., \& Falkenberg, E. S. (2011). Daily life consequences of hearing loss in the elderly. Disability and rehabilitation, 33(22-23), 2179-2185. doi: $10.3109 / 09638288.2011 .563815$

Soreira, F. M. (2008). La cantidad a manos llenas. La expresión de la cuantificación en la lengua de signos española. CIUDAD: CNSE

Sorenson Communications (2005). Sorensoon VRS (video relay services). http://www.sorensonvrs.com

Southall, K., Gagné, J. P., \& Leroux, T. (2006). Factors that influence the use of assistance technologies by older adults who have a hearing loss. International Journal of Audiology, 45(4), 252-259. doi:10.1080/14992020500258586

Souza, A., Kelleher, A., Cooper, R., Cooper, R. A., Iezzoni, L. I., \& Collins, D. M. (2010). Multiple sclerosis and mobility-related assistive technology: systematic review of literature. Journal Of Rehabilitation Research And Development, 47(3), 213223.doi:10.1682/JRRD.2009.07.0096

Spencer, L. J., Barker, B. A., \& Tomblin, J. B. (2003). Exploring the language and literacy outcomes of pediatric cochlear implant users. Ear and hearing, 24(3), 236-247. doi: 10.1097/01.AUD.0000069231.72244.94

Spencer, P., \& Marschark, M. (2003). Cochlear implants. In M. Marschark \& P. Spencer: Oxford handbook of deaf studies, language, and education, (pp. 434-448). New York: Oxford 
Spencer, L. J., Tomblin, J. B., \& Gantz, B. J. (2012). Growing up with a cochlear implant: Education, vocation, and affiliation. Journal of Deaf Studies and Deaf Education, 17(4), 483-498.

Spicer, D. (2009). Deaf awareness for communicators-Exploring how to improve the experience of those with hearing impairments. Communicator, 18.

Spicer, J., Schmidt, R., Ward, C. D., \& Pinnington, L. L. (2005). Evaluation of text telephones designed for people with impaired hearing or speech. Journal of medical engineering \& technology, 29(3), 137-144. doi:10.1080/030919005000067769

Spencer, L. J., Barker, B. A, \& Tomblin, J. B. (2003) Exploring the language and literacy outcomes of pediatric cochlear implant users. Ear and Hearing 24(3): 236-247. doi:10.1097/01.AUD.0000069231.72244.94

Stanney, K.M, \& Maxey, J. (1997). Socially centered design. In G. Salvendy (Ed.): Handbook of Human Factors and Ergonomics (pp. 637-656). New York: Wiley.

Steel, E., Gelderblom, G. J., \& de Witte, L. P. (2011). Development of an AT selection tool using the ICF model. Technology and Disability, 23(1), 1-6.

Steel, D. M., \& Gray, M. A. (2009). Baby boomers' use and perception of recommended assistive technology: A systematic review. Disability and Rehabilitation: Assistive Technology, 4(3), 129-136. doi: 10.1080/17483100902767175

Stein, J. (2013). Review of Assistive technologies and other supports for people with brain impairment. Cognitive and Behavioral Neurology, 26(3), 167-167. doi: 10.1097/WNN.0b013e31829795bc

Steinberg, A. G., Barnett, S., Meador, H. E., Wiggins, E. A., \& Zazove, P. (2006). Health care system accessibility: Experiences and perceptions of deaf people. Journal of General Internal Medicine, 21(3), 260-266. doi:10.1111/j.1525-1497.2006.00340.x

Stewart, D. (2002). The new ICF: international classification of functioning, disability and health. Concepts and implementation issues for occupational therapists. Occupational Therapy Now, 4(4), 17-21.

Stinson, M., Chase, K., \& Kluwin, T. (1990). Self-perceptions of social relationships in hearing-impaired adolescents. Boston, MA: Paper presented at the convention of the American Educational Research Association.

Stinson, M., \& Kluwi, T. (2003). Educational consequences of alterative school placements. In M. Marschark \& P. Spencer: Oxford Handbook of Deaf Studies, Language, and Education (pp. 52-64). New York: Oxford University Press. 
Stinson, M., \& Lang, H. (1994). Full inclusion: A path for integration or insolation? American Annals of the Deaf, 139, 156-159.

Stinson, M., \& Whitmire, K. (1992). Students' view of their social relationships. In T.Kluwein, D. Moores, \& M. Gaustad: Toward effective public programs for deaf students: Context, process, and outcomes (pp. 149-174). New York: Teachers College Press.

Stinson, M., Whitmire, K., \& Kluwin, T. (1996). Self-perceptions of social relationships in hearing-impaired adolescents. Journal of Education Psychology, 88(1), 132-143.

Stokoe, W.C. (1960). Sign Language Structure. Studies in linguistic: occasional papers. Buffalo. Universtiy of Buffalo.

Stokoe, W.C. (1974). Classification and description of sign language. Current trends in linguistic. In T. A. Sebeok (Ed.): Current trends in linguistic. The Hague. Mouton

Stucki, G., Ewert, T., \& Cieza, A. (2002). Value and application of the ICF in rehabilitation medicine. Disability and rehabilitation, 24(17), 932-938. doi:10.1080/09638280210148594

Stucki, G., Üstün, T. B., \& Melvin, J. (2005). Applying the ICF for the acute hospital and early post-acute rehabilitation facilities. Disability and rehabilitation, 27(7-8), 349-352. doi:10.1080/09638280400013941

Svirsky, M., Robbins, A., Kirk, K., Pisoni, D., \& Miyamoto, R. (2000). Language development in profoundly deaf children with cochlear implants. Psychological Science, 11, 153-158. doi:10.1111/1467-9280.00231

Swedish Institute of Assistive Technology (2010). The Heart Study.

Switzer, M. E., \& Williams, B. R. (1967). Life Problems of Deaf People: Prevention and Treatment. Archives of Environmental Health: An International Journal, 15(2), 249256.

Talha, K. S., Wan, K., Za'ba, S. K., Razlan, Z. M., \& Shahriman, A. B. (2013). Speech Analysis Based On Image Information from Lip Movement. IOP Conference Series: Materials Science and Engineering, 53, 012016. doi:10.1088/1757-899X/53/1/012016

Tamblay N, Natalia, Villalobos A, Iván, Pastene G, Alejandro, \& Rahal E, Maritza. (2008). Impacto social del uso de audífonos en adultos mayores. Revista de otorrinolaringología y cirugía de cabeza y cuello, 68(1), 21-26.

Tambs, K. (2004). Moderate effects of hearing loss on mental health and subjective wellbeing: results from the Nord-Trøndelag Hearing Loss Study. Psychosomatic Medicine, 66(5), 776-782. doi:10.1097/01.psy.0000133328.03596.fb 
The American Occupational Therapy Association. (2002).About Occupational Therapy. The Institute for Matching Person \& Technology (2010). Matching Person and Technology Thomas, C., Cromwell, J., \& Miller, H. (2006). Community Mental Health Teams' perspectives on providing care for Deaf people with severe mental illness. Journal of Mental Health, 15(3), 301-313. doi:10.1080/09638230600700300

Thornberry, D. (2004). Connecting to learn--educational \& assistive technology for people with disabilities (Book). Disability \& Rehabilitation, 26(11), 686-686.

Tinetti, M., Baker, D., Gottschalk, M., Williams, C. , Pollack, D. \& Garrett, P. (1999). Homebased multicomponent rehabilitation program for older persons after hip fracture: a randomized trial. Archives of Physical Medicine and Rehabilitation, 80(8), 916-922.

Tomita, M., Mann, W. C., \& Welch, T. R. (2001). Use of assistive devices to address hearing impairment by older persons with disabilities. International Journal of Rehabilitation Research, 24(4), 279-290.

Tong, A., Sainsbury, P., \& Craig, J. (2007). Consolidated criteria for reporting qualitative research (COREQ): a 32-item checklist for interviews and focus groups. International Journal for Quality in Health Care, 19(6), 349-357. doi:10.1093/intghc/mzm042

Torrijo, M. L. (2005). La educación de las personas con sordera: la Escuela Oralista española (No. 43). Universitat de València.

Trachtman, L. H. (1991). A review of practices among information resource programs on assistive technology. Assistive Technology: The Official Journal Of RESNA, 3(2), 5966.

Trefler, E., \& Crislip, D. (1985). No aid, an Etran, a Minspeak: A comparison of efficiency and effectiveness during structured use. Augmentative and Alternative Communication, 1, 151-155.

Trindade, D. Guimarães, C., Antunes, D., da Silva, R., García, L., \& Fernandes, S. (2013). Communication and cooperation pragmatism: Ananalysis of a community of practiceby non-deaf and deaf to study sign language. In M. D. Lytras et al.: Knowledge Management, Information Systems, E-learning, and Knowledge Management Research, (pp. 191-205). Springer Berlin Heidelberg.

Troya, F. G. (1998). Bilingüismo y biculturalismo en la educación del niño sordo. Concepto, bases que lo sustentan y tendencias actuales. Revista de Logopedia, Foniatría y Audiología, 18(2), 75-84. 
Tsai, E., \& Fung, L. (2005). Perceived constraints to leisure time physical activity participation of students with hearing impairment. Therapeutic Recreation Journal, 39(3), 192-206.

Tucker, B. P. (1998). Deaf culture, cochlear implants, and elective disability. Hastings Center Report, 28(4), 6-14.

Tung, J. Y., Stead, B., Mann, W., Pham, B., \& Popovic, M. R. (2015). Assistive technologies for self-managed pressure ulcer prevention in spinal cord injury: A scoping review. Journal of Rehabilitation Research \& Development, 52(2), 131-145. doi: 10.1682/JRRD.2014.02.0064

Tuntland, H., Kjeker, I., Nordheim, I., Falzon,L., Jamtuedt, G. \& Hagen, K. (2010). The Chrane review of Assistive Technology for rheumatoid arthritis. European Journal Physical Rehabilitation, 46, 261-268.

Turner-Smith, A., \& Devlin, A. (2005). E-learning for assistive technology professionals--a review of the TELEMATE project. Medical Engineering \& Physics, 27(7), 561-570.

Tye-Murray N., Tyler R.S., \&Woodworth G.G. (1992) Performance over time with a nucleus or ineraid cochlear implant. Ear Hear, 13, 200-209.

Tye-Murray, N., Spencer, L., \& Woodworth, G., G. (1995) Acquisition of speech by children who have prolonged cochlear implant experience. Journal of Speech and Hearing Research, 38, 327-337.

Uhlmann, R. F., Larson, E. B., Rees, T. S., Koepsell, T. D., \& Duckert, L. G. (1989). Relationship of hearingimpairment to dementia and cognitivedysfunction in olderadults. JAMA, 261(13), 1916-1919.

United Nations (2006). Convention on the Rights of People with Disabilities [Online], Article 26-Habilitation and Rehabilitation.

Vanderheiden, G., \& Kelso, D. (1987). Comparative analysis of fixed-vocabulary communication acceleration techniques. Augmentative and Alternative Communication, 3(4), 196-206.

Van Hoesel, R. J. (2012). Contrasting benefits from contralateral implants and hearing aids in cochlear implant users. Hearing Research, 288, 100-113.

doi: 10.1016/j.heares.2011.11.014

Van Naarden Braun, K., Yeargin-Allsopp, M. \& Lollar, P. (2006). Factors associated with leisure activity among young adults with developmental disabilities. Research in Developmental Disabilities, 27, 567-583.doi: 10.1016/j.ridd.2005.05.008 
Velasco, C. \& Perez., I. (2009). Sistemas y recursos de apoyo a la comunicación y al lenguaje de los alumnos sordos. Revista Latinoamericana de educación inclusiva, 3(1), 77-93.

Vermeire, K., Brokx, J. P., Wuyts, F. L., Cochet, E., Hofkens, A., \& Van de Heyning, P. H. (2005). Quality-of-life benefit from cochlear implantation in the elderly. Otology \& Neurotology, 26(2), 188-195.

Verza, R., Carvalho, M. L., Battaglia, M. A., \& Uccelli, M.(2006) An interdisciplinary approach to evaluating the need for assistive technology reduces equipment abandonment. Multiple Sclerosis, 12, 88-93.

Viader, M., \& Pertusa, E. (1996). Reflexiones sobre la escritura y la alfabetización de los niños sordos. Revista de Logopedia, Foniatría y Audiología, 16(2), 79-85.

Viedma, A. (2009). Entrevistas. En J. Callejo, \& A. Viedma: Introducción a las Técnicas de Investigación Social. Madrid: UNED.

Vincent, C., Deaudelin, I., \& Hotton, M. (2007). Pilot on evaluating social participation following the use of an assistive technology designed to facilitate face-to-face communication between deaf and hearing persons. Technology and Disability, 19(4), 153-167.

Waa. Proyecto EASTIN (2005). Red europea de información sobre las tecnologías para la discapacidad y la autonomía. Minusval, 153, 17-34.

Wang, J. (2013). Bilingual working memory capacity of professional Auslan / English interpreters. Interpreting, 15(2), 139-167. doi:10.1075/intp.15.2.01wan

Warnicke, C..\& Plejert, C. (2012). Turn-organisation in mediated phone interaction using Video Relay Service (VRS). Journal of Pragmatics,44, 1313-

1334.doi:10.1016/j.pragma.2012.06.004

Washington, D.C.: Gallaudet University Press. Troubleshooting of Cochlear Implants for Children. Top Language Disorders, 23(1), 46-56.

Wehmeyer, J. (2014). Eye-tracking deaf and hearing viewing of sign language interpreted news broadcasts. Journal of Eye Movement Research, 7(1), 1-16.

Wehmeyer, M.L., Smith, S.J., Palmer, S.B \& Davies, D.K (2004). Technology use by students with intellectual disabilities: an Overview. Journal of Special Education Technology, 19(4), 7-21.

Werngren-Elgström, M., Iwarsson, S., Elmståhl, S., \& Dehlin, O. (2005). ADL dependence and perceived health among elderly deaf sign-language users: A comparison with a matched group of elderly hearing people. Scandinavian Journal of Occupational Therapy, 12(2), 81-88. doi:10.1080/11038120510031743 
Weiss-Lambrou, R., Tremblay, C., LeBlanc, R., Lacoste, M., \& Dansereau, J. (1999). Wheelchair seating aids: How satisfied are consumers? Assistive Technology, 11, 4253.

Wessels, R., de Witte, L., Andrich, R., Ferrario, M., Persson, J., \& Oberg, B., (2000). IPPA, a user-centred approach to assess effectiveness of assistive technology provision. Technoloy Disability, 13,105-115.

Wheeler, A., Archbold, S., Gregor, S., \& Skipp, A. (2007). Cochlear implants: The young people's perspective. Journal of Deaf Studies and Deaf Education, 12(3), 303-316.

Whiteneck, G. \& Dijkers, M. P. (2009). Difficult to measure constructs: conceptual and methodological issues concerning participation and environmental factors. Archives of Physical Medicine and Rehabilitation, 90 (11 suppl), S22-35.

Wielandt, T., \& Strong, J. (2000). Compliance with prescribed adaptive equipment: A literature review. The British Journal of Occupational Therapy, 63(2),65-75.

Wielandt, T. \& Scherer, M.,J.(2004). Reducing AT abandonment: Proposed principles for AT selection and recommendation [Online]. Available at: http://www.ebility.com/articles/at_selection.php

Wilcock, A. (2003). Making sense of what people do: Historical perspectives. Journal of Occupational Science, 10 (1), 4-6.

Wilcock, A., \& Townsend, E. (2000). Occupational terminology interactive dialogue: Occupational justice. Journal of Occupational Science, 7(2), 84-86.

Williams, W., B., Stemach, G., Wolfe, S., Stanger, C. (1995). Lifespace access profile: Assistive technology assessment and planning for individuals with severe or multiple disabilities. Lifespace Access Assistive Technology Systems.

Williger, B., \& Lang, F. R. (2015). Hearing Aid Use in Everyday Life: Managing Contextual Variability. Gerontology, 61(2), 158-165. doi:10.1159/000366062

Wisconsin Assistive Technology Initiative (1998). Assessing students' needs for assistive technology: A resource manual for school district teams. Wisconsin Assistive Technology Initiative.

Witte T., \& Kuzel, A. (2000).Elderly deaf patients' heath care experiences. Journal of the American Board of Family Practice 2000; 13(1), 17-22.

Wolfe, J., Schafer, E., Parkinson, A., John, A., Hudson, M., Wheeler, J., \& Mucci, A. (2013). Effects of input processing and type of personal frequency modulation system on 
speech-recognition performance of adults with cochlear implants. Ear and hearing, 34(1), 52-62.

Wood, S. A., \& Lutman, M. E. (2004). Relativebenefits of linear analogue and advanced digital hearingaids. International Journal of Audiology, 43(3), 144-155.

Woodward, J.(1972). Implications for sociolinguistic research among the deaf. Sign Language Studies 1, 1-7.

World Federation of Occupational Therapists. (2010) WFOT Information: What is Occupatioal Therapy?

World Health Organization. (2001). ICF: International classification of functioning, disability, and health. Geneva.

Wu, Y. \& Bentler, R. (2012) Do older adults have social lifestyles that place fewer demands on hearing? Journal of the American Academy of Audiology, (23)9, 697-711. Doi: 10.3766/jaaa.23.9.4.

Yamada, M., Nishiwaki, Y., Michikawa, T., \& Takebayashi, T. (2012). Self-Reported Hearing Loss in Older Adults Is Associated with Future Decline in Instrumental Activities of Daily Living but Not in Social Participation. Journal of the American Geriatrics Society, 60(7), 1304-1309.

Yeagle, J. D., Ceh, K. M., \& Francis, H. W.(2010). Geriatric cochlear implantation. Operative Techniques in Otolaryngology-Head and Neck Surgery, 21(4), 266-271.

Yen, T. H., Liou, T. H., Chang, K. H., Wu, N. N., Chou, L. C., \& Chen, H. C. (2014). Systematic review of ICF core set from 2001 to 2012. Disability and rehabilitation, 36(3), 177-184.

Yorkston, K. M. (1992). Treatment EfficacyDysarthria. Journal of Speech, Language, and Hearing Research, 39(5), 46-57.

Young, G., \& Killen, D. (2002) Receptive and expressive language skills of children with five years of experience using a cochlear implant. Annals of Otology Rhinology and Laryngology, 111, 802-810.

Zabala, J. S. (1995). The SETT framework: critical areas to consider when making informed assistive technology decisions. Houston, TX: Region IV Education Service Center.

Zabala, J. S. (1996). SETTing the stage for success: Building success through effective use of assistive technology. Proceedings of the Southeast Augmentative Communication Conference (pp. 129-187). Birmingham, AL: United Cerebral Palsy of Greater Birmingham. Recuperado el 25 de octubre de 2004 desde http://www.joyzabala.com. 
Zahedi, M., Mashal, H., \&Salehi, S. M. (2011). An online community for the deaf. Procedia Computer Science, 3, 1089-1093. doi:10.1016/j.procs.2010.12.177

Zahid, A., \& Boyle, B. (2013). Using impact measurement to establish confidence in emergent assistive technology services - First phase translation of the PIADS outcome measurement tool for implementation in an arabic context. In Assistive Technology Research Series (Vol. 33, pp. 1071-1077).

Zand, D. H., \& Pierce, K. J. (Eds.). (2011). Resilience in deaf children: adaptation through emerging adulthood. New York: Springer. doi:10.1007/978-1-4419-7796-0

Zhao, F., Bai, Z., \& Stephens, D. (2008). The relationship between changes in self-rated quality of life after cochlear implantation and changes in individual complaints. Clinical Otolaryngology, 33(5), 427-434.

Zohdi, I., AbdelMessih, M. W., El Shennawy, A. M., Badreldin, B. M., \& Ashour, G. (2014). Statistical Analysis of Various Factors Affecting the Results of Cochlear Implantation. Journal of International Advanced Otology, 10(2), 118-123. doi:10.5152/iao.2014.33

Zola, I. K. (1993). Self, identity and the naming question: reflections on the language of disability. Social Science \& Medicine, 36(2), 167-173. 


\section{ANEXO I: CUESTIONARIO DE NUEVAS TECNOLOGÍAS}

CUESTIONARIO SOBRE LAS NUEVAS TECNOLOGÍAS- SVISUAL 
Por favor, conteste a tods las presuntes aunque le resulten algungs de elos extrahas. Graclas por wu colsboración.

Género
I Mujer
I Wardon

Ind que su eded.

¿En qué cludad/provincla vive?

LQué kengua usa habituglmente?

$\Gamma$ Lengus de signos

$\Gamma$ Lengus orial

I Ambas

Indique el mamento de la pérdida auditiva "Prelacutiva lantes de las tres aflas a adquisiclón del lengusle arall a postlocutivo [despues de los 3 aflos de edod o después de adquirir el lenguse arall

IT Prelocutho

I Postlocutivo

Indlque el grado de pêrdida auditha "Hposcusila [eonserva restos auditivas) o cofosis [péridida total de audición]

r. Hipoacusia

¿que grado de discapacldad tiene recanocido?

Su domiclla habitual se encuentra ubicado en... "Urbano (cludad] y rural (pueblo)

F Entorno urbano

5 Entorno rural 
¿Qué estudias tiene finalizados?

C Elemental CActuaimente, E.s.o)

C Bachillerato

C clelo grado medio

5 colo erada superior

f Untwersidad

5 Máster/Doctorado

5 otra:

¿Conoce $\gamma$ usa productos consideradoi nuevas teconologias? "Entendiendo nuevas tecnalogias comac informática, internet $\gamma$ las telecomunicociones imóvi...]

C si

C $\mathrm{NO}$

De la slouiente lista marque las productos que usa y manejo adecusdamente de forma habitual

$\Gamma$ internet

$\Gamma$ Redes sociales: uhype

$\Gamma$ Móvel

$\Gamma_{\text {svisual }}$

$\Gamma$ Oovoc

$\Gamma$ Audifono

$\Gamma$ implante coclear

$\Gamma$ Equipos FM

$\Gamma$ Bude maenético

$\Gamma$ otro: 
Usa tecnologias de video para comunicarse en qué casos: "Svisual, Dovoo, Skype, móvil.

I Hablar con amigos o familiares

$\Gamma$ Asuntos labarales

$\Gamma$ Asuntos educativos

$\Gamma$ Servicios santarios

$\Gamma$ otro:

Antes cuando no habis videos de intermediacion y necesitabs realizar una llamada usaba:

( Teléfono senallo (sin ningún tipo de adaptacián)

C Drs

C. Pedia a otra persona que realizase la llamoda

Con un intêrprete como mediador

- otra:

¿Conoce el Svaual? "Svesual: serviclo de video interpretación
C si
C No

¿Utiliza el Swsual? "Swsual servicio de video interpretación

C. si

C NO 
ESCALA DE IMPACTO PSICOSOCIAL. DE PRODUCTOS DE APOYO.

Cada palabra o frase indlcada a continuaciön describe un aspecto del usuarlo que puede verse

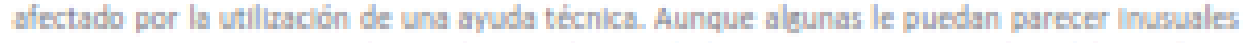
E Importante que responda sodes y cads una de las preguntas. Pars cads palabro o frose propuesta ponga una "X" en la casilla que refleje más adecusdamente el efecto producida por utillwar: Swsual (En caso de no utillwarlo responda al cuestlonarlo segin cree que le rucederia en los sigulentes aspectosil La exala se englobs en 7 puntuaciones skendo la menor -3 (ho duminuido) y la mogror 3 (ha aumentadol gradas al usa del Sysubl.

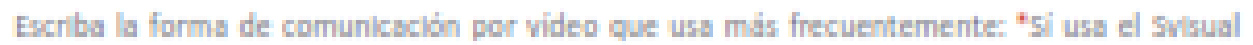
por fawor relene este cuestionario en base a esta herramienta. Gracias

$\Gamma$ Susud
$\Gamma$ gowoo
$\Gamma$ shpe
$\Gamma$ Movil
$\Gamma$ otro:

¿Con qué frecuencla usa el producto anterlomente marcsdo?

i Todas los diog

I Varlas veces al día

C 1 veza la semans

C $2 \cdot 3$ veces is la semans

C 1 ver al mes

if 2 -3 vects al mes

(1) Cadames

C. Cada $2-3$ meses

5 Nunca

otro:

Competencla. Capacidad para hacer bien las cosss Importantes que tiene que hacer en la vida.
(5) 3 Ho disminuldo
r -2
i -1
C olrual
C 1
C 2
(f) 3 Ha deumentado

Felicidad. "Estado de alegria y blenestur, semirse sat sfecho con la vids.

r 3 Ha disminuido 


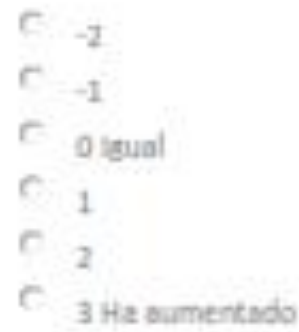

Independencia. "Que no depende, o necesite arvida externa, de alguien o de aleo constantemente

C. 3 Ha disminuido

$r-2$

$r-1$

C. Digual

e 1

C 2

P: 3 Ha cumestodo

Sentirse a la altura de las circunstoncias. Sentirse capaz de manejar las situaciones de la vida y las pequehas dificultades.

5 I Ha disminuido

C -2

$r-1$

r. o idual

C. 1

r. 2

C. 3 Ha oumentado

\section{Confusión. No poder pensar claramente o no poder actusr con decisión}
C. -3 Ha disminuirio
$r_{-2}$
C. -1
o. ImuI
r. 1
$\mathrm{r} 2$
c. 3 Ha aumentadn

Eficacia. Gestión eficaz de las tareas diarias.
$r-3$ Ha disminuido
$r \quad-2$
C -1
C. Digual 


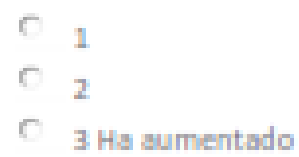

Autoestima. Sentimiento de estima y aerado hscia uno mismo como persona.

C -3 Ha disminuido

C -2

C -1

o oleual

C 1

C 2

C. 3 Ha aumentado

Productividad. Capaz de conseguir hacer más cosas en un día.

C $-3 \mathrm{Ha}$ disminuido

C -2

C -1

c oleual

C 1

C 2

r. $3 \mathrm{Ha}$ sumentado

Seguridad. Sentirse seguro en vez de vulnerable o inseguro.

C -3 Ha disminuido

C -2

C -1

o oleual

C 1

$\mathrm{C}_{2}$

C 3 Ha sumentado

Frustración. Sentimiento de desilusión e irritación por la falta de progreso en la consecución de sus deseos; sentirse decepcionado.
C. -3 Ha disminuido
C -2
C -
5 o Igual
C 1
C 2
c $3 \mathrm{Ha}$ aumentado 
Sentirse útil. Sentirse de ayuda para Vd. mismo y para los demb́s; consigue hacer las cosas.

C . $3 \mathrm{Ha}$ disminuido

C -2

C -1

C o ligual

C 1

C 2

C. 3 Ha sumentado

Confianza en sí mismo. Sentirse sezuro y confiado en uno mismo como persona y en sus capacidades.
C. -3 Ha disminuido
C -2
C -1
C olrual
C 1
$\mathrm{C}_{2}$
C. 3 Ha sumentsdo

Pericia. Tener los conocimientos requeridos en un área u ocupación.

C. -3 Ha disminuido

C -2

C -1

C olgual

r 1

C 2

C. 3 Ha sumentado

Aptitud. Sentirse capaz y dispuesto a demostrar sus conocimientos realizando bien las cosas.
C -3 Ha disminuldo
C -2
C -1
C o irual
C 1
C 2
C 3 Ha sumentado

Bienestar. Sentirse a zusto, bien, optimista acerca de su vida y su futuro.

C. $-3 \mathrm{Ha}$ disminuido 


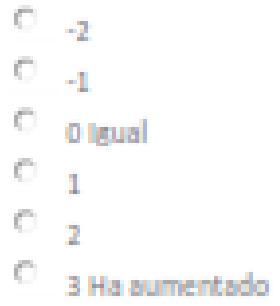

Sentirse capaz. Sentirse en mejores condiciones para poder hacer aleo; sentirse más apto.

C. -3 Ha disminuido

C -2

C -1

o o igual

C 1

C 2

C. 3 Ha sumentado

Calidad de vida. Grado de satisfacción con su vida.

C. -3 Ha disminuido

C -2

C -1

o o igual

C 1

C 2

(5) 3 Ha sumentado

Realización. Posibiidad de aplicar sus conocimientos y capacidades en la reslización de las taress u actividades.

C. 3 Ha disminuido

C -2

C.-1

o o igual

C 1

ก 2

C. 3 Ha sumentado

Sensación de poder. Sensación de fuerza interior; sentir que vd. tiene una influencis significativa sobre su propia vida.

C. -3 Ha disminuido

C. -2

C -1

o olgual 


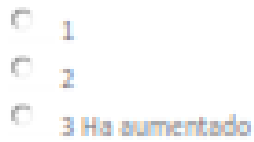

Sensación de control. Sentirse capar de poder hacer lo que quiere, dentro de su entomo

C. -3 Ha disminuido

C -2

C -1

C oleual

C 1

$\mathrm{C}_{2}$

C 3 Ha sumentado

\section{Sentirse a disgusto .Torpe, incómodo o avergontado}

C -3 Ha disminuldo

C -2

C -1

C o irual

$C_{1}$

$\mathrm{C}_{2}$

C. 3 Ha sumentado

Dispuesto a darse oportunidades. Sentirse dispuesto a ssumir algunos riesgos y a aceptar nuevos retos

(C) -3 Ha disminuido

C -2

C -1

c o leual

C 1

C 2

C. 3 Ha sumentado

Capacidad para participar. Capar de intervenir en actividades, junto con otras personas.

C -3 Ha disminuido

C -2

C - -1

Co oleual

( 1

$\mathrm{C}_{2}$

C. 3 Ha sumentado

Deseoso de probar nuevas cosas. Estar predispuesto a afrontar nuevas vivencias y aventuras. 


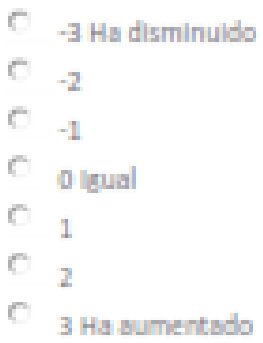

Capacidad para adaptarne a las actividades cotidlanan. Capacidad de afrontar los cambios capacidad de ser flexible reupecto al modo de rewlirar las tarean basicas para que le renulten mas manelables.

C. -3 Ha disminuido

C -2

C - -1

5 o leual

r 1

r 2

f 3 Ha sumentado

Capacidad para aprowechar las oportunidades. Disposición para actuar rópidamente y con seguridsd cuando hay alguns oportunidad de mejorar aleo en su vida.
C $-3 \mathrm{Ha}$ disminuido
C. -2
C -1
C oloual
(c) 1
(5) 2
(5) 3 Ha sumentado

\section{CUESTIONARIO SOBRE EL. USO DE TECNOLOGIAS}

Conteste todas las cuestiones marcando la opción que se aplique a usted con mayor exactitud. SI no está mury seguro acerca de la respuesta, eluja la categoria neutral.

1.- Tecnolagiss que usa con frecuencla: Enumere las tecnologiss que usa más frecuentemente (por ejemplo: ordenador, móvi...)

2.- Experiencias globales con las tecnologias utlltradas La evalusción es 1 siendo un valor positivo, 2 neutral y 3 un valor negativo 
$\begin{array}{lll}1 & 2 & 3\end{array}$

Son satisfactorias of C C Sen frustrantes

123

Apovan a mi creatividad $\mathrm{C} C \mathrm{C}$ interfieren con mil creatividad

123

Son estimulantes $r$ r $r$ sondesesperantes

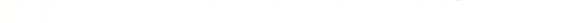

123

Son estimulantes of o sondesesperantes
123

Me acercan a la gente $r$ r $r$ Meseparan de la gente

123

Aumentan mi mutpestima $r$ i $\subset$ Bajan mi autoestima

3.- Perspectivas sobre tecnologias. La evaluocido es 1 - blendo un valor positiva, $z$ neutral $y 3$ un valor negativo

$\begin{array}{lll}1 & 2 & 3\end{array}$ 


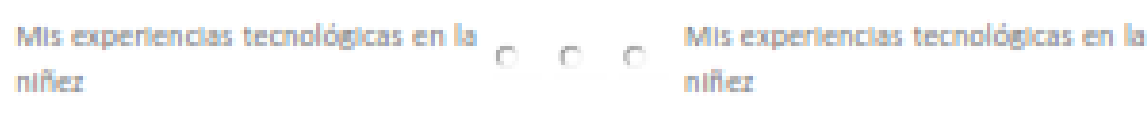

\section{3}

Mis experiencias tecnológicas en la escuela

Mis experiencias tecnológicas en la Mis experiend ss techolde cas en la

$1 \quad 2 \quad 3$

Mis experiencias tecnológicas en $\cap \cap \cap$ Mis experiencias tecnológicas en
casa

La evaluacion es 1 siendo un valor positivo, 2 neutral y 3 un valor negativo

$1 \quad 2 \quad 3$
Mis experienclas tecnológlcas más o $c$ o Mis experlencias tecnológlcas más recientes recientes

\section{$1 \quad 2 \quad 3$}

Estoy a gusto con la tecnologia $\cap \circ \cap$ Me intimida la tecnologia

\section{3}

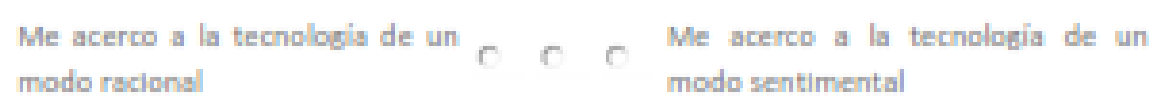




\begin{tabular}{|c|c|c|c|c|}
\hline $\begin{array}{l}\text { Me slento bien rodeado de } \\
\text { tecnologia }\end{array}$ & $r$ & $r$ & $r$ & $\begin{array}{l}\text { Slento ansledad rodeado de } \\
\text { tecnologia }\end{array}$ \\
\hline & 1 & 2 & 3 & \\
\hline $\begin{array}{l}\text { Otras personas me anliman a usar } \\
\text { tecnologia }\end{array}$ & $r$ & $r$ & 0 & $\begin{array}{l}\text { Otras personas me desaniman a } \\
\text { usar tecnologia }\end{array}$ \\
\hline & 1 & 2 & 3 & \\
\hline $\begin{array}{l}\text { Prefiero ser activo (deporte, } \\
\text { caminar..) }\end{array}$ & r & $c$ & $r$ & $\begin{array}{l}\text { Prefiero actividades pasivas } \\
\text { (lectura, TV) }\end{array}$ \\
\hline
\end{tabular}


La evaluacion es 1 siendo un valor positivo, 2 neutral y 3 un valor negativo

123

Prefiero actividades en grupo o $r \quad r$ Prefiero actividades en solitario

123

Mis actividades son satisfactorias $\subset \cap \cap$ Mis actividades son frustrantes

$1 \quad 2 \quad 3$

Regularmente busco $\mathrm{C} \cap \mathrm{C}$ Mis actividades no han camblado
actividades novedosas

4.- Caracteristicas personales/sociales "La evaluacion es 1 siendo un velor positivo, 2 neutral y 3 un valor negativo

\section{3}

Tranguilo/calmado $\mathrm{C} \cap$ Ansioso

$\begin{array}{lll}1 & 2 & 3\end{array}$

Feliz \& \& \& Depresivo

$\begin{array}{lll}1 & 2 & 3\end{array}$

Tolerante $C \quad C \quad C$ Enfadado of frustrado 
La evaluacion es 1 siendo un valor positivo, 2 neutral y 3 un valor negativo

$$
123
$$

Con experiencias positivas of \& $\odot$ Con perspectivas negativas

$$
123
$$

Expresivo/extravertido o $\mathrm{C}$ silencioso/retraido

$$
123
$$

Paclente $\mathrm{C}$ o $\mathrm{C}$ impaciente

$$
123
$$

Motivado \& $\mathrm{f}$ ( Desmotivado

$$
123
$$

Perseverante $\mathrm{C}$ o fácllmente desanimado

\author{
123
}

Soy una persona racional $r$ o $c$ soy una persona impulsiva 
La evaluacion es 1 siendo un valor positivo, 2 neutral y 3 un valor nezativo

\begin{tabular}{|c|c|c|c|}
\hline $\begin{array}{l}\text { Frecuentemente interactio con } \\
\text { amigos }\end{array}$ & $r$ & $n$ & $\begin{array}{l}\text { Casl nunca interactio con amigos / } \\
\text { no familiares }\end{array}$ \\
\hline
\end{tabular}

$\begin{array}{lll}1 & 2 & 3\end{array}$

Tenep uns buena sersación de r r r Tengo una pobre sensaciön de
bienestar

$\begin{array}{lll}1 & 2 & 3\end{array}$

Say fisicamente independiente $r$ r soy fialcamente dependiente

$\begin{array}{lll}1 & 2 & 3\end{array}$

Soy emocionalmente independiente $r \quad r \quad r$ soy emocionalmente dependiente 
ANEXO II: CUESTIONARIO DE AUDÍFONOS/I.C 
Cuestionario sobre los audífonos y otros productos de apoyo de amplificación.

Estimado Sr. / Sra.

gracias por su visita. Rellenando esta breve encuesta, nos ayudará a obtener los mejores resultados.

1. Género
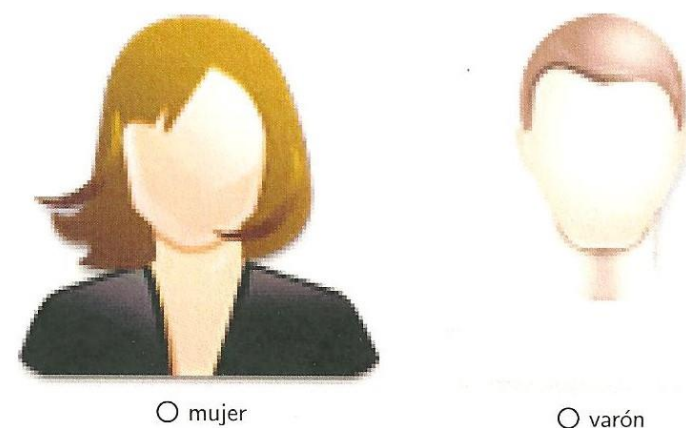

2. Indique su edad

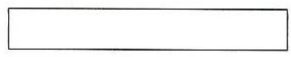

3. Su estado civil es:

O Soltero/soltera

O Casado/Casada

O Viudo/Viuda

O Otro

4. ¿Qué lengua usa habitualmente?
Lengua de signos
$O$ Lengua oral
O Ambas

¿Jsurvio Generado por Survio 
5. Indique el momento de la pérdida auditiva

Prelocutiva (antes de los tres años o adquisición del lenguaje oral) o postlocutiva (después de los 3 años de edad o después de adquirir el lenguaje oral)

Prelocutivo

Postlocutivo

6. ¿En qué provincia vive?

7. Indique el grado de pérdida auditiva

Hipoacusia (conserva restos auditivos) o cofosis (pérdida total de audición)

Hipoacusia

Cofosis

8. Su grado de pérdida es...
$\bigcirc$ Leve
Moderado
Severo
Profundo

9. Su domicilio habitual se encuentra ubicado en:

Urbano (ciudad) y rural (pueblo)

Urbano

Rural

10. ¿Qué estudios tiene finalizados?
Elemental
Bachillerato
Ciclo grado medio
Ciclo grado superior
$\bigcirc$ Universidad
Máster/Doctorado
Otros 
11. ¿Cónoce y usa productos denominados nuevas tecnologías ?

Entendiendo nuevas tecnologías como: informática, Internet y las telecomunicaciones (móvil...)

O Sí

No

12. ¿Usa audífono?

O Sí

No

13. ¿Qué tipo de audífono utiliza?

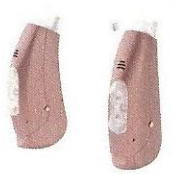

Retroauricular

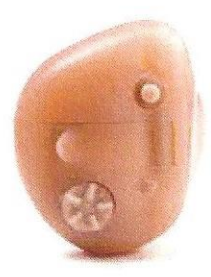

Intracanal

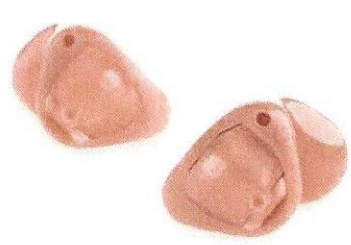

Otro

14. ¿En que situaciones usa los audífonos?

$\square$ Hablar con amigos o familiares

$\square$ Asuntos laborales

$\square$ Asuntos educativos

$\square$ Servicios sanitarios

$\square$ Actividades de ocio; ver la t.v, andar...

$\square$ Otra

15. ¿Con qué frecuencia usa el audifono?

Todos los días

Semanalmente

Mensualmente 
16. Cada palabra o frase indicada a continuación describe un aspecto del usuario que puede verse afectado por la utilización del audífono. Aunque algunas le puedan parecer inusuales es importante que responda a todas y cada una de las preguntas. Para cada palabra o frase propuesta marque la casilla que refleje más adecuadamente el efecto producido por utilizar el audífono.

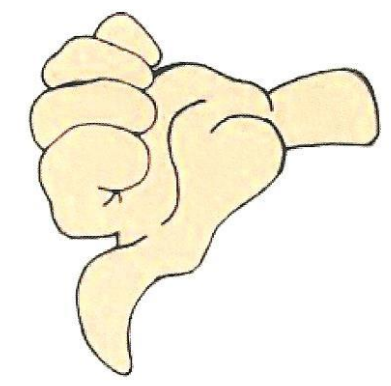

$\bigcirc$ Los valores negativos significan que con el uso del audífono ha disminuido

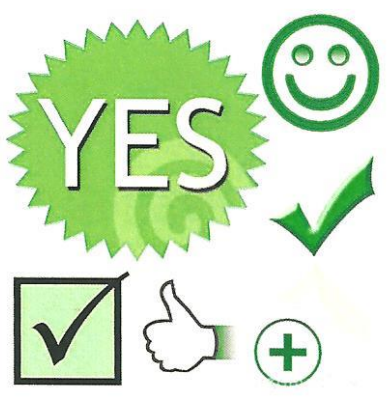

Los valores positivos significan que con el uso del audífomo ha aumentado

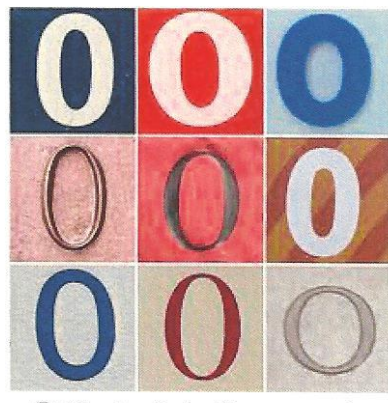

O El valor 0 significa que no ha habido ningún cambio con el uso de audífono

17. Al utilizar el audifono mi competencia ha:

Capacidad para hacer bien las cosas importantes que tiene que hacer en la vida.

\begin{tabular}{|c|c|c|c|c|c|c|c|}
\hline & $\begin{array}{c}-3 \mathrm{Ha} \\
\text { dis- } \\
\text { minuido }\end{array}$ & -2 & -1 & $\begin{array}{l}1 \mathrm{Ha} \text { au- } \\
\text { mentado } \\
\text { mucho }\end{array}$ & 1 & 2 & $\begin{array}{l}3 \mathrm{Ha} \text { au- } \\
\text { mentado }\end{array}$ \\
\hline Competencia & 0 & 0 & 0 & 0 & 0 & 0 & 0 \\
\hline
\end{tabular}

18. Al utilizar el audifono mi felicidad ha

Estado de alegría y bienestar; sentirse satisfecho con la vida.

\begin{tabular}{|c|c|c|c|c|c|c|}
\hline $\begin{array}{c}-3 \mathrm{Ha} \\
\text { dis- } \\
\text { minuido }\end{array}$ & -2 & -1 & Igual & 1 & 2 & $\begin{array}{l}3 \mathrm{Ha} \text { au- } \\
\text { mentado }\end{array}$ \\
\hline 0 & 0 & 0 & 0 & 0 & 0 & 0 \\
\hline
\end{tabular}

19. Al utilizar el audifono mi independencia ha

Que no depende, o necesita ayuda externa, de alguien o de algo constantemente.

\begin{tabular}{|c|c|c|c|c|c|c|}
\hline $\begin{array}{c}-3 \mathrm{Ha} \\
\text { dismin- } \\
\text { udo }\end{array}$ & -2 & -1 & Igual & 1 & 2 & $\begin{array}{l}3 \mathrm{Ha} \mathrm{au}- \\
\text { mentado }\end{array}$ \\
\hline 0 & 0 & 0 & 0 & 0 & 0 & 0 \\
\hline
\end{tabular}

Independencia 
20. Al utilizar el audifono mi competencia en sentirse a la altura de las circunstancias ha

Sentirse capaz de manejar las situaciones de la vida y las pequeñas dificultades.

\begin{tabular}{|c|c|c|c|c|c|c|c|}
\hline & $\begin{array}{l}-3 \mathrm{Ha} \\
\text { dis- } \\
\text { minuido }\end{array}$ & -2 & -1 & Igual & 1 & 2 & $\begin{array}{l}3 \mathrm{Ha} \text { au- } \\
\text { mentado }\end{array}$ \\
\hline $\begin{array}{l}\text { Sentirse a la altura de las cir- } \\
\text { cunstancias }\end{array}$ & 0 & 0 & $\mathrm{O}$ & 0 & 0 & 0 & 0 \\
\hline
\end{tabular}

21. Al utilizar el audifono mi confusión ha

No poder pensar claramente o no poder actuar con decisión.

$\begin{array}{ccccccc}\begin{array}{c}-3 \mathrm{Ha} \\ \text { dis- } \\ \text { minuido }\end{array} & -2 & -1 & \text { Igual } & 1 & 2 & \begin{array}{c}3 \mathrm{Ha} \text { au- } \\ \text { mentado }\end{array} \\ 0 & 0 & 0 & 0 & 0 & 0 & 0\end{array}$

22. Al utilizar el audifono mi eficacia ha

Gestión eficaz de las tareas diarias.

$\begin{array}{ccccccc}-3 \mathrm{Ha} \\ \begin{array}{c}\text { dis- } \\ \text { minuido }\end{array} & -2 & -1 & \text { lgual } & 1 & 2 & \begin{array}{l}3 \mathrm{Ha} \text { au- } \\ \text { mentado }\end{array}\end{array}$

23. Al utilizar el audifono mi autoestima ha

Sentimiento de estima y agrado hacia uno mismo como persona.

$\begin{array}{ccccccc}\begin{array}{c}-3 \mathrm{Ha} \\ \text { dis- } \\ \text { minuido }\end{array} & -2 & -1 & \text { Igual } & 1 & 2 & \begin{array}{c}3 \mathrm{Ha} \text { au- } \\ \text { mentado }\end{array} \\ 0 & 0 & 0 & 0 & 0 & 0 & 0\end{array}$

24. Al utilizar el audifono mi productividad ha

Capaz de conseguir hacer más cosas en un día.

\begin{tabular}{|c|c|c|c|c|c|c|c|}
\hline & $\begin{array}{c}-3 \mathrm{Ha} \\
\text { dis- } \\
\text { minuido }\end{array}$ & -2 & -1 & Igual & 1 & 2 & $\begin{array}{l}3 \mathrm{Ha} \text { au- } \\
\text { mentado }\end{array}$ \\
\hline roductividad & 0 & 0 & 0 & 0 & 0 & 0 & 0 \\
\hline
\end{tabular}


25. Al utilizar el audifono mi seguridad ha

Sentirse seguro en vez de vulnerable o inseguro.

$\begin{array}{ccccccc}-3 \mathrm{Ha} & & & & 3 \mathrm{Ha} \text { au- } \\ \text { dis- } & -2 & -1 & \text { Igual } & 1 & 2 & \text { mentado } \\ \text { minuido } & -2 & & \end{array}$

Seguridad

○ 0

o

$0 \quad 0$

O

O

26. Al utilizar el audifono mi frustración ha

Sentimiento de desilusión e irritación por la falta de progreso en la consecución de sus deseos; sentirse decepcionado.

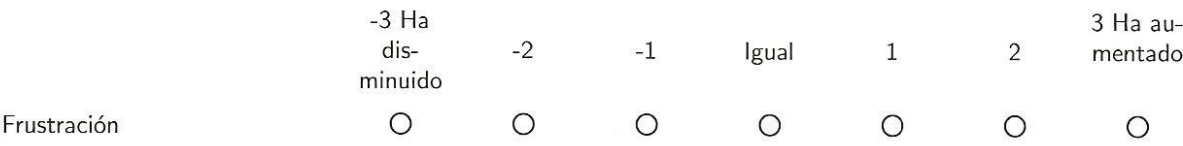

27. Al utilizar el audífono me siento más útil

Sentirse de ayuda para Vd. mismo y para los demás; consigue hacer las cosas.

$\begin{array}{ccccccc}\begin{array}{c}-3 \mathrm{Ha} \\ \text { dis- }\end{array} & -2 & -1 & \text { Igual } & 1 & 2 & \begin{array}{c}\text { 3. } \mathrm{Ha} \\ \text { aumen- } \\ \text { tado }\end{array}\end{array}$

Sentirse útil

○

28. Al utilizar el audífono mi confianza en mí mismo ha

Sentirse seguro y confiado en uno mismo como persona y en sus capacidades.

$\begin{array}{cccccccc} & \begin{array}{c}-3 \mathrm{Ha} \\ \text { dis- } \\ \text { minuido }\end{array} & -2 & -1 & \text { Igual } & 1 & 2 & \begin{array}{c}3 \mathrm{Ha} \text { au- } \\ \text { mentado }\end{array} \\ \text { Confianza en sí mismo } & 0 & 0 & 0 & 0 & 0 & 0 & 0\end{array}$

29. Al utilizar el audifono mi pericia ha

Tener los conocimientos requeridos en un área u ocupación.

\begin{tabular}{|c|c|c|c|c|c|c|c|}
\hline & $\begin{array}{l}-3 \mathrm{Ha} \\
\text { dis- } \\
\text { minuido }\end{array}$ & -2 & -1 & Igual & 1 & 2 & $\begin{array}{l}3 \mathrm{Ha} \text { au- } \\
\text { mentado }\end{array}$ \\
\hline Pericia & 0 & 0 & 0 & 0 & 0 & 0 & 0 \\
\hline
\end{tabular}


30. Al utilizar el audifono mi aptitud ha

Sentirse capaz y dispuesto a demostrar sus conocimientos realizando bien las cosas.

\begin{tabular}{|c|c|c|c|c|c|c|c|}
\hline & $\begin{array}{c}-3 \mathrm{Ha} \\
\text { dis- } \\
\text { minuido }\end{array}$ & -2 & -1 & 4 & 1 & 2 & $\begin{array}{l}3 \mathrm{Ha} \text { au- } \\
\text { mentado }\end{array}$ \\
\hline Aptitud & 0 & 0 & 0 & 0 & 0 & 0 & 0 \\
\hline
\end{tabular}

31. Al utilizar el audifono mi bienestar ha

Sentirse a gusto, bien, optimista acerca de su vida y su futuro.

\begin{tabular}{|c|c|c|c|c|c|c|c|}
\hline & $\begin{array}{c}-3 \mathrm{Ha} \\
\text { dis- } \\
\text { minuido }\end{array}$ & -2 & -1 & Igual & 1 & 2 & $\begin{array}{l}3 \mathrm{Ha} \text { au- } \\
\text { mentado }\end{array}$ \\
\hline ienestar & 0 & 0 & 0 & 0 & 0 & 0 & 0 \\
\hline
\end{tabular}

32. Al utilizar audífono mi siento más capaz

Sentirse en mejores condiciones para poder hacer algo; sentirse más apto.

\begin{tabular}{|c|c|c|c|c|c|c|c|}
\hline & $\begin{array}{c}-3 \mathrm{Ha} \\
\text { dis- } \\
\text { minuido }\end{array}$ & -2 & -1 & Igual & 1 & 2 & $\begin{array}{l}3 \mathrm{Ha} \text { au- } \\
\text { mentado }\end{array}$ \\
\hline Sentirse capaz & 0 & 0 & 0 & 0 & 0 & 0 & 0 \\
\hline
\end{tabular}

33. Al utilizar el audifono mi calidad de vida ha

Grado de satisfacción con su vida.

\begin{tabular}{|c|c|c|c|c|c|c|}
\hline & $\begin{array}{l}-3 \mathrm{Ha} \\
\text { dis- } \\
\text { minuid }\end{array}$ & -2 & -1 & Igual & 1 & 2 \\
\hline Calidad de vida & 0 & 0 & 0 & 0 & 0 & 0 \\
\hline
\end{tabular}

34. Al utilizar el audifono mi realización ha:

Posibilidad de aplicar sus conocimientos y capacidades en la realización de las tareas u actividades.

\begin{tabular}{|c|c|c|c|c|c|c|c|}
\hline & $\begin{array}{c}-3 \mathrm{Ha} \\
\text { dis- } \\
\text { minuido }\end{array}$ & -2 & -1 & Igual & 1 & 2 & $\begin{array}{l}3 \mathrm{Ha} \text { au- } \\
\text { mentado }\end{array}$ \\
\hline Realización & 0 & 0 & 0 & 0 & 0 & 0 & 0 \\
\hline
\end{tabular}


35. Al utilizar el audifono mi sensación de poder ha

Sensación de fuerza interior; sentir que Vd. tiene una influencia significativa sobre su propia vida.

\begin{tabular}{|c|c|c|c|c|c|c|}
\hline $\begin{array}{c}-3 \mathrm{Ha} \\
\text { dis- } \\
\text { minuido }\end{array}$ & -2 & -1 & Igual & 1 & 2 & $\begin{array}{l}3 \mathrm{Ha} \text { au- } \\
\text { mentado }\end{array}$ \\
\hline 0 & 0 & 0 & 0 & 0 & 0 & 0 \\
\hline
\end{tabular}

36. Al utilizar el audifono mi sensación de control ha

Sentirse capaz de poder hacer lo que quiere, dentro de su entorno.

$\begin{array}{ccccccc}\begin{array}{c}-3 \mathrm{Ha} \\ \text { dis- } \\ \text { minuido }\end{array} & -2 & -1 & \text { Igual } & 1 & 2 & \begin{array}{l}3 \mathrm{Ha} \text { au- } \\ \text { mentado }\end{array}\end{array}$

Sensación de control$$
\text { O }
$$$$
\bigcirc
$$

$\bigcirc$

$\bigcirc$

$\bigcirc$

37. Sentirse a disgusto al utilizar el audifono

Torpe, incómodo o avergonzado.

\begin{tabular}{|c|c|c|c|c|c|c|}
\hline $\begin{array}{l}-3 \mathrm{Ha} \\
\text { dis- } \\
\text { minuido }\end{array}$ & -2 & -1 & Igual & 1 & 2 & $\begin{array}{l}3 \mathrm{Ha} \text { au- } \\
\text { mentado }\end{array}$ \\
\hline 0 & 0 & 0 & 0 & 0 & 0 & 0 \\
\hline
\end{tabular}

38. Al utilizarel audifono usted está dispuesto a darse oportunidades

$\begin{array}{lccccccc} & \begin{array}{c}-3 \mathrm{Ha} \\ \text { dismin- } \\ \text { udio }\end{array} & -2 & -1 & \text { Igual } & 1 & 2 & \begin{array}{l}3 \mathrm{Ha} \text { au- } \\ \text { mentado }\end{array} \\ \begin{array}{l}\text { Dispuesto a darse oportu- } \\ \text { nidades }\end{array} & 0 & 0 & 0 & 0 & 0 & 0 & 0\end{array}$

39. Al utilizar audífono mi capacidad para participar en actividades ha

Capaz de intervenir en actividades, junto con otras personas.

\begin{tabular}{|c|c|c|c|c|c|c|c|}
\hline & $\begin{array}{c}-3 \mathrm{Ha} \\
\text { dis- } \\
\text { minuido }\end{array}$ & -2 & -1 & Igual & 1 & 2 & $\begin{array}{l}3 \mathrm{Ha} \text { au- } \\
\text { mentado }\end{array}$ \\
\hline Capacidad para participar & O & $\mathrm{O}$ & $\mathrm{O}$ & $\mathrm{O}$ & O & $\mathrm{O}$ & O \\
\hline
\end{tabular}


40. Al utilizar el audifono mi deseoso de probar cosas nuevas ha

Estar predispuesto a afrontar nuevas vivencias y aventuras.

$\begin{array}{lccccccc} & \begin{array}{c}-3 \mathrm{Ha} \\ \text { dis- } \\ \text { minuido }\end{array} & -2 & -1 & \text { Igual } & 1 & \begin{array}{l}3 \mathrm{Ha} \text { au- } \\ \text { mentado }\end{array} \\ \begin{array}{l}\text { Deseoso de probar cosas } \\ \text { nuevas }\end{array} & 0 & 0 & 0 & 0 & 0 & 0 & 0\end{array}$

41. Al utilizar el audífono mi capacidad para adaptarme a las actividades ha...

Capacidad de afrontar los cambios;capacidad de ser flexible respecto al modo de realizar las tareas básicas para que le resulten más manejables.

\begin{tabular}{|c|c|c|c|c|c|c|}
\hline $\begin{array}{l}-3 \mathrm{Ha} \\
\text { dis- } \\
\text { minuido }\end{array}$ & $\begin{array}{c}-2 \mathrm{Ha} \\
\text { dis- } \\
\text { minuido } \\
\text { bastante }\end{array}$ & $\begin{array}{l}-1 \mathrm{Ha} \\
\text { dis- } \\
\text { minuido } \\
\text { poco }\end{array}$ & Igual & $\begin{array}{l}1 \mathrm{Ha} \text { au- } \\
\text { mentado } \\
\text { poco }\end{array}$ & $\begin{array}{l}2 \mathrm{Ha} \text { au- } \\
\text { mentado } \\
\text { bastante }\end{array}$ & $\begin{array}{l}3 \mathrm{Ha} \text { au- } \\
\text { mentado } \\
\text { mucho }\end{array}$ \\
\hline 0 & 0 & 0 & 0 & 0 & 0 & 0 \\
\hline
\end{tabular}

Capacidad para adaptarse a las actividades

42. Al utilizar el audífono mi capacidad para aprovechar oportunidades

Disposición para actuar rápidamente y con seguridad cuando hay alguna oportunidad de mejorar algo en su vida.

\begin{tabular}{|c|c|c|c|c|c|c|}
\hline $\begin{array}{c}-3 \mathrm{Ha} \\
\text { dis- } \\
\text { minuido }\end{array}$ & -2 & -1 & Igual & 1 & 2 & $\begin{array}{l}3 \mathrm{Ha} \text { au- } \\
\text { mentado }\end{array}$ \\
\hline 0 & 0 & 0 & 0 & 0 & 0 & 0 \\
\hline
\end{tabular}

Capacidad para aprovechar las oportunidades

43. A continuación se le realizarán una serie de cuestiones en cuanto a las tecnologías en general,por favor conteste todas las cuestiones marcando la opción que se aplique a usted con mayor exactitud. Si no está muy seguro acerca de la respuesta elija la categoría neutral.Tecnologías que usa con frecuencia. Enumerelas (Por ejemplo: ordenador, móvil, skype...) 
44. Experiencias globales con las tecnologías utilizadas

Si no está muy seguro acerca de la respuesta elija la categoría neutral.

$\begin{array}{lccc} & \text { Valor positivo: } & \text { Neutral } & \text { Valor negativo:- } \\ \text { Son satisfactorias }(+) \text { o son frustrantes }(-) & 0 & 0 & 0 \\ \begin{array}{l}\text { Apoyan a mi creatividad }(+) \text { o interfieren } \\ \text { con mi creatividad }(-)\end{array} & 0 & 0 & 0 \\ \begin{array}{l}\text { Son estimulantes }(+) \text { o son desesperantes } \\ (-)\end{array} & 0 & 0 & 0 \\ \begin{array}{l}\text { Me acercan a la gente }(+) \text { o me separan } \\ \text { de la gente }(-)\end{array} & 0 & 0 & 0 \\ \begin{array}{l}\text { Aumentan mi autoestima }(+) \text { o bajan mi } \\ \text { autoestima }(-)\end{array} & 0 & 0 & 0\end{array}$

45. Perspectivas sobre tecnologías

Evalúa cada pregunta de forma positiva $(+)$, negativa $(-) \circ$ neutral. Si no está muy seguro acerca de la respuesta, elija la categoría neutral

$\begin{array}{lccc} & \text { Valor positivo }(+) & \text { Neutral } & \text { Valor negativo }(-) \\ \text { Mis experiencias tecnológicas en la niñez } & 0 & 0 & 0 \\ \text { Mis experiencias tecnológicas en la escuela } & 0 & 0 & 0 \\ \text { Mis experiencias tecnológicas en casa } & 0 & 0 & 0 \\ \begin{array}{l}\text { Mis experiencias tecnológicas más re- } \\ \text { cientes }\end{array} & 0 & 0 & 0\end{array}$

\section{Perspectivas sobre tecnologías segunda parte}

Si no está muy seguro acerca de la respuesta, elija la categoría neutral.

Estoy a gusto con la tecnología $(+) / \mathrm{Me}$ intimida la tecnología (-)

Me acerco a la tecnología de un modo racional $(+)$ o me acerco a la tecnología de un modo sentimental $(-)$

Me siento bien rodeado de tecnología $(+)$ o siento ansiedad rodeado de tecnología (-)

Otras personas me animan a usar tecnología $(+)$ o otras personas me desaniman a usar tecnología (-)

$\begin{array}{ccc}\text { Valor positivo: }+ & \text { Neutral } & \text { Valor negativo:- } \\ 0 & 0 & 0 \\ 0 & 0 & 0 \\ 0 & 0 & 0 \\ 0 & 0 & 0\end{array}$


47. Sus actividades típicas

Si no está muy seguro acerca de la respuesta, elija la categoría neutral Valor positivo $(+) \quad$ Neutral Valor negativo $(-)$

Prefiero ser activo (deporte, caminar) $(+)$ o $\mathrm{O}$ O prefiero actividades pasivas (lectura, tele-

$\bigcirc$

0

Actividades en grupo (positivo) o actividades en solitario (-)

Mis actividades son satisfactorias $(+) 0$ mis actividades son frustrantes(-)

Regularmente busco actividades novedosas $(+)$ o mis actividades no han cambiado durante mucho tiempo

O

O 0 $\bigcirc$

$\bigcirc$

$\bigcirc$

48. Algunas de sus características personales/sociales. Parte 1

Indique con que característica personal se identifica mayor sino sabe o no esta seguro marque la casilla neutral

\begin{tabular}{|c|c|c|c|}
\hline & Valor positivo: + & Neutral & Valor negativo: \\
\hline Tranquilo $(+)$ o ansioso (-) & O & 0 & 0 \\
\hline Feliz (+) o Depresivo (-) & 0 & $\bigcirc$ & 0 \\
\hline $\begin{array}{l}\text { Con expectativas positivas }(+) \text { o expecta- } \\
\text { tivas negativas }(-)\end{array}$ & 0 & $\mathrm{O}$ & 0 \\
\hline Expresivo $(+)$ o retraido $(-)$ & 0 & 0 & 0 \\
\hline Paciente $(+)$ o impaciente $(-)$ & 0 & 0 & O \\
\hline Motivado $(+)$ o desmotivado $(-)$ & 0 & O & O \\
\hline $\begin{array}{l}\text { Perseverante }(+) \text { o fácilmente desanimado } \\
(-)\end{array}$ & 0 & 0 & 0 \\
\hline
\end{tabular}

Perseverante $(+)$ o fácilmente desanimado 
49. Algunas de sus características personales/sociales segunda parte.

Indique la opción que mejor se le aplique a usted si no esta seguro elija la respuesta neutral.

$$
\text { Valor positivo }(+) \quad \text { Neutral Valor negativo }(-)
$$

Soy una persona racional $(+)$ o soy una persona impulsiva (-)

$\mathrm{O}$

$\bigcirc$

$\mathrm{O}$

Frecuentemente interactúo con la fa-

O

$\bigcirc$

O

milia/cónyuge $(+)$ o casi nunca interactúo con mi familia/cónyuge.(-)

Frecuentemente interactúo con amigos $(+)$

o casi nunca interactúo co mi amigos (-)

O 0

Tengo una buena sensación de bienestar $(+)$ o tengo una pobre sensación de bienestar (-)

Soy físicamente independiente $(+)$ o soy físicamente dependiente $(-)$

Soy emocionalmente independiente $(+)$ o soy emocionalmente dependiente $(-)$

O

$\bigcirc$

O $\quad 0 \quad 0$

O 0

50. Tiene algún problema respecto al uso de los audífono como dolor en el pabellón auditivo u otro tipo de molestia que le gustaría compartir. Gracias por su colaboración

Gracias por invertir tu tiempo en responder esta encuesta. 


\section{ANEXO III: CUESTIONARIO ORIGINAL PIADS}

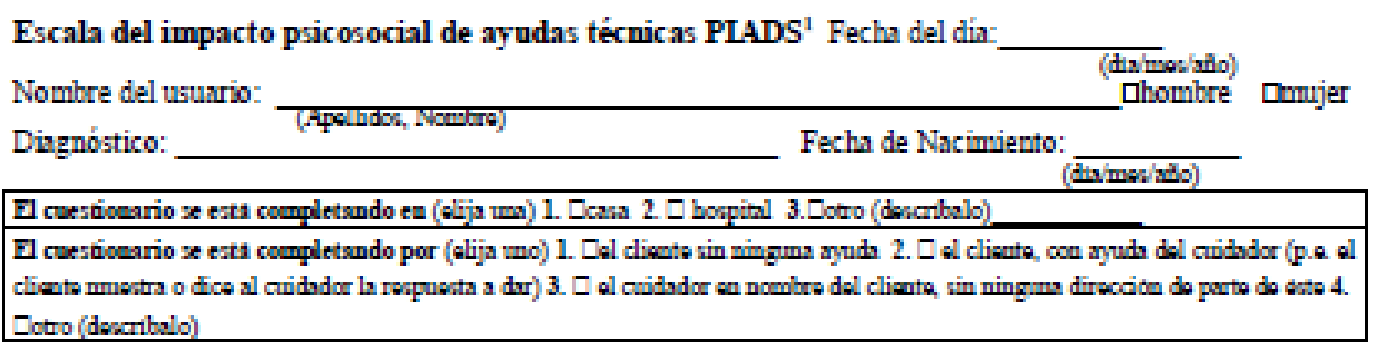

Cada palabra o frase indicada a contimacion describe un apecto del uvario que paede verse afectado por la utilizacion de una aynda tocrica. Ansque alguas le puedan parecer imususles os importante que reaponda a todas y cada una de las preguntas. Para cada palabra o frase propuesta pongz una " $\mathrm{X}$ " an la casilla qae rafleje mes adecusdamente el efacto producido por utilinar:

\begin{tabular}{|c|c|c|c|c|c|c|c|c|}
\hline \multicolumn{8}{|l|}{ (Indigas al nomblre de la xyuda) } & \multirow[b]{2}{*}{ His anmentado } \\
\hline Ha diminimido & 3 & -2 & -1 & 0 & 1 & 2 & 3 & \\
\hline 1) Competencis & $\square$ & $\square$ & $\square$ & $\square$ & 口 & $\square$ & $\square$ & \\
\hline 2) Folicidad & $\square$ & $\square$ & $\square$ & $\square$ & $\square$ & $\square$ & $\square$ & \\
\hline 3) Independencia & [ & Q & 口 & 므 & 口 & 田 & [ & \\
\hline 4) Sentirve a la altarn de las circunstamcias & $\square$ & $\square$ & $\square$ & $\square$ & 口 & $\square$ & $\square$ & \\
\hline 5) Confusion & $\square$ & $\square$ & $\square$ & $\square$ & $\square$ & $\square$ & $\square$ & \\
\hline 6) Eficacia & ㅁ & 口 & 口 & ㅁ & 무 & 口 & 口 & \\
\hline 7) Autoestims & ㅁ & 口 & $\square$ & ㅁ & ㅁ & 口 & 口 & \\
\hline 8) Productividad & $\square$ & $\square$ & $\square$ & $\square$ & ㅁ & Q & $\square$ & \\
\hline 9) Segaridad & $\square$ & $\square$ & $\square$ & $\square$ & $\square$ & $\square$ & $\square$ & \\
\hline 10) Frustracion & $\square$ & $\square$ & $\square$ & $\square$ & ㅁ & 므 & $\square$ & \\
\hline 11) Sentires util & 口 & $\square$ & $\square$ & $\square$ & 口 & $\square$ & $\square$ & \\
\hline 12) Confianta en st mismo & $\square$ & $\square$ & $\square$ & $\square$ & ㅁ & $\square$ & $\square$ & \\
\hline 13) Poricia & ㅁ & $\square$ & 口 & ㅁ & 무 & $\square$ & $\square$ & \\
\hline 14) Aptitnd & [ & Q & 口 & 口 & 口 & 口 & 口 & \\
\hline 15) Bienestar & $\square$ & $\square$ & $\square$ & $\square$ & 口 & $\square$ & $\square$ & \\
\hline 16) Sentirue capaz & $\square$ & $\square$ & $\square$ & $\square$ & ㅁ & $\square$ & $\square$ & \\
\hline 17) Calidad de vida & ㅁ & $\square$ & ㅁ & ㅁ & 무 & ㅁ & ㅁ & \\
\hline 15) Reslizacion & घ & Q & 口 & 口 & Q & 口 & 口 & \\
\hline 19) Senszcion de poder & $\square$ & 口 & $\square$ & $\square$ & ㅁ & 口 & $\square$ & \\
\hline 20) Sensacion de control & $\square$ & $\square$ & $\square$ & $\square$ & $\square$ & $\square$ & $\square$ & \\
\hline 21) Sentirte a disgusto & घ & D & 口 & ㅁ & 言 & ( & [ & \\
\hline 22) Dispuesto a darwe oportunidader & $\square$ & 口 & $\square$ & $\square$ & 口 & 口 & $\square$ & \\
\hline 23) Capacidad para participar & ㅁ & $\square$ & $\square$ & 口 & 口 & 口 & 口 & \\
\hline 24) Desecko de probar muevas conas & ㅁ & 口 & $\square$ & 口 & ㅁ & 口 & $\square$ & \\
\hline $\begin{array}{l}\text { 25) Capacidad para adaptarse a las actividades de la } \\
\text { vida diaria. }\end{array}$ & $\square$ & $\square$ & $\square$ & $\square$ & 口 & 口 & $\square$ & \\
\hline 26) Capacidad para aprovechar las oportanidades & ㅁ & $\square$ & $\square$ & $\square$ & ㅁ. & 口 & 口 & \\
\hline
\end{tabular}




\section{ANEXO IV: VÍDEOS PARA EL ESTUDIO 1 ADAPTADO}

Cuestionario sociodemográfico
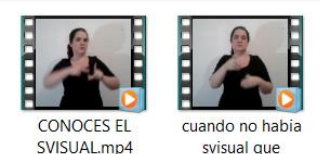

svisual que
usabas dts, movil, ils.mp 4

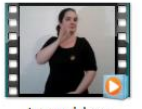

tu pueblo o

ciudad.mp4

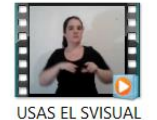

USAS EL SVISUA SI O NO.mp4

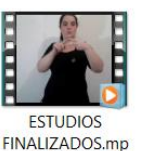

ESTUDIOS
FINALIZADOS.m
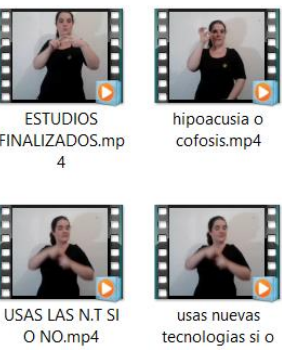

hipoacusia 0
cofosis.mp4
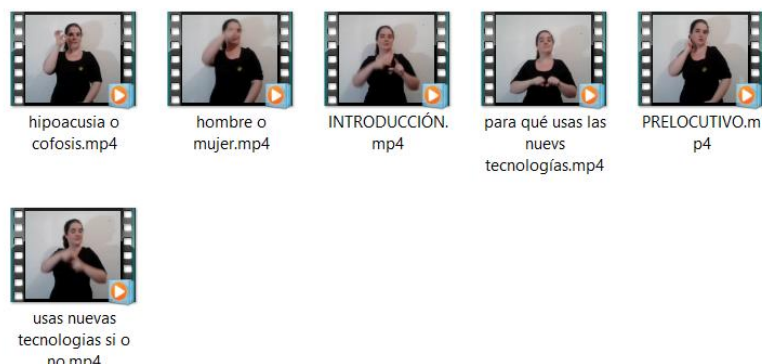

Escala PIADS
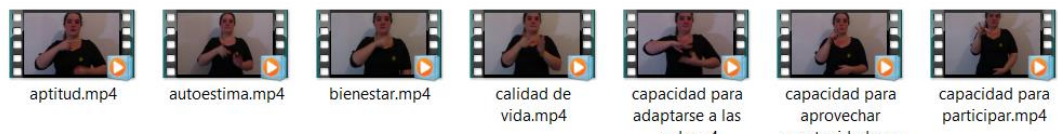

capacidad para participar.mp4

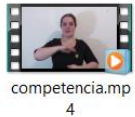

oportunidades
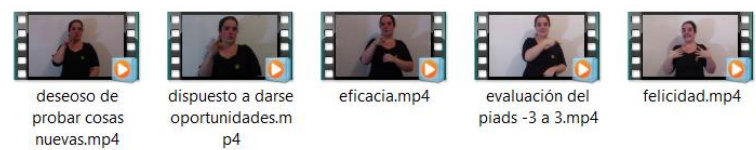
deseoso de
probar cosas nuevas.mp4 p4
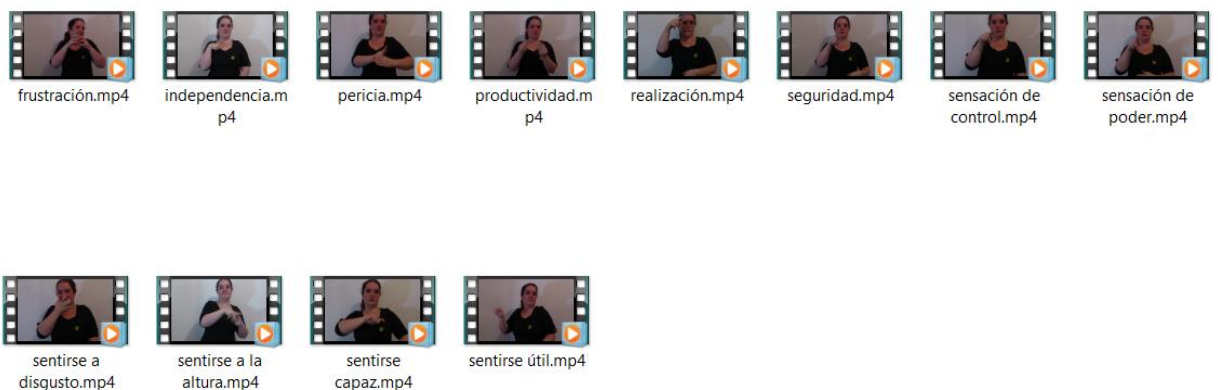
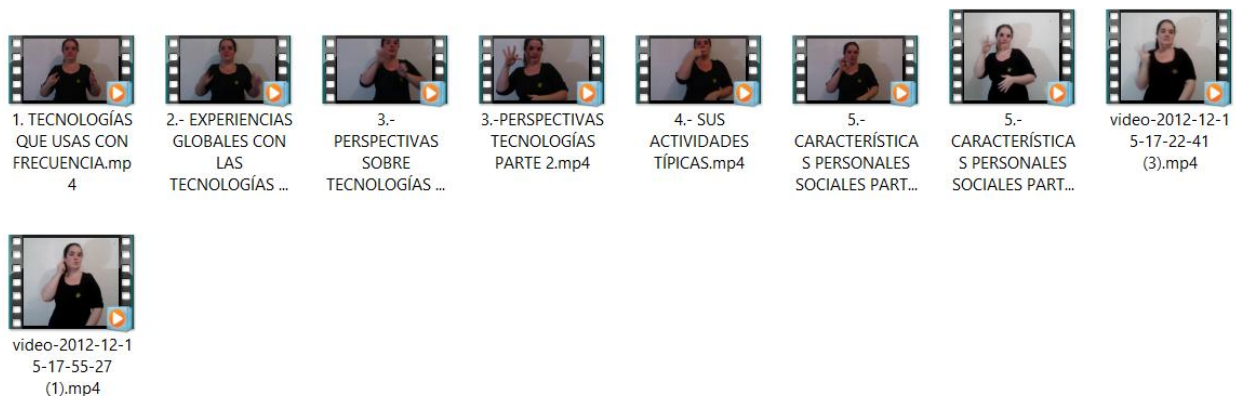


\section{ANEXO V: CONSENTIMIENTO INFORMADO \\ Impreso CBE-A3}

Declaración de consentimiento informado

He sido informado de que mi participación en este experimento es voluntaria. He sido informado de que mi participación no implica riesgo para la salud o molestia alguna. He sido informado de que el investigador adquiere el compromiso de responder a cualquier pregunta que se le haga sobre los procedimientos, diseños o hipótesis una vez concluida la investigación. He sido informado de que soy libre de retirarme del experimento en cualquier momento sin penalización de ningún tipo, y de que recibiré la bonificación correspondiente al tiempo empleado en el laboratorio.

Doy mi consentimiento informado para participar en este estudio sobre el impacto psicosocial asociado al uso de productos de apoyo para la comunicación. Consiento la publicación de los resultados del estudio siempre que la información sea anónima o se muestre de manera agregada de modo que no pueda llevarse a cabo una clara asociación entre mi identidad y los resultados. Entiendo que, aunque se guardará un registro de mi participación en el experimento, el investigador adquiere el compromiso de que todos los datos experimentales recogidos de mi participación sólo serán identificados por un número y en ningún caso se mostrarán asociados a mi identidad.

He sido informado de la responsabilidad que asumo con mi participación para el adecuado desarrollo del conocimiento científico. Por último, es importante que no comente las características de los procedimientos o los objetivos de este experimento hasta que haya concluido toda la investigación.

Investigador/a: Estíbaliz Jiménez Arberas

Participante:

Fecha: 


\section{ANEXO VI: Consentimiento informado grupos focales}

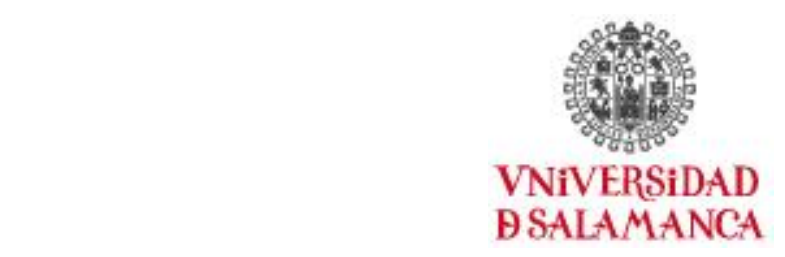

MODELO DE CONSENTIMIENTO INFORMADO DEL PACIENTE O COLABORADOR

Impreso CBE-A1

Yo ${ }^{1}$

He tenido oportunidad de efectuar preguntas sobre el estudio.

He recibido respuestas satisfactorias.

He recibido suficiente información en relación con el estudio.

He hablado con la Investigadora: ESTÍBALIZ JIMÉNEZ ARBERAS

Entiendo que la participación es voluntaria.

Entiendo que puedo abandonar el estudio:

- $\quad$ Cuando lo desee.

- Sin que tenga que dar explicaciones.

También he sido informado de forma clara, precisa y suficiente de los siguientes extremos que afectan a los datos personales que se contienen en este consentimiento y en la ficha o expediente que se abra para la investigación:

-Estos datos serán tratados y custodiados con respeto a mi intimidad y a la vigente normativa de protección de datos.

-Sobre estos datos me asisten los derechos de acceso, rectificación, cancelación y oposición que podré ejercitar mediante solicitud ante el investigador responsable en la dirección de contacto que figura en este documento.

Doy mi consentimiento sólo para la obtención de datos sobre mi ejecución en las tareas necesarias en la investigación de la que se me ha informado y para que sean utilizadas los datos resultantes exclusivamente en ella, sin posibilidad de compartir o ceder éstas, en todo o en parte, a ningún otro investigador, grupo o centro distinto del responsable de esta investigación o para cualquier otro fin. 
Declaro que he leído y conozco el contenido del presente documento, comprendo los compromisos que asumo y los acepto expresamente. Y, por ello, firmo este consentimiento informado de forma voluntaria para MANIFESTAR MI DESEO DE PARTICIPAR EN ESTE ESTUDIO DE INVESTIGACIÓN SOBRE LOS PRODUCTOS DE APOYO PARA PERSONAS SORDAS/PERSONAS CON DISCAPACIDAD AUDITIVA hasta que decida lo contrario. Al firmar este consentimiento no renuncio a ninguno de mis derechos.

Nombre del paciente o sujeto colaborador:

Fecha:

\section{Nombre del investigador: ESTÍBALIZ JIMÉNEZ ARBERAS}

Identificación del Grupo/Instituto//Centro/Otros, responsable de la investigación, cuando no se trate de proyectos individuales:

Fecha:

Dirección de contacto del Investigador y/o del Grupo....responsables de la investigación y del tratamiento de los datos:

ESTÍBALIZ JIMÉNEZ ARBERAS

INSTITUTO UNIVERSITARIO DE INTEGRACIÓN EN LA COMUNIDAD

FACULTAD DE PSICOLOGÍA - AVDA DE LA MERCED 109-131, 37005 SALAMANCA

NOTAS

${ }^{1}$ Indicar el nombre completo 